Yvan Gutnik

\title{
Estudo dos Piezoeletretos na Detecção de Descargas Parciais em Transformadores
}

Dissertação de Mestrado apresentada à Escola de Engenharia São Carlos da Universidade da Universidade de São Paulo como parte dos requisitos para obtenção do título de Mestre em Ciências, Programa de Pós-Graduação em Engenharia Elétrica.

Área de Concentração: Sistemas Elétricos de Potência.

Orientador: Prof. Tit. Ruy Alberto Corrêa Altafim.

São Carlos 
AUTORIZO A REPRODUÇÃO TOTAL OU PARCIAL DESTE TRABALHO, POR QUALQUER MEIO CONVENCIONAL OU ELETRÔNICO, PARA FINS DE ESTUDO E PESQUISA, DESDE QUE CITADA A FONTE.

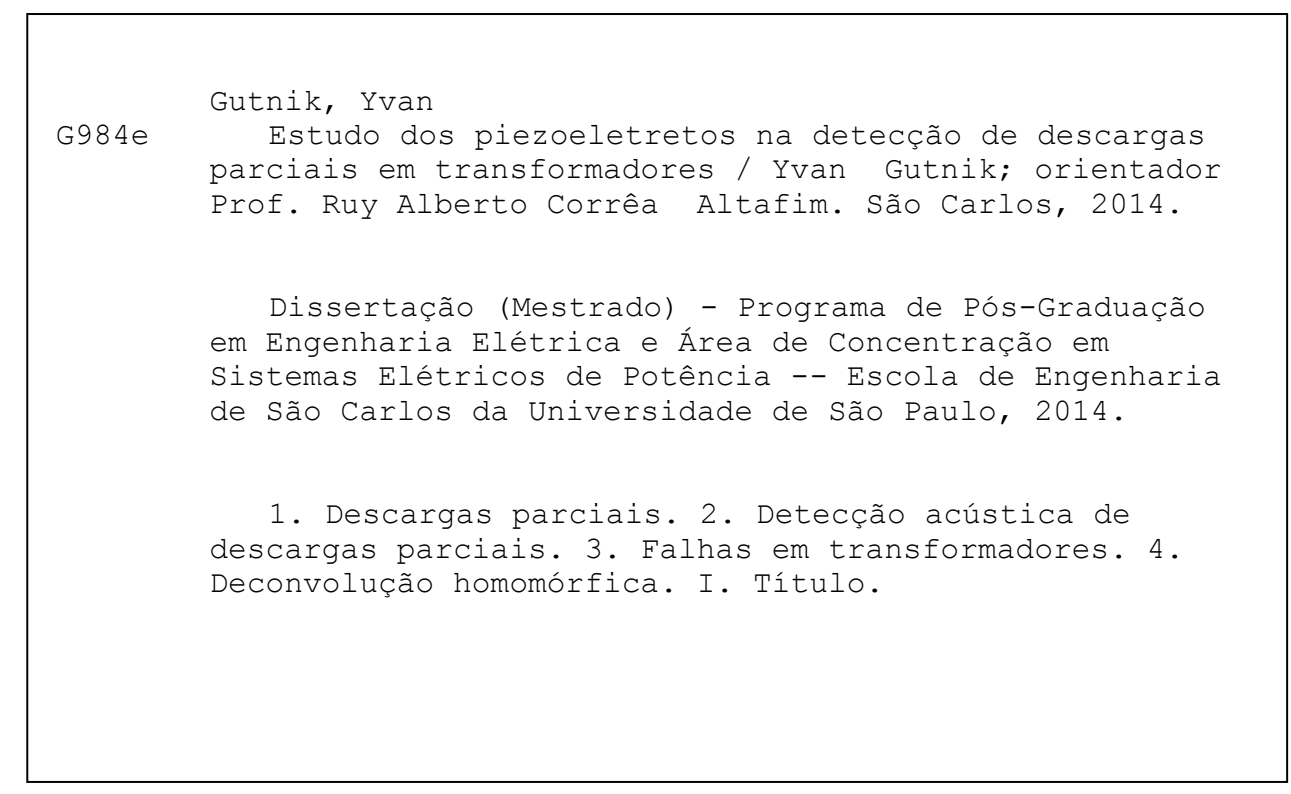




\section{FOLHA DE JULGAMENTO}

Candidato: Engenheiro YVAN GUTNIK.

Título da dissertação: "Estudo dos piezoeletretos na detecção de descargas parciais em transformadores".

Data da defesa: 25/04/2014

\section{Comissão Julgadora:}

Prof. Titular Ruy Alberto Corrêa Altafim (Orientador)

(Escola de Engenharia de São Carlos/EESC)

Prof. Dr. Arnaldo Gakiya Kanashiro

(Instituto de Eletrotécnica e Energia/IEE-USP)

Profa. Dra. Cacilda de Jesus Ribeiro

(Universidade Federal de Goiás/UFG)
Resultado:
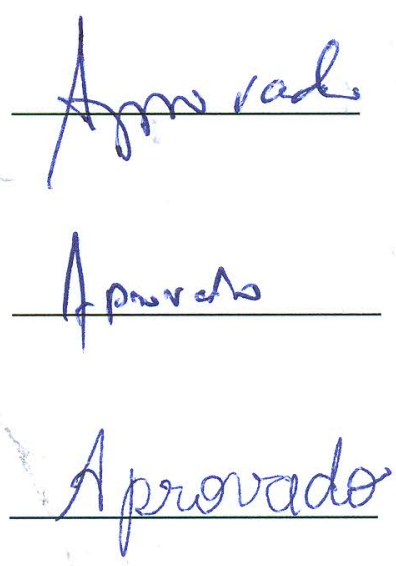

Coordenador do Programa de Pós-Graduação em Engenharia Elétrica e Presidente da Comissão de Pós-Graduação:

Prof. Titular Denis Vinicius Coury 



\section{Dedicatória}

A meus pais, Jorge e Vera. 



\section{Agradecimentos}

Primeiramente a Deus, pela misericórdia e graça que me alcançou e alcança a todo o que nele crê.

Aos meus pais e a minha irmã, por estarem sempre comigo em qualquer situação.

Aos grandes amigos, que não desistiram de serem meus grandes amigos.

Ao professor Ruy Alberto Corrêa Altafim, pelo incentivo na realização deste projeto; ao professor Ruy Alberto Pisani Altafim pelo apoio.

À professora Cacilda de Jesus Ribeiro, por conceder os sensores padrão na medição das descargas parciais.

Ao professor Paulo Roberto Veronese, pela ajuda no desenvolvimento dos circuitos eletrônicos. Ao professor Marcelo Basílio Joaquim, pela ajuda no processamento de todas as medidas.

À FAPESP, pela concessão da bolsa de mestrado e o auxílio de reserva técnica. À companhia ELEKTRO e a ANEEL, pelo financiamento do projeto.

Por fim, a todos que contribuíram direta e indiretamente para a realização deste trabalho. 



\section{Epígrafe}

O que as suas mãos tiverem que fazer, que o façam com toda a sua força, pois na sepultura, para onde você vai, não há atividade nem planejamento, não há conhecimento nem sabedoria.

Eclesiastes 9:10 (NVI).

Ó profundidade da riqueza da sabedoria e do conhecimento de Deus! Quão insondáveis são os seus juízos e inescrutáveis os seus caminhos! Quem conheceu a mente do Senhor? Ou quem foi seu conselheiro? Quem primeiro lhe deu, para que ele o recompense? Pois dele, por ele e para ele são todas as coisas. A ele seja a glória para sempre! Amém. Romanos 11:33-36 (NVI). 



\section{Resumo}

\section{GUTNIK, Y. Estudo dos piezoeletretos na detecção de descargas parciais}

em transformadores. 298 f. Dissertação de Mestrado (Mestrado em Engenharia Elétrica) - Escola de Engenharia de São Carlos, Universidade de São Paulo, São Carlos, 2014.

A detecção de descargas parciais em transformadores consiste em importante metodologia de manutenção preventiva e preditiva. Neste contexto, a proposta desta pesquisa com o uso de sensores acústicos de piezoeletreto apresenta-se como um tema original e altamente relevante no desenvolvimento da tecnologia brasileira. A multidisciplinaridade do tema exigiu a realização de uma extensa pesquisa bibliográfica envolvendo os temas descargas parciais, métodos de detecção das descargas, piezeletricidade, eletretos, piezoeletretos, técnicas de manufatura do

piezoeletreto proposto para a detecção de descargas e ferramentas de processamento de sinais, sendo a principal a deconvolução homomórfica. O Trabalho evoluiu para a elaboração de um primeiro protótipo laboratorial, constituído basicamente de um sensor piezoeletreto e um circuito amplificador, ambos abrigados em um invólucro metálico para assegurar uma blindagem eletromagnética. Os primeiros ensaios, em face da característica "sui generis" do protótipo, apontaram para a necessidade de novos circuitos e aprimoramento das metodologias desses ensaios laboratoriais, as quais também fazem parte do escopo deste trabalho. O desenvolvimento de um sistema de alta tensão autônomo, eletromagneticamente blindado e gerador de descargas elétricas impulsivas é um exemplo dos circuitos mencionados. A nova metodologia de testes buscou apresentar a evolução do comportamento acústico de uma descarga em diferentes ambientes, isto é, desde sinais sem ecos até sinais carregados com ecos e distorcidos pelo meio. Finalizando o trabalho, outra contribuição importante foi a decisão de analisar os sinais acústicos das descargas parciais pela deconvolução homomórfica, que mostrou ser essencial na remoção de ecos e na reconstrução do sinal acústico original.

Palavras Chave: Descargas parciais. Detecção acústica de descargas parciais. Falhas em transformadores. Deconvolução homomórfica. 



\begin{abstract}
GUTNIK, Y. Study of piezoelectrets for detecting partial discharge in transformers. 298 f. Dissertação de Mestrado (Mestrado em Engenharia Elétrica) Escola de Engenharia de São Carlos, Universidade de São Paulo, São Carlos, 2014.

Partial discharges acoustic detection is a very important preventive and predictive maintenance tool for transformers. In this research, a new acoustic piezoelectric sensor, based in Brazilian technology, was presented. However, before the construction of the prototype, an extensive literature was analyzed, including partial discharge, methods of discharges detection, piezoelectricity, electrets, piezoelectrets, manufacturing of the piezoelectret proposed to detection of discharges and signal processing tools, in special the homomorphic deconvolution. Basically, the prototype developed consists of a piezoelectret sensor and an amplifier circuit, assembled in a special metallic box, to shield any electromagnetic interference. During the tests, it was detected the need to create new circuits and to improve laboratory methodologies. A new impulse high-voltage generator electromagnetically shielded can be cited as an example of these circuits here developed. The new testing methodology aimed to present the evolution of the acoustic behavior of a discharge in different environments, in other words, from signals without echoes to signals containing echoes and distorted by the environment. In the processing signals context, another important contribution was the decision to analyze the acoustic signals of partial discharges by homomorphic deconvolution, which has allowed the reconstruction of the original acoustic signal without echo.
\end{abstract}

Key-words: Partials discharges. Acoustic detection of partial discharges. Transformer fails. Homomorphic deconvolution. 



\section{Lista de Figuras}

Figura 1: Curva taxa de falhas tipo "banheira" de um transformador.............................. 25

Figura 2: Tipos de descargas parciais. (A): superficial. (B): externa. (C): interna............ 38

Figura 3: Fotografias dos canais de descargas parciais........................................... 41

Figura 4: Tamanhos típicos de compartimentos gasosos em dielétricos sólidos.................. 42

Figura 5: Curva de Paschen para o ar............................................................... 43

Figura 6: Representação do início da ocorrência de uma DP......................................... 44

Figura 7: Modelo a-b-c para DPs em tensões alternadas. (A): Esquemático de um isolante

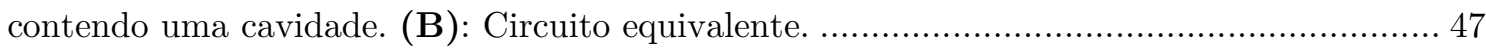

Figura 8: Ocorrência de DPs na presença de tensão alternada....................................... 48

Figura 9: Esquemático do modelo por aproximação de campo......................................... 49

Figura 10: Intensidade da DP versus a deterioração da isolação..................................... 53

Figura 11: Categoria dos métodos de detecção de descargas parciais................................. 55

Figura 12: Circuitos básicos para medição de DPs................................................. 57

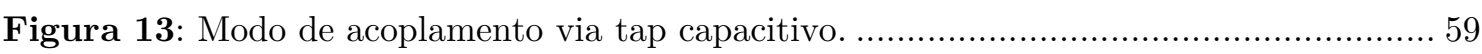

Figura 14: Principais componentes do sistema de mediação de DPs.................................. 60

Figura 15: Circuito equivalente do dispositivo de acoplamento. .................................. 61

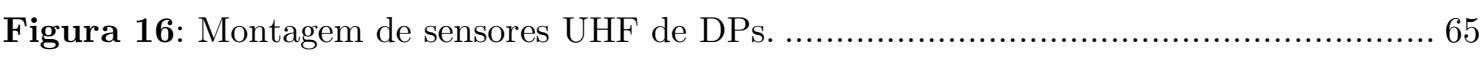

Figura 17 (A): Sistema experimental para deteç̧ão e medição ópticas de DPs. (B):

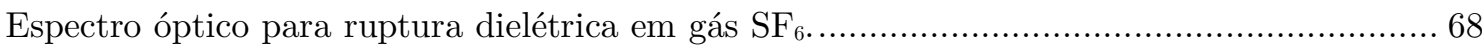

Figura 18: Forças atuantes num grupo de partículas que estão "confinadas" em um tubo. 72

Figura 19 (A): efeito piezelétrico direto. (B): efeito piezelétrico indireto. ....................... 81

Figura 20 (A): Representação esquemática de cargas aprisionadas nos polímeros celulares após carregamento. (B): Deformação das cavidades quando a estrutura é submetida à

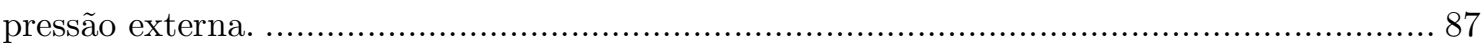

Figura 21: Imagem do primeiro piezoeletreto termoformado. ..................................... 87

Figura 22: Esquemático ilustrando a preparação das bolhas termoformadas entre dois filmes

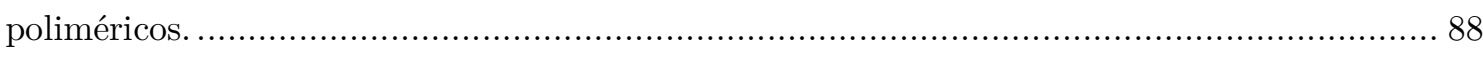

Figura 23: Micrografia eletrônica de um piezoeletreto celular de PP (polipropileno).......... 88

Figura 24: Sistema Homomórfico representado em diagrama de blocos. Possui operação de

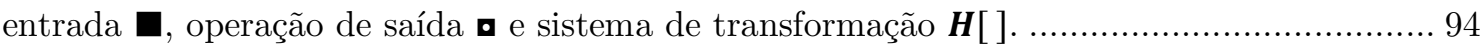

Figura 25: Sistema Homomórfico representado na forma canônica. Possui operação de entrada $\mathbf{\square}$, operação de saída $\mathbf{\mathbf { a }}$ e sistema de transformação $\boldsymbol{H}[$ ] . ................................... 95

Figura 26: Forma canônica do Sistema Homomórfico com a operação de convolução como

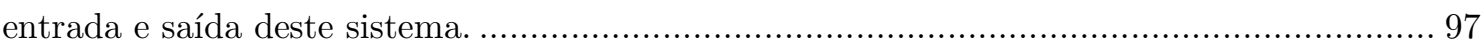


Figura 27: Sistema da Figura 26 com o sinal $x(n)$ representado em termos de sua

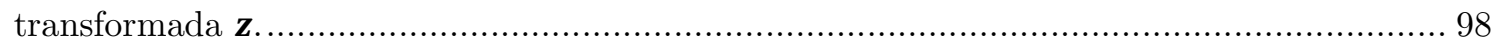

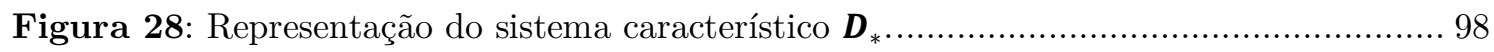

Figura 29 (A): Curva típica para fase de $\boldsymbol{X}(\mathbf{z})$. (B): Valor principal da fase da curva

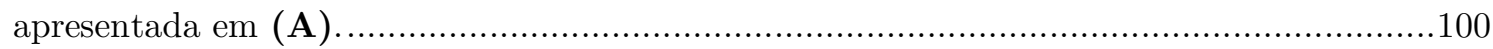

Figura 30: Representação do sistema característico inverso..........................................103

Figura 31: Realização do sistema característico $\boldsymbol{D}_{*}$ para estrada de fase mínima...............112

Figura 32 (A): Vista superior do piezoeletreto de FEP laminado. A imagem mostra o eletrodo circular depositado sobre quatro canaletas abertas (responsáveis pelo efeito piezelétrico). (B): Modelo esquemático de distribuição de cargas no piezoeletreto de canaletas abertas.

Figura 33: Gráfico da parte real da capacitância, ordenada à esquerda, e da parte imaginária, ordenada à direita, determinada pelo piezoeletreto de canais tubulares com quatro diferentes alturas de canais conforme indicado.

Figura 34 (A): Fotografia do primeiro transdutor acústico. (B): Diagrama esquemático. 121

Figura 35: Circuito esquemático do transdutor acústico. Versão Inicial.

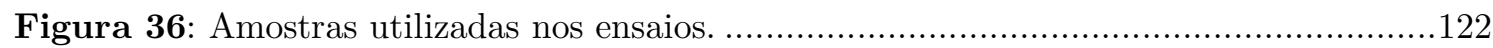

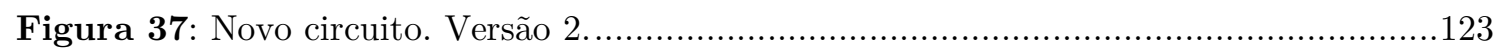

Figura 38: Circuito versão final: utilizado na realização de todos os ensaios.....................123

Figura 39: Resposta em frequência teórica do circuito da Figura 38................................124

Figura 40: Ruído captado por ambos os circuitos: versão 2 e versão final com ganho menor.

Figura 41 (A): Foto ilustrativa do sensor padrão. (B): Esquemático de conexões do sensor padrão com outros equipamentos.

Figura 42 (A): Esquemático do circuito desacoplador fonte/sensor/sinal conectado aos demais equipamentos. (B): Fotografia do desacoplador (somente) montado. As siglas "O", "S" e "A" representam os pontos de conexão do osciloscópio, sensor e alimentação

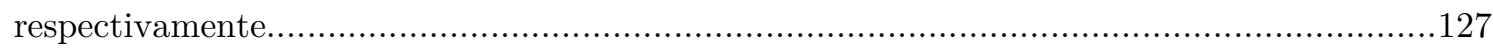

Figura 43: Resposta em frequência do desacoplador fonte/sensor/sinal. ..........................128

Figura 44: Foto do sistema gerador de pulsos de alta tensão....................................129

Figura 45: Diagrama elétrico esquemático do sistema de alta tensão...............................130

Figura 46: Esquemático do circuito de acionamento do sistema gerador de descargas. ......131

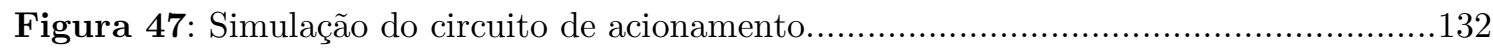

Figura 48 (A): Esquemático do circuito de medição do pulso de descarga. (B): Fotografia

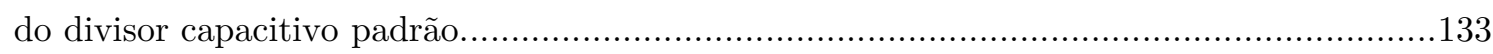

Figura 49: Pulso de corrente passante pelo Centelhador para diversos gaps.....................134 
Figura 50 (A): Fotografia do primeiro centelhador imerso em óleo. (B): Fotografia do sistema montado na realização dos primeiros ensaios. (C): Fotografia da tela do osciloscópio referente a uma das primeiras aquisições de descargas 136

Figura 51 (A): Fotografia do ensaio de descargas elétricas na câmara anecóica. (B): esquemático de uma vista em corte da gaiola blindada que contem o centelhador.

Figura 52: Fotografia do centelhador com indicação da distância real entre as pontas......138 Figura 53: Resposta temporal média das três amostras para a descarga na câmara anecóica. 139

Figura 54: Resposta temporal média dos três sensores para a descarga na câmara anecóica. 140

Figura 55: Fotografia da gaiola anecóica com anteparo para geração de eco. 140

Figura 56: Resposta do sinal com e sem eco para as três amostras de piezoeletreto. .........141

Figura 57: Resposta do sinal com e sem eco para os três sensores padrão. .142

Figura 58: Comparação entre o sinal original (em azul) e o mesmo sinal original em fase mínima (em verde) para todas as amostras de piezoeletreto e sensores padrão. .146

Figura 59: Espectro do sinal original em fase mínima para todas as amostras de

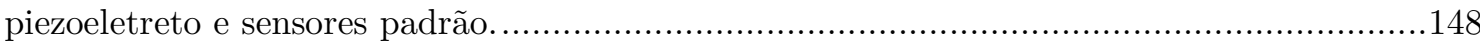

Figura 60: Curvas cepstrais do sinal com eco das amostras de piezoeletreto.....................150

Figura 61: Curvas cepstrais do sinal com eco dos sensores padrão. .151

Figura 62: Sinal original (em fase mínima) e sinal reconstruído para cada amostra de piezoeletreto. .152

Figura 63: Sinal original (em fase mínima) e sinal reconstruído para cada sensor padrão..153 Figura 64 (A): Fotografia da caixa 1 com centelhador e cabo de alta tensão (vermelho). (B): Fotografia da caixa 2 com centelhador e cabo de alta tensão (vermelho). 155

Figura 65: Resposta em frequência do filtro utilizado para filtrar os sinais das amostras de piezoeletreto 156

Figura 66: Resposta em frequência do filtro utilizado para filtrar os sinais dos sensores padrão. .157

Figura 67: Resposta temporal média filtrada e não filtrada para cada amostra de piezoeletreto. Descarga em ar, caixa 1 158

Figura 68: Resposta temporal média filtrada e não filtrada para cada sensor padrão. Descarga em ar, caixa 1. 159

Figura 69: Cepstro para quatro janelas distintas referentes às respostas das amostras de piezoeletreto. Descarga em ar, caixa 1. .161

Figura 70: Cepstro para quatro janelas distintas referentes às respostas dos sensores padrão. Descarga em ar, caixa 1. .162

Figura 71: Reconstrução do sinal original para as três amostras de piezoeletreto analisandose quatro janelas distintas do sinal. Descarga em ar, caixa 1. 
Figura 72: Reconstrução do sinal original para os três sensores padrão analisando-se quatro janelas distintas do sinal. Descarga em ar, caixa 1.

Figura 73: Espectro de frequência para as três amostras de piezoeletreto analisando-se quatro janelas distintas do sinal. Descarga em ar, caixa 1. 165

Figura 74: Espectro de frequência para os três sensores padrão analisando-se quatro janelas distintas do sinal. Descarga em ar, caixa 1. 166

Figura 75: Comportamento da distância Euclidiana e de Chebychev, ambas normalizadas, entre o sinal remodelado e reconstruído de acordo com o fator de compressão aplicado no espectro do sinal original, para todas as amostras e sensores. Descarga em ar, caixa1.........168

Figura 76: Espectro do sinal original, reconstruído e remodelado para todas as amostras de piezoeletreto. Descarga em ar, caixa 1 .

Figura 77: Espectro do sinal original, reconstruído e remodelado para todos os sensores padrão. Descarga em ar, caixa 1 .

Figura 78: Sinal remodelado, reconstruído e processado para todas as amostras de piezoeletreto. Descarga em ar, caixa 1.

Figura 79: Sinal remodelado, reconstruído e processado para todos os sensores padrão. Descarga em ar, caixa 1.

Figura 80: Resposta temporal média filtrada e não filtrada para cada amostra de piezoeletreto. Descarga em óleo, caixa 1. 176

Figura 81: Resposta temporal média filtrada e não filtrada para cada sensor padrão. Descarga em óleo, caixa 1. 177

Figura 82: Comportamento da distância Euclidiana e de Chebychev, ambas normalizadas, entre o sinal remodelado e reconstruído de acordo com o fator de compressão aplicado no espectro do sinal original, para todas as amostras e sensores. Descarga em óleo, caixa 1.....179 Figura 83: Espectro do sinal original, reconstruído e remodelado para todas as amostras de piezoeletreto. Descarga em óleo, caixa 1.

Figura 84: Espectro do sinal original, reconstruído e remodelado para todos os sensores padrão. Descarga em óleo, caixa 1 . 181

Figura 85: Sinal remodelado, reconstruído e processado para todas as amostras de piezoeletreto. Descarga em óleo, caixa 1. 182

Figura 86: Sinal remodelado, reconstruído e processado para todos os sensores padrão. Descarga em óleo, caixa 1. 183

Figura 87: Vista em corte da caixa 2 com esquemático do posicionamento do microfone, posto fora da caixa, e centelhador, interno à caixa. 185

Figura 88: Resposta temporal média filtrada e não filtrada para cada amostra de piezoeletreto referente à posição P1. Descarga em ar, caixa 2 ... 186 Figura 89: Resposta temporal média filtrada e não filtrada para cada amostra de piezoeletreto referente à posição P2. Descarga em ar, caixa 2 . 187 
Figura 90: Resposta temporal média filtrada e não filtrada para cada amostra de

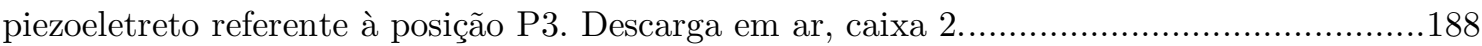
Figura 91: Resposta temporal média filtrada e não filtrada para cada amostra de piezoeletreto referente à posição $\mathrm{P} 4$. Descarga em ar, caixa 2 ...... 189

Figura 92: Resposta temporal média filtrada e não filtrada para cada amostra de piezoeletreto referente à posição $\mathrm{P} 5$. Descarga em ar, caixa 2 . 190

Figura 93: Resposta temporal média filtrada e não filtrada para cada sensor padrão referente à posição P1. Descarga em ar, caixa 2. 191

Figura 94: Resposta temporal média filtrada e não filtrada para cada sensor padrão referente à posição P2. Descarga em ar, caixa 2.

Figura 95: Resposta temporal média filtrada e não filtrada para cada sensor padrão referente à posição P3. Descarga em ar, caixa 2.

Figura 96: Resposta temporal média filtrada e não filtrada para cada sensor padrão referente à posição P4. Descarga em ar, caixa 2. 194

Figura 97: Resposta temporal média filtrada e não filtrada para cada sensor padrão referente à posição P5. Descarga em ar, caixa 2.

Figura 98: Sinal remodelado (azul), reconstruído (verde) e processado (vermelho) para todas as amostras de piezoeletreto e sensores padrão. Descarga em ar, caixa 2, posição P1. .202

Figura 99: Sinal remodelado (azul), reconstruído (verde) e processado (vermelho) para todas as amostras de piezoeletreto e sensores padrão. Descarga em ar, caixa 2, posição P2 .203

Figura 100: Sinal remodelado (azul), reconstruído (verde) e processado (vermelho) para todas as amostras de piezoeletreto e sensores padrão. Descarga em ar, caixa 2, posição P3.204 Figura 101: Sinal remodelado (azul), reconstruído (verde) e processado (vermelho) para todas as amostras de piezoeletreto e sensores padrão. Descarga em ar, caixa 2, posição P4.205 Figura 102: Sinal remodelado (azul), reconstruído (verde) e processado (vermelho) para todas as amostras de piezoeletreto e sensores padrão. Descarga em ar, caixa 2, posição P5.206 Figura 103: Resposta temporal média filtrada e não filtrada para cada amostra de piezoeletreto referente à posição P1. Descarga em óleo, caixa 2......................................207

Figura 104: Resposta temporal média filtrada e não filtrada para cada amostra de piezoeletreto referente à posição P2. Descarga em óleo, caixa 2 .208

Figura 105: Resposta temporal média filtrada e não filtrada para cada amostra de piezoeletreto referente à posição P3. Descarga em óleo, caixa 2 .......................................209

Figura 106: Resposta temporal média filtrada e não filtrada para cada amostra de

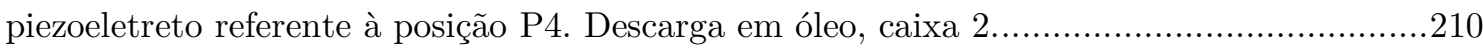
Figura 107: Resposta temporal média filtrada e não filtrada para cada amostra de piezoeletreto referente à posição P5. Descarga em óleo, caixa 2.

Figura 108: Resposta temporal média filtrada e não filtrada para cada sensor padrão referente à posição P1. Descarga em óleo, caixa 2. .212 
Figura 109: Resposta temporal média filtrada e não filtrada para cada sensor padrão referente à posição P2. Descarga em óleo, caixa 2 . 213

Figura 110: Resposta temporal média filtrada e não filtrada para cada sensor padrão referente à posição P3. Descarga em óleo, caixa 2. .214

Figura 111: Resposta temporal média filtrada e não filtrada para cada sensor padrão referente à posição P4. Descarga em óleo, caixa 2. 215

Figura 112: Resposta temporal média filtrada e não filtrada para cada sensor padrão referente à posição P5. Descarga em óleo, caixa 2. 216

Figura 113: Sinal remodelado (azul), reconstruído (verde) e processado (vermelho) para todas as amostras de piezoeletreto e sensores padrão. Descarga em óleo, caixa 2, posição P1.

Figura 114: Sinal remodelado (azul), reconstruído (verde) e processado (vermelho) para todas as amostras de piezoeletreto e sensores padrão. Descarga em óleo, caixa 2, posição P2.

Figura 115: Sinal remodelado (azul), reconstruído (verde) e processado (vermelho) para todas as amostras de piezoeletreto e sensores padrão. Descarga em óleo, caixa 2, posição P3.

Figura 116: Sinal remodelado (azul), reconstruído (verde) e processado (vermelho) para todas as amostras de piezoeletreto e sensores padrão. Descarga em óleo, caixa 2, posição P4. .225

Figura 117: Sinal remodelado (azul), reconstruído (verde) e processado (vermelho) para todas as amostras de piezoeletreto e sensores padrão. Descarga em óleo, caixa 2, posição P5.

Figura 118: Fotografia do novo microfone de piezoeletreto. .......................................253

Figura 119: Esquemático construído no Simulink para contagem de cruzamentos por zero. .263

Figura 120: Modelo de uma coluna de ar, composta de elementos de volume, contida num tubo rígido. 


\section{Lista de Tabelas}

Tabela 1: Causas típicas de falhas em transformadores. 26

Tabela 2: Erro percentual relativo na detecção do início do eco para tempo teórico de 23,3 us.

Tabela 3: Distância entre o sinal original (em fase mínima) e reconstruído pela distância Euclidiana e de Chebyshev...... 154

Tabela 4: Quantidade de cruzamentos por zero, por amostra de piezoeletreto, por janela. Descarga em ar, caixa 1. .161

Tabela 5: Quantidade de cruzamentos por zero, por sensor padrão, por janela. Descarga em ar, caixa 1

Tabela 6: Distâncias mínimas e fatores de compressão referentes a estas distâncias para cada amostra de piezoeletreto e sensor padrão (DE: distância Euclidiana; DC: distância de Chebychev). Descarga em ar, caixa 1. 169

Tabela 7: Média das relações sinal/ruído $(\mu)$, desvio padrão $(\sigma)$, menor relação $(M R)$ e coeficiente de variação percentual $(\boldsymbol{C v})$ para cada grupo de 25 medidas de todas as amostras e sensores. Descarga em ar, caixa 1. 169

Tabela 8: Quantidade de cruzamentos por zero, por amostra/sensor, por janela. Descarga em óleo, caixa 1 177

Tabela 9: Distâncias mínimas e fatores de compressão referentes a estas distâncias para cada amostra de piezoeletreto e sensor padrão (DE: distância Euclidiana; DC: distância de Chebychev). Descarga em óleo, caixa 1

Tabela 10: Média das relações sinal/ruído $(\mu)$, desvio padrão $(\sigma)$, menor relação $(M R)$ e coeficiente de variação percentual $(\boldsymbol{C v})$ para cada grupo de 25 medidas de todas as amostras e sensores. Descarga em óleo, caixa 1.

Tabela 11: Quantidade de cruzamentos por zero de acordo com a posição de medida, por amostra de piezoeletreto, por janela. Descarga em ar, caixa 2. 196

Tabela 12: Quantidade de cruzamentos por zero de acordo com a posição de medida, por sensor padrão, por janela. Descarga em ar, caixa 2 .

197

Tabela 13: Tempo de corte, em us, na curva cepstral para as amostras e sensores conforme a posição de medida. Descarga em ar, caixa 2. 197

Tabela 14: Distâncias mínimas e fatores de compressão referentes a estas distâncias para cada amostra de piezoeletreto e sensor padrão de acordo com a posição de medida (DE: distância Euclidiana; DC: distância de Chebychev). Descarga em ar, caixa 2 
Tabela 15: Média das relações sinal/ruído $(\mu)$, desvio padrão $(\sigma)$, menor relação $(M R)$ e coeficiente de variação percentual $(\boldsymbol{C} \boldsymbol{v})$ para todas as amostras e sensores de acordo com a posição de medida. Descarga em ar, caixa 2. 199

Tabela 16: Média dos fatores de compressão $(\mu)$, desvio padrão e coeficiente de variação $(\boldsymbol{C} \boldsymbol{v})$ para cada amostra/sensor referente às descargas em ar para as caixas 1 e 2. 201

Tabela 17: Média geral dos fatores de compressão $(\mu)$, desvio padrão e coeficiente de variação $(\boldsymbol{C v})$ para cada grupo de amostras/sensores referente às descargas em ar para as caixas 1 e 2 . .202

Tabela 18: Quantidade de cruzamentos por zero de acordo com a posição de medida, por amostra de piezoeletreto e sensor padrão, por janela. Descarga em óleo, caixa 2.

Tabela 19: Tempo de corte, em us, na curva cepstral para as amostras e sensores conforme posição de medida. Descarga em óleo, caixa 2. .218

Tabela 20: Distâncias mínimas e fatores de compressão referentes a estas distâncias para cada amostra de piezoeletreto e sensor padrão de acordo com a posição de medida (DE: distância Euclidiana; DC: distância de Chebychev). Descarga em óleo, caixa 2 . .219 Tabela 21: Média das relações sinal/ruído $(\mu)$, desvio padrão $(\sigma)$, menor relação $(M R)$ e coeficiente de variação percentual $(\boldsymbol{C} \boldsymbol{v})$ para todas as amostras e sensores de acordo com a posição de medida. Descarga em óleo, caixa 2.

Tabela 22: Média dos fatores de compressão $(\mu)$, desvio padrão e coeficiente de variação $(\boldsymbol{C v})$ para cada amostra/sensor referente às descargas em óleo para as caixas 1 e 2 .

Tabela 23: Média geral dos fatores de compressão $(\mu)$, desvio padrão e coeficiente de variação $(\boldsymbol{C} \boldsymbol{v})$ para cada grupo de amostras/sensores referente às descargas em óleo para as caixas 1 e 2 . 


\section{Sumário}

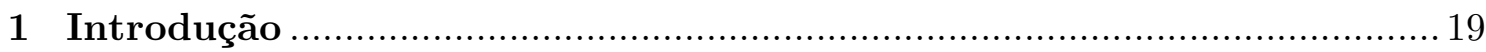

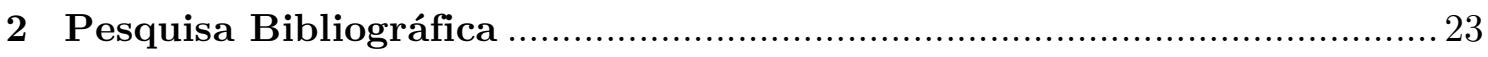

2.1 Procedimento de manutenção de transformadores ........................................ 23

2.2 Principais tópicos sobre descarga parcial ............................................. 28

2.2.1 Termos e definições..................................................................... 29

2.2.2 Visão histórica da descarga parcial ................................................. 33

2.2.3 Descargas parciais propriamente ditas ............................................... 37

2.2.3.1 Ocorrência das DPs ................................................. 37

2.2.3.2 Classificação das DPs..................................................... 37

2.2.3.3 Descargas superficiais....................................................... 38

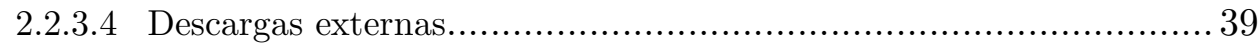

2.2.3.5 Descargas internas ..................................................... 40

2.2.4 Princípios físicos das DPs ........................................................ 42

2.2.5 DPs em tensões alternadas .......................................................... 46

2.2.6 Relação entre a DP e a degradação dos isolantes ................................... 51

2.3 Métodos de detecção de DP .................................................................. 53

2.3.1 Método elétrico.................................................................... 56

2.3.1.1 Método elétrico convencional ............................................ 56

2.3.1.2 Método HF/VHF.................................................... 64

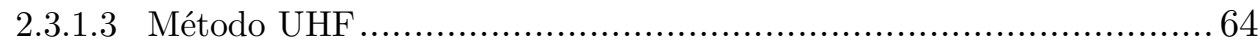

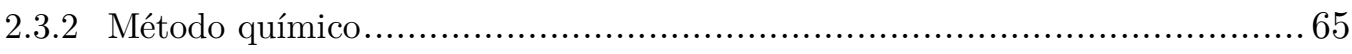

2.3.3 Método óptico e opto-acústico.................................................. 67

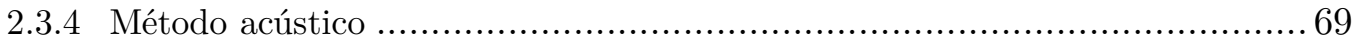

2.3.4.1 Um pouco de história ................................................... 69

2.3.4.2 Princípios da propagação acústica ....................................... 71 
2.3.4.3 Considerações sobre a detecção de descargas..............................76

2.4 Piezeletricidade, eletretos e piezoeletretos .................................................. 80

2.4.1 Piezeletricidade: princípios, história e aplicações .....................................80

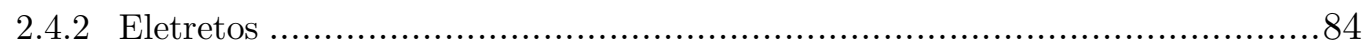

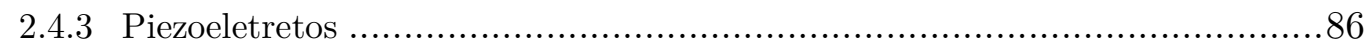

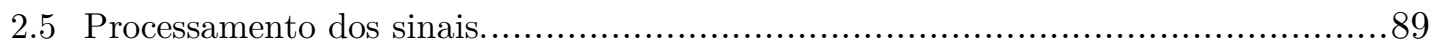

2.5.1 Deconvolução Linear ............................................................... 90

2.5.2 A Deconvolução Homomórfica................................................................93

2.5.2.1 Princípio generalizado de superposição ..........................................93

2.5.2.2 Sistemas homomórficos para convolução: forma canônica ................96

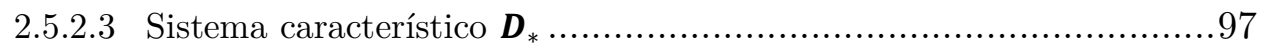

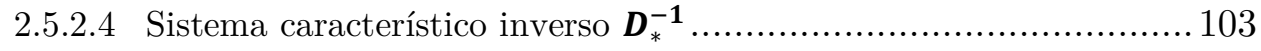

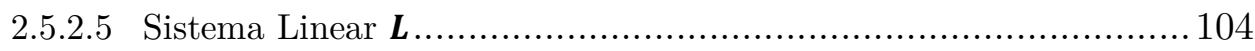

2.5.2.6 Cepstro complexo e suas propriedades.................................. 105

2.5.2.7 Sequências de fase mínima e máxima ..................................... 111

2.5.2.8 Ponderação exponencial....................................................... 114

2.5.2.9 Considerações sobre o cálculo do cepstro complexo..................... 115

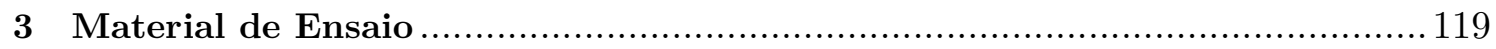

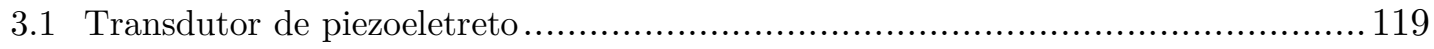

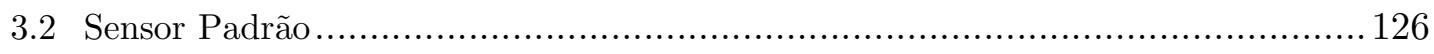

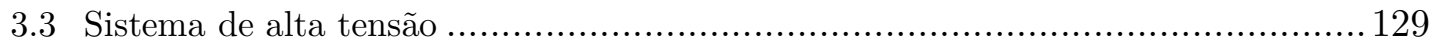

4 Ensaios, Resultados e Análise dos Resultados...................................... 135

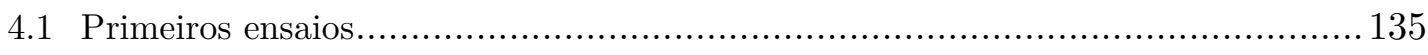

4.2 Proposta de Novos Ensaios........................................................ 137

4.2.1 Descarga Numa Câmara Anecóica …............................................... 137

4.2.2 Descarga em Caixas de Alumínio.................................................... 155

4.2.2.1 Análise para a caixa 1: descarga em ar................................. 155

4.2.2.2 Análise para a caixa 1: descarga em óleo .............................. 175 
4.2.2.3 Análise para a caixa 2: descarga em ar .............................. 184

4.2.2.4 Análise para a caixa 2: descarga em óleo.................................. 206

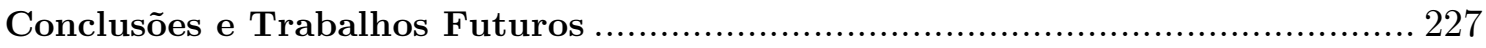

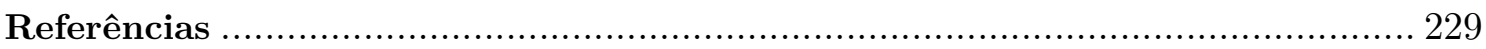

Anexo A: Dados das respostas em frequência dos sensores padrão .................. 249

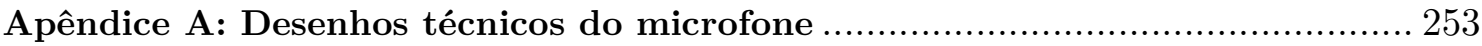

Apêndice B: Programas executados no Matlab® ......................................... 263

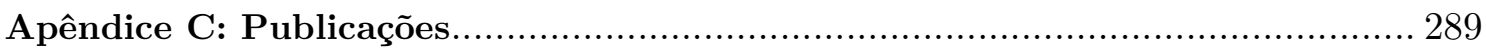

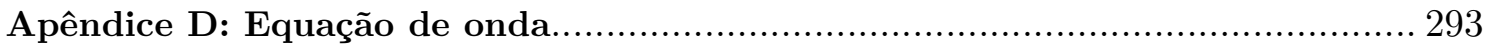





\section{Capítulo 1}

\section{Introdução}

Transformadores são equipamentos que possuem como principal função a adequação dos níveis de tensão nos sistemas elétricos, atuando como elos entre a geração, transmissão e distribuição de energia elétrica. Ademais, são os equipamentos de elevado custo, exigem, normalmente, maiores cuidados. Em contraponto, com a demanda de energia elétrica cada vez maior, no que se refere à qualidade de energia e a continuidade dos serviços, os transformadores, em especial os de distribuição, têm sido muitas vezes sobrecarregados muito acima de seu valor nominal. Este fato provoca, em primeira instância, a redução de seu tempo de vida a valores muito abaixo de seu nominal de 30 anos. Adiciona-se a esta problemática a busca constante pelas concessionárias na redução das interrupções de energia não programadas, e a melhoria de seu sistema de manutenção.

Surge, nesse contexto, a monitoração em tempo real e on-line dos transformadores, em especial os de distribuição, como uma das melhores soluções.

Dentre os parâmetros que são passíveis desse tipo de monitoramento e que tem forte correlação com a degradação dos transformadores são as descargas parciais (DPs), que ocorrem em cavidades de ar existentes em todos os componentes isolantes, sejam estes sólidos ou líquidos (KREUGER, 1989; PAOLLETI, 1999).

Diversas técnicas e equipamentos podem ser encontrados no mercado e na literatura para identificar as DPs. Entretanto, destacam-se quatro tipos específicos para transformadores, ou seja:

- Método elétrico: no qual o equipamento de medição da descarga parcial é parte integrante do circuito onde esta descarga ocorre, empregando um capacitor de acoplamento para medir as cargas elétricas geradas na DP. É empregado, atualmente, para monitorar além dos transformadores praticamente todos os grandes equipamentos desde geradores, cabos de alta tensão a banco de capacitores (LEMKE, 2008). 
- Método acústico. Baseado na emissão acústica da descarga, tanto na frequência audível quanto ultrassônica. Sua grande vantagem reside na possibilidade de localizar, internamente ao transformador, os pontos mais prováveis da ocorrência das DPs, além de ser um método imune a ruídos eletromagnéticos (HAROLD, 1979).

- Método químico. Este método, um dos mais tradicionais, consiste na análise cromatográfica dos gases dissolvidos no óleo isolante do transformador. Segundo consta na literatura, a quantidade e os tipos de gases dissolvidos no óleo fornecem indícios de sua normalidade ou do provável tipo de ocorrência de falha ou dano interno (IEC 60599-1999; IEEE C57.104-1991).

- Método óptico. É um método invasivo, que emprega sensores fotossensíveis para detecção luminosa da descarga que ocorre internamente ao transformador. Permite registrar comprimentos de onda de $350 \mathrm{~nm}$ a $700 \mathrm{~nm}$ para descargas em óleo (SCHWARZ et al., 2005, 2007).

Todavia, ao mesmo tempo em que as concessionárias de energia buscam a monitoração de seus equipamentos on-line, elas também procuram fazê-lo da forma mais econômica possível.

Neste cenário, este trabalho surge como uma proposta bastante promissora, por desenvolver um transdutor acústico com tecnologia 100\% nacional e de baixo custo, aplicado à deteç̧ão de descargas parciais em transformadores de distribuição de energia.

É importante salientar que a proposta também pode ser aplicada em transformadores de transmissão, e não somente aos de distribuição. A ideia primária de se aplicar em transformadores de distribuição reside no fato de que estes praticamente não possuem monitoramento ao longo de sua vida. Ademais, a proposta foca transformadores de distribuição que atenda a clientes "Vips", ou seja, aqueles que exigem uma melhor qualidade de energia.

Para tanto, este trabalho foi organizada procurando dar uma visão sistêmica da multidisciplinariedade do tema. No segundo capítulo é apresentada uma extensa pesquisa bibliográfica referente às descargas parciais, métodos de detecção de descargas em transformadores com foco no método acústico, o fenômeno da 
piezeletricidade, os eletretos, os piezoeletretos poliméricos e também ferramentas matemáticas utilizadas para processar os sinais acústicos de descargas.

No capítulo três será apresentado o microfone de piezoeletreto que foi desenvolvido e que se pretende utilizar na aplicação proposta. Também serão apresentados os sensores padrão os quais foram utilizados como referência de medida para comparação com o microfone, e o sistema de alta tensão construído com a finalidade de se gerar descargas elétricas. O objetivo principal deste capítulo é caracterizar ao máximo os principais componentes utilizados para a realização de todas as medidas.

Já no capítulo 4 serão apresentadas todas as medidas realizadas em diversas situações e ambientes, o processamento destas medidas e discussões referentes a cada situação proposta.

O capítulo 5 apresentará as conclusões pertinentes a tudo que foi realizado e alcançado nesta pesquisa e também os trabalhos futuros.

Por fim, o Anexo A apresenta as respostas em frequência dos sensores padrão, os quais foram utilizados como referência de medida nos experimentos. No Apêndice A estão os desenhos técnicos do novo microfone construído para a realização dos experimentos. Já no Apêndice B estão as principais rotinas elaboradas no Matlab® para o processamento de todas as medidas coletadas nos ensaios. No Apêndice C estão as publicações realizadas durante esta pesquisa e o Apêndice D apresenta a dedução da equação de onda no que diz respeito à propagação sonora em gases. 


\section{Capítulo 2}

\section{Pesquisa Bibliográfica}

Neste capítulo serão apresentados os procedimentos de manutenção e monitoramento de transformadores, os principais tópicos sobre descarga parcial, os métodos de detecção de descargas parciais, sensores específicos a cada método, o fenômeno da piezeletricidade, os eletretos e piezoeletretos e a ferramenta matemática conhecida como deconvolução homomórfica.

\subsection{Procedimento de manutenção em transformadores}

Segundo consta em Donald et al. (1999), os problemas relacionados a um transformador são caracterizados como aqueles provenientes de um defeito ou uma deficiência. Este defeito pode se desenvolver para uma falha, caso o defeito esteja relacionado a processos de deterioração e condições de sobrecarga do transformador. Estes problemas podem demorar anos até se chegar a uma situação de falha. Todavia, as consequências de uma situação de falha podem ser bastante indesejáveis. É importante diferenciar os conceitos "defeito" e "falha". O defeito é caracterizado por alguma anormalidade presente num equipamento de modo que, ainda assim, está em operação. Já a falha é a ocorrência de um sinistro que leve o equipamento a sair de operação. Por isso é que se havia dito: um defeito pode se desenvolver para uma situação de falha (Donald et al, 1999).

Ainda segundo Donald et al. (1999), comenta-se ainda que as causa de problemas para os transformadores, tais como a retração dos materiais isolantes e a umidade excessiva, levam muitos anos para desenvolver-se num problema; todavia, quando surge o problema, este ocorre de forma inesperada. O monitoramento contínuo permite uma ação corretiva oportuna, ou seja: não muito cedo, de modo a poupar recursos e não muito tarde, tendo-se como consequência altos custos para se reparar o problema. Dessa forma, este procedimento facilita e agiliza a manutenção 
do transformador, evitando paradas não programadas e amenizando custos para as concessionárias e transtornos para os consumidores finais. Em geral, a manutenção de transformadores instalados em subestações realiza-se periodicamente, buscando-se acompanhar o estado deste transformador conforme o decorrer de sua vida. Ademais, o tempo de vida médio de um transformador de potência, segundo Wang et al. (2002), varia de 20 a 35 anos. Este tempo pode ser estendido, na prática, para 60 anos, desde que haja manutenção apropriada.

Basicamente, segundo consta em Altwegg et al. (1999) e Kardec et al. (2003), existem três tipos de manutenção que podem ser aplicadas aos transformadores, as quais são:

- Manutenção corretiva: tem como propósito restaurar as condições de funcionamento do equipamento quando há defeitos ou falhas. Este tipo de manutenção pode ser realizado de forma programada ou não. A programada, referindo-se ao caso de defeito, possui menor custo, rapidez e qualidade de serviço; já manutenção corretiva não programada, para o caso de falha, é de elevado custo, pois geralmente neste caso o equipamento saiu de operação e não há tempo para se programar o serviço.

- Manutenção preventiva: Como o próprio nome o diz, este tipo de manutenção busca prevenir que o sistema sofra defeitos ou falhas futuras causadas pelo desgaste natural desse sistema. Este tipo de manutenção é realizado de forma periódica ou conforme prescreve o fabricante.

- Técnica preditiva: basicamente busca-se a antecipação de uma ocorrência, seja defeito ou falha. São métodos de diagnósticos que, através da aquisição contínua de dados do equipamento, define se uma manutenção preventiva é ou não necessária. Em última análise, esta técnica objetiva o maior desempenho que se possa conseguir de um equipamento.

No presente caso, a proposta de aplicação de um transdutor para detecção de DP (vide definição no item 2.2.1) configura-se numa ideia de técnica preditiva, ou seja, com o monitoramento constante do transformador poder-se-á ter uma ideia de quão intensas e periódicas estão sendo as descargas parciais neste transformador. Caso as descargas se intensifiquem com o decorrer do tempo, tem-se um indício de que o equipamento precisa ser reparado antes que ocorra uma falha. Vale salientar 
que a descarga elétrica total difere da descarga parcial em alguns aspectos, mais bem descrito no item 2.2 deste trabalho.

Em última análise, a manutenção de um transformador é realizada com o intuito de minimizar falhas. A Figura 1 apresenta a taxa de falhas durante o tempo de vida de um transformador típico. A primeira parte da curva, região de número 1 , refere-se à situação durante os primeiros anos de instalação, concentrando as falhas a projetos mal elaborados, erros durante a manufatura do equipamento, problemas de montagem e transporte. Na região 2, diz-se que é a região de vida útil (maturidade). Nesta região as taxas de falhas são constantes com o tempo. Segundo Pena (2003), é justamente nesta região que o equipamento apresenta seu melhor rendimento caso se for "aplicada uma política e uma estratégia adequada de técnicas preditivas associadas a uma manutenção preventiva". Por fim, a região 3 é conhecida como região de envelhecimento ou obsolescência. Nesta fase, a taxa de falhas cresce rapidamente com o tempo, em virtude das perdas das características elétricas e mecânicas dos componentes do equipamento.

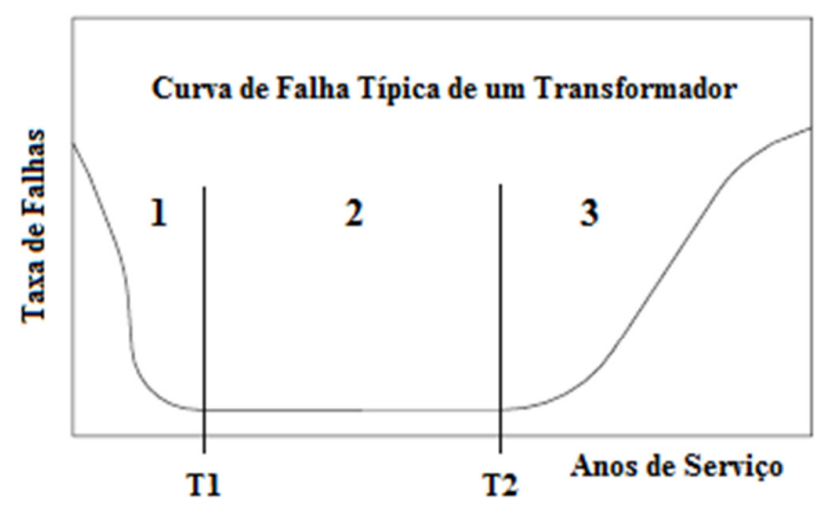

Figura 1: Curva taxa de falhas tipo "banheira" de um transformador.

Fonte: Modificado de Wang et al. (2002).

Neste contexto, Morais (2004) comenta que na adoção da filosofia de manutenções periódicas, muitas falhas são evitadas, mas em contrapartida são produzidos muitos desligamentos desnecessários e onerosos. Já Wang et al. (2002) tem aludido uma crescente necessidade de se realizar diagnósticos não-intrusivo aos transformadores, para mais bem definir suas manutenções e evitar sua retirada de operação. Esta nova filosofia tem sido evidenciada pela desregulamentação que ocorreu no sistema elétrico e a busca da mitigação de custos pelas concessionárias de 
energia elétrica. Aqui as técnicas de monitoramento contínuo assumem papel de destaque na identificação precoce de falhas.

Falhas em transformadores, de modo geral, são definidas nas seguintes situações, conforme consta em Cigre (1983) e Kogan (1988):

- Qualquer interrupção forçada em virtude de um dano sofrido pelo transformador em seus enrolamentos, em seu comutador, ou em qualquer de suas conexões internas.

- Problemas que requeiram a remoção do transformador de serviço para uma instalação de reparo, ou que exigem uma reparação extensiva em campo. Alguns problemas típicos desta situação: produção excessiva de gás e níveis de umidade elevados.

Menciona-se que as falhas ocorridas em um transformador podem ser de origem elétrica, térmica ou mecânica. As causas dessas falhas diferem entre internas e externas. A Tabela 1 lista estas causas. Além das falhas que podem ocorrer no tanque principal do transformador, também podem ocorrer falhas nas buchas, comutadores e acessórios do transformador (WANG et al., 2002).

Tabela 1: Causas típicas de falhas em transformadores.

\begin{tabular}{cc}
\hline Causas Internas & Causas Externas \\
\hline Deterioração da isolação & Descargas atmosféricas \\
\hline Perda do enrolamento de fixação & Operações de chaveamento \\
Superaquecimento & Sobrecarga no sistema \\
Oxigênio & Faltas no sistema (curto-circuito) \\
Umidade & --- \\
\hline Contaminação de particulados no óleo & -- \\
isolante & --- \\
Descarga parcial & -- \\
\hline Erros de projeto e manufatura & -- \\
\hline
\end{tabular}

Fonte: Wang et al. (2002). 
Numa análise um pouco mais acurada, a maioria das causas internas para a ocorrência de uma falha provoca, de modo geral, a deterioração da isolação do transformador. A presença de superaquecimento, oxigênio, umidade, particulados no óleo, deterioram os componentes isolantes do transformador e podem provocar ou intensificar o fenômeno de descarga parcial.

Foi realizada um levantamento por Grechko et al. (1996) num período de cinco anos e constataram que $51 \%$ dos transformadores pesquisados sofreram falhas devido às seguintes causas:

- Umidade, contaminação e envelhecimento que provocou a perda da rigidez dielétrica dos componentes do transformador.

- Danos no enrolamento ou descompressão do enrolamento por forças de curtocircuito.

- Danos nas buchas do transformador causado pela perda da rigidez dielétrica dos isoladores internos.

Note que a maioria das causas de falhas, para esta pesquisa, é de origem dielétrica, ou seja, a perda da rigidez dielétrica dos materiais isolantes do transformador foi a principal causa da ocorrência de falhas. Outra pesquisa realizada por Cigre (1983) afirma que $41 \%$ das falhas eram devidas a troca de tap do transformador em carga e $19 \%$ se relacionavam aos enrolamentos. Ainda: $53 \%$ das falhas eram de origem mecânica e 31\% de origem dielétrica. Ademais, pesquisas anteriores e resultados de investigação mostram que, a troca de tap em carga, problemas nos enrolamentos, envelhecimento dos isolantes e contaminação foram as principais causas de falhas em transformadores (WANG et al., 2002).

A ideia do constante monitoramento da descarga parcial presente em um transformador reside no seguinte fato: uma das causas de falhas de transformadores é ruptura dielétrica. As falhas nos dielétricos que compõem o transformador são muitas vezes precedidas pela atividade da descarga parcial. A significância da elevação quer no nível de descarga parcial em si, ou a elevação na taxa do nível de descarga pode fornecer uma indicação inicial de que mudanças estão ocorrendo dentro do transformador. Desde que a descarga parcial pode evoluir até a ruptura completa do dielétrico, torna-se interessante acompanhar este parâmetro continuamente (on-line). Em geral, descargas parciais em óleo produz o gás hidrogênio, de modo que este fica dissolvido no próprio óleo. No entanto, o hidrogênio dissolvido pode não ser 
detectável, pois depende do local da fonte da descarga parcial e do tempo necessário para que o óleo com hidrogênio dissolvido chegue até o local do sensor, no caso de um monitoramento contínuo deste óleo. Por outro lado, esta abordagem de monitoramento contínuo do óleo é interessante, haja vista que se pode evitar a detecção de um falso negativo, factível de ocorrer em testes periódicos de gases dissolvidos em óleo. Mais especificamente, entre um teste e outro pode ocorrer um defeito, gerar gás e os testes podem não detectar essa ocorrência, tendo em vista que estes testes foram realizados periodicamente. As fontes de descargas parciais mais comumente encontradas estão localizadas nas cavidades dos isolantes sólidos, partículas metálicas e as bolhas de gás gerado devido a alguma condição de falha. Entretanto, a devida interpretação dos resultados das atividades de descarga parcial não é simples. Não existem regras que relacionam o tempo de vida restante do transformador com a atividade de descarga parcial. Como parte da rotina de testes de aceitação de fábrica, o transformador é projetado e testado de modo a ter um baixo nível de descarga parcial abaixo de um nível especificado. A partir de uma monitoração constante, o diagnóstico de que o nível de descarga parcial ultrapassou determinado patamar é motivo de atenção, mas isso geralmente não exige uma ação imediata. Esta realidade mostra uma das muitas dificuldades encontradas no diagnóstico de descarga parcial. Os resultados precisam ser interpretados de acordo com o conhecimento que se tem do equipamento em análise (DONALD et al., 1999).

Por fim nota-se que, embora o monitoramento da descarga parcial não seja o fator decisivo para a manutenção ou não do transformador, esta serve como indício de que uma manutenção não muita tardia deva ser realizada. Portanto, a medição constante do nível de descarga parcial, associada a técnicas de cromatografia e estudos sobre o equipamento em questão podem se configurar em fatores decisivos para a manutenção ou não de um transformador.

\subsection{Principais tópicos sobre descarga parcial}

Antes de iniciar o estudo propriamente dito sobre as descargas parciais, é essencial que seja feita uma uniformização da nomenclatura existente, conforme consta em ASTM D1868-07 (2007). 


\subsubsection{Termos e definições}

- Ionização: é o processo pelo qual os elétrons são retirados ou transferidos para átomos ou moléculas neutras de modo a formas íons positivos ou negativos.

- Descarga Parcial: uma descarga elétrica que curto-circuita parcialmente o material isolante, ou seja, apenas uma determinada porção deste, entre seus respectivos condutores. Esta descarga elétrica, que é regida pelo transitório do processo de ionização gasosa, pode assumir a forma de qualquer faísca caracterizada como a de um canal de descarga estreito ou de um brilho difuso (glow) em expansão ou um canal de descarga substancialmente ampliado. As descargas parciais podem ocorrer em cavidades fechadas, contendo gás, localizadas dentro dos sistemas de isolantes. Sempre são iniciadas quando a tensão através da cavidade supera a tensão de ruptura (BARTNIKAS, 2002).

- Corona: descarga parcial visível em gás próxima ao condutor. Embora este termo também seja utilizado em referencia à descarga parcial em geral, neste trabalho refere-se somente a uma descarga parcial visível em gás próxima ao condutor.

- Descarga parcial contínua: descargas que se repetem em intervalos regulares de tempo, como por exemplo, as descargas que ocorrem em ciclos de tensão alternada ou uma descarga que ocorra pelo menos uma vez por minuto quando uma tensão direta é aplicada.

- Tensão de início da descarga parcial (PDIV): a tensão mais baixa nas quais descargas parciais contínuas, com magnitude acima de certo valor definido (o qual pode definir o valor do limite de ruído de fundo admissível) ocorrem com a aplicação de uma tensão que é gradualmente aumentada (vide Nota 1). Quando se aplica tensão alternada, o PDIV é expresso como sendo $1 / \sqrt{2}$ do valor da tensão de pico. Muitos testes e parâmetros da amostra de ensaio podem alterar este valor, e em alguns casos a reprodutibilidade dificilmente pode ser atingida. 
Nota 1: muitos fatores podem influenciar no valor de PDIV e PDEV incluindo a taxa na qual a tensão é incrementada ou decrementada, bem como o histórico de tensão aplicada à amostra. Em muitos casos é muito difícil obter o mesmo valor para ensaios subsequentes. Além disso, o caráter "contínuo" da descarga parcial é por vezes bastante difícil de definir, e uma análise arbitrária a respeito disso pode levar a diferentes valores de PDIV ou PDEV.

- Tensão de extinção da descarga parcial (PDEV): a tensão mais elevada na qual a descarga parcial, com magnitude acima de certo valor definido, já não ocorre quando a tensão é gradativamente diminuída a partir de um valor acima da tensão de início da descarga (vide nota acima). Quando se aplica tensão alternada, o PDEV é expresso como sendo $1 / \sqrt{2}$ do valor da tensão de pico. Muitos testes e parâmetros da amostra de ensaio podem alterar este valor, e em alguns casos a reprodutibilidade dificilmente pode ser atingida.

- Tensão de pulso da descarga parcial: a tensão de pulso terminal resultante de uma descarga parcial que é representada por uma fonte de tensão aplicada repentinamente a uma capacitância série do sistema de isolamento sob teste, e que pode ser detectada nos terminais do sistema sob condições de circuito aberto. A forma, tempo de subida e magnitude da tensão $V_{t}$ do pulso de descarga parcial é dependente da geometria da cavidade, do seu tamanho, da natureza de seus limites, tipo de gás presente e pressão a que está submetido, bem como dos parâmetros e o meio de transmissão entre o local da descarga e o detector de pulso de descarga. Os pulsos de descarga parcial do tipo "centelha" (spark) terão tempo de subida substancialmente mais curto do que as do tipo "brilho difuso" (glow) (BARTNIKAS, 2005).

- Carga $\left(\boldsymbol{Q}_{\boldsymbol{t}}\right)$ da descarga parcial: a magnitude de uma descarga parcial em um sistema isolante expresso em termos da carga transferida que é medida nos terminais do sistema. A medida de carga em geral não é equivalente à carga transferida no local da descarga, e tem relação com a energia da descarga. Para pequenas amostras que podem ser tratadas, ou modeladas, como um simples aglomerado de capacitores, a carga é igual ao produto da capacitância do sistema de isolamento pela tensão de impulso, ou seja: 


$$
Q_{t}=C_{t} V_{t}
$$

Sendo:

$Q_{t}=$ Carga da descarga parcial $(C)$.

$C_{t}=$ Capacitância da amostra do sistema de isolamento ( $\left.F\right)$.

$V_{t}=$ Valor de pico da tensão de pulso aparecendo em $C_{t}$.

- Nível da descarga parcial: a magnitude da maior descarga recorrente durante uma observação de descargas contínuas.

- Corrente média $\left(\boldsymbol{I}_{\boldsymbol{t}}\right)$ da descarga: o somatório das magnitudes absolutas de cada descarga durante certo intervalo de tempo dividido por este intervalo de tempo. Quando a descarga é medida em Coulomb e o tempo em segundos, o cálculo da corrente em amperes pode ser expresso por:

$$
I_{t}=\frac{\sum_{t_{o}}^{t_{1}} Q_{1}+Q_{2}+\cdots+Q_{n}}{t_{1}-t_{0}}
$$

Sendo:

$$
\begin{array}{ll}
I_{t} & =\text { Corrente média }(A) . \\
t_{0} & =\text { Tempo de partida }(s) . \\
t_{1} & =\text { Tempo de parada }(s) . \\
Q_{1}, Q_{2}, \ldots, Q_{n} & =\text { Carga de cada pulso de DP, de } 1 \text { a } n(C) .
\end{array}
$$

- Taxa quadrática: é o somatório dos quadrados das magnitudes de cada descarga durante certo intervalo de tempo dividido por este intervalo de tempo. A taxa quadrática é expressa em (Coulomb)² por segundo.

- Energia $(\boldsymbol{W})$ da descarga parcial: a energia utilizada a partir da fonte de tensão de teste como resultado de uma descarga individual. É o produto da magnitude $Q$ da descarga e do valor instantâneo $V$ da tensão na amostra de teste no início da descarga (WHITEHEAD, 1951). Assim, a energia do pulso de descarga $i$ é: 


$$
W_{i}=Q_{i} V_{i}
$$

Sendo:

$$
\begin{aligned}
W_{i}= & \text { Energia da descarga parcial (Watt-segundo }=\text { Joule). } \\
Q_{i}= & \text { Magnitude da descarga parcial (vide item "Carga da descarga } \\
& \text { parcial"). } \\
V_{i}= & \text { Valor instantâneo da tensão de teste aplicada no momento da } \\
& \text { descarga }(V) .
\end{aligned}
$$

- Perda de energia $(\boldsymbol{P})$ na descarga parcial: o somatório das energias retiradas da fonte de tensão de teste para cada descarga individual que ocorrem num período de tempo, dividido por este período de tempo.

$$
P=\frac{1}{T} \sum_{i=1}^{i=m} Q_{i} V_{i}
$$

Sendo:

$$
\begin{aligned}
P & =\text { Potência da descarga (Watts). } \\
T & =\text { Período de tempo (s). } \\
m & =\text { Número de pulsos ao final do período } T . \\
Q_{i} V_{i} & =\begin{array}{l}
\text { Energia do pulso da descarga } i \text { (vide item "Energia }(W) \text { da descarga } \\
\end{array}
\end{aligned}
$$

Quando a descarga parcial é analisada em questão de altura de pulso em um segundo de intervalo de tempo, então a energia dissipada, $P$, pode ser determinada por:

$$
P=\sum_{j=1}^{i} n_{j} Q_{j} V_{j}
$$

Sendo:

$P=$ Potência dissipada no pulso de descarga (Watts).

$n_{j}=$ Taxa de recorrência do pulso da descarga " $j "$ em pulsos/segundos. 
$Q_{j}=\begin{aligned} & \text { O valor correspondente de carga da descarga parcial em coulomb para } \\ & \text { um pulso em particular. }\end{aligned}$ $V_{j}=$ Valor instantâneo da tensão aplicada, em volts, quando o pulso de descarga $j$ ocorre (vide Narbut (1965)).

Se a suposição apontada por Vogel (1972) é levada em conta, tal que $V_{j} \Delta C_{j} \simeq C_{j} \Delta V_{j}$ (onde $\Delta C_{j}$ é o aumento incremental na capacitância $C_{t}$ devido à queda $\Delta V_{j}$ em $V_{j}$ como resultado da descarga $j$ ) então o somatório acima deve ser multiplicado por 1/2. Entretanto, esta hipótese não é, em geral, confirmada na prática.

- Perda de energia aparente $\left(\boldsymbol{P}_{\boldsymbol{a}}\right)$ : o somatório do produto de todas as amplitudes de pulso pela tensão rms de ensaio.

$$
P_{a}=I_{t} V_{s}
$$

Sendo:

$$
\begin{aligned}
P_{a} & =\text { Perda de energia aparente (Watts) no intervalo de tempo } \\
& \text { considerado. } \\
I_{t}= & \text { Corrente média da descarga }(A) . \\
V_{s}= & \text { Tensão rms aplicada no ensaio }(V) .
\end{aligned}
$$

- Taxa de pulso (n) da descarga parcial: é a média de pulsos que ocorre em um segundo ou em um determinado intervalo de tempo especificado. A contagem de pulsos pode ser restringida a uma magnitude limiar ou a uma faixa: limites superior e inferior.

- Pulso de descarga parcial: um pulso de tensão ou corrente que ocorre num lugar designado em um circuito como resultado de uma descarga parcial.

\subsubsection{Visão histórica da descarga parcial}

Os primeiros trabalhos científicos sobre descarga parcial foram realizados por Lichtenberg e publicados em 1777. Lichtenberg realizou o registro das formas da descarga corona em um plano fotográfico, o qual era constituído de um bastão e de 
um plano. As fotografias assim geradas são conhecidas como figuras de Lichtenberg. Este constatou que as formas de descarga variavam de acordo com o tipo de tensão aplicada, magnitude e polaridade (COBINE, 1941; GOLDMAN et al., 1982). Esta técnica, que possui metodologia e diagnósticos bem definidos, sendo bastante antiga, foi utilizada por um bom tempo no estudo de descargas elétricas (TAKAHASHI, 1979).

A importância dos estudos de Lichtenberg mais tarde foi referenciada em Merril e Von Hippel (1939), no qual se enfatiza que a importância do trabalho de Lichtenberg também reside no fato de que as formas das descargas, em "estrelas" ou "faíscas", revelaram novos aspectos das descargas em meio gasoso.

Posteriormente aos trabalhos de Lichtenberg, Townsend, em seus estudos sobre processos de ionização gasosa, apresentou os primeiros cálculos que relacionavam a tensão elétrica com o processo de descarga corona, cálculos estes que são utilizados até o dia de hoje (COBINE, 1941; GOLDMAN et al., 1982). Dentre seus trabalhos publicados, Electricity in Gases (TOWNSEND, 1915) apresenta os vários mecanismos presentes na formação e propagação de descargas elétricas em meio gasoso. No ano 1929 Peek apresentou, em Dielectric phenomena in High-voltage Engineering (PEEK, 1929), uma estimativa para o cálculo do campo elétrico crítico, campo imediatamente antes da formação da descarga corona, através de equações empíricas. O estudo foi dirigido para alguns arranjos em particular, como cilindros coaxiais e condutores paralelos (ANDERSON, 1982; COBINE, 1941). Suas equações são utilizadas ainda hoje em virtude da simplicidade e dos resultados satisfatórios que produzem. Por fim Loeb et al. (1940) e Kuffel et al. (2000) deram as contribuições teóricas finais com respeito ao fenômeno de descargas parciais.

Desde o início do século passado, quando a tecnologia de alta tensão foi introduzida nos sistemas de geração e transmissão, foi percebido que a descarga elétrica, de modo geral, era um fator crucial no envelhecimento dos componentes isolantes que compunham os aparatos de alta tensão (LEMKE, 2008). Seguido deste estudo, vários outros trabalhos referentes à degradação dos equipamentos elétricos mediante a presença de descargas foram publicados: Arman et al. (1936); Austen et al., (1941, 1944); Dawes et al. (1926, 1929, 1930); Dubsky (1919); Fortescue et al. (1931); Kuiser (1922); Mason (1951); Peek (1929). Dentre esses, destaca-se o trabalho de Mason (1951), no qual foram realizados estudos sobre a deterioração e a ruptura de alguns materiais quando há descargas internas a estes dielétricos. Neste trabalho, 
entre outros pontos a salientar, a tensão de início da descarga, a magnitude e a energia liberada por cada descarga, a localização e o número de descargas ocorridas para diferentes vacúolos (compartimentos gasosos fechados) foram estudadas pela técnica da eletrofotografia. Constatou-se também que a taxa de deterioração aumenta rapidamente com o aumento da tensão e que a deterioração do material dielétrico é maior quando o vacúolo é adjacente ao eletrodo.

Com a evolução das tensões de transmissão, houve também a necessidade de melhorias substanciais nos materiais isolantes. Neste interim, criou-se um dos primeiros equipamentos para medição de descarga parcial, o Klydonograph, que registrava surtos de tensão em papel fotográfico.

Com o passar do tempo novos equipamentos e métodos foram inventados. Pode-se mencionar Arman (1936), que relatou vários métodos para medição de DP. Já equipamentos de medição de descarga no nível industrial começaram a surgir em meados do século passado. Dentre os equipamentos desenvolvidos na época, cita-se Mole (1952) com seu detector de descarga AC e Dakin (1960) medindo a carga transferida numa descarga corona pelo método de ponte capacitiva. Estes equipamentos contribuíram essencialmente para novas realizações na tecnologia de descarga parcial (LEMKE, 2008).

Nos idos dos anos de 1970, houve a necessidade da medição de descarga parcial de baixa intensidade, devido à introdução de materiais isolantes nos cabos de energia. Isso direcionou as pesquisas para a melhora dos sistemas de medição e para a localização das descargas ao longo dos cabos (LEMKE, 2008). Um exemplo de pesquisa direcionada à medição e localização de descargas em cabos foi um trabalho publicado por Beyer et al. (1982) sobre um método para detecção e localização de DP distribuída em cabos de alta tensão. Este método apresentou $99.8 \%$ de precisão na localização da descarga e sensibilidade de 1 pC.

Buscando-se uma padronização na metodologia de análise e diagnóstico das DP, no ano de 1968, a norma IEC 270 foi lançada. Basicamente tratava-se dos procedimentos de medição e análise dos sinais de DP para equipamentos de alta tensão. Versões posteriores foram editadas de forma que a terceira edição, IEC 60270, vem sendo cada vez mais utilizada para testes de garantia de qualidade em transformadores de potência (LEMKE, 2008). 
Paralelamente a isto, desde a década de setenta testes de DPs em comutadores isolados a gás, genericamente chamados de GIS (Gas Insulated Substation), eram realizados. Entretanto, havia o problema de ruídos eletromagnéticos presentes nos sinais de DP. Procurando amenizar os efeitos destes ruídos, novos métodos começaram a ser estudados. Um método elétrico não convencional foi a medição da DP em alta frequência (UHF); frequências estas que estão na faixa de $300 \mathrm{MHz}$ até 3 GHz. Já em outra situação, métodos acústicos passaram a ser utilizados para detecção e localização de descargas parciais em transformadores (LEMKE, 2008).

Desde esta mesma época, anos de 1970, os instrumentos analógicos vêm sendo substituídos por sistemas digitais com o objetivo de cumprir o crescente interesse técnico e científico sobre a natureza estocástica da DP. Inicialmente utilizava-se o analisador multicanal de altura de pulso. Este basicamente era um equipamento que possuía vários canais de medidas no que diz respeito às variáveis observáveis em um fenômeno de descarga. Por exemplo: pode-se medir amplitude do sinal de DP, fase e carga aparente (LEMKE, 2008). Bartnikas (1973) utiliza este analisador para a medição da distribuição dos pulsos de descarga parcial em diversos equipamentos elétricos: transformadores, capacitores e cabos. Poucos anos mais tarde esta técnica foi substituída por sistemas de medição computadorizada capazes de realizarem a aquisição, processamento e visualização em fase dos sinais de descarga. Atualmente a mediação de DP é uma técnica bastante comum, tanto em laboratório quanto em campo. Ademais, sistemas analógicos para redução e até a rejeição de ruídos foram gradativamente substituídos por modernas ferramentas digitais de filtragem de sinais. Uma dessas ferramentas é a análise por componentes independentes (ICA) para extração cega de ruídos em sinais de DP em transformadores e geradores. Esta ferramenta é uma técnica de processamento de sinais que busca a extração de fontes independentes a partir da mistura de fontes desconhecidas, que foram obtidas através de medições. Dessa forma, o objetivo do ICA é encontrar "direções coordenadas entre componentes mais independentes e não necessariamente ortogonais que representem as observações" (CUENCA, 2005, p. 4).

Dessa forma, as padronizações de medição e classificação de descargas parciais obtidas em laboratório têm sido utilizadas para diagnostico em campo de equipamentos de alta tensão, como cabos de energia, transformadores e máquinas elétricas. 


\subsubsection{Descargas parciais propriamente ditas}

No que se refere às descargas parciais quanto à ocorrência, definição, classificação, mecanismos envolvidos, degradação provocada pela atividade das mesmas entre outras informações pertinentes, os próximos itens a seguir esclarecem isto.

\subsubsection{Ocorrência das DPs}

De modo geral, as descargas parciais ocorrem devido a imperfeições presentes nos isolantes. Estas imperfeições geram estresses elétricos seja nas superfícies ou internamente a estes materiais isolantes. Devido à criação de cargas espaciais, a ocorrência da descarga parcial depende da intensidade do campo nas proximidades destas imperfeições, bem como o tipo de tensão elétrica aplicada, AC ou DC, assim como tensões transitórias de chaveamento e de impulsos (LEMKE, 2008).

A norma IEC 60270 (BRITISH STANDARD, 2001) geralmente refere-se à medição de descargas parciais de equipamentos elétricos, componentes ou sistemas de tensões AC de até $400 \mathrm{~Hz}$. Somente uma pequena parte se refere a particularidades de teste de descarga parcial com tensões DC.

\subsubsection{Classificação das DPs}

De um ponto de vista físico, a criação de uma avalanche de elétrons autossustentada ocorre somente em gases. Consequentemente, descargas em dielétricos sólidos e líquidos ocorrem somente em vacúolos gasosos, como vazios ou fissuras em sólidos assim como bolhas de ar em líquidos. Logo, o fenômeno de DP, que ocorre em ar ambiente, como o glow, o streamer e a leader discharge, também pode acontecer em compartimentos gasosos fechados. O pulso de carga criado pela descarga glow, geralmente referido como descargas Townsend, é normalmente da ordem de poucos picocoulombs. A descarga streamer cria pulsos de carga entre 10 e 100 pC. A transição da descarga parcial tipo streamer para a leader discharge ocorre se a carga do pulso da descarga excede o valor de 1000 pC (LEMKE, 2008).

De modo geral, as descargas parciais são iniciadas quando o campo elétrico dentro dos vacúolos gasosos excede o campo elétrico intrínseco do gás presente. Em 
isolantes, o evento da descarga parcial é consequência do aumento do campo elétrico em virtude das imperfeições presentes (LEMKE, 2008).

Portanto, a norma IEC 60270 (B S, 2001) define descarga parcial como:

Uma descarga elétrica que curto-circuita somente uma parte do isolante entre seus respectivos condutores e que pode ou não ocorrer adjacente ao condutor. Descargas parciais são, geralmente, consequências de uma concentração local de estresse elétrico no isolante ou na superfície deste. Normalmente, essas descargas se apresentam em pulsos que duram menos que 1 us.

Dessa forma, a descarga parcial pode ser classificada de acordo com a sua origem, ou seja, onde ocorre e a forma que esta acontece e se desenvolve. Pode ser do tipo superficial, externa, pode ocorrer em um vacúolo interno a um material sólido, pode ocorrer devido a contaminantes em líquidos isolante, ou devido a bolhas, entre outras situações. De maneira geral, Mason (1995) aborda três tipos de descargas: a superficial, a externa e a interna. A Figura 2 apresenta as classificações básicas de uma descarga.

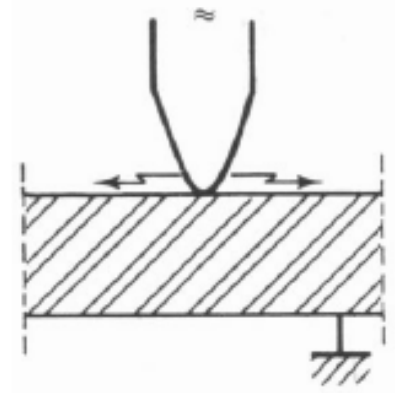

(A)

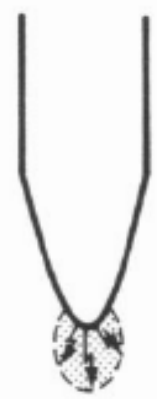

(B)

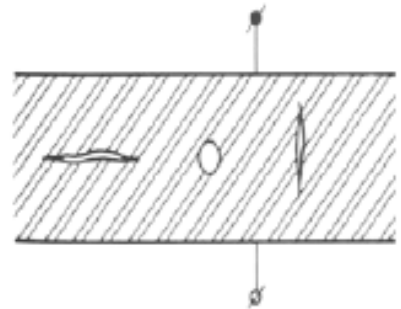

(C)

Figura 2: Tipos de descargas parciais. (A): superficial. (B): externa. (C): interna.

Fonte: Modificado de Kreuger (1989).

\subsubsection{Descargas superficiais}

Este tipo de descarga ocorre em gases, líquidos ou na superfície de um material dielétrico. Geralmente esta descarga parte do eletrodo em direção à superfície do dielétrico. Para a ocorrência deste tipo de descarga é necessário que a componente de 
campo elétrico tangente à superfície exceda certo valor crítico. Daí o processo de descarga superficial é iniciado (GULSKI, 1995). Estas descargas ocasionam alterações na superfície do dielétrico, de forma que caminhos condutores são iniciados e que se propagam ao longo da direção do campo elétrico. Este é um fenômeno conhecido como trilhamento, e que pode levar à ruptura completa do material dielétrico (MASON, 1995). Estas descargas são comuns em cabos protegidos e terminações de cabos isolados, em saias de isoladores e no sistema de alívio de barras de geradores (KREUGER, 1989).

\subsubsection{Descargas externas}

Descarga parcial externa: é a que ocorre em ar ambiente e, geralmente, pode ser referida como "descarga corona". Próximo da tensão de início desta descarga, a descarga glow e o streamer podem aparecer (vide Figura 3(A)). Esta situação é muito comum em eletrodos tipo ponta ou que possuam pequenos raios de curvatura na sua extremidade. Este tipo de descarga, o glow e o streamer, são possíveis, pois há uma forte concentração de campo elétrico nas pontas. Sendo assim, quando o campo supera a rigidez dielétrica do gás presente ao redor desta ponta, a descarga se inicia. Já descarga tipo leader discharge permanente ocorre somente em longos gaps de ar, excedendo a gama de metros (LEMKE, 2008).

As descargas externas desencadeiam processos químicos tais que podem ser prejudiciais ou não aos materiais isolantes. O fato de ser prejudicial reside na criação de subprodutos e a forma com que estes interagem com o dielétrico. Quando se trata de uma descarga em ar ambiente, a criação destes subprodutos é constantemente substituída pelo gás circulante local. Portanto, processos de descarga em ar ambiente puro podem ser considerados reversíveis e, dessa forma, geralmente não são prejudiciais. Já as Descargas externas em ar ambiente propagando-se ao longo de uma superfície dielétrica sólida podem tornar-se prejudiciais, pois estas descargas desencadeiam processos de degradação irreversíveis. Devido às componentes normal e tangencial do vetor de campo elétrico, descargas similares à leader discharge podem ser iniciadas, que frequentemente são referidas como "descargas de Toepler" ou "descarga delta". Este tipo de descarga supera grande distancias de gap, mesmo se a tensão de ensaio gerada é apenas poucos $\mathrm{kV}$ acima da tensão de início da descarga. Adicionalmente, a superfície do isolante sólido pode ser corroída progressivamente em 
virtude da alta temperatura local provocada pela passagem dos canais da leader discharge (LEMKE, 2008).

Mais especificamente, descargas coronas em ar produzem ozônio. Este tipo gás pode causar fissuras nas isolações poliméricas. Ademais, óxidos de nitrogênio em conjunto com vapor d'água geralmente corroem metais e formam depósitos condutores na isolação provocando o trilhamento do material.

Considerando os sistemas de isolamento, as descargas externas reversíveis em ar são importantes, por exemplo, para classificação de anéis de isoladores utilizados em linhas de transmissão de alta tensão bem como para a seleção de eletrodos utilizados em instalações de testes de alta tensão. Descargas delta irreversíveis podem inflamar buchas de transformadores e terminações de cabos de alta tensão devidos, como já fora mencionado, a imperfeições locais de campo (LEMKE, 2008).

\subsubsection{Descargas internas}

Como foram mencionadas, as descargas parciais ocorrem devido a imperfeições. No caso de líquidos (vide Figura 3(B)), e sólidos, (vide Figura 3(C)) isolantes assim como em gás enclausurado são classificadas como descargas internas. A descarga elétrica autossustentada, como já fora dito, ocorre somente gás ou ainda em compartimentos gasosos fechados. Logo, a descarga em sólidos isolantes é somente possível de ser iniciada em cavidades que contenham ar, como vazios e rachaduras ou ainda em algum defeito da estrutura molecular deste sólido. Cavidades vazias que contenham ar podem surgir na estrutura de materiais isolantes devido a causas distintas, dependendo da natureza do material e do processo de manufatura. Num caso particular de materiais termoplásticos como o polietileno, a falha pode ocorrer durante o processo de injeção do polímero em virtude da infiltração de ar atmosférico. Para polímeros termofixos, como, por exemplo, as resinas epóxi, a formação dos vacúolos pode se dar no decorrer do processo de cura do material, podendo ser causado pela infiltração do ar atmosférico ou a formação de gases residuais provenientes de reações químicas (BOGGS, 1990). Além de fatores relacionados ao processo de manufatura do isolante, a variedade de estresses a que o material é submetido ao longo de sua vida contribuem para o aparecimento de vacúolos gasosos (GJAERDE, 1997). 


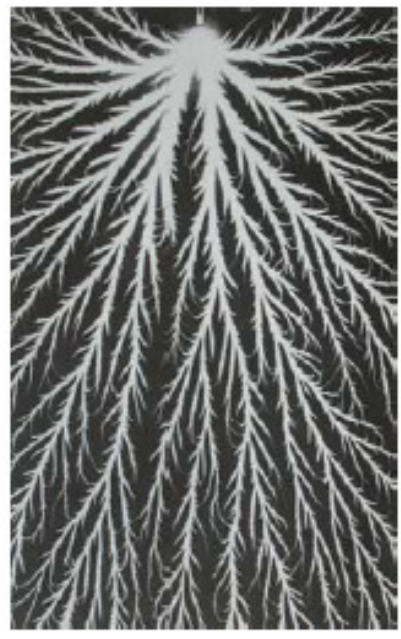

(A): streamer em ar.

Fonte: Lemke (1967).

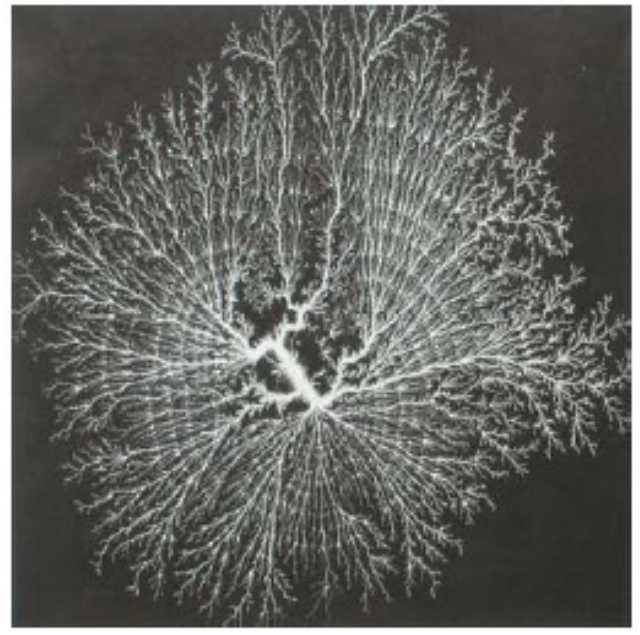

(B): leader discharge em óleo.

Fonte: Hauschild (1970).

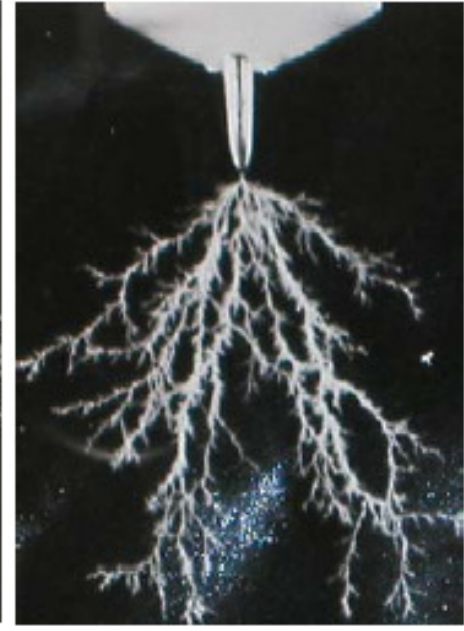

(C): treeing (arborescência) em polimetilmetacrilato.

Fonte: Pilling (1976).

Figura 3: Fotografias dos canais de descargas parciais.

Já em líquidos isolantes, a descarga parcial aparece com mais frequência em bolhas de gases. Estas bolhas são originárias a partir de fenômenos térmicos e elétricos e também devido à presença de vapor d'água, que pode ser gerado em regiões que tenham campo elétrico concentrado (LEMKE, 2008).

Há outro detalhe de que a descarga interna pode se dar numa região completamente circundada pelo dielétrico ou na interface entre o dielétrico e o eletrodo (KREUGER, 1989). No que tange as tensões de início e fim da descarga parcial, assim como a magnitude e o padrão da resolução em fase, estes parâmetros são regidos não somente pelo tipo de defeito e a pressão do gás nas cavidades internas, mas também pelo tipo de geometria que o defeito apresenta conforme mostra a Figura 4 (LEMKE, 2008).

Em componentes isolantes, as descargas internas são importantes quando se tratam de cabos e transformadores de potência e instrumentos que utilizam resina isolante fundida. Nestes casos, as "arborescências elétricas" (vide Figura 3(C)) podem se propagar de forma muito lenta ou rápida. De modo mais específico, a ruptura dielétrica pode ocorrer em alguns segundos ou pode demorar até anos para que o dielétrico seja completamente rompido. Ademais, a arborescência é um fenômeno de pré-ruptura que ocorre no material dielétrico. Sua origem é devida à contínua atividade de DPs, podendo estar presente em cavidades ou defeitos dos componentes 
isolantes ou ainda ocasionadas por algum tipo de falha na interface entre dielétrico e eletrodo (DISSADO, 1992; KREUGER, 1989).

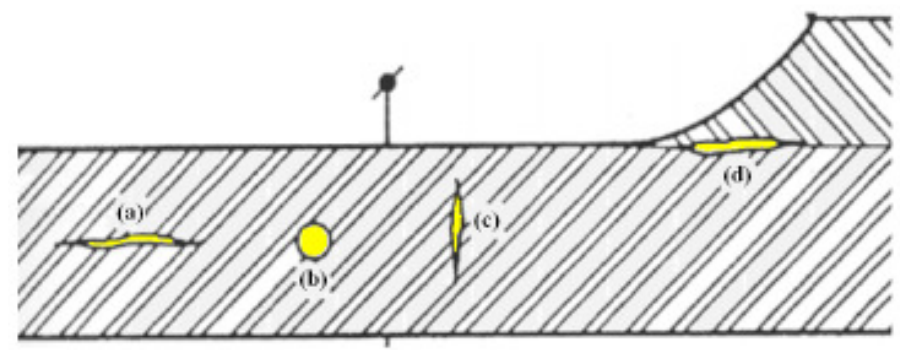

Figura 4: Tamanhos típicos de compartimentos gasosos em dielétricos sólidos.

Fonte: Modificado por Paulino (2010) de Kreuger (1989).

Vale salientar que as descargas internas também podem aparecer na interface de dielétricos sólidos e líquidos. Este tipo de situação pode ser danoso para o dielétrico sólido se houver a formação do "delta" ao longo deste. Também tem o caso das descargas internas em subestações isoladas a gás (GIS). Nesta situação, as descargas internas geralmente são iniciadas por partículas que são fixas ou livres, e também podem ser prejudiciais, pois há a possibilidade da dissociação do gás $\mathrm{SF}_{6} \mathrm{em}$ subprodutos. Há possibilidade da deterioração do material sólido isolante ou a criação substâncias perigosas tais que podem dar início à ruptura dielétrica total na ocorrência de uma sobretensão (LEMKE, 2008).

\subsubsection{Princípios físicos das DPs}

Para que uma DP aconteça em um vacúolo preenchido com algum tipo de gás, duas condições devem ser atendidas. Uma dessas condições que é necessária, mas não é suficiente, é que o campo elétrico no interior da cavidade, $E_{I}$, deve ser igual ou superior ao campo mínimo de ruptura $E_{R}$. Esta situação determina o campo elétrico $E_{I}$ que dá início à ocorrência das descargas (BOGGS, 1990; FUJIMOTO et al., 1992; MORSHUIS, 1993(a), 1995). Ademais, deve existir um campo elétrico, denominado campo de extinção $E_{E}$ que, abaixo deste, cessa a atividade de DP (NIEMEYER et al., 1991).

É importante ressaltar que as magnitudes de $E_{I}$ e $E_{R}$ são dependentes de diversos parâmetros, ou seja, das propriedades do gás presente na cavidade, como temperatura e, principalmente, a pressão, a geometria e o tamanho da cavidade e o 
mecanismo específico de descarga (DISSADO, 1992; FUJIMOTO et al., 1992; MORSHUIS, 1993(a), 1995; NIEMEYER, 1991). Se houver possibilidade de relacionar o valor de $E_{I}$ com a tensão aplicada, levando-se em consideração a forma e a localização da cavidade, bem como a presença de cargas superficiais, a tensão de início da descarga, PDIV ou $V_{I}$, pode ser estimada (BRAUN, 1991; FUJIMOTO et al., 1992). De igual modo, um valor de tensão, denominado tensão de extinção $(\mathrm{PDEV})$, pode ser relacionada ao campo $E_{E}$. Lembra-se que a norma ASTM D1868-07 (2007) menciona que os valores fixos de tensão de início, PDIV, e extinção, PDEV, da atividade de DP, na prática, são difíceis de serem obtidos em virtude dos muitos parâmetros que regem o fenômeno. Note que os autores citados estão de acordo com a norma, pois estes mencionam a possibilidade de se relacionar campo elétrico na cavidade com tensão aplicada, o que, na prática, é bem difícil de realizar.

Geralmente é estabelecida uma analogia entre descargas parciais ocorridas em cavidades circundadas por dielétrico e a ocorrência de descargas entre eletrodos metálicos. Dessa forma, os valores de $E_{R}$ e, consequentemente, a tensão de ruptura, $V_{R}$, descritos pela curva de Paschen, são bastante utilizadas em estudos de descargas ocorrendo nestas cavidades (MASON, 1995; MORSHUIS, 1995). Uma curva típica de Paschen, para o ar, está apresentada na Figura 5.

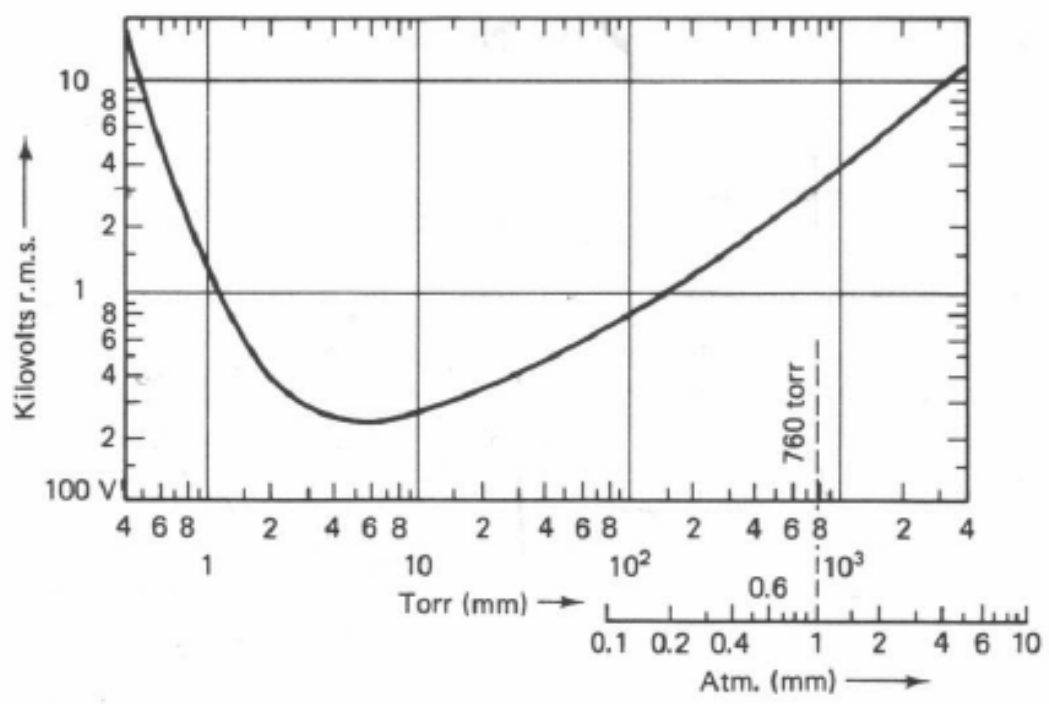

Figura 5: Curva de Paschen para o ar.

Fonte: Kreuger (1989). 
É importante mencionar que o valor de $V_{I}$ não é necessariamente o mesmo do valor de $V_{R}$ em virtude da existência de um tempo de atraso, $\Delta t$, para a ocorrência da primeira descarga. Portanto, a diferença entre $V_{I}$ e $V_{R}$ é denominada sobretensão $\Delta V$ (BOGGS, 1990; DEVINS, 1984; MORSHUIS, 1993(a)). A Figura 6 apresenta o início da ocorrência de uma descarga parcial descrita nestes termos.

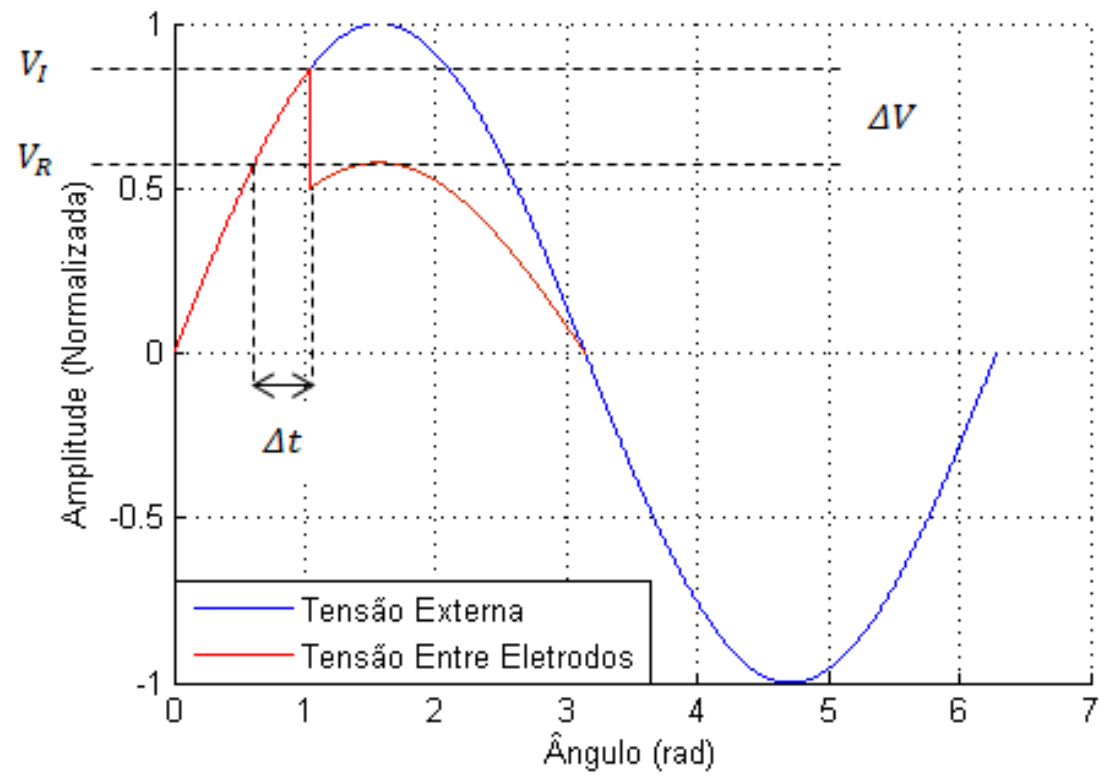

Figura 6: Representação do início da ocorrência de uma DP.

O campo elétrico na cavidade, $E_{I}$, pode ser calculado em função do campo elétrico macroscópico médio aplicado no restante do material dielétrico ou em função do campo aplicado $E_{A}$. Isto é possível desde que esta cavidade possua uma geometria regular, o dielétrico seja considerado homogêneo e não haja presença de cargas superficiais e espaciais no interior da cavidade. Para uma cavidade que seja plana, tem-se:

$$
E_{I}=\varepsilon_{r} E_{A}
$$

Para uma cavidade esferoidal, segue:

$$
E_{I}=\frac{3 \varepsilon_{r}}{1+2 \varepsilon_{r}} E_{A}
$$


Onde $\varepsilon_{r}$ é a permissividade relativa do dielétrico. Para ilustrar, os valores da permissividade relativa do polietileno e do epóxi são 2,2 e 4,0 respectivamente (KU, 1987). A magnitude de $E_{A}$ é proporcional à tensão aplicada $V_{A}$ (GUTFLEISCH et al., 1995; KREUGER, 1989).

Com a primeira condição satisfeita, deve-se agora fornecer um elétron à cavidade para que o processo de avalanche eletrônica seja desencadeado e, consequentemente, o processo de descarga seja iniciado. Há dois principais mecanismos de geração de elétrons iniciais que são: a fotoionização do gás no interior do vazio e a emissão de elétrons a partir da superfície interna da cavidade (EDIN, 2001).

O processo de fotoionização consiste basicamente na ionização das partículas de gás a partir da absorção de radiação proveniente de uma fonte externa (HOWATSON, 1970; NASSER, 1971). No caso de descargas parciais em cavidades gasosas, o processo de fotoionização depende da interação entre a radiação cósmica, ou radiação de fundo, com o gás presente nesta cavidade ou com a própria superfície desta cavidade (GUTFLEISCH, 1995). Salienta-se que o processo de geração de elétrons iniciais pode ainda ser induzido através de outros tipos de radiação ionizante. Dentre estes se encontram os raios- $\gamma$, raios-X e raios-UV (NIEMEYER, 1991).

Sobre o processo de fotoionização, quando um átomo absorve um fóton incidente (fotoabsorção), há possibilidade da ocorrência de dois fenômenos. No primeiro, denominado fotoexcitação, um elétron sai de uma banda de menor energia para uma banda com maior energia. Ao retornar à banda original, o excesso de energia será devolvido na forma de um novo fóton. No segundo fenômeno, denominado fotoionização, o fóton possui energia suficiente para ionizar um átomo e, dessa forma, produzir um fotoelétron. É importante salientar que o fenômeno de fotoionização também pode ocorrer como resultado da radiação emitida pelo próprio gás. Isto se dá quando átomos excitados retornam ao seu estado fundamental, ou quando átomos ionizados reagem com íons negativos para formarem moléculas neutras (HOWATSON, 1970; NASSER, 1971).

Com respeito ao mecanismo de emissão, na realidade, são dois mecanismos possíveis: emissão por campo e emissão por impacto de moléculas metaestáveis deixadas por descarga prévia. Antes de a primeira descarga acontecer, o número de elétrons localizados em armadilhas próximas ou na superfície da cavidade é muito 
pequeno e, portanto, a probabilidade de ocorrer à emissão por campo é muito baixa. Ademais, para que o processo de emissão por campo ocorra, a necessidade de que um campo elétrico elevado seja aplicado no corpo de prova deve ser satisfeita (GUTFLEISCH, 1995). Uma vez iniciada a atividade de DP, há elevação do número de elétrons disponíveis na superfície da cavidade. Consequentemente, a probabilidade de emissão por campo aumenta devido ao processo de emissão por impacto (NIEMEYER, 1991).

Sabe-se que o processo de geração de elétrons iniciais é estocástico. Esta situação configura-se na principal causa do caráter aleatório das atividades das DPs. Portanto, existe um tempo estatístico de atraso $(\Delta t)$ que é o tempo necessário para que a primeira descarga ocorra (DISSADO et al., 1992; MORSHUIS, 1993(a), 1995; NIEMEYER, 1991). Este tempo depende da taxa de elétrons criados e do campo aplicado. A taxa de geração de elétrons em uma cavidade de $1 \mathrm{~mm}^{3}$, nas condições ambiente, é em torno de $4 \times 10^{-3}$ elétrons/segundo; isto resulta num $\Delta t$ de aproximadamente 10 minutos (MORSHUIS, 1993(a)). Sendo assim, pode ocorrer durante um teste de DP na forma convencional, isto é, aplicação de um campo muito elevado em um tempo muito curto (em média 1 minuto), o campo mínimo de ruptura ser facilmente excedido, sem a ocorrência, todavia, da DP (BOGGS, 1990). Ademais, neste tipo de ensaio, a aplicação de um campo elevado pode comprometer a vida útil do sistema de isolação em teste (FUJIMOTO et al., 1992).

Ocorrendo a primeira descarga, as próximas descargas apresentarão tempos de atraso $(\Delta t)$ bastante pequenos, da ordem de milissegundos, sendo este valor diversas ordens de grandeza maior que o tempo de formação de uma avalanche eletrônica (BOGGS, 1990; DISSADO et al., 1992; MORSHUIS, 1993(a), 1995). Dessa forma, a sobretensão $\Delta V$ obtida a partir da curva de Paschen é considerada o parâmetro de maior importância no processo de descarga por estresse elétrico (DEVINS, 1984; MORSHUIS, 1993(a)).

\subsubsection{DPs em tensões alternadas}

De modo simplificado, existem duas aproximações distintas que são utilizadas para descrição do comportamento das DPs em cavidades quando uma tensão alternada é aplicada: o modelo de circuito equivalente e o modelo de aproximação por campo elétrico. 
O primeiro modelo, denominado de circuito a-b-c, busca apresentar um circuito equivalente que é, na realidade, uma aproximação simplificada para facilitar a compreensão da ocorrência das descargas parciais em tensão alternada (BARTNIKAS, 1979). A Figura 7 apresenta um esquema ilustrativo deste modelo como um todo, ou seja, o isolante contendo uma cavidade e o circuito equivalente. Sobre o circuito apresentado na Figura $7(\mathrm{~B})$, tem-se que " $C_{a}$ " corresponde à capacitância do dielétrico em bom estado, ou seja, como se não houvesse a cavidade; " $C_{b}$ " representa a capacitância do dielétrico em série com a capacitância da cavidade, representada por " $C_{c}$ ". A chave $S$ simula a descarga e é controlada pela tensão $V_{C}$ aplicada à cavidade. Esta chave permanece fechada por um curto período de tempo, no qual a correte $i_{C}(t)$ está presente. $O$ resistor $R_{C}$ simula o período de tempo durante o qual a descarga se desenvolve e é finalizada. A descarga de corrente $i_{C}(t)$, a qual não pode ser medida, teria uma forma regida pelos processos de descarga em ar, e, em geral, é similar a uma função de Dirac. D'outra forma, geralmente esta descarga de corrente é um pulso bastante curto da ordem de nanossegundos (KUFFEL et al., 2000).

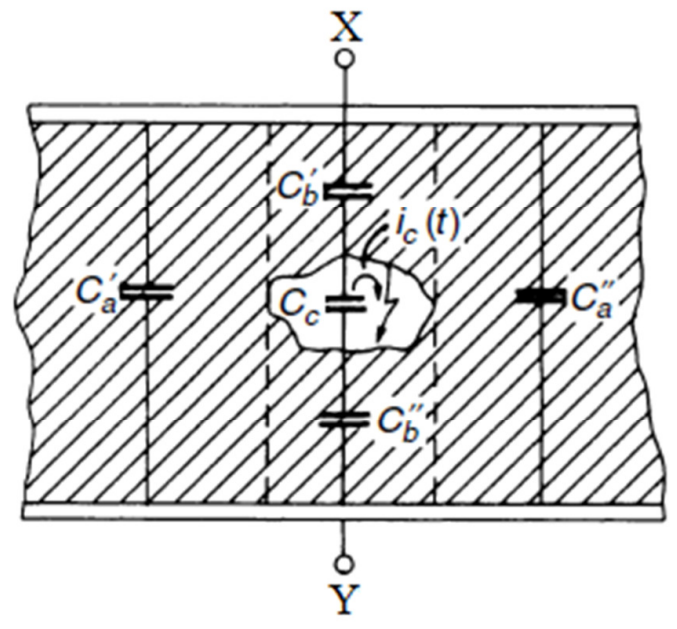

(A)

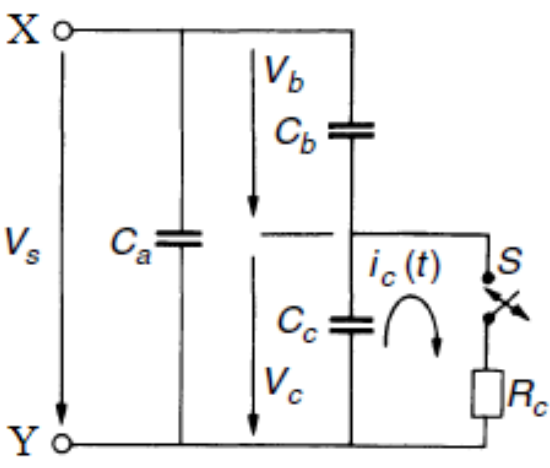

(B)

Figura 7: Modelo a-b-c para DPs em tensões alternadas. (A): Esquemático de um isolante contendo uma cavidade. (B): Circuito equivalente.

Fonte: Modificado de Kuffel et al. (2000).

De acordo com este modelo, quando a tensão $V_{C}$ no interior da cavidade atinge a tensão de início, $V_{I}$, uma descarga ocorre na cavidade e a tensão elétrica cai. Terminada a descarga, a tensão sobre a cavidade torna a aumentar. Esta tensão é 
obtida pela superposição do campo elétrico aplicado e do campo residual formado pelas cargas superficiais que foram deixadas na parede da cavidade depois da última descarga. Novamente, quando a tensão sobre a cavidade atinge a tensão de início, uma nova descarga ocorre. Este fenômeno repete-se diversas vezes no decorrer do semiciclo da tensão alternada, de forma que é possível encontrar grupos regulares de descargas recorrentes (BARTNIKAS, 1979; KREUGER, 1989).

É importante observar que o modelo a-b-c não considera fatores como geometria, localização da cavidade e presença de cargas espaciais. Portanto, a simples operação do circuito equivalente não corresponde, necessariamente, a gama de processos físicos que se desenvolvem em um sistema físico real (KELEN et al., 1995; McALLISTER, 1997; PEDERSEN et al., 1991). Buscando-se uma representação mais próxima do real, outros modelos têm sido propostos. Estes modelos se baseiam em circuitos com parâmetros distribuídos e na utilização de softwares especiais de projeto e simulação (AGORIS et al., 1993; GAFVERT et al., 2003; KOLEV et al., 1999).

Para uma representação um pouco mais próxima do real, tem sido proposto um modelo por aproximação de campo elétrico, apresentado na Figura 8. Este modelo, embora qualitativo, é útil para uma melhor explicação dos fenômenos que regem uma descarga parcial em tensão alternada (BOGGS, 1990; EDIN, 2001).

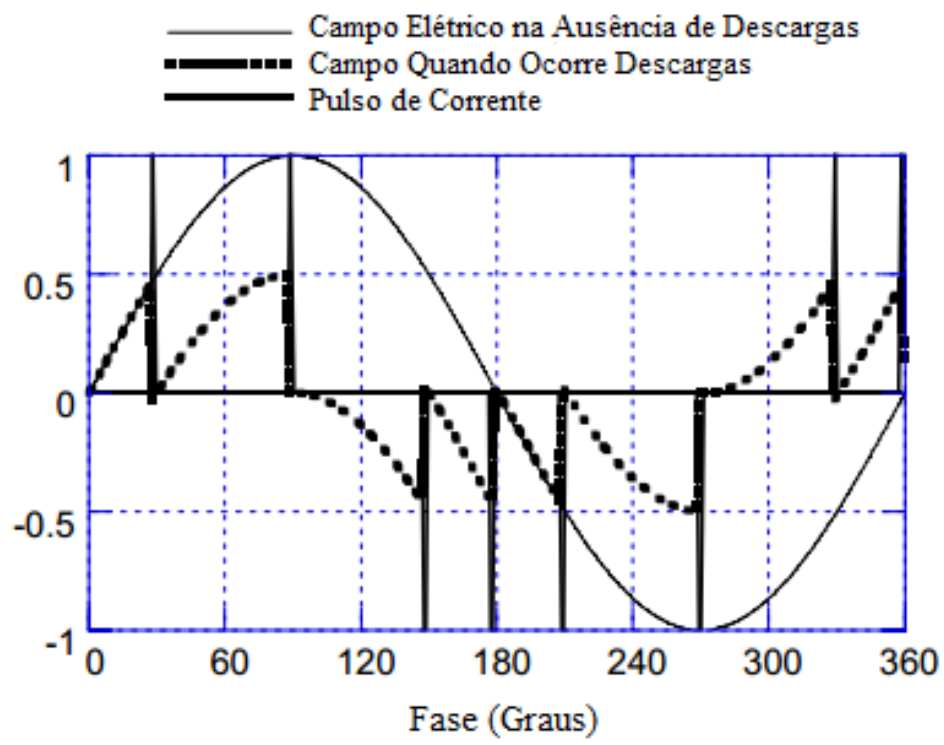

Figura 8: Ocorrência de DPs na presença de tensão alternada.

Fonte: Modificado de Edin (2001). 
O modelo por aproximação de campo considera uma cavidade esférica envolta por algum material dielétrico, e uma tensão AC é aplicada ao dielétrico por meio de dois eletrodos metálicos, conforme apresenta a Figura 9. Antes de tudo, não há presença de cargas superficiais e espaciais. Ademais, antes da ocorrência da primeira descarga, o campo elétrico na cavidade é aproximadamente uniforme, ou seja, de certa forma o mesmo em todos os pontos da cavidade. Também considera que este campo varia proporcionalmente à tensão aplicada. Com as condições de ocorrência da DP satisfeitas, a primeira descarga é disparada. Nisto, as cargas liberadas neste evento são aceleradas pelo campo local para as paredes da cavidade, onde são depositadas. Dessa forma, o campo local passa a ser a superposição, ou a soma, do campo devido à tensão aplicada ao dielétrico e do novo campo gerado pelas cargas superficiais e espaciais. As próximas descargas serão regidas pelo campo total no interior da cavidade, de forma que a descarga seguinte ocorrerá quando o campo de início for novamente atingido. É importante frisar que o processo de descarga parcial pode ocorrer mesmo quando a tensão externa aplicada for nula. Isto é verdade, pois, as cargas depositadas na parede da cavidade podem fazer com que o campo interno seja suficientemente grande de forma a causar uma nova descarga. Portanto, o campo gerado pelas cargas depositadas provoca uma mudança na atividade da DP de modo que o processo passa a ser regido pelo campo elétrico local e não mais pela tensão aplicada. (BOGGS, 1990; EDIN, 2001).

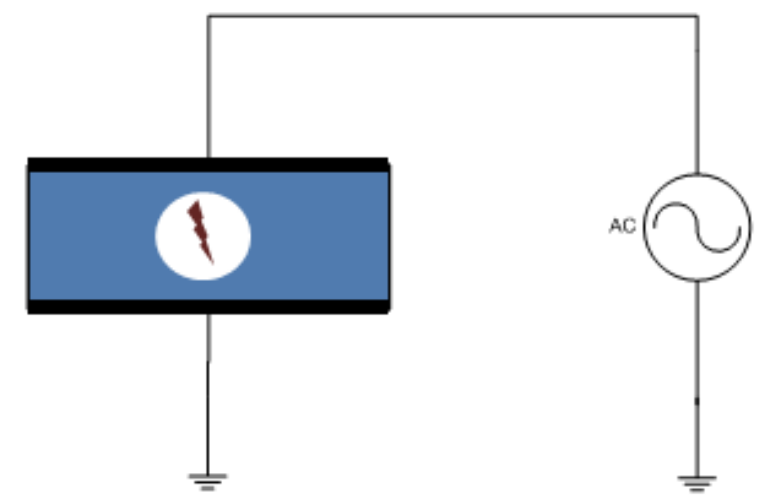

Figura 9: Esquemático do modelo por aproximação de campo.

Em Morshuis (1993 (a)) existe um estudo bastante amplo referente aos mecanismos e processos físicos relacionados na ocorrência de descargas parciais em cavidades para tensões alternadas. Este estudo menciona que, sendo satisfeitas as 
condições necessárias para o início da descarga e, uma vez iniciado o processo de avalanche eletrônica, uma quantia razoável de cargas espaciais é construída na cavidade. Nesta situação, a característica da descarga na cavidade passa a ser determinada por dois processos que são competitivos entre si:

- o primeiro é o processo de ionização do gás interno à cavidade. Este processo reforça o campo no interior desta cavidade por meio do acúmulo de cargas espaciais formada por íons positivos;

- no segundo, a corrente de deslocamento, fluindo pelo circuito externo, faz com que o campo local seja reduzido.

Portanto, qual dos dois processos será dominante dependerá do valor da sobretensão aplicada. Esta é a diferença entre a tensão de início da descarga e a tensão mínima de ruptura determinada pela curva de Paschen (vide Figuras 5 e 6).

Pode-se estabelecer uma comparação entre os mecanismos de descargas ocorridas em gás para eletrodos metálicos e os mecanismos de DPs ocorridas em cavidades fechadas. Estes mecanismos, para as DPs, são denominados avalanche (Townsend) e canal (Streamer) (BARTNIKAS et al., 1993, MORSHUIS, 1993(a)). Para sobretensões elevadas, em torno de 5\%, o processo de construção de carga espacial se dá de forma rápida e o mecanismo dominante é o tipo canal. Já para o caso de sobretensões baixas, tipicamente 1\%, ocorre que o efeito da construção da carga espacial é superado pelo da corrente de condução e, neste caso, o mecanismo predominante é o tipo avalanche. Simplificadamente, a descarga do tipo avalanche, como o nome o diz, consiste de uma avalanche autossustentada com sucessores iniciados no catodo. Já a descarga tipo canal consiste basicamente de avalanches sucessivas, iniciadas no próprio gás presente no interior da cavidade e a partir de fótons de alta energia. Estas avalanches sucessivas, por sua vez, são geradas a partir da ionização do campo de carga espacial (MORSHUIS, 1993(a)). Os autores Bartnikas et al. (1979), Devins (1984) e Dissado et al. (1992) apresentam maiores detalhes dos mecanismos de descarga Townsend e Streamer. Um dado importante é que pode ser feita uma distinção entre as descargas tipo avalanche e canal quanto às suas respectivas magnitudes, ou seja, a descarga tipo avalanche tem sua magnitude aumentando linearmente com a sobretensão e independe da altura da cavidade. Já a descarga tipo canal tem sua magnitude praticamente insensível ao aumento da sobretensão e esta descarga aumenta de acordo com o tamanho da cavidade. 


\subsubsection{Relação entre a DP e a degradação dos isolantes}

As DPs provocam degradação num dielétrico devido, grosseiramente, a dois principais processos: oxidação do polímero e ataques por particulados nitrogenados (íons de nitrogênio). A interação entre a atividade de DP numa cavidade ou vacúolo e a região dielétrica que a cerca é bastante complexa e muitos parâmetros relacionados a isto foram identificados e estudados. Parte da complexidade deriva do fato que o material dielétrico é modificado (envelhece) em virtude da atividade de descarga parcial, ao mesmo tempo em que os mecanismos da descarga parcial mudam com o envelhecimento do material dielétrico (MORSHUIS, 1993(b); TEMMEN, 2000). Porém, quando a cavidade está constantemente submetida a estresse elétrico e a ocorrência de DPs, pode ser estabelecida uma relação entre os mecanismos de descarga tipo avalanche e canal com estágios de envelhecimento do material (MORSHUIS, 1993(a), 1995).

Na ocorrência contínua de DPs sob a ação de campos elétricos alternados elevados, a degradação por ataque de íons de nitrogênio leva a formação de pits, ou fossos, na superfície do dielétrico (MORSHUIS, 1995). Caso haja oxigênio no interior da cavidade, produtos altamente oxidantes, como o ozônio, serão formados no processo de descarga. Com a ocorrência de reações químicas, os gases hidrogênio, monóxido de carbono, metano e dióxido de carbono são produzidos (TANAKA, 1986; WOLTER et al., 1982). Os gases gerados podem, então, reagirem com radicais poliméricos produzindo ácidos que tem a características de serem condutivos. Os subprodutos destas reações químicas depositam-se na cavidade onde ocorria a DP (HOLBOLL, 1992; HUDON et al. 1990; MORSHUIS, 1990, 1993(a)). Como resultado, o campo ao redor da cavidade é reduzido, e as descargas, extintas (GAMEZ-GARCIA, 1987). Note-se que cavidades inicialmente preenchidas com ar são, em geral, uniformemente oxidadas, o que acaba gerando uma camada condutiva de alguns micrometros. As reações químicas prosseguem até que todo o oxigênio seja consumido. Daí o bombardeamento por íons de nitrogênio leva a ocorrência de pitting e, posteriormente, à formação de treeing (arborescências) (KIM et al., 2004; TANAKA, 1986). De modo geral, estes efeitos tem como consequência a redução do tempo estatístico de atraso e da tensão de início (GUTFLEISCH et al., 1995; MORSHUIS, 1993(a), 1995). 
Especificamente para cavidades, como já foi mencionado, o modelo a-b-c tem sido utilizado apenas para explicar a distribuição de tensões no dielétrico, conforme apresentou a Figura 7. Entretanto, a análise do modo progressivo de falha destas cavidades tem sugerido a existência de uma componente resistiva em paralelo com a capacitância que representa a cavidade. Ademais, as descargas, uma vez iniciadas, usualmente crescem em magnitude com o tempo de stress a que esta cavidade está submetida; todavia, estas descargas podem se tornar curtos-circuitos em decorrência de filmes semicondutores produzidos dentro da cavidade. Dessa forma, ocorre a extinção destas descargas. Estes filmes semicondutores, citados anteriormente, podem ser constituídos da carbonização de elementos orgânicos isolantes da própria cavidade do material, devido à presença do arco elétrico. Portanto, o modelo de DP de uma cavidade é semelhante ao modelo do próprio meio isolante (FLURSCHEIM, 1982; PAOLETTI, 1999).

Modos de falha real tem indicado uma queda na intensidade da DP pouco antes de ocorrer à falha propriamente dita. Isto se dá quando o arco interno carboniza uma região onde a componente resistiva do modelo torna-se pequena o suficiente de modo a evitar um acúmulo de tensão sobre a cavidade. Esta nova e pequena componente resistiva permite maiores fluxos de corrente e, consequentemente, aquecimento adicional e danos ao material. O modelo em questão, um capacitor em paralelo com uma resistência, se correlaciona com o modo real de falha da DP numa cavidade, com a componente resistiva permitindo a passagem de mais corrente de fuga do que o aumento da DP no decorrer do tempo. Uma das formas de se constatar este componente resistivo é por meio do fenômeno da arborescência ocorrida na superfície de um material isolante. A relação entre a arborescência e a atividade de DP numa superfície isolante é da seguinte forma: danos de arborescência são precedidos inteiramente por intenso aquecimento causado por correntes de fuga. Estas correntes fluem através de qualquer película de umidade presente na superfície isolante. Tendo em vista que a película é bastante ampla e contínua, o calor associado à corrente de fuga é espalhado sobre uma vasta área e é dissipado. Entretanto, o aquecimento provoca a evaporação da película. Isto faz com que a película se divida em pequenas "piscinas" ou "ilhas". Cada ruptura na película tende a interromper um segmento de corrente de fuga, causando um minúsculo arco elétrico. Embora o arco seja de pequena intensidade, isto resulta num aquecimento local. O calor causado pelo arco da corrente de fuga é suficiente para causar o colapso molecular e químico da isolação de base. Em materiais orgânicos, um subproduto 
frequentemente encontrado pela ação do arco é o carbono. Dessa forma, esse minúsculo arco ocorrendo ao longo da superfície pode ser representado pela atividade de DPs (PAOLLETI, 1999; WESTINGHOUSE, 1976). A Figura 10 apresenta o modo de falha na deterioração de uma isolação relacionada ao comportamento da intensidade da DP.

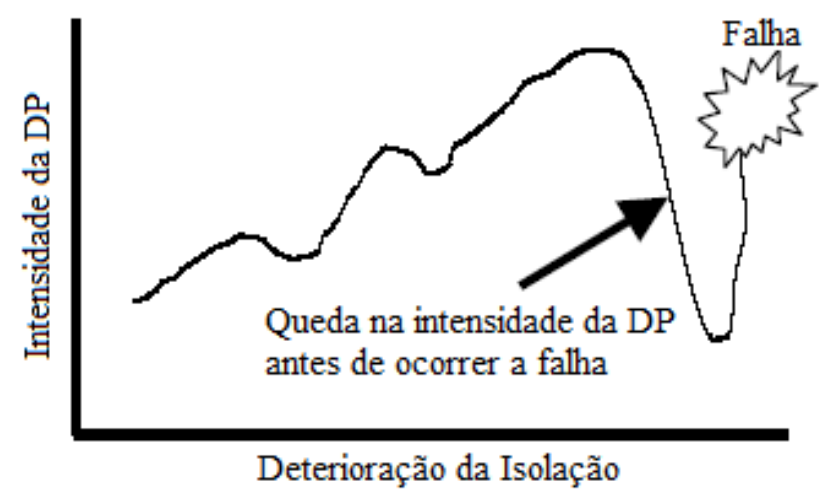

Figura 10: Intensidade da DP versus a deterioração da isolação.

Fonte: Modificado de Paoletti (1999).

A importância deste tipo de informação (Figura 10) reside no fato de que, monitorando-se constantemente um equipamento desde o início de seu funcionamento, pode-se relacionar a intensidade da DP com a situação do dielétrico que o compõe. Não que isto signifique que o equipamento deva ser posto fora de operação imediatamente no caso de uma queda brusca na intensidade da DP; porém, uma análise mais acurada deve ser realizada para averiguar a real gravidade do problema.

\subsection{Métodos de detecção de DP}

Antes de apresentar os métodos de detecção propriamente dito, Muhr et al. (2005) menciona que, no contexto de aparatos gerais de alta tensão, quando se comenta sobre a medição, detecção e análise de DPs, na realidade é referida uma possível forma de diagnóstico num equipamento de alta tensão. Para ser mais específico, existem três formas possíveis de se fazer diagnósticos em aparatos de alta 
tensão, de modo que a análise de DPs é um destes modos. No decorrer do texto a seguir, tem-se uma breve descrição de dois destes modos: a análise do dielétrico e tensão de ruptura, e um detalhamento maior no método de detecção, medida e análise de DPs.

- Diagnóstico do Dielétrico. Basicamente se trata da observação e avaliação do efeito entre o campo eletromagnético e o material. Num dielétrico há diferentes mecanismos de polarização, e a reação deste dielétrico frente a estes mecanismos é analisada. O tipo de material presente com seus devidos parâmetros como capacitância, fator de dissipação e resistência de isolamento podem contribuir com informações sobre mudanças na estrutura do dielétrico. Dessa forma, o objetivo é a detecção de mudanças estruturais, umidade, poluição e descargas elétricas (MUHR et al., 2005).

- Diagnóstico de tensão de ruptura. Este método abrange os procedimentos para a determinação da rigidez dielétrica do material isolante em determinadas condições. Dessa forma, defeitos no material ou na estrutura podem ser indicados com a aplicação apropriada de modelos de teste ou no próprio componente. A ideia básica do teste da tensão de ruptura é aplicar alta tensão ao isolador ou material isolante de forma que se limite a corrente elétrica. A tensão é elevada até que seja alcançado o nível desejado. Se o meio ou dispositivo oferece resistência suficiente à tensão aplicada, a ruptura dielétrica dá lugar a um arco elétrico. Salienta-se que o gerador de tensão deve limitar a corrente de modo a limitar a energia do arco elétrico. Sendo assim, danos não serão causados na área que o arco ocorre e investigações futuras poderão ser realizadas. Diversas formas de tensão, como por exemplo, contínua, degrau ou ainda rampa, são utilizadas para o diagnóstico da tensão de ruptura. A tensão admissível que o material suporta pode ser avaliada com a aplicação de tensão contínua, crescente ou ainda simétrica de modo a promover a auto cura do material, tais como em gases e líquidos. Nos sólidos, a ruptura conduz a destruição do material e perda do dispositivo (MUHR et al., 2005).

- Diagnóstico por DP. Diagnosticar um equipamento por descarga parcial é uma das formas de se averiguar a integridade de seus componentes isolantes, visto que a DP ocorre em virtude de imperfeições presentes no próprio 
dielétrico, quer seja gás, líquido ou sólido. Evidente que o evento em si da DP tem um tempo de atuação bastante curto sobre dielétrico. Por outro lado, a atividade constante da DP pode ter um efeito bastante danoso em sistemas de isolamentos a base de compostos orgânicos, degradando as características elétricas destes componentes. Isto pode levar a uma ruptura do dielétrico e, consequentemente, a uma falha do equipamento (MUHR et al., 2005).

A multiplicidade de fontes de DPs bem como as diversas caraterísticas peculiares presentes neste fenômeno, como por exemplo, a sobreposição de DPs, colocam exigências elevadas para o processo de diagnóstico. Portanto, vários métodos têm surgido na literatura de modo a suprir os diversos problemas que se tem encontrado no diagnóstico de DPs. Notar-se-á que não existe um método que solucione todos os problemas referentes ao diagnóstico de DP, mas que um método pode servir para complementar outro.

A Figura 11 apresenta os principais métodos que serão abordados nesta dissertação. Evidente que os métodos são genéricos, ou seja, aplicáveis a vários equipamentos. Porém, o foco é estudar estes métodos com aplicação em transformadores. Os itens a seguir discutem os métodos listados com um foco maior no método acústico, que é a proposta de aplicação do transdutor de piezoeletreto.

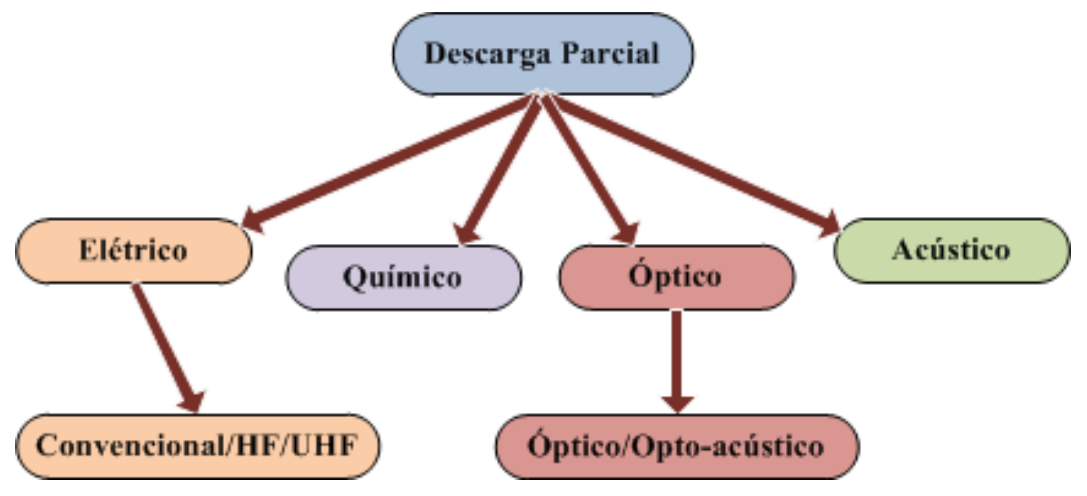

Figura 11: Categoria dos métodos de detecção de descargas parciais. 


\subsubsection{Método elétrico}

Como já fora apresentado na Figura 11, existem três formas de detecção de DPs no que tange ao método elétrico. Os itens a seguir apresentarão brevemente os circuitos e sensores quanto às formas de detecção deste método.

\subsubsection{Método elétrico convencional}

Para o caso do método elétrico convencional, existem três circuitos básicos, apresentados na Figura 12, para mediação de DPs que diferem entre si no arranjo da impedância de mediação $Z_{m}$. Estes circuitos podem ser inferidos da norma IEC 60270 . De modo geral, a ideia de medição trata-se de uma queda de tensão sobre uma impedância de medição, queda esta causada por impulsos de corrente no circuito exterior à amostra. Geralmente, a impedância de medição consiste num resistor de mediação, um indutor para filtrar as correntes de determinadas frequências e um capacitor de medição.

Na Figura 12(A), a impedância de medição $Z_{m}$ está em série com o capacitor de acoplamento $C_{k}$. O filtro de ruído, denotado por $Z_{n}$, tem a intenção de bloquear ruídos eletromagnéticos provenientes do lado de alta tensão do transformador de teste $T_{r}$. Também impede a fuga do sinal de DP pelo lado de alta tensão do transformador. Ademais, deve ser tomado o devido cuidado para que as conexões de alta tensão e aterramento sejam projetadas de tal forma que se elimine ao máximo as interferências eletromagnéticas sobre os resultados dos testes de descarga parcial (LEMKE, 2008). Note ainda que, neste tipo de configuração, o objeto de teste possui uma extremidade aterrada. Dessa forma tem-se a vantagem de que o equipamento de medição é protegido de falhas provenientes do objeto em ensaio (CUENCA, 2005). Já na Figura 12(B), a impedância de medição $Z_{m}$ está conectada em série com o terra do objeto de teste. Isto faz com que a sensibilidade de detecção da DP aumente substancialmente. Neste caso, o caminho de retorno para os transientes de altas frequências das DPs é formado pelo capacitor de acoplamento $C_{k}$. Este circuito, entretanto, requer uma interrupção da conexão de terra do aparato de alta tensão sob teste. Na prática isto é possível somente em alguns casos. Esta configuração de circuito é utilizada em situações que lado de baixa tensão do objeto de teste fica isolado do aterramento. Note: a corrente que flui através do objeto de ensaio também está passando pela impedância de medição $Z_{m}$. Pode acontecer que esta corrente seja extremante 
elevada, na ocorrência inesperada de um breakdown (ruptura dielétrica), de modo que se configure numa situação de risco para a impedância de mediação $Z_{m}$ (LEMKE, 2008).

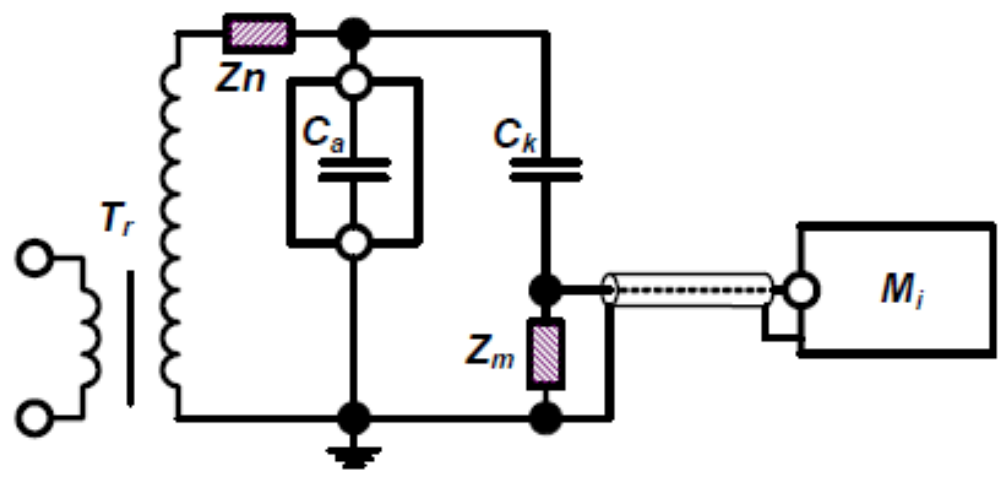

(A): Impedância de medição $Z_{m}$ em série com o capacitor de acoplamento $C_{k}$.

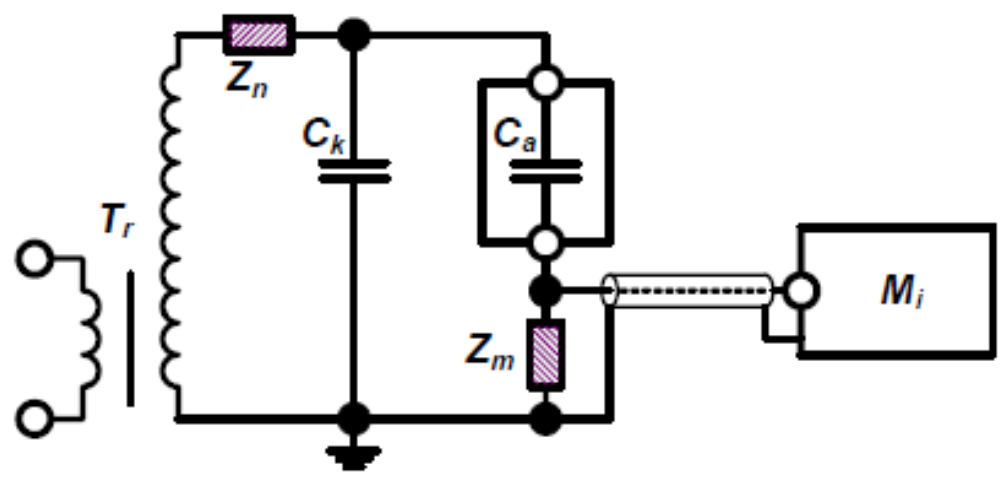

(B): Impedância de medição $Z_{m}$ em série com o objeto de teste $C_{a}$.

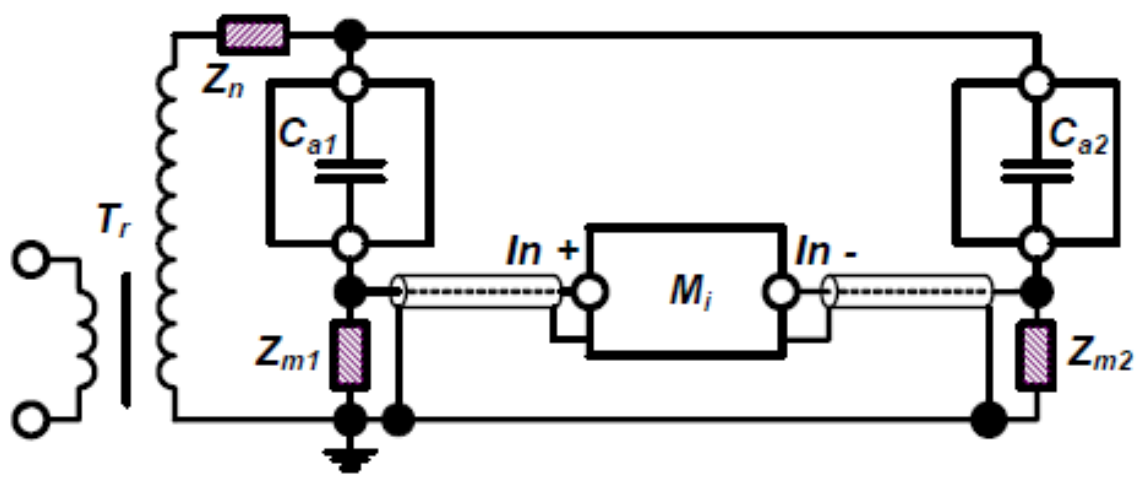

(C): Ponte balanceada utilizando o braço $\left(C_{a 2}, Z_{m 2}\right)$ como referência em paralelo com o braço de teste $\left(C_{a 1}, Z_{m 1}\right)$.

Figura 12: Circuitos básicos para medição de DPs.

Fonte: Modificado por Lemke (2008) de B S (2001). 
Sendo:

$$
\begin{aligned}
T_{r}=\begin{array}{l}
\text { Transformador de teste de alta } \\
\text { tensão. }
\end{array} & Z_{n}=\text { Filtro de ruído. } \\
C_{a}=\begin{array}{l}
\text { Capacitância do objeto de teste. } \\
\text { Impedância de medição como }
\end{array} & C_{k}=\begin{array}{l}
\text { Capacitor de acoplamento. } \\
Z_{m}=\begin{array}{l}
\text { parte do dispositivo de } \\
\text { acoplamento. }
\end{array}
\end{array} M_{i}=\begin{array}{l}
\text { Equipamento de medição de } \\
\text { DP. }
\end{array}
\end{aligned}
$$

Por fim, na Figura 12(C), a forma de medição é em ponte equilibrada. A ideia é a eliminação em certa medida de ruídos eletromagnéticos que perturbam sensivelmente as medidas de descargas parciais. Nesta topologia, ambos os braços, o de medição e o de referência, tem composição similar à configuração ilustrada na Figura 12(B), ou seja, o capacitor de acoplamento $C_{k}$ não é utilizado. Com o ajuste das impedâncias $Z_{m 1}$ e $Z_{m 2}$, a ponte pode ser balanceada de forma que os ruídos de modo comum possam ser eliminados eficazmente por meio do amplificador diferencial, que geralmente é parte integrante do instrumento de medida de DPs. De modo a garantir alta rejeição de modo comum, a ponte deve ser construída a mais simétrica possível. Dessa forma, é aconselhável utilizar um objeto de ensaio complementar no ramo de referência, em que os parâmetros como capacitância virtual, geometria entre outros sejam equivalentes ao objeto de ensaio. O desempenho da rejeição de ruídos pode ser melhorado ainda mais se o amplificador diferencial é combinado diretamente com as impedâncias de medição $Z_{m 1}$ e $Z_{m 2}$, colocadas dentro da área de alta tensão sob teste (LEMKE, 2008).

É importante observar que, das possibilidades de circuito de medição oferecidas pela norma IEC 60270, a configuração mais utilizada é a que está apresentada na Figura 12(A). Nessa topologia de circuito, o capacitor de acoplamento impede que a tensão nas frequências industriais seja transferida para a impedância de medição, e assim torne-se num caminho preferencial para os pulsos de corrente de DPs. Todavia, menciona-se que, a devida escolha do circuito de medição deve estar atrelada às características do equipamento que se deseja medir as DPs. Um exemplo disto é o caso de se medir DPs em equipamentos que possuam capacitância elevada, como capacitores de potência. Neste caso, o circuito que mais se adequa é o ilustrado na Figura 12(C). Para o caso de medição de descargas parciais em transformadores de potência, pesquisas têm sido desenvolvidas por várias décadas, de modo que se 
formaram linhas de pesquisas em detecção e localização de DPs. Nas duas situações, detecção e localização, várias condições são requeridas, como, por exemplo, baixo nível de ruído, calibração e sensibilidade adequada dos instrumentos de medição. Um detalhe importante a ser observado é que a medição de DPs em transformadores é dificultada pela acessibilidade aos circuitos internos e complexidade dos mesmos, que são extremamente indutivos (CUENCA, 2005)

Em transformadores, a norma IEC 60270 dá diretriz quanto a contornar os problemas de medição de DPs. Nesse caso, o método de medição se dá por meio de uma bucha, que na realidade é um tap capacitivo. A Figura 13 apresenta o esquemático do circuito como um todo.

Nesta configuração, o capacitor de acoplamento $C_{k}$ é equivalente à capacitância da bucha de alta tensão $C_{1}$, e a impedância de medição, como parte essencial do dispositivo de acoplamento, é conectada ao tap de uma bucha capacitiva graduada, geralmente destinada à medição de fator de perda. Ressalta-se que este tipo de circuito é utilizado com grande eficácia em ensaios de tensão induzida em líquidos imersos em transformadores de potência (LEMKE, 2008).

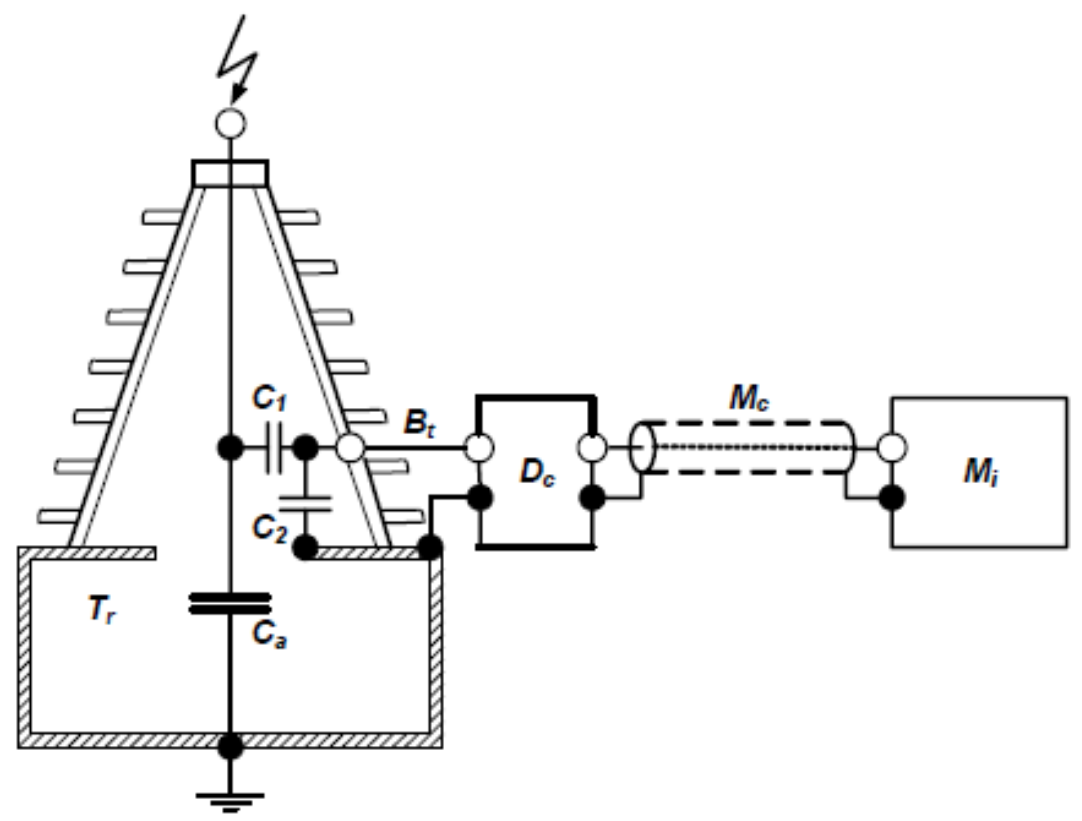

Figura 13: Modo de acoplamento via tap capacitivo.

Fonte: Lemke (2008). 
Sendo:

$T_{r}=$ Transformador sob teste. $\quad B_{t}=$ Tap da bucha.

$C_{a}=$ Capacitância do objeto de teste. $\quad D_{c}=$ Dispositivo de acoplamento.

$C_{1}=\begin{aligned} & \text { Capacitância de alta tensão da } \quad M_{c}=\text { Cabo de Medida. } \\ & \text { bucha. }\end{aligned}$

$C_{2}=\begin{aligned} & \text { Capacitância de baixa tensão da } \quad M_{i}=\text { Instrumento de medida } . \\ & \text { bucha. }\end{aligned}$

Portanto, os principais componentes dos circuitos utilizados para medição de DPs estão apresentados na Figura 14. Um detalhe importante a salientar é que a ideia de funcionamento do capacitor de acoplamento é a transferência de altas frequências dos sinais de DPs, proveniente da capacitância $C_{a}$ do objeto de teste, para o dispositivo de acoplamento. Simultaneamente, a tensão de ensaio é atenuada a um nível que não ofereça risco ao sistema de medição. Nota-se que a capacitância $C_{k}$ deve ser escolhida suficientemente grande de forma a minimizar a interferência de capacitâncias parasitas do circuito de medição. Estas interferências atuam de forma a reduzir as magnitudes dos pulsos de descarga parcial que são transferidos ao dispositivo de acoplamento. Ademais, a condição $C_{k} / C_{a}>0,1$ tem se mostrado interessante para medições com sensibilidade satisfatórias (LEMKE, 2008).

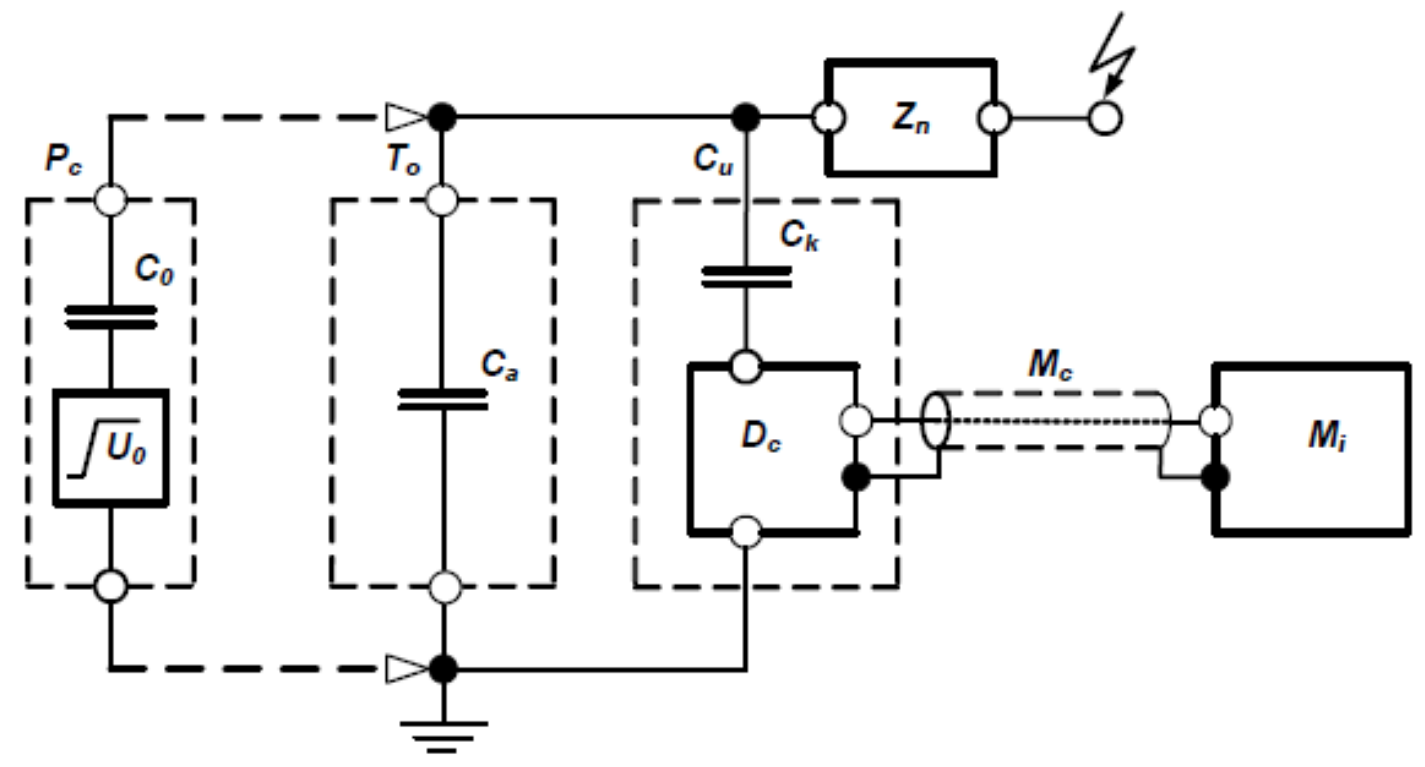

Figura 14: Principais componentes do sistema de mediação de DPs.

Fonte: Lemke (2008). 
Sendo:

$P_{c}=$ Calibrador de DPs.

$C_{0}=$ Capacitor de calibração.

$U_{0}=$ Gerador de degrau.

$T_{0}=$ Objeto de teste.

$C_{a}=$ Capacitância do objeto de teste.

$Z_{n}=$ Filtro de ruído.
$C_{u}=$ Unidade de acoplamento da DP.

$C_{k}=$ Capacitor de acoplamento.

$D_{c}=$ Dispositivo de acoplamento.

$M_{c}=$ Cabo de Medida.

$M_{i}=$ Instrumento de medida.

Quanto à impedância de medição $Z_{m}$, e de modo mais geral, o dispositivo de acoplamento, está apresentado na Figura 15. O dispositivo de acoplamento $D_{c}$ é formado, a princípio, por quatro terminais de rede, algumas vezes referenciado como um quadripolo. É equipado com a impedância de medição $Z_{m}$, como parte principal do sistema que converte os pulsos de corrente de DPs em pulsos de tensão elétrica equivalente. Estes pulsos são encaminhados por um cabo de medição ao instrumento de medição $M_{i}$ de DP. Adicionalmente, o dispositivo de acoplamento é provido de elementos suplementares para filtragem do sinal a fim de eliminar componentes harmônicas provenientes da fonte de tensão AC.

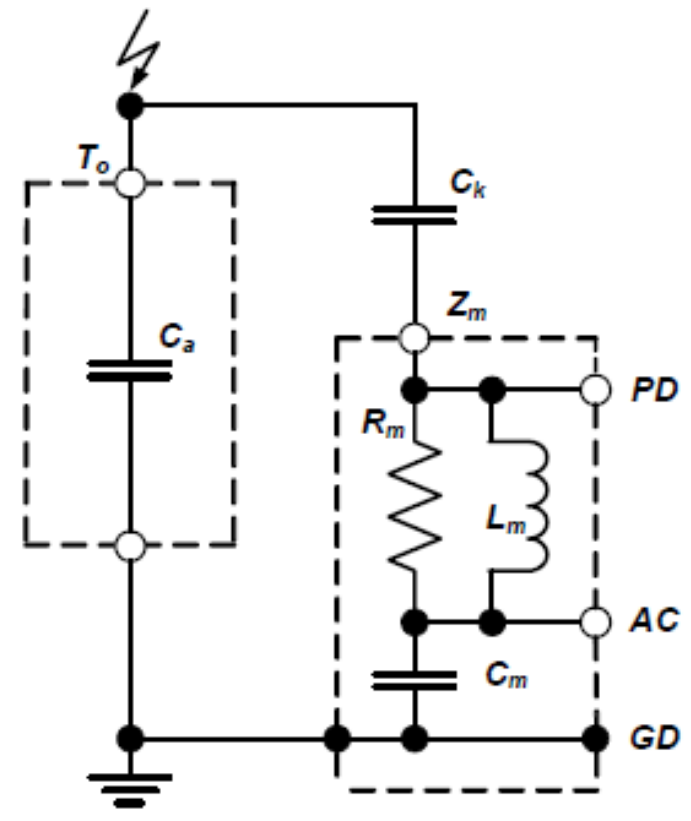

Figura 15: Circuito equivalente do dispositivo de acoplamento.

Fonte: Lemke (2008). 
Sendo:

$T_{o}=$ Objeto de teste. $\quad R_{m}=$ Resistor de medição.

$C_{a}=$ Capacitância do objeto de teste. $\quad C_{m}=$ Capacitor de medição.

$C_{k}=$ Capacitor de acoplamento. $\quad P D=$ Pulsos de saída de DP.

$Z_{m}=$ Impedância de medição. $\quad A C=$ Tensão de ensaio $A C$ de saída.

$L_{m}=$ Indutor Shunt. $\quad G D=$ Terminal terra.

Ademais, uma unidade de proteção contra sobretensões rápidas é necessária de modo a suprimir as sobretensões advindas de uma ruptura dielétrica inesperada (breakdown) que possa ocorrer no objeto de teste. De modo a assegurar uma transmissão de sinal de DP ótimo, o dispositivo de acoplamento deve estar localizado tão próximo quanto possível do capacitor de acoplamento $C_{k}$ e, por motivos de segurança, sempre dentro da área de teste de alta tensão. A ligação em série do capacitor de acoplamento $C_{k}$ com a impedância de medição $Z_{m}$ forma um filtro passa altas, conforme está evidenciado na Figura 15. Isto determina o limite inferior da frequência $f_{1}$ que o circuito impõe a medição completa de uma DP. Se o valor de $f_{1}$ é especificado e $L_{m}$ é inicialmente desconsiderado, o valor requerido para o capacitor de acoplamento pode ser obtido simplesmente para um dado valor do resistor de medição $R_{m}$ pensando-se no caso de um filtro passa altas do tipo $R C$ (LEMKE, 2008).

Para que fique mais bem esclarecido, toma-se o seguinte exemplo. Considere:

- Resistor de medição: $R_{m}=500 \Omega$.

- Frequência de corte: $f_{1}=100 \mathrm{kHz}$.

Utilizando uma fórmula para frequências de corte, segue:

$$
\begin{gathered}
f_{1}=\frac{1}{2 \pi \cdot C_{k} \cdot R_{m}} \leftrightarrow C_{k}=\frac{1}{2 \pi \cdot f_{1} \cdot R_{m}} \therefore \\
C_{k}=3.2 n F
\end{gathered}
$$

Este é valor requerido para o capacitor de acoplamento, desconsiderando inicialmente a presença da indutância $L_{m}$. É importante observar que, no presente contexto, deve ser tomado o devido cuidado para que a corrente que fui através de $C_{k}$ não cause uma queda de tensão considerável em $R_{m}$ de modo que venha a danificar a entrada do instrumento de medição de descarga parcial (LEMKE, 2008). Se, por 
exemplo, uma tensão de excitação com frequência de $400 \mathrm{~Hz}$ é aplicada para induzir o teste de DPs em transformadores, a impedância capacitiva referente ao capacitor de acoplamento é dada por:

$$
\begin{gathered}
Z_{C}=\frac{1}{2 \pi \cdot f_{a c} \cdot C_{k}} \rightarrow Z_{C}=\frac{1}{2 \pi \cdot 400 \cdot 3.2 \cdot 10^{-9}} \therefore \\
Z_{C}=125 \mathrm{k} \Omega
\end{gathered}
$$

Todavia, Lemke (2008) menciona que o divisor de tensão para $f_{a c}=400 \mathrm{~Hz}$ é dado pela relação de $500 \Omega / 125 k \Omega=1 / 250$. Consequentemente, para uma tensão de ensaio de, por exemplo, $U_{a c}=200 \mathrm{kV}$, provoca uma queda de tensão sobre a resistência de medição de $200 \mathrm{kV} / 250=800$. Para reduzir esta tensão, que pode ser danosa ao equipamento de medição, é colocado em paralelo ao resistor de medição um indutor conforme está esquematizado na Figura 15. Um cuidado deve ser tomado para que o limite inferior da frequência de corte não decresça substancialmente. Esta condição é acompanhada por:

$$
\begin{gathered}
L_{m}>\frac{10 \cdot R_{m}}{2 \pi \cdot f_{1}} \rightarrow L_{m}>\frac{10 \cdot 500}{2 \pi \cdot 100 \cdot 10^{3}} \therefore \\
L_{m}>8 \mathrm{mH}
\end{gathered}
$$

Foi assumido previamente que a máxima frequência de ensaio era de $400 \mathrm{~Hz}$. Portanto, a impedância indutiva será de:

$$
Z_{l}=2 \pi \cdot f_{a c} \cdot L_{m} \rightarrow Z_{l}=20 \Omega
$$

Note que o resultado final será o divisor de tensão composto de $R_{m}$ e $L_{m}$ conectados em paralelo e ligados em série com o capacitor de acoplamento $C_{k}$. Dessa forma, o fator a que a tensão estará dividida será de $20 \Omega / 125 k \Omega=1 / 6250$, aproximadamente. Portanto, para uma tensão de ensaio de $200 \mathrm{kV}$, a tensão no capacitor de medição será de $32 \mathrm{~V}$, que é um valor aceitável (LEMKE, 2008).

A fim de exibir os pulsos de descarga parcial com resolução em fase, utilizando um osciloscópio ou algum tipo de computador baseado no sistema de medição de DP, o dispositivo de acoplamento pode ser configurado como está apresentado na Figura 15. Neste caso, o ramo de baixa tensão do divisor capacitivo é representado por um 
capacitor de medição designado $C_{m}$. Devido a grande diferença do espectro de frequências da tensão de ensaio e dos pulsos de DPs, ambos os sinais aparecem completamente separados nas saídas "AC" e "PD" respectivamente. Se, por exemplo, a tensão de ensaio de $200 \mathrm{kV}$ é novamente considerada, e deseja-se que a tensão AC de saída seja de $20 \mathrm{~V}$, isso implicará numa relação de transformação de 1:10000. Dessa forma, para o capacitor de acoplamento calculado anteriormente, $C_{k}=3,2 n F$, o capacitor de medição terá que possuir o valor de $C_{m}=32 \mu F$ para que seja satisfeita a condição de transformação (LEMKE, 2008). Note que a função do indutor, apresentado na Figura 15, é dupla, ou seja: impedir que os pulsos de DPs passem para o ramo inferior, isto é, $C_{m}$, e formar um caminho de baixa impedância para a tensão de ensaio, a qual é de baixa frequência. Isto é necessário, pois se deseja que esta tensão não interfira na medição dos pulsos de DPs. Já o resistor de $R_{m}$ tem como função gerar a queda de tensão com a passagem do pulso de corrente. Por ser um pulso, é como se fosse um curto circuito para o capacitor de medição $C_{m}$, não interferindo na saída AC, conforme apresenta a Figura 15.

\subsubsection{Método HF/VHF}

Com frequências que vão de 0.3 a $30 \mathrm{MHz}(\mathrm{HF})$ e 30 a $300 \mathrm{MHz}(\mathrm{VHF})$, o objetivo deste método é a captação de sinais elétricos emitidos por eventos de DPs. Um exemplo disso é a ocorrência de descargas parciais em isoladores poliméricos, que apresentam duração de vários nanossegundos no ponto de origem. Para mediação de DPs neste tipo de método, sensores indutivos e capacitivos são utilizados (MUHR et al., 2005).

Como exemplo de um sensor indutivo de medição de DP, um indutor toroidal envolve um condutor, por exemplo, um cabo de energia. Quando ocorre um pulso de corrente elétrica, este induz uma tensão no sensor que é proporcional a corrente. A vantagem deste método é a separação galvânica da alta tensão durante a aquisição do sinal de DP, bem como a localização exata do local de falta (MUHR et al., 2005).

\subsubsection{Método UHF}

Pulsos de descarga parcial de duração muito curta, menor que nanossegundos, produzem ondas eletromagnéticas, cujo espectro de frequências chega a GHz. Para ser mais específico, a faixa abrangente para o método UHF vai de $300 \mathrm{MHz}$ e $3 \mathrm{GHz}$. Em 
estruturas coaxiais, como por exemplo, GIS, os impulsos de DPs acabam por gerar ondas eletromagnéticas. Por esta razão, sensores capacitivos, similares a antenas, são utilizados para detecção destas ondas transientes.

Dois tipos básicos de sistema de detecção são utilizados: o de banda estreita, com intervalo de alguns mega-hertz, e o de banda larga, chegando a $2 \mathrm{GHz}$. A Figura 16(A) e 16(B) ilustram duas situações nas quais este sensor pode ser utilizado em um aparato de alta tensão: externamente e internamente.

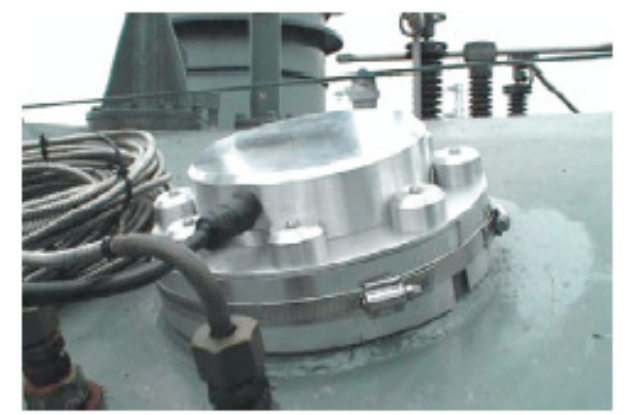

(A): Montagem externa de um sensor UHF no tanque de um transformador.

Fonte: Judd et al. (2005).

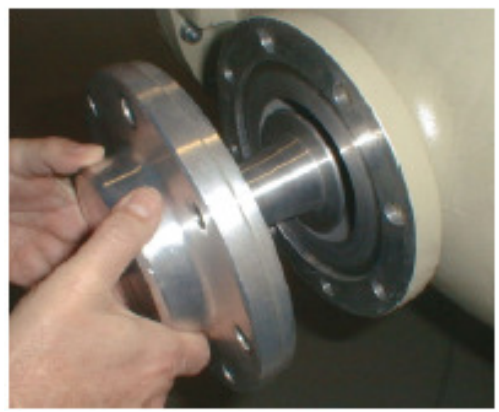

(B): Vista em corte e montagem interna de um sensor UHF tipo disco de descarga parcial.

Fonte: Neumann et al. (2000).

Figura 16: Montagem de sensores UHF de DPs.

\subsubsection{Método químico}

Como já fora mencionado, este método, um dos mais tradicionais, consiste na análise cromatográfica dos gases dissolvidos no óleo isolante do transformador. Segundo consta na literatura, a quantidade e os tipos de gases dissolvidos no óleo fornecem indícios de sua normalidade ou do provável tipo de ocorrência de defeito ou dano interno (IEEE C57.104-1991).

Em breve pesquisa sobre a "cromatografia", verificou-se que a formação de gases em transformadores foi documentada, pela primeira vez, em 1919, no The Electric Journal, onde afirmava que, através da passagem da corrente elétrica pelo óleo isolante, era possível constatar a formação de hidrocarbonetos. Somando-se a isto, a desintegração de moléculas de óleo na presença de altas temperaturas, ocorria a produção de gases (MEYERS et al., 1981). Mas só em 1960 fez-se a identificação de gases gerados por anormalidade tipo elétrica em transformadores imersos em óleo mineral isolante, e no Brasil após 1970 (SÁ et al., 1993). 
A análise cromatográfica de gases dissolvidos em óleo isolante constitui num dos principais métodos para detectar falhas e avaliar as condições de operação que possam estar ocorrendo internamente ao transformador de potência. Os gases gerados no óleo, depois de identificados, transformam-se na primeira indicação do mau funcionamento do equipamento (IEC 60599-1999).

Existem vários métodos normalizados e reconhecidos para análise dos gases dissolvidos em óleo isolante. Através de uma amostra, manipula-se a mesma de modo a extrair os gases dissolvidos, objetivando que estes sejam injetados no cromatógrafo. Neste equipamento, a amostra injetada é transportada por um gás através de um tubo de separação chamado "coluna". Os gases hélio ou nitrogênio geralmente são utilizados para esse transporte e são denominados "gases de arraste". Para quantificação de uma amostra cuja concentração é desconhecida, deve-se injetar um padrão conhecido no equipamento. O tempo de retenção do padrão e sua área serão comparados com os dados obtidos a partir da amostra e utilizados para o cálculo da concentração desconhecida (LUPI, 2012; MEYERS et al., 1981).

Segundo a norma IEEE C57.104-1991 verifica-se que cada tipo de defeito gera um ou mais gases. Estes surgem do aumento da degradação do óleo quando próximo de alguma falha. O método cromatográfico é capaz de avaliar vários tipos de gases e, portanto, sendo possível identificar e diagnosticar os defeitos desde os estágios iniciais ou algum tempo após a falha. Dentre os gases gerados internamente aos transformadores, que são utilizados para diagnósticos de falha interna, são citados principalmente os seguintes:

- Gases combustíveis: $\mathrm{H}_{2}$ (Hidrogênio); $\mathrm{CH}_{4}$ (Metano); $\mathrm{C}_{2} \mathrm{H}_{6}$ (Etano); $\mathrm{C}_{2} \mathrm{H}_{4}$ (Etileno); $\mathrm{C}_{2} \mathrm{H}_{2}$ (Acetileno).

- Gases não Combustíveis - $\mathrm{O}_{2}$ (Oxigênio); $\mathrm{N}_{2}$ (Nitrogênio); CO (Monóxido de Carbono); $\mathrm{CO}_{2}$ (Dióxido de Carbono).

Ademais, existem diversos métodos utilizados para análise de gases dissolvidos em óleos isolantes. Porém, os mais utilizados para diagnóstico de defeitos e falhas ou acompanhamento do estado do transformador de potência são os que seguem.

- Rogers na revisão da NBR 7274/IEC 60599-1999.

- Rogers previsto na IEEE C57. 104-1991.

- Rogers versão 1975 modificada (ROGERS, 1975).

- Doernenburg previsto na IEEE C57. 104-1991. 
- Doernenburg 1991 (DOERNENBURG et al., 1991).

- Proposto pelo Laboratoire Central dês Industries Électriques (LCIE).

- Triangulo de Duval (DUVAL, 1989).

É importante mencionar que uma desvantagem do método químico, especificamente a análise cromatográfica, é de caráter integrativo, de forma que não há possibilidade de fazer afirmações sobre o estado de funcionamento do equipamento. Ademais, não é possível mensurar a carga aparente da descarga parcial, tão pouco localizar onde se dá a sua atividade (MUHR et al., 2005).

\subsubsection{Método óptico e opto-acústico}

Existem, basicamente, dois métodos fundamentais que podem ser exploradas para a detecção óptica de DP. Um método é a deteç̧ão óptica direta dos sinais que são produzidos durante um impulso de DP. Outro método, também chamado optoacústico, baseia-se nos efeitos acústicos causados por uma DP. Neste caso, a onda acústica causada pela DP influencia fibras ópticas que são colocados no interior do equipamento. Dessa forma, o sinal óptico que é transmitido através da fibra, é comparado com um sinal de referência de modo que se torne possível à obtenção do sinal de DP (SCHWARZ et al., 2008).

Até o presente momento não houve uso extensivo dos métodos de óptica para detecção de DPs, por motivos de equipamentos que possam realizar o monitoramento dessas descargas. O fato é que os métodos ópticos necessitam de algum contato visual para detecção da atividade de DP. Entretanto, tem sido bem sucedida a medição e monitoramento de linhas aéreas por meio deste método (SCHWARZ et al., 2007). De modo geral, as linhas aéreas podem ser examinadas de forma bastante confortável com sistemas ópticos, pois o contato visual é favorecido nessa situação. Com o problema de contato visual para aplicação dos métodos ópticos, estes, portanto, são basicamente aplicáveis para sistemas de isolamentos gasosos e também, embora haja restrições, em materiais líquidos isolantes. Um agravante é a inviabilidade da detecção e localização de uma fonte de DP que esteja escondida atrás de alguma parte do equipamento. Ademais, os efeitos da atenuação e dispersão provocadas pela distância dos materiais isolantes entre o local da imperfeição e o sensor, tem mostrado grande influencia na eficiência da detecção da DP (SCHWARZ et al., 2005, 2007). 
Um dado interessante é que a aplicação do método de detecção óptica de DP para equipamentos isolados a gás tem-se mostrado promissor. Um esquemático para um sistema dessa natureza é apresentado na Figura 17(A). Numa parte da subestação isolada a gás existe uma pequena janela onde é colocado um sensor óptico contendo fotomultiplicadores. Estes multiplicadores tem um range de detecção ótima, de modo que o espectro óptico das aquisições é posteriormente comparado com os comprimentos de onda que normalmente ocorrem numa atividade de DP. Esta configuração fornece circunstâncias ideias para detecção óptica de modo que interferências causadas por outras fontes de luz podem ser negligenciadas (SCHWARZ et al., 2008). A Figura 17(B) apresenta um espectro óptico típico de uma descarga em gás $\mathrm{SF}_{6}$.

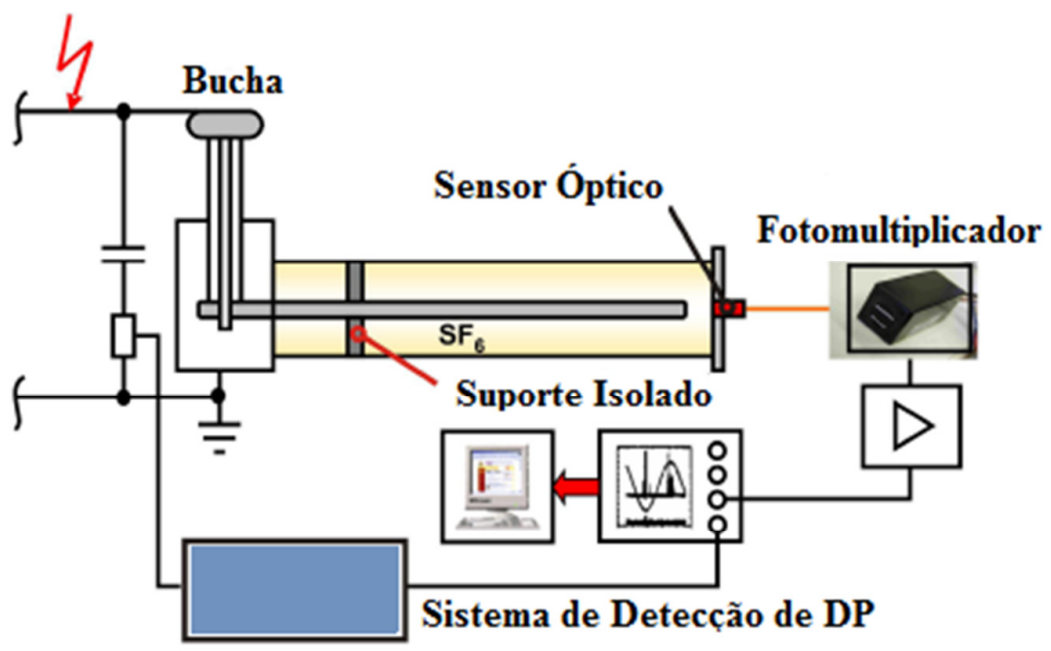

(A)

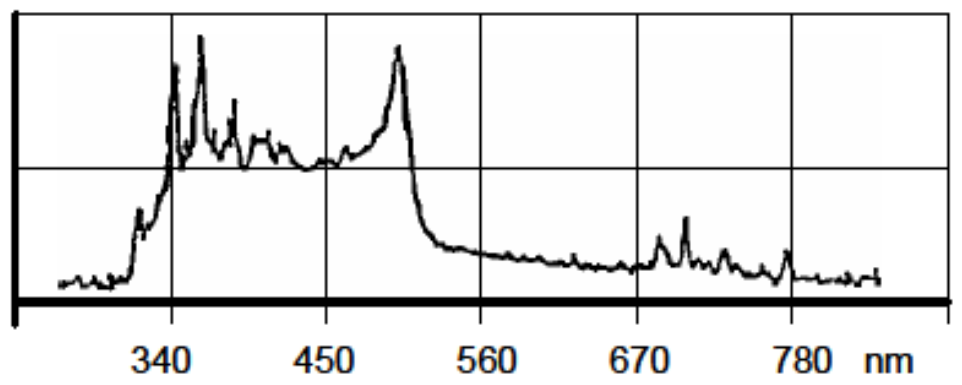

(B)

Figura 17 (A): Sistema experimental para detecção e medição ópticas de DPs. (B): Espectro óptico para ruptura dielétrica em gás $\mathrm{SF}_{6}$.

Fonte (A): Modificado de Schwarz et al. (2008). Fonte (B): Schwarz et al. (2007). 
É interessante salientar que, em gases a baixa pressão, apenas uma pequena parta da energia da DP é convertida em luz, ou seja, 1\% apenas (FORSYTH, 1998). Em líquidos e sólidos esta parte é ainda menor em comparação com a energia total liberada. Em questão de espectro óptico, se a descarga ocorre no caso do gás hidrogênio, seu espectro concentra-se no visível, com uma parte menor na região de infravermelho. Já para o gás $\mathrm{SF}_{6}$, o espectro está distribuído entre o ultravioleta e a região azul/verde do visível. As emissões em óleo são predominantemente formadas por hidrogênio e hidrocarbonetos, como metano, etano e etílicos (grupo etílico), de modo que a região espectral está entre 350 e $700 \mathrm{~nm}$, dependendo ainda da composição do óleo (SCHWARZ et al., 2007).

As medições de DPs pelo método óptico possuem vantagens bastante interessantes. Um delas, de aplicação prática bastante interessante, é que toda a medição é isolada galvanicamente. Na realidade não há influência eletromagnética nas medições e todo o sistema de detecção óptica é quase imune a sinais indesejados. As desvantagens, entretanto, são: possibilidade de perda de calibração, a área de cobertura limitada e os problemas com acessibilidade (SCHWARZ et al., 2008).

\subsubsection{Método acústico}

Neste subtópico será apresentado o método acústico de detecção descargas. Será mostrado um pouco da história da detecção de descargas, também uma abordagem da propagação do som em gases, líquidos e sólidos e também algumas considerações sobre a detecção acústica da DP.

\subsubsection{Um pouco de história}

De modo geral, a deteç̧ão de DPs pelo método acústico está relacionada ao som, seja no audível ou ultrassônico, produzido por uma descarga qualquer. Pode-se dizer que a ideia de "escutar" uma descarga é bem antiga, já que a associação entre relâmpagos e o som vindo de um trovão era conhecida por Lucretius já no século primeiro (MONRO, 1952, p. 81). Sabia-se que primeiro vinha o relâmpago e em seguida o trovão. Bem mais adiante, quando se pode medir o tempo com precisão, tornou-se viável a medida de velocidade do som no ar. Foi Marsenne (1588 - 1648) que chegou ao valor de 316,46 m/s utilizando um pêndulo (BERANEK, 1949, p. 3). 
Dessa forma, pode-se estimar a distância do ouvinte do trovão, por exemplo, até o local onde ocorreu a descarga atmosférica (UMAN, 1969, p. 182).

Com a aurora da era elétrica, em torno de 1874, ficou claro que faíscas produzidas no ar e em altas tensões geravam emissões acústicas semelhantes a um relâmpago, todavia em escala bastante reduzida. Com tensões cada vez maiores sendo utilizadas, descargas coronas em regiões com altos estresses elétricos em aparatos de alta tensão, tais como os condutores não isolados de linhas de alta tensão, poderiam ser vistas a olho nu no escuro, de modo que a descarga era associada a emissões acústicas percebidas pelo ouvido humano (HAROLD, 1979).

Como já afirmado anteriormente, logo se percebeu que a descarga corona era extremamente danosa à isolação elétrica de modo que se poderiam causar falhas elétricas nos equipamentos. Interessante que, logo no início da engenharia elétrica, quando descargas ocorriam frequentemente no ar, o ouvido humano serviu como um valioso detector e localizador de descargas, mostrando sensibilidade bastante elevada para esta questão. Mais tarde, evidentemente, microfones e transdutores ultrassônicos com sensibilidade superior para altas frequências (acima de $20 \mathrm{kHz}$ ), foram desenvolvidos, mas não foram tão utilizados para a deteç̧ão de descargas uma vez que técnicas de detecção elétrica com amplificadores de banda estreita, NEMA 107 (1964), e a banda larga, IEC 270 (1968), mostraram-se mais sensíveis e confiáveis. Entretanto, nas duas décadas que se seguiram, com a introdução e crescimento de equipamentos de alta tensão mais complexos, os métodos acústicos para detecção e localização de descargas mostraram-se bastante interessantes. Transdutores constituídos de materiais cerâmicos piezelétricos e amplificadores de estado sólido de baixo ruído e em circunstâncias favoráveis, mostraram-se com sensibilidade comparável a técnicas elétricas de detecção de descargas. Sensores acústicos, corretamente projetados, são imunes a ruídos eletromagnéticos e, por esta razão, são bastante úteis para a verificação da existência de uma descarga elétrica. Atualmente são utilizados rotineiramente para detecção e localização de descargas internas em transformadores de potência e também para encontrar locais de radio-interferência causadas por descargas associadas a linhas de transmissão de alta tensão (HAROLD, 1979).

Um pouco mais recentemente, métodos acústicos têm sido utilizados para detecção de descargas e particulados em GIS que contenham $\mathrm{SF}_{6}$, na localização de cavidades nos isolamentos de máquinas rotativas de grande porte, na monitoração da 
atividade de descargas internas de capacitores de alta tensão, e também como fator de viabilização na detecção de descargas durante os testes de sondas de baixa pressão. Ademais, um campo bastante promissor que está sendo explorado é a aplicação de guias de ondas acústicas utilizadas para extrair emissões ultrassônicas provenientes de descargas elétricas de estruturas complexas de isolação que estejam profundamente enterradas (HAROLD, 1979).

\subsubsection{Princípios da propagação acústica}

Como já fora percebido no subtópico anterior, existe uma relação entre um processo de falha em dielétricos e a propagação de ondas sonoras. Nas duas situações necessita-se de um meio, moléculas propriamente ditas, para a ocorrência do fenômeno (AZEVEDO, 2009). Existe uma exceção, que é a possibilidade de emissão de elétrons em um gap. Portanto, para um processo de falha dielétrica qualquer, seja streamer (canais em gases), trilhamento de uma superfície isolante ou arborescência (treeing) elétrica em um sólido isolante, sempre haverá a necessidade de um meio para que isto venha a ocorrer. Até mesmo em meios isolantes a vácuo, com pressões de até $10^{-8} \mathrm{~Pa}$, possuem uma quantidade razoável de moléculas, $10^{6} / \mathrm{cm}^{3}$, de modo que, mesmo sendo "vácuo", pode ocorrer um processo de falha (HAROLD, 1986).

Uma forma de se avaliar um dielétrico segura e não destrutivamente é através do estudo de propagação de ondas sonoras neste dielétrico. Esta avaliação diz respeito, por exemplo, a velocidade molecular ou empacotamento. Para melhor esclarecer sabe-se que, num meio gasoso, a velocidade de propagação sonora e velocidade molecular são bastante próximas. Evidentemente que a temperatura afeta esta última velocidade, a molecular. Ademais, em óleo isolante a velocidade da onda acústica está fortemente atrelada ao grau de empacotamento molecular. Logo, analisando-se a velocidade de propagação das ondas sonoras no dielétrico em questão, informações sobre estrutura e estado destes materiais podem ser obtidas. Utilizandose a audição para realizar a análise, podem-se constatar pequenas falhas por meio dos sons emitidos decorrentes de atividades de DPs (HAROLD, 1986).

Parâmetros como, impedância acústica característica do meio, velocidade de propagação da onda no meio e absorção sofrida pela onda sonora, devem ser observados quando se realiza a detecção de descargas parciais pelo método acústico (HAROLD, 1986). Um tratamento mais formal para propagação acústica é através da 
equação de onda. A dedução desta equação, conforme já mencionado, está no Apêndice D.

De modo geral, a velocidade de propagação do som num líquido é determinada pelas propriedades elásticas do líquido. Para um gás, a velocidade é determinada pela equação de estado para transformações adiabáticas e, para um sólido, pela lei de Hooke. A Figura 18 apresenta as forças que atuam sobre um pequeno volume de líquido, ou seja, uma partícula acústica. Nesta figura, " $S$ " é a área do "tubo"; " $p(x)$ " é a pressão, que na verdade depende do espaço e do tempo, aplicada a este tubo; " $\Delta x "$ é o comprimento do volume diferencial de densidade específica $\rho_{L}$ (LUNDGAARD, 1992).

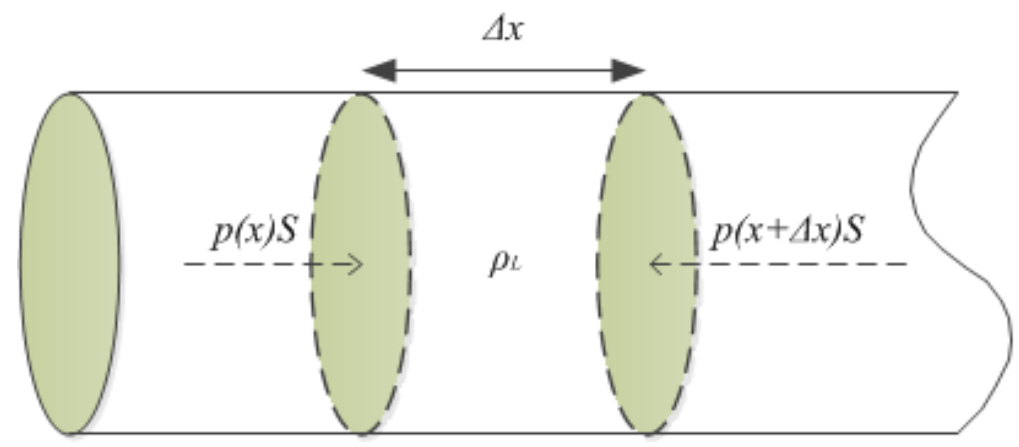

Figura 18: Forças atuantes num grupo de partículas que estão "confinadas" em um tubo.

Fonte: Adaptado de Lundgaard (1992).

O somatório das forças que atuam na partícula faz com que esta se mova com velocidade vetorial $\vec{v}$. Para uma onda plana, a razão entre a pressão sonora vetorial $\vec{p}$ e velocidade da partícula é denominada de impedância acústica específica e é dada conforme a equação (2.13). Impedância acústica e impedância elétrica são análogas e pode ser expressa na forma complexa se pressão e velocidade estão fora de fase. Entretanto, para ondas planas, a impedância acústica torna-se num escalar, conforme apresenta a equação (2.14). Esta é denominada de impedância acústica característica do meio. A relação entre o movimento da partícula e a propagação da onda acústica é fundamental para o tipo de propagação, e isto é determinado pelos parâmetros do material. A intensidade acústica, que é o valor médio do fluxo de energia por unidade de área e perpendicular a direção de propagação da onda, é outra medida importante. Esta pode ser expressa tanto em questão do valor de pico da pressão, dado por $P$, 
quanto do valor de pico da velocidade, dada por $V$. A equação (2.15) apresenta a expressão da intensidade sonora I (LUNDGAARD, 1992). Ademais, a expressão $\overline{v p}$ na equação (2.15) representa a média do produto da pressão pela velocidade das partículas em um meio fluído. Isto é equivalente à potência recebida por unidade de área.

$$
\begin{aligned}
\vec{Z} & =\frac{\vec{p}}{\vec{v}} \\
Z_{0} & =\rho_{0} c
\end{aligned}
$$

Com relação à equação (2.14):

$Z_{0}=$ Impedância acústica caraterística dada $\mathrm{em} \mathrm{kg} / \mathrm{m}^{2} \mathrm{~s}$.

$\rho_{0}=$ Densidade do material dada em $\mathrm{kg} / \mathrm{m}^{3}$.

$c=$ Velocidade, em $\mathrm{m} / \mathrm{s}$, de propagação do som no material.

$$
I=\overline{v p}=\frac{P}{2 \rho_{0} c}=\frac{V \rho_{0} c}{2}
$$

No tratamento de problemas práticos, é muito comum o uso do decibel, que é uma forma de normalizar as intensidades sonoras a partir de uma intensidade referencial. Tomando-se uma intensidade sonora referencial $I_{0}$ e uma pressão $p_{0}$, terse-á a seguinte relação entre intensidade e pressão, apresentada na equação (2.16), ambos os membros na escala decibel ou logarítmica.

$$
10 \log _{10}\left(\frac{I}{I_{0}}\right)=20 \log _{10}\left(\frac{p}{p_{0}}\right)
$$

A diferença do fator 10 para o fator 20 na expressão (2.16) é causada pela relação quadrática entre intensidade e pressão, da mesma forma que potência e tensão elétrica estão relacionadas de forma quadrática (BALLOU, 1987).

Quando uma onda se propaga através de uma estrutura, a intensidade sonora decresce em função da distância da fonte. Isto é resultado de vários mecanismos como, por exemplo, difusão de onda, absorção e dispersão de frente de onda. Este fenômeno resulta na redução da intensidade de onda que se afasta da fonte. Em um meio sem perdas, a intensidade de uma onda esférica decresce inversamente 
proporcional à área de frente de onda, ou seja, inversamente proporcional ao quadrado da distância da fonte. Já em ondas cilíndricas, ou seja, uma fonte pontual em uma placa, a intensidade decresce inversamente proporcional à distância da fonte (LUNDGAARD, 1992).

Entretanto, sabe-se que quando uma onda sonora propaga-se de um meio para outro, ocorre um fenômeno denominado reflexão. O coeficiente de reflexão $R_{0}$ é dado conforme a equação (2.17) (HAROLD, 1986).

$$
R_{0}=\frac{\rho_{1} c_{1}-\rho_{2} c_{2}}{\rho_{1} c_{1}+\rho_{2} c_{2}}=\frac{\left(Z_{1}-Z_{2}\right)}{\left(Z_{1}+Z_{2}\right)} \frac{\left(Z_{1}+Z_{2}\right)}{\left(Z_{1}+Z_{2}\right)}=\frac{\left(Z_{1}-Z_{2}\right)^{2}}{\left(Z_{1}+Z_{2}\right)^{2}}
$$

Sendo:

$\rho_{1}, \rho_{2}=$ Densidade dos meios 1 e 2, respectivamente.

$c_{1}, c_{2}=$ Velocidade de propagação de onda dos meios 1 e 2, respectivamente.

$Z_{1}, Z_{2}=$ Impedâncias acústica características dos meios 1 e 2, respectivamente.

Também é interessante apresentar o coeficiente de transmissão $T_{0}$ da onda acústica. Este informa a parcela de intensidade sonora que foi transmitida de um meio para outro. Tomando-se $I_{t}$ com a intensidade sonora transmitida e $I_{i}$ a intensidade sonora incidente, o coeficiente de transmissão para uma onda plana com incidência normal à superfície de separação é dado conforme a equação (2.18) (LUNDGAARD, 1992).

$$
T_{0}=\frac{I_{t}}{I_{i}}=\frac{4 Z_{1} Z_{2}}{\left(Z_{1}+Z_{2}\right)^{2}}
$$

Note ainda que, a soma dos coeficientes de reflexão e transmissão resulta em:

$$
\begin{gathered}
R_{0}+T_{0}=\frac{\left(Z_{1}-Z_{2}\right)^{2}}{\left(Z_{1}+Z_{2}\right)^{2}}+\frac{4 Z_{1} Z_{2}}{\left(Z_{1}+Z_{2}\right)^{2}}=\frac{Z_{1}^{2}+2 Z_{1} Z_{2}+Z_{2}{ }^{2}}{\left(Z_{1}+Z_{2}\right)^{2}} \therefore \\
R_{0}+T_{0}=\frac{\left(Z_{1}+Z_{2}\right)^{2}}{\left(Z_{1}+Z_{2}\right)^{2}}=1
\end{gathered}
$$


Ou seja, o princípio da conservação da energia permanece válido. É importante salientar que a velocidade de propagação da onda sonora depende do meio, se este é gasoso, líquido incompressível ou compressível ou ainda sólido. Dessa forma, as equações de (2.19) a (2.22) descrevem, para cada situação, as respectivas velocidades (HAROLD, 1986).

$$
\begin{gathered}
c_{1}=\sqrt{\frac{\gamma P}{\rho}} \\
c_{2}=\sqrt{\frac{K}{\rho}} \\
c_{3}=\sqrt{\frac{\gamma K}{\rho}} \\
c_{4}=\sqrt{\frac{Y}{\rho(1-b)}}, \quad b=2 \sigma^{2}(1-\sigma)
\end{gathered}
$$

Sendo:

$c_{1}=$ Velocidade da onda num meio gasoso.

$c_{2}=$ Velocidade da onda num líquido incompressível.

$c_{3}=$ Velocidade da onda num líquido compressível.

$c_{4}=$ Velocidade da onda num sólido.

$\gamma \quad=$ Razão do calor específico.

$P \quad=$ Pressão do gás.

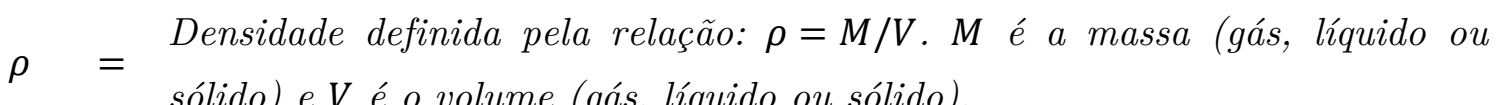

$K=$ Constante de volume.

$Y=$ Constante de Young ou módulo de elasticidade.

$\sigma=$ Constante de Poisson.

Um último parâmetro que ainda falta tratar é sobre a atenuação da propagação de ondas acústicas. É conhecido que este parâmetro é bastante complexo e depende de parâmetros como absorção molecular, viscosidade e temperatura do meio. Todavia, foi desenvolvido um modelo matemático por Stokes e Kirchoff, que é 
baseado na temperatura e fricção interna. Dessa forma, o coeficiente de absorção $A_{B}$ de uma onda sonora é dado conforme a equação (2.23) (SIVIAN, 1947).

$$
A_{B}=\frac{4 \pi^{2} f^{2}}{c^{3} \rho_{0}}\left[\frac{4}{3} \eta+\frac{(\gamma-1)}{C_{p}} k\right]
$$

Sendo:

$\eta \quad=$ Coeficiente de viscosidade.

$f=$ Frequência da onda sonora.

$\rho_{0} \quad=$ Densidade do meio.

$c=$ Velocidade do som no meio.

$\gamma=$ Razão do calor específico.

$C_{p}=$ Calor específico à pressão constante.

$k=$ Condutividade térmica do meio.

Mesmo se tratando de um modelo aproximado, algumas particularidades são consideradas na equação (2.23). Como exemplo, está embutido nesta equação o efeito atenuador que a viscosidade causa na onda sonora, o efeito provocado pelo inverso da densidade e o efeito cúbico inverso da velocidade de propagação da onda (HAROLD, 1986). Sendo a atenuação da onda sonora, em sólidos, aproximadamente proporcional à frequência, pode-se inferir que a velocidade de propagação da onda não é constante, pois o sinal de onda sonora é, na realidade, deformado ao longo do percurso, além de atenuado. Portanto, a onda sonora capturada pelo sensor acústico não corresponde à onda sonora real que fora emitida pela fonte (KUNDU et al., 2006).

\subsubsection{Considerações sobre a detecção de descargas}

Sendo a detecção de DPs pelo método acústico a captação de ondas mecânicas provenientes dessas descargas, pode-se dizer o que som gerado por uma descarga é proveniente, na maioria das vezes, por canais de corrente (streamers) para o caso de transformadores imersos em óleos isolantes. Estes se formam dentro de cavidades preenchidas com gás. Na presença do calor, estas cavidades se expandem provocando microexplosões que se propagam por meio do óleo isolante do transformador na categoria de ondas de pressão. Esta situação é bem análoga à formação de trovões depois de ocorrida uma descarga atmosférica. (LAZAREVICH, 2003). 
Com a formação de ondas sonoras, estas devem percorrer uma distância $\Delta S$ até que cheguem ao sensor acústico, que, para o caso de transformadores, geralmente é fixado na parede externa do tanque principal. Mais acuradamente, a velocidade de propagação não é constante e depende de diversos parâmetros. Todavia, para o caso de óleo isolante de transformador, adota-se o valor o de $1413 \mathrm{~m} / \mathrm{s}$ a $20{ }^{\circ} \mathrm{C}$ para a velocidade do som no óleo. Correções na velocidade de propagação devido a variações de temperatura e umidade geralmente não aumentam a precisão de localização da fonte de descarga, pois as incertezas presentes no próprio material são superiores à incerteza presente na velocidade de propagação. Dessa forma, a aproximação dada pela expressão (2.24) é razoável para o cálculo da distância entre detector e fonte da descarga (IEEE C57.127-2007).

$$
\Delta S=c \Delta t
$$

Com relação à localização da fonte de descargas, sensores colocados em diferentes locais do tanque do transformador, ou seja, a diferentes distâncias da fonte, terão tempos de chegada distintos. Para um sistema puramente acústico, é possível detectar a diferença no tempo de chegada da onda sonora de um sensor em relação ao outro. Isto permite estimar a diferença das duas distâncias do caminho de propagação. Na combinação dos sistemas elétrico e acústico, pode-se mensurar o tempo decorrido entre o instante da descarga e a onda acústica captada pelo sensor, de modo que a distância absoluta entre fonte e sensor é factível de ser determinada. Para cada situação, sistema puramente acústico ou combinado, os procedimentos de localização da fonte de descarga são distintos (IEEE C57.127-2007). Um dado interessante é que, no sistema puramente acústico e com relação ao método dos tempos distintos de chagada, os procedimentos para a localização da descarga são similares ao que ocorrem para se localizar um terremoto, mas estendido a três dimensões (COLE, 1997).

Na simplificação do problema da localização da fonte de descargas, considerase que a onda sonora se propaga direta e retilineamente da descarga para o sensor acústico. Isto dificilmente ocorre, haja vista as reflexões e refrações que ocorrem em diferentes materiais no interior do transformador. Um exemplo disso é a presença de algum obstáculo no caminho de propagação da onda sonora. Isto ocasiona um atraso na chegada do sinal acústico até o sensor. Outra situação é que a onda pode viajar por meio deste obstáculo, onde a velocidade de propagação seja maior que no óleo, 
causando a impressão de que a fonte de descarga está mais próxima do sensor quando, na realidade, não está. Um procedimento que ajuda a evitar este tipo de equívoco é a realização dos cálculos da localização da descarga diversas vezes e para várias localizações de sensores (IEEE C57.127-2007).

Kundu et al. (2006) também menciona que existem dois modos de se detectar descargas em transformadores. O primeiro é denominado sistema acústico composto, pois se trata do método acústico conjugado com o elétrico. O tempo de atraso entre o evento da descarga e a detecção elétrica é da ordem de microssegundos. Sendo assim, considera-se que a detecção elétrica ocorre no instante zero. Portanto, com a diferença de tempo entre a detecção elétrica e acústica e a velocidade de propagação da onda sonora no meio em estudo, é possível localizar a fonte de descarga pelo cálculo das distâncias entre os sensores acústicos e a fonte. Já a segunda forma de detecção de descargas, denominada sistema acústico simples, toma por base a impossibilidade de se utilizar a detecção elétrica. Dessa forma, realiza-se a instalação de vários sensores externamente ao equipamento sob teste de modo que, coletando-se as informações provenientes de cada sensor, pode-se estimar a localização da fonte de descargas. A norma IEEE C57.127-2007 menciona que a instalação de sensores externamente ao transformador permite o reposicionamento dos mesmos, possibilitando um melhor desempenho do sistema em questão de definição dos sinais capturados. Tem-se a flexibilidade de transportar todo o sistema de medição a outro transformador e a facilidade de adaptação nos transformadores existentes. Todavia, a desvantagem é a baixa imunidade a ruídos externos.

A combinação do sistema elétrico e acústico traz a vantagem de que o sistema elétrico confirma que o sensor acústico está, de fato, detectando uma descarga e não um ruído externo. Ademais, a detecção elétrica serve como referência temporal para o sensor acústico. Entretanto, existe a desvantagem de que dificilmente se obtém um sinal elétrico livre de ruídos quando se realiza ensaios em campo. Portanto, este tipo de sistema de mediação é mais conveniente de ser aplicado em laboratórios. Tem ainda o agravante de que é necessário o desligamento do equipamento sob teste para a instalação do sistema de detecção pelo método elétrico, fazendo com que este sistema composto, elétrico e acústico, se torne pouco viável para aplicação em transformadores que estejam em operação.

Já sistemas de detecção acústica simples tem a grande vantagem de ser imune a interferências eletromagnéticas, fazendo com sua aplicação em campo seja mais 
viável em relação ao método composto (LAZAREVICH, 2003; LUNDGAARD et al., 2000). Ademais, o monitoramento on-line é mais apropriado para este tipo de técnica. Todavia, sabe-se que o sistema é imune a ruídos eletromagnéticos, mas não a ruídos mecânicos em geral. Uma fonte de ruídos mecânicos importante para o caso de transformadores são as vibrações provenientes do núcleo. O interessante é que as frequências que compõem estas vibrações são menores que as geradas pelas DPs (LAZAREVICH, 2003).

Conforme apontado por Eleftherion (1995) existem alguns problemas com relação ao método de detecção acústica. Isto é devido à natureza bastante complexa da forma de propagação de ondas sonoras. Portanto, os problemas são os seguintes:

- A propagação das ondas sonoras não é perfeitamente esférica.

- Há ocorrência de diversas reflexões sofridas pelas ondas sonoras, provocando múltiplos caminhos de propagação e enfraquecimento do sinal acústico.

- Perturbações, como absorção e dispersão, que o óleo mineral provoca nas ondas sonoras.

Outro problema referente ao método de detecção acústica é com relação à fonte de ondas sonoras. Para o caso de transformadores, a fonte de ondas sonoras pode ser origem mecânica, térmica ou ainda de descargas propriamente ditas (IEEE C57.1272007).

Tem ainda o inconveniente da onda sonora se propagar por um caminho estrutural e não pelo óleo. É o caso da onda sonora colidir com o tanque do transformador e propagar-se por meio deste. Nesta situação a frequência da onda sonora é mantida, e a forma e velocidade de propagação são alteradas. Nesta situação, pode ocorrer da onda que viaja pela estrutura do transformador chegar primeiro ao sensor em relação à onda que viaja pelo óleo. Sendo assim, o cálculo da distância entre a fonte da descarga e sensor poderá estar incorreta (IEEE C57.1272007).

Uma forma para diferenciar entre ondas que se propagam por caminhos estruturais daquelas que se propagam pelo óleo é analisando o modo de vibração. Em fluídos, como óleo, por exemplo, estes suportam somente ondas longitudinais, ou seja, ondas de pressão. Já os sólidos, como o aço, suportam vários tipos de movimentos ondulatórios. Logo, ondas sonoras se propagando em óleo provocam ondas longitudinais e transversais na parede do tanque. Um detalhe importante é que 
problemas relacionados à propagação de ondas por caminhos estruturais em transformadores podem ser sensivelmente reduzidos se o sensor acústico for instalado dentro do tanque principal (IEEE C57.127-2007).

Por fim, a medição de DPs pelo método acústico somente não fornece uma estimativa da severidade do problema. Um sistema de classificação e banco de dados baseados em relatos de casos semelhantes do problema pode ajudar na análise. Ademais, pode indicar também a necessidade de se utilizar um diagnóstico mais avançado, como, por exemplo, a cromatografia dos gases presentes no óleo do transformador, que proporcionem meios para identificar a causa e a gravidade do problema (IEEE C57.127-2007).

\subsection{Piezeletricidade, eletretos e piezoeletretos}

Neste tópico são apresentados alguns conceitos pertinentes a esta dissertação para uma melhor compreensão do trabalho a ser desenvolvido, que consiste no desenvolvimento de um transdutor acústico baseado em piezoeletretos para medição de descargas parciais em transformadores. Para isso, será apresentado o que é o efeito piezelétrico, o que é um piezoeletreto e alguns conceitos que o envolvem.

\subsubsection{Piezeletricidade: princípios, história e aplicações}

O dicionário de termos técnicos da National Aeronautics and Space Administration (NASA) define piezeletricidade como sendo "a propriedade exibida por alguns materiais cristalinos assimétricos quando estão sujeitos a uma deformação mecânica, em direção apropriada, exibindo uma polarização elétrica proporcional à pressão".

Em 2002, Reimund Gerhard-Multhaupt (2002) generalizou essa definição afirmando que a piezeletricidade é um fenômeno estritamente linear, que relaciona qualquer deslocamento mecânico a uma tensão elétrica, ou qualquer tensão elétrica a um deslocamento mecânico como causa e efeito.

A piezeletricidade foi descoberta em 1880, pelos irmãos Pierre e Jaques Curie, quando estes observaram o aparecimento de cargas superficiais em alguns materiais 
de estrutura cristalina (BOTTOM, 1968). Notaram que estas estruturas apresentavam uma geometria molecular bipolar com alinhamento assimétrico. Com a polarização, cargas elétricas são induzidas nas superfícies desses materiais, o que mantém a estrutura em equilíbrio elétrico. Quando uma força externa ou tensão elétrica é aplicada, esse equilíbrio é perturbado gerando uma movimentação das cargas e, por consequência, o efeito da piezeletricidade (LANG, 2005; TRAINER, 2003). Para o caso de uma excitação mecânica gerando uma resposta elétrica denomina-se piezeletricidade direta; já quando uma excitação elétrica provoca uma resposta mecânica nomeia-se de piezeletricidade indireta (BALLATO, 1996; BASSO et al., 2006; KRESSMANN, 2001). A Figura 19 apresenta um esquemático de como se dá o efeito da piezeletricidade.

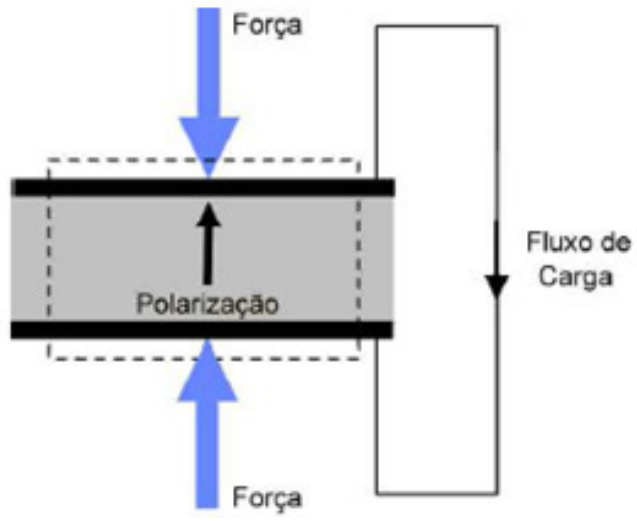

(A)

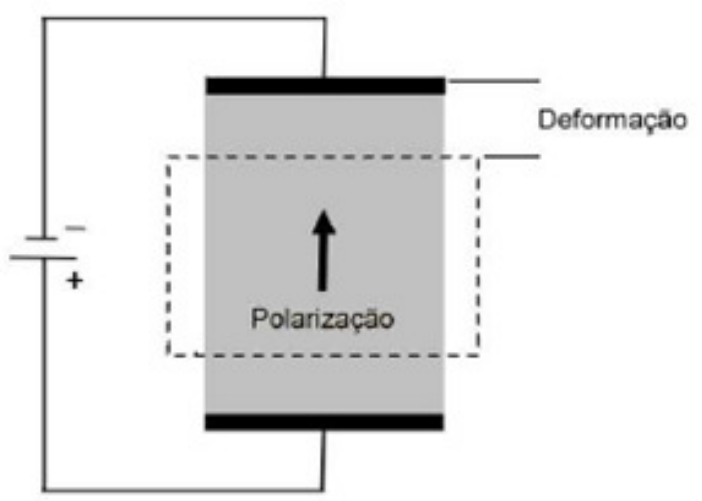

(B)

Figura 19 (A): efeito piezelétrico direto. (B): efeito piezelétrico indireto.

Fonte: Modificado de Falconi (2010).

Os irmãos Curie se basearam nas suposições de Coulomb que, nas décadas de 1780 e 1790, observou o surgimento de cargas elétricas pela simples compressão de materiais cristalinos. Um pouco depois de Coulomb, em 1819, Antoine César Becquerel constatou o efeito piezelétrico presente em alguns materiais cristalinos quando submetidos a esforços mecânicos. Becquerel atribuiu este comportamento a propriedades presentes na estrutura do material cristalino. Em 1881, Lippmann encontrou o efeito inverso da piezeletricidade, aplicando cargas elétricas na superfície do material, e obtendo como resultado uma deformação mecânica. Os irmãos Curie, analisando tais resultados, verificam que os coeficientes piezelétricos, direto e inverso, apresentavam resultados iguais. Foi no mesmo ano que Wilhelm Gottlieb Hankel 
sugeriu o termo "piezeletricidade", sendo amplamente aceito pela comunidade científica (BALLATO, 1996).

Foi no ano de 1893 que Willian Thomson, mais conhecido pelo nome de Lorde Kelvin, desenvolveu um modelo atômico objetivando explicar o efeito piezelétrico. Já no ano de 1894, pode-se alcançar um tratamento mais formal nos estudos da piezeletricidade pelos trabalhos publicados de Pierre Maurice Marie Duhem e Frederich Pockels. Foi no mesmo ano que Woldemar Voigt relacionou os coeficientes piezelétricos com tensores mecânicos. Durante um bom tempo, o efeito piezelétrico permaneceu sem uma aplicação prática a nível industrial, até que Paul Langevin desenvolveu a primeira aplicação, construindo o sonar, muito utilizado durante a época da primeira guerra mundial para localizar submarinos. Langevin passou a ser conhecido como "o pai do sonar" e da disciplina de Ultrassônica. Outra importantíssima contribuição foi quando , em 1921, Cady empregou o efeito piezelétrico encontrado nos cristais de quartzo, na estabilização de osciladores. Isso possibilitou Bechmann implementar tais osciladores para um efetivo controle de frequência em circuitos eletrônicos (BALLATO, 1996).

Já no final da segunda guerra mundial, o efeito piezelétrico foi constatado em cerâmicas de titanato de bário $\left(\mathrm{BaTiO}_{3}\right)$. Este tipo de cerâmica piezelétrica permaneceu até o início da década de 50, quando foi possível produzir cerâmicas mais eficientes, como o PZT, nomeado de titanato zirconato de chumbo (TRAINER, 2003).

Durante os anos 50, outros trabalhos foram desenvolvidos com os biopolímeros, a exemplo da celulose e fibras de colágeno. Estes trabalhos mostraram que materiais dessa natureza também apresentavam o efeito piezelétrico (FUKADA, 2000; FURUKAWA, 1989; RICHARDSON, 1989). Com estes resultados, as pesquisas foram incentivadas no estudo da piezeletricidade em polímeros. No ano de 1969, Kawai constatou que filmes de PVDF polarizados também atuavam como materiais piezelétricos (FUKADA, 2000). Este avanço, a piezeletricidade em polímeros, desencadeou uma série de vantagens sobre os materiais cerâmicos, visto que os polímeros são materiais menos densos, mais flexíveis e fáceis de serem manufaturados (CAPRON et al., 1986).

Com o decorrer do tempo, outros polímeros com estrutura molecular bipolar também foram polarizados por meio do método térmico, todavia, a maioria não 
apresentou coeficientes piezelétricos que possibilitassem aplicação a nível comercial. Evidente que houve exceções, como o Nylon 11 e a mistura de cianeto de vinilideno (VDCN) com vinilacetato (VAc) (FURUKAWA, 1989).

Dessa forma, a busca de polímeros que apresentassem coeficientes piezelétricos mais elevados passou a ser a principal motivação nas pesquisas que envolviam piezeletricidade. Nessa busca, encontrou-se uma solução na produção de alguns compósitos, a exemplo do PZT/PVDF, que foi utilizado em aplicações que envolviam transdutores flexíveis (FEDOSOV et al., 2008; FURUKAWA, 1989).

Para contornar o problema do baixo coeficiente piezelétrico para os polímeros, as soluções propostas sempre mencionavam que a piezeletricidade estava atrelada à orientação molecular assimétrica. Esta estrutura não e própria de eletretos formados por meio de cargas elétricas aprisionadas. Dessa forma, isso indicava que os eletretos poliméricos apresentavam uma forma de polarização que exibia o efeito piezelétrico (ALTAFIM, 2010).

A hipótese de que se poderia aprisionar carga em materiais apolares foi comprovada em 1979 quando, Wada e Hayakawa, construíram transdutores com camadas de eletretos sobrepostas (KACPRZYK et al., 1994; WADA et al., 1976). Nota-se que o conceito envolvido nos ECMs já sugeria a existência deste fenômeno.

Atualmente sabe-se que, além da característica natural de certos materiais, a piezeletricidade também pode ser obtida em cerâmicas e materiais poliméricos por meio da aplicação de um campo elétrico intenso. O campo é responsável por alinhar as moléculas bipolares na direção do mesmo. Após a remoção do campo e cura do material, este mesmo material apresentará campos elétricos residuais. Estudos posteriores mostraram que, no caso de polímeros, a polarização pode ocorrer de duas formas, tanto pela orientação dipolar como pelo aprisionamento de cargas elétricas em armadilhas energéticas.

Materiais amorfos policristalinos e substâncias parcialmente cristalinas são exemplos bem sucedidos de substâncias onde as cargas elétricas podem ser aprisionadas em armadilhas devido, principalmente, a sua estrutura molecular anisotrópica. Um exemplo de material polimérico com essas propriedades é o Teflon FEP®, cujas estruturas microscópicas retêm principalmente cargas negativas com grande facilidade, em armadilhas superficiais profundas. Estas cargas elétricas, 
quando aprisionadas, permanecem estáveis, presas à estrutura molecular do teflon por um longo período de tempo (GERHARD-MULTHAUPT, 1999).

Com a possibilidade de se obter o efeito piezelétrico em filmes apolares de maneira simples, tornou-se possível o desenvolvimento de dispositivos miniaturizados e a integração com transistores. Dentre estes dispositivos, podem-se citar aplicações que envolvem sistemas micro eletromecânicos (MEMS). Nestes sistemas, a vantagem da miniaturização permitiu aplicação em diversas áreas da ciência, como mecatrônica, óptica e biológica (BALLATO, 1995; GOEL, 2003). Outra aplicação que se beneficiou da versatilidade dos polímeros é a pele artificial eletrônica (E-skins), composta por transistores orgânicos impressos em finas camadas de filmes poliméricos, formando grandes áreas flexíveis sensíveis a pressão (SOMEYA et al., 2005). Todavia são aplicações que estão em fase de desenvolvimento.

\subsubsection{Eletretos}

Paralelamente e de forma independente surgem as pesquisas sobre eletretos. Este termo (eletreto) propriamente dito foi estabelecido por Oliver Heaviside, no ano de 1892, traduzindo uma analogia aos magnetos ou ímãs permanentes conhecidos na época, a fim de justificar o fato dos dielétricos polares exibirem um campo elétrico residual.

Pode-se dizer que os estudos sobre eletretos tiveram início no ano de 1732, embora existam relatos na Grécia antiga de materiais capazes de atrair outros materiais. Neste ano, Gray descreve que materiais como ceras e resinas, após serem derretidos e resfriados em conchas de ferro, adquiriam a propriedade de exercer um poder de atração permanente (SESSLER, 1987).

Um pouco mais adiante, em 1839, Michael Faraday definiu os materiais nos quais atuavam forças elétricas como dielétricos. Faraday mostrou que, nestes materiais, as cargas não se moviam livremente quando influenciadas por um campo elétrico externo, de modo que ficavam aprisionadas no material após a remoção do campo. Também é interessante ressaltar que, somente em 1839, Michael Faraday na realização de seus estudos, observou um estranho fenômeno em capacitores que ao serem carregados, devido à ação de um campo elétrico externo, estes capacitores apresentavam uma carga elétrica residual mesmo após a retirada do campo e consequente curto-circuito momentâneo em seus terminais (HILCZER et al., 1986). 
Sistemáticas pesquisas no campo dos eletretos começaram a se desenvolver com o físico japonês Mototaro Eguchi, a partir de 1919. Com resinas vegetais, cera de carnaúba e cera de abelha, Eguchi formou eletretos através do processo térmico desenvolvido por Gray. Ele denominou esse efeito de "força atrativa perpétua". Após submeter o material a um elevado campo elétrico e alta temperatura, Eguchi também observou que o material polarizado apresentava cargas elétricas de polaridades opostas àquelas aplicadas pela fonte externa. Entretanto, no decorrer de alguns dias, ocorria uma inversão da polaridade das cargas presentes na superfície do material, isto é, o eletreto formado inicialmente por cargas de polaridades opostas às originadas pelos eletrodos, dava lugar às cargas de mesma polaridade do campo elétrico aplicado (FUKADA, 2000; GROSS, 1950; SESSLER, 1987).

Bernard Gross e Denard, em 1944, explicaram este fato denominando as cargas elétricas presentes no material de heterocargas e homocargas, ao passo que as heterocargas "desaparecem" rapidamente e as homocargas, mais estáveis, perduram por vários anos. Isso foi possível após Gross aprimorar a técnica de corrente termo estimulada (TSC), que se trata de aquecer, a uma taxa constante, um material dielétrico previamente polarizado e mensurar a corrente passante. Portanto, as cargas injetadas pelos eletrodos, e que possuíam a mesma polarizada destes, denominou-se homocargas; já as heterocargas, de polaridade oposta aos eletrodos, eram provenientes de alinhamento de dipolos e/ou movimentação de íons impuros presentes no material (GUTMANN, 1948; SESSLER, 1999, 2006).

Gross e Denard também realizaram estudos complementares do comportamento das cargas elétricas frente à temperatura de preparo da amostra, relatando que a temperatura de preparo influencia diretamente na quantidade de cargas presente no eletreto.

Assim pode-se afirmar que a principal propriedade de um eletreto é ser um armazenador de cargas e detentor de um campo elétrico que permanece no material, mesmo sem a tensão aplicada sobre a amostra. Dois são os fenômenos que explicam a presença de um campo elétrico residual em um material dielétrico: a polarização dielétrica e o aprisionamento de cargas elétricas por armadilhas energéticas.

Todavia, durante um bom tempo o eletreto foi visto como um dielétrico que possuía uma polarização molecular apenas. Para ser mais específico, foi a partir dos anos 60 que o conceito de eletretos sofreu uma mudança no sentido de designar não 
apenas um dielétrico com polarização molecular, mas também dielétricos que possuam apenas cargas elétricas injetadas, ou seja, homocargas (HILCZER, et al., 1986).

Outros processos de formação de eletretos foram desenvolvidos e, geralmente, para a formação dos eletretos, os filmes poliméricos são submetidos a um processo de carregamento por efeito corona (GIACOMETTI, GERHARD-MULTHAUPT, SESSLER, e outros). Contudo, devido ao elevado tempo de exposição e custos envolvidos no processo, Altafim et al. (1992, 1998) elaborou um método de carregamento aplicando uma onda de tensão impulsiva, com um pico elevado, diretamente sobre o filme polimérico. Gerhard-Multhaupt et al. (2002) e Altafim et al. (2003) já utilizam o processo impulsivo com grande eficiência e curtíssimo tempo de carga.

\subsubsection{Piezoeletretos}

Recentemente, a família de polímeros piezo-, piro- e ferroelétricos recebeu um novo membro chamado "piezoeletreto", ou seja, espumas poliméricas carregadas eletricamente. Já em 1970, as propriedades piezo e piroelétrico de polímeros não polares carregados eletricamente foram teoricamente prevista e experimentalmente estudados (WADA et al., 1976). No entanto, o interesse desapareceu por causa do fraco efeito piezo-piroelétrico obtido na época. Essa situação alterou-se substancialmente ao longo da última década e um considerável número de polímeros celulares e porosos com grande efeito piezelétrico foram identificados e desenvolvidos. Quando surgem descargas elétricas nas cavidades gasosas do polímero, cargas elétricas de polaridades opostas separam-se e ficam aprisionadas em sua superfície, formando dipolos elétricos de grandes dimensões, que em combinação com as propriedades elásticas do material induzem o desejado efeito piezo ou piroelétrico nesses polímeros. Veja a Figura 20.

Os piezoeletretos termoformados foram desenvolvidos, após inúmeras tentativas, por Altafim et al. (2005) como uma alternativa para criar cavidades homogêneas e bem controladas. Nesta busca, cavidades de dimensões milimétricas provaram também possuir altos coeficientes piezelétricos. A primeira proposta desse desenvolvimento encontra-se na Figura 21. 


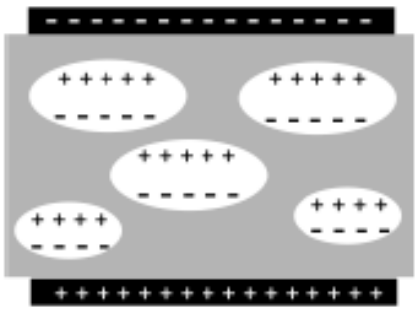

(A)

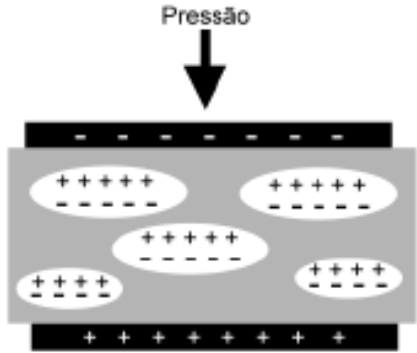

(B)

Figura 20 (A): Representação esquemática de cargas aprisionadas nos polímeros celulares após carregamento. (B): Deformação das cavidades quando a estrutura é submetida à pressão externa.

Fonte: Modificado de Altafim (2010).

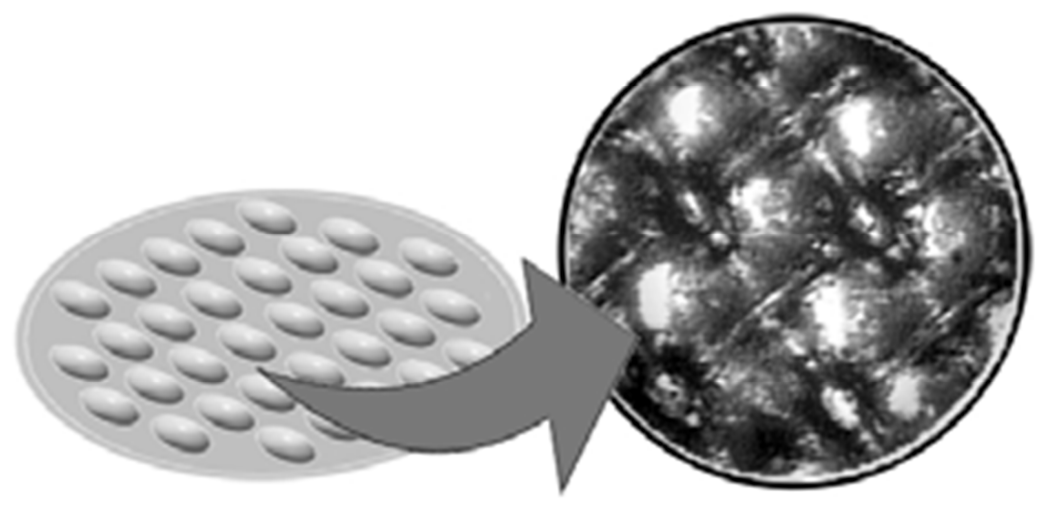

Figura 21: Imagem do primeiro piezoeletreto termoformado.

Fonte: Altafim et al. (2003).

Visando aplicações industriais, os piezoeletros devem apresentar estabilidade térmica e cavidades bem controladas e uniformes (QUI, 2010). Várias estratégias foram propostas para preparar piezoeletros deste tipo. A primeira foi desenvolvida por Altafim et al. (2006) e consiste em uma pilha de dois filmes de FEP colocados entre duas placas metálicas cilíndricas que podem ser aquecidas de forma independente. Uma das placas é completamente sólida, e na outra existem pequenos furos conectados a uma bomba de vácuo. Uma grade de metal adicional é colocada entre a pilha de filmes FEP e a placa de fundo, completando o conjunto. Quando o ar é retirado através dos orifícios da placa de fundo por uma bomba de vácuo, o filme FEP adjacente é sugado para dentro das aberturas da grade de metal, conforme apresentado pela Figura 22, possibilitando a formação de bolhas na estrutura (ALTAFIM et al. 2005, 2006). 
Alguns artigos merecem destaque para este trabalho, como, por exemplo, o de Xunlin (2010), que faz uma revisão bibliográfica completa sobre os novos materiais poliméricos tipos celulares e porosos, e uma nova classe que vem ganhando destaque: a dos termoformados. Nesse artigo, Xunlin destaca os processos de fabricação e caracterização em especial com relação à resposta em frequência desses novos materiais. Na figura 23 encontra-se um detalhe microscópico de um dos piezoeletretos tipo celular. Ali podem ser vistos os vacúolos de ar no interior do polímero e que depois serão carregados eletricamente, tornando-se macro dipolos.

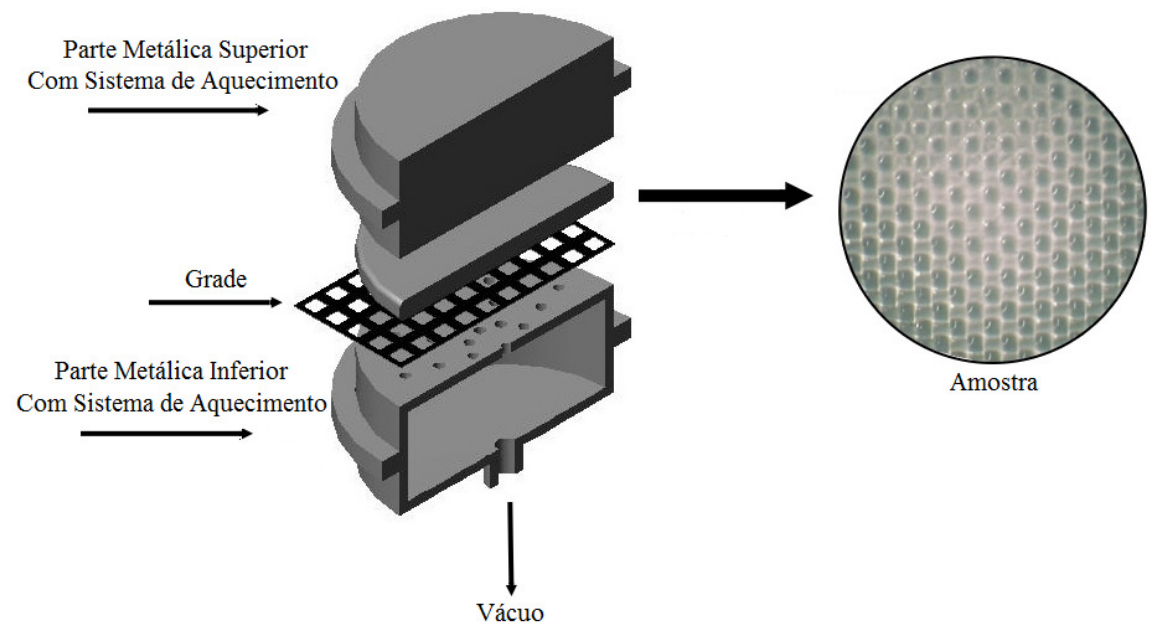

Figura 22: Esquemático ilustrando a preparação das bolhas termoformadas entre dois filmes poliméricos.

Fonte: Modificado de Altafim et al. (2006).

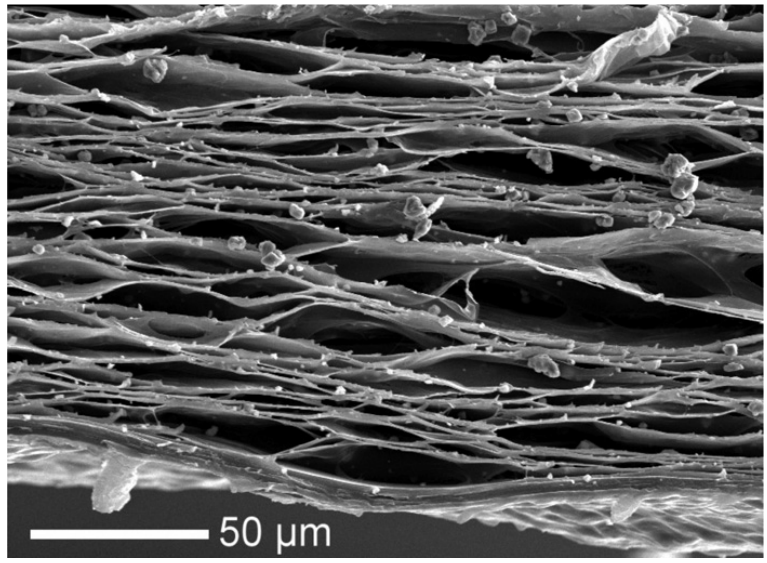

Figura 23: Micrografia eletrônica de um piezoeletreto celular de PP (polipropileno).

Fonte: Xunlin (2010). 
Depois surgiu uma série de desenvolvimentos, sendo um dos mais importantes apresentados na tese de doutorado de Altafim (2010). Ali as cavidades foram tratadas como canaletas e puderam ser mais bem dimensionadas, inclusive com relação ao controle das frequências de ressonância. Esses piezoeletretos estão sendo usados como elementos principais deste trabalho e serão tratados no capítulo três.

\subsection{Processamento dos sinais.}

Neste subtópico é apresentada a principal ferramenta de processamento que será utilizada no capítulo quatro, onde estão descritos todos os experimentos, desde o ensaio de descarga numa câmara anecóica até o ensaio de uma descarga em óleo e dentro de uma caixa de alumínio. Conforme será mostrado posteriormente, o problema básico do processamento dos sinais acústicos de descarga envolverá a remoção de ecos. Uma primeira aproximação do sistema em estudo é considerar a convolução de um sinal original, ou sem eco, com uma função trem de pulsos, não sendo necessário que os pulsos sejam igualmente espaçados. Tendo em vista que estes dois sinais estão combinados por convolução, ao processo de separação destas duas componentes se dá o nome de deconvolução. Primeiramente será apresentada brevemente a deconvolução linear e, em seguida, a deconvolução homomórfica, que é a ferramenta utilizada no processamento de todas as medidas.

Antes de prosseguir, a ideia de convolução de sinais parte do seguinte pressuposto: qualquer sinal discreto $x(n)$ pode ser representado conforme apresenta a equação (2.25).

$$
x(n)=\sum_{k=-\infty}^{+\infty} x(k) \delta(n-k)
$$

Onde a função $\delta(n-k)$ é a função impulso, que somente tem valor igual a um quando o argumento tem valor nulo, isto é, $n=k$. Em se tratando se sistemas lineares discretos e invariantes ao deslocamento, a transformação $T$ sobre a entrada $x(n)$ terá como resultado a saída $y(n)$, que é dada pela equação (2.26.2). Vale lembrar que esta é a definição básica de sistema: uma transformação sobre uma entrada gerando uma saída. 


$$
\begin{gathered}
y(n)=T[x(n)]=T\left[\sum_{k=-\infty}^{+\infty} x(k) \delta(n-k)\right]=\sum_{k=-\infty}^{+\infty} x(k) T[\delta(n-k)] \therefore \\
y(n)=\sum_{k=-\infty}^{+\infty} x(k) h(n-k)=x(n) * h(n)
\end{gathered}
$$

Onde $h(n-k)$ é chamada de resposta ao impulso do sistema para entrada $\delta(n-k)$, ou seja, a saída provocada por um impulso; e o símbolo * indica convolução de $x(n)$ e $h(n)$. Vale salientar que o operador somatório é linear e, portanto, o operador $T$ pode adentrar a este e ser aplicado somente ao impulso, já que $x(k)$ é apenas um escalar. Dessa forma, conhecendo-se a forma de $h(n)$, pode-se obter a saída $y(n)$ para qualquer entrada $x(n)$ por meio do produto de convolução.

Em processamento de sinais sísmicos, por exemplo, sabe-se que a reposta do sistema sísmico ao impulso, $h(n)$, é chamada de função de refletividade e está relacionada à composição do solo em questão de camadas. Portanto, um dos interesses neste caso é saber sobre a estratificação do solo por meio da função de refletividade $h(n)$ (GOMES, 1998). Note que o procedimento é como que o inverso daquele estabelecido na equação (2.26.2): tem-se $y(n)$ e deseja-se obter $h(n)$.

\subsubsection{Deconvolução Linear}

Exemplificando uma aplicação, a técnica de deconvolução linear foi amplamente utilizada no processamento de sinais sísmicos. Neste exemplo, a deconvolução linear parte do pressuposto estabelecido na equação (2.26.2), ou seja:

$$
y(n)=f(n) * h(n)+r(n)
$$

Sendo:

$y(n)=$ Traço sísmico ou sismograma.

$f(n)=$ Pulso fonte aplicado ao sistema sísmico.

$h(n)=$ Função refletividade.

$r(n)=$ Ruído inerente ao meio ambiente. 
Aplicando-se o operador de autocorrelação $\varphi$ na equação (2.27) e considerando $\varphi_{y}(n), \quad \varphi_{f}(n)$ e $\varphi_{h}(n)$ a função de autocorrelação de $y(n), f(n)$ e $h(n)$ respectivamente, tem-se a equação (2.28.3). Neste caso, a função de autocorrelação de um ruído pode ser desprezada. Neste tipo de situação é comum considerar a função $h(n)$ não correlacionável, isto é, a função refletividade quase não possui relação consigo mesma. Deste modo, o elemento realmente expressivo da função é o elemento nulo, ou seja, $\varphi_{h}(0)$.

$$
\begin{gathered}
\varphi[y(n)]=\varphi[f(n) * h(n)+r(n)]=\varphi[f(n) * h(n)]+\varphi[r(n)] \rightarrow \\
\rightarrow \varphi_{y}(n)=\varphi_{f}(n) * \varphi_{h}(n)=\varphi_{f}(n) * \varphi_{h}(0) \delta(n)=\varphi_{f}(n) * \delta(n) \varphi_{h}(0) \therefore \\
\varphi_{y}(n)=\varphi_{h}(0) \varphi_{f}(n)
\end{gathered}
$$

Feita as devidas considerações, conclui-se que a função de autocorrelação do traço sísmico é proporcional à função de autocorrelação do pulso fonte. Dessa forma, filtros de deconvolução podem ser desenvolvidos a partir das informações fornecidas pela função de autocorrelação do sismograma. Na literatura, este procedimento de deconvolução do traço sísmico é conhecido como filtragem inversa. Apenas para ilustrar esta aplicação numa situação idealizada, um filtro inverso nominado como $f^{-1}(n)$ é tal que, aplicando-o a ambos os membros da equação (2.27) e desconsiderando o ruído, segue que:

$$
\begin{gathered}
y(n) * f^{-1}(n)=f(n) * h(n) * f^{-1}(n)=f(n) * f^{-1}(n) * h(n)=\delta(n) * h(n) \therefore \\
y(n) * f^{-1}(n)=h(n)
\end{gathered}
$$

Isto é: não havendo ruídos ambientais, é possível recuperar a função refletividade. O filtro inverso ideal $f^{-1}(n)$ pode ser projetado da seguinte forma: Seja a transformada de Fourier do pulso fonte dado por $F(\Omega)$. Dessa forma, o filtro inverso $F^{-1}(\Omega)$, é tal que:

$$
\begin{gathered}
\left|F^{-1}(\Omega)\right|=\frac{1}{|F(\Omega)|} \\
\arg \left(F^{-1}(\Omega)\right)=-\arg (F(\Omega))
\end{gathered}
$$


Particularmente, existem duas abordagens principais na deconvolução linear, que é a filtragem ótima de Wiener e a deconvolução preditiva, ambos projetados por meio do método dos mínimos quadrados. No primeiro caso, os filtros de Wiener procuram converter o sismograma na função de refletividade e o projeto destes requer, a priori, o conhecimento do pulso fonte. No segundo caso, a aplicação é voltada para dereverberação do traço sísmico. Os trabalhos de Robinson (1957) e Rice (1962) abordam a filtragem inversa no domínio do tempo utilizando o método dos mínimos quadrados partindo, inicialmente, da função de autocorrelação aplicada ao traço sísmico, que é o procedimento demonstrado anteriormente. Assume-se que esta função de autocorrelação do traço sísmico seja equivalente à função de autocorrelação do pulso fonte. Tomando-se apenas um pequeno número de defasamentos da função de autocorrelação do traço sísmico em relação ao comprimento total do sinal, restringe-se o pulso fonte a um curto período de duração. Tendo em vista que a função de autocorrelação e o espectro de potência são relacionados por meio de transformadas de Fourier, é equivalente dizer que, comparativamente à série refletora, o espectro de potência do pulso fonte varia lentamente no que diz respeito à frequência. Dessa forma, a deconvolução no domínio do tempo remove as componentes com variações lentas do espectro de potência mantendo as componentes com variações rápidas que, provavelmente, representa a série refletora. Assim nota-se que a filtragem inversa baseada no método dos mínimos quadrados explora a diferença entre pulso fonte e traço sísmico, ou seja, o modo como o espectro de potência varia com a frequência e o sucesso deste procedimento é determinado pela magnitude dessa diferença. Deve ser mencionado que uma série refletora do tipo "randômica" possui espectro de amplitude branco ou plano somente em um sentido estatístico. O espectro de uma série randômica em particular, todavia, não será plano, ou seja, possuirá ambas componentes de variações lentas e rápidas (STOFFA et al., 1974).

Observa-se ainda que, em filtragem inversa utilizando mínimos quadrados, deve-se pressupor o espectro de fase do pulso fonte, tendo em vista que a aplicação da função de autocorrelação destruiu toda a informação sobre a fase do sinal. Em geral assume-se que o pulso fonte seja de fase mínima (o item 2.5.2.6, propriedade P2, explica o que é uma sequência de fase mínima). O espetro de fase pode ser mais bem tratado da mesma forma que se tratou o espectro de potência, ou seja, associar componentes com variações lentas ao sinal fonte e componentes com variações rápidas com a série refletora, tendo em vista que o procedimento básico da 
deconvolução no domínio tempo, ou linear, é exatamente este: a remoção de componentes de variações lentas do espectro de potência, que representam o sinal fonte, mantendo as componentes de variações rápidas, que provavelmente representa a série refletora. Entretanto, isto só é possível para o caso da série refletora ser de fase mínima (STOFFA et al., 1974).

\subsubsection{A Deconvolução Homomórfica}

O procedimento de deconvolução homomórfica difere dos demais procedimentos, pois transforma um produto convolucional em uma soma. É um procedimento não linear que exigirá a definição de superposição generalizada, a qual será apresentada logo a seguir. Uma vantagem digna de nota é que neste caso não há necessidade do prévio conhecimento do pulso fonte. Ademais, este pulso não precisa ser de fase mínima nem a série refletora não correlacionável, como o era no caso da filtragem de Wiener e deconvolução preditiva.

É importante mencionar que o principal problema em questão, a remoção de ecos, está baseada num modelo de sistemas lineares invariantes ao deslocamento, conforme estabelece a equação (2.26.2). Em outras palavras, o modelo de composição de sinais, conforme mencionado anteriormente, se dá por meio do produto de convolução de modo que o cepstro do sinal será composto de dois termos: um que diz respeito ao pulso fonte e outro, a série refletora. O termo cepstro designa o sinal no domínio cepstral. Isto se tornará claro mais adiante.

\subsubsection{Princípio generalizado de superposição}

Antes de mostrar este princípio, é importante frisar que o sistema a ser apresentado está baseado na numa generalização dos sistemas lineares. Isto é importante, pois sistemas lineares invariantes ao deslocamento são relativamente fácies de análise e caracterização, proporcionando uma representação matemática elegante e facilmente tratável e também pela possibilidade de se projetar estes sistemas para realizar uma variedade de funções úteis no processamento de sinais. Um exemplo clássico, quando se utiliza a transformada de Fourier, é a remoção de componentes de frequência de um sinal quando estas ocupam bandas distintas. Neste caso um filtro linear resolve suficientemente o problema. O fato de que sistemas 
lineares são relativamente de fácil análise e útil na separação de sinais combinados por adição é uma consequência direta do princípio da superposição.

De modo geral, os sistemas lineares podem ser definidos considerando que, para quaisquer entradas $x_{1}(n)$ e $x_{2}(n)$ e qualquer escalar $c$, e sendo $L$ o operador de transformação do sistema, são válidas as seguintes operações:

$$
\begin{gathered}
L\left[x_{1}(n)+x_{2}(n)\right]=L\left[x_{1}(n)\right]+L\left[x_{2}(n)\right]=y_{1}(n)+y_{2}(n) \\
L\left[c x_{1}(n)\right]=c L\left[x_{1}(n)\right]=c y_{1}(n)
\end{gathered}
$$

Entretanto, pode ocorrer que os sinais não estejam combinados por adição e sim por convolução, por exemplo. Isto requer a consideração da classe de sistemas não lineares que obedecem a um princípio generalizado de superposição. Para a generalização do princípio da superposição, consideraremos o símbolo "ם" para combinação de entradas, "ם" para combinação de saídas, " $\theta$ " para combinação de entradas com escalares e "§" para combinação de saídas com escalares. Sendo $H$ o novo operador do sistema, as equações (2.31) e (2.32) podem ser reescritas da seguinte forma:

$$
\begin{gathered}
H\left[x_{1}(n) \mathbf{\square} x_{2}(n)\right]=H\left[x_{1}(n)\right] \mathbf{0} H\left[x_{2}(n)\right]=y_{1}(n) \mathbf{d} y_{2}(n) \\
H\left[c \vartheta x_{1}(n)\right]=c \diamond H\left[x_{1}(n)\right]=c \diamond y_{1}(n)
\end{gathered}
$$

Estes sistemas, que são não lineares, obedecem ao princípio generalizado de superposição, possuindo uma operação de entrada $\mathbf{a}$ e uma operação de saída $\mathbf{0}$, conforme apresenta a Figura 24.

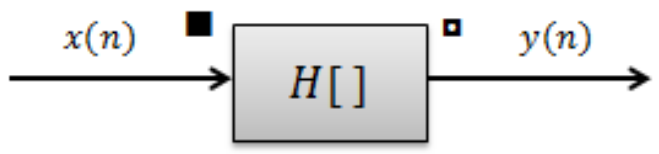

Figura 24: Sistema Homomórfico representado em diagrama de blocos. Possui operação de entrada operação de saída ם sistema de transformação $\boldsymbol{H}[$ ].

Sistemas dessa natureza são representados algebricamente por transformações lineares entre espaços vetoriais e têm sido classificados como sistemas homomórficos. Evidente 
que os sistemas lineares são um caso particular desse tipo de sistema onde e representa adição e $\theta$ e $\diamond$ representa multiplicação. A teoria de espaço vetorial linear contém o formalismo matemático necessário para a representação desta classe de sistemas e pode ser encontrada em Oppenheim $(1965,1967)$. As entradas e saídas do sistema podem ser interpretadas como vetores em espaços vetoriais de forma que as regras - D representem adição vetorial e $\theta$ e $\diamond$ representem multiplicação escalar. Sendo assim, o operador $H[$ ] do sistema será uma transformação algébrica do espaço vetorial de entrada para o espaço vetorial de saída.

É possível mostrar que, se as entradas do sistema constituem um espaço vetorial com as operações $\mathbf{\square}$ e $\theta$ representando adição vetorial e multiplicação escalar e as saídas do sistema constituir um espaço vetorial com a e $\diamond$ correspondendo à adição vetorial e multiplicação escalar, portanto do os sistemas dessa classe podem ser representados como três sistemas em cascata, conforme apresenta a Figura 25 (OPPENHEIM, 1975).

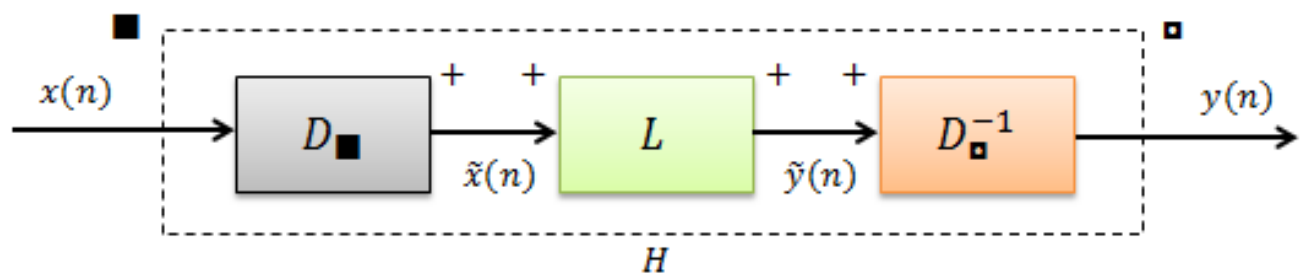

Figura 25: Sistema Homomórfico representado na forma canônica. Possui operação de entrada operação de saída a e sistema de transformação $\boldsymbol{H}[$ ].

O primeiro sistema, $D_{\mathbf{\square}}$, possui as propriedades apresentadas nas equações (2.35) e (2.36). Nota-se que este sistema obedece ao princípio da superposição generalizada, visto que a operação de entrada é $\mathbf{\square}$ e a de saída é +. O efeito deste sistema é transformar a combinação das entradas, segundo a regra $\mathbf{\square}$, em uma combinação linear dos sinais transformados. Similarmente, as equações (2.31) e (2.32) representa o sistema $L$, que é um sistema linear convencional, com a seguinte diferença: as entradas agora são $\tilde{x}_{1}(n)$ e $\tilde{x}_{2}(n)$ em vez de $x_{1}(n)$ e $x_{2}(n)$; as novas saídas, consequentemente, serão $\tilde{y}_{1}(n)$ e $\tilde{y}_{2}(n)$. Por fim, o sistema $D_{\mathbf{a}}^{-1}$ tem as propriedades apresentadas nas equações (2.37) e (2.38).

$$
D_{\square}\left[x_{1}(n) \square x_{2}(n)\right]=D_{\square}\left[x_{1}(n)\right]+D_{\square}\left[x_{2}(n)\right]=\tilde{x}_{1}(n)+\tilde{x}_{2}(n)
$$




$$
\begin{gathered}
D_{\mathbf{a}}\left[c \theta x_{1}(n)\right]=c D_{\mathbf{\square}}\left[x_{1}(n)\right]=c \tilde{x}_{1}(n) \\
\left.D_{\mathbf{a}}^{-1}\left[\tilde{y}_{1}(n)+\tilde{y}_{2}(n)\right)\right]=D_{\mathbf{a}}^{-1}\left[\tilde{y}_{1}(n)\right] \mathbf{0} D_{\mathbf{a}}^{-1}\left[\tilde{y}_{2}(n)\right]=y_{1}(n) \mathbf{d} y_{2}(n) \\
D_{\mathbf{a}}^{-1}\left[c \tilde{y}_{1}(n)\right]=c \theta D_{\mathbf{a}}^{-1}\left[\tilde{y}_{1}(n)\right]=c \theta \tilde{y}_{1}(n)
\end{gathered}
$$

Visto que o sistema $D_{\boldsymbol{\square}}$ é fixado pelas operações $\square$ e $\theta$, isto o torna característico desta classe de operações e, portanto, é chamado de sistema característico. Da mesma forma o sistema $D_{\mathbf{0}}$ é característico para a operação Ademais, é sabido que todos os sistemas homomórficos com mesma operação de entrada e saída diferem apenas na parte linear. Este resultado é de fundamental importância, pois uma vez determinado o sistema característico, fica-se com um problema de filtragem linear. Como exemplo, deseja-se recuperar $x_{1}(n)$ do sinal:

$$
x(n)=x_{1}(n) \mathbf{\square} x_{2}(n)
$$

Escolhendo-se adequadamente o filtro linear de modo que se tenha:

$$
\tilde{y}(n)=\tilde{x}_{1}(n)
$$

Fazendo-se $D_{\mathbf{\square}}=D_{\mathbf{a}}$, teremos que:

$$
y(n)=D^{-1}\left[\tilde{x}_{1}(n)\right]=x_{1}(n)
$$

Portanto, deve-se escolher adequadamente o filtro linear que seja capaz de separar as componentes $\tilde{x}_{1}(n)$ e $\tilde{x}_{2}(n)$ de modo a realizar da perfeita separação das componentes $x_{1}(n)$ e $x_{2}(n)$ do sinal. O modo que se pode aproximar esta situação do ideal dependerá da operação $\mathbf{\square}$ das propriedades das componentes $x_{1}(n)$ e $x_{2}(n)$ do sinal.

\subsubsection{Sistemas homomórficos para convolução: forma canônica}

Uma abordagem comum na separação de componentes de sinais combinados por convolução, procedimento também conhecido como deconvolução, é a filtragem linear inversa. Infelizmente, visto que sistemas lineares não são associados com a estrutura de combinações convolucionais, a filtragem inversa requer o conhecimento detalhado de uma das componentes do sinal. Alternativamente, somos levados a 
considerar a classe de sistemas homomórficos os quais obedecem ao princípio generalizado de superposição (OPPENHEIM, 1966, 1969; SCHAFER, 1969).

Considerando uma sequência combinada pelo produto de convolução dado na equação (2.42):

$$
x(n)=\sum_{k=-\infty}^{+\infty} x_{1}(k) x_{2}(n-k)=x_{1}(n) * x_{2}(n)
$$

Constata-se que o produto de convolução discreto satisfaz os postulados algébricos para adição vetorial e, consequentemente, é possível a escolha de uma classe de sistemas homomórficos. A multiplicação escalar de um número inteiro $\alpha$, é equivalente à convolução repetida de $x(n)$ com ela própria, $\alpha$ vezes. Já a multiplicação escalar quando $\alpha$ não é inteiro, é uma generalização deste procedimento (OPPENHEIM, 1965; SCHAFER, 1969).

A forma canônica do sistema homomórfico para convolução é apresentada na Figura 26. O sistema característico $D_{*}$ tem as propriedades apresentadas nas equações a seguir.

$$
\begin{gathered}
D_{*}\left[x_{1}(n) * x_{2}(n)\right]=D_{*}\left[x_{1}(n)\right]+D_{*}\left[x_{2}(n)\right]=\tilde{x}_{1}(n)+\tilde{x}_{2}(n) \\
D_{*}\left[c \theta x_{1}(n)\right]=c D_{*}\left[x_{1}(n)\right]=c \tilde{x}_{1}(n)
\end{gathered}
$$

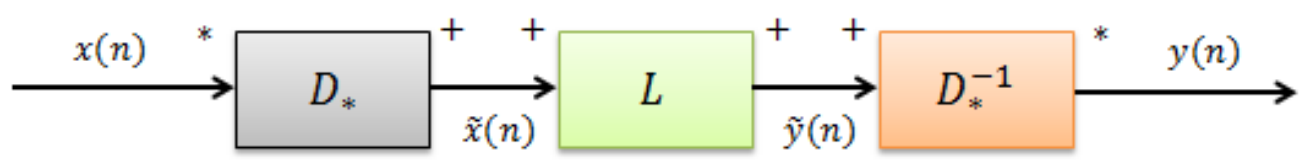

Figura 26: Forma canônica do Sistema Homomórfico com a operação de convolução como entrada e saída deste sistema.

\subsubsection{Sistema característico $D_{*}$}

A chave para a representação matemática do sistema característico $D_{*}$ está no fato de que a transformada $z$, aplicada à equação (2.42), é: 


$$
X(z)=X_{1}(z) \cdot X_{2}(z)
$$

Ou seja, tem-se a propriedade de transformar um produto de convolução numa multiplicação das respectivas transformadas. Dessa forma, esta transformada pode ser vista como um sistema homomórfico, com operação de convolução na entrada e multiplicação na saída. Tem-se, portanto, um sistema homomórfico multiplicativo. Sendo assim, representando-se um sinal pela sua transformada $z$, o sistema canônico da Figura 26 pode ser substituído um novo sistema homomórfico apresentado na Figura 27. Haja vista que a transformada $z$ é, geralmente, complexa, o uso do logaritmo complexo deve ser utilizado.

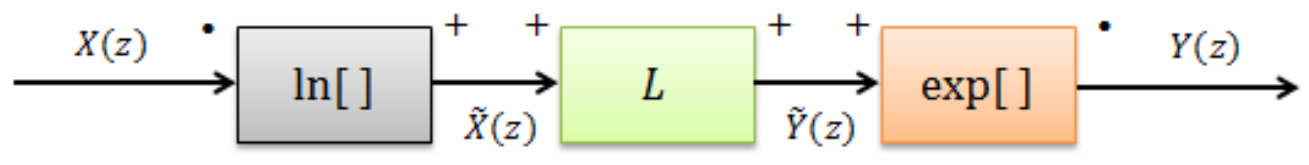

Figura 27: Sistema da Figura 26 com o sinal $\boldsymbol{x}(\boldsymbol{n})$ representado em termos de sua transformada $\boldsymbol{z}$.

Quando sinais são representados como sequências ao invés de sua transformada $z$, pode-se formalmente representar o sistema característico conforme a Figura 28. Este é composto de três sistemas em cascata, onde $Z^{-1}$ é a transformada $Z$ inversa. É interessante notar que as transformadas $Z$ e $Z^{-1}$ são lineares no sentido convencional, da mesma forma que são transformações homomórficas entre espaços vetoriais convolucionais e multiplicativos.

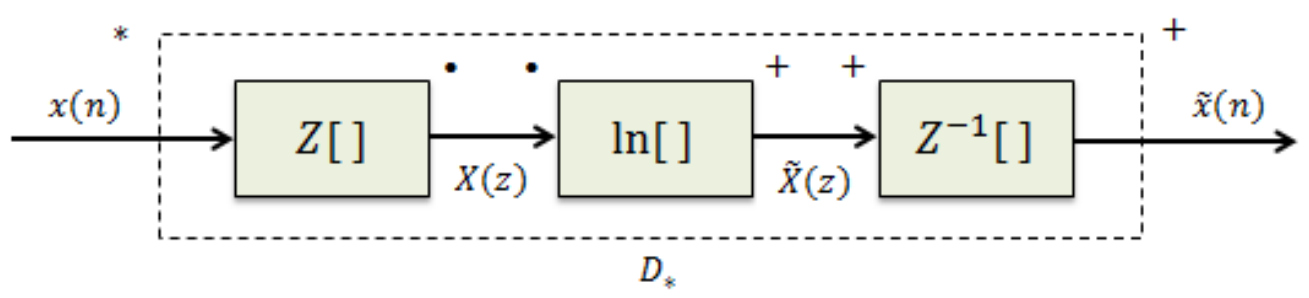

Figura 28: Representação do sistema característico $\boldsymbol{D}_{*}$.

Existem algumas considerações implícitas no que diz respeito à representação do sistema característico $D_{*}$. Primeiro, o logaritmo complexo, $\ln [X(z)]$, deve ser univocamente definido, ou seja: 


$$
\ln [X(z)]=\ln \left[X_{1}(z) \cdot X_{2}(z)\right]=\ln \left[X_{1}(z)\right]+\ln \left[X_{2}(z)\right]=\tilde{X}(z)
$$

Também, $\tilde{X}(z)$ precisa ser uma transformada válida. E terceiro, objetivando que $\tilde{x}(n)$ seja univocamente definido, deve-se escolher uma região de convergência. Admitindo que $x(n)$ e $\tilde{x}(n)$ sejam sequências reais e estáveis, consequentemente as regiões de convergência de $X(z)$ e $\tilde{X}(z)$ devem incluir o círculo unitário. Para o caso de $\tilde{X}(z)$ representar uma transformada $z$ bilateral, $\tilde{X}(z)$ pode ser expandida em série de Laurent, conforme a equação (2.47), de modo que a região de convergência inclua o círculo unitário. Isto é, $\tilde{X}(z)$ deve ser analítica na região que inclua o círculo unitário. A equação (2.48) expressa $\tilde{X}(z)$ neste circulo.

$$
\begin{gathered}
\tilde{X}(z)=\ln [X(z)]=\sum_{n=-\infty}^{\infty} \tilde{x}(n) z^{-n} \\
\tilde{X}\left(e^{j w}\right)=\tilde{X}_{R}\left(e^{j w}\right)+j \tilde{X}_{I}\left(e^{j w}\right)
\end{gathered}
$$

Desde que $\tilde{x}(n)$ seja real, deve-se ter que $\tilde{X}_{R}\left(e^{j w}\right)$ seja uma função par e $\tilde{X}_{I}\left(e^{j w}\right)$, ímpar em $w$. Ademais, $\tilde{X}\left(e^{j w}\right)$ deve ser periódica em $w$ com período igual a $2 \pi$. A implicação mais importante da analiticidade de $\tilde{X}(z)$ no círculo unitário é que $\tilde{X}\left(e^{j w}\right)$ precisa ser uma função contínua em $w$. Notando que:

$$
\begin{gathered}
X\left(e^{j w}\right)=\left|X\left(e^{j w}\right)\right| e^{j a r g}\left[X\left(e^{j w}\right)\right] \rightarrow \\
\rightarrow \tilde{X}\left(e^{j w}\right)=\ln \left|X\left(e^{j w}\right)\right|+j \arg \left[X\left(e^{j w}\right)\right] \therefore \\
\tilde{X}_{R}\left(e^{j w}\right)=\ln \left|X\left(e^{j w}\right)\right| \\
\tilde{X}_{I}\left(e^{j w}\right)=\arg \left[X\left(e^{j w}\right)\right]
\end{gathered}
$$

As equações (2.50) e (2.51) devem ser funções contínuas em $w$. Na condição de que $X(z)$ não tenha zeros no círculo unitário, a continuidade de $\tilde{X}_{R}\left(e^{j w}\right)$ é garantida pelo fato de que $X\left(e^{j w}\right)$ é analítica no círculo unitário. Todavia, a continuidade de $\tilde{X}_{I}\left(e^{j w}\right)$ depende da definição de logaritmo complexo. Portanto, as condições de que $\tilde{X}(z)$ é uma transformada $z$ válida e a remoção de ambiguidades do logaritmo complexo, expresso na segunda parte da equação (2.49.2), são condições interrelacionadas. 
O problema da unicidade e analiticidade do logaritmo complexo é apresentado na Figura 29. Especificamente, na Figura 29(A) está ilustrada uma típica curva de fase para $X(z)$, de modo que a transformada $z$ foi avaliada no círculo unitário. Já a Figura 29(B) apresenta o valor principal da fase desta curva.

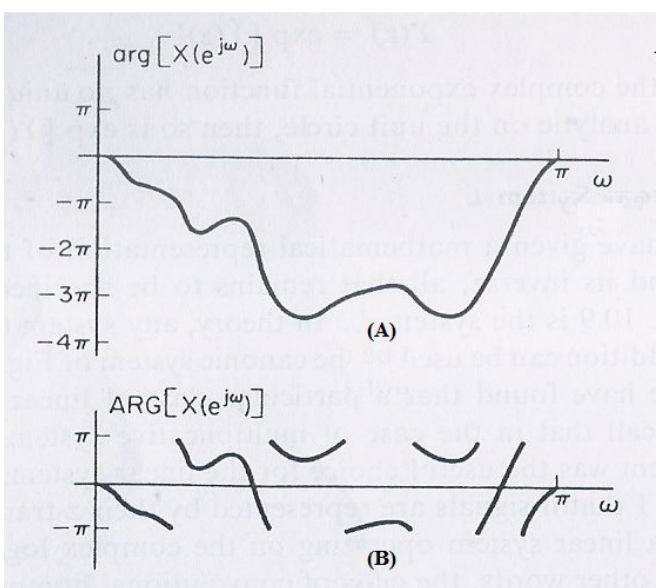

Figura 29 (A): Curva típica para fase de $\boldsymbol{X}(\mathbf{z})$. (B): Valor principal da fase da curva apresentada em (A).

Fonte: Modificado de Oppenheim (1975).

Considerando o caso de $X(z)$ representar o produto de duas transformadas $z$, $X_{1}(z)$ e $X_{2}(z)$, a curva da Figura $29(\mathrm{~A})$ pode ser interpretada como sendo o resultado da soma de cada uma das curvas de fase contínua de $X_{1}(z)$ e $X_{2}(z)$. Esta duas curvas, apresentadas nas Figuras 29(A) e 29(B), são representações válidas da fase de $X(z)$ se a condição da equação (2.52) for satisfeita.

$$
e^{j \arg [X(z)]}=e^{j A R G[X(z)]}
$$

Todavia, nota-se que a curva do valor principal não pode corresponder, via de regra, à soma de duas curvas de valor principal de fase das transformadas $X_{1}(z)$ e $X_{2}(z)$. Ademais, $A R G[X(z)]$ é uma função descontínua e, dessa forma, não satisfaz às condições de continuidade que resulta do fato de que $X(z)$ deve ser analítica no círculo unitário. Todavia este problema é contornado a partir do modo que se define o logaritmo complexo. Assume-se que o logaritmo complexo contínuo é obtido a partir da integração de sua derivada (OPPENHEIM, 1975). Sendo assim: 


$$
\begin{aligned}
\frac{d}{d z} \ln [X(z)]=\frac{d}{d z} \tilde{X}(z) & =\tilde{X}^{\prime}(z)=\frac{1}{X(z)} \frac{d}{d z} X(z) \therefore \\
\tilde{X}^{\prime}(z) & =\frac{X^{\prime}(z)}{X(z)}
\end{aligned}
$$

Onde o símbolo ' em $\tilde{X}^{\prime}(z)$, por exemplo, indica operação de derivada, que neste caso é em relação à $z$. No circulo unitário o símbolo ' também significará derivação com o detalhe que é em relação à $w$. Dessa forma:

$$
\frac{d}{d w} \ln \left[X\left(e^{j \omega}\right)\right]=\tilde{X}^{\prime}\left(e^{j \omega}\right)=\frac{X^{\prime}\left(e^{j \omega}\right)}{X\left(e^{j \omega}\right)}=\frac{X_{R}{ }^{\prime}\left(e^{j w}\right)+j X_{I}^{\prime}\left(e^{j w}\right)}{X_{R}\left(e^{j w}\right)+j X_{I}\left(e^{j w}\right)}
$$

Multiplicando o numerador e o denominador da equação anterior por $X_{R}\left(e^{j w}\right)-$ $j X_{I}\left(e^{j w}\right)$, segue que:

$$
\begin{gathered}
\tilde{X}^{\prime}\left(e^{j \omega}\right)=\frac{X_{R}{ }^{\prime}\left(e^{j w}\right) X_{R}\left(e^{j w}\right)+X_{I}{ }^{\prime}\left(e^{j w}\right) X_{I}\left(e^{j w}\right)}{X_{R}{ }^{2}\left(e^{j w}\right)+X_{I}^{2}\left(e^{j w}\right)} \\
+j \frac{X_{R}\left(e^{j w}\right) X_{I}{ }^{\prime}\left(e^{j w}\right)-X_{R}{ }^{\prime}\left(e^{j w}\right) X_{I}\left(e^{j w}\right)}{X_{R}{ }^{2}\left(e^{j w}\right)+X_{I}^{2}\left(e^{j w}\right)}
\end{gathered}
$$

Inferindo da equação (2.48) que:

$$
\tilde{X}^{\prime}\left(e^{j w}\right)=\tilde{X}_{R}^{\prime}\left(e^{j w}\right)+j \tilde{X}_{I}^{\prime}\left(e^{j w}\right)
$$

Conclui-se, ao relacionar as equações (2.55) e (2.56) que:

$$
\tilde{X}_{I}{ }^{\prime}\left(e^{j \omega}\right)=\frac{X_{R}\left(e^{j w}\right) X_{I}{ }^{\prime}\left(e^{j w}\right)-X_{R}{ }^{\prime}\left(e^{j w}\right) X_{I}\left(e^{j w}\right)}{X_{R}^{2}\left(e^{j w}\right)+X_{I}^{2}\left(e^{j w}\right)}
$$

Observa-se ainda que:

$$
\arg \left[X\left(e^{j w}\right)\right]=\tan ^{-1} \frac{X_{I}\left(e^{j w}\right)}{X_{R}\left(e^{j w}\right)}
$$

Sendo assim: 


$$
\begin{gathered}
\frac{d}{d w}\left[\arg \left[X\left(e^{j w}\right)\right]\right]=\frac{d}{d w}\left(\tan ^{-1} \frac{X_{I}\left(e^{j w}\right)}{X_{R}\left(e^{j w}\right)}\right)=\frac{1}{1+\left(\frac{X_{I}\left(e^{j w}\right)}{X_{R}\left(e^{j w}\right)}\right)^{2}} \frac{d}{d w}\left(\frac{X_{I}\left(e^{j w}\right)}{X_{R}\left(e^{j w}\right)}\right) \rightarrow \\
\rightarrow \arg ^{\prime}\left[X\left(e^{j w}\right)\right]=\frac{X_{R}^{2}\left(e^{j w}\right)}{X_{R}^{2}\left(e^{j w}\right)+X_{I}^{2}\left(e^{j w}\right)} \frac{X_{I}{ }^{\prime}\left(e^{j w}\right) X_{R}\left(e^{j w}\right)-X_{I}\left(e^{j w}\right) X_{R}\left(e^{j w}\right)}{X_{R}{ }^{2}\left(e^{j w}\right)} \therefore \\
\arg ^{\prime}\left[X\left(e^{j w}\right)\right]=\frac{X_{R}\left(e^{j w}\right) X_{I}{ }^{2}\left(e^{j w}\right)-X_{R}{ }^{\prime}\left(e^{j w}\right) X_{I}\left(e^{j w}\right)}{X_{R}{ }^{j}\left(e^{j w}\right)+X_{I}{ }^{2}\left(e^{j w}\right)}=\tilde{X}_{I}{ }^{\prime}\left(e^{j \omega}\right)
\end{gathered}
$$

Integrando-se a equação (2.57) em relação à $w$, pode-se aplicar a condição: $\arg \left[X\left(e^{j w}\right)\right]_{w=0}=0$, de modo a garantir que $\arg \left[X\left(e^{j w}\right)\right]$ seja uma função ímpar e contínua em $w$ (OPPENHEIM, 1975). Dessa forma, utilizando-se a transformada $z$ bilateral, a equação (2.53.2) e assumindo que a função $\ln [X(z)]$ seja analítica, pode-se escrever que:

$$
\begin{gathered}
\tilde{X}(z)=\sum_{n=-\infty}^{\infty} \tilde{x}(n) z^{-n} \rightarrow \tilde{X}^{\prime}(z)=\sum_{n=-\infty}^{\infty}[-n \tilde{x}(n)] z^{-n-1}=\frac{X^{\prime}(z)}{X(z)} \therefore \\
\sum_{n=-\infty}^{\infty}[-n \tilde{x}(n)] z^{-n}=z \frac{X^{\prime}(z)}{X(z)}
\end{gathered}
$$

Aplicando a transformada $z$ inversa na equação (2.60.2), tem-se:

$$
\begin{gathered}
-n \tilde{x}(n)=\frac{1}{2 \pi j} \oint_{C} z \frac{X^{\prime}(z)}{X(z)} z^{n-1} d z \therefore \\
\tilde{x}(n)=-\frac{1}{2 \pi j n} \oint_{C} z \frac{X^{\prime}(z)}{X(z)} z^{n-1} d z, \quad n \neq 0
\end{gathered}
$$

Onde $C$, na integral da equação (2.61.1) ou (2.61.2), representa um contorno fechado, que envolve a origem, na região de convergência de $\tilde{X}(z)$. Especificamente no caso de $n=0$, tem-se:

$$
\tilde{x}(0)=\frac{1}{2 \pi} \int_{-\pi}^{\pi} \ln \left|X\left(e^{j w}\right)\right| d w
$$


Por fim, existe a possibilidade de derivar uma equação de diferenças que represente o sistema característico $D_{*}$. Tomando por base a equação (2.53.2), tem-se que:

$$
z X^{\prime}(z)=z \tilde{X}^{\prime}(z) \cdot X(z)
$$

Aplicando a transformada $z$ inversa, seque que:

$$
\begin{gathered}
n x(n)=\sum_{k=-\infty}^{\infty} k \tilde{x}(k) x(n-k) \leftrightarrow \\
\leftrightarrow x(n)=\sum_{k=-\infty}^{\infty}\left(\frac{k}{n}\right) \tilde{x}(k) x(n-k), n \neq 0
\end{gathered}
$$

Isto é, a equação (2.64.2) apresenta a relação implícita que há entre $x(n)$ e $\tilde{x}(n)$.

\subsubsection{Sistema característico inverso $D_{*}^{-1}$}

A representação matemática do sistema característico inverso é feita com base em $D_{*}$ e está apresentado na Figura 30.

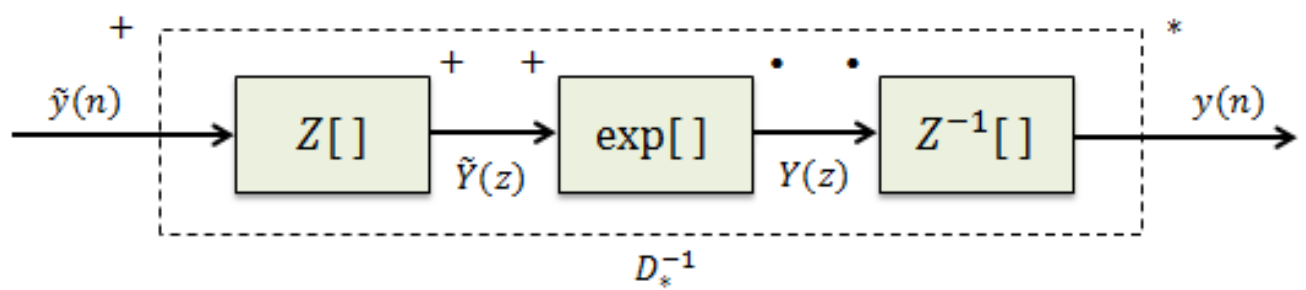

Figura 30: Representação do sistema característico inverso.

Por definição, deve-se ter que:

$$
D_{*}^{-1}\left[D_{*}[x(n)]\right]=x(n)
$$

Neste caso, a transformação é de adição para uma convolução. Considerando $x(n)$ e $\tilde{x}(n)$ sequências estáveis, pode-se afirmar que $\tilde{y}(n)$ e $y(n)$ também serão 
estáveis. Neste caso, a região de convergência de $Y(z)$ e $\tilde{Y}(z)$ incluirá o círculo unitário. Dessa forma:

$$
y(n)=\frac{1}{2 \pi j} \oint_{C^{\prime}} Y(z) z^{n-1} d z
$$

Onde $C^{\prime}$ indica um contorno fechado que é um círculo unitário. Ademais:

$$
Y(z)=\exp [\tilde{Y}(z)]
$$

Já que a função exponencial complexa não possui problemas de unicidade e, se $\tilde{Y}(z)$ é analítica no círculo unitário, $Y(z)$ também o será.

\subsubsection{Sistema Linear $L$}

Com os sistemas $D_{*}$ e $D_{*}^{-1}$ representados matematicamente, resta especificar o sistema linear $L$ pertencente ao sistema canônico apresentado na Figura 26. Teoricamente, qualquer sistema que obedeça ao princípio da superposição aditiva pode ser utilizado no sistema canônico mencionado. Porém, na prática encontra-se uma classe particular de sistemas lineares que é bastante utilizada. Para sistemas multiplicativos, um sistema linear invariante no tempo é uma escolha comum para o sistema linear em questão. Como no caso da Figura 27, se os sinais são representados por suas transformadas $z$, então se pode pensar num sistema linear operando no logaritmo complexo da transformada $z$. Em outras palavras, a classe de sistemas homomórficos convolucionais é semelhante à classe de sistemas homomórficos multiplicativos; entretanto, os papeis de "domínio do tempo" e "domínio da frequência" estão, em certo sentido, permutados. Embora um sistema linear invariante no tempo possa ser, teoricamente, utilizado, existe um interesse particular em se considerar uma classe de sistemas lineares invariantes na frequência para os quais:

$$
\tilde{Y}\left(e^{j \omega}\right)=\frac{1}{2 \pi} \int_{-\pi}^{\pi} X\left(e^{j \omega}\right) L\left(e^{j(\omega-\varphi)}\right) d \varphi
$$


Para este tipo de sistema, a saída da transformada de Fourier é obtida a partir do logaritmo complexo $\tilde{X}\left(e^{j \omega}\right)=\ln \left[X\left(e^{j \omega}\right)\right]$, por uma convolução periódica de variável contínua. Alternativamente, este sistema possui uma representação no domínio do tempo como segue.

$$
\begin{gathered}
\tilde{y}(n)=l(n) \tilde{x}(n) \leftrightarrow \\
\leftrightarrow l(n)=\frac{\tilde{y}(n)}{\tilde{x}(n)}
\end{gathered}
$$

Sendo $l(n)$ é a transformada inversa de $L\left(e^{j \omega}\right)$. Note que $l(n)$ faz o papel de uma função de transferência no tempo. Por isso que se havia dito que os domínios do tempo e da frequência estão, de certo modo, trocados. Desde que $x(n), \tilde{x}(n), y(n)$ e $\tilde{y}(n)$ sejam assumidas sequências reais e estáveis, segue que $l(n)$ será real e, em geral, estável. Ademais, a utilidade desta classe de sistemas e os devidos critérios de projeto dependem das propriedades de gerais e específicas de $\tilde{x}(n)$, que são particulares a cada aplicação.

\subsubsection{Cepstro complexo e suas propriedades}

Conforme apresentado na Figura 28, o termo $\tilde{x}(n)$, que é a saída do sistema $D_{*}$, é chamado de cepstro (do inglês cepstrum). Foi Bogert et al. (1963) quem estabeleceu o termo "cepstrum" a partir da "readequação" de algumas letras da palavra inglesa spectrum. Um dos fatos que estes autores observaram é que, um sinal contendo apenas um eco, pode ser representado no tempo como segue:

$$
x(t)=s(t)+\alpha s(t-\tau)
$$

No domínio da frequência, a nova representação desse sinal passa a ser:

$$
\begin{aligned}
& X(f)=S(f)+\alpha S(f) e^{j f \tau} \leftrightarrow \\
& \leftrightarrow X(f)=S(f)\left(1+\alpha e^{j f \tau}\right)
\end{aligned}
$$

Particularmente, a densidade espectral desse sinal pode ser expressa como: 


$$
\begin{gathered}
|X(f)|^{2}=|S(f)|^{2}\left|\left(1+\alpha e^{j f \tau}\right)\right|^{2} \therefore \\
|X(f)|^{2}=|S(f)|^{2}\left(1+\alpha^{2}+2 \alpha \cos (f \tau)\right)
\end{gathered}
$$

Dessa forma, percebe-se que a densidade espectral do sinal com um eco tem a forma de um envelope, que corresponde ao espectro do sinal original. Este "envelope" modula a função periódica de frequência, que é a contribuição do espectro do eco. Aplicando-se o logaritmo ao espectro, o produto é convertido em soma de duas componentes, de modo que:

$$
C(f)=\log \left[|X(f)|^{2}\right]=\log \left[|S(f)|^{2}\right]+\log \left(1+\alpha^{2}+2 \alpha \cos (f \tau)\right)
$$

Portanto, $C(f)$ foi visto como uma forma de onda a qual possuía um componente periódico somado, cuja "frequência fundamental" corresponde ao atraso $\tau$ do eco. Em análise convencional de formas de ondas temporais, estas componentes periódicas aparecem como linhas ou picos acentuados no espectro de frequência (Fourier). Portanto, o "espectro" do logaritmo do espectro igualmente apresentaria um pico quando a forma de onda temporal original contivesse um eco. Este novo domínio de representação "espectral" não é domínio da frequência nem do tempo. Sendo assim, para evitar confusão enquanto se enfatizava a conexão de conceitos familiares, Bogert et al. (1963) escolheu o nome domínio quefrency (paráfrase de Frequency). Já o espectro do logaritmo do espectro de uma forma de onda temporal foi nominado de cepstrum. Muitos dos termos que havia no glossário do artigo de Bogert et al. (1963) desapareceram ao passo que o termo cepstrum permaneceu e tornou-se parte do léxico do processamento digital de sinais (OPPENHEIM, 2004). Neste caso, o conceito de cepstro estava ligado à detecção de eco e não à deconvolução do sinal propriamente dita. Sendo assim, a informação da fase do sinal não era importante. Neste trabalho o termo cepstro, que é à saída do sistema característico $D_{*}$ apresentado na Figura 28, diz respeito ao uso do logaritmo do módulo da transformada $z$ para o cálculo de $\tilde{x}(n)$. Já o cepstro complexo (do inglês complex cepstrum), sendo o novo termo (complexo) introduzido por Oppenheim (1968), se refere ao fato de que as informações de amplitude e fase foram utilizadas. D'outra forma, fez-se o uso do logaritmo complexo no cálculo de $\tilde{x}(n)$. 
As sequências que possuem transformadas $z$ racionais são úteis e favoráveis para análise. Seja, portanto, $x(n)$ uma sequência real que possua transformada $z$ no seguinte formato:

$$
X(z)=\frac{A z^{r} \prod_{k=1}^{m_{i}}\left(1-a_{k} z^{-1}\right) \prod_{k=1}^{m_{o}}\left(1-b_{k} z\right)}{\prod_{k=1}^{p_{i}}\left(1-c_{k} z^{-1}\right) \prod_{k=1}^{p_{o}}\left(1-d_{k} z\right)}
$$

Tal que $\left|a_{k}\right|,\left|b_{k}\right|,\left|c_{k}\right|$ e $\left|d_{k}\right|$ são menores que um. Desse modo, os fatores (1$\left.a_{k} z^{-1}\right)$ e $\left(1-c_{k} z^{-1}\right)$ correspondem aos zeros e polos dentro do circulo unitário. Já os termos $\left(1-b_{k} z\right)$ e $\left(1-d_{k} z\right)$ correspondem aos zeros e polos fora do circulo unitário. Tais transformadas $z$ são típicas de sequências compostas pela soma de sequências exponenciais. Quando não há polos, ou seja, o denominador da equação (2.74) é unitário, esta equação corresponde a uma sequência de comprimento finito.

Calculando-se $\ln [X(z)]$ conforme definido anteriormente e a partir da equação (2.74), pode-se escrever que:

$$
\begin{gathered}
\tilde{X}(z)=\ln (A)+\ln \left(z^{r}\right)+\sum_{k=1}^{m_{i}} \ln \left(1-a_{k} z^{-1}\right)+\sum_{k=1}^{m_{o}} \ln \left(1-b_{k} z\right) \\
-\sum_{k=1}^{p_{i}} \ln \left(1-c_{k} z^{-1}\right)-\sum_{k=1}^{p_{o}} \ln \left(1-d_{k} z\right)
\end{gathered}
$$

Caso se considere cada termo da equação (2.75) como uma transformada $z$, então as propriedades de $\tilde{x}(n)$ dependerá da composição de propriedades da transformada $z$ inversa de cada termo. Para sequências reais, $A$ é real e, se é positivo, o termo $\ln (A)$ contribui, simplesmente, para $\tilde{x}(0)$. Especificamente:

$$
\tilde{x}(0)=\ln (A)
$$

Se $A<0$, fica mais difícil determinar a contribuição do termo $\ln |A|$ no cepstro complexo. Similarmente, o termo $z^{r}$ diz respeito somente a um atraso ou avanço na sequência $x(n)$. Se $r=0$, o termo $\ln \left(z^{r}\right)$ desaparece da equação (2.75). Entretanto, para $r \neq 0$, haverá uma contribuição não nula ao cepstro complexo. Mesmo sendo factíveis os casos de $A<0$ e/ou $r \neq 0$, este procedimento não oferece qualquer vantagem real, pois se duas transformadas da forma da equação (2.75) forem 
multiplicadas, não será possível prever a contribuição tanto de $A$ quanto de $r$ de cada uma. Esta situação é análoga, em filtragem linear, quando se soma dois sinais onde cada um possui um nível DC. Na prática, estas questões são evitadas medindo-se o sinal algébrico de $A$ e o valor de $r$ de modo que, alterando-se a entrada, a transformada $z$ terá a nova forma apresentada na equação (2.77) (OPPENHEIM, 1975; SCHAFER, 1969).

$$
X(z)=|A| \frac{\prod_{k=1}^{m_{i}}\left(1-a_{k} z^{-1}\right) \prod_{k=1}^{m_{o}}\left(1-b_{k} z\right)}{\prod_{k=1}^{p_{i}}\left(1-c_{k} z^{-1}\right) \prod_{k=1}^{p_{o}}\left(1-d_{k} z\right)}
$$

Da mesma que se obteve na equação (2.75), tem-se neste caso:

$$
\begin{aligned}
\tilde{X}(z)= & \ln |A|+\sum_{k=1}^{m_{i}} \ln \left(1-a_{k} z^{-1}\right)+\sum_{k=1}^{m_{o}} \ln \left(1-b_{k} z\right) \\
& -\sum_{k=1}^{p_{i}} \ln \left(1-c_{k} z^{-1}\right)-\sum_{k=1}^{p_{o}} \ln \left(1-d_{k} z\right)
\end{aligned}
$$

Com exceção do termo $\ln |A|$ da equação (2.78), todos os outros termos têm a forma de $\ln \left(1-\alpha z^{-1}\right)$ e $\ln (1-\beta z)$. Levando-se em conta que estes fatores representam transformadas $z$ com regiões de convergência que incluem o círculo unitário, pode-se expandir cada um desses termos em séries de potências, ou seja:

$$
\begin{aligned}
& \ln \left(1-\alpha z^{-1}\right)=-\sum_{n=1}^{\infty} \frac{\alpha^{n}}{n} z^{-n}, \quad|z|>|\alpha| \\
& \ln (1-\beta z)=-\sum_{n=1}^{\infty} \frac{\beta^{n}}{n} z^{n}, \quad|z|<\left|\beta^{-1}\right|
\end{aligned}
$$

Com as equações (2.79) e (2.80), é evidente que para entradas com transformadas $Z$ racionais conforme apresentado na equação (2.77), pode-se determinar a forma geral de $\tilde{x}(n)$ que é:

$$
\begin{gathered}
\tilde{x}(n)=\ln |A|, \quad n=0 \\
\tilde{x}(n)=-\sum_{k=1}^{m_{i}} \frac{a_{k}^{n}}{n}+\sum_{k=1}^{p_{i}} \frac{c_{k}^{n}}{n}, n>0
\end{gathered}
$$




$$
\tilde{x}(n)=-\sum_{k=1}^{m_{o}} \frac{b_{k}{ }^{-n}}{n}+\sum_{k=1}^{p_{o}} \frac{d_{k}^{-n}}{n}, n<0
$$

Para um caso particular de sequências de comprimento finito, o segundo termo do lado direito das equações (2.81.2) e (2.81.3) se anula. A partir das equações (2.81), podem-se observar as propriedades P1 a P4 (OPPENHEIM, 1975):

P1: O cepstro complexo decai tão rapidamente quanto $1 / n$, ou seja:

$$
|\tilde{x}(n)|<C\left|\frac{\alpha^{n}}{n}\right|, \quad-\infty<n<\infty
$$

Onde $C$ é uma constante e $\alpha$ é igual ao máximo de $\left|a_{k}\right|,\left|b_{k}\right|,\left|c_{k}\right|$ e $\left|d_{k}\right|$. Esta propriedade pode ser vista, também, na equação (2.61.2).

* P2: Se $x(n)$ é de fase mínima $(X(z)$ não possui polos ou zeros fora do circulo unitário), então:

$$
\tilde{x}(n)=0, \quad n<0
$$

P3: Se $x(n)$ é de fase máxima $(X(z)$ não possui polos ou zeros dentro do circulo unitário), então:

$$
\tilde{x}(n)=0, n>0
$$

* P4: Embora $x(n)$ tenha duração finita, $\tilde{x}(n)$ terá duração infinita.

Em Tribolet (1978) são mencionadas outras propriedades que serão apresentadas a seguir, numeradas na sequência.

* P5: O cepstro complexo de uma convolução de dois ou mais sinais, é a soma de cada cepstro complexo individualmente.

* P6: Sendo $\tilde{q}(n)$ o cepstro complexo de um pulso $q(n)$, cujo espectro é suave, $\tilde{q}(n)$ tende a ficar concentrado ao redor de baixos valores de tempo. Esta propriedade provém do fato de que uma sequência $q(n)$, que possua espectro 
$\left|Q\left(e^{j \omega}\right)\right|^{2}$ suave, é forçada a ter polos e zeros relativamente de banda larga. Comparativamente à propriedade $\mathrm{P} 1$, isto significa que $\left|\frac{\alpha^{n}}{n}\right|$ decai mais rapidamente que $\frac{1}{n}$.

As informações a seguir serão úteis para as propriedades P7 e P8. Portanto, denota-se por $p(n)$ um trem de pulso tendo o seguinte formato:

$$
p(n)=\sum_{k=1}^{M} p_{k} \delta\left(n-n_{k}\right), \quad n_{k+1}>n_{k}, \quad p_{k} \neq 0, \quad \forall k
$$

O par ordenado $\left(p_{k}, n_{k}\right), k=1, \ldots, M$, denota os tempos de chegada e amplitude associados a cada impulso de $p(n)$. De modo geral, define-se um "trem de pulso periódico" com período $T>1$, de forma que os tempos de chegada sejam múltiplos de $T$, ou seja:

$$
n_{k}=n_{k-1}+l_{k} T, \quad k=2, \ldots, M, \quad \forall l_{k}>0
$$

* P7: O cepstro complexo $\tilde{p}(n)$ de um trem de pulso periódico $p(n)$, também será um trem de pulso com mesmo período, isto é:

$$
\tilde{p}(n)=\sum_{n=-\infty}^{\infty} \tilde{p}(k) \delta(n-k T)
$$

* P8: Considere um trem de pulso, $p(n)$, fase mínima para o qual o primeiro "período" é $T_{1}$, de modo que:

$$
n_{2}-n_{1}=T_{1}
$$

Portanto, o cepstro complexo é nulo no intervalo $0<n<T_{1}$. Em geral, $\tilde{p}(n)$ é não nulo somente nos instantes $0, n_{2}-n_{1}, n_{3}-n_{1}, \ldots, n_{m}-n_{1}$ assim como em todas as combinações lineares positivas destes instantes. Um resultado similar pode ser obtido para trem de pulso de fase máxima

* P9: A estrutura cepstral de um trem de pulsos de fase mista pode ser bastante sensível a menor mudança de amplitude dos pulsos. Em geral, o cepstro do 
trem de pulso de fase mista apresenta uma estrutura bastante elaborada que, dentro dos limites impostos pela presente compreensão do mapeamento cepstral, não oferecem pistas sobre a estrutura de tempo correspondente e viceversa.

\subsubsection{Sequências de fase mínima e máxima}

Existem algumas implicações importantes decorrentes das propriedades P2 a $\mathrm{P} 4$. Associando a um único fator de transformada $z$ uma sequência de fase mínima, ou seja, que não possua polos ou zeros fora do circulo unitário $\left(m_{o}=p_{o}=0\right)$, segue que:

$$
X(z)=|A| \frac{\prod_{k=1}^{m_{i}}\left(1-a_{k} z^{-1}\right)}{\prod_{k=1}^{p_{i}}\left(1-c_{k} z^{-1}\right)}
$$

Evidente que $x(n)=\tilde{x}(n)=0$ para $n<0$. Dessa forma, para entradas de fase mínima, a sequência $\tilde{x}(n)$ é causal. Neste caso, a representação matemática de $D_{*}$ pode ser significativamente simplificada. Sabe-se que a transformada $z$ de uma sequência causal é completamente determinada pela parte real da transformada de Fourier (OPPENHEIM, 1975). Sendo ambas as sequências causais, $x(n)$ e $\tilde{x}(n)$, devese, portanto, calcular somente o logaritmo do módulo da transformada para obtenção de $\tilde{x}(n)$.

$$
\tilde{X}_{R}\left(e^{j w}\right)=\ln \left|X\left(e^{j w}\right)\right|
$$

Rememorando que a transformada inversa de Fourier de $\tilde{X}_{R}\left(e^{j w}\right)$ é equivalente à parte par de $\tilde{x}(n)$ (OPPENHEIM, 1975), e denominando $\tilde{x}_{p}(n)$ o cepstro de $x(n)$, tem-se que:

$$
\tilde{x}_{p}(n)=\frac{\tilde{x}(n)+\tilde{x}(-n)}{2}
$$

Desde que $\tilde{x}(n)=0$ para $n<0$, tem-se ainda que:

$$
\tilde{x}(n)=\tilde{x}_{p}(n) u_{\alpha}(n)
$$




$$
u_{\alpha}(n)= \begin{cases}0, & n<0 \\ 1, & n=0 \\ 2, & n>0\end{cases}
$$

Todas as operações para o cálculo de $\tilde{x}(n)$ estão apresentadas na Figura 31. Nesta figura, o símbolo $\mathrm{F}$ denota a transformada de Fourier e o símbolo $\mathrm{F}^{-1}$, a transformada inversa. Note que nos casos de entradas de fase mínima (ou máxima), o cepstro complexo é obtido, somente, a partir do cepstro. Este procedimento é chamado de: "cálculo do cepstro complexo a partir de uma realização de fase mínima".

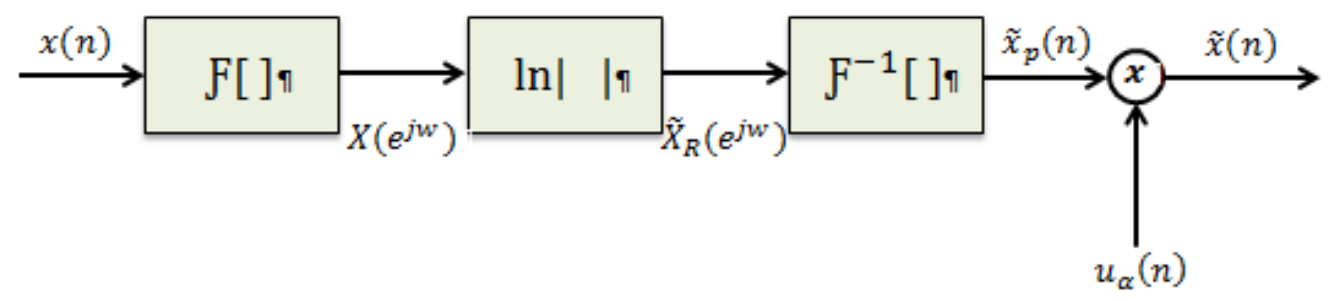

Figura 31: Realização do sistema característico $\boldsymbol{D}_{*}$ para estrada de fase mínima.

Realiza-se, também, o procedimento análogo para o cálculo do cepstro complexo para sequências de fase máxima. Da mesma forma utiliza-se o logaritmo do módulo da transformada de Fourier. Tendo como base a Figura 31, com a diferença de que se utilizará $u_{\beta}(n)$ em vez de $u_{\alpha}(n)$, o cepstro complexo é calculado como segue.

$$
\begin{aligned}
& \tilde{x}(n)=u_{\beta}(n) \tilde{x}_{p}(n) \\
& u_{\beta}(n)= \begin{cases}2, & n<0 \\
1, & n=0 \\
0, & n>0\end{cases}
\end{aligned}
$$

Por fim consideraremos o mesmo procedimento adotado para sequências de fase mínima, apresentado na Figura 31, aplicado para sequências de fase mista. Este tipo de sequência, $x(n)$, excetuando-se uma componente de fase linear, pode ser escrito como segue.

$$
x(n)=x_{\min }(n) * x_{\max }(n)
$$


Com relação à equação (2.94): $x_{\min }(n)=0$ para $n<0$ (componente causal), é a sequência de fase mínima; $x_{\max }(n)=0$ para $n>0$ (componente anticausal), é a sequência de fase máxima. Dessa forma, o logaritmo do módulo da transformada de Fourier da equação (2.94) terá a forma de:

$$
\begin{gathered}
\tilde{X}_{R}\left(e^{j \omega}\right)=\ln \left|X_{\min }\left(e^{j \omega}\right)\right|+\ln \left|X_{\max }\left(e^{j \omega}\right)\right| \leftrightarrow \\
\leftrightarrow \tilde{X}_{R}\left(e^{j \omega}\right)=\tilde{X}_{R(\min )}\left(e^{j \omega}\right)+\tilde{X}_{\mathrm{R}(\max )}\left(e^{j \omega}\right)
\end{gathered}
$$

Dessa forma, a transformada inversa será:

$$
\tilde{x}_{p}(n)=\tilde{x}_{p(\min )}+\tilde{x}_{p(\max )}
$$

De modo que:

$$
\begin{aligned}
\tilde{x}_{p(\min )} & =\frac{\tilde{x}_{\min }(n)+\tilde{x}_{\min }(-n)}{2} \\
\tilde{x}_{p(\max )} & =\frac{\tilde{x}_{\max }(n)+\tilde{x}_{\max }(-n)}{2}
\end{aligned}
$$

Tendo em vista que $\tilde{x}_{\min }(-n)=\tilde{x}_{\max }(n)=0$ para $n>0$, é como multiplicar $\tilde{x}_{p}(n)$ por $u_{\alpha}(n)$, ou seja:

$$
\tilde{y}(n)=\tilde{x}_{p} u_{\alpha}(n)= \begin{cases}\tilde{x}_{\min }(n)+\tilde{x}_{\max }(-n), & n \geq 0 \\ 0, & n<0\end{cases}
$$

Aplicando o sistema inverso em relação ao que fora apresentado na Figura 31, segue que:

$$
\begin{gathered}
\tilde{Y}\left(e^{j \omega}\right)=\tilde{X}_{\min }\left(e^{j \omega}\right)+\tilde{X}_{\max }\left(e^{-j \omega}\right) \rightarrow \\
\rightarrow Y\left(e^{j \omega}\right)=\exp \left[\tilde{Y}\left(e^{j \omega}\right)\right]=X_{\min }\left(e^{j \omega}\right) X_{\max }\left(e^{-j \omega}\right) \therefore \\
y(n)=x_{\min }(n) * x_{\max }(-n)
\end{gathered}
$$

Sendo $\left|X_{\max }\left(e^{j \omega}\right)\right|=\left|X_{\max }\left(e^{-j \omega}\right)\right|$, conclui-se que o procedimento apresentado resulta numa sequência de fase mínima, conforme apresentam as equações (2.98) 
juntamente com a propriedade P2, cujo espectros de amplitudes de $y(n)$ e $x(n)$ são idênticos (OPPENHEIM, 1976).

Este tipo de procedimento é interessante quando se tem uma sequência de fase mista e deseja-se obtê-la em fase mínima, levando-se em conta, obviamente, que as informações de fase do sinal original serão perdidas.

Uma aplicação bastante interessante deste procedimento é no processamento de sinais de voz, tendo em vista que o ouvido humano é pouco sensível às variações de fase (OLIVEIRA, 1992; OPPENHEIM, 1976; RABINER, 1978).

\subsubsection{Ponderação exponencial}

Em virtude das propriedades especiais de sequências de fase mínima, é interessante obtê-las a partir de sequências de fase mista. Um dos meios para isto é a ponderação exponencial deste tipo de sequências, ou seja, a multiplicação por $\alpha^{n}$ de uma sequência $x(n)$ para obtenção de $x_{\text {pond }}(n)$, como segue.

$$
x_{\text {pond }}(n)=\alpha^{n} x(n)
$$

Dois pontos importantes devem ser considerados: o efeito de uma ponderação exponencial numa convolução e também numa transformada $z$ e sua região de convergência. Para análise do primeiro ponto, seja $x(n)$ dado por:

$$
x(n)=\sum_{k=-\infty}^{\infty} x_{1}(k) x_{2}(n-k)
$$

Para esta sequência ponderada exponencialmente, segue que:

$$
\begin{gathered}
x_{\text {pond }}(n)=\alpha^{n} \sum_{k=-\infty}^{\infty} x_{1}(k) x_{2}(n-k)=\sum_{k=-\infty}^{\infty} \alpha^{k} x_{1}(k) \alpha^{n-k} x_{2}(n-k) \therefore \\
x_{\text {pond }}(n)=\sum_{k=-\infty}^{\infty} x_{1(\text { pond })}(k) x_{2(\text { pond })}(n-k)
\end{gathered}
$$

Ou seja, a ponderação de uma convolução de duas sequências é equivalente à convolução dessas duas sequências ponderadas separadamente de modo que: 


$$
\begin{aligned}
& x_{1(\text { pond })}(n)=\alpha^{n} x_{1}(n) \\
& x_{2(\text { pond })}(n)=\alpha^{n} x_{2}(n)
\end{aligned}
$$

O segundo ponto refere-se ao efeito da ponderação exponencial numa transformada $z$. Neste caso, a transformada $z$ da equação (2.100) é:

$$
X_{\text {pond }}(z)=\sum_{n=-\infty}^{\infty} \alpha^{n} x(n) z^{-n}=X\left(\alpha^{-1} z\right)
$$

Dessa forma, se $X(z)$ possui um pólo ou zero em $z=z_{0}$, então $X_{\text {pond }}(z)$ terá esse pólo ou zero em $\alpha z_{0}$. Logo, se a região de convergência de $X(z)$ é $R_{1}<|z|<R_{2}$, então a região de convergência de $X_{\text {pond }}(z)$ será $\alpha R_{1}<|z|<\alpha R_{2}$.

No caso de se ter uma sequência $x(n)=0$ para $n<0$, mas que seja de fase mista pode-se torna-la em fase mínima por meio de uma ponderação exponencial apropriada. É como foi apresentado: multiplica-se $x(n)$ por $\alpha^{n}, \quad \alpha<1$ e suficientemente pequeno, para que possa mover todos os pólos ou zeros, que estejam foram do círculo unitário, para dentro deste. Vemos, então, que a ponderação exponencial pode ser bastante útil tendo em vista a preservação do produto de convolução e permitir uma distribuição mais conveniente de pólos e zeros. Isto acrescenta um grau de liberdade na análise homomórfica de sinais, uma vez sequências de impulsos de fase mínima possuem uma estrutura cepstral que podem ser facilmente determinadas.

\subsubsection{Considerações sobre o cálculo do cepstro complexo}

De modo geral, o sistema característico $D_{*}$ é representado pelas seguintes equações:

$$
\begin{gathered}
X\left(e^{j \omega}\right)=\sum_{n=-\infty}^{\infty} x(n) e^{-j \omega n} \\
\tilde{X}\left(e^{j \omega}\right)=\ln \left[X\left(e^{j \omega}\right)\right] \\
\tilde{x}(n)=\frac{1}{2 \pi} \int_{-\pi}^{\pi} \tilde{X}\left(e^{j \omega}\right) e^{j \omega n} d \omega
\end{gathered}
$$


Uma vez que computadores digitais trabalham com sequências de comprimento finito, pode-se tomar apenas um número finito de pontos da transformada de Fourier. Isto é, ao invés de se utilizar da transformada de Fourier, deve-se utilizar a Transformada Discreta de Fourier. Deve-se notar que a transformada da Fourier é equivalente à transformada $z$ para $r=1$, haja vista que $z=r e^{j w}$. Sendo assim, as equações (2.105) devem ser reescritas como seguem:

$$
\begin{gathered}
X(k)=\left.X\left(e^{j \omega}\right)\right|_{w=(2 \pi / N) k}=\sum_{n=0}^{N-1} x(n) e^{-j(2 \pi / N) k n} \\
\tilde{X}(k)=\left.\ln \left[X\left(e^{j \omega}\right)\right]\right|_{w=(2 \pi / N) k}=\ln [X(k)] \\
\tilde{x}_{a}(n)=\frac{1}{N} \sum_{k=0}^{N-1} \tilde{X}(k) e^{j(2 \pi / N) k n}
\end{gathered}
$$

Pelo teorema da amostragem para a transformada $z$, a relação entre o cepstro complexo calculado $\tilde{x}_{a}(n)$ e o desejado $\tilde{x}(n)$ é dado por:

$$
\tilde{x}_{a}(n)=\sum_{k=-\infty}^{\infty} \tilde{x}(n+k N)
$$

Tendo em vista que o cepstro complexo, em geral, possui duração infinita, $\tilde{x}_{a}(n)$ será uma versão de $\tilde{x}(n)$ com aliasing. Porém, a propriedade P1 nos diz que $\tilde{x}(n)$ decai tão rapidamente quanto uma sequência exponencial. Desse modo é de se esperar que a aproximação entre $\tilde{x}_{a}(n)$ e $\tilde{x}(n)$ se torne cada vez melhor com $N$ cada vez maior. Sendo assim, pode ser necessário acrescentar zeros na sequência de entrada, visando que o logaritmo complexo seja amostrado numa taxa suficientemente alta, de modo que o aliasing não venha ocorrer de forma prejudicial no cálculo do cepstro complexo.

Deve-se mencionar, também, sobre o cálculo da fase da transformada de Fourier, $\operatorname{ARG}\left[X\left(e^{j \omega}\right)\right]$. O problema da existência de $\tilde{X}\left(e^{j \omega}\right)$, o que remete ao caso da não ambiguidade do logaritmo complexo quando aplicado sobre $X\left(e^{j \omega}\right)$, requer que a fase de $X\left(e^{j \omega}\right)$ seja uma função contínua. Uma vez que os computadores, em geral, utilizam a função arco-tangente para o cálculo do valor principal, o argumento de $X\left(e^{j \omega}\right)$ pertence ao intervalo $-\pi<\operatorname{ARG}\left[X\left(e^{j \omega}\right)\right]<\pi$, conforme já foi apresentado na Figura 29(B). 
Para solucionar os problemas de descontinuidade, existe uma operação denominada "Unwrapping" de fase, mencionado em Tribolet (1977). De modo geral, esta operação detecta as descontinuidades provenientes da função arco-tangente e as corrige pela soma de múltiplos inteiros de $2 \pi$. É importante frisar que o tamanho da DFT (Transformada Discreta de Fourier) utilizada exerce um papel importante no desempenho do algoritmo de correção da fase. Isto é verídico, pois quanto maior a dimensão da DFT, mais próximas entre si estarão às amostras de $\operatorname{ARG}\left[X\left(e^{j \omega}\right)\right]$, o que confere maior precisão no processo. Com amostras muito afastadas entre si, o algoritmo pode detectar falsas descontinuidades no argumento de $X\left(e^{j \omega}\right)$, comprometendo o cálculo do cepstro complexo.

No caso do Matlab®, por exemplo, a função que calcula o cepstro complexo, cceps (própria deste software), já está embutido o algoritmo de correção de fase, garantindo que o cepstro complexo seja calculado de forma correta. Deve-se ter o cuidado, obviamente, de que a DFT tenha dimensão adequada, conforme mencionado anteriormente. 


\section{Capítulo 3}

\section{Material de Ensaio}

Após exposto o capítulo anterior, pretende-se neste apresentar os materiais e métodos utilizados para a realização de todos os ensaios. Salienta-se que boa parte deste capítulo são resultados preliminares alcançados nesta pesquisa, pois foi necessária a construção de boa parte dos equipamentos para a realização dos experimentos.

\subsection{Transdutor de piezoeletreto}

Diferentes métodos e polímeros podem ser empregados para produzir piezoeletretos com elevados coeficientes piezelétricos. No entanto, apenas alguns procedimentos permitem produzir piezoeletretos termicamente estáveis e com completo controle dos parâmetros geométricos das cavidades, que garantem uma reprodutibilidade dos transdutores. Dentre esses, o processo de laminação de filmes com molde foi selecionado para produzir o piezoeletreto utilizado nesse trabalho, devido a resultados prévios que mostraram uma piezeletricidade estável a $80{ }^{\circ} \mathrm{C}$ de $160 \mathrm{pC} / \mathrm{N}$ (ALTAFIM, 2009). Para tal, o piezoeletreto foi fabricado com filmes de 50 $\mu \mathrm{m}$ de fluoroetilenopropileno (FEP) laminados a $300{ }^{\circ} \mathrm{C}$ com um molde de politetrafluoroetileno (PTFE) de $100 \mu \mathrm{m}$ entre eles, conforme descrito em Altafim (2010). A estrutura polimérica foi transformada em piezoeletreto depois que eletrodos circulares de alumínio foram depositados e uma tensão DC de $3 \mathrm{kV}$ foi aplicada de forma direta sobre os eletrodos (ALTAFIM, 2010). A Figura 32(A) mostra uma vista superior de um piezoeletreto formado por esse processo e Figura 32(B) apresenta um esquemático da distribuição de cargas neste tipo de piezoeletreto depois da aplicação da tensão DC de $3 \mathrm{kV}$. A Figura 33 apresenta um gráfico das medidas da capacitância real e imaginária das amostras de piezoeletreto. 


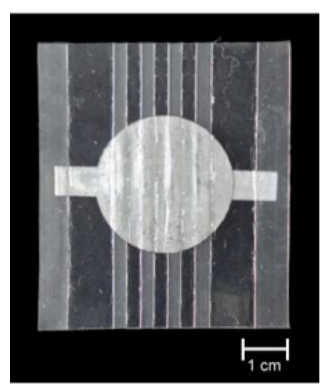

(A)

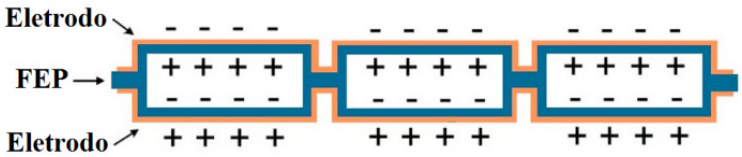

(B)

Figura 32 (A): Vista superior do piezoeletreto de FEP laminado. A imagem mostra o eletrodo circular depositado sobre quatro canaletas abertas (responsáveis pelo efeito piezelétrico). (B): Modelo esquemático de distribuição de cargas no piezoeletreto de canaletas abertas.

Fonte (A): Altafim (2010). Fonte (B): Modificado de Altafim et al. (2009).

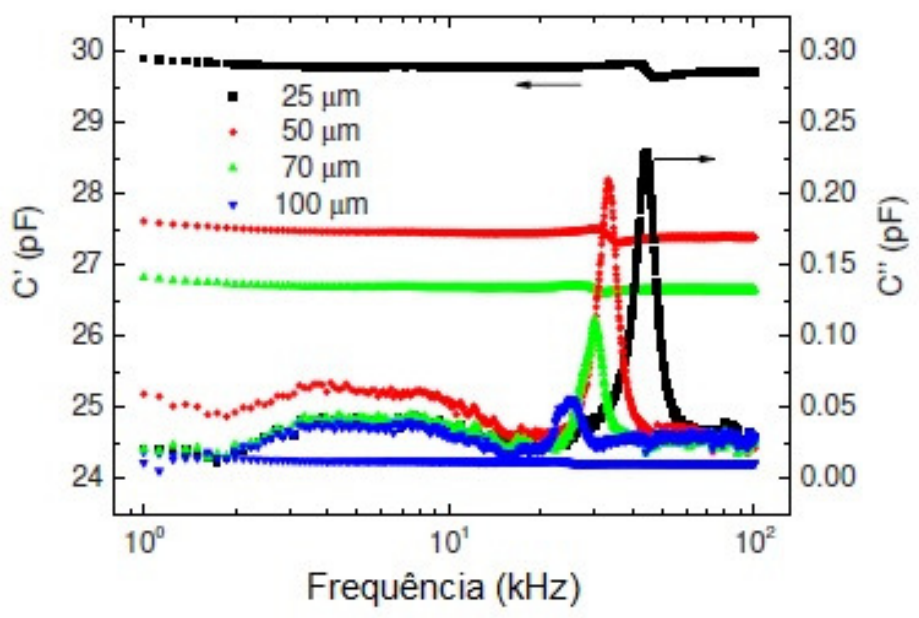

Figura 33: Gráfico da parte real da capacitância, ordenada à esquerda, e da parte imaginária, ordenada à direita, determinada pelo piezoeletreto de canais tubulares com quatro diferentes alturas de canais conforme indicado.

Fonte: Modificado de Altafim et al. (2009).

Como se vê na Figura 33, a amostra com canaleta de $100 \mu \mathrm{m}$ de altura, que é o caso adotado, possui capacitância imaginária mais plana em detrimento às outras. Esta capacitância está relacionada às perdas do material. Neste caso representa a propriedade de vibração das canaletas, ou seja, quanto maior a vibração (perdas), maior será o efeito piezelétrico. Num primeiro caso de estudo isto é interessante, pois a resposta em frequência é aproximadamente plana.

Um protótipo inicial foi construído com a intenção de se realizar testes iniciais com o piezoeletreto. Este transdutor acústico de piezoeletreto é constituído 
basicamente do piezoeletreto, de um amplificador de alta impedância e de um invólucro que se presta para a blindagem do sistema como um todo. A Figura 34 apresenta uma fotografia deste transdutor e um esquemático do mesmo.

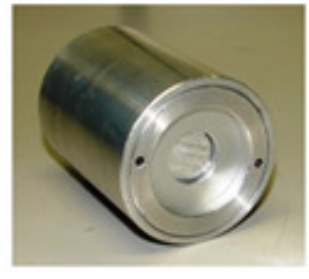

(A)

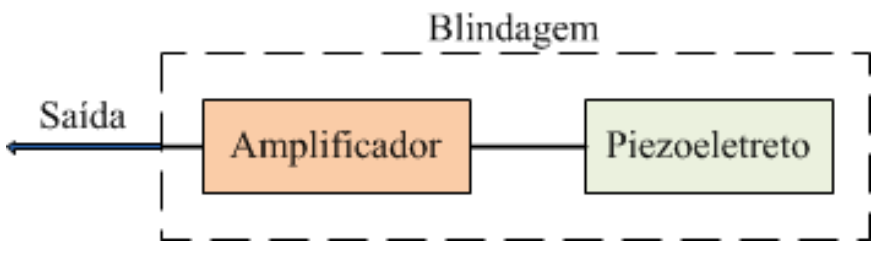

(B)

Figura 34 (A): Fotografia do primeiro transdutor acústico. (B): Diagrama esquemático.

Por ser uma versão protótipo, o circuito amplificador é basicamente um "casador" de impedâncias. Neste, o ganho como um todo é em torno e 5 (absoluto), ou $14 \mathrm{~dB}$ aproximadamente. A Figura 35 apresenta um esquemático deste circuito, que é alimentado por um módulo externo, o qual é composto basicamente de uma bateria de $9 \mathrm{~V}$ em série com uma resistência de $3,9 \mathrm{k} \Omega$.

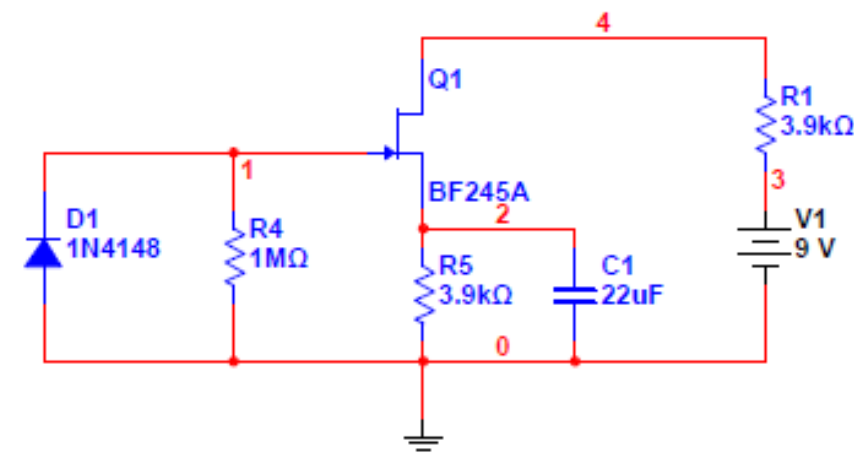

Figura 35: Circuito esquemático do transdutor acústico. Versão Inicial.

Neste circuito, o sinal elétrico proveniente do piezoeletreto é aplicado sobre o diodo D1, ou ligado em paralelo, e este sinal é então amplificado pelo transistor JFET (BF245A). Neste caso, a amplificação é principalmente em potência, pois o sinal proveniente da amostra possui tensão, mas não corrente elétrica. Este é o motivo de se chamar este circuito de "casador" de impedância. O sinal de saída amplificado é 
retirado diretamente dos pontos de alimentação do circuito que fica dentro do invólucro, ou seja, pontos 4 e 0 (referencial).

Como se pode observar na Figura 32(A), a área do piezoeletreto é relativamente pequena e o circuito mostrado na Figura 35 é de ganho relativamente baixo. Primeiramente, fizeram-se novas amostras, especificamente três, de modo que a área do piezoeletreto fosse maior. Dessa forma, a resposta piezelétrica torna-se maior, pois há uma área maior exposta ao meio externo. A Figura 36 apresenta uma fotografia das três amostras em escala e numeradas. As dimensões das canaletas e materiais utilizados para a confecção destas novas amostras são as mesmas descritas anteriormente.

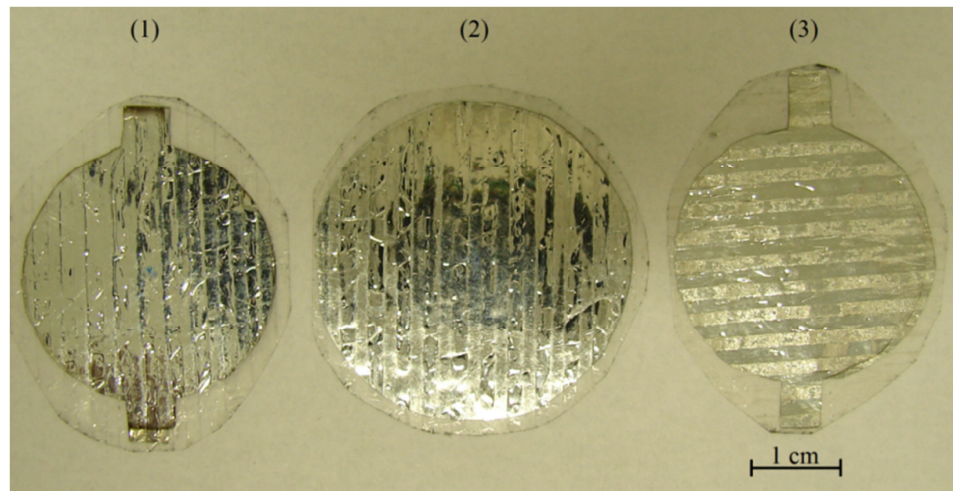

Figura 36: Amostras utilizadas nos ensaios.

O circuito apresentado na Figura 35 tem resposta em frequência plana que vai de $100 \mathrm{~Hz}$ atingindo a casa de $100 \mathrm{MHz}$ para a frequência de corte. Embora seja bastante interessante este fato, o problema está no baixo ganho. Para tanto, inicialmente projetou-se outro circuito de ganho maior. Este circuito está apresentado na Figura 37. A ideia básica desse circuito foi de acrescentar um amplificador de instrumentação (INA111AP) de modo a amplificar o sinal. A configuração do transistor JFET permanece. O que é acrescido são os capacitores C3 e C4 de modo a captar somente o sinal AC, proveniente da modulação do canal do transistor JFET, e injetar esse sinal no amplificador INA. O objetivo de se conectar o resistor R8 e o capacitor C5 em paralelo com o resistor de ganho R3 é para manter o ganho em altas frequências, fazendo com que este amplificador, como um todo, tenha resposta praticamente plana até $1 \mathrm{MHz}$. O sinal amplificado é retirado a partir da resistência de carga R7. Neste circuito, o ganho total é em torno de 15,7 (absoluto) ou 23,9 dB. 


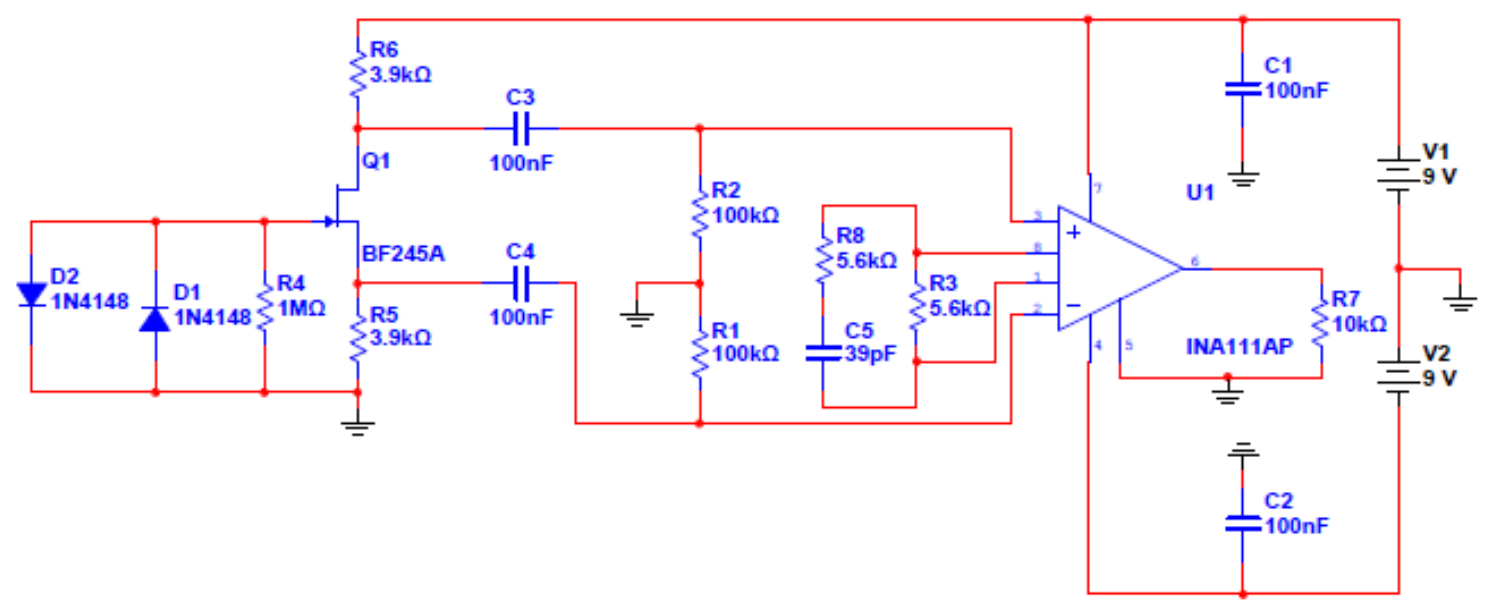

Figura 37: Novo circuito. Versão 2.

Entretanto, constatou-se que o universo de medidas para este tipo de piezoeletreto, conforme consta em Altafim (2010), foi de até $100 \mathrm{kHz}$. Não que o piezoeletreto não possa responder a frequências superiores, mas, para efeito de pesquisa, deve-se considerar esta frequência como sendo a máxima captável pelo piezoeletreto em questão. Sendo assim, uma versão final foi proposta e executada, conforme apresenta a Figura 38.

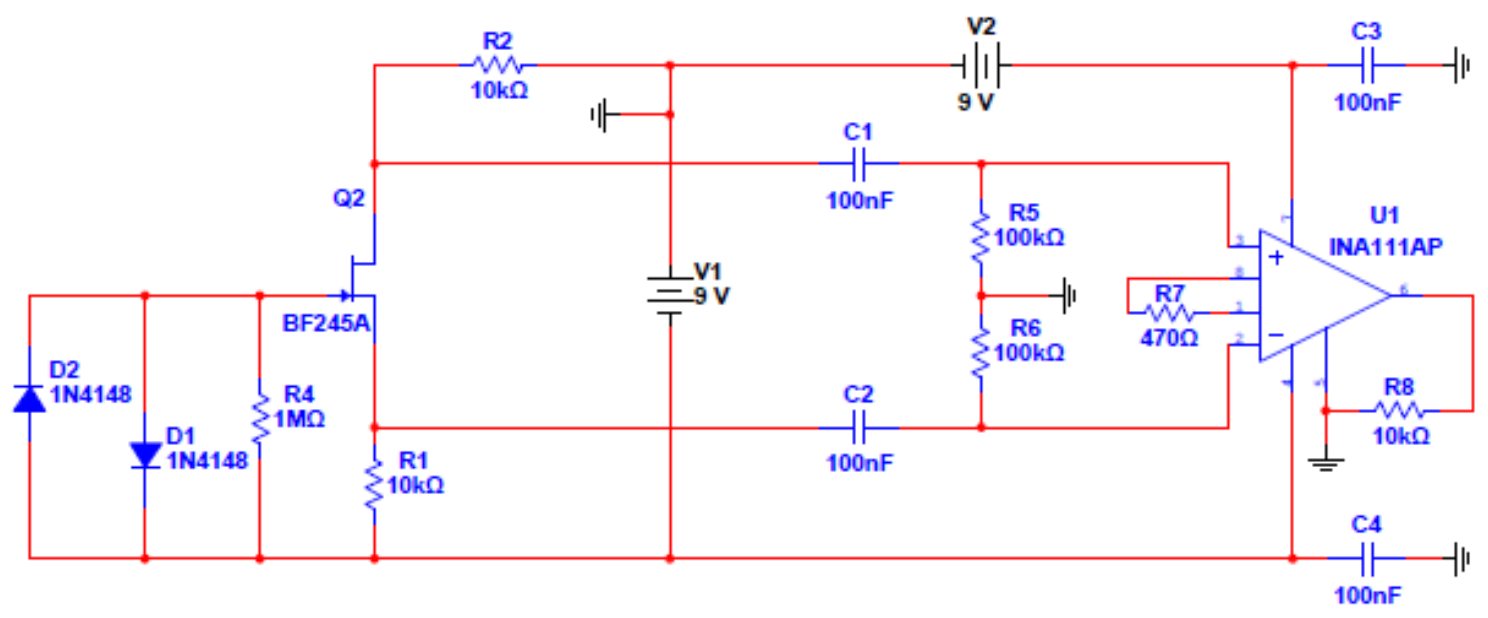

Figura 38: Circuito versão final: utilizado na realização de todos os ensaios.

A versão final difere em alguns aspectos da versão 2: é um circuito um pouco mais simples, de maior ganho, aproximadamente 189 (absoluto) ou 45,5 dB e menos suscetível a ruídos eletromagnéticos. Será notável que o ajuste do ganho foi necessário, principalmente nos ensaios que envolveram descargas elétricas realizadas 
dentro de caixas de alumínio. O som produzido pela descarga foi bastante baixo, de modo que o amplificador apresentado na Figura 37 praticamente não "percebeu" a ocorrência da mesma. A Figura 39 apresenta a resposta em frequência para o circuito da Figura 38. Note-se que o ganho deste circuito é praticamente plano para as frequências abaixo de $100 \mathrm{kHz}$, satisfazendo, dessa forma, os objetivos desta pesquisa.

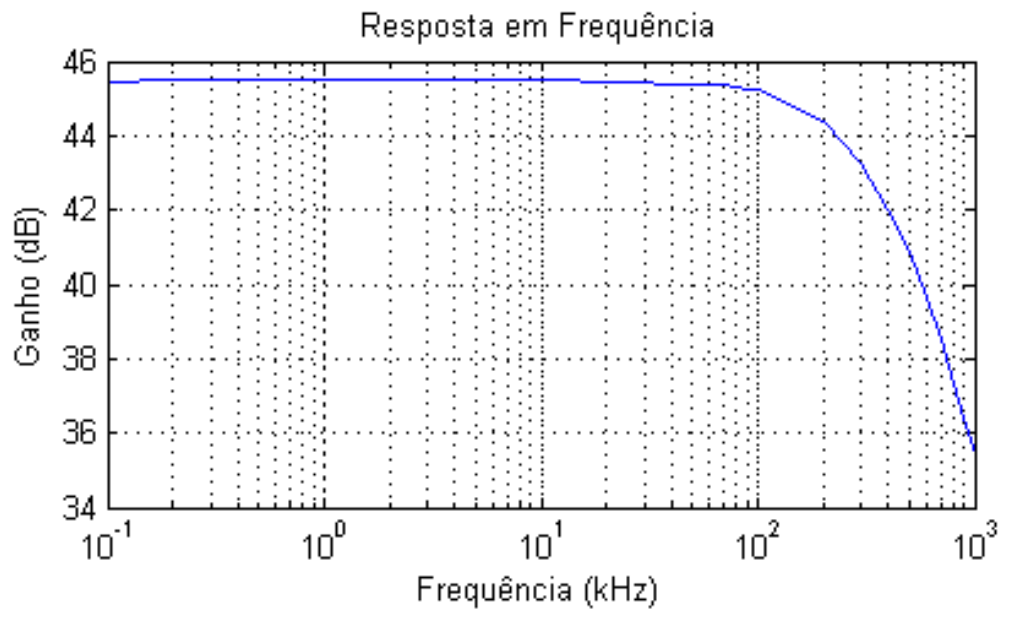

Figura 39: Resposta em frequência teórica do circuito da Figura 38.

O princípio de funcionamento deste novo circuito, versão final, é o mesmo daquele apresentado na Figura 37. Chama-se a atenção para o detalhe de que o transistor da Figura 38 está alimentado de forma diferente em relação ao circuito da Figura 37: a referência, ou terra, do circuito não está em contato com a amostra. Em questão de funcionamento do circuito em si, nada muda. Mas este artifício traz a seguinte vantagem: ao tocar com as mãos o corpo do transdutor, que é de alumínio e está conectado à referência do circuito, não haverá contato elétrico direto com a amostra. Dessa forma, o circuito tornou-se menos suscetível a ruídos eletromagnéticos provenientes do meio externo.

Para mostrar a suscetibilidade do circuito a ruídos eletromagnéticos, mesmo que de forma mais qualitativa à quantitativa, os circuitos das Figuras 37 e 38 foram expostos a ruídos provenientes de uma lâmpada fluorescente. O ensaio é bastante simples: com o transdutor de piezoeletreto montado e alimentado, aproximou-o de uma lâmpada, numa distância não maior que dois centímetros, e captou-se o sinal via osciloscópio. Entretanto, o circuito da Figura 38 deveria possuir ganho próximo ao circuito da Figura 37. Para tanto, outro foi montado diferindo apenas no quesito 
ganho: o resistor R7 tinha valor de $5,1 \mathrm{k} \Omega$ produzindo, dessa forma um ganho total de, aproximadamente, 19,4 (absoluto) ou 25,7 dB. A Figura 40 apresenta os sinais captados da lâmpada fluorescente por ambos os circuito: versão 2 e versão final com ganho menor. Para efeito de comparação, a amplitude pico-a-pico do sinal ruidoso para o circuito versão 2 foi de $24 \mathrm{mV}$; já para o circuito na versão final, com ganho menor, foi de $4,4 \mathrm{mV}$, ou seja, mais de cinco vezes menor em comparação com outro circuito.

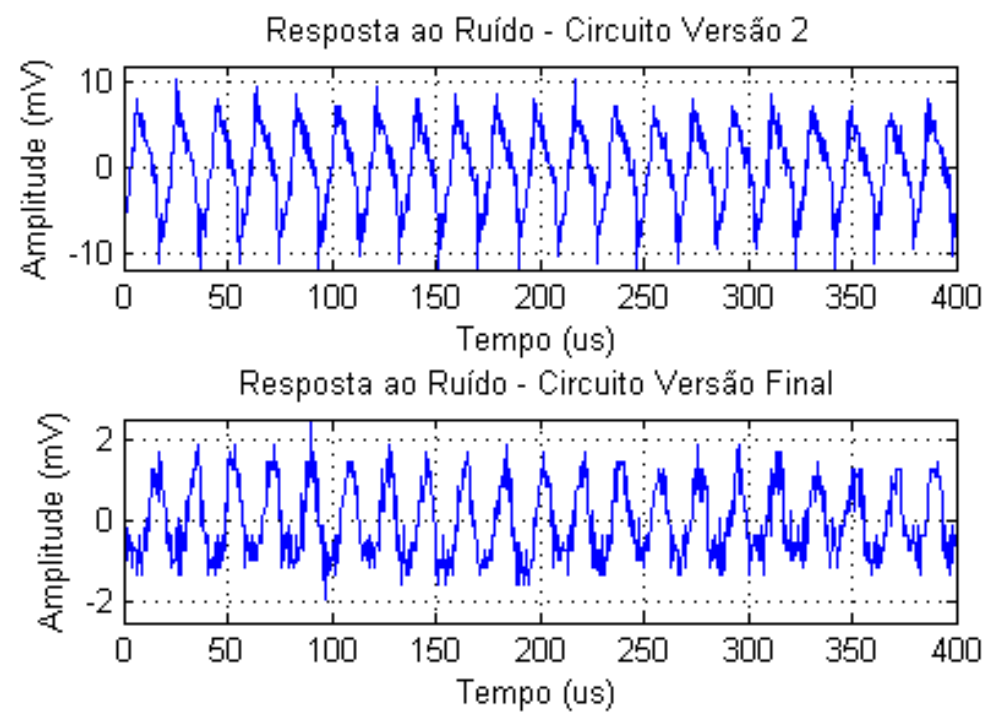

Figura 40: Ruído captado por ambos os circuitos: versão 2 e versão final com ganho menor.

O objetivo de toda esta discussão sobre o circuito adotado para realização dos ensaios é duplo: primeiro mostra-se o avanço e o aprendizado adquiridos com o melhoramento de um circuito simples e de baixo ganho para um mais sofisticado, de alto ganho e operante na faixa de frequência adequada à pesquisa; segundo, o fator blindagem do sistema como um todo foi crucial para a realização dos experimentos. Sendo assim, o fato de blindar melhor o transdutor, utilizando-se um circuito menos suscetível a ruídos eletromagnéticos, teve importante papel na qualidade de todas as medidas que foram realizadas. Conforme já mencionado, no Apêndice A está apresentado cada componente do novo transdutor, ou microfone, de piezoeletreto utilizado em todos os ensaios. Amostras de piezoeletreto maiores e o circuito de alto ganho foram os fatores motivacionais para a construção de um novo microfone. 


\subsection{Sensor Padrão}

De modo a se ter uma referência para comparação das medidas, um sensor de emissão acústica padrão também foi utilizado na realização de todos os ensaios a que o transdutor de piezoeletreto foi submetido. Especificamente, utilizaram-se três sensores que foram cedidos pela Escola de Engenharia Elétrica, Mecânica e de Computação da Universidade Federal de Goiás (EMC/UFG). A Figura 41 apresenta uma foto ilustrativa deste sensor e um esquemático de como este deve ser conectado a outros equipamentos para que opere adequadamente. É importante frisar que este sensor vem com pré-amplificador integrado em seu próprio encapsulamento. Conforme já mencionado, no Anexo A é apresentado as respostas em frequência dos três sensores padrão utilizado nos experimentos. É importante mencionar que existem aplicações deste sensor na detecção de DPs em transformadores, conforme consta em Mistras (2010(a)). Nota-se que o sensor é apenas uma peça de todo um conjunto, cuja finalidade é localizar fontes de descargas parciais no interior de um transformador.

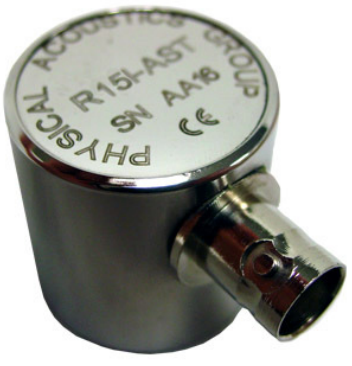

(A)

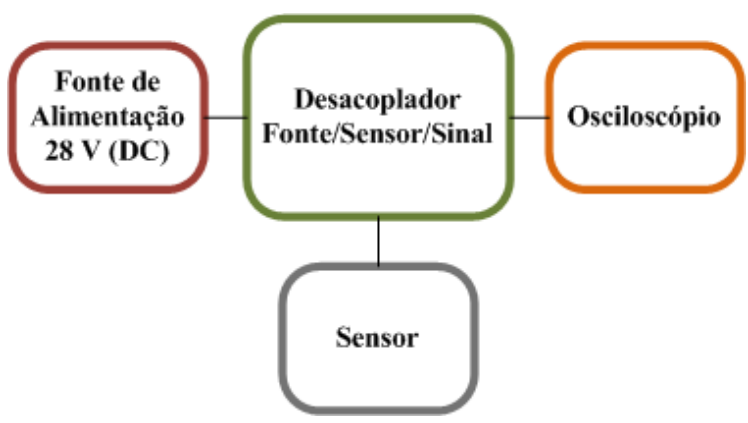

(B)

Figura 41 (A): Foto ilustrativa do sensor padrão. (B): Esquemático de conexões do sensor padrão com outros equipamentos.

Fonte (A): Mistras (2010(b))

A necessidade de se construir um desacoplador fonte/sinal/sensor provém do fato que a conexão BNC no sensor é única, ou seja, pelo mesmo ponto de conexão alimenta-se o sensor e retira-se o sinal de resposta. A Figura 42 apresenta o esquemático do circuito que foi construído para a realização desta função e uma fotografia deste desacoplador montado. Este desacoplador foi baseado no que fora 
proposto em Kil et al. (2008), de modo que realizou-se uma simplificação neste circuito obtendo-se praticamente o mesmo resultado de resposta em frequência.

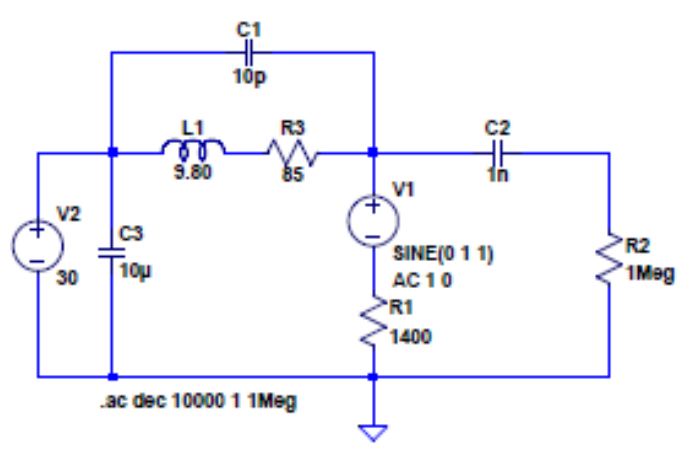

(A)

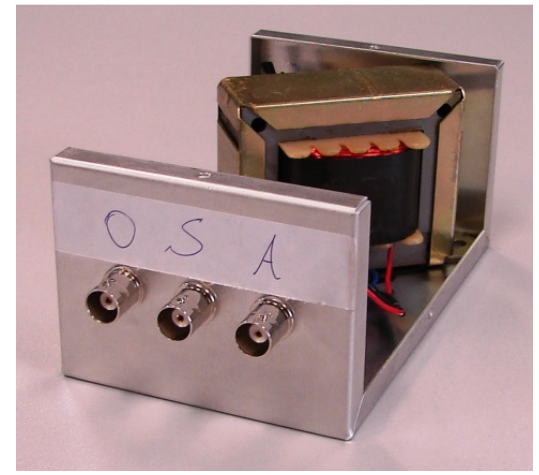

(B)

Figura 42 (A): Esquemático do circuito desacoplador fonte/sensor/sinal conectado aos demais equipamentos. (B): Fotografia do desacoplador (somente) montado. As siglas "O", "S" e "A" representam os pontos de conexão do osciloscópio, sensor e alimentação respectivamente.

É importante notar que, comparativamente à Figura 41(B), a fonte de alimentação, Figura 42(A), está representada pela fonte V2 (DC) de 30 V. Esta tensão foi obtida a partir de uma fonte de bancada marca Minipa modelo MPL 1303M. O sensor é representado pela fonte V1 (AC) em séria com a resistência de $1400 \Omega$. Este valor de resistência foi considerado, pois experimentalmente se verificou que, aplicando $28 \mathrm{~V}$ (valor nominal de alimentação) diretamente ao sensor, este consumia, sem estar excitado, em torno de $20 \mathrm{~mA}$. Daí se chegou ao valor dado a R1. Por fim o osciloscópio esta representado pela resistência de R2. Uma observação importante a se fazer é sobre o valor de V2: como há queda de tensão sobre R3, a tensão de alimentação precisou ser maior para que se obtivesse $28 \mathrm{~V}$, aproximadamente, sobre o sensor.

Constata-se, portanto, que o desacoplador é formado pelos elementos nominados como L1, R3, C1, C2 e C3. Neste caso, o indutor L1 em série com a resistência R3 foi obtido a partir do primário de um transformador 220/12 V. Dessa forma, o valor da indutância deve ser bastante elevado de modo a permitir que a tensão DC, proveniente de V2, alimente o sensor e que sinais AC não "retornem" à fonte V2. Este é o princípio de se desacoplar uma fonte DC do sensor que está sendo alimentado. $\mathrm{O}$ valor de $\mathrm{L} 1$ foi obtido a partir de um equipamento específico que mede impedância elétrica (HP 4284A - Precision LCR Meter) e a resistência foi obtida a 
partir da medida de resistência do primário do transformador por um multímetro. Nesta medida de resistência, o multímetro é mais confiável, pois o efeito pelicular é praticamente desprezível. O capacitor C1 tem a função de proteger o sensor dos efeitos de uma sobretensão que o indutor L1 pode causar. Isto é verdade se, por descuido, alguém vier a desconectar o sensor, quando alimentando por V2 via L1 e R3, do desacoplador. Para coletar o sinal puramente AC do sensor via osciloscópio, utilizou-se o capacitor $\mathrm{C} 2$ e, finalmente, o capacitor C3 atua como um filtro da fonte de alimentação.

Com estes dados em mãos, o circuito da Figura 42(A) foi simulado em questão de resposta em frequência, ou seja, o quanto o desacoplador distorce o sinal proveniente do sensor representado por V1 e R1. Fez-se uma varredura de $1 \mathrm{~Hz}$ a 1 $\mathrm{MHz}$ de modo o que o sinal de entrada fosse dado por V1 e o de saída sobre a resistência R2, que representa o osciloscópio. A Figura 43 apresenta o gráfico em questão. A linha pontilhada da Figura 43 refere-se à reposta em fase e linha contínua, em amplitude. Percebe-se que, para frequências acima de $1 \mathrm{kHz}$, a resposta é praticamente idêntica ao sinal de entrada, ou seja, quase não há distorção em amplitude e em fase. Em termos de operação, está mais que satisfatório, pois abrange o universo de medidas referente a esta pesquisa.

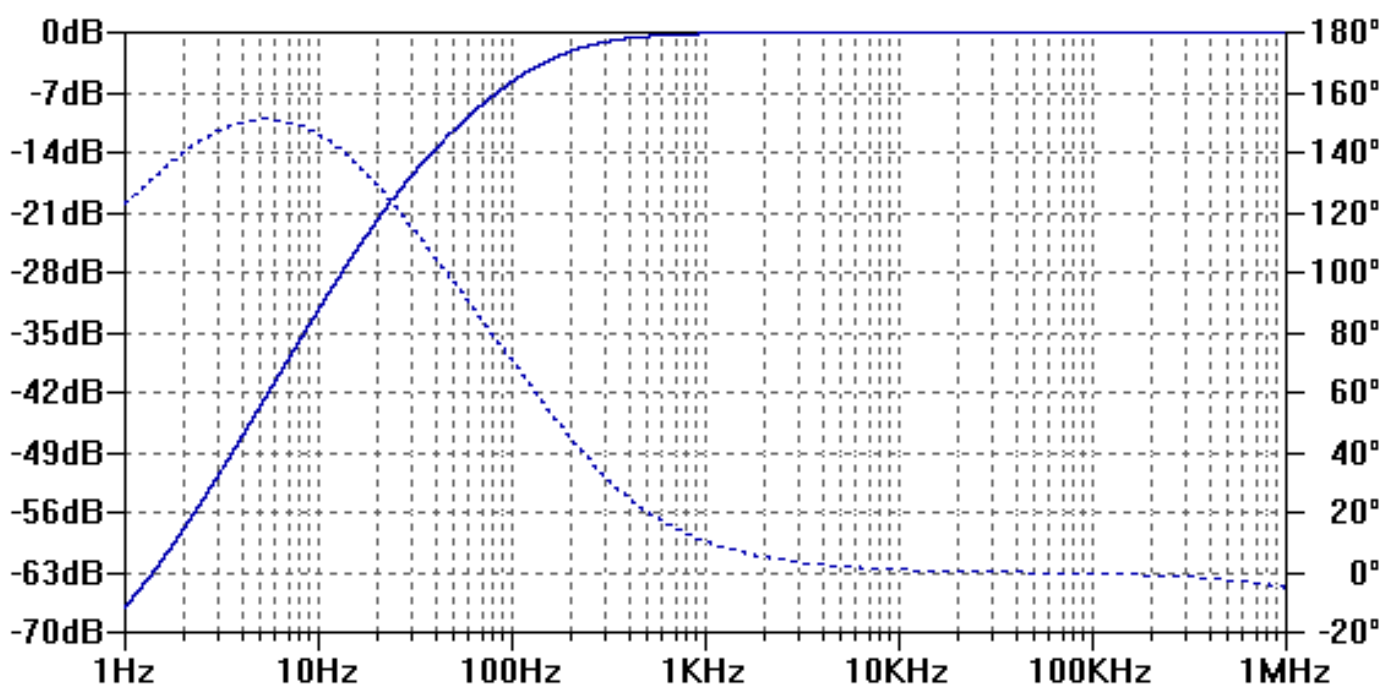

Figura 43: Resposta em frequência do desacoplador fonte/sensor/sinal. 


\subsection{Sistema de alta tensão}

A Figura 44 apresenta uma foto de um sistema gerador de pulsos de altas tensões construído para se gerar descargas elétricas. Este sistema foi idealizado para operar de modo autônomo, ou seja, sem alimentação externa, apenas a base de baterias. Em termos estruturais, é uma caixa de alumínio na qual o circuito está montado na tampa. Logo de início constatou-se esta necessidade em virtude da blindagem eletromagnética: as primeiras descargas foram realizadas dentro do próprio sistema. Sendo assim, o interesse residia em captar somente os sinais acústicos e blindar os sinais eletromagnéticos. Isto se tornará mais claro quando for descrita a realização da primeira aquisição de descarga.

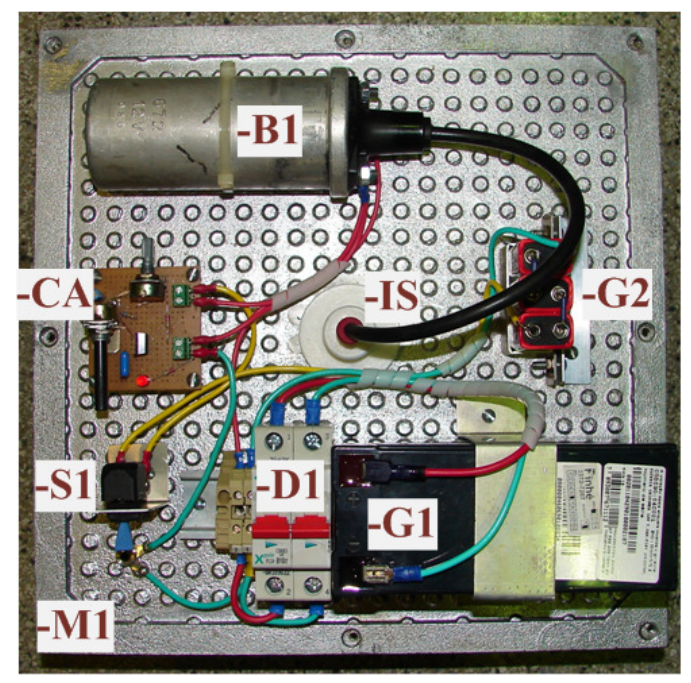

Figura 44: Foto do sistema gerador de pulsos de alta tensão.

Na Figura 45 há um diagrama elétrico que tem por finalidade apresentar as conexões do sistema como um todo. Não se trata, necessariamente, de um diagrama completo de todo o sistema. As siglas presentes nas Figuras 44 e 45 dizem respeito aos mesmos elementos, ou seja, "B1" refere-se a uma bobina que gera pulsos de alta tensão. A conexão denominada "AT", na Figura 45, significa "alta tensão": é um cabo que suporta alta tensão e conecta a bobina "B1" ao isolador "IS". Este isolador permite uma conexão para dentro da caixa. O elemento denominado "G1" é uma bateria de $12 \mathrm{~V}$ que tem por finalidade alimentar a bobina "B1"; "G2", que é um banco de três baterias de $9 \mathrm{~V}$, alimenta o circuito de acionamento, denominado de 
"CA". Este circuito tem a finalidade de "chavear" o primário da bobina "B1" de modo a se obter pulsos de alta tensão no secundário desta, ou seja, na conexão "AT". A chave "S1" serve para energizar o circuito de acionamento e o disjunto "D1" serve proteção e energização da bobina "B1".

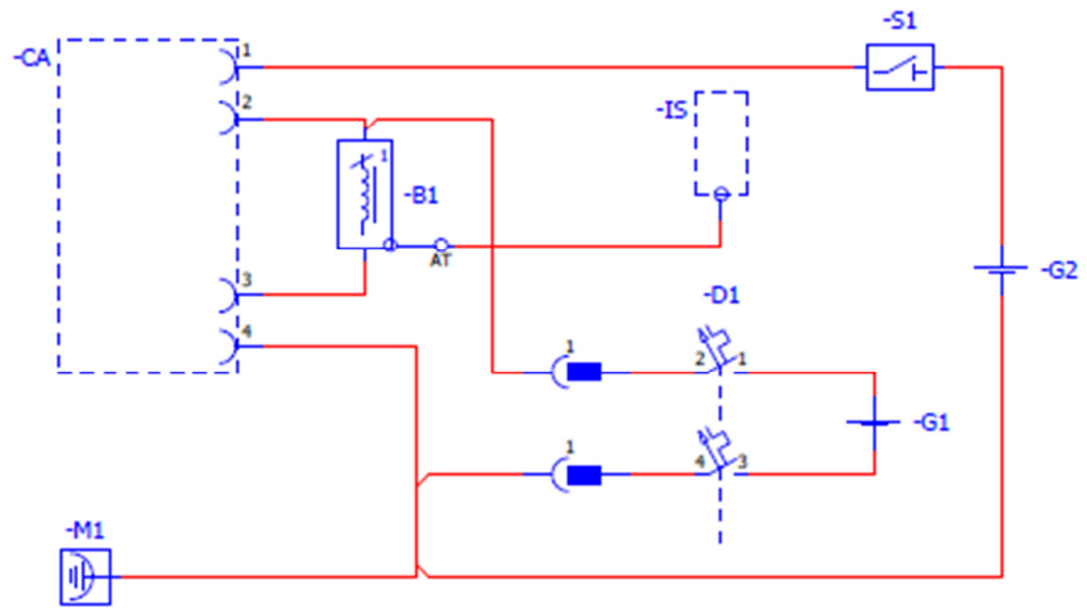

Figura 45: Diagrama elétrico esquemático do sistema de alta tensão.

Considerou-se importante separar os circuitos de acionamento e potência por questão de segurança: o sistema somente gera altas tensões se a chave "S1" estiver fechada e o disjuntor "D1", armado. Por fim, "M1" representa tanto o referencial dos circuitos quanto a massa do sistema: tudo está conectado a um único ponto de aterramento. Neste caso, aproveitou-se a carcaça de alumínio para esta finalidade. O princípio de funcionamento da geração de descargas neste sistema é baseado no corte, quase que instantâneo, da corrente elétrica passante numa bobina. Isto é feito eletronicamente por meio de um transistor MOSFET. A Figura 46 apresenta um esquemático deste circuito de acionamento.

Neste circuito, P1M0 representa um potenciômetro de $1 \mathrm{M} \Omega$; P470, de $470 \Omega$. O conjunto L1 mais R4 representa o primário de bobina utilizada em automóveis. O procedimento de medida da indutância e resistência desta bobina foi o mesmo na medida de L1 e R3 apresentados na Figura 42(A). A tensão de $28 \mathrm{~V}$ é proveniente de um banco de três baterias de 9 volts cada. Já a tensão de $12 \mathrm{~V}$ provém de uma bateria de 12 volts. A ideia de funcionamento é a seguinte: o capacitor C1 é carregado até determinada tensão. O tempo de carregamento é definido pelo conjunto 
P1M0, R1 e C1. Dessa forma, alterando-se a resistência do potenciômetro P1M0, alterasse o tempo de carregamento do capacitor C1. Atingida determinada tensão, o transistor de unijunção 2N2646 emite um pulso do emissor para a base b1 (vide datasheet do componente). O tempo de duração deste pulso pode ser comparado a um descarregamento do tipo $\mathrm{RC}$, formado pelo conjunto $\mathrm{C} 1$ mais $\mathrm{P} 470$ principalmente. $\mathrm{O}$ resistor R3 serve como resistência mínima para funcionamento do sistema e o capacitor C2 tem o objetivo de "arredondar" o pulso. Dessa forma, com o ajuste de P470, pode-se regular quanto tempo o transistor IRF540N permanecerá saturado. Isto está relacionado à energia que será fornecida ao primário da bobina e, consequentemente, à energia que será liberada na descarga.

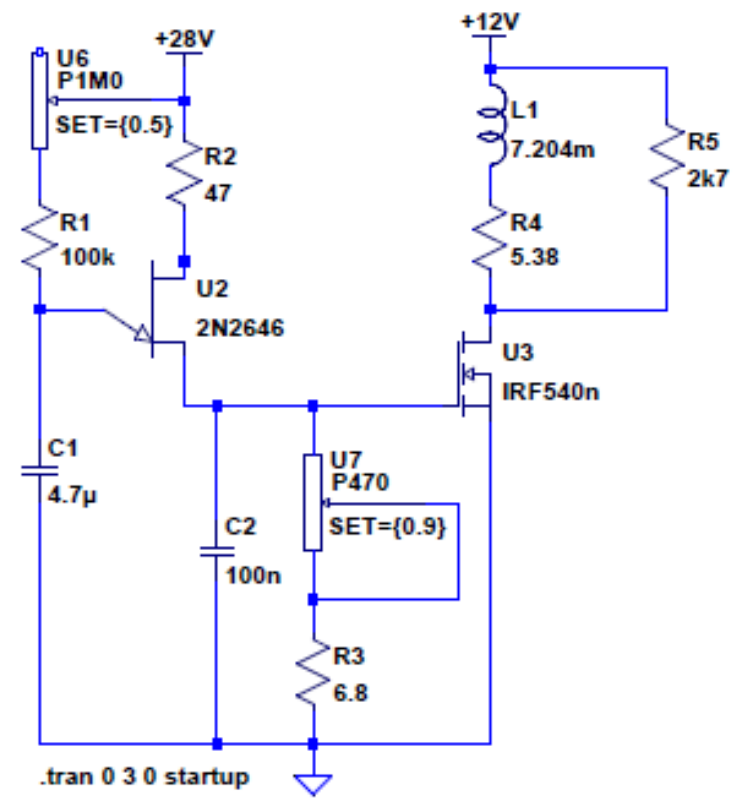

Figura 46: Esquemático do circuito de acionamento do sistema gerador de descargas.

A Figura 47 apresenta o gráfico de uma simulação realizada com o circuito da Figura 46. Neste gráfico, a tensão V(n008) refere-se à tensão aplicada ao gate do transistor IRF540N e V(n007) é a tensão sobre o dreno do transistor. I(L1) e a corrente passante no primário da bobina. O potenciômetro P1M0 foi ajustado de tal forma que entre os pulsos houvesse um intervalo de 2 segundos aproximadamente. $\mathrm{O}$ objetivo desse ajuste é que se possa captar uma descarga por vez. 


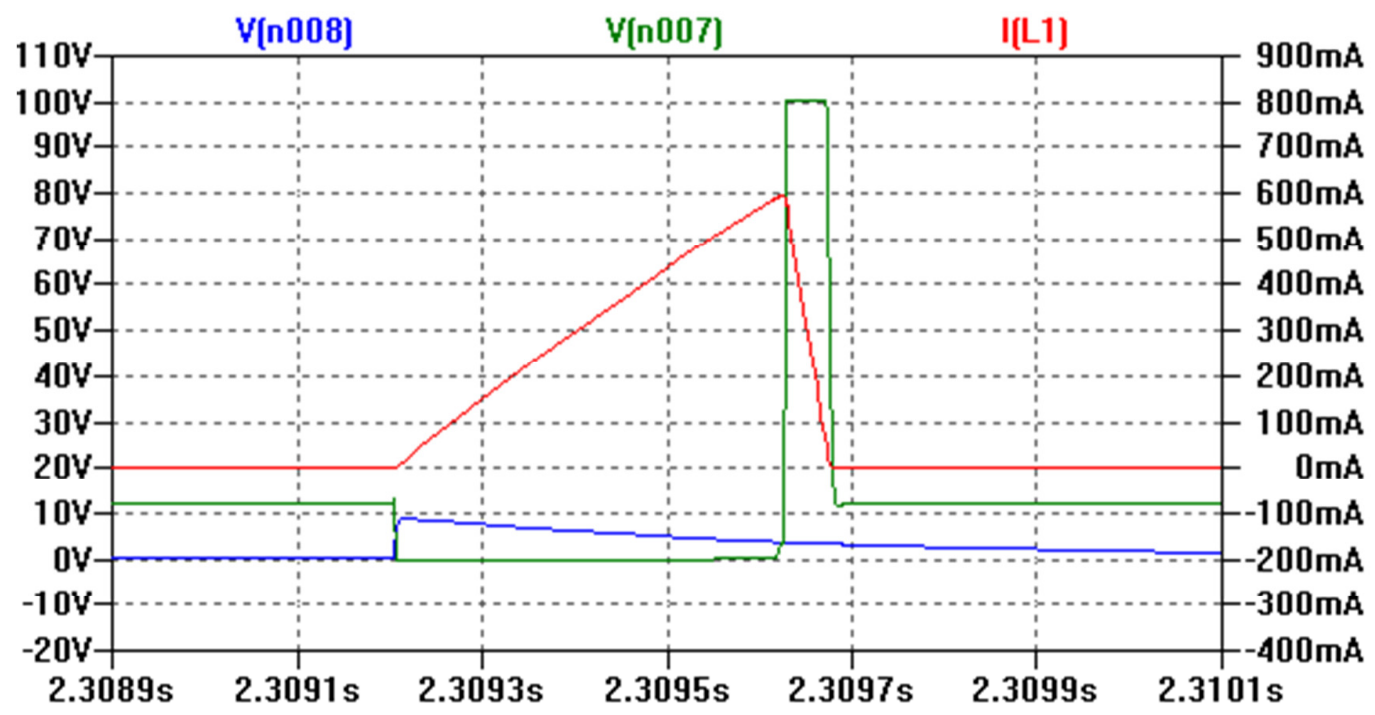

Figura 47: Simulação do circuito de acionamento.

Havendo tensão no gate do transistor, a tensão no dreno vai a zero e o primário da bobina começa a carregar. A partir de certo ponto, o transistor corta, a tensão no dreno se eleva até a casa de 100 volts e a corrente no primário retorna a zero. É durante este pulso de tensão, provocado pela tentativa de corte da corrente no primário da bobina, que se obtém alta tensão no secundário. É importante observar que a tensão chega a 100 volts, pois existe, internamente ao transistor, um diodo zener de 100 volts conectado em antiparalelo entre o dreno e a fonte (vide datasheet do componente). Dessa forma, a corrente flui pelo transistor, mas em forma de pulso. Ademais: o resistor R5, colocado em paralelo com o primário da bobina, tem um importante papel no amortecimento das demais oscilações que surgem depois do pulso principal. Sem este resistor pode ocorrer mais de uma descarga no secundário da bobina.

Para finalizar, foi necessário medir o pulso de descarga gerado no secundário da bobina. Para tanto, com a utilização de um divisor capacitivo padrão (marca Haefely; capacitância de 500 pF; mede tensões de até 400 kV), montou-se um circuito de medição conforme apresentado na Figura 48(A). O princípio de medida deste circuito é a queda de tensão sobre uma resistência. De imediato, o "formato" da tensão é o mesmo da corrente passante pela resistência de $270 \Omega$, pois o elemento é, a priori, puramente resistivo. Deve-se mencionar que a escolha para este valor de resistência foi regido pela duração do pulso medido: quanto maior o valor, mais lento apresentava-se o pulso. Portanto, padronizou-se um pulso com duração de, no 
máximo, 1 us acarretando, dessa forma, a escolha da resistência com valor de $270 \Omega$. Outro detalhe, o componente denominado "Centelhador" representa, na verdade, a gaiola anecóica como um todo, apresentada na Figura 51.

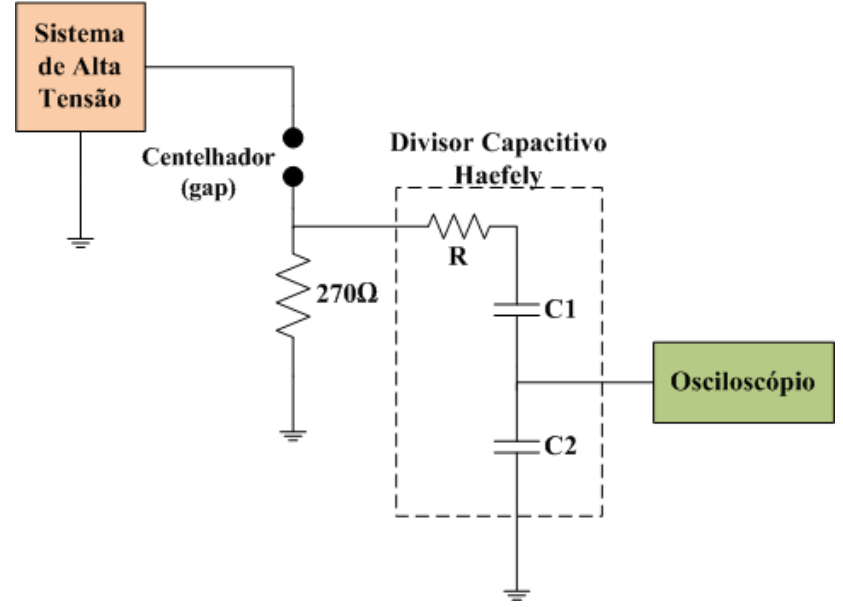

(A)

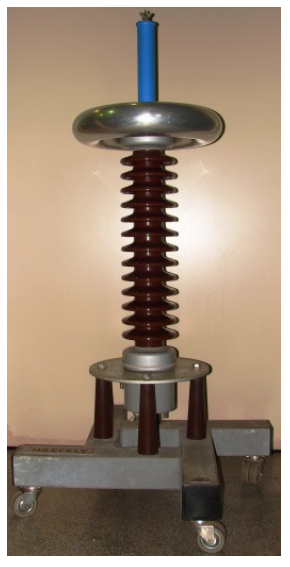

(B)

Figura 48 (A): Esquemático do circuito de medição do pulso de descarga. (B): Fotografia do divisor capacitivo padrão.

Sobre a Figura 48, $R=115,5 \Omega$; os capacitores $C 1$ e $C 2$ produzem uma relação de transformação de 1/306,4. Uma observação importante é que, depois desta medida, a resistência de $270 \Omega$ foi transferida para o lado de alta tensão, ou seja, uma das pontas do "Centelhador" ficou permanentemente aterrada. Em termos de operação de circuito, nada muda, pois o conceito de "gap" é de uma "chave": quando ocorre um arco elétrico é que esta "chave" fecha; do contrário, está permanentemente aberta. É importante mencionar que esta modificação foi necessária, pois a blindagem que "envolve" o Centelhador propriamente dito permanece aterrada, conferindo segurança aos ensaios.

Fizeram-se medidas para diversos "gaps" objetivando averiguar se isto influenciava no "formato" da descarga. A Figura 49 apresenta o comportamento da corrente elétrica passante no gap. De imediato constata-se que, normalizando-a para todas as medidas, o "formato" da descarga permaneceu praticamente inalterado. $\mathrm{Na}$ configuração de medida do pulso de corrente apresentado na Figura 48(A) e não incluindo o gap de $0,05 \mathrm{~mm}$, a tensão de ruptura para os demais gaps ficou entre 1,5 $\mathrm{kV}$ e $2 \mathrm{kV}$. No caso de descarga tipo ponta-ponta, a tendência é que a tensão de ruptura seja menor em comparação, por exemplo, à modalidade esfera-esfera. Isto 
ocorre devido ao campo elétrico ser mais intenso nas pontas, facilitando o desenvolvimento da descarga. Em Roth (1959) encontra-se um estudo, entre outros, sobre a tensão de ruptura para diversas configurações de eletrodos e tipos de tensão aplicada aos mesmos. Pode parecer fora de padrão, mas a descarga referente ao gap de 0,05 $\mathrm{mm}$ foi importante documentar neste gráfico, pois este foi gap no caso em que se realizou descarga em óleo mineral isolante. A motivação de se utilizar um gap tão pequeno partiu do fato que o som produzido pela descarga estava saturando o sensor padrão. Portanto, reduziu-se ao máximo o gap neste tipo de ensaio de forma que o sensor padrão capta-se o sinal acústico da descarga sem estar saturado. Isto se tornará mais claro quando se mostrar as formas de ondas provenientes dos sinais acústicos destas descargas, no próximo capítulo.

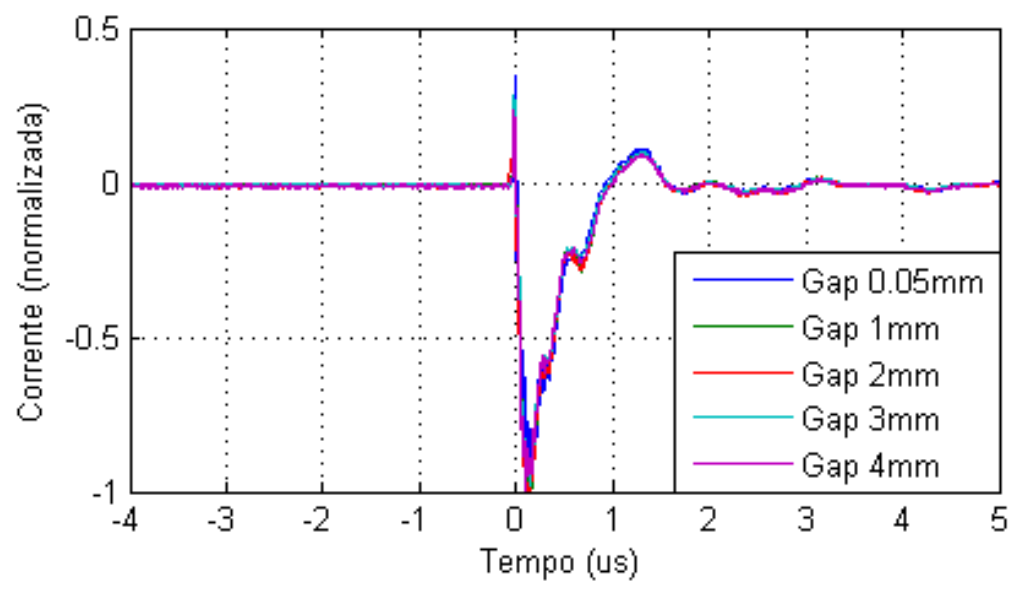

Figura 49: Pulso de corrente passante pelo Centelhador para diversos gaps. 


\section{Capítulo 4}

\section{Ensaios, Resultados e Análise dos Resultados}

O capítulo anterior objetivou apresentar os principais equipamentos construídos e utilizados para a realização de todos os ensaios. É importante observar que alguns outros equipamentos serão apresentados neste capítulo por questão didática, ou seja, é proposto o ensaio, e logo em seguida tem-se o resultado e a análise pertinente ao resultado. O presente capítulo tem por objetivo mostrar não somente a deteç̧ão acústica de descarga nas mais diversas situações, mas também um pouco do histórico da pesquisa em questão de dificuldades, acertos e descobertas. Primeiramente apresentaremos os primeiros ensaios de detecção acústica de descarga que foram realizados no início desta pesquisa. Em seguida será apresentada uma metodologia de estudo que foi consequência da realização destes ensaios iniciais. Resultados e análises completam este capítulo.

\subsection{Primeiros ensaios}

As primeiras descargas foram realizadas em óleo em virtude de o primeiro transdutor possuir baixo ganho (vide Figuras 34 e 35) e pela constatação de que uma descarga gerada em óleo produz um som muito mais intenso. Para realização desse primeiro experimento, um centelhador tipo ponta-ponta foi construído de modo que a descarga ocorresse entre estas pontas. O corpo do sistema que contem as pontas era de teflon, em virtude de sua excelente propriedade isolante e também por ser um material inerte no óleo. As pontas eram de latão e a distância entre as mesmas era ajustável. A Figura 50(A) apresenta uma foto do centelhador, imerso em óleo, dentro da caixa de alumínio que nada mais é a caixa que suporta o sistema de alta tensão. Lembra-se que o circuito como um todo está montado na tampa desta caixa e, portanto, o interior está vazio. Note ainda que o contato entre o secundário da bobina e uma das pontas do centelhador é realizado por meio do isolador "IS" (vide Figura 44). Já a Figura 50(B) apresenta como foi esquematizado o ensaio. Note que o

microfone foi posicionado do lado de fora da caixa de alumínio que contem o 
centelhador e "por cima" do sistema de alta tensão foi colocada outra caixa de alumínio com o objetivo de blindar os sinais eletromagnéticos proveniente das descargas. Veja ainda que nas frestas entre as caixas foi colocado papel alumínio de modo a garantir melhor a blindagem. Finalizando, a Figura 50(C) apresenta o aspecto acústico de uma descarga apresentada na tela de um osciloscópio.

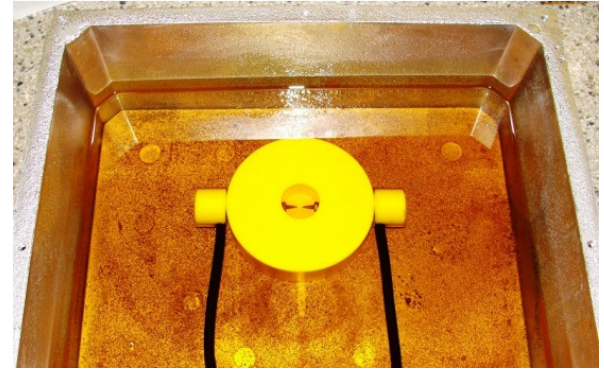

(A)

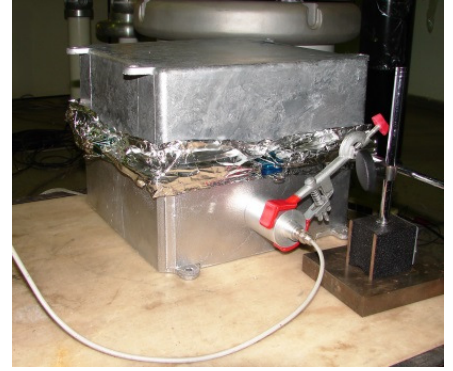

(B)

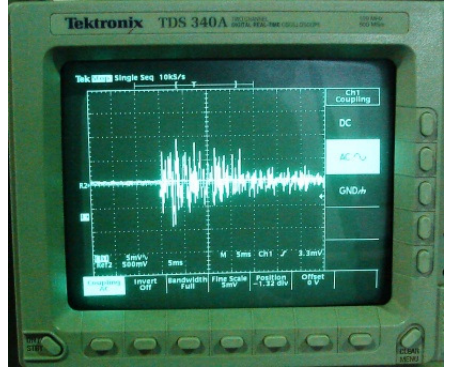

(C)

Figura 50 (A): Fotografia do primeiro centelhador imerso em óleo. (B): Fotografia do sistema montado na realização dos primeiros ensaios. (C): Fotografia da tela do osciloscópio referente a uma das primeiras aquisições de descargas.

Entretanto logo se percebeu um problema: o local onde ocorriam as descargas, na Figura 50(A), causava distorções no sinal acústico. Isto em virtude de efeitos de reverberação e reflexão (eco) que ocorrem dentro da pequena câmara onde esta descarga se desenvolve. Ademais, há o efeito de distorção não somente por esta pequena câmara, mas também a caixa como um todo também distorce o sinal. Foi por isso que se começou a estudar o sinal acústico de uma descarga livre de efeitos de reverberação e eco. Depois se realizou descargas dentro de caixas de alumínio, onde o meio envolvente era, numa situação, ar e noutra, óleo mineral isolante. Mais especificamente, idealizou-se uma metodologia de estudo baseada no princípio de que um sinal acústico de descarga, numa primeira aproximação, é a composição de vários sinais "puros" defasados e atenuados no tempo. Os próximos subitens tornarão esta ideia mais clara, onde esta metodologia está sintetizada:

1. Caracterização de um sinal acústico de descarga sem a presença de ecos e/ou reverberações.

2. Estudo e deconvolução homomórfica de sinal acústico de descarga possuindo um único eco.

3. Estudo e deconvolução homomórfica de sinais acústicos de descargas em diferentes geometrias (caixas de alumínio) e meios (ar e óleo). 
O objetivo é, a partir da deconvolução homomórfica dos sinais, retornar ao sinal de descarga "puro", ou seja, que não possua ecos e/ou reverberações.

\subsection{Proposta de Novos Ensaios}

A partir deste tópico serão apresentados os ensaios mencionados anteriormente e também ferramentas de processamento de sinais principalmente no que diz respeito à remoção de ecos.

\subsubsection{Descarga Numa Câmara Anecóica}

Com o objetivo de se eliminar ecos e reverberações, o ensaio de detecção acústico de uma descarga deveria ser realizado dentro de uma câmara anecóica. Ademais, não basta eliminar ecos e reverberações, mas é necessário blindar os sinais eletromagnéticos provenientes da descarga. Para tanto, uma gaiola envolvida em tela de alumínio foi construída de modo que envolvesse o centelhador. A Figura 51(A) apresenta uma fotografia da gaiola dentro da câmara anecóica e a Figura 51(B), um esquemático em corte de como foi construída esta gaiola.

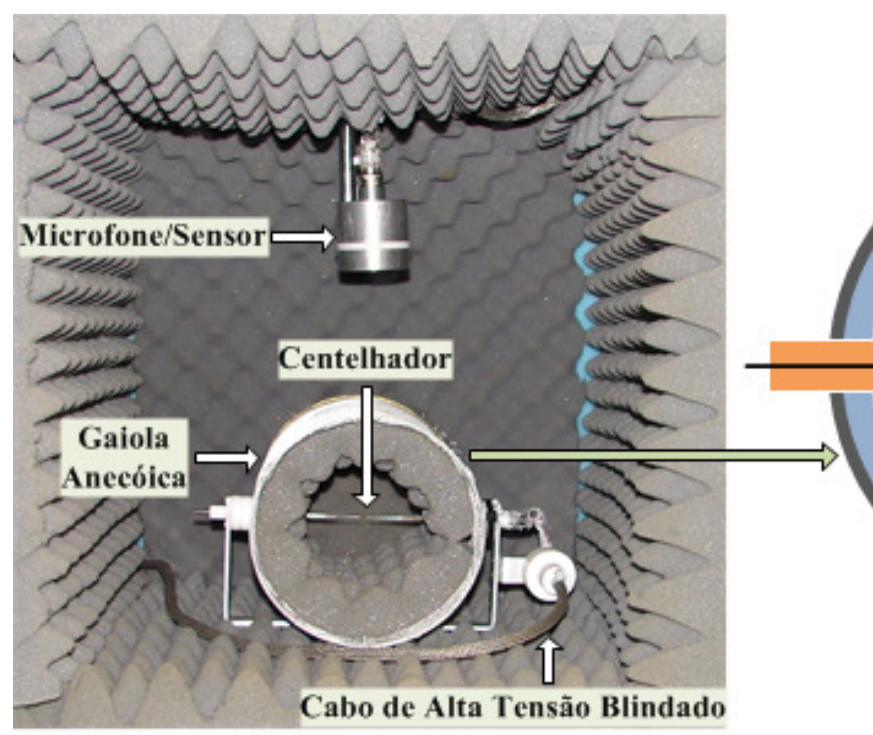

(A)

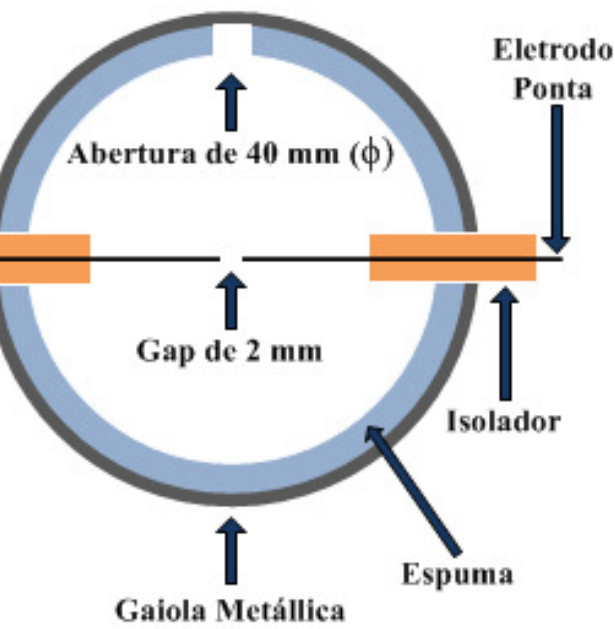

(B)

Figura 51 (A): Fotografia do ensaio de descargas elétricas na câmara anecóica. (B): Esquemático de uma vista em corte da gaiola blindada que contem o centelhador. 
A gaiola anecóica é, basicamente, um cilindro com dimensões de $15 \mathrm{~cm}$ de diâmetro e $30 \mathrm{~cm}$ de comprimento. A armação deste cilindro é composta por três anéis de alumínio, um em cada extremidade e outro no centro. Estes anéis são unidos por três hastes também de alumínio que estão igualmente espaçadas na circunferência destes anéis. Ademais, uma tela de alumínio envolve toda esta armação, conferindo blindagem ao sistema. Evidentemente que, durante os ensaios, as extremidades deste cilindro foram "tampadas" com espuma e tela de alumínio objetivando a completa remoção de ecos e blindagem total do sistema. Por fim, preso na armação da gaiola está o centelhador, o qual é composto de duas pontas e um suporte com isoladores para fixação dessas pontas. Note que nesta câmara, Figura 51, está presente o transdutor, logo acima, e a gaiola com um furo na espuma de aproximadamente 40 mm de diâmetro, permitindo a passagem do som gerado pela faísca até o transdutor. A distância entre o centelhador e o transdutor/sensor é de aproximadamente $18 \mathrm{~cm}$. Evidentemente que se utilizou o mesmo sistema de alta tensão, apresentado na Figura 44, para se gerar descargas neste ensaio. A conexão entre esse sistema e a gaiola é realizada por meio de um cabo de alta tensão blindado. Na Figura 52 há um detalhamento do centelhador com indicação da distância real entre as pontas, ou seja, esta distância foi medida antes de se tirar a fotografia.

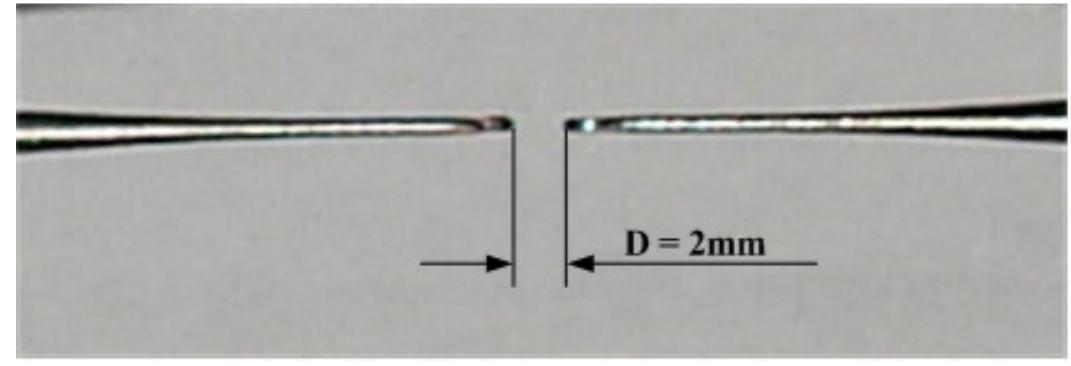

Figura 52: Fotografia do centelhador com indicação da distância real entre as pontas.

Fizeram-se várias medidas, um total de 25 para cada uma das três amostras de piezoeletretos, calculou-se a forma de onda média obtendo-se o gráfico da Figura 53. Os dados de temperatura ambiente e umidade relativa são de $20{ }^{\circ} \mathrm{C} \quad 60 \%$ respectivamente. Note que o sinal acústico da descarga é bastante "sucinto", ou seja, tem duração bem curta, menos de 0,5 milissegundos, se comparado ao sinal apresentado na Figura 50(C), o qual tem duração de dezenas de milissegundos. Embora o formato das repostas sejam bastante próximos, de imediato percebe-se que 
as amplitudes não são igualmente próximas, comparando-se as amostras 1 e 2 com a amostra 3. Um dos fatores que provavelmente teve influência nisto, foi o processo de metalização das amostras. Neste procedimento não se tem controle da espessura camada de alumínio depositada sobre a superfície da amostra. Dessa forma, a espessura dos eletrodos, esquematizados na Figura 32(B), pode conferir maior ou menor dureza às canaletas o que altera, de imediato, a amplitude da resposta piezelétrica da amostra. Em termos de resposta em frequência do piezoeletreto em si, pouca influência exerce a espessura do eletrodo. Esta é determinada, principalmente, pela geometria das canaletas. Isto pode ser constatado pelo formato dos sinais, os quais são bastante próximos a menos de uma normalização.

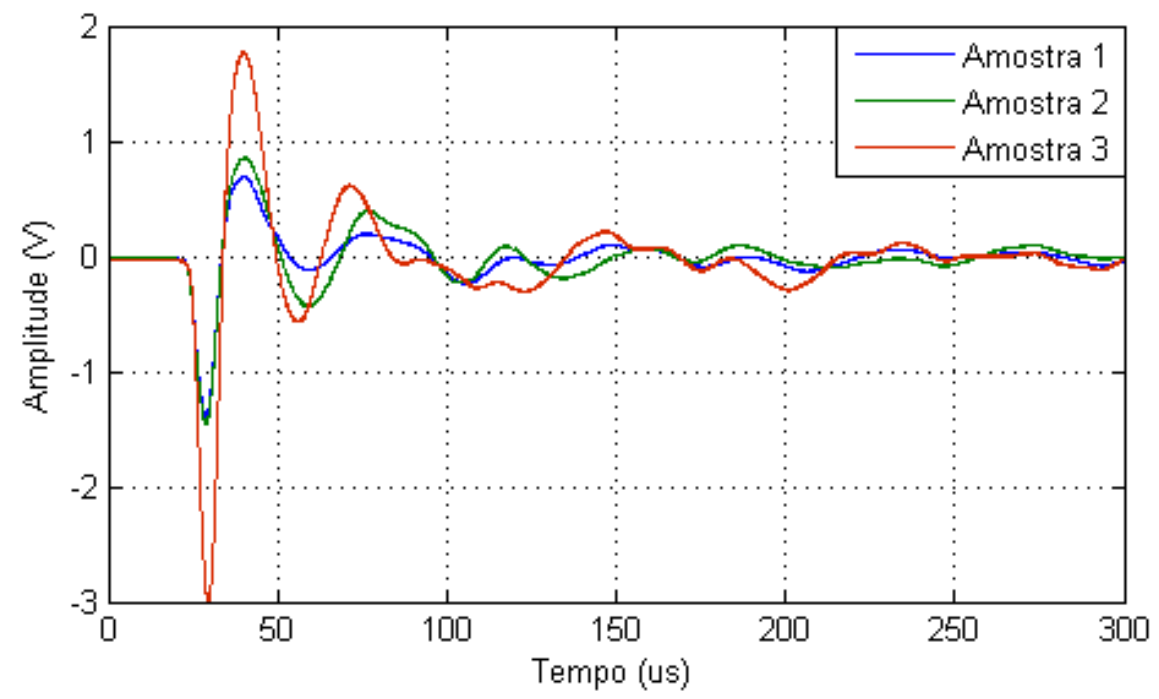

Figura 53: Resposta temporal média das três amostras para a descarga na câmara anecóica.

Para efeito de comparação e estudo, o mesmo ensaio foi realizado utilizando-se os sensores padrão. Os gráficos estão apresentados na Figura 54. Nota-se que os sinais dos sensores são bastante semelhantes tanto em forma quanto em amplitude. Entretanto, estes sinais diferem dos sinais da Figura 53 em questão espectro de frequência, ou seja, as amostras de piezoeletreto respondem em uma frequência mais baixa em relação aos sensores padrão. Isto pode ser visto nos gráficos da resposta em frequência de cada sensor padrão, que está em torno de $150 \mathrm{kHz}$, conforme consta no Anexo A.

Com o objetivo de se remover ecos do sinal, num primeiro momento repetiu-se o ensaio de descarga na câmara anecóica com a seguinte modificação: um anteparo foi 
posto logo abaixo do centelhado a uma distância de, aproximadamente, $4 \mathrm{~mm}$. A Figura 55 apresenta uma fotografia do anteparo próximo ao centelhador dentro da gaiola anecóica. Este anteparo é um disco de madeira envernizada com $10 \mathrm{~cm}$ de diâmetro e $1 \mathrm{~cm}$ de espessura. O anteparo foi posicionado de modo simétrico ao centelhador, ou seja, o centro do disco está bem próximo do local onde ocorre a centelha. As Figuras 56 e 57 apresentam, cada uma, três gráficos contendo duas formas de ondas distintas em cada um: uma forma de onda diz respeito ao sinal sem eco, que é o mesmo da Figura 53 e 54 respectivamente; outra se refere ao sinal com eco. Nesta situação realizaram-se 25 medidas deste novo tipo de sinal para cada amostra/sensor e calculou-se o sinal médio.

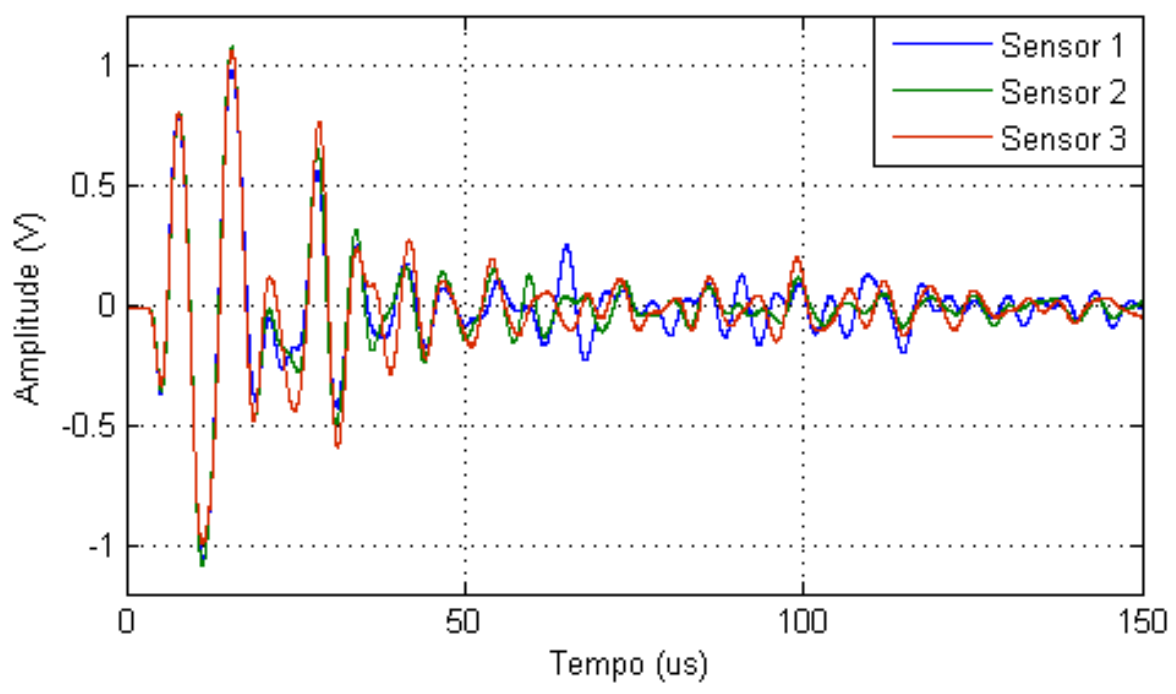

Figura 54: Resposta temporal média dos três sensores para a descarga na câmara anecóica.

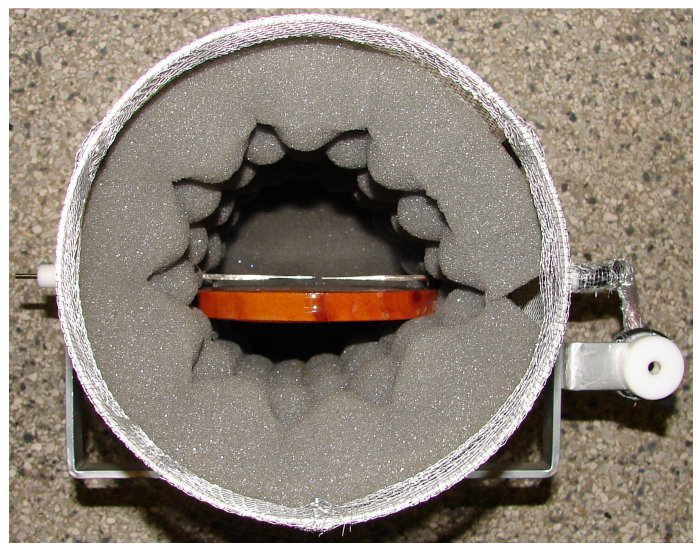

Figura 55: Fotografia da gaiola anecóica com anteparo para geração de eco. 

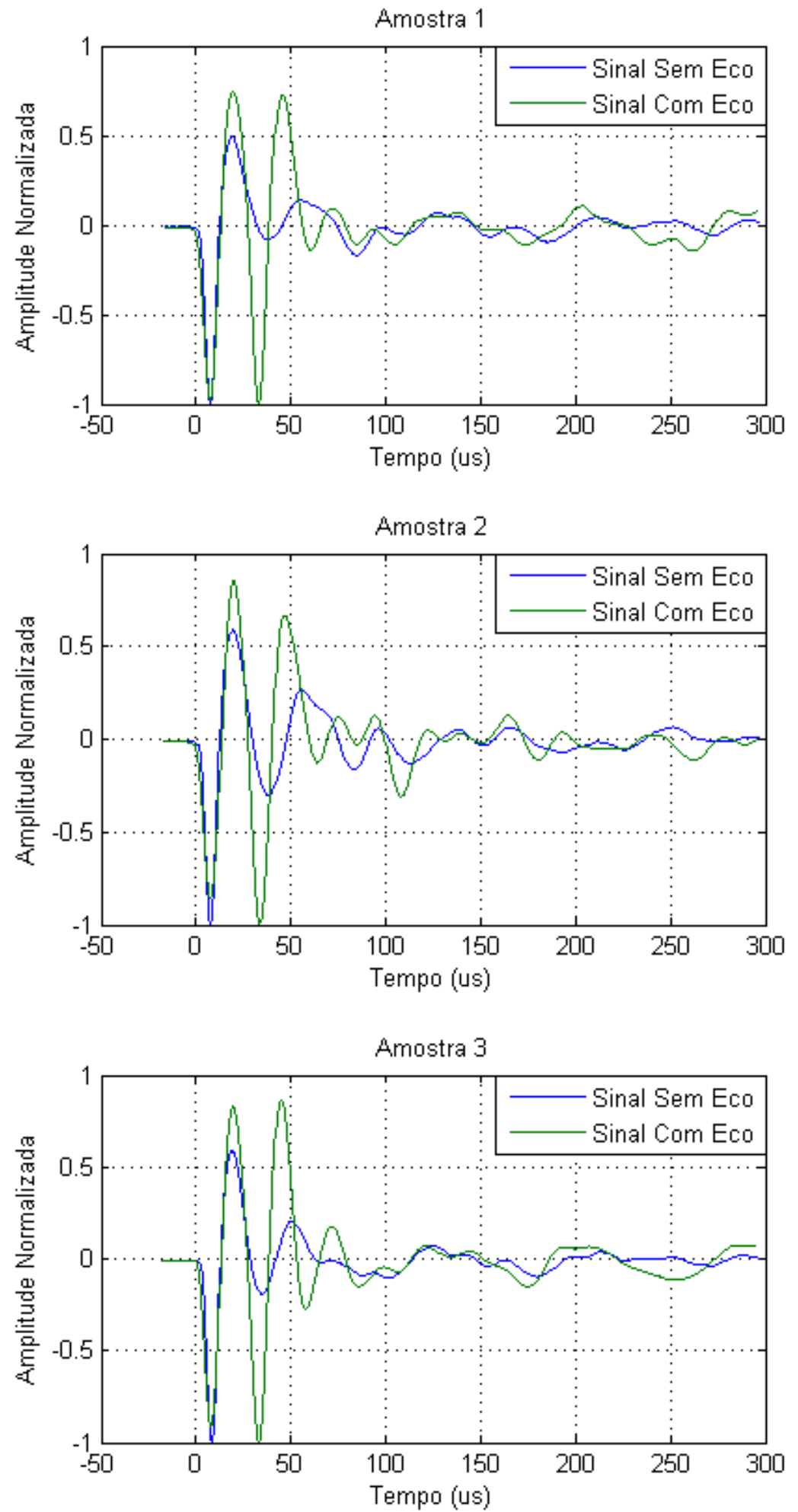

Figura 56: Resposta do sinal com e sem eco para as três amostras de piezoeletreto.

Intuitivamente constata-se que o eco começa a somar-se ao sinal original no entorno de 25 us para os gráficos da Figura 56, e 20 us para os gráficos da Figura 57. 

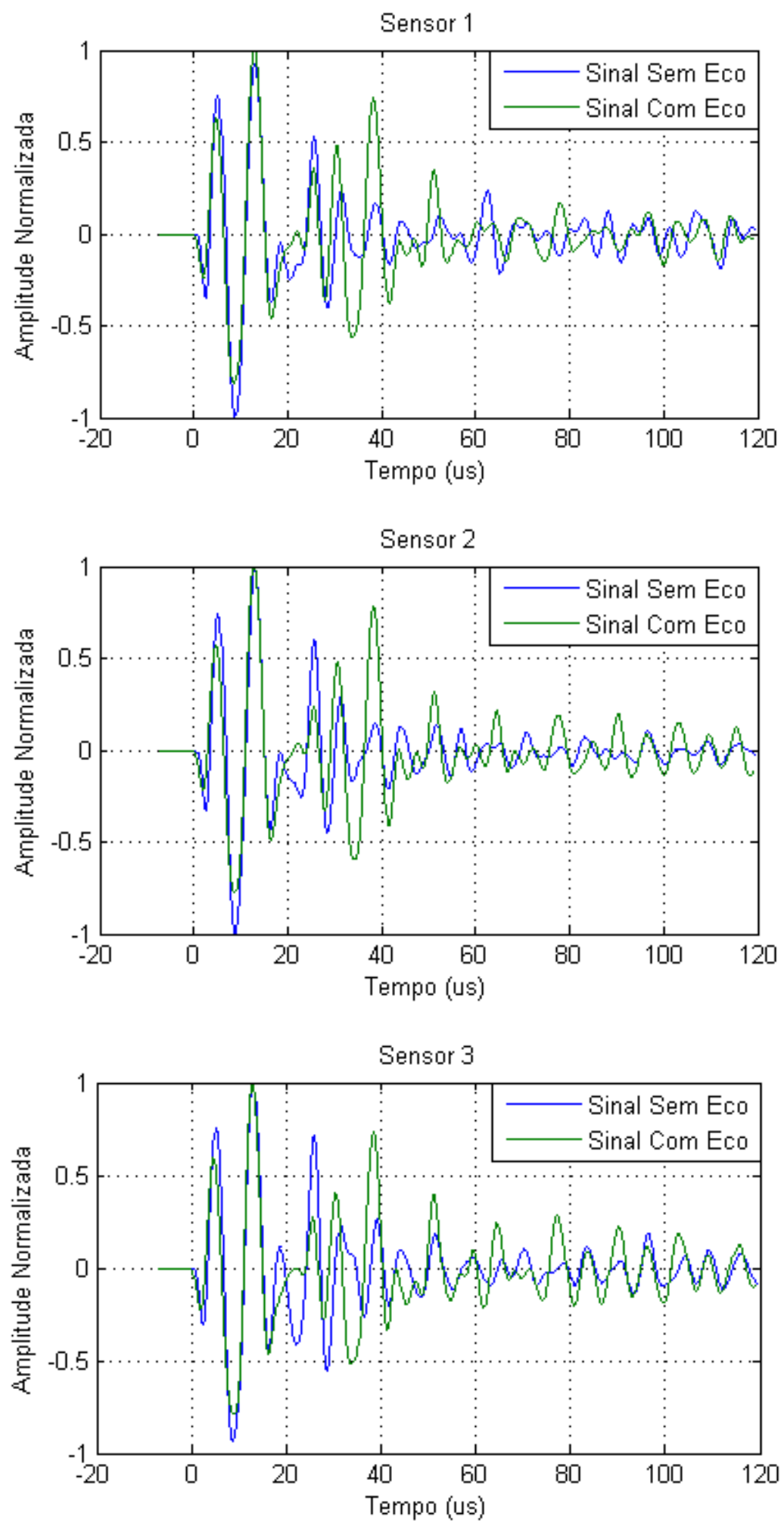

Figura 57: Resposta do sinal com e sem eco para os três sensores padrão.

Em sistemas reverberantes, um sinal pode ser representado como uma soma de certo número de sinais sobrepostos e atrasados no tempo, ou ecos, ou ainda a soma de 
alguma forma de onda básica. Os exemplos para este tipo de situação são muitos, incluindo gravação de áudio, detecção por radar e sonar, medidas sísmicas e eletrofisiológicas. Em alguns casos a reverberação é vista como uma distorção no sinal de saída e, portanto, deseja-se recuperar a forma de onda básica. Em outros, o padrão dos ecos podem ser desejados na caracterização de estruturas físicas ou processos (OPPENHEIM, 1975).

Neste caso deseja-se eliminar um eco de um sinal. Considera-se, numa situação generalizada, uma sequência $x(n)$ cujo somatório dos $M$ sinais replicados, escalonados e atrasados no tempo é dado a seguir, ou seja:

$$
\begin{gathered}
x(n)=s(n) * p(n)=\sum_{k=0}^{M-1} A_{k} s\left(n-n_{k}\right) \leftrightarrow \\
x(n)=s(n)+\sum_{k=1}^{M-1} A_{k} s\left(n-n_{k}\right)
\end{gathered}
$$

Sendo:

$x(n)=$ Sinal com eco.

$s(n)=$ Sinal original ou sem eco.

$A_{k}=$ Fator de atenuação do eco $k$ com $A_{0}=1$.

$n_{k}=$ Atraso do sinal de eco $k \operatorname{com} n_{0}=0$.

$p(n)=$ Trem de pulsos.

Note ainda que a equação (4.1.1) pode ser escrita como a convolução do sinal original com um trem de pulsos, ou seja, é possível escrever $x(n)$ como um produto de convolução. Prosseguindo, aplicando-se a transformada de Fourier na equação (4.1.2), tem-se:

$$
X(w)=S(w)+\sum_{k=1}^{M-1} A_{k} S(w) e^{-j w n_{k}}=S(w)\left(1+\sum_{k=1}^{M-1} A_{k} e^{-j w n_{k}}\right)
$$

Aplicando-se o logaritmo complexo a ambos os membros da equação (4.2), segue: 


$$
\ln [X(w)]=\ln [S(w)]+\ln \left(1+\sum_{k=1}^{M-1} A_{k} e^{-j w n_{k}}\right)
$$

Como já mencionado anteriormente, com a aplicação do operador logaritmo separou-se o sinal original de suas componentes de atenuação e atraso. Não há mais um fator multiplicativo sobre $S(w)$ como é no caso da transformada de Fourier, mas o caso agora é de soma de $\ln [S(w)]$, somente, com um conjunto de exponenciais complexas, $\ln \left(1+\sum_{k=1}^{M-1} A_{k} e^{-j w n_{k}}\right)$. Por fim, aplicando-se a transformada inversa de Fourier e lembrando que esta transformada possui a propriedade da linearidade, segue que:

$$
\tilde{x}(n)=\tilde{s}(n)+\tilde{p}(n)
$$

Sendo:

$\tilde{x}(n)=$ Cepstro complexo do sinal com eco.

$\tilde{s}(n)=$ Cepstro complexo do sinal original ou sem eco.

$\tilde{p}(n)=$ Cepstro complexo da função refletividade.

No presente caso de aplicação, utilizou-se o cálculo do cepstro somente (ou ainda "cepstro real"), o qual foi suficiente para a reconstrução do sinal sem eco, não necessitando o cálculo do cepstro complexo. Em outros termos, aplicou-se o logaritmo natural ao módulo da transformada de Fourier, isto é: $\ln |X(w)|$ em vez de $\ln [X(w)]$. Conforme mencionado no item 2.5.2.7, um sinal fase mista pode ser representado conforme a equação (2.94) a menos de uma componente de fase linear, ou seja:

$$
x(n)=x_{\min }(n) * x_{\max }(n)
$$

A partir de uma realização em fase mínima (Figura 31) neste sinal de fase mista resultou em:

$$
\begin{gathered}
\tilde{y}(n)=\tilde{x}_{p} u_{\alpha}(n)= \begin{cases}\tilde{x}_{\min }(n)+\tilde{x}_{\max }(-n), & n \geq 0 \\
0, & n<0\end{cases} \\
u_{\alpha}(n)= \begin{cases}0, & n<0 \\
1, & n=0 \\
2, & n>0\end{cases}
\end{gathered}
$$


Posteriormente, a aplicação do sistema inverso, equações (4.7.1) a (4.7.3), resultou num sinal de fase mínima cujo espectro é idêntico ao sinal de fase mista, tendo em vista que $\left|X_{\max }\left(e^{j \omega}\right)\right|=\left|X_{\max }\left(e^{-j \omega}\right)\right|$. Note que, neste caso em particular, o sistema linear $L$ é como aquele que realiza a operação de multiplicação de $u_{\alpha}(n)$ em $\tilde{x}_{p}$.

$$
\begin{gathered}
\tilde{Y}\left(e^{j \omega}\right)=\tilde{X}_{\min }\left(e^{j \omega}\right)+\tilde{X}_{\max }\left(e^{-j \omega}\right) \rightarrow \\
Y\left(e^{j \omega}\right)=X_{\min }\left(e^{j \omega}\right) X_{\max }\left(e^{-j \omega}\right) \leftrightarrow \\
\leftrightarrow y(n)=x_{\min }(n) * x_{\max }(-n)
\end{gathered}
$$

A importância deste resultado no processamento dos sinais reside na seguinte simplificação: a priori não se sabe se os sinais são de fase mínima, máxima ou mista, sendo a forma mais geral os sinais de fase mista. De fato que não importa saber que tipos de sinais são estes, pois serão processados de acordo com a realização em fase mínima de modo a garantir que estes sinais tornar-se-ão em fase mínima. Sendo uma das temáticas deste trabalho a remoção de ecos com o objetivo de se recuperar o sinal original, em termos de deconvolução homomórfica os sinais serão processados em fase mínima e reconstruídos a partir deste procedimento. Dessa forma, os sinais reconstruídos serão, portanto, comparados com os sinais originais. É importante mencionar que, com a aplicação do procedimento de realização em fase mínima, as informações sobre a fase do sinal serão perdidas, embora o espectro seja exatamente o mesmo. De modo a comparar melhor os sinais reconstruídos com os originais, estes também serão processados em fase mínima. A Figura 58 apresenta uma comparação entre os sinais originais e estes mesmos processados em fase mínima. De imediato nota-se que os sinais originais e originais em fase mínima referentes às amostras de piezoeletreto praticamente não sofreram alterações no tempo, ao passo que os sinais dos sensores sofreram alterações mais intensas. Portanto, a comparação do sinal reconstruído com o sinal original será mais "realística" se este sinal for processado em fase mínima antes da comparação. Já a Figura 59 apresenta o espectro dos sinais originais das amostras de piezoeletreto e sensores padrão.

As curvas do cepstro são apresentadas nas Figuras 60 e 61, que são referentes aos sinais com eco das Figuras 56 e 57 respectivamente. Para os sinais das amostras de piezoeletreto utilizou-se de uma janela de 2000 pontos, de modo que 1000 pontos são zeros acrescentados no início deste sinal. Este procedimento refina o cálculo da 
Transformada Discreta de Fourier, em questão de precisão, o que acarreta o melhoramento do cálculo do cepstro.
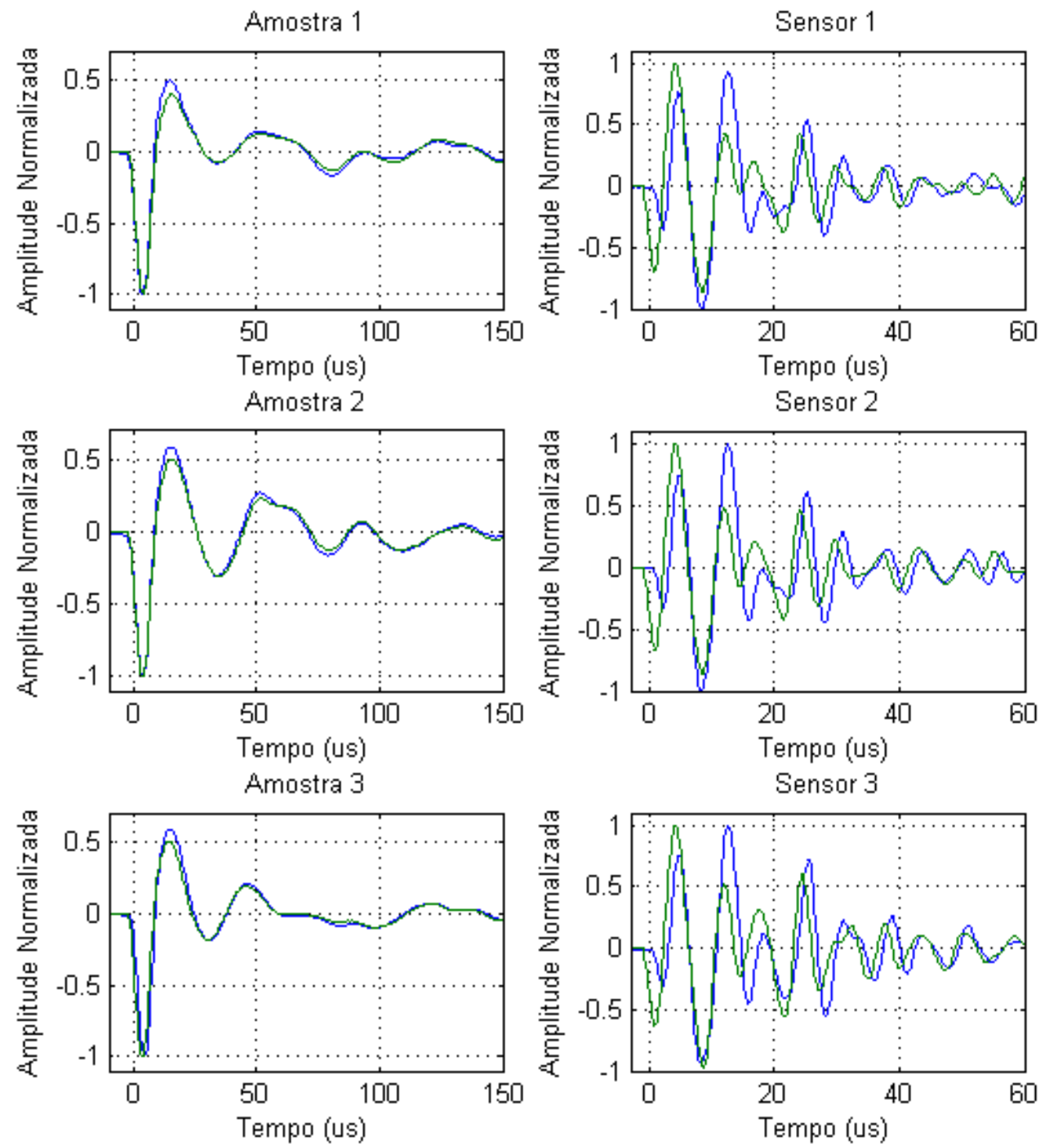

Figura 58: Comparação entre o sinal original (em azul) e o mesmo sinal original em fase mínima (em verde) para todas as amostras de piezoeletreto e sensores padrão.

Estes sinais foram, inicialmente, amostrados a uma taxa de $200 \mathrm{MSa} / \mathrm{s}$. Neste caso, cada sinal foi sub-amostrado da seguinte forma: toma-se um ponto a cada 100 pontos. Portanto, a nova taxa de amostragem passou a ser $2 \mathrm{MSa} / \mathrm{s}$, sendo mais que suficiente para representar o sinal. Para os sinais dos sensores padrão, procedeu-se da mesma forma. Neste caso, a taxa de amostragem foi $500 \mathrm{MSa} / \mathrm{s}$. Este sinal também 
foi sub-amostrado da mesma forma que o anterior, de modo que a nova taxa de amostragem passou a ser $5 \mathrm{MSa} / \mathrm{s}$, o que também é suficiente. Adianta-se que o fato de se acrescentar zeros ao sinal não prejudica a detecção do início do eco, visto que atraso no tempo é fase na frequência. Como se está trabalhando com cepstro, a fase do sinal não importa neste tipo cálculo.

Salienta-se que está apresentado apenas parte do cepstro tanto na Figura 60 quanto na Figura 61, pois a ênfase está na detecção do eco. Note que há um "tempo" em destaque em cada curva cepstral e o interesse está justamente aí: é neste "tempo" que inicia o eco (OPPENHEIM, 1975). Por exemplo, para a amostra 1 (Figura 60), o tempo é 25,5 us; para o sensor 1 (Figura 61) é o ponto 24,8 js. Para efeito de comparação, a distância do centelhador ao anteparo é de $4 \mathrm{~mm}$, portanto, o sinal de eco percorreu $8 \mathrm{~mm}$. Considerando a velocidade de propagação do som de $343,4 \mathrm{~m} / \mathrm{s}$ (a $20^{\circ} \mathrm{C}$ ), o tempo necessário para percorrer esta distância é de 23,3 $\mu$ s. Dessa forma, podem-se calcular os erros percentuais cometidos por cada amostra e sensor na detecção do início do eco. É o que apresenta a Tabela 2: o erro percentual relativo entre o tempo detectado pela curva cepstral e o tempo teórico.

Tabela 2: Erro percentual relativo na detecção do início do eco para tempo teórico de 23,3 ps.

\begin{tabular}{ccc}
\hline Amostras/Sensores & Tempo Calculado (us) & Erro (\%) \\
\hline Amostra 1 & 25,5 & 9,4 \\
\hline Amostra 2 & 25,6 & 9,4 \\
\hline Amostra 3 & 26,0 & 11,6 \\
Sensor 1 & 24,8 & 6,4 \\
\hline Sensor 2 & 25,4 & 9,0 \\
Sensor 3 & 25,0 & 7,3 \\
\hline
\end{tabular}

Constata-se que os erros percentuais são relativamente pequenos e ainda: os erros apresentados pelas amostras estão na mesma ordem de grandeza dos erros apresentados pelos sensores. Ademais: em termos de distância, um erro percentual relativo no tempo de $11,6 \%$ implica em $0,9 \mathrm{~mm}$ aproximadamente para um percurso de $8 \mathrm{~mm}$. Outra observação importante, comparando-se as curvas cepstrais, é o fato que as curvas das amostras detectaram melhor o início do eco em comparação às curvas cepstrais dos sensores. Num primeiro momento, talvez a motivação disto resida na maior "simplicidade" da forma de onda acústica de descarga captada pelas 
amostras de piezoeletreto em comparação à forma de onda captada pelos sensores. Outro dado interessante é a comparação entre o espectro do pulso captado pelas amostras de piezoeletreto com o espectro do pulso captado pelos sensores padrão, conforme apresentou a Figura 59: pode-se deduzir que o espectro apresentado pelas amostras seja mais suave do que os espectros apresentados pelos sensores. Lembra-se que o espectro é o mesmo, não importando se o sinal é o original ou o original em fase mínima. Sendo assim, pela propriedade P6 pode-se afirmar que o cepstro do pulso das amostras de piezoeletreto ficará mais concentrado ao redor de baixos valores de tempo em comparação ao cepstro dos sensores padrão. Dessa forma, o pico de detecção do eco ficará mais evidente no caso das amostras em relação aos sensores.
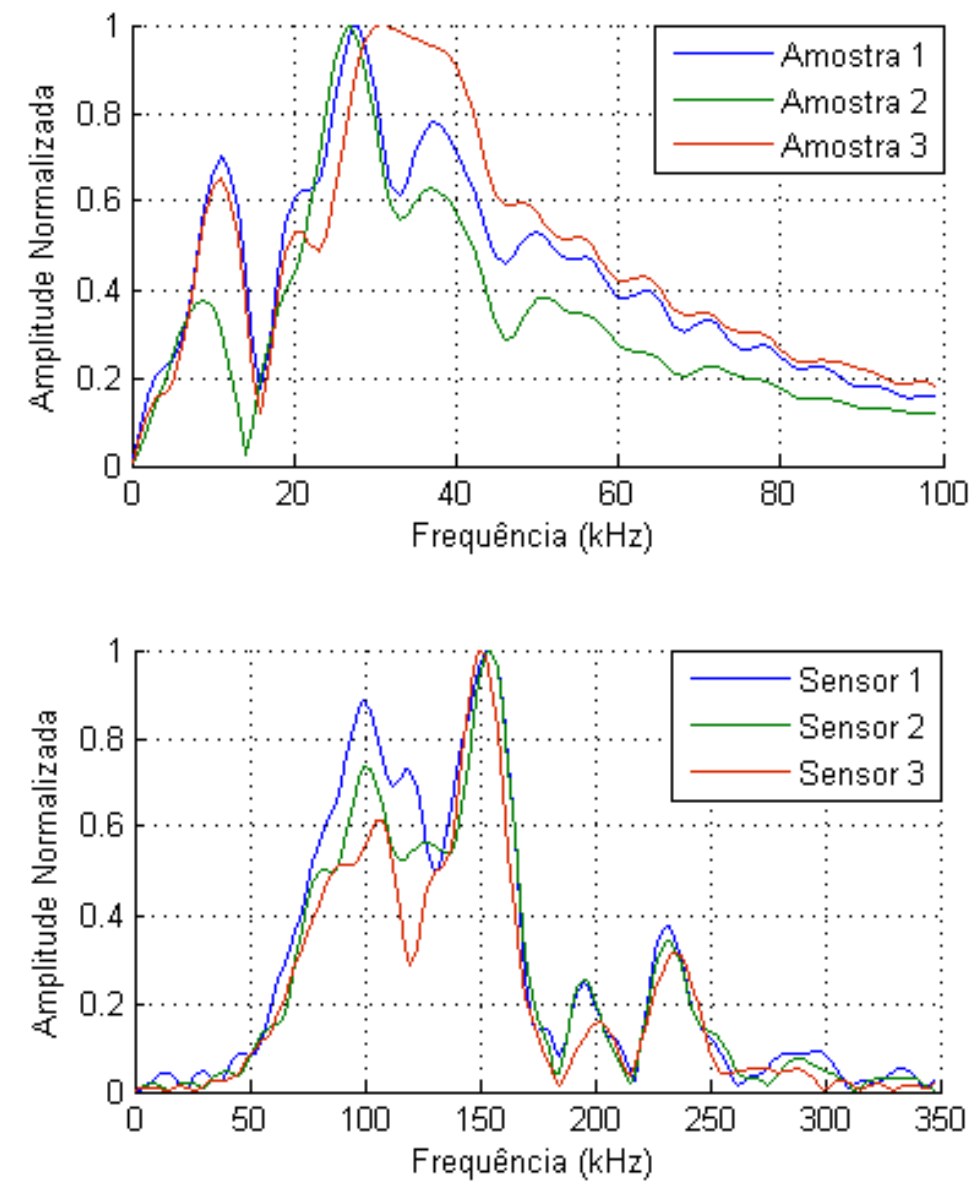

Figura 59: Espectro do sinal original em fase mínima para todas as amostras de piezoeletreto e sensores padrão. 
Por outro lado, sabe-se que o cepstro contém todas as contribuições somadas do sinal original e os ecos. Como o sinal tende a se concentrar ao redor de baixos valores de tempo, uma boa solução é aplicar um "filtro passa-baixas ideal" nas curvas obtidas (TRIBOLET, 1979). Definindo como corte em "23,5 us" para os cepstros da Figura 60, "24 us" para os cepstros da Figura 61 e reconstruindo o sinal com janelamento em fase mínima, obtiveram-se os gráficos das Figuras 62 e 63 . É importante frisar que o processamento realizado nos sinais com eco é em fase mínima com a janela de corte menor em relação à que é aplicada num sinal qualquer para obtê-lo somente em fase mínima, conservando o espectro. De modo a evitar um passo a mais no processamento, ou seja, processar o sinal em fase mínima e tornar a calcular o cepstro para remover o eco, este procedimento é equivalente a calcular o cepstro uma única vez, aplicar o filtro passa-baixas mencionado acima e reconstruir o sinal em fase mínima. De outra forma: reconstrói-se o sinal original com janelamento em fase mínima a partir do sinal com eco.

Com o objetivo de se mensurar a similaridade entre as formas de ondas obtidas, foi utilizada a bem conhecida distância Euclidiana e a distância de Chebychev, a qual possui a propriedade de ser sensível a distâncias métricas maiores. A ideia é avaliar quais dos sinais reconstruídos mais se parecem com os sinais originais. Como se sabe, tanto uma distância quanto outra é implementada de acordo com a seguinte equação:

$$
d=\sqrt[p]{\sum_{k=1}^{N}\left[x_{o}(k)-x_{r}(k)\right]^{p}}
$$

Onde $x_{o}(k)$ representa o ponto $k$ do sinal original e $x_{r}(k)$, o ponto $k$ do sinal reconstruído. Se $p=2$, tem-se a distância Euclidiana; se $p \rightarrow \infty$, tem-se a distância de Chebyshev. A Tabela 3 apresenta as distâncias entre o sinal original em fase mínima (modelo) e o reconstruído (teste) para cada amostra/sensor. Para o cálculo de todas as distâncias, tomou-se a janela que vai de zero a 200 ps, num total de 400 pontos, de cada sinal apresentado na Figura 62; no caso dos sinais da Figura 63, a janela foi de zero a $80 \mu \mathrm{s}$, correspondendo também a 400 pontos. Embora não sendo a janela toda, a janela tomada corresponde a mais de $98 \%$ da energia do sinal original. Portanto, a janela adotada é mais que suficiente para representar cada um dos sinais originais, além de equalizar o número de pontos de todos os sinais para análise. 

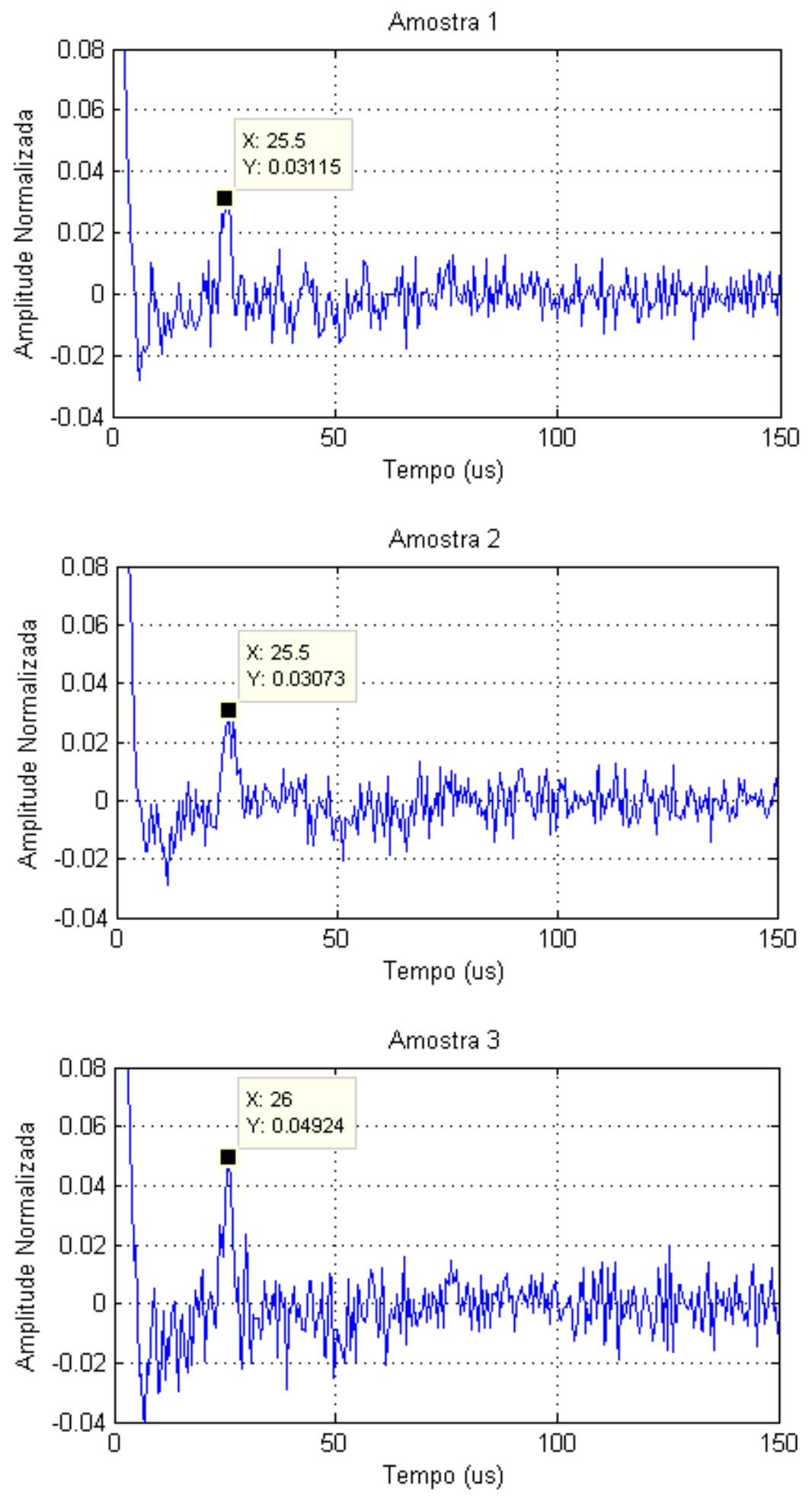

Figura 60: Curvas cepstrais do sinal com eco das amostras de piezoeletreto. 

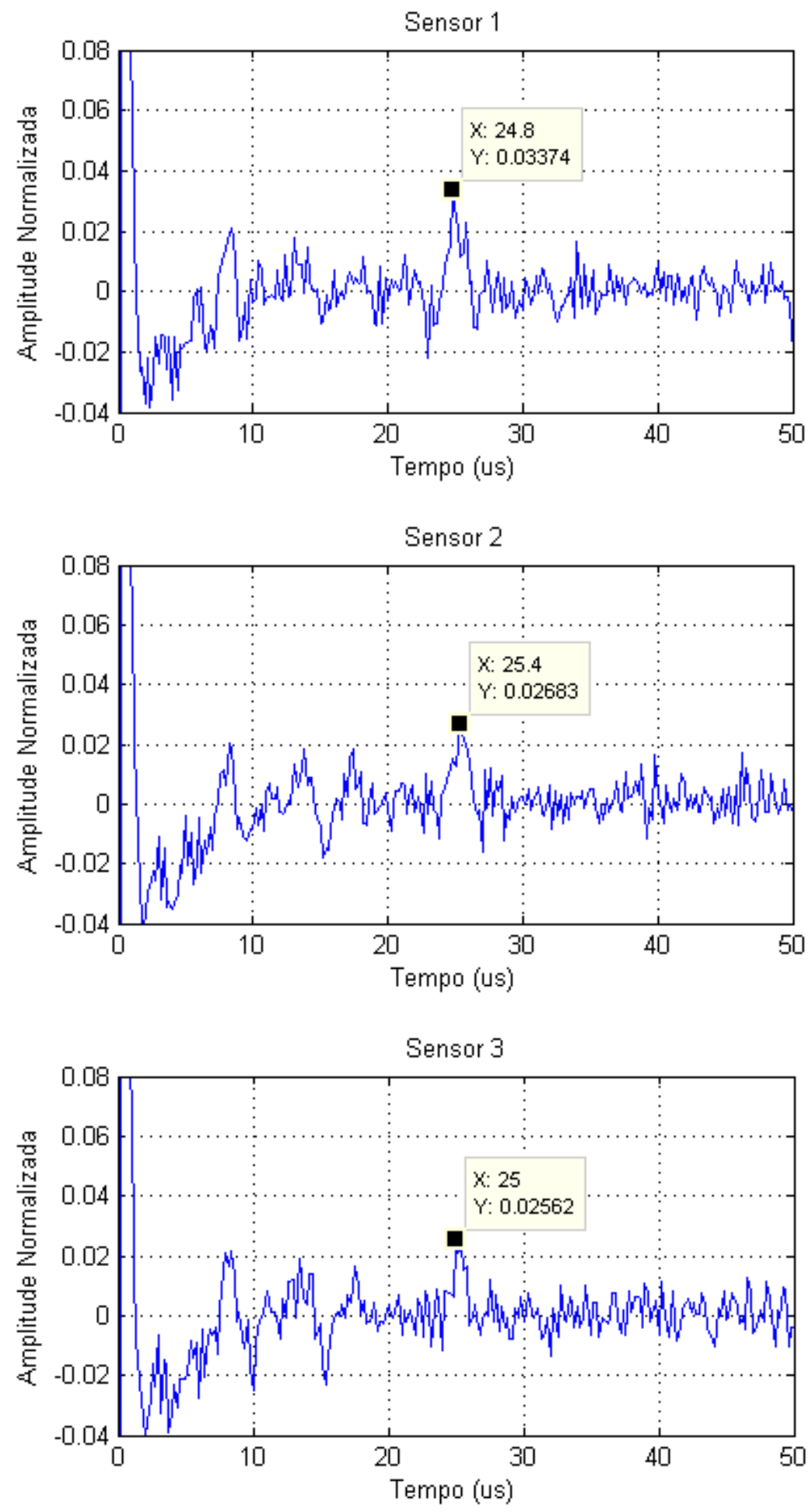

Figura 61: Curvas cepstrais do sinal com eco dos sensores padrão. 

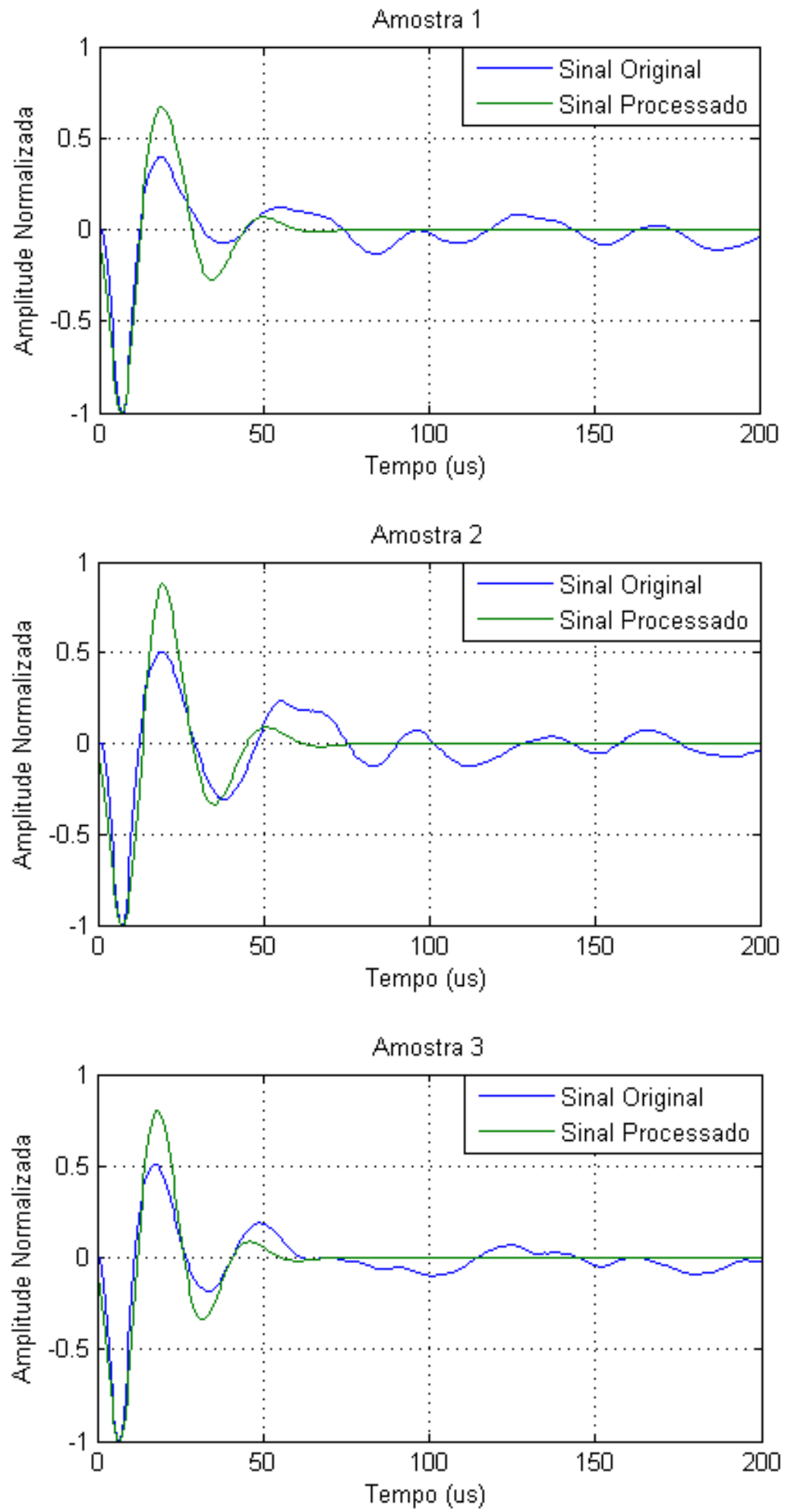

Figura 62: Sinal original (em fase mínima) e sinal reconstruído para cada amostra de piezoeletreto. 

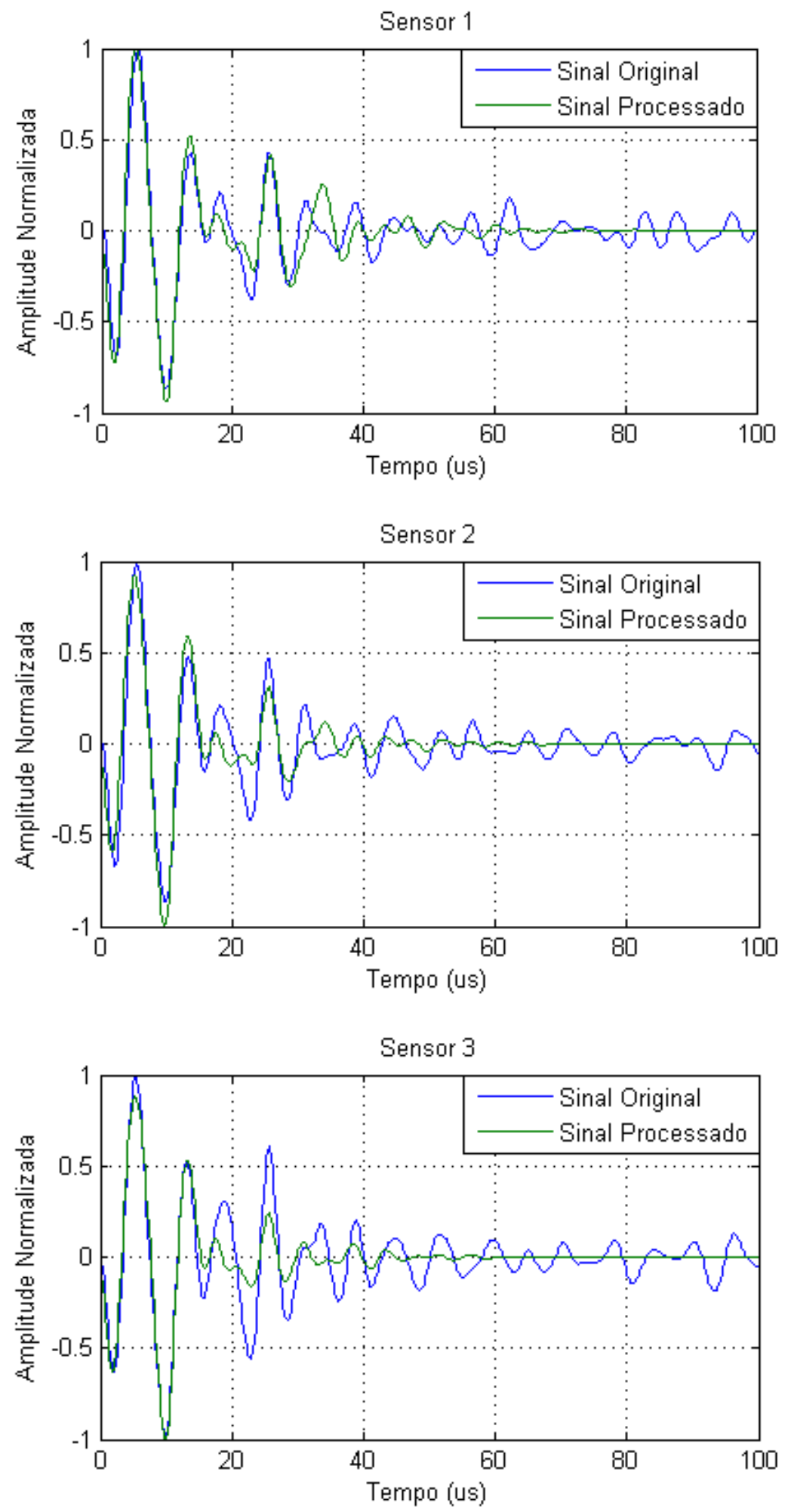

Figura 63: Sinal original (em fase mínima) e sinal reconstruído para cada sensor padrão. 
Tabela 3: Distância entre o sinal original (em fase mínima) e reconstruído pela distância Euclidiana e de Chebyshev.

\begin{tabular}{ccc}
\hline Amostras/Sensores & Distância Euclidiana & Distância de Chebychev \\
\hline Amostra 1 & 1,93 & 0,274 \\
Amostra 2 & 2,28 & 0,376 \\
Amostra 3 & 1,76 & 0,314 \\
Sensor 1 & 1,95 & 0,258 \\
Sensor 2 & 2,21 & 0,318 \\
Sensor 3 & 2,52 & 0,400 \\
\hline
\end{tabular}

Analisando-se a Tabela 3 verifica-se uma boa proximidade entre os valores das distâncias, Euclidiana ou de Chebychev, calculadas para as amostras e sensores. De modo geral pode-se dizer que são equivalentes. A primeira vista, parece que a reconstrução dos sinais dos sensores padrão foi mais bem sucedida em relação às amostras; todavia é possível inferir que, a partir do calculo das distâncias, em ambos os casos a reconstrução foram satisfatórios. Talvez o bom resultado apresentado pela reconstrução dos sinais das amostras se deve a um fato já mencionado: a maior "simplicidade" do pulso acústico de descarga captado pelas amostras em comparação ao pulso captado pelos sensores. A motivação de se comparar a distância Euclidiana e de Chebyshev é a de verificar a forma que cada técnica calcula a similaridade entre formas de onda. Comparando as distâncias valor a valor para as amostras, seria de esperar que para a amostra 3 a distância de Chebychev fosse menor que 0,274, o que não é. Isto é explicado pela equação (4.8): a distância Euclidiana calcula a similaridade de forma mais distribuída, privilegiando um pouco mais distâncias métricas maiores em relação a menores, ao passo que a distância de Chebychev privilegia, na verdade, a maior diferença entre os sinais comparados. Portanto, a informação a ser extraída é a seguinte: a melhor reconstrução entre as amostras de piezoeletreto é para a amostra 3, haja vista que a distância Euclidiana é uma medida de energia: quanto menor, maior a similaridade. Mesmo assim, os sinais comparados não possuem a menor diferença máxima (distância de Chebychev) entre si, ou seja, entre o sinal original (fase mínima) e o reconstruído. Uma observação: daqui por diante, quando se mencionar sinal original ou sem eco, será sempre este sinal em fase mínima. 


\subsubsection{Descarga em Caixas de Alumínio}

Utilizando-se eletrodos ponta iguais aos apresentados na Figura 52, com mesmo gap de $2 \mathrm{~mm}$, o ensaio foi repetido dentro de caixas de alumínio. Num primeiro momento a descarga ocorreu em ar, e não em óleo, como havia sido nos primeiros ensaios apresentados na Figura 50. Especificamente, a caixa apresentada na Figura 64(A), caixa 1 daqui por diante, é uma caixa nova e possui dimensões de 200x200x100 mm. Com estas dimensões, o centelhador precisou ser posto na diagonal. Já a caixa 2, Figura 64(B), também é nova e tem dimensões de 300x300x100 mm. Neste caso, pode-se variar a posição do centelhador dentro da caixa e o local onde o microfone era posicionado externamente. É importante mencionar que cada caixa possui seu centelhador e um cabo de alta tensão. Este cabo é vermelho e aparece em ambas as fotografias das caixas 1 e 2 .

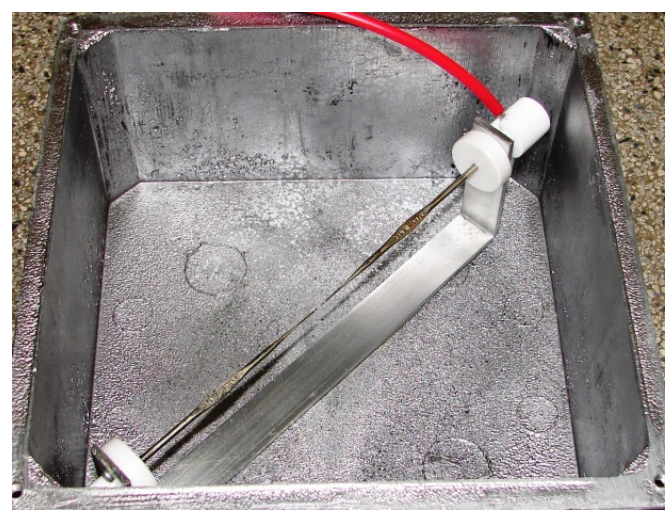

(A)

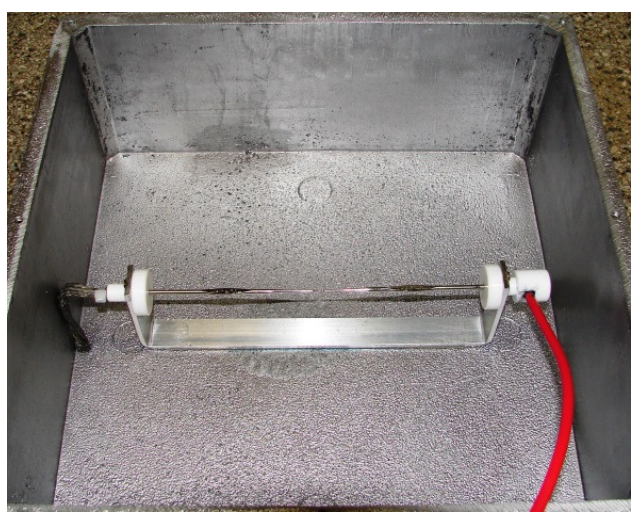

(B)

Figura 64 (A): Fotografia da caixa 1 com centelhador e cabo de alta tensão (vermelho). (B): Fotografia da caixa 2 com centelhador e cabo de alta tensão (vermelho).

\subsubsection{Análise para a caixa 1: descarga em ar}

Mencionou-se que a localização do centelhador foi possível somente na diagonal da caixa, tendo em vista a preservação das dimensões deste, conforme apresentou a Figura 64(A). Verificou-se que o posicionamento do microfone/sensor, nas quatro faces laterais, é simétrico um em relação ao outro. Portanto, escolheu-se uma única face e posicionou-se o microfone/sensor no centro desta face. Dessa forma, a posição de medida de ambos na face lateral da caixa foi sempre a mesma para todos os experimentos. 
Para cada amostra de piezoeletreto e sensor padrão realizaram-se 25 medidas tomando-se o valor médio destas medidas. Filtrou-se cada resposta temporal média com um filtro FIR aplicado, neste filtro, janelamento de Kaiser. Para as respostas das amostras de piezoeletreto, o filtro possuía frequência da banda passante de $55 \mathrm{kHz}$ e frequência de corte de $60 \mathrm{kHz}$. Neste caso o filtro teve suporte de 505 elementos. Estes sinais acústicos de descarga foram amostrados a uma taxa de $2 \mathrm{MSa} / \mathrm{s}$ e, portanto, a máxima frequência de Nyquist é de $1 \mathrm{MHz}$. Já para as respostas dos sensores padrão, o filtro tinha frequência de banda passante de $1 \mathrm{MHz}$ e corte em 1,1 $\mathrm{MHz}$, de modo que este filtro teve suporte de 127 elementos. Neste caso a taxa de amostragem era $10 \mathrm{MSa} / \mathrm{s}$ e, da mesma forma, a máxima frequência de Nyquist era de $5 \mathrm{MHz}$. As repostas em frequência de cada filtro são apresentadas nas Figuras 65 e 66.
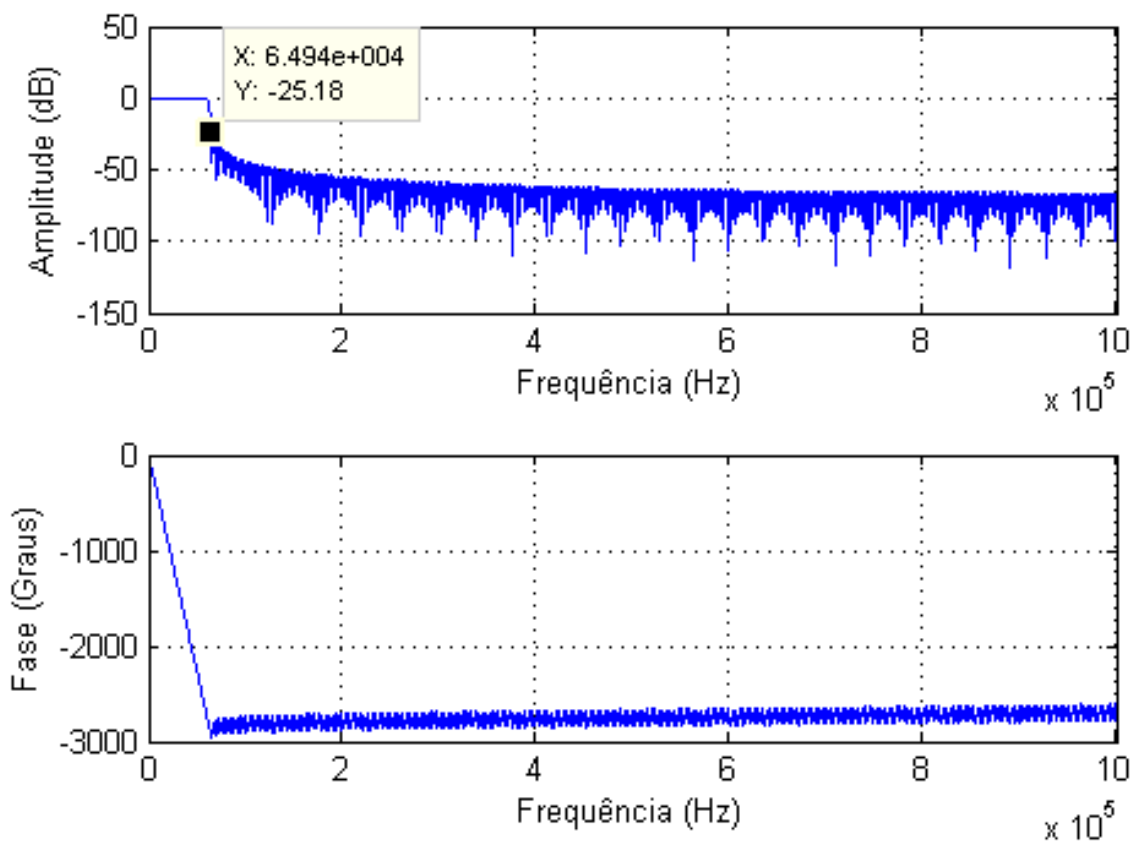

Figura 65: Resposta em frequência do filtro utilizado para filtrar os sinais das amostras de piezoeletreto.

A Figura 67 apresenta a resposta temporal média, filtrada e não filtrada, para cada amostra de piezoeletreto; a Figura 68 apresenta o mesmo para cada sensor padrão. Numa primeira observação é difícil perceber a forma de onda original do sinal, isto é, do sinal que não possui ecos e reverberações, apresentados nas Figuras 53 e 54. É importante frisar que o sinal inicia no instante zero, ou seja, no momento que 
ocorre a descarga. Mesmo procurando blindar todo o sistema, um pouco de ruído eletromagnético ainda assim escapa. Este ruído é bastante perceptível nos gráficos referentes às respostas médias, ou seja, os gráficos em azul das Figuras 67 e 68. Não é de se preocupar com este ruído, visto que é um evento muito rápido e foi praticamente eliminado na filtragem.
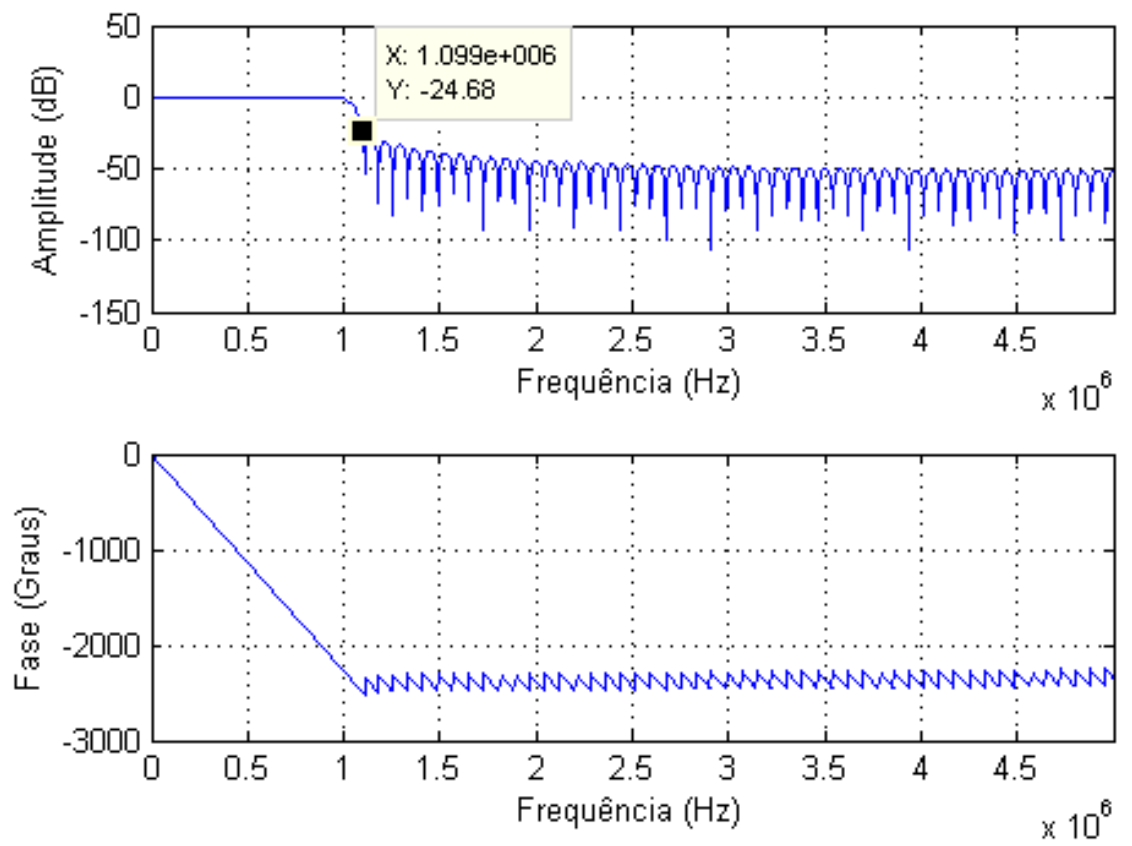

Figura 66: Resposta em frequência do filtro utilizado para filtrar os sinais dos sensores padrão.

Com relação ao processamento, constatou-se uma particularidade interessante em relação aos sinais das amostras de piezoeletreto. Durante a reconstrução do sinal original, ou sem eco, esta reconstrução era mais bem sucedida em janelas "temporalmente próximas" do instante da descarga, ou seja, próxima do instante zero. Para mostrar este fato, tomaram-se quatro janelas distintas dos sinais filtrados, começando do instante zero, com duração de $5 \mathrm{~ms}$ cada. Sendo assim, a janela J1 refere-se ao período de zero a $5 \mathrm{~ms}$; a janela $\mathrm{J} 2$, de $5 \mathrm{~ms}$ a $10 \mathrm{~ms}$ e assim por diante até a janela J4, que vai de $15 \mathrm{~ms}$ a $20 \mathrm{~ms}$. Cada janela tinha suporte de 10000 pontos e, neste caso, não se realizou nenhuma sub-amostragem objetivando não prejudicar a reconstrução do sinal, diferentemente do caso anterior (eco na câmara anecóica), cuja taxa de amostragem era muito superior. Um detalhe interessante é que o tempo total envolvido, de zero a $20 \mathrm{~ms}$, é suficiente para análise do sinal como um todo, pois aproximadamente $80 \%$ da energia total do sinal está neste intervalo de tempo. 
Similarmente para os sinais dos sensores padrão, cada janela de análise teve duração de $1 \mathrm{~ms}$ num total de quatro janelas também, partindo do instante zero. Em termos de energia para o tempo total de análise, $4 \mathrm{~ms}$, esta energia representa mais de $95 \%$ da energia do sinal como um todo.
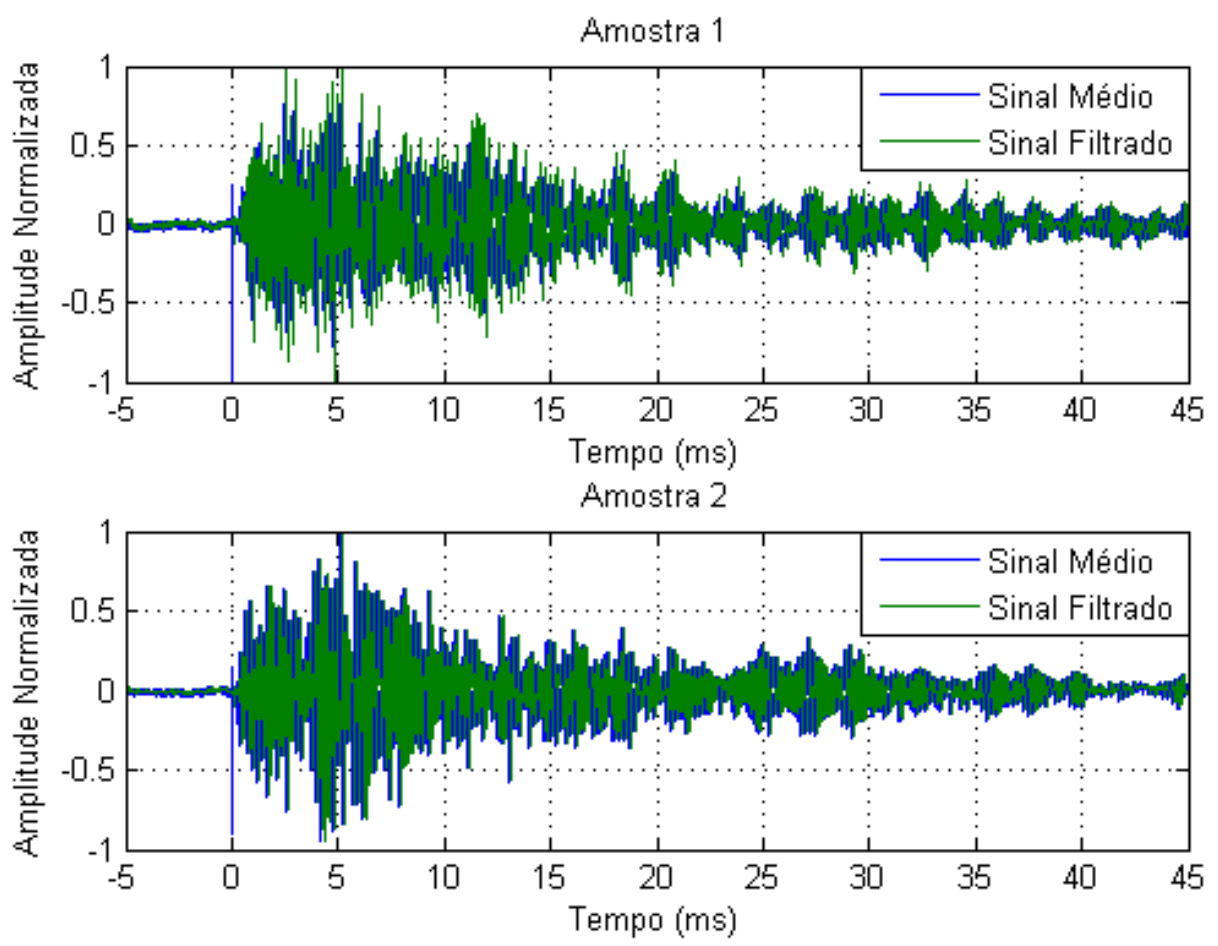

Amostra 3

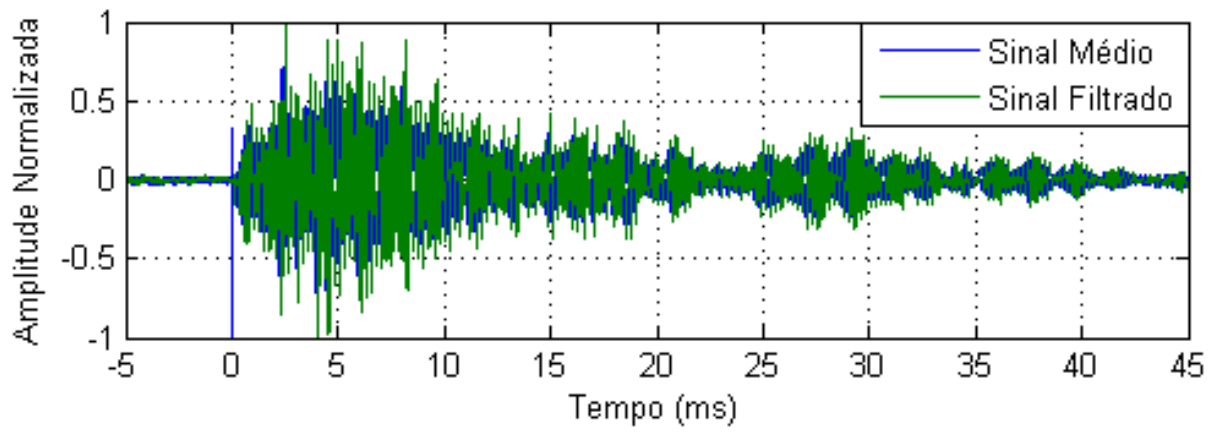

Figura 67: Resposta temporal média filtrada e não filtrada para cada amostra de piezoeletreto. Descarga em ar, caixa 1.

As Figuras 69 e 70 apresentam as curvas cepstrais referentes às quatro janelas dos sinais das amostras e sensores, respectivamente. Já as Figuras 71 e 72 apresentam os sinais reconstruídos para as quatro janelas referentes aos sinais das amostras e 
sensores, respectivamente. Nesta situação, tomaram-se 70 pontos (corte realizado no "tempo" de 34,5 us) das curvas cepstrais (Figura 69) para reconstrução dos sinais das amostras apresentados na Figura 71, e 90 pontos (corte em 8,9 us) das curvas cepstrais (Figura 70) para reconstrução dos sinais dos sensores apresentados na Figura 72.
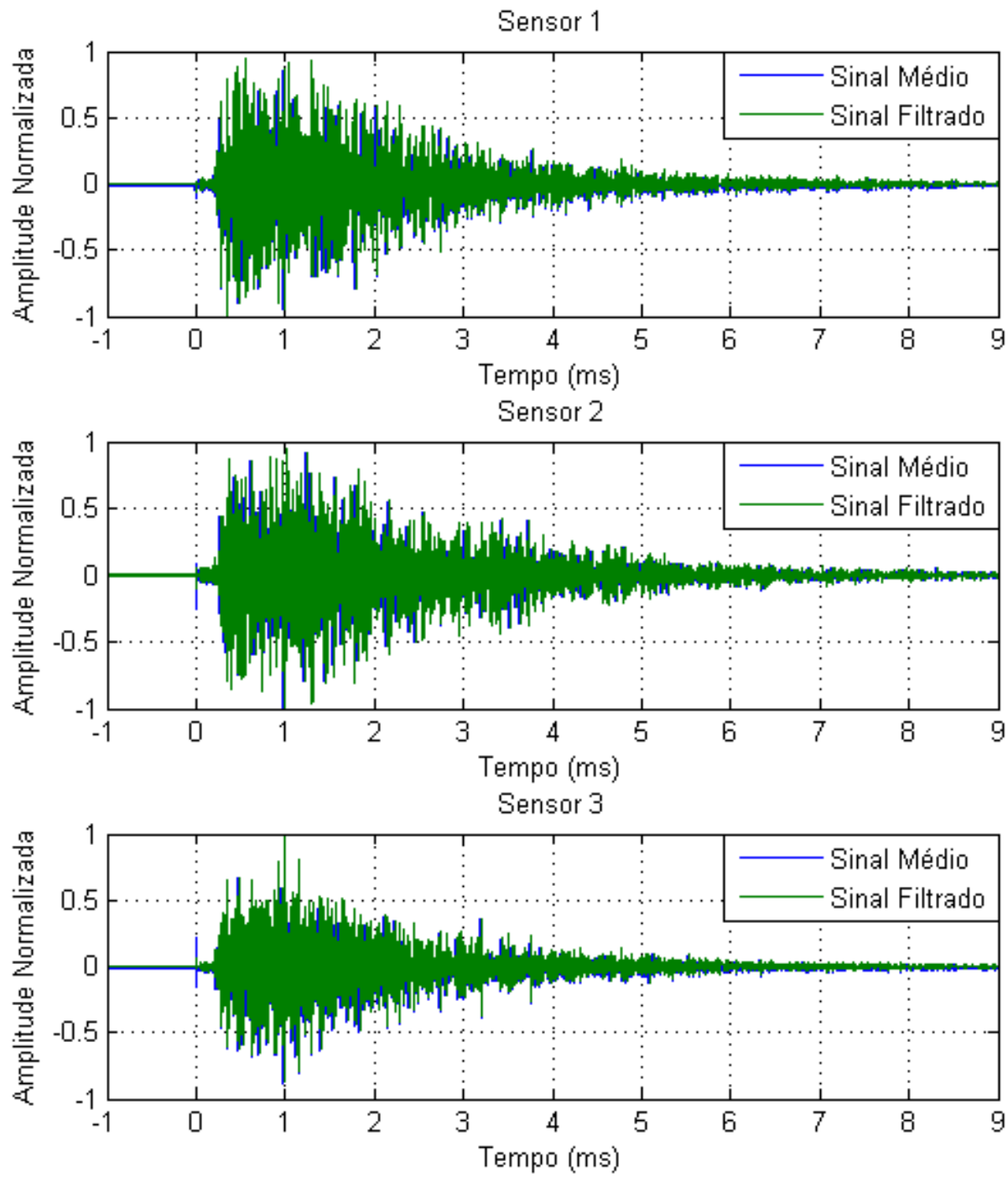

Figura 68: Resposta temporal média filtrada e não filtrada para cada sensor padrão. Descarga em ar, caixa 1.

De modo geral as curvas cepstrais são bastante similares entre si. Em comparação com as curvas obtidas na Figura 60 ou 61, essas curvas possuem uma 
forma bastante suave devido, provavelmente, à filtragem realizada no sinal. Não é evidente algum pico de eco sendo que, na realidade, existem muitos ecos e reverberações. Todavia os picos que sinalizam os ecos estão afastados da origem, de modo que dificilmente serão percebidos devido ao decaimento $1 / n$ característico da curva cepstral (propriedade P1). Como o interesse baseia-se na detecção acústica de descarga, daqui por diante apresentaremos somente os sinais reconstruídos. A motivação é que o novo meio (caixas) imprime muitos ecos e reverberações no sinal, de modo que a recuperação do sinal original é mais salutar por representar, a priori, a assinatura de uma descarga.

No que diz respeito aos sinais reconstruídos, Figuras 71 e 72 , evidente que a reconstrução é mais bem sucedida para janelas próximas do instante zero quando se trata dos sinais das amostras. No caso dos sinais dos sensores padrão, a diferença não é tão evidente quando se alteram as janelas como foi no caso anterior. Ocorre que no início do sinal está presente tanto sinais de baixa frequência quanto de alta frequência. Uma indicação deste fato é a quantidade de cruzamentos por zero que ocorrem em cada janela. A Tabela 4 apresenta os cruzamentos por zero para cada amostra de piezoeletreto por janela (J1 a J4); já a Tabela 5 apresenta o mesmo para os sensores padrão.

É evidente a queda do número de cruzamentos por zero comparando-se as primeiras janelas com as últimas. Para confirmar o fato de que o sinal possui um espectro de frequência mais rico próximo ao instante zero (ocorrência da descarga), a Figura 73 apresenta os espectros de frequências por amostra, por janela. Já a Figura 74 apresenta o mesmo para os sensores padrão. Neste caso cada janela foi normalizada em energia para o cálculo do espectro, o qual é apresentado em dB. Este procedimento de normalização é realizado conforme a equação (4.9.2), ou seja, o sinal de energia normalizada, $x_{N}(n)$, será o sinal $x(n)$, de energia $A$ e suporte $M$, dividido pela raiz quadrada da energia deste mesmo sinal. As equações apresentadas em (4.9.1) mostram o desenvolvimento para se chegar à equação (4.9.2).

$$
\begin{gathered}
E[x(n)]=\sum_{k=0}^{M-1} x(k)^{2}=A \rightarrow E\left[x_{N}(n)\right]=\frac{1}{A} \sum_{k=0}^{M-1} x(k)^{2}=\sum_{k=0}^{M-1}\left(\frac{x(k)}{\sqrt{A}}\right)^{2}=1 \therefore \\
x_{N}(n)=\frac{x(n)}{\sqrt{A}}
\end{gathered}
$$



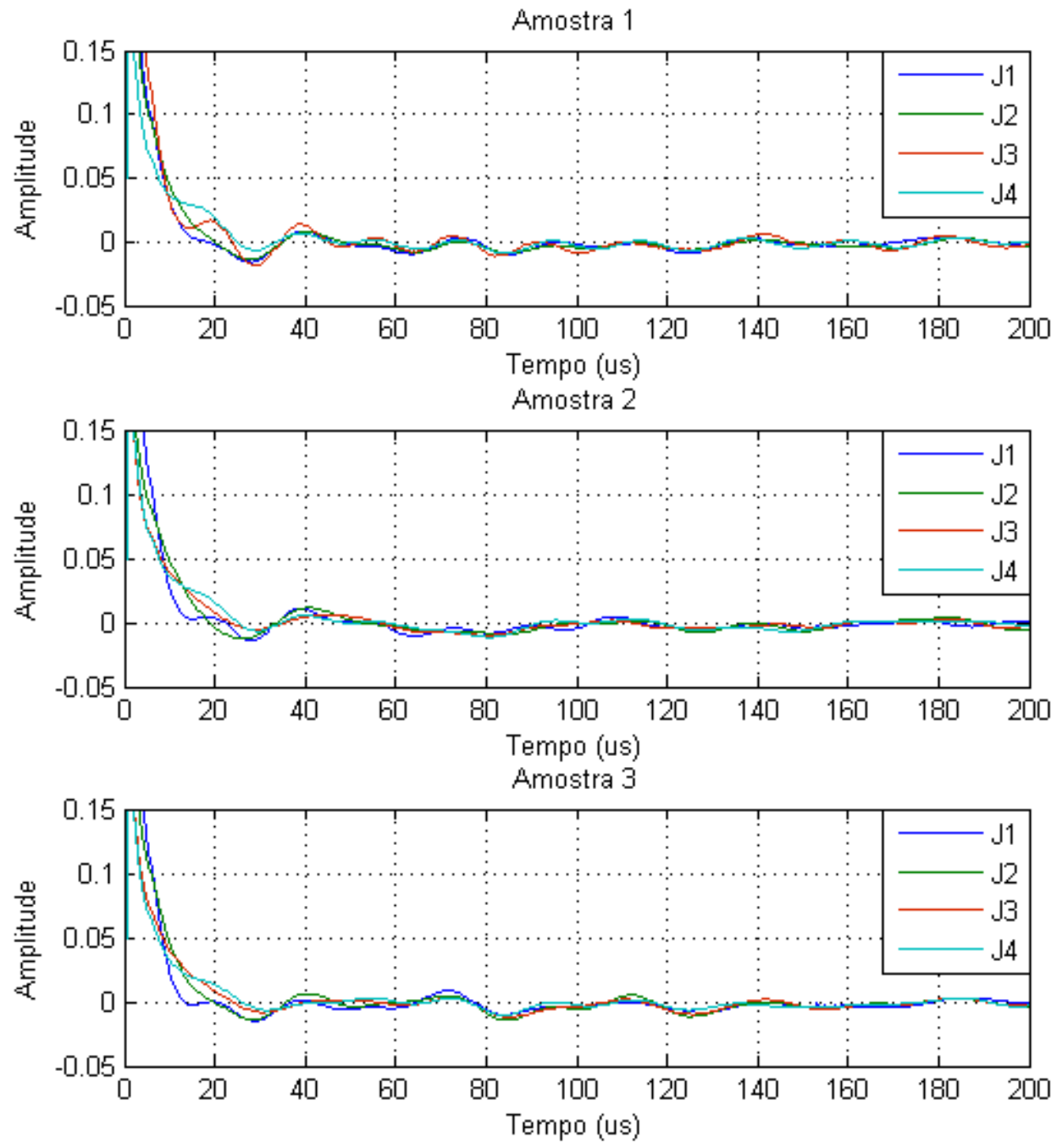

Figura 69: Cepstro para quatro janelas distintas referentes às respostas das amostras de piezoeletreto. Descarga em ar, caixa 1.

Tabela 4: Quantidade de cruzamentos por zero, por amostra de piezoeletreto, por janela. Descarga em ar, caixa 1.

\begin{tabular}{ccccc}
\hline Amostras & $\mathbf{0 - 5} \mathbf{~ m s}$ & $\mathbf{5 - 1 0} \mathbf{~ m s}$ & $\mathbf{1 0 - 1 5} \mathbf{~ m s}$ & $\mathbf{1 5 - 2 0} \mathbf{~ m s}$ \\
\hline Amostra 1 & 121 & 75 & 49 & 51 \\
Amostra 2 & 124 & 65 & 69 & 50 \\
Amostra 3 & 125 & 67 & 71 & 44 \\
\hline
\end{tabular}



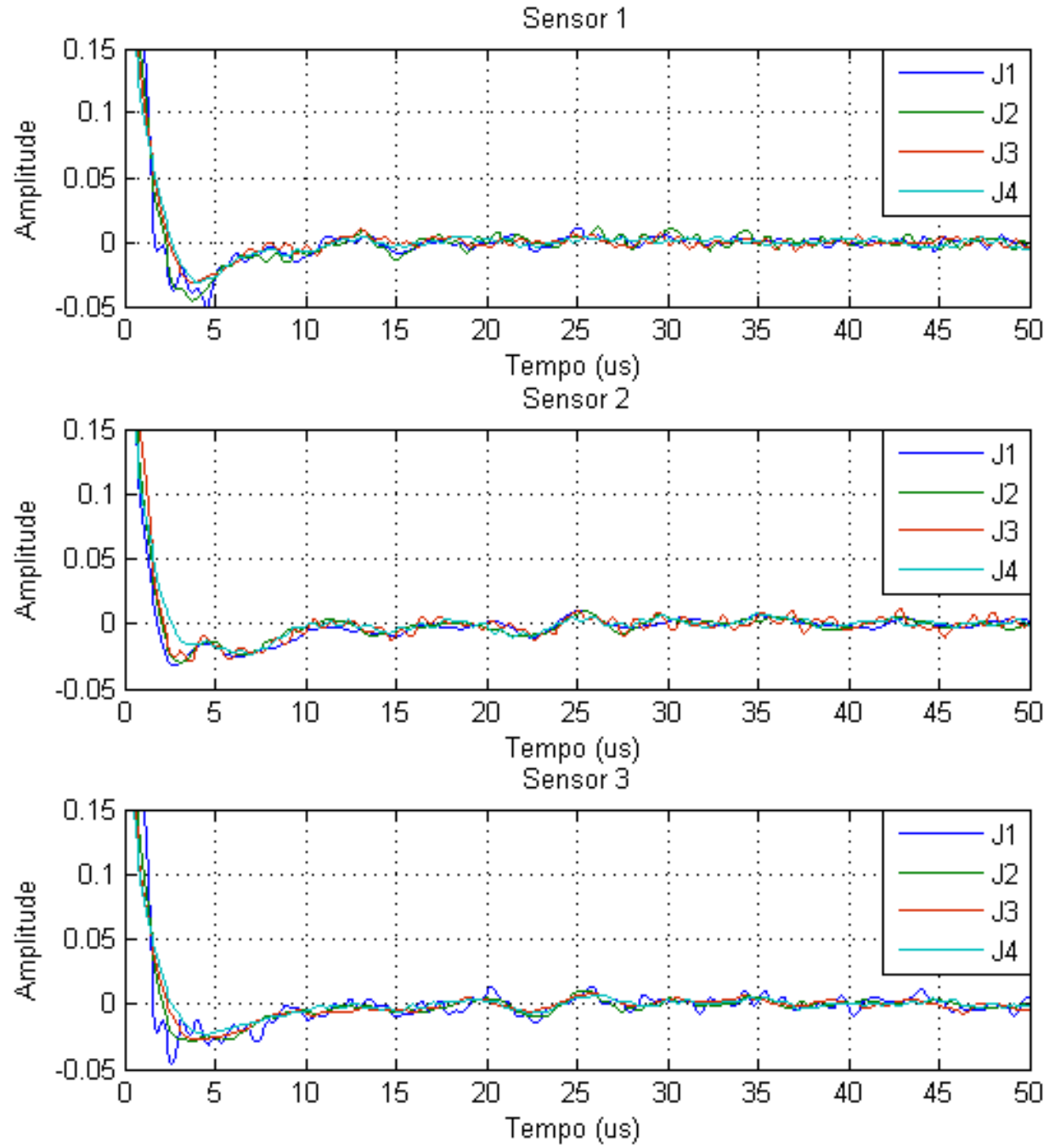

Figura 70: Cepstro para quatro janelas distintas referentes às respostas dos sensores padrão. Descarga em ar, caixa 1.

Tabela 5: Quantidade de cruzamentos por zero, por sensor padrão, por janela. Descarga em ar, caixa 1.

\begin{tabular}{lcccc}
\hline Sensores & $\mathbf{0 - 1} \mathbf{~ m s}$ & $\mathbf{1 - 2} \mathbf{~ m s}$ & $\mathbf{2 - 3} \mathbf{~ m s}$ & $\mathbf{3 - 4} \mathbf{~ m s}$ \\
\hline Sensor $\mathbf{1}$ & 208 & 183 & 171 & 178 \\
Sensor 2 & 241 & 184 & 164 & 148 \\
Sensor 3 & 209 & 187 & 175 & 155 \\
\hline
\end{tabular}



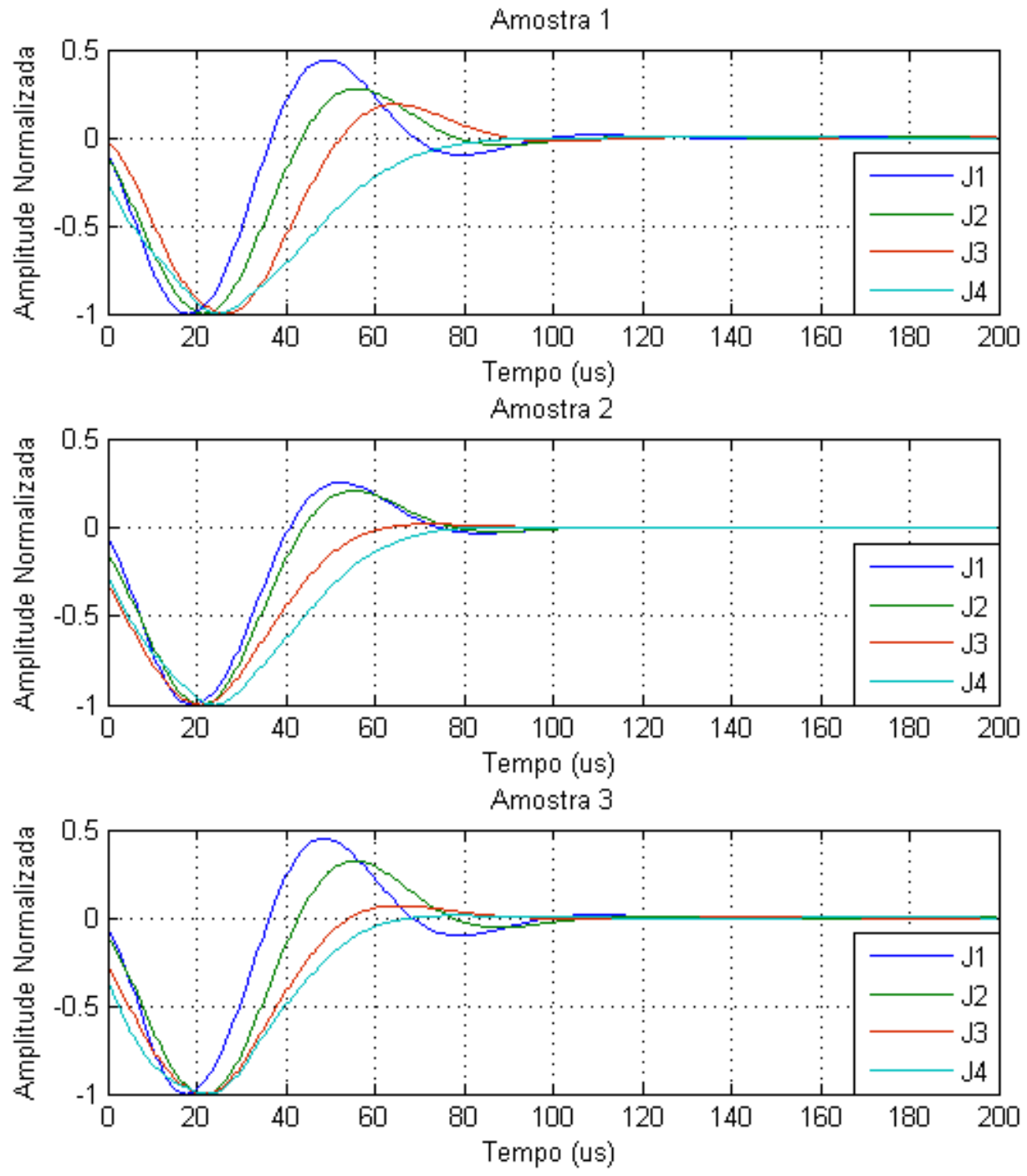

Figura 71: Reconstrução do sinal original para as três amostras de piezoeletreto analisando-se quatro janelas distintas do sinal. Descarga em ar, caixa 1.

É perceptível, principalmente no caso da Figura 73, que a curva referente à janela J1 (em azul) está acima das outras curvas para frequências mais altas, ou seja, possui maior relevância em termos de riqueza de espectro. Isto é suficiente para definirmos que todas as análises, doravante, serão realizadas tomando-se como base a primeira janela subsequente à ocorrência da descarga. Em termos de monitoramento on-line isto é interessante, pois a ideia é tomar janelas consecutivas é analisa-las constantemente. Na ocorrência de uma descarga, a melhor janela para detectar este evento, a priori, é justamente a que segue o evento. As demais também apresentarão 
alguma informação de que ocorreu uma descarga, mas não tão relevante quanto à janela que estiver mais próxima "temporalmente" da ocorrência da descarga.
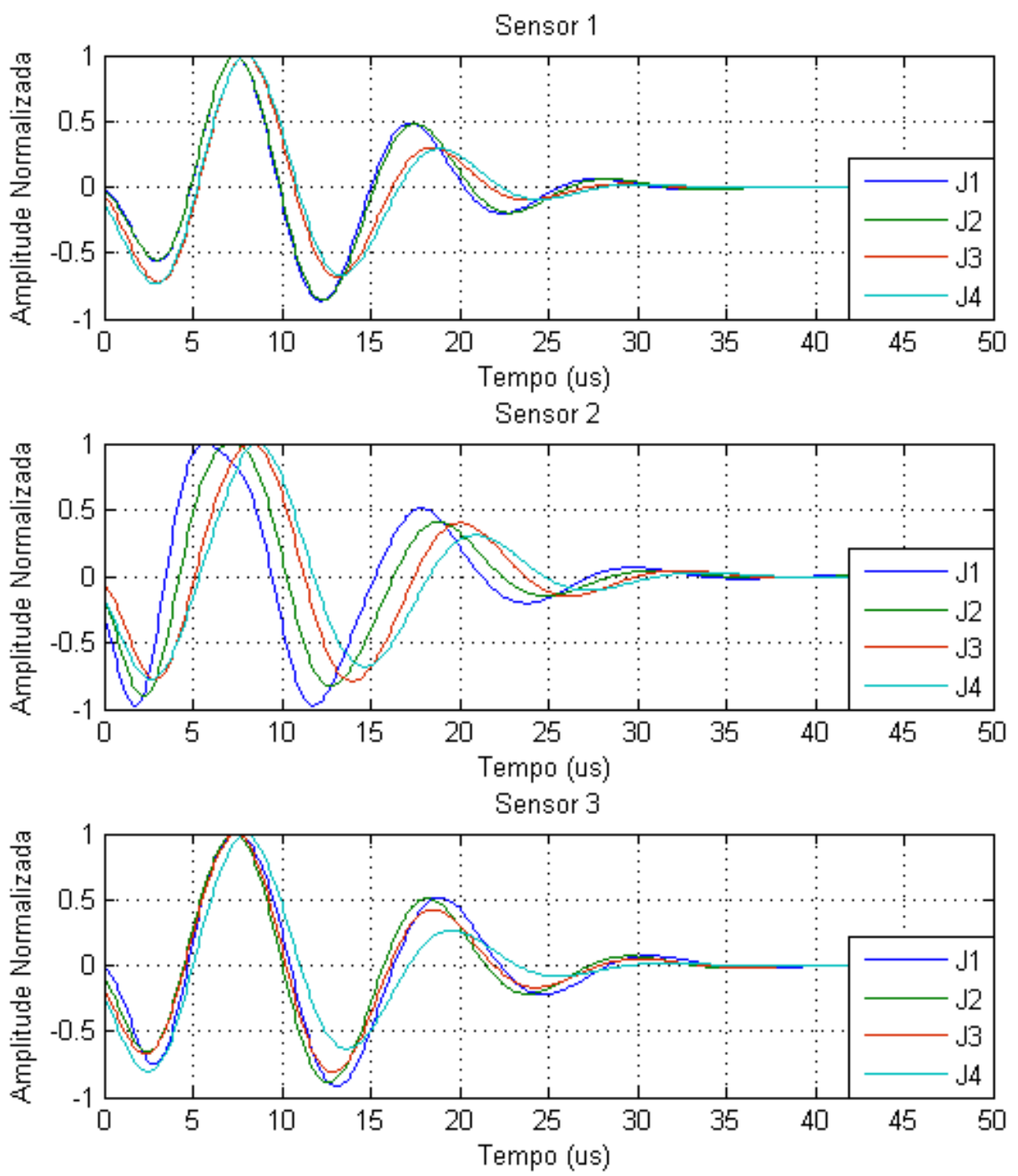

Figura 72: Reconstrução do sinal original para os três sensores padrão analisando-se quatro janelas distintas do sinal. Descarga em ar, caixa 1.

Por fim, é importante ressaltar a influência do coeficiente de absorção $A_{B}$, mencionado na equação (2.23), nestes resultados expostos até aqui. Tomando como base o caso da descarga em ar na caixa 1 , quase todos os parâmetros de $A_{B}$ podem ser considerados constantes para uma onda acústica propagando-se dentro desta caixa, desde que, obviamente, temperatura, pressão e umidade também sejam constantes. 
Isto é até intuitivo, pois variáveis como: coeficiente de viscosidade do meio, densidade, velocidade de propagação sonora, calor específico à pressão constante entre outras podem ser consideradas constantes. A variável que sofre alteração substancial é a frequência da onda sonora. Tendo em vista que o som captado pelas amostras e sensores aponta para a existência de várias frequências no sinal como um todo, e o coeficiente de absorção tem relação quadrática com a frequência, isto está de acordo com o seguinte fato: a maior riqueza de frequências para janelas mais próximas, no tempo, do instante da descarga em detrimento a janelas mais afastadas.
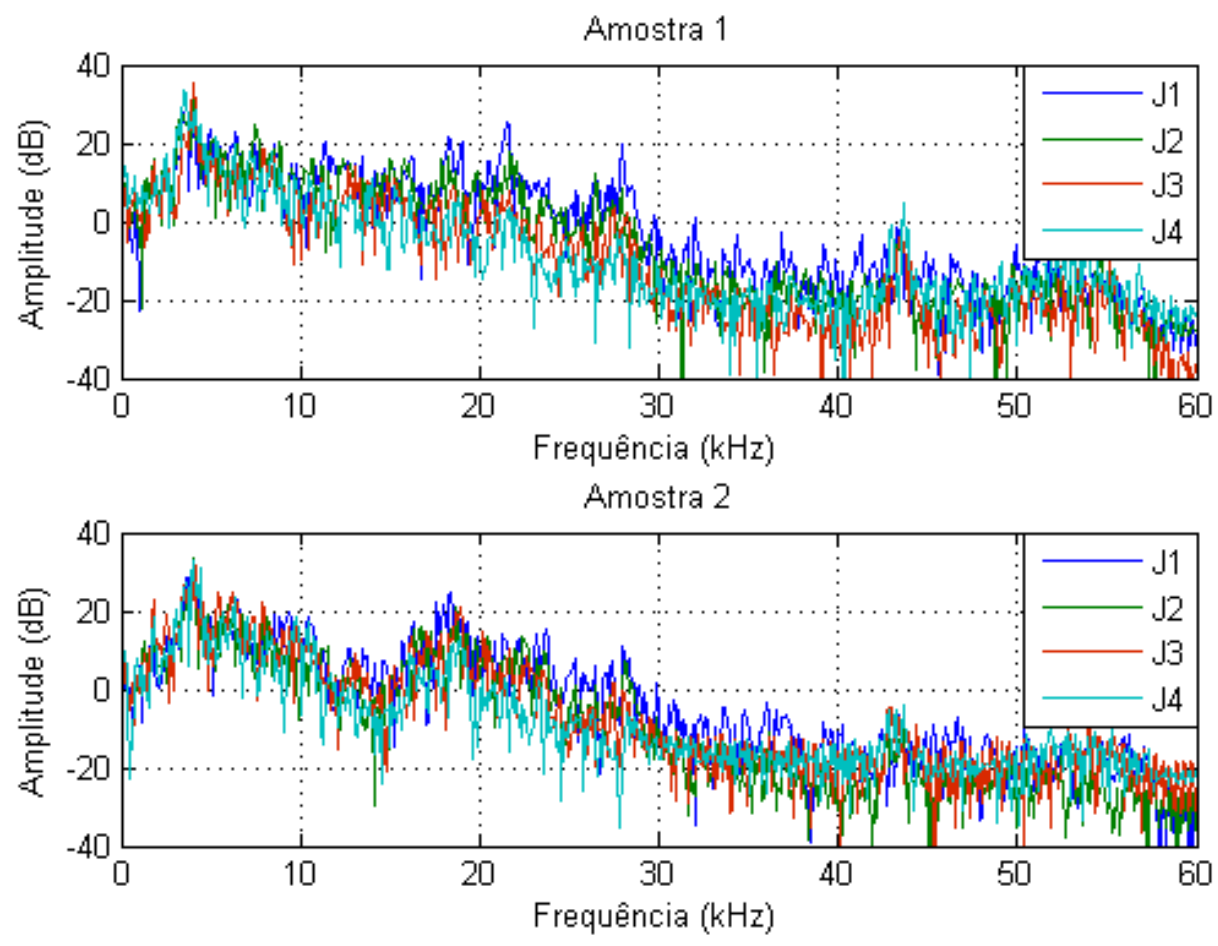

Amostra 3

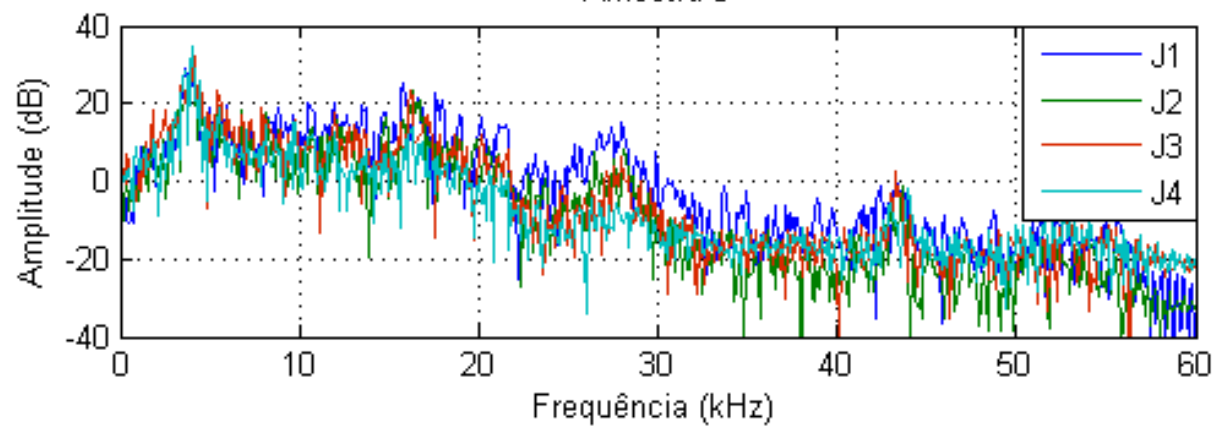

Figura 73: Espectro de frequência para as três amostras de piezoeletreto analisando-se quatro janelas distintas do sinal. Descarga em ar, caixa 1. 

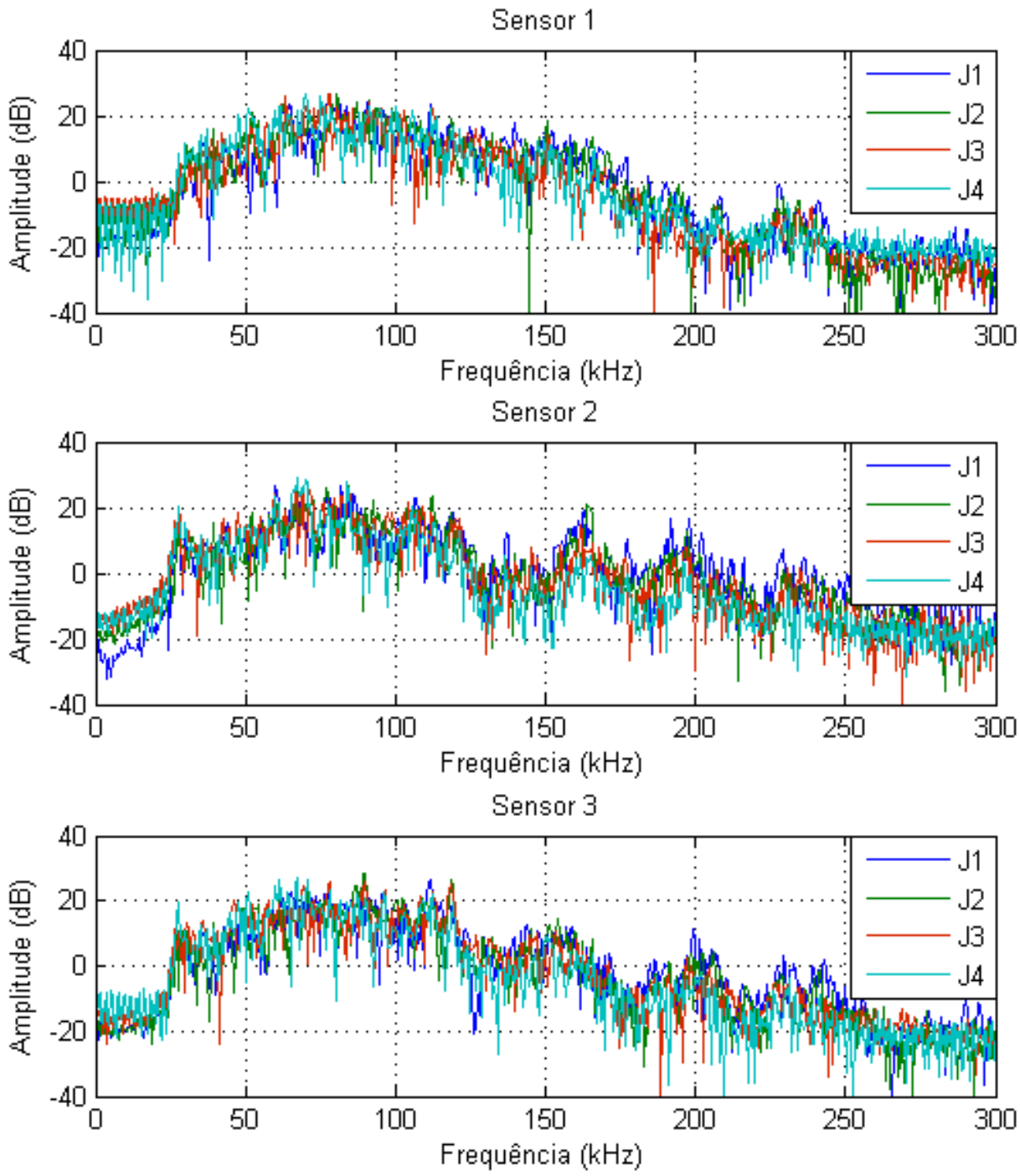

Figura 74: Espectro de frequência para os três sensores padrão analisando-se quatro janelas distintas do sinal. Descarga em ar, caixa 1.

Por ser uma relação quadrática a absorção será muito mais intensa para frequências mais altas, confirmando o direcionamento da análise apenas para a janela subsequente ao instante da descarga. O tamanho ótimo desta janela é uma questão a ser respondida num estudo posterior. Por hora, as janelas de $5 \mathrm{~ms}$ para os sinais das amostras e 1ms para os sinais dos sensores mostraram-se satisfatórias para os objetivos desta pesquisa, tanto para o caso de descarga em ar quanto em óleo. 
Com o objetivo de comparar o sinal original (lembrando que é sempre em fase mínima) com o reconstruído, foi necessário uma "readequação" no sinal original para esse fim. Ocorre que o sinal reconstruído possui uma forma parecida em relação ao sinal original, todavia numa escala de tempo diferente. Quando se removeu um único eco na câmara anecóica, boa parte da forma foi preserva. No presente caso, descarga numa caixa de alumínio, é como se o sinal original sofresse uma "contração" na frequência. Mais especificamente, verificou-se que a caixa tem a propriedade de privilegiar algumas frequências em detrimento de outras. As Tabelas 45 apresentaram que a quantidade de cruzamentos por zero decai à medida que o tempo passa. Os gráficos das Figuras 71 a 74 confirmaram que componentes de alta frequência desaparecem rapidamente com o passar do tempo. Sendo a excitação, ou a descarga em si, a mesma, tanto na câmara anecóica quanto na caixa, é natural concluir que tende a prevalecer frequências mais baixas em oposição a altas. Portanto, a solução para este impasse, sinais semelhantes, mas em escala de tempos distintos, foi encontrada no que se chama, neste trabalho, de "remodelagem de espectro". Este artifício é um dos pontos mais importantes de toda esta pesquisa, e isto se tornará mais claro quando se analisar o caso de descarga na caixa 2. Por enquanto, a remodelagem do espectro do sinal sem eco é realizada por meio de uma interpolação e sub-amostragem neste espectro. Esta remodelagem está de acordo com a menor distância obtida entre o sinal reconstruído e o novo sinal obtido a partir do espectro remodelado. A interpolação e sub-amostragem é realizada da seguinte forma: toma-se do espectro do sinal original e realiza-se uma interpolação de nível 10, isto é, o espectro que possuía 2000 pontos passa a ter 20000 pontos. Se o fator de compressão do espectro for, por exemplo, 2,5, então será tomado um ponto a cada 25 pontos de um total de 20000, em vez de um ponto a cada " 2,5 " pontos de 2000, situação que não teria sentido caso não fosse realizada a interpolação de nível $10 . \mathrm{Na}$ realidade far-se-á uma varredura para vários fatores de compressão, variando de um a quatro com incremento de 0,1. A Figura 75 apresenta o comportamento da distância Euclidiana e de Chebychev, ambas normalizadas, entre o sinal remodelado e reconstruído de acordo com o fator de compressão, e referente a cada amostra de piezoeletreto e sensor padrão. A Tabela 6 apresenta todas as distâncias reais mínimas entre o sinal remodelado e reconstruído e o fator de compressão correspondente. As Figuras 76 e 77 apresentam os espectros dos sinais originais, remodelados e reconstruídos para todas as amostras e sensores respectivamente. Em todas as remodelagens, doravante, utilizar-se-á dos fatores de compressão calculados pela 
distância Euclidiana, pois, como já foi mencionado, é um tipo de medida de energia. Sendo assim, a menor "energia" implica na maior similaridade. É importante frisar que o único espectro que está sendo remodelado é do sinal original ou sem eco (Figuras 53 e 54); o sinal reconstruído provém da deconvolução homomórfica e é comparado com o sinal original que passou pelo processo de remodelamento.
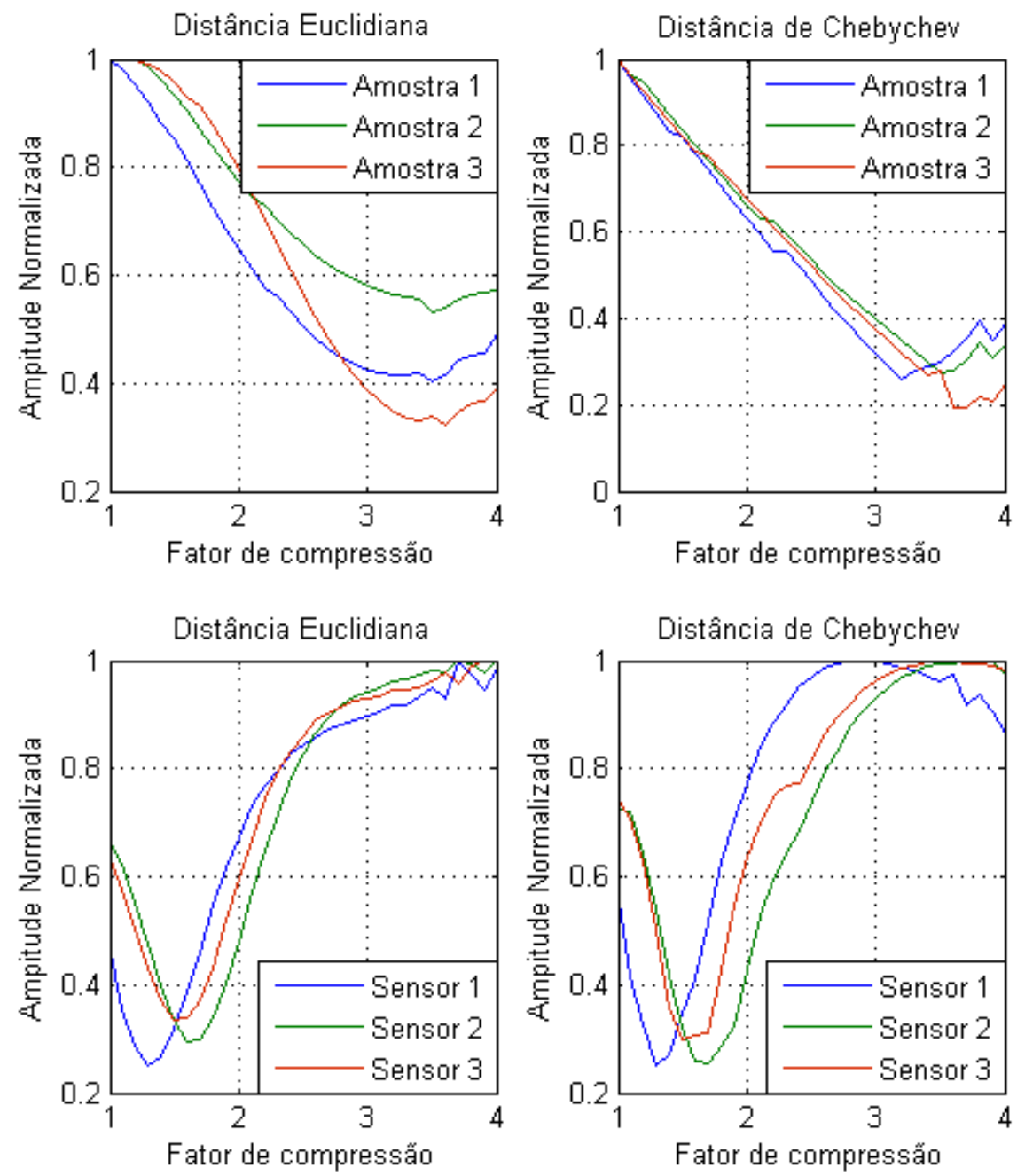

Figura 75: Comportamento da distância Euclidiana e de Chebychev, ambas normalizadas, entre o sinal remodelado e reconstruído de acordo com o fator de compressão aplicado no espectro do sinal original, para todas as amostras e sensores. Descarga em ar, caixa1.

De imediato verifica-se boa proximidade entre os fatores de compressão calculados via distância Euclidiana e de Chebychev os quais estão apresentados na Tabela 6. Ainda verifica-se o fato de que todas as distâncias são menores para o caso 
das amostras em comparação aos sensores. Mais uma vez isto pode apontar para uma maior simplicidade do pulso captado pelas amostras em detrimento ao captado pelos sensores. Quanto aos espectros apresentados nas Figuras 76 e 77, nota-se a tendência do espectro do sinal remodelado se ajustar ao espectro do sinal reconstruído e isto é mais evidente para o caso dos sensores. Porém, todas as curvas destas figuras não estão normalizadas e, analisando-se com cuidado as curvas da Figura 76, constata-se que o espectro remodelado é relativamente próximo do espectro do sinal reconstruído a menos de um offset. Isto será mais perceptível quando se comparar todos os sinais no tempo. Com relação a todas as medidas realizadas, ou seja, os grupos de 25 medidas para cada amostra/sensor, a Tabela 7 apresenta as médias das relações sinal/ruído, o desvio padrão, a menor relação sinal/ruído e o coeficiente de variação de Pearson (em \%), definido pelo quociente entre o desvio padrão e a média.

Tabela 6: Distâncias mínimas e fatores de compressão referentes a estas distâncias para cada amostra de piezoeletreto e sensor padrão (DE: distância Euclidiana; DC: distância de Chebychev). Descarga em ar, caixa 1.

\begin{tabular}{ccccc}
\hline Amostras/Sensores & DE & Fator (via DE) & DC & Fator (via DC) \\
\hline Amostra 1 & 2,49 & 3,5 & 0,291 & 3,2 \\
Amostra 2 & 3,68 & 3,5 & 0,336 & 3,5 \\
Amostra 3 & 2,16 & 3,6 & 0,234 & 3,6 \\
\hline Sensor 1 & 3,91 & 1,3 & 0,406 & 1,3 \\
Sensor 2 & 4,92 & 1,6 & 0,477 & 1,7 \\
\hline Sensor 3 & 5,50 & 1,5 & 0,515 & 1,5 \\
\hline
\end{tabular}

Tabela 7: Média das relações sinal/ruído $(\mu)$, desvio padrão $(\sigma)$, menor relação $(M R)$ e coeficiente de variação percentual $\left(\boldsymbol{C}_{\boldsymbol{v}}\right)$ para cada grupo de 25 medidas de todas as amostras e sensores. Descarga em ar, caixa 1.

\begin{tabular}{ccccc}
\hline Amostras/Sensores & $\boldsymbol{\mu}$ & $\boldsymbol{\sigma}$ & $\boldsymbol{M R}$ & $\boldsymbol{C}_{\boldsymbol{v}}(\boldsymbol{\%})$ \\
\hline Amostra 1 & 13,0 & 4,03 & 6,95 & 31,0 \\
\hline Amostra 2 & 36,91 & 12,21 & 17,64 & 33,1 \\
\hline Amostra 3 & 21,75 & 7,83 & 10,31 & 36,0 \\
\hline Sensor 1 & 847,5 & 139,1 & 641,6 & 16,4 \\
\hline Sensor 2 & 1065,9 & 232,0 & 550,1 & 21,8 \\
\hline Sensor 3 & 882,6 & 170,9 & 440,3 & 19,4 \\
\hline
\end{tabular}


Este coeficiente $\left(C_{v}\right)$ tem a propriedade de mensurar a dispersão relativa dos dados, que neste caso são as relações sinal/ruído. A ideia e comparar a dispersão das relações sinal/ruído entre amostras e sensores. Para o cálculo de cada relação sinal/ruído referente às amostras, foi tomada a energia do sinal no período de zero a $5 \mathrm{~ms}$ (onde há sinal e ruído) e dividiu-se pela energia do sinal no período de $-5 \mathrm{~ms}$ a zero (onde há somente ruído). Para o caso dos sensores, tomou-se a energia do sinal no período de zero a $1 \mathrm{~ms}$ e dividiu-se pela energia do sinal no período de $-1 \mathrm{~ms}$ a zero.

A Figura 78 apresentará os sinais remodelados e reconstruídos para cada amostra de piezoeletreto. Haverá ainda um terceiro sinal, denominado de "Sinal Processado" que diz respeito a uma das 25 formas de onda coletadas para cada amostra de piezoeletreto. Esta forma de onda será filtrada pelo filtro apresentado na Figura 65; em seguida será aplicada a deconvolução homomórfica no sentido de se recuperar o sinal original. Especificamente esta forma de onda é a que apresenta a menor relação sinal/ruído. Este procedimento é uma forma de averiguarmos a capacidade de processamento desta ferramenta quando se há ruído ambiente presente. O fato de se coletar 25 medidas de um mesmo evento e calcular média já atenua, consideravelmente, o ruído presente na forma de onda. Portanto, dispondo apenas de um filtro e da deconvolução, pretende-se comparar este novo sinal, denominado de sinal processado, com o sinal reconstruído, proveniente do sinal médio deconvolvido homomorficamente, e com o sinal remodelado, proveniente da compressão do espectro do sinal original. O corte na curva cepstral ocorreu em 39,5 us (ou utilizou-se 80 pontos da curva cepstral) para a amostra 1, 33,5 us (ou 68 pontos) para a amostra 2 e 49,5 us (ou 100 pontos) para a amostra 3 no que diz respeito aos "sinais reconstruídos". A Figura 79 apresentará o mesmo para os sensores padrão com a diferença, obviamente, de que o filtro a ser utilizado é o que foi apresentado na Figura 66. Neste caso, o corte no cepstro foi realizado em 12,9 us (130 pontos) para todos os sensores. Salienta-se que não existe uma regra específica para realizar o corte na curva cepstral de modo a reconstruir o melhor sinal possível. Tendo em vista que as diferentes componentes do sinal tendem a ocupar partes distintas no cepstro (ver equação (4.4) com propriedade P6), depende da habilidade do operador em como realizar o corte para o melhor resultado possível. Os dados de corte apresentados anteriormente foram, a priori, os melhores encontrados para os sinais reconstruídos. Com relação aos sinais processados, o corte ocorreu em 33,5 ps para todas as amostras; para os sensores, permaneceu em 12,9 us. Isto foi necessário, pois começou 
aparecer componentes indesejáveis na reconstrução do sinal processado. Daí o motivo de restringir o corte para esta situação, e o resultado pode ser visto na Figura 78.

Amostra 1
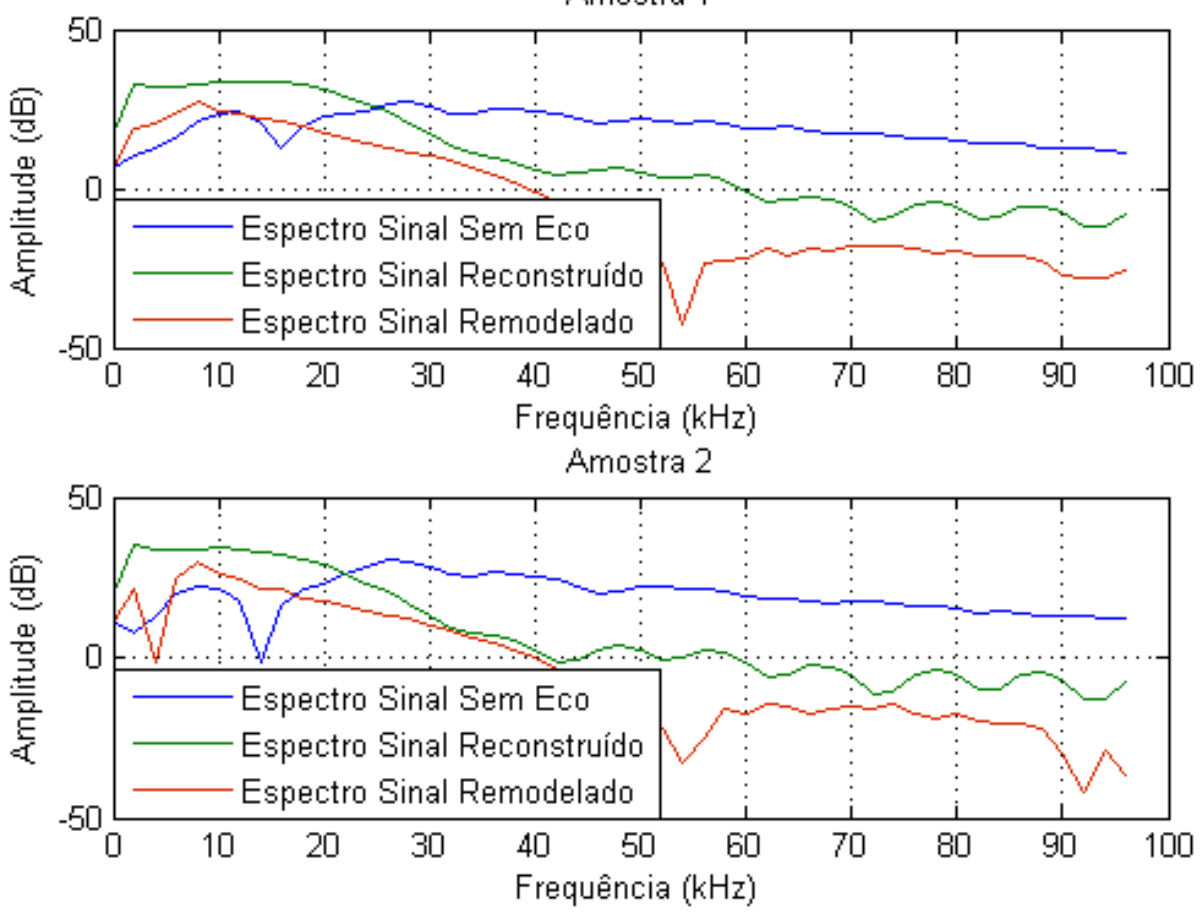

Amostra 3

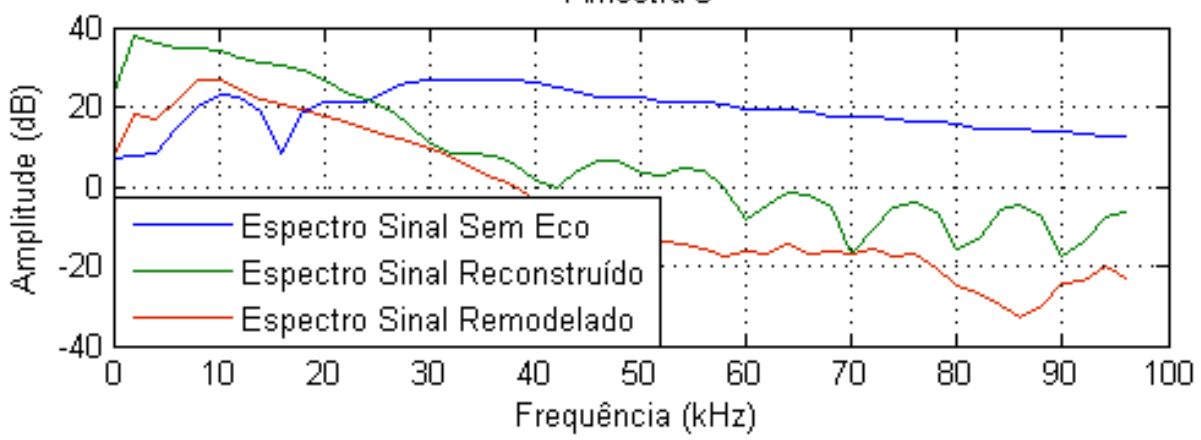

Figura 76: Espectro do sinal original, reconstruído e remodelado para todas as amostras de piezoeletreto. Descarga em ar, caixa 1.

Analisando-se a Tabela 7, é evidente a diferença entre as relações sinal/ruído das amostras e dos sensores. É pelo menos 23 vezes maior tomando-se a relação média sinal/ruído do sensor 1 em comparação com a relação média sinal/ruído da amostra 2. Sobre o coeficiente de variação, as amostras apresentaram uma dispersão um pouco maior em relação aos sensores. Mesmo assim, os sinais reconstruídos e 
processados apresentados nas Figuras 78 e 79 mostraram-se bastante similares, principalmente no caso da Figura 78, onde a relação sinal/ruído estava entre 7 e 17. Novamente, em termos de monitoramento on-line, mesmo com uma relação sinal ruído tão baixa, pode-se recuperar o sinal original respeitando as distorções que o meio provoca no mesmo. Neste caso, a aplicação de um fator de compressão no espectro de frequência do sinal original, ou sem eco, mostrou-se interessante para comparação entre os sinais remodelados, reconstruídos e processados. O próximo subitem analisará o caso da descarga em óleo na mesma caixa.
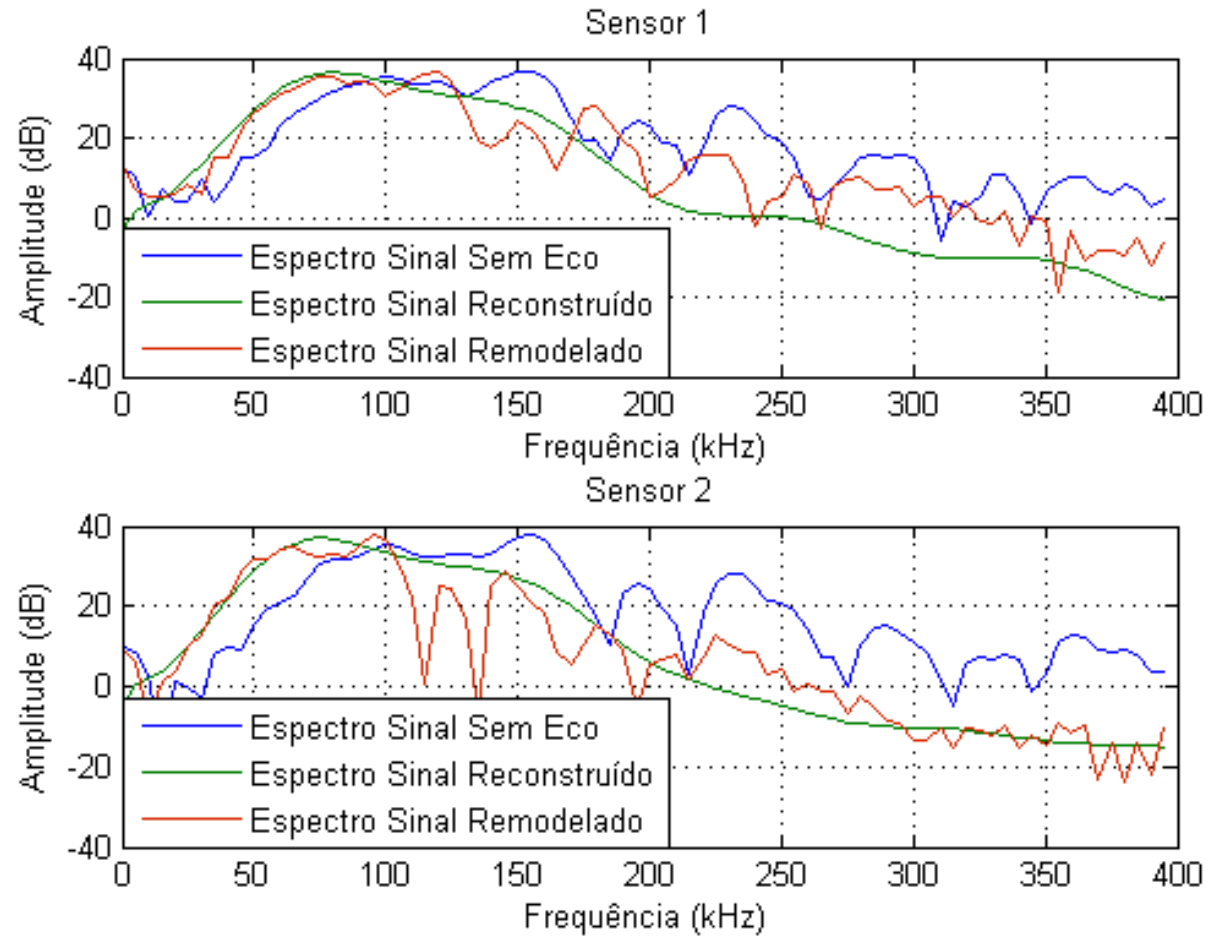

Sensor 3

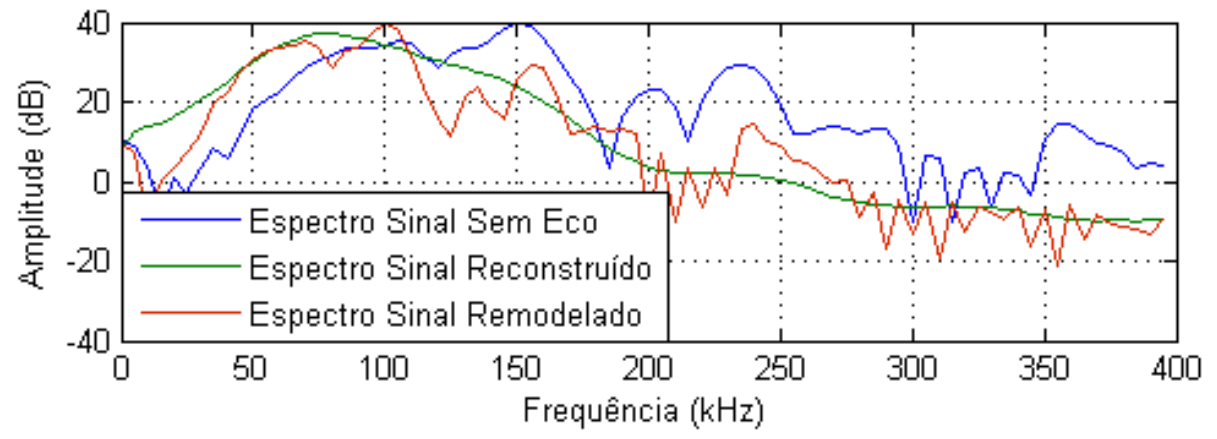

Figura 77: Espectro do sinal original, reconstruído e remodelado para todos os sensores padrão. 

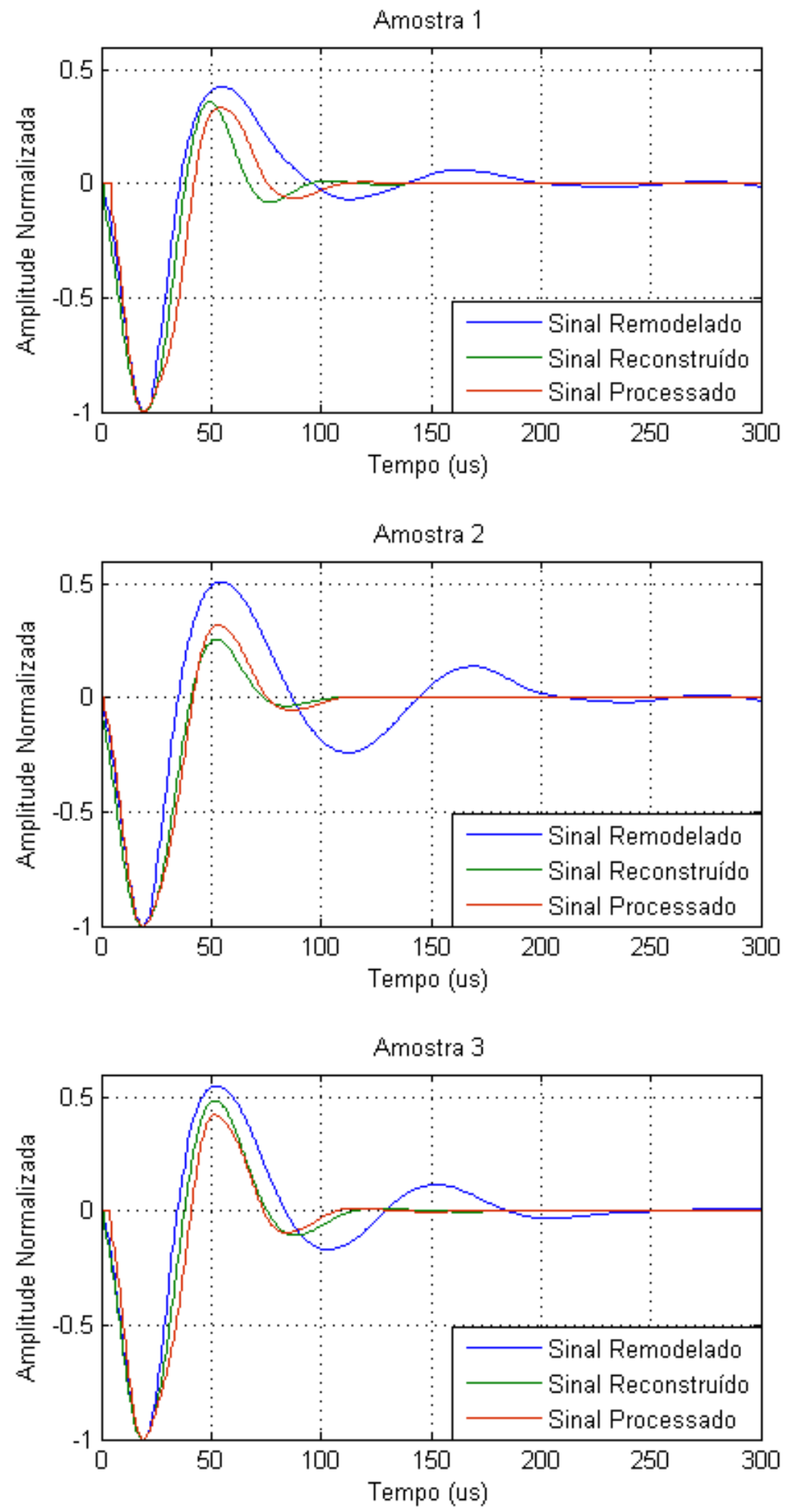

Figura 78: Sinal remodelado, reconstruído e processado para todas as amostras de piezoeletreto. Descarga em ar, caixa 1. 

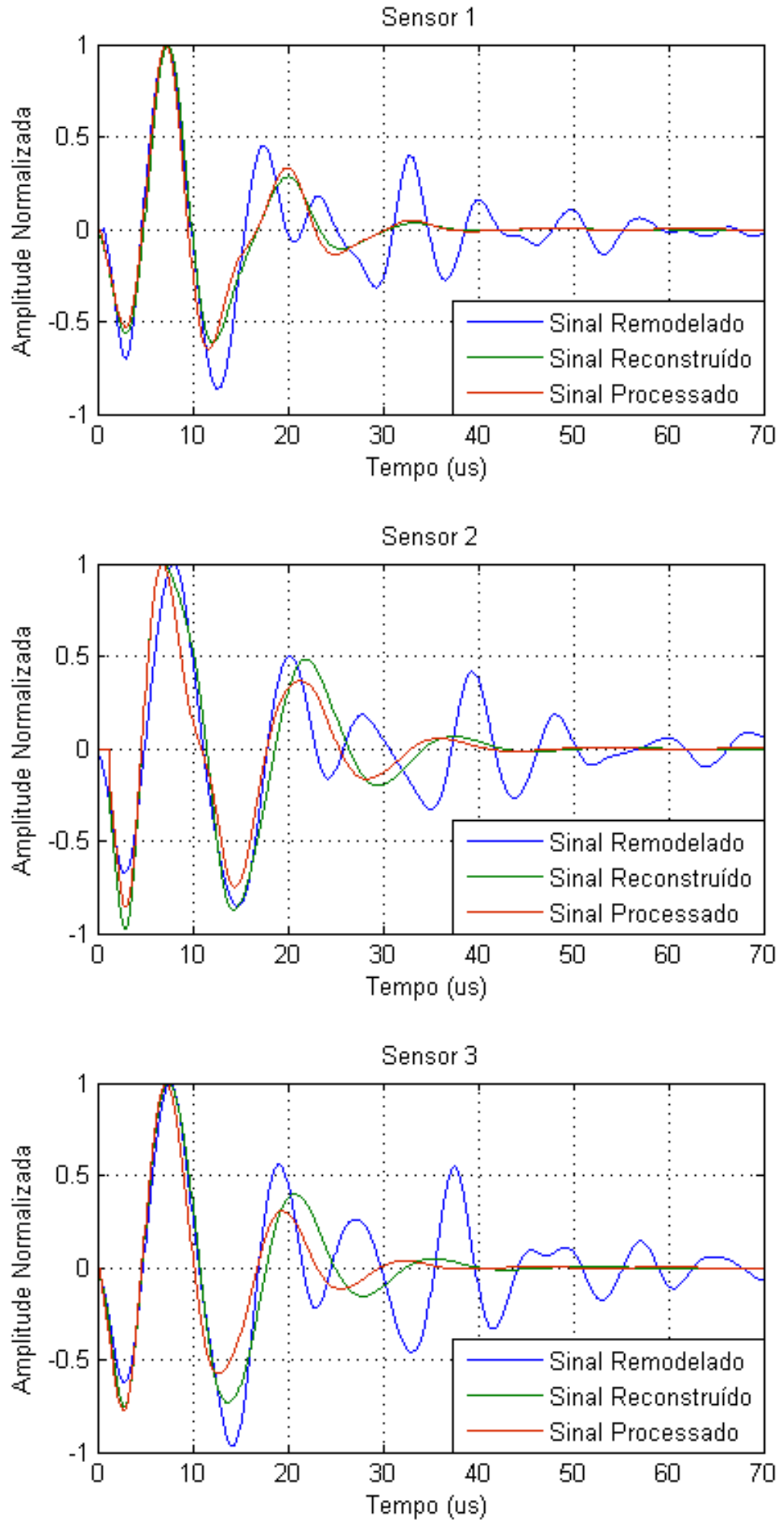

Figura 79: Sinal remodelado, reconstruído e processado para todos os sensores padrão. Descarga em ar, caixa 1. 


\subsubsection{Análise para a caixa 1: descarga em óleo}

O procedimento de análise nesta situação foi o mesmo para as descargas realizadas em ar. Neste caso, encheu-se $90 \%$ da caixa com óleo mineral isolante utilizado em transformadores. Este óleo era novo, a temperatura e umidade ambiente estavam em torno de $20{ }^{\circ} \mathrm{C}$ e $60 \%$, respectivamente. A medida do gap utilizado no ensaio variou entre $0,05 \mathrm{~mm}$ e $0,1 \mathrm{~mm}$, medida esta tomada com o auxílio de um calibre de lâminas de aço. A motivação de um gap bastante reduzido, conforme mencionado anteriormente, está no som produzido: para gaps maiores houve saturação das medidas quando se utilizou o sensor padrão. Portanto reduziu-se ao máximo o gap de modo a evitar este problema. A Figura 80 apresenta os sinais temporais médios filtrados e não filtrados referente às amostras de piezoeletreto; a Figura 81 apresenta o mesmo com relação aos sensores padrão. Ambos os sinais foram amostrados a uma taxa de $10 \mathrm{MSa} / \mathrm{s}$. Os filtros são os mesmos com a exceção do filtro utilizado nos sinais das amostras: a nova taxa de amostragem elevou o suporte deste filtro de 505 elementos para 2519 elementos. Entretanto o sinal tem suporte de 100000 pontos, ou seja, o filtro representa apenas 2,52\% do sinal. Com respeito aos sinais acústicos de descarga (Figuras 80 e 81), de imediato constata-se que a duração dos que procedem das amostras de piezoeletreto é até dez vezes menores, se comparado com os sinais captados na descarga em ar. Isto pode ser um indício de que o novo meio, óleo mineral, seja mais atenuante em comparado ao ar. Pode indicar ainda que o novo meio como um todo privilegiou altas frequências em detrimento a baixas, tendo em vista que a duração dos sinais é praticamente a mesma para os sinais dos sensores padrão. Esta hipótese tem como base que sensores respondem bem para frequências altas, conforme apresenta o Anexo A. Se este for o caso, a predominância de altas frequências em oposição às baixas, faz sentido, pois, como já foi mencionada, a relação entre o coeficiente de absorção e a frequência da onda sonora no meio é quadrática. Dessa forma, esta onda tende a desaparecer rapidamente como o passar do tempo. Daí o motivo da duração ser bem menor, dos sinais das amostras, para o caso de descarga em óleo em comparação ao caso de descarga em ar. É importante frisar que uma coisa são as frequências privilegiadas pelo meio e outra é o coeficiente de absorção correspondente a cada frequência.

Prosseguindo na análise, a Tabela 8 apresenta a quantidade de cruzamentos por zeros de acordo com a janela, que neste caso também são quatro, começando do zero e com duração de $1 \mathrm{~ms}$ cada. Pelos dados apresentados pelos sensores, parece 
que a presença de frequências mais altas no sinal como um todo é maior quando se compara esta tabela com a Tabela 5. Já para os dados apresentados pelas amostras de piezoeletreto, o que se pode supor é que um mesmo conjunto de frequências próximas está presente em boa parte do sinal. Isto é evidenciado pela diferença máxima da quantidade de cruzamento por zeros, que está em torno de $15 \%$ quando se compara todas as janelas. Também pode ser visto que algo próximo desta mesma porcentagem, quando se compara a janela J1 (0 a $1 \mathrm{~ms}$ ) com a janela J4 (3 a $4 \mathrm{~ms})$ nesta mesma Tabela 8 com relação aos dados dos sensores.
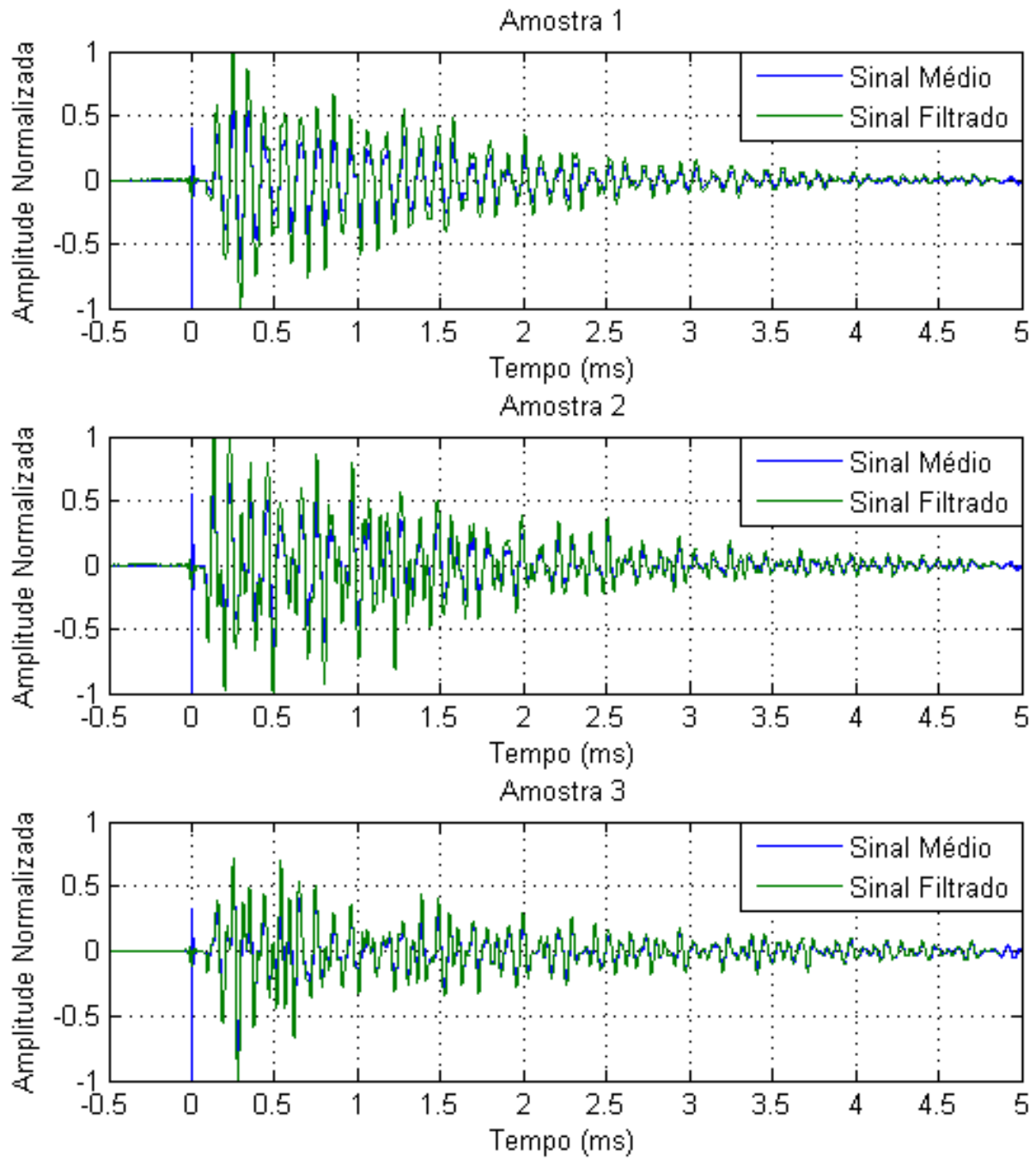

Figura 80: Resposta temporal média filtrada e não filtrada para cada amostra de piezoeletreto. Descarga em óleo, caixa 1. 

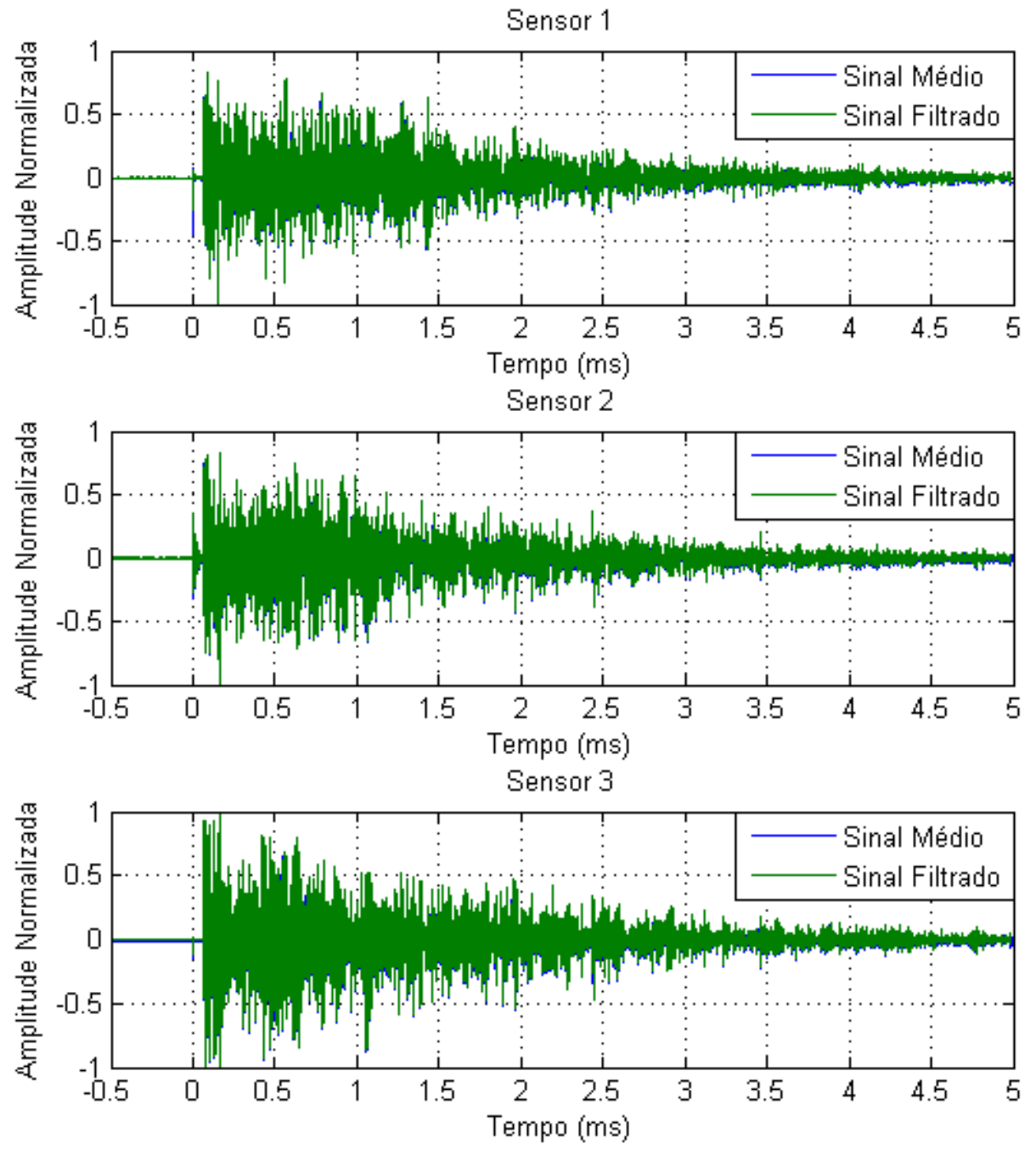

Figura 81: Resposta temporal média filtrada e não filtrada para cada sensor padrão. Descarga em óleo, caixa 1.

Tabela 8: Quantidade de cruzamentos por zero, por amostra/sensor, por janela. Descarga em óleo, caixa 1.

\begin{tabular}{ccccc}
\hline Amostras/Sensores & $\mathbf{0 - 1} \mathbf{~ m s}$ & $\mathbf{1 - 2} \mathbf{~ m s}$ & $\mathbf{2 - 3} \mathbf{~ m s}$ & $\mathbf{3 - 4} \mathbf{~ m s}$ \\
\hline Amostra 1 & 20 & 19 & 20 & 23 \\
Amostra 2 & 25 & 31 & 26 & 30 \\
Amostra 3 & 28 & 29 & 28 & 27 \\
Sensor 1 & 273 & 277 & 230 & 232 \\
Sensor 2 & 267 & 251 & 256 & 226 \\
Sensor 3 & 249 & 252 & 243 & 228 \\
\hline
\end{tabular}


Com a finalidade, agora, de se recuperar o sinal original, necessita-se realizar uma sub-amostragem nos sinais das amostras de piezoeletreto, para que o tempo de análise se equalize com o caso de análise da descarga em ar. Como a taxa de amostragem foi de $10 \mathrm{MSa} / \mathrm{s}$, realizando uma sub-amostragem de 1 para 5 (toma-se um ponto a cada cinco), a nova taxa passa a ser $2 \mathrm{MSa} / \mathrm{s}$. A janela de análise, de 5 ms, passa a ter suporte de 10000 pontos, em vez de 50000 pontos, para essa nova taxa de amostragem, a qual é suficiente para representar o sinal. Para os sinais dos sensores padrão, permanece a janela de $1 \mathrm{~ms}$ com a mesma taxa de amostragem.

Da mesma forma que se procedeu no caso da descarga em ar, a Figura 82 apresenta o comportamento das distâncias Euclidianas e de Chebychev entre o sinal remodelado e reconstruído de acordo com o fator de compressão utilizado. A Tabela 9 apresenta as distâncias mínimas encontradas na Figura 82 e o valor destas de acordo com o fator de compressão. A Tabela 10 contem as médias das relações sinal/ruído, os desvios padrão, os coeficientes de variação percentual e a menor relação sinal/ruído para cada grupo de 25 medidas referente a cada amostra/sensor.

Tabela 9: Distâncias mínimas e fatores de compressão referentes a estas distâncias para cada amostra de piezoeletreto e sensor padrão (DE: distância Euclidiana; DC: distância de Chebychev). Descarga em óleo, caixa 1.

\begin{tabular}{ccccc}
\hline Amostras/Sensores & DE & Fator (via DE) & DC & Fator (via DC) \\
\hline Amostra 1 & 2,43 & 2,3 & 0,305 & 2,4 \\
Amostra 2 & 2,66 & 2,1 & 0,287 & 2,1 \\
Amostra 3 & 2,28 & 2,1 & 0,276 & 2,2 \\
Sensor 1 & 3,67 & 1,1 & 0,404 & 1,0 \\
Sensor 2 & 3,90 & 1,1 & 0,456 & 1,0 \\
Sensor 3 & 4,80 & 1,1 & 0,571 & 1,0 \\
\hline
\end{tabular}

A Figura 83 apresenta o espectro do sinal original, reconstruído e remodelado a partir das menores distâncias Euclidianas mencionadas na Tabela 9. A Figura 84 apresenta o mesmo para os sensores padrão. Como já foi mencionado, o interesse não está em analisar as curvas cepstrais, mas os sinais reconstruídos. Por isso que não serão apresentados os gráficos destas curvas. 
Tabela 10: Média das relações sinal/ruído $(\mu)$, desvio padrão $(\sigma)$, menor relação $(M R)$ e coeficiente de variação percentual $\left(\boldsymbol{C}_{\boldsymbol{v}}\right)$ para cada grupo de 25 medidas de todas as amostras e sensores. Descarga em óleo, caixa 1.

\begin{tabular}{ccccc}
\hline Amostras/Sensores & $\boldsymbol{\mu}$ & $\boldsymbol{\sigma}$ & $\boldsymbol{M R}$ & $\boldsymbol{C}_{\boldsymbol{v}}(\mathbf{\%})$ \\
\hline Amostra 1 & 1774,9 & 273,5 & 1377,0 & 15,4 \\
Amostra 2 & 2694,3 & 453,8 & 2063,8 & 16,8 \\
Amostra 3 & 1776,3 & 223,8 & 1336,8 & 12,6 \\
Sensor 1 & 857,5 & 98,7 & 731,0 & 11,5 \\
Sensor 2 & 1004,8 & 98,3 & 785,7 & 9,8 \\
\hline Sensor 3 & 1700,2 & 109,4 & 1455 & 6,4 \\
\hline
\end{tabular}
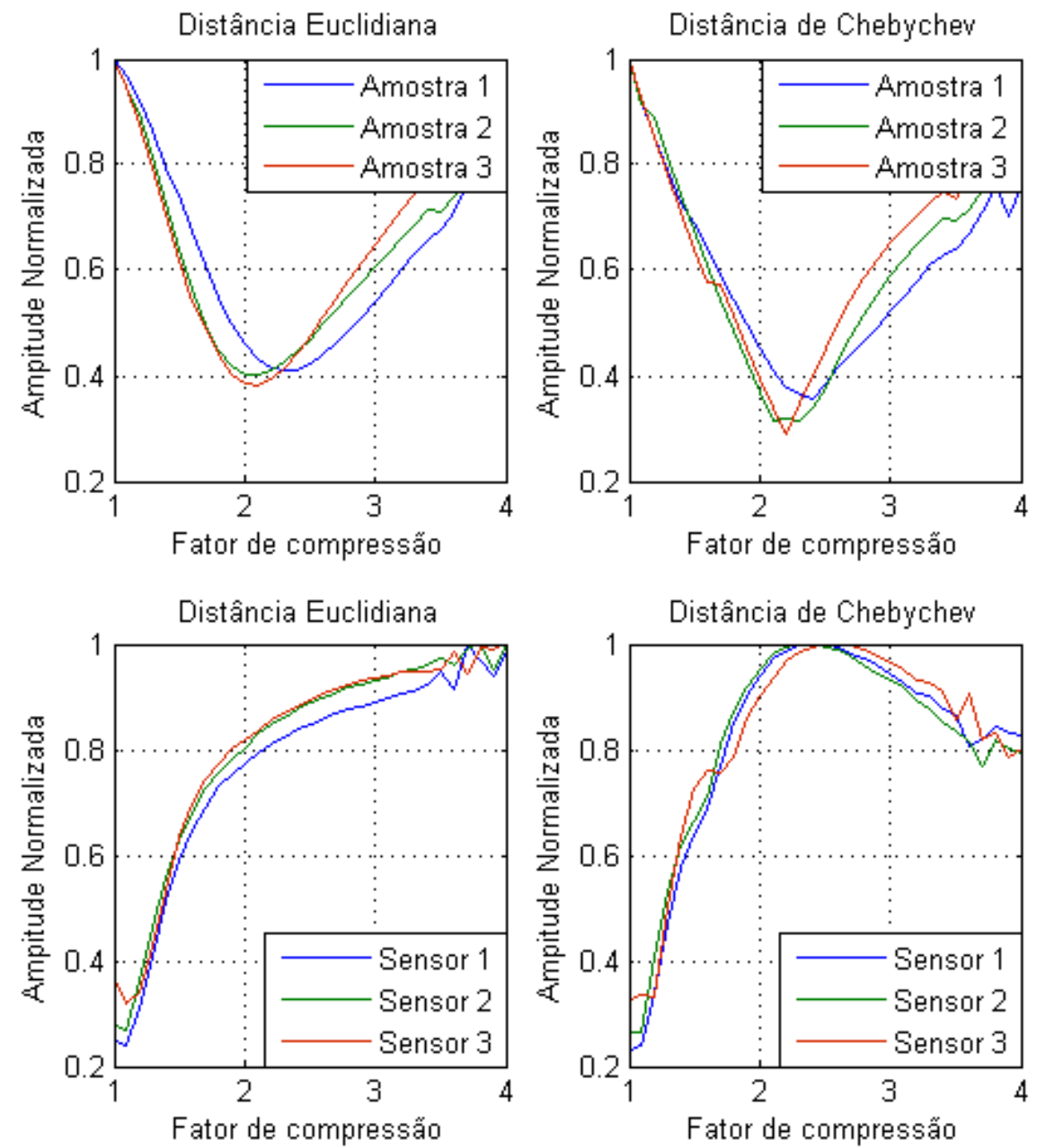

Figura 82: Comportamento da distância Euclidiana e de Chebychev, ambas normalizadas, entre o sinal remodelado e reconstruído de acordo com o fator de compressão aplicado no espectro do sinal original, para todas as amostras e sensores. Descarga em óleo, caixa 1. 
Amostra 1
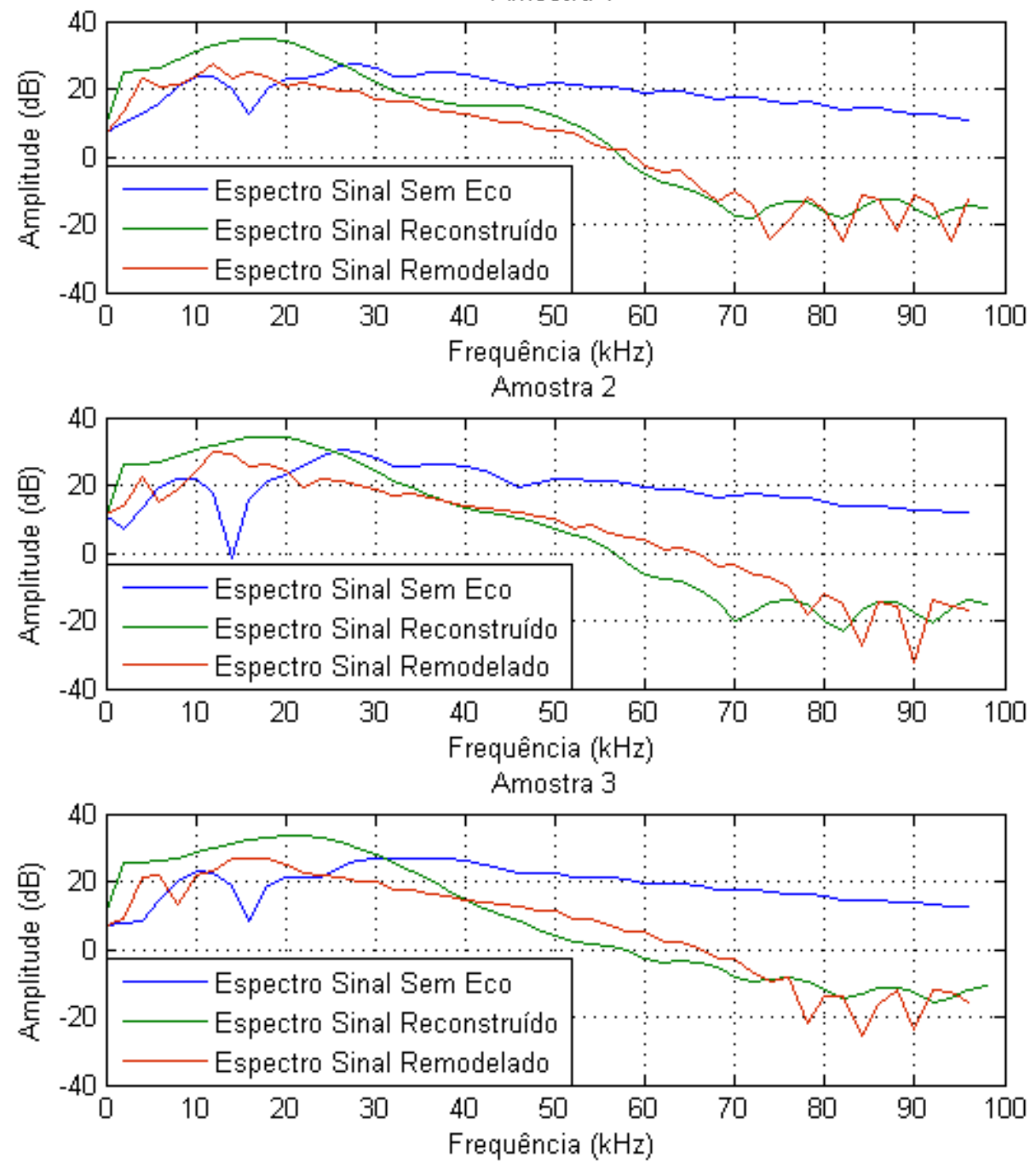

Figura 83: Espectro do sinal original, reconstruído e remodelado para todas as amostras de piezoeletreto. Descarga em óleo, caixa 1.

Por Fim, a Figura 85 apresenta os sinais remodelados e reconstruídos para cada amostra de piezoeletreto; a Figura 86 apresenta o mesmo para os sensores padrão. Lembra-se que o sinal remodelado provém do espectro do sinal original quando se aplica um fator compressão neste espectro; o sinal reconstruído procede da forma de onda média que foi filtrada e deconvolvida homomorficamente, objetivando a recuperação do sinal original; o sinal processado diz respeito a uma forma de onda, cuja relação sinal/ruído é a menor das 25 medidas coletadas para cada amostra/sensor, que foi filtrada e deconvolvida. 

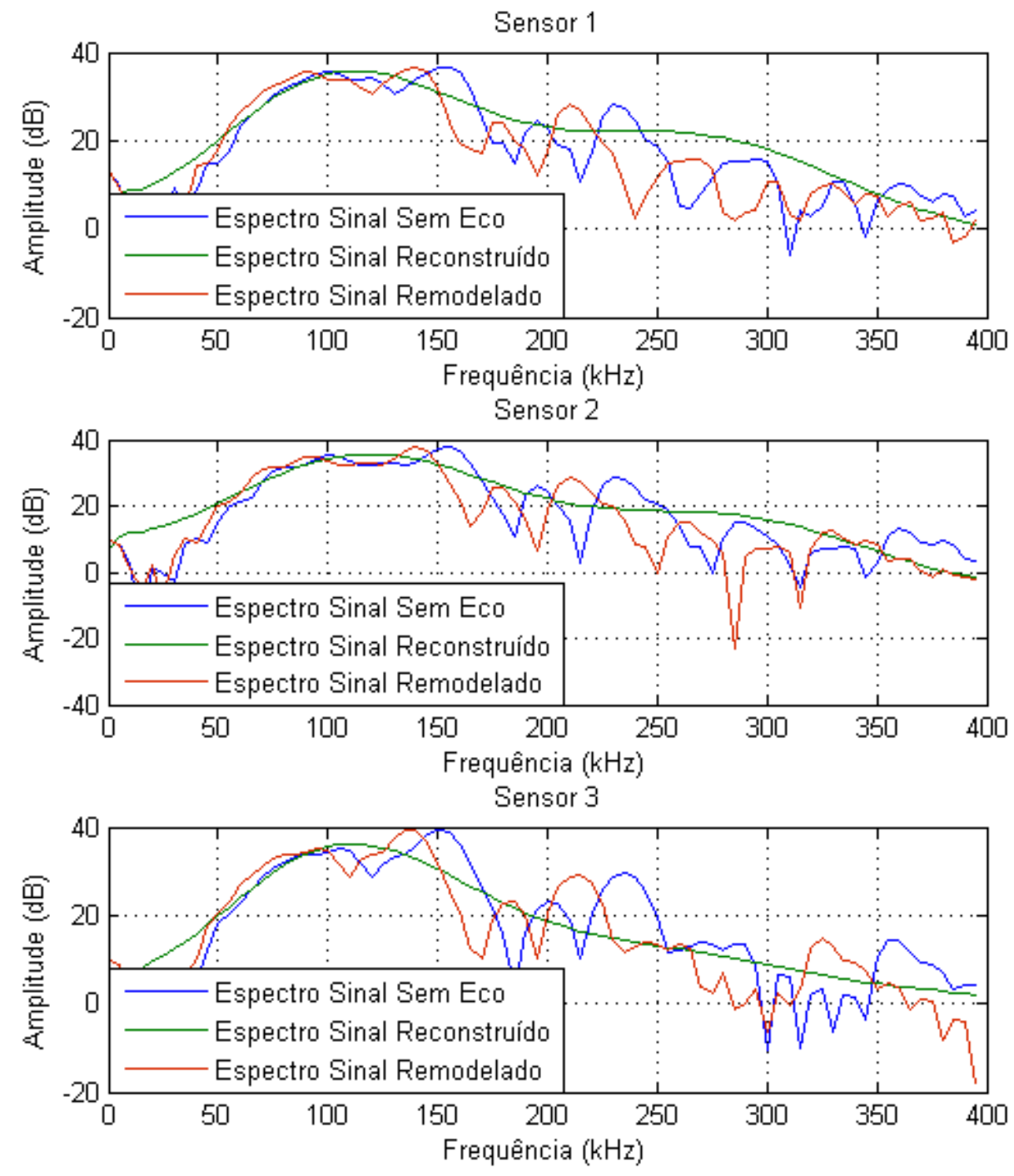

Figura 84: Espectro do sinal original, reconstruído e remodelado para todos os sensores padrão.

Descarga em óleo, caixa 1.

É importante mencionar que, para os sinais reconstruídos apresentados nas Figuras 85 e 86, os cortes nas curvas cepstrais foram realizados em 32 us (ou 65 pontos) para a amostra $1,29,5$ us (ou 60 pontos) para a amostra 2 e 25,5 us (ou 52 pontos) para a amostra 3. Para todos os sensores o corte foi realizado em 6,9 $\mathrm{\mu s}$ (ou 70 pontos). Para os sinais processados, o corte permaneceu em 6,9 us para todos os sensores, todavia foi de 28 us (ou 57 pontos) para a amostra 1, 27,5 us (ou 56 pontos) para a amostra 2 e 24,5 us (ou 50 pontos) para a amostra 3. 

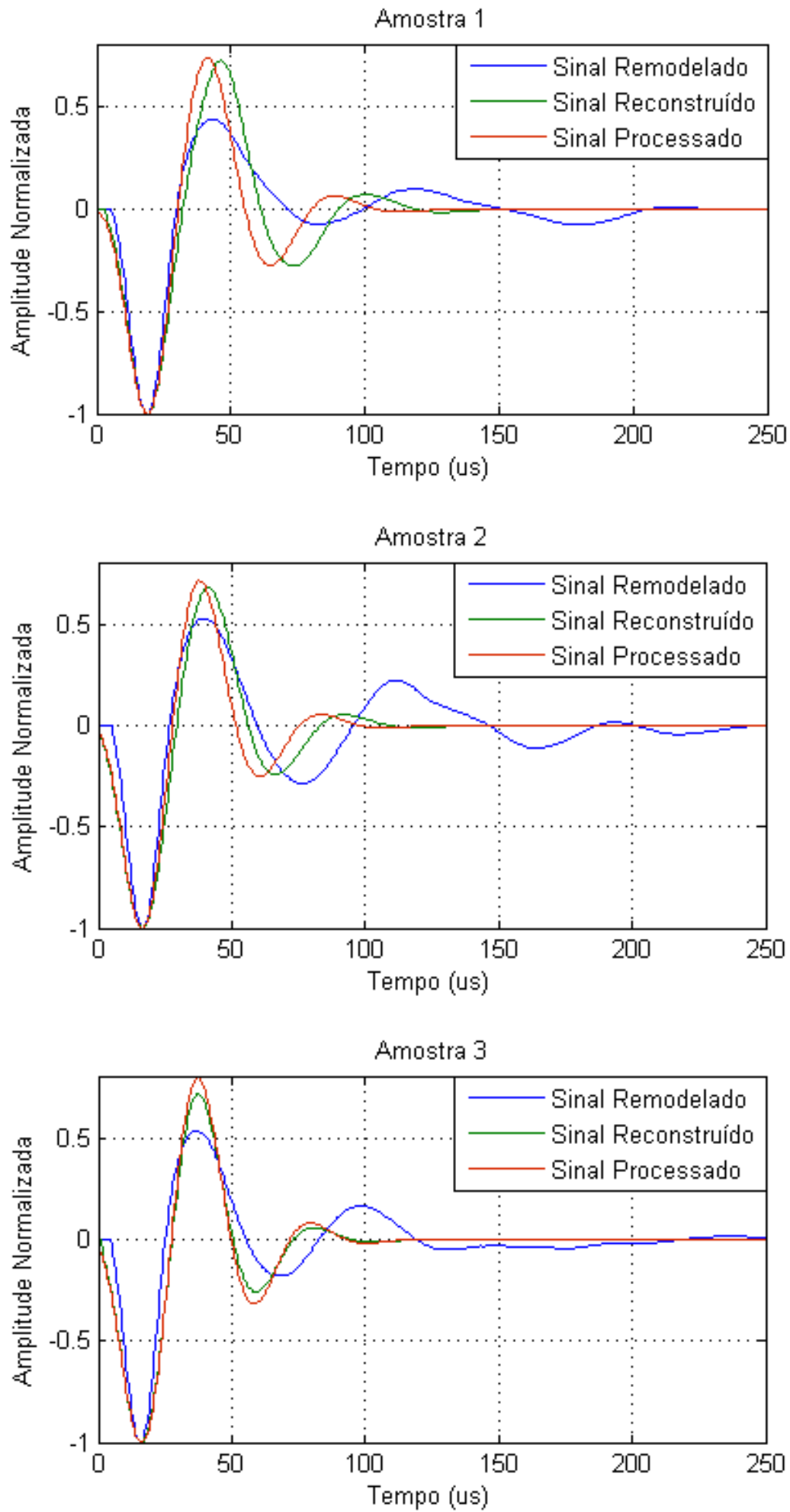

Figura 85: Sinal remodelado, reconstruído e processado para todas as amostras de piezoeletreto. Descarga em óleo, caixa 1. 

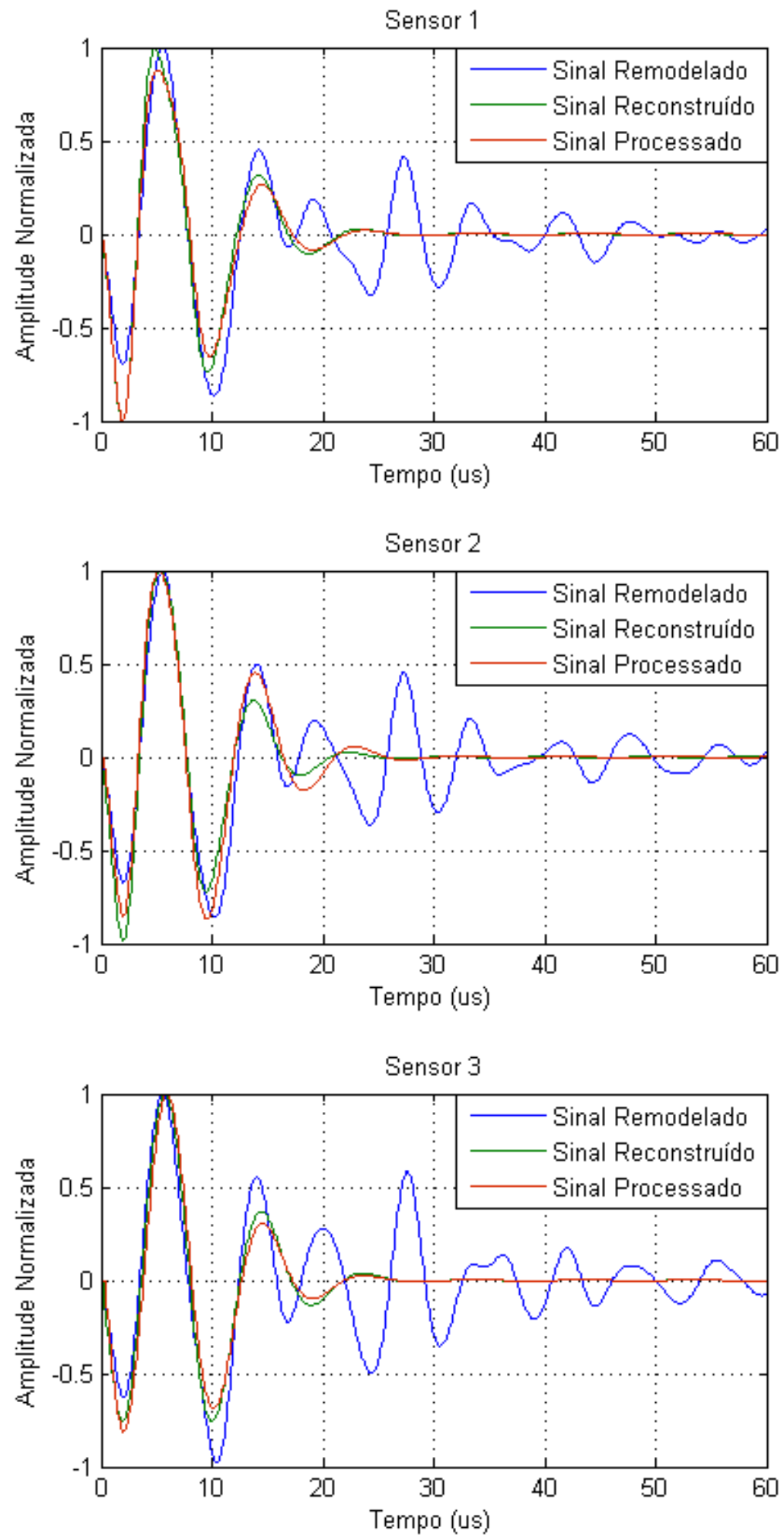

Figura 86: Sinal remodelado, reconstruído e processado para todos os sensores padrão. Descarga em óleo, caixa 1. 
É digno de nota que o corte foi o mesmo para todos os sensores padrão, tanto neste caso de descarga em óleo quanto em ar. Já para as amostras de piezoeletreto houve certa variação no corte quando se buscava o melhor sinal reconstruído. Talvez isso aponte para um estudo da melhor geometria a ser construída para abrigar as amostras, de modo a produzir microfones mais semelhantes entre si. Pelos fatores de compressão apresentados na Tabela 9 e sendo estes, sem exceção, menores comparativamente aos apresentados na Tabela 6 (descarga em ar), isto provavelmente aponta para o fato de que os sinais de descarga em óleo apresentam uma riqueza maior de componentes de altas frequências em relação aos sinais de descarga em ar. As distâncias Euclidianas entre o sinal remodelado e o reconstruído, comparando valor a valor entre as Tabela 6 e 9, são relativamente próximos, com a observação de que, para os sensores padrão, as distâncias são um pouco menores para este caso. Isto pode indicar que a reconstrução destes sinais teve um sucesso parecido com relação ao caso da descarga em ar; a comparação das Figuras 79 e 86 sustentam esta hipótese. Outro fator digno de nota são as relações sinal/ruído apresentadas na Tabela 10: em todos os casos, a média destas relações apresentadas pelas amostras foi superior a media apresentada pelos sensores. Mesmo na pior situação de relação sinal/ruído, na maioria dos casos as amostras apresentaram valor superior em relação aos sensores. Ademais, os coeficientes de variação sofreram redução, tanto para as amostras quanto para os sensores. Isto pode ser um indicativo de que a descarga em óleo seja menos suscetível a variações de intensidade sonora em relação à descarga em ar. Com respeito à Figura 85, claramente se vê a boa reconstrução dos sinais em comparação com os que foram apresentados na Figura 78 (descarga em ar). Quanto aos sinais dos sensores, Figura 86, pode-se dizer que os sinais reconstruídos são praticamente os mesmos comparados aos da Figura 79. Provavelmente isto é resultado da alta relação sinal/ruído em ambos os casos: descarga em ar e óleo.

\subsubsection{Análise para a caixa 2: descarga em ar}

Nesta nova situação, caixa 2, as posições do centelhador e microfone estão esquematizadas na Figura 87. Note que a posição marcada no microfone já define qual será a posição do centelhador dentro da caixa. Dessa forma, os gráficos serão nominados conforme a posição do microfone. É importante mencionar que os sensores padrão foram posicionados nos mesmos locais do microfone e conforme a nomenclatura de posição apresentada na Figura 87. De modo a simplificar a análise, 
haja vista o que foi realizado para a caixa 1, neste caso será apresentado os sinais coletados de cada posição, as tabelas de cruzamentos por zero, dos fatores de compressão do espectro juntamente com as distâncias mínimas e os gráficos contendo os sinais remodelados, reconstruídos e processados. Portanto, as Figuras 88 a 92 apresentam as respostas temporais médias filtradas e não filtradas para todas as amostras de piezoeletreto referentes às posições P1 a P5. Da mesma forma que se procedeu no caso de descarga em ar, caixa 1, estes sinais foram amostrados a uma taxa de $2 \mathrm{MSa} / \mathrm{s}$ calculando-se, em seguida, o sinal médio das 25 medidas para cada amostra. Filtrou-se este sinal com o mesmo filtro utilizado nos sinais das descargas em ar referente à caixa 1. Já as Figuras 93 a 97 apresentam o mesmo referentes aos sensores padrão. A taxa de amostragem foi de $10 \mathrm{MSa} / \mathrm{s}$, a mesma do caso anterior. Realizaram-se a mesma quantidade de medidas e utilizou-se o mesmo filtro do caso anterior também.
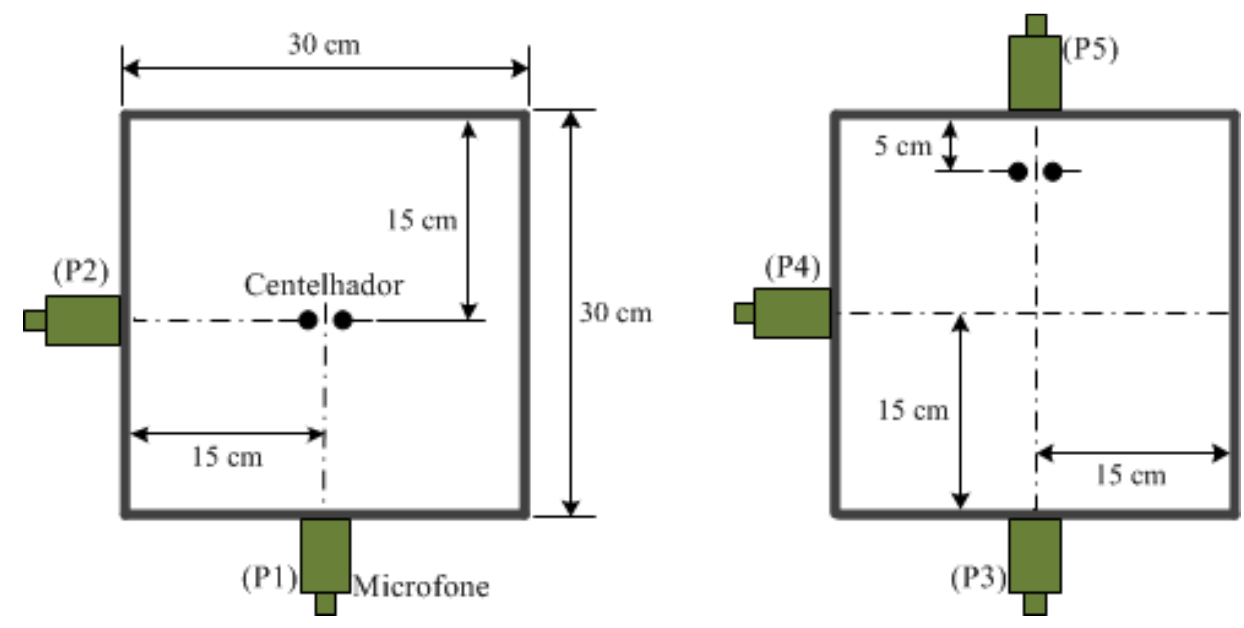

Figura 87: Vista em corte da caixa 2 com esquemático do posicionamento do microfone, posto fora da caixa, e centelhador, interno à caixa.

Nota-se que os sinais referentes às amostras de piezoeletreto pouco diferem quando se muda o local de medida e/ou o centelhador. Uma diferença pouco perceptível é o tempo que separa o instante da descarga, instante zero, e o início do sinal acústico. Todavia, no caso da posição P5, principalmente, este tempo de separação é menor se comparado, por exemplo, ao sinal coletado na posição P3. Já para os sinais referentes aos sensores padrão, a primeira vista, percebe-se que algumas posições tem uma assinatura específica. A assinatura da posição P5, por exemplo, 
difere muito de todas as outras. As assinaturas das posições P3 e P4 são próximas, todavia distintas das assinaturas das posições P1 e P2.
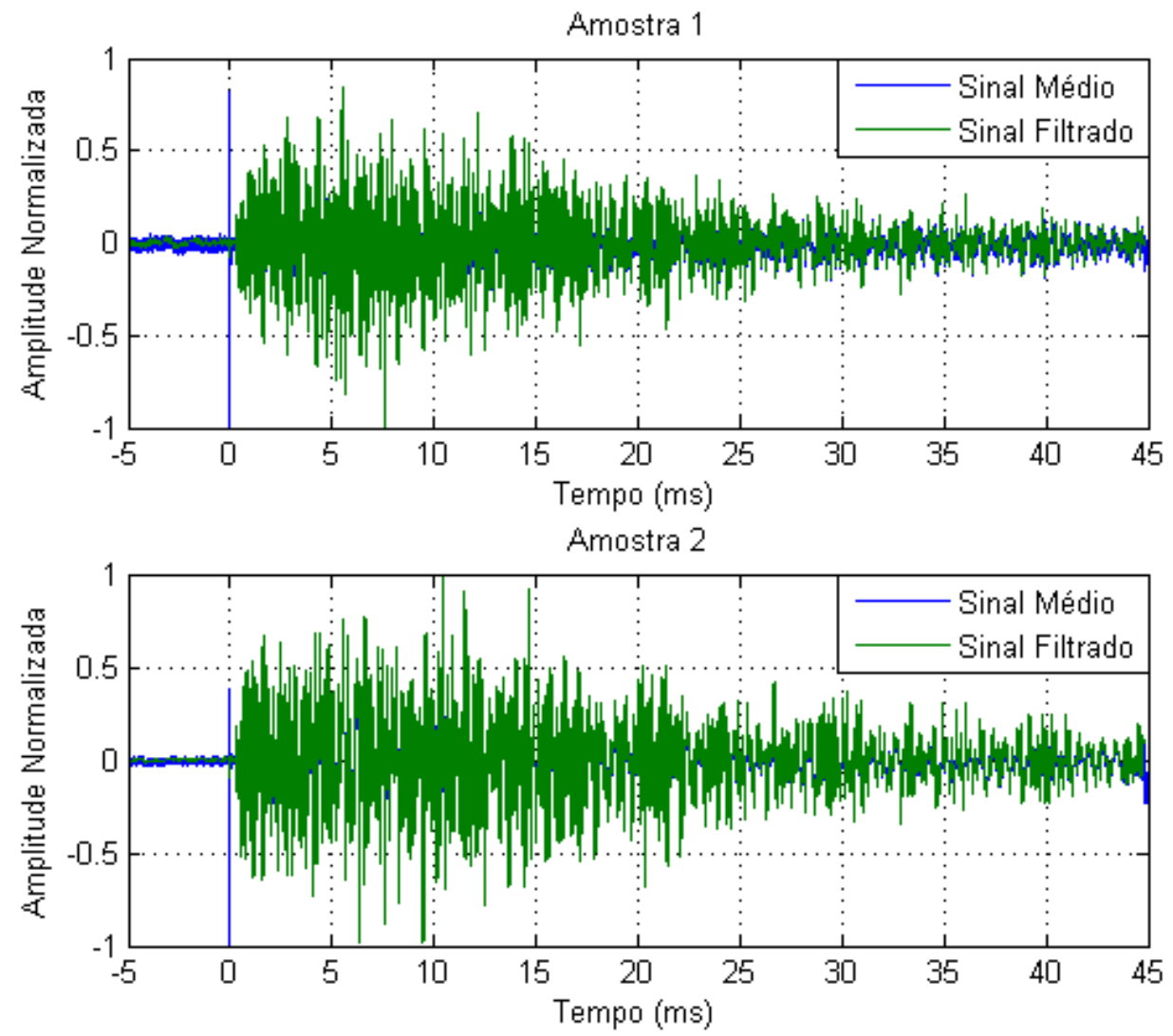

Amostra 3

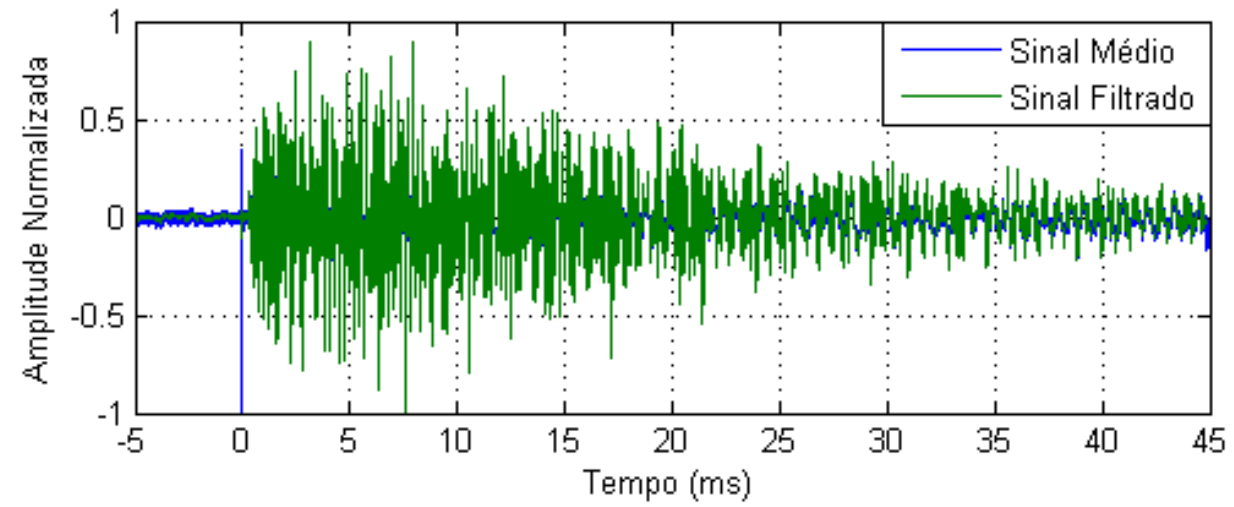

Figura 88: Resposta temporal média filtrada e não filtrada para cada amostra de piezoeletreto referente à posição P1. Descarga em ar, caixa 2. 

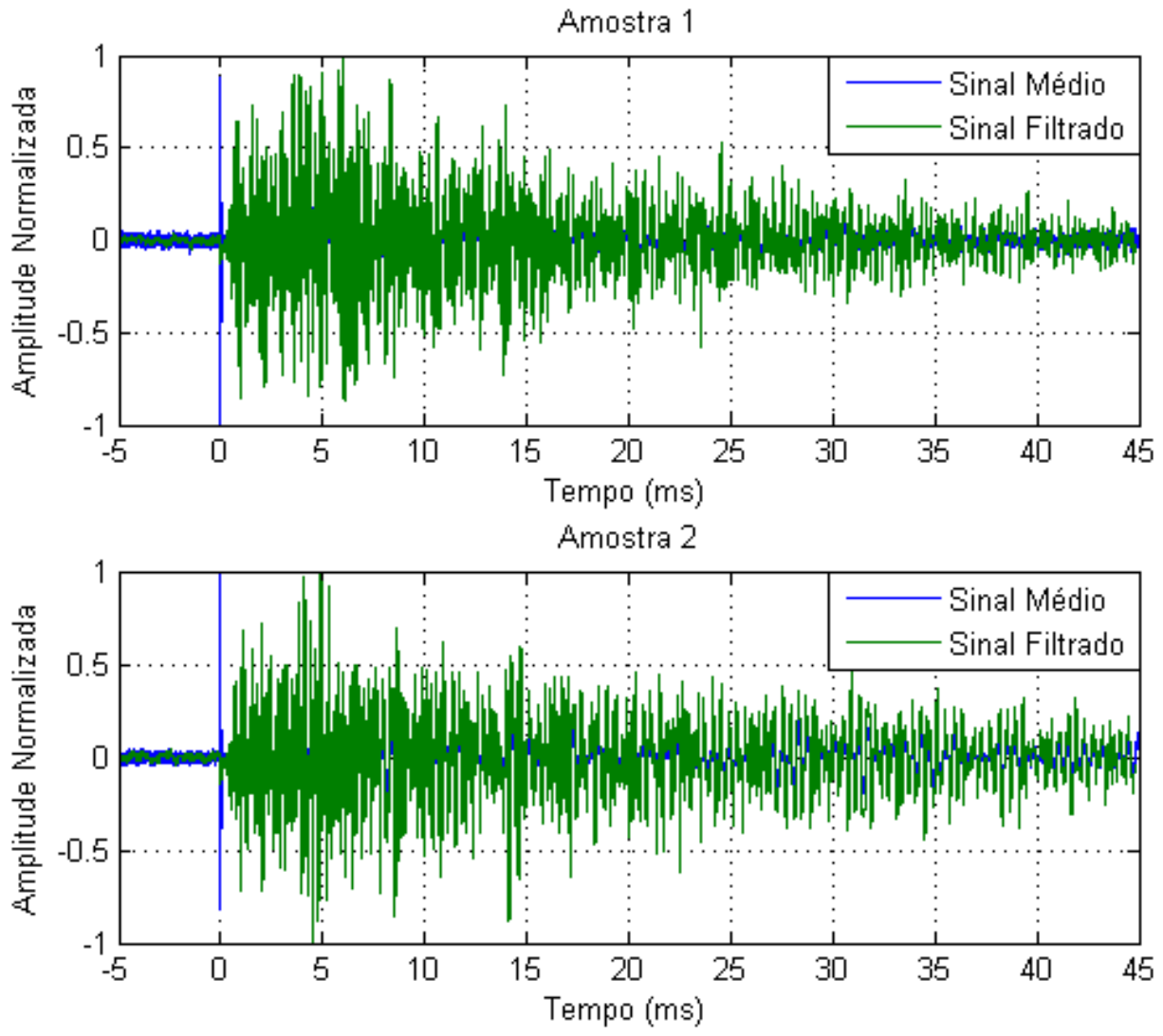

Amostra 3

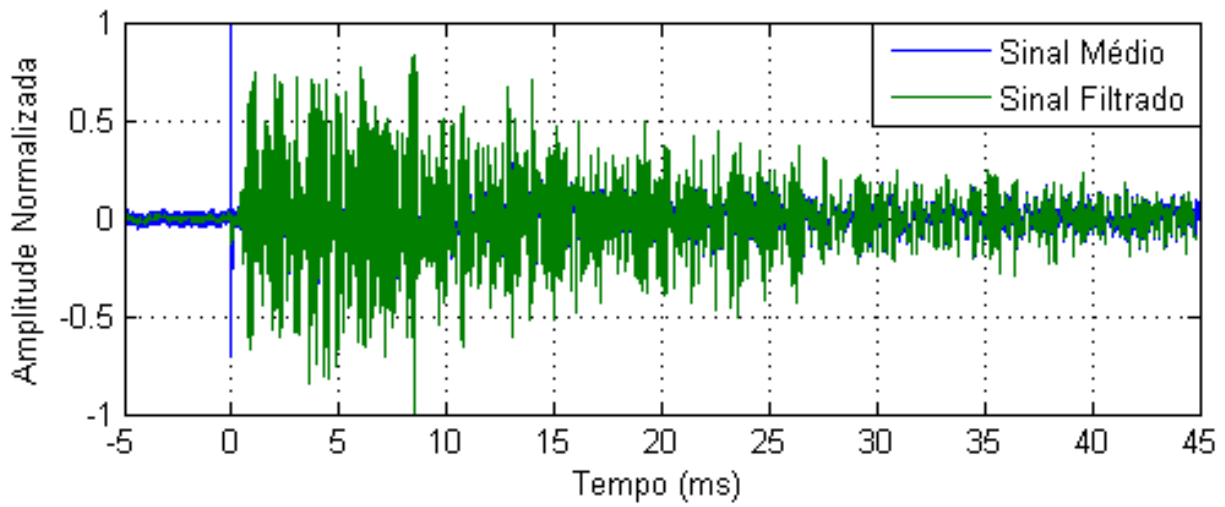

Figura 89: Resposta temporal média filtrada e não filtrada para cada amostra de piezoeletreto referente à posição P2. Descarga em ar, caixa 2. 

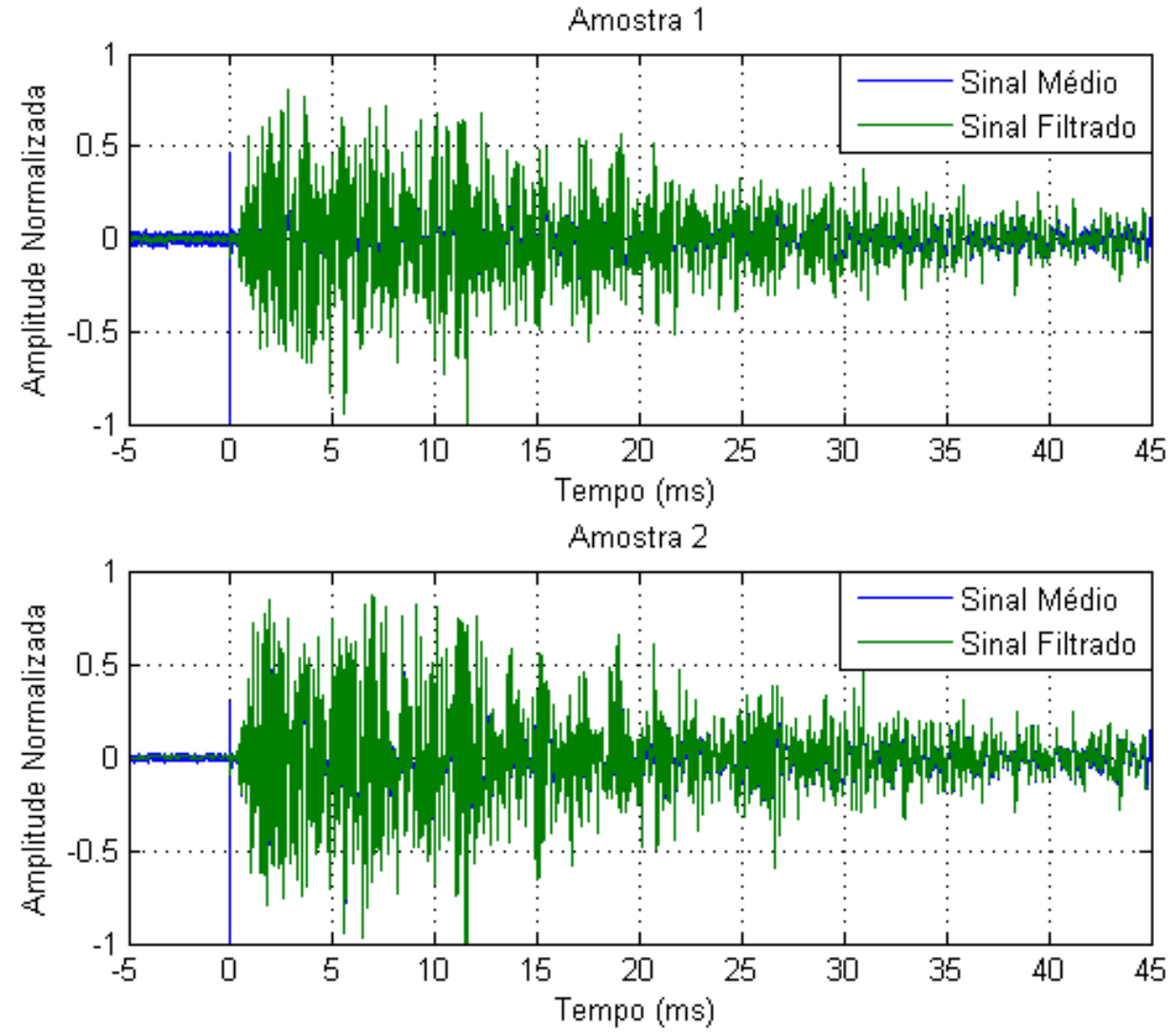

Amostra 3

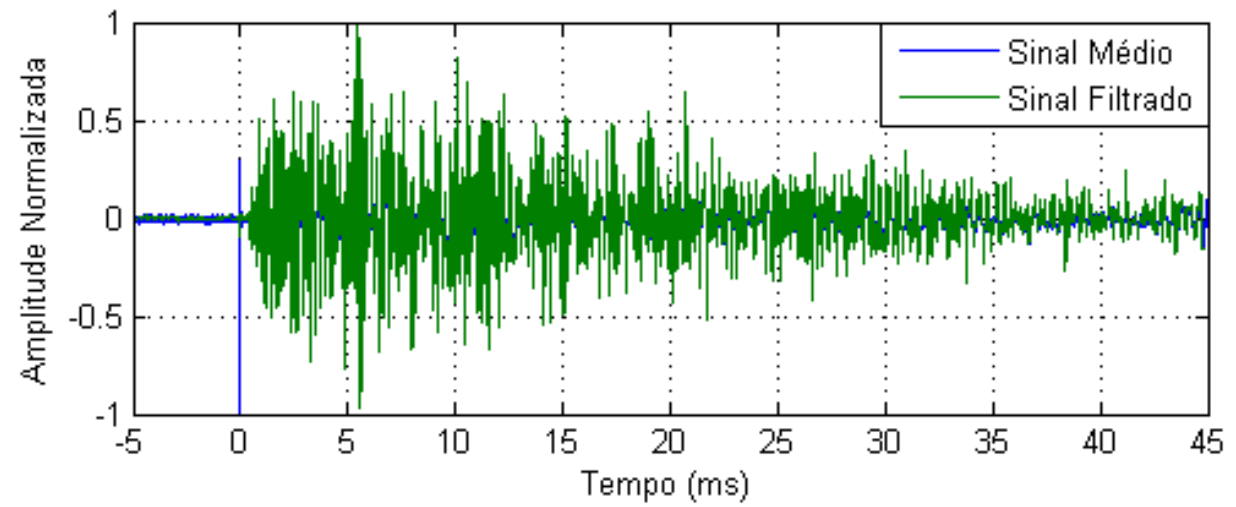

Figura 90: Resposta temporal média filtrada e não filtrada para cada amostra de piezoeletreto referente à posição P3. Descarga em ar, caixa 2. 

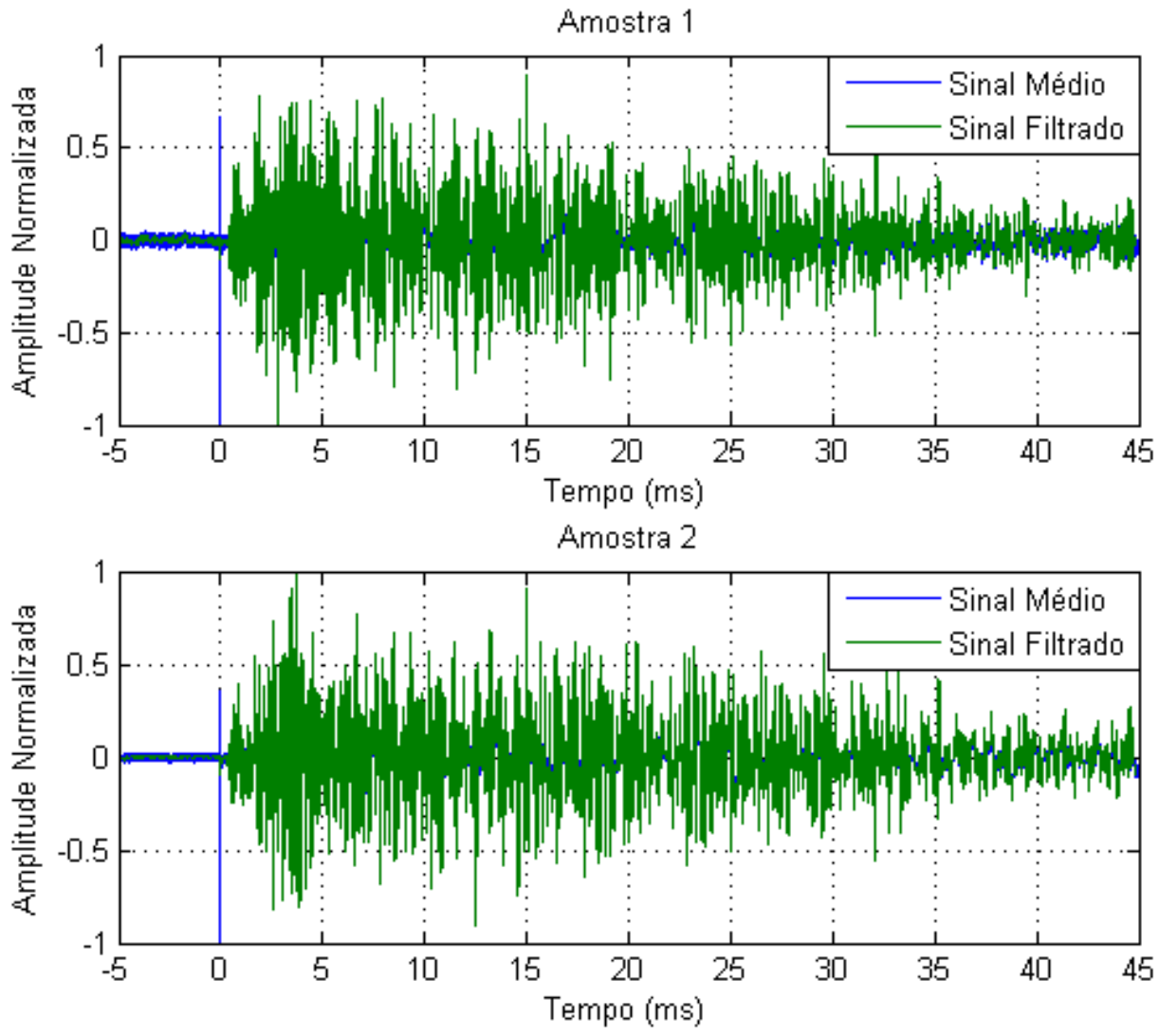

Amostra 3

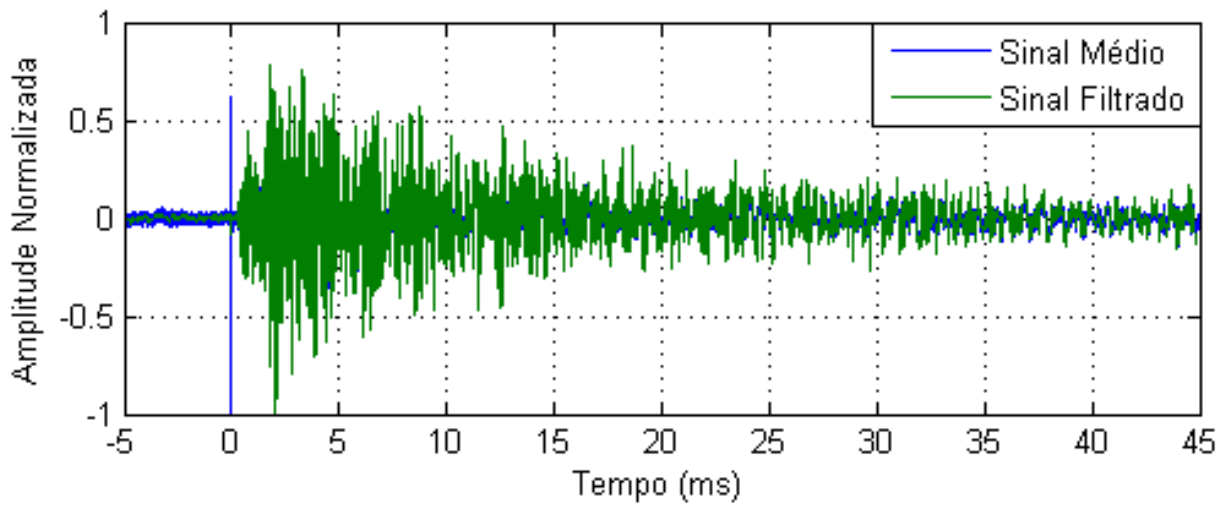

Figura 91: Resposta temporal média filtrada e não filtrada para cada amostra de piezoeletreto referente à posição $\mathrm{P} 4$. Descarga em ar, caixa 2. 

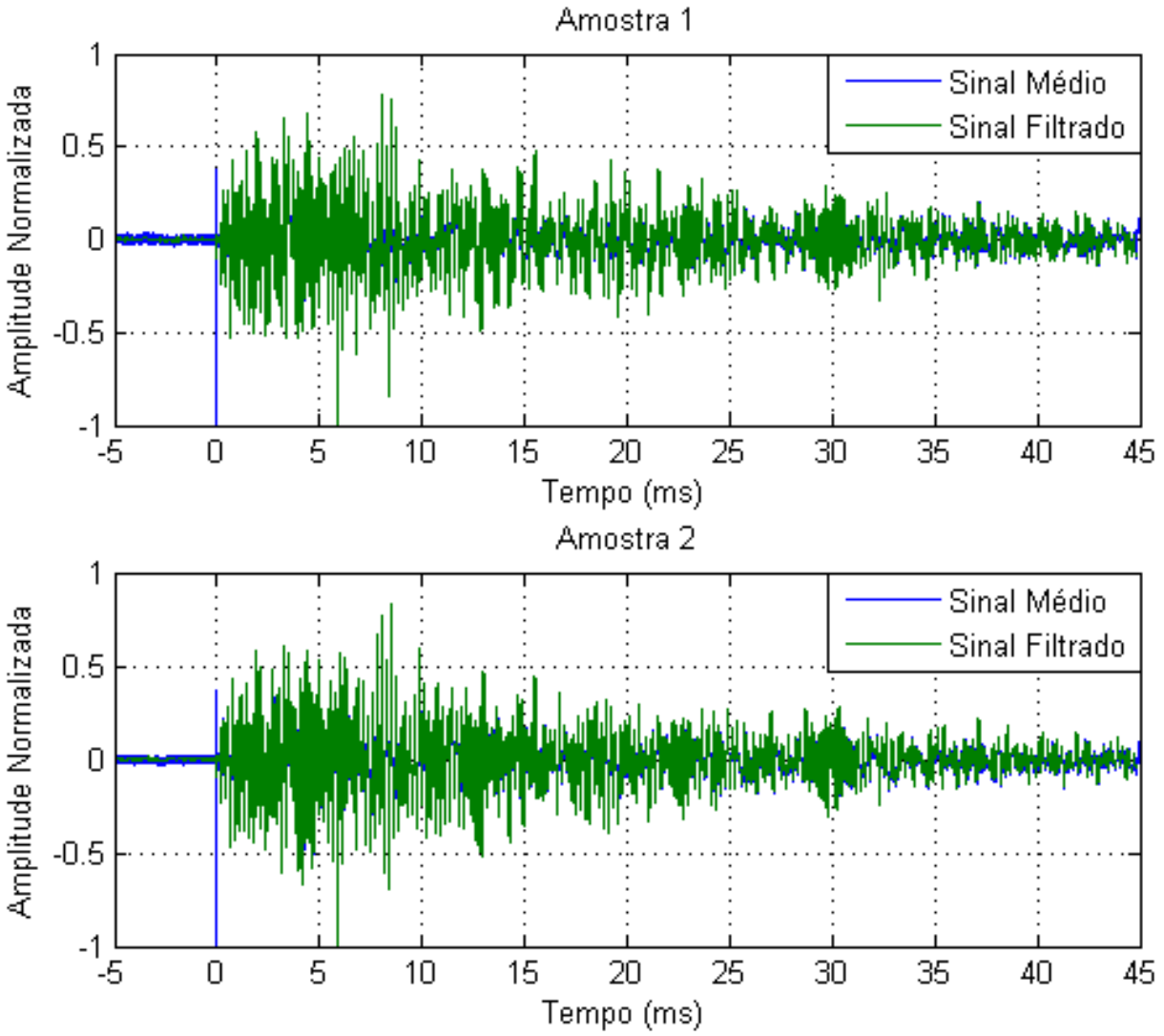

Amostra 3

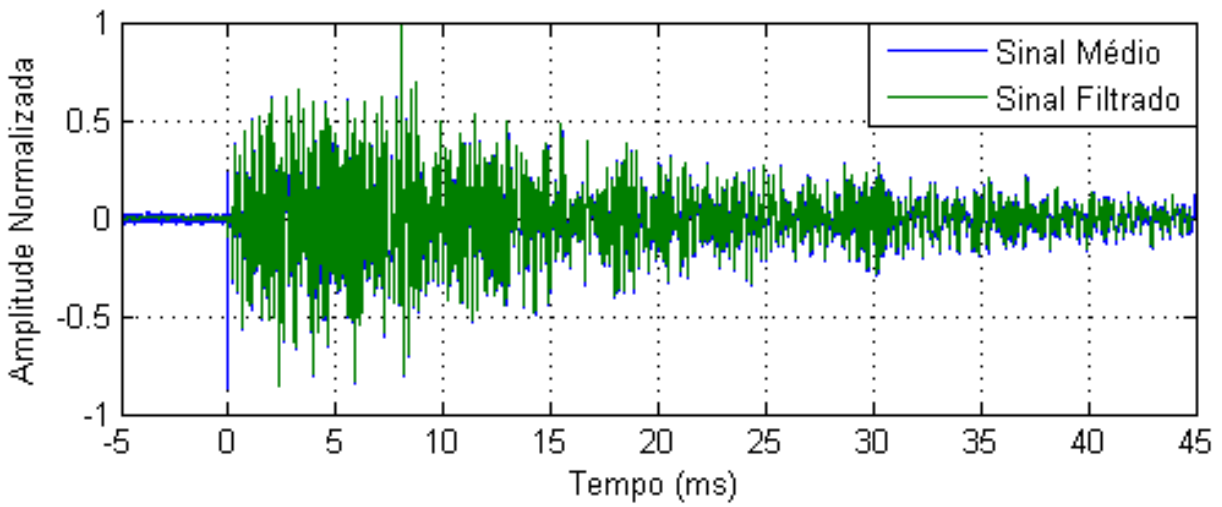

Figura 92: Resposta temporal média filtrada e não filtrada para cada amostra de piezoeletreto referente à posição P5. Descarga em ar, caixa 2. 

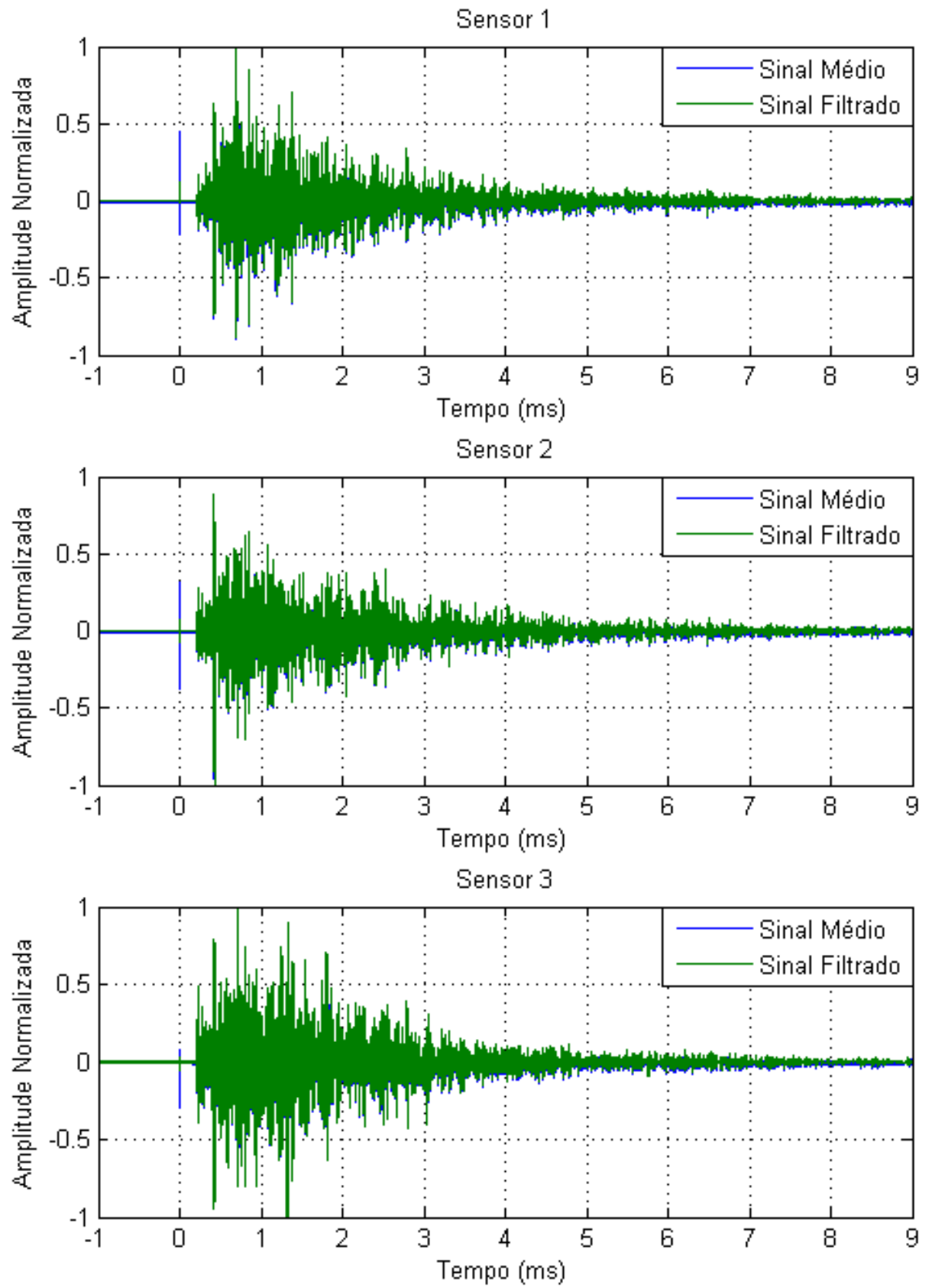

Figura 93: Resposta temporal média filtrada e não filtrada para cada sensor padrão referente à posição P1. Descarga em ar, caixa 2. 

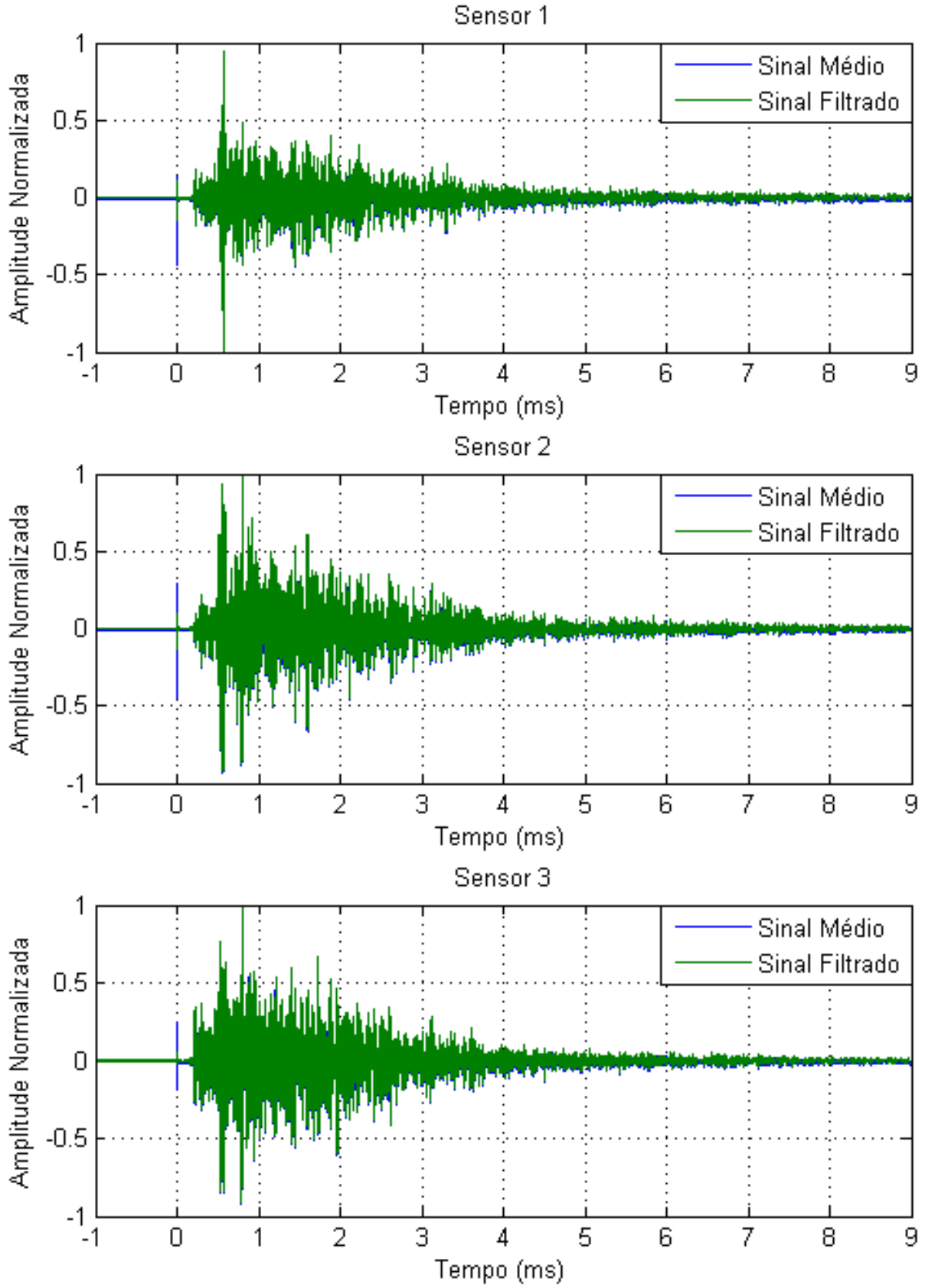

Figura 94: Resposta temporal média filtrada e não filtrada para cada sensor padrão referente à posição P2. Descarga em ar, caixa 2. 

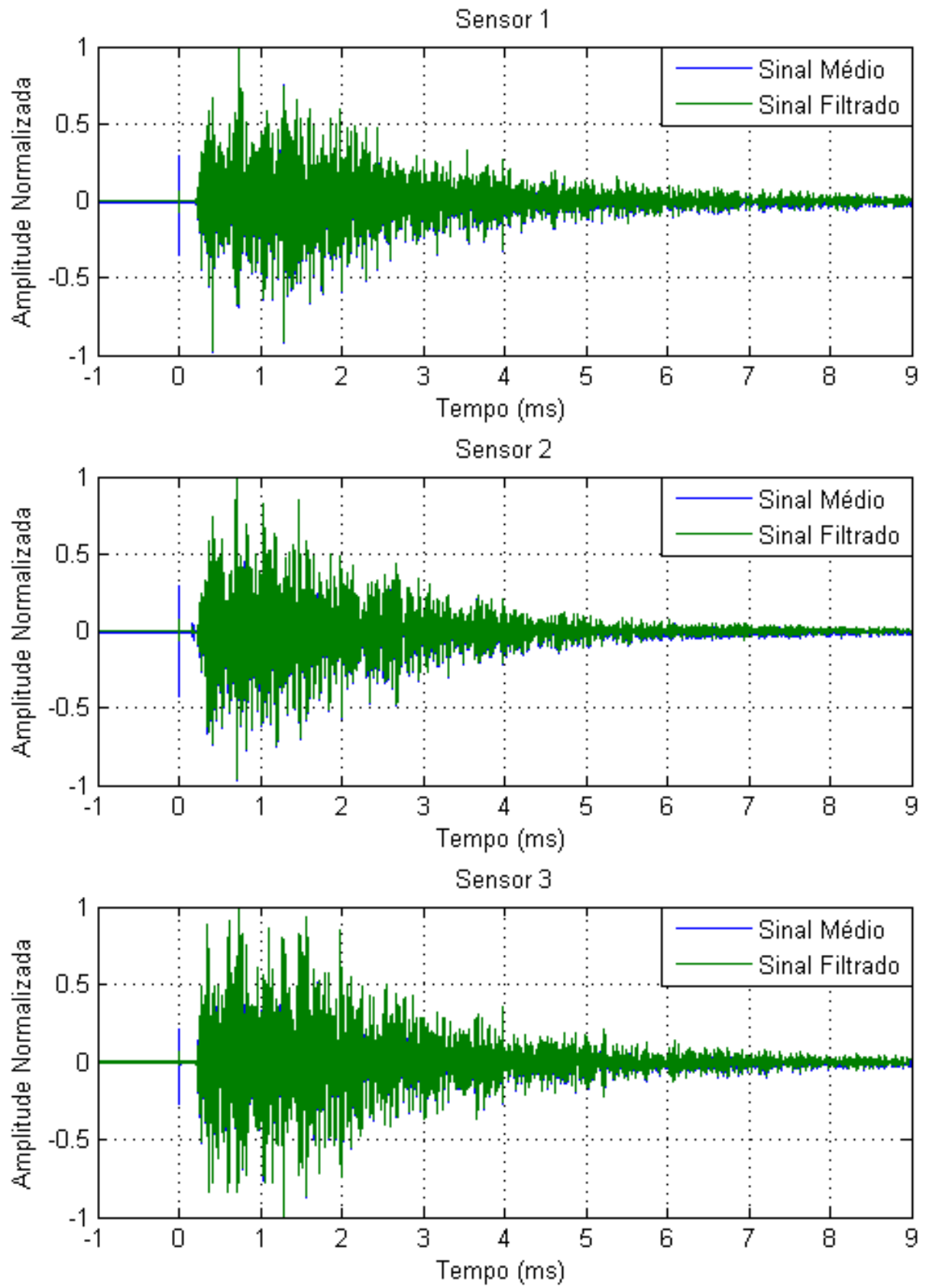

Figura 95: Resposta temporal média filtrada e não filtrada para cada sensor padrão referente à posição P3. Descarga em ar, caixa 2. 

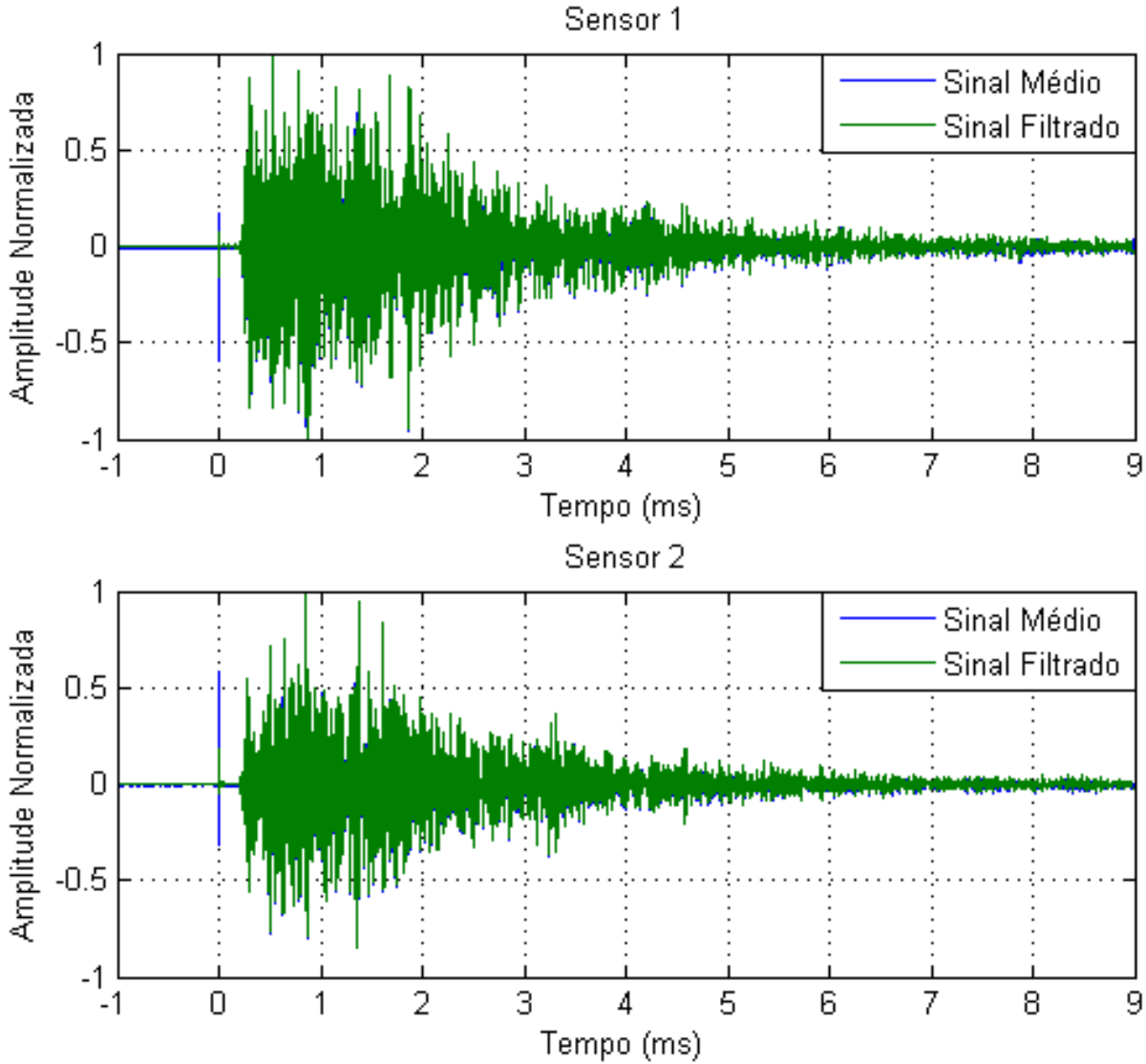

Sensor 3

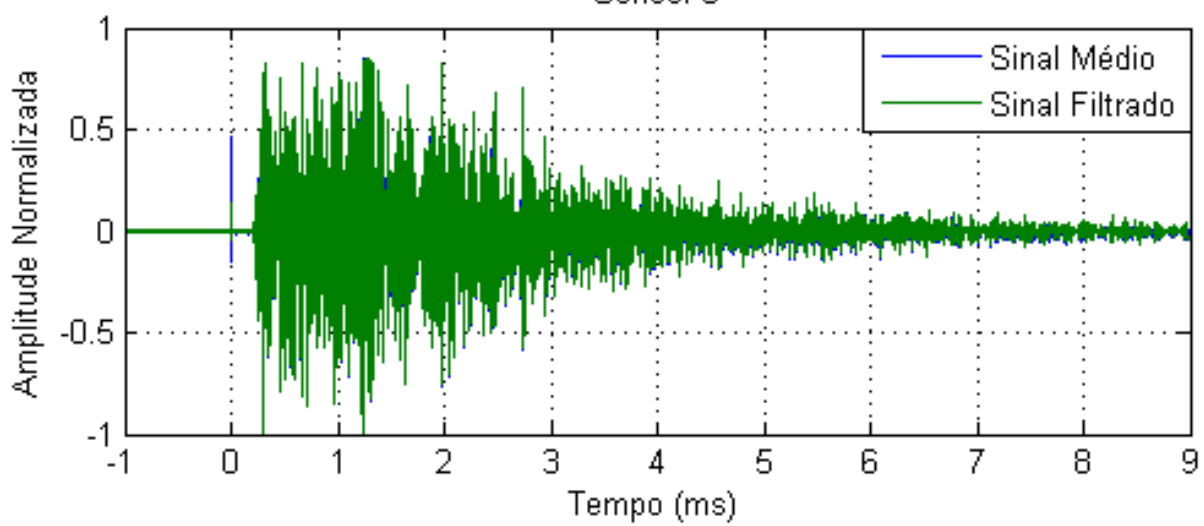

Figura 96: Resposta temporal média filtrada e não filtrada para cada sensor padrão referente à posição P4. Descarga em ar, caixa 2. 

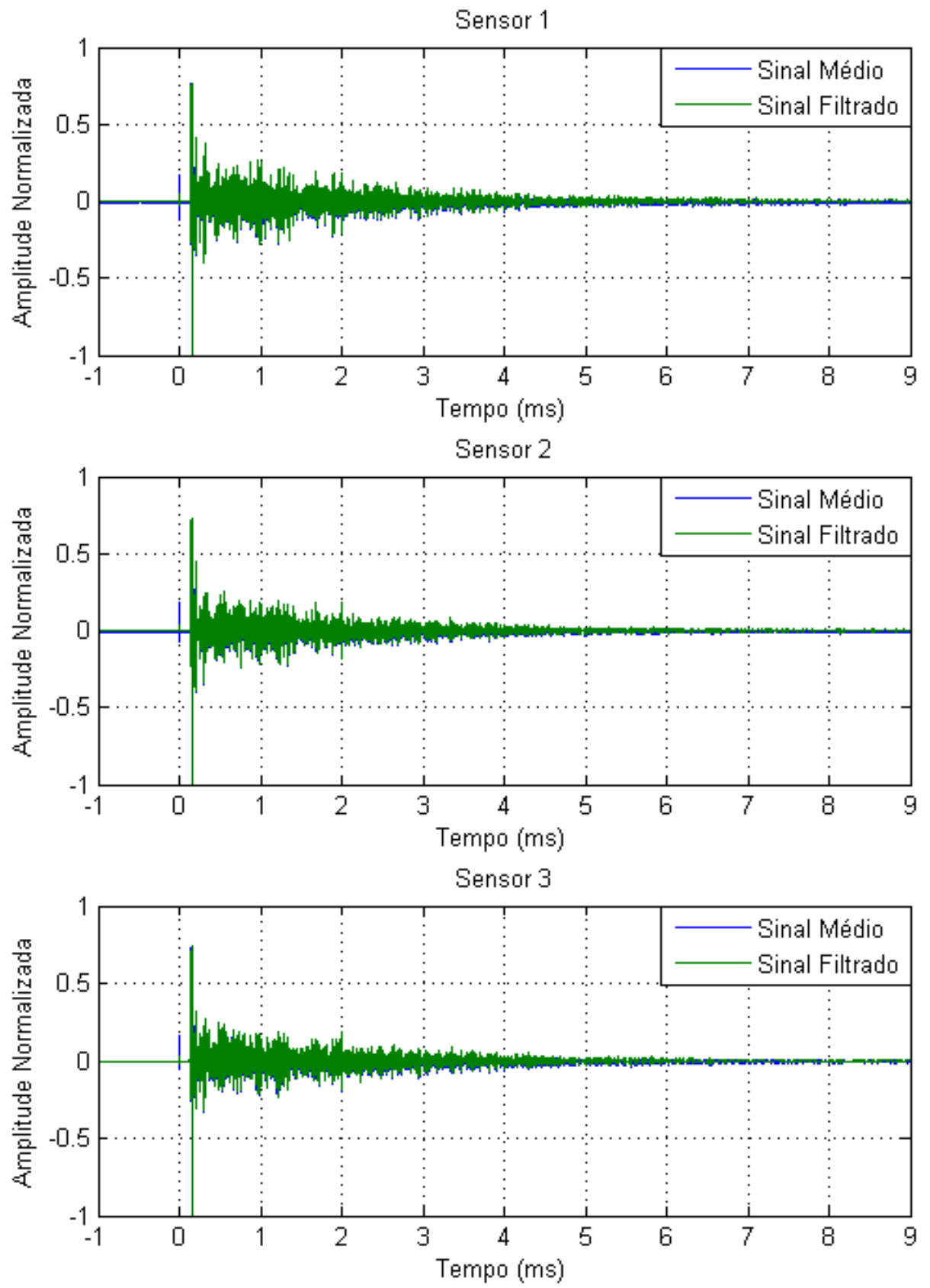

Figura 97: Resposta temporal média filtrada e não filtrada para cada sensor padrão referente à posição P5. Descarga em ar, caixa 2.

A Tabela 11 apresenta a quantidade de cruzamentos por zero com relação a cada posição de medida, cada amostra de piezoeletreto, cada janela e esta com duração de $5 \mathrm{~ms}$, da mesma forma que se procedeu no caso de descarga em ar, caixa 
1. A Tabela 12, por sua vez, apresentará o mesmo para os sensores padrão. Como é de praxe, neste caso a janela tem duração de $1 \mathrm{~ms}$. A Tabela 13 apresenta os tempos de corte, em us, nas curvas cepstrais para cada amostra/sensor. Como se sabe este tempo de corte está relacionado à reconstrução do sinal para posterior comparação com o sinal remodelado. A Tabela 14 contém os fatores de compressão aplicados aos espectros dos sinais originais das amostras e sensores, juntamente com as distâncias Euclidianas e de Chebychev para cada amostra/sensor e posição de medida. Neste caso foi necessário readequar a varredura dos fatores de compressão: em vez de um a quatro, como foi no caso da caixa 1, para de um a nove. Já a Tabela 15 contem as médias das relações sinal/ruído para cada amostra/sensor bem como os desvios padrão correspondente para cada posição de medida. Também contem a menor relação sinal/ruído para cada grupo de 25 medidas, da mesma forma que se procedeu na análise da caixa 1, e o coeficiente de variação percentual.

Tabela 11: Quantidade de cruzamentos por zero de acordo com a posição de medida, por amostra de piezoeletreto, por janela. Descarga em ar, caixa 2.

\begin{tabular}{cccccc}
\hline \multirow{2}{*}{ Posição } & Amostras & \multicolumn{5}{c}{ Janelas } \\
& & $\mathbf{0 - 5} \mathbf{~ m s}$ & $\mathbf{5 - 1 0} \mathbf{~ m s}$ & $\mathbf{1 0 - 1 5} \mathbf{~ m s}$ & $\mathbf{1 5 - 2 0} \mathbf{~ m s}$ \\
\hline \multirow{3}{*}{$\mathbf{P 1}$} & Amostra 1 & 146 & 126 & 83 & 78 \\
& Amostra 2 & 100 & 76 & 57 & 51 \\
& Amostra 3 & 161 & 103 & 79 & 58 \\
\hline \multirow{3}{*}{ P2 } & Amostra 1 & 87 & 87 & 69 & 70 \\
& Amostra 2 & 115 & 77 & 54 & 56 \\
\hline \multirow{3}{*}{ P3 } & Amostra 3 & 89 & 70 & 61 & 60 \\
& Amostra 1 & 89 & 75 & 58 & 72 \\
& Amostra 2 & 81 & 54 & 57 & 60 \\
\hline \multirow{3}{*}{ P4 } & Amostra 3 & 83 & 61 & 63 & 61 \\
\hline \multirow{2}{*}{ P5 } & Amostra 1 & 80 & 69 & 62 & 59 \\
& Amostra 2 & 84 & 65 & 62 & 55 \\
& Amostra 3 & 175 & 111 & 90 & 79 \\
\hline & Amostra 1 & 92 & 61 & 67 & 48 \\
\hline & Amostra 2 & 98 & 60 & 62 & 50 \\
\hline
\end{tabular}


Comparando-se as Tabelas 11 e 12, nota-se claramente que a quantidade de cruzamentos por zero cai à medida que se avança nas janelas do sinal para todas as posições de medida. Este resultado foi constatado na análise da caixa 1, descarga em ar, e se repete aqui, principalmente quando se compara primeira e última janela.

Tabela 12: Quantidade de cruzamentos por zero de acordo com a posição de medida, por sensor padrão, por janela. Descarga em ar, caixa 2.

\begin{tabular}{cccccc}
\hline \multirow{2}{*}{ Posição } & Sensores & \multicolumn{5}{c}{ Janelas } \\
& & $\mathbf{0 - 1} \mathbf{~ m s}$ & $\mathbf{1 - 2} \mathbf{~ m s}$ & $\mathbf{2 - 3} \mathbf{~ m s}$ & $\mathbf{3 - 4} \mathbf{~ m s}$ \\
\hline \multirow{3}{*}{$\mathbf{P 1}$} & Sensor 1 & 186 & 145 & 139 & 139 \\
& Sensor 2 & 187 & 148 & 129 & 130 \\
& Sensor 3 & 190 & 161 & 148 & 134 \\
\hline \multirow{2}{*}{ P2 } & Sensor 1 & 176 & 167 & 161 & 131 \\
& Sensor 2 & 208 & 178 & 160 & 147 \\
& Sensor 3 & 213 & 189 & 160 & 147 \\
\hline \multirow{2}{*}{ P3 } & Sensor 1 & 208 & 159 & 148 & 131 \\
& Sensor 2 & 215 & 159 & 150 & 142 \\
& Sensor 3 & 241 & 166 & 147 & 142 \\
\hline \multirow{2}{*}{ P4 } & Sensor 1 & 199 & 162 & 153 & 143 \\
& Sensor 2 & 239 & 169 & 155 & 155 \\
& Sensor 3 & 214 & 160 & 150 & 136 \\
\hline \multirow{2}{*}{ P5 } & Sensor 1 & 190 & 164 & 168 & 140 \\
& Sensor 2 & 210 & 168 & 168 & 152 \\
& Sensor 3 & 197 & 177 & 167 & 151 \\
\hline
\end{tabular}

Tabela 13: Tempo de corte, em us, na curva cepstral para as amostras e sensores conforme a posição de medida. Descarga em ar, caixa 2.

\begin{tabular}{cccccc}
\hline Posição de Medida & P1 & P2 & P3 & P4 & P5 \\
Amostras/Sensores & & & & & \\
\hline Amostra 1 & 33,5 & 69,5 & 74,5 & 69,5 & 33,5 \\
Amostra 2 & 33,5 & 69,5 & 79,5 & 59,5 & 33,5 \\
Amostra 3 & 34,5 & 69,5 & 59,5 & 34,5 & 34,5 \\
Sensor 1 & 12,9 & 9,9 & 8,9 & 7,9 & 8,9 \\
Sensor 2 & 12,9 & 9,9 & 8,9 & 11,9 & 8,9 \\
Sensor 3 & 12,9 & 9,9 & 8,9 & 7,9 & 8,9 \\
\hline
\end{tabular}


Tabela 14: Distâncias mínimas e fatores de compressão referentes a estas distâncias para cada amostra de piezoeletreto e sensor padrão de acordo com a posição de medida (DE: distância Euclidiana; DC: distância de Chebychev). Descarga em ar, caixa 2.

\begin{tabular}{|c|c|c|c|c|c|}
\hline Posição & Amostras/Sensores & $\mathrm{DE}$ & Fator (via DE) & $\mathrm{DC}$ & Fator (via DC) \\
\hline \multirow{6}{*}{$\mathbf{P} 1$} & Amostra 1 & 2,11 & 2,9 & 0,240 & 2,9 \\
\hline & Amostra 2 & 3,54 & 3,5 & 0,334 & 3,7 \\
\hline & Amostra 3 & 2,80 & 3,1 & 0,307 & 3,3 \\
\hline & Sensor 1 & 3,80 & 1,5 & 0,367 & 1,5 \\
\hline & Sensor 2 & 4,25 & 1,8 & 0,390 & 1,7 \\
\hline & Sensor 3 & 5,69 & 1,6 & 0,512 & 1,6 \\
\hline \multirow{6}{*}{ P2 } & Amostra 1 & 2,68 & 6,0 & 0,284 & 5,7 \\
\hline & Amostra 2 & 3,87 & 7,3 & 0,317 & 7,2 \\
\hline & Amostra 3 & 2,97 & 6,9 & 0,378 & 8,3 \\
\hline & Sensor 1 & 3,65 & 1,4 & 0,394 & 1,3 \\
\hline & Sensor 2 & 5,11 & 1,4 & 0,502 & 1,5 \\
\hline & Sensor 3 & 4,95 & 1,3 & 0,549 & 1,2 \\
\hline \multirow{6}{*}{ P3 } & Amostra 1 & 2,75 & 7,0 & 0,307 & 7,1 \\
\hline & Amostra 2 & 2,95 & 5,0 & 0,281 & 4,5 \\
\hline & Amostra 3 & 2,70 & 7,7 & 0,248 & 7,7 \\
\hline & Sensor 1 & 3,96 & 1,4 & 0,397 & 1,4 \\
\hline & Sensor 2 & 3,99 & 1,5 & 0,434 & 1,5 \\
\hline & Sensor 3 & 5,80 & 1,5 & 0,548 & 1,5 \\
\hline \multirow{6}{*}{$\mathrm{P} 4$} & Amostra 1 & 2,99 & 6,0 & 0,335 & 7,6 \\
\hline & Amostra 2 & 3,42 & 7,9 & 0,399 & 8,0 \\
\hline & Amostra 3 & 2,44 & 2,8 & 0,275 & 3,0 \\
\hline & Sensor 1 & 4,19 & 1,4 & 0,416 & 1,5 \\
\hline & Sensor 2 & 4,36 & 1,5 & 0,427 & 1,6 \\
\hline & Sensor 3 & 5,46 & 1,5 & 0,549 & 1,5 \\
\hline \multirow{6}{*}{ P5 } & Amostra 1 & 2,37 & 3,6 & 0,263 & 3,6 \\
\hline & Amostra 2 & 3,64 & 5,0 & 0,348 & 3,6 \\
\hline & Amostra 3 & 3,13 & 3,6 & 0,295 & 3,6 \\
\hline & Sensor 1 & 3,73 & 1,3 & 0,386 & 1,2 \\
\hline & Sensor 2 & 4,08 & 1,2 & 0,437 & 1,2 \\
\hline & Sensor 3 & 4,97 & 1,3 & 0,576 & 1,2 \\
\hline
\end{tabular}


Tabela 15: Média das relações sinal/ruído $(\mu)$, desvio padrão $(\sigma)$, menor relação $(M R)$ e coeficiente de variação percentual $\left(\boldsymbol{C}_{\boldsymbol{v}}\right)$ para todas as amostras e sensores de acordo com a posição de medida.

Descarga em ar, caixa 2.

\begin{tabular}{|c|c|c|c|c|c|}
\hline Posição & Amostras/Sensores & $\mu$ & $\sigma$ & $M R$ & $C_{v}(\%)$ \\
\hline \multirow{6}{*}{$\mathbf{P} 1$} & Amostra 1 & 8,45 & 0,861 & 6,61 & 10,2 \\
\hline & Amostra 2 & 37,28 & 3,37 & 30,92 & 9,0 \\
\hline & Amostra 3 & 11,92 & 1,38 & 9,48 & 11,6 \\
\hline & Sensor 1 & 453,7 & 25,82 & 402,6 & 5,7 \\
\hline & Sensor 2 & 491,2 & 54,16 & 384,9 & 11,0 \\
\hline & Sensor 3 & 589,0 & 34,73 & 509,8 & 5,9 \\
\hline \multirow{6}{*}{ P2 } & Amostra 1 & 9,65 & 0,76 & 8,31 & 7,9 \\
\hline & Amostra 2 & 6,30 & 1,56 & 3,18 & 24,8 \\
\hline & Amostra 3 & 19,27 & 1,46 & 15,08 & 7,6 \\
\hline & Sensor 1 & 351,0 & 71,7 & 246,2 & 20,4 \\
\hline & Sensor 2 & 790,9 & 202,2 & 383,2 & 25,6 \\
\hline & Sensor 3 & 642,5 & 103,5 & 493,6 & 16,1 \\
\hline \multirow{6}{*}{ P3 } & Amostra 1 & 13,12 & 1,52 & 9,29 & 11,6 \\
\hline & Amostra 2 & 76,15 & 9,87 & 45,41 & 13,0 \\
\hline & Amostra 3 & 38,87 & 4,91 & 29,52 & 12,6 \\
\hline & Sensor 1 & 487,1 & 111,8 & 293,8 & 23,0 \\
\hline & Sensor 2 & 793,5 & 104,1 & 611,1 & 13,1 \\
\hline & Sensor 3 & 1054,2 & 305,1 & 440,8 & 28,9 \\
\hline \multirow{6}{*}{ P4 } & Amostra 1 & 10,02 & 0,77 & 8,43 & 7,4 \\
\hline & Amostra 2 & 33,99 & 3,24 & 27,89 & 9,5 \\
\hline & Amostra 3 & 10,46 & 0,74 & 8,70 & 7,1 \\
\hline & Sensor 1 & 1167,8 & 238,1 & 815,1 & 20,4 \\
\hline & Sensor 2 & 769,7 & 139,2 & 514,2 & 18,1 \\
\hline & Sensor 3 & 1063,3 & 238,9 & 560,2 & 22,5 \\
\hline \multirow{6}{*}{ P5 } & Amostra 1 & 21,06 & 2,80 & 15,70 & 13,3 \\
\hline & Amostra 2 & 38,54 & 4,45 & 30,70 & 11,5 \\
\hline & Amostra 3 & 51,24 & 6,95 & 38,63 & 13,6 \\
\hline & Sensor 1 & 197,2 & 9,95 & 169,0 & 5,0 \\
\hline & Sensor 2 & 217,1 & 8,67 & 195,8 & 4,0 \\
\hline & Sensor 3 & 163,2 & 12,20 & 130,3 & 7,5 \\
\hline
\end{tabular}

As Figuras 98 a 102 apresentam os sinais remodelados, reconstruídos e processados para cada amostra de piezoeletreto e sensor padrão. Lembra-se que o 
"sinal processado" refere-se à forma de onda captada cuja relação sinal/ruído é a menor das 25 coletadas para cada amostra/sensor. Neste caso não houve necessidade de se reduzir o tempo de corte na curva cepstral para reconstrução do sinal processado, ou seja, o tempo foi o mesmo tanto para os sinais reconstruídos quanto para os processados.

Analisando-se a Tabela 14, nota-se uma boa estabilidade dos fatores de compressão quanto aos sensores padrão. E estes fatores estão bastante próximos dos que foram apresentados na Tabela 6 (descarga em ar, caixa 1). Esta observação é muito importante, tendo em vista que isto pode apontar para a conclusão de que não importa muito o tipo de caixa ou a posição de medida, o sinal reconstruído via deconvolução homomórfica será similar ao sinal original (em fase mínima) com um fator de compressão aplicado no espectro deste, ou seja, o sinal remodelado. O mesmo já não se verifica para as amostras de piezoeletreto. Especificamente para as posições P2 a P4, os fatores variaram, com exceção do fator da posição P4/amostra 3, entre 5,0 e 7,9. Provavelmente isto ocorreu em decorrência da baixa relação sinal/ruído (Tabela 15) juntamente com a posição de medida: para as posições P1 e P5, mesmo tendo-se uma baixa relação sinal/ruído, os sinais reconstruídos, Figuras 98 a 102, não apresentaram as mesmas distorções constatadas nos sinais referentes às posições P2 a P4. Ademais, para estas posições (P2 a P4) foi necessário avançar o tempo de corte na curva cepstral, de modo que se tornasse mais evidente a semelhança entre os sinais remodelados e reconstruídos. E nesse avanço apareceram componentes que distorceram os sinais reconstruídos, ou seja, além do sinal básico reconstruído que se observou nas posições P1 e P5, outras componentes foram inseridas prejudicando a reconstrução dos sinais. No caso dos sensores, onde a relação sinal/ruído é bastante superior, praticamente não se verificou distorções para todas as posições. Mesmo assim é digno de nota que, quase todas as distâncias Euclidianas mensuradas para os sinais das amostras foram menores que a as distâncias dos sinais dos sensores, ou seja, tem-se uma similaridade maior para os sinais reconstruídos das amostras. Quanto à Tabela 15, embora ainda pequena a relação sinal/ruído para as amostras, o coeficiente de variação, no geral, foi menor quando se compara com a Tabela 7. Já para os sensores houve uma sensível variação de acordo com a posição de medida. Por exemplo: para as posições P1 e P5 houve queda comparando-se com a Tabela 7, ao passo que, para as demais posições, os coeficientes apresentaram-se de certa forma próximos ou superiores comparando-se com a mesma tabela. Provavelmente isto mostre que as dispersões relativas das relações sinal/ruído provenientes dos sensores 
sejam mais sensíveis quando se muda a posição de medida. Todavia, analisando-se as Figuras 98 a 102, a priori isto não exerceu influência nos sinais reconstruídos e processados. Talvez porque a relação sinal/ruído apresentou-se consideravelmente elevada, mesmo para a menor relação.

Prosseguindo na análise, a Tabela 16 apresenta a média, o desvio padrão e o coeficiente de variação dos fatores de compressão para cada amostra/sensor referentes às duas caixas, e com respeito à situação de descarga em ar. Observa-se que estes são valores aproximados. Todos os dados foram calculados baseados nas Tabelas 6 e 14 .

Tabela 16: Média dos fatores de compressão $(\mu)$, desvio padrão e coeficiente de variação $\left(\boldsymbol{C}_{\boldsymbol{v}}\right)$ para cada amostra/sensor referente às descargas em ar para as caixas 1 e 2 .

\begin{tabular}{cccc}
\hline Amostras/Sensores & $\boldsymbol{\mu}$ & $\boldsymbol{\sigma}$ & $\boldsymbol{C}_{\boldsymbol{v}}(\boldsymbol{\%})$ \\
\hline Amostra 1 & 4,83 & 1,70 & 35,2 \\
Amostra 2 & 5,37 & 1,87 & 34,8 \\
Amostra 3 & 4,62 & 2,12 & 45,8 \\
Sensor 1 & 1,38 & 0,075 & 5,4 \\
\hline Sensor 2 & 1,50 & 0,20 & 13,3 \\
\hline Sensor 3 & 1,45 & 0,123 & 8,4 \\
\hline
\end{tabular}

Realmente chama atenção quando se analisa o coeficiente de variação dos sensores padrão, ou seja, o peso percentual do desvio padrão na média é relativamente pequeno. Este é um dado bastante interessante, isto é, não importa muito o tipo de caixa ou a posição de medida: o fator de compressão espectral é praticamente o mesmo para todas essas situações, de acordo com cada sensor. Já para as amostras, como os fatores de compressão variaram consideravelmente, isto resultou em coeficientes de variação superiores em relação aos dos sensores. Isto é um indicativo de melhora a ser realizado no microfone, e talvez a principal seja a elevação da relação sinal/ruído nos casos de descarga em ar. A Tabela 17 apresenta a média geral de todos os fatores de compressão, o desvio padrão e o coeficiente de variação percentual tomando-se todas as amostras e sensores. Como se vê, um coeficiente de variação de, aproximadamente, $10 \%$ para os sensores, reafirma a certa independência do tipo de caixa e localização da medida para a reconstrução de um mesmo sinal. Quanto à forma destes sinais reconstruídos, as Figuras 98 a 102 apresentam que são praticamente os mesmos quando se comparam com os sinais remodelados. 
Tabela 17: Média geral dos fatores de compressão $(\mu)$, desvio padrão e coeficiente de variação $\left(\boldsymbol{C}_{\boldsymbol{v}}\right)$ para cada grupo de amostras/sensores referente às descargas em ar para as caixas 1 e 2.

\begin{tabular}{cccc}
\hline & $\boldsymbol{\mu}$ & $\boldsymbol{\sigma}$ & $\boldsymbol{C}_{\boldsymbol{v}}(\boldsymbol{\%})$ \\
\hline Amostras & 4,94 & 1,82 & 36,8 \\
Sensores & 1,44 & 0,142 & 9,9 \\
\hline
\end{tabular}
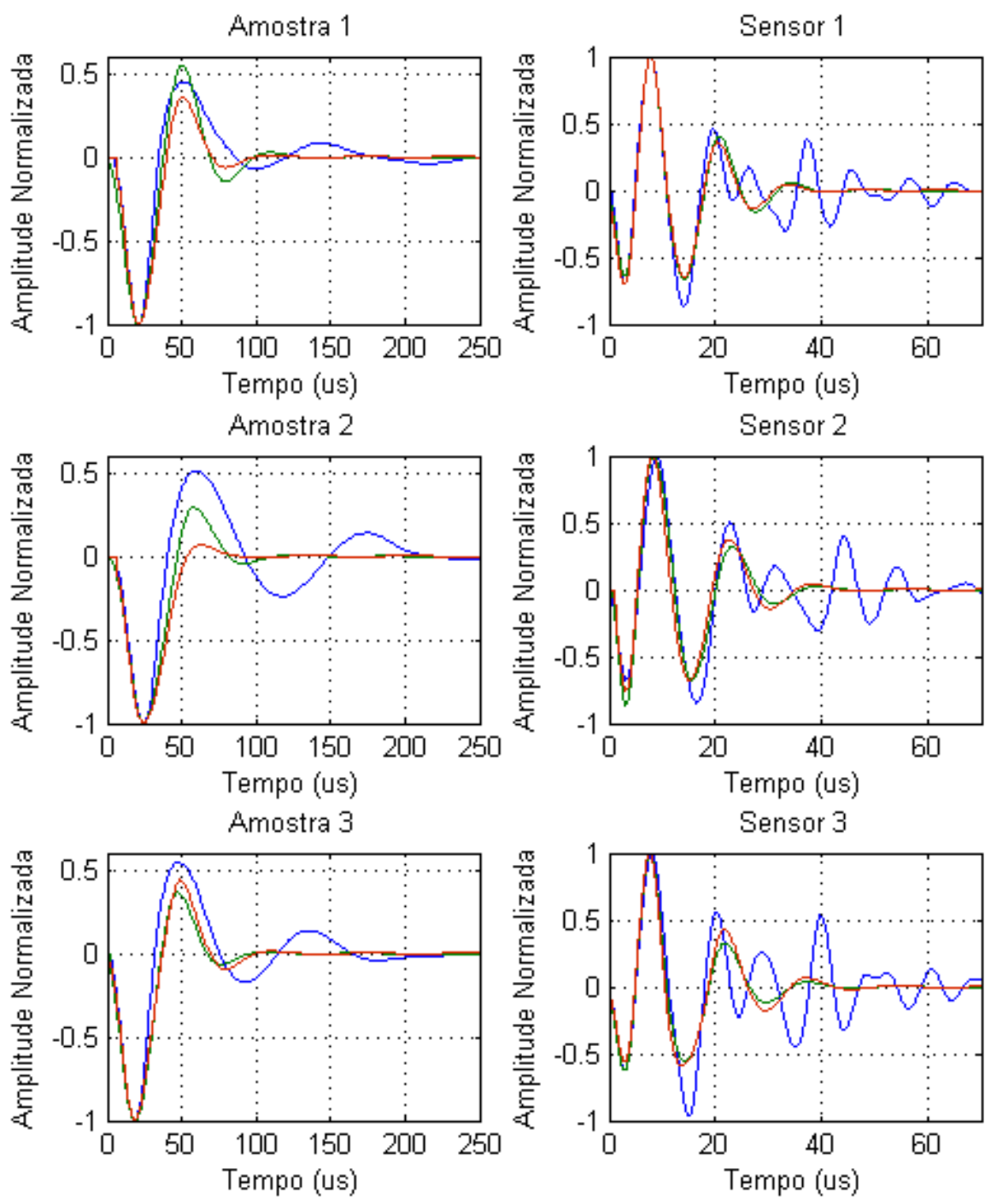

Figura 98: Sinal remodelado (azul), reconstruído (verde) e processado (vermelho) para todas as amostras de piezoeletreto e sensores padrão. Descarga em ar, caixa 2, posição P1. 

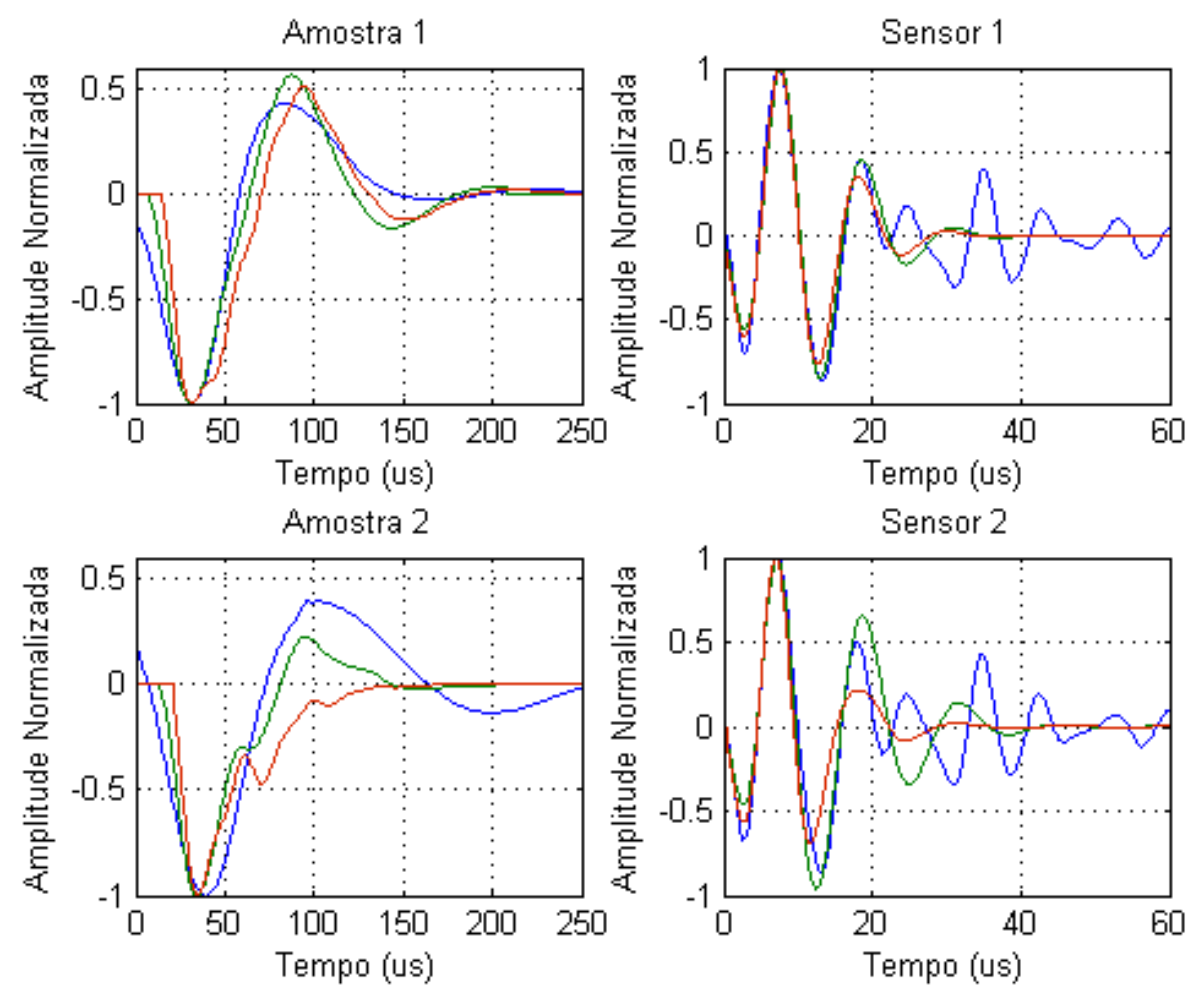

Amostra 3
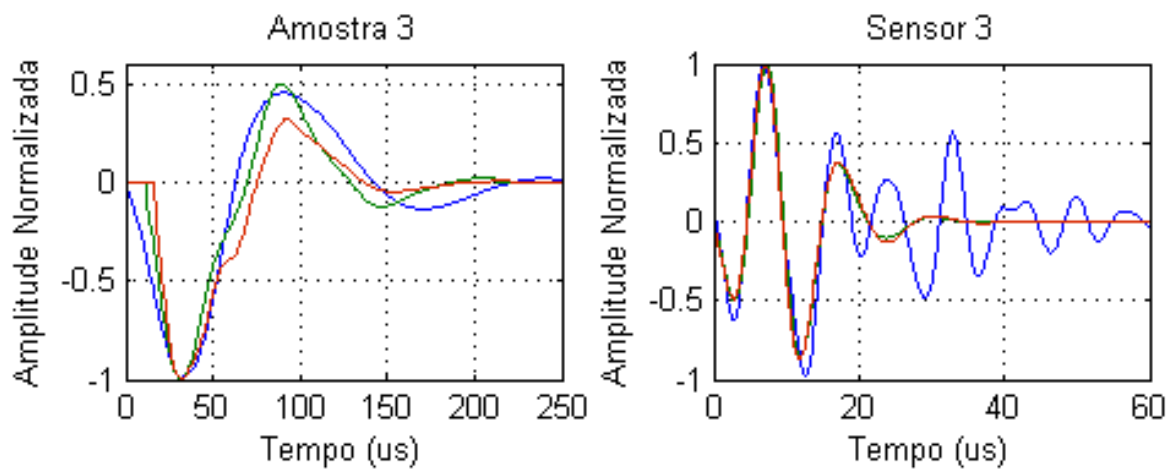

Figura 99: Sinal remodelado (azul), reconstruído (verde) e processado (vermelho) para todas as amostras de piezoeletreto e sensores padrão. Descarga em ar, caixa 2, posição P2.

Por fim, é importante mencionar que, neste caso, a amplitude de pico a pico dos sinais das amostras foi menor comparando-se com os sinais provenientes da caixa 1. Por exemplo: a amplitude de pico a pico máxima para a caixa 1, amostra 1, ficou em torno de $81 \mathrm{mV}$. Comparando-se com a medida tomada na posição P1 para a caixa 2, pois o centelhador está no centro em ambos os casos, a amplitude de pico a pico máxima foi de, aproximadamente, $47 \mathrm{mV}$, ou seja, quase a metade do valor. Já a amplitude de pico a pico máxima para o sensor 1, por exemplo, ficou em torno de 351 $\mathrm{mV}$ e $339 \mathrm{mV}$, caixa 1 e 2 (posição P1) respectivamente. Portanto, a queda na 
amplitude do sinal captado pelas amostras pode ter sido o responsável pela queda na qualidade dos sinais reconstruídos, quando se compara a Figura 78 (descarga em ar, caixa 1) com as Figuras 98 a 102. O motivo da queda das amplitudes dos sinais pode estar associado à resposta em frequência da própria amostra, haja vista que esta possui reposta aproximadamente plana (Figura 33) e os sensores ressoam em torno de $150 \mathrm{kHz}$, conforme apresenta o Anexo A.
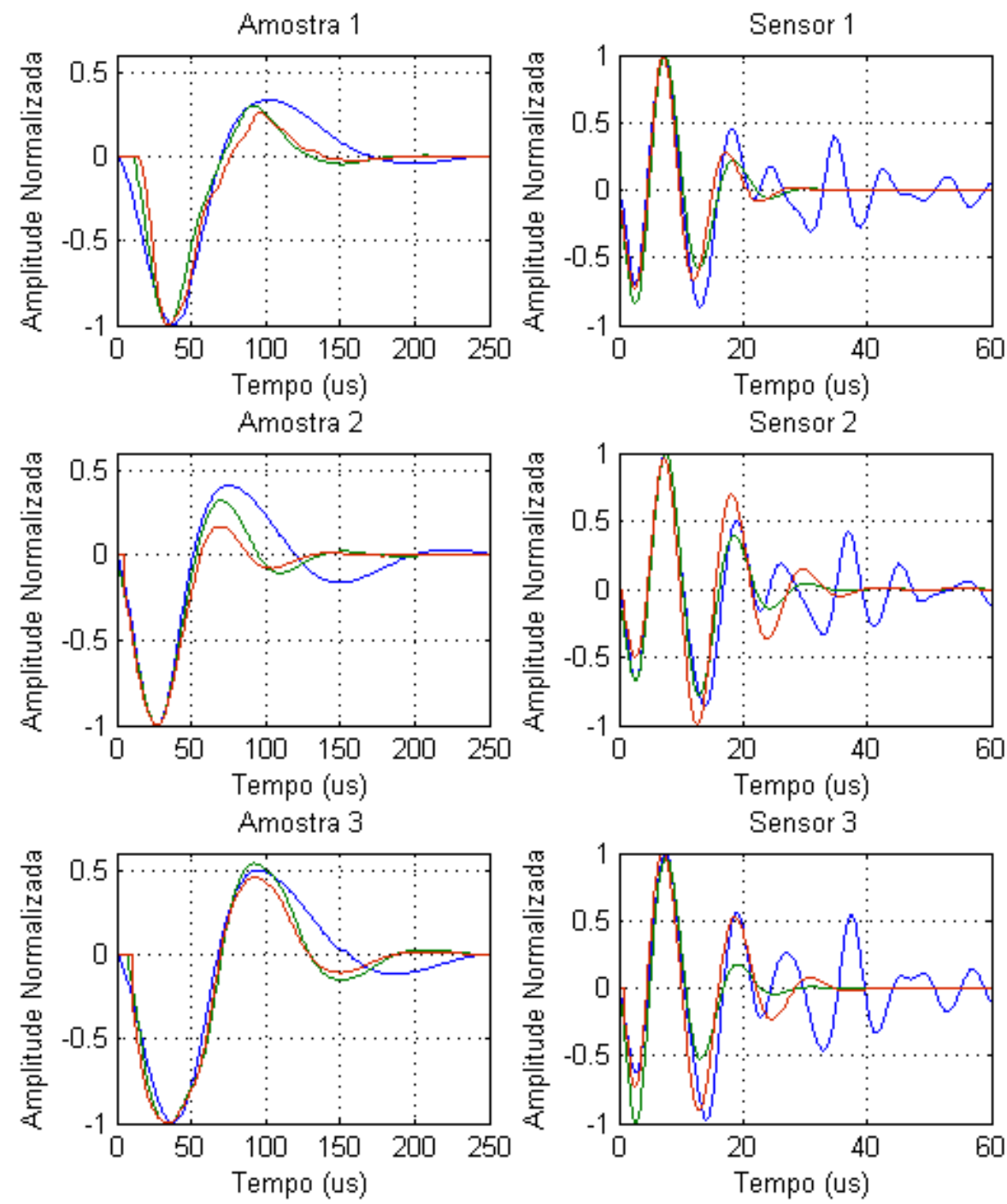

Figura 100: Sinal remodelado (azul), reconstruído (verde) e processado (vermelho) para todas as amostras de piezoeletreto e sensores padrão. Descarga em ar, caixa 2, posição P3. 

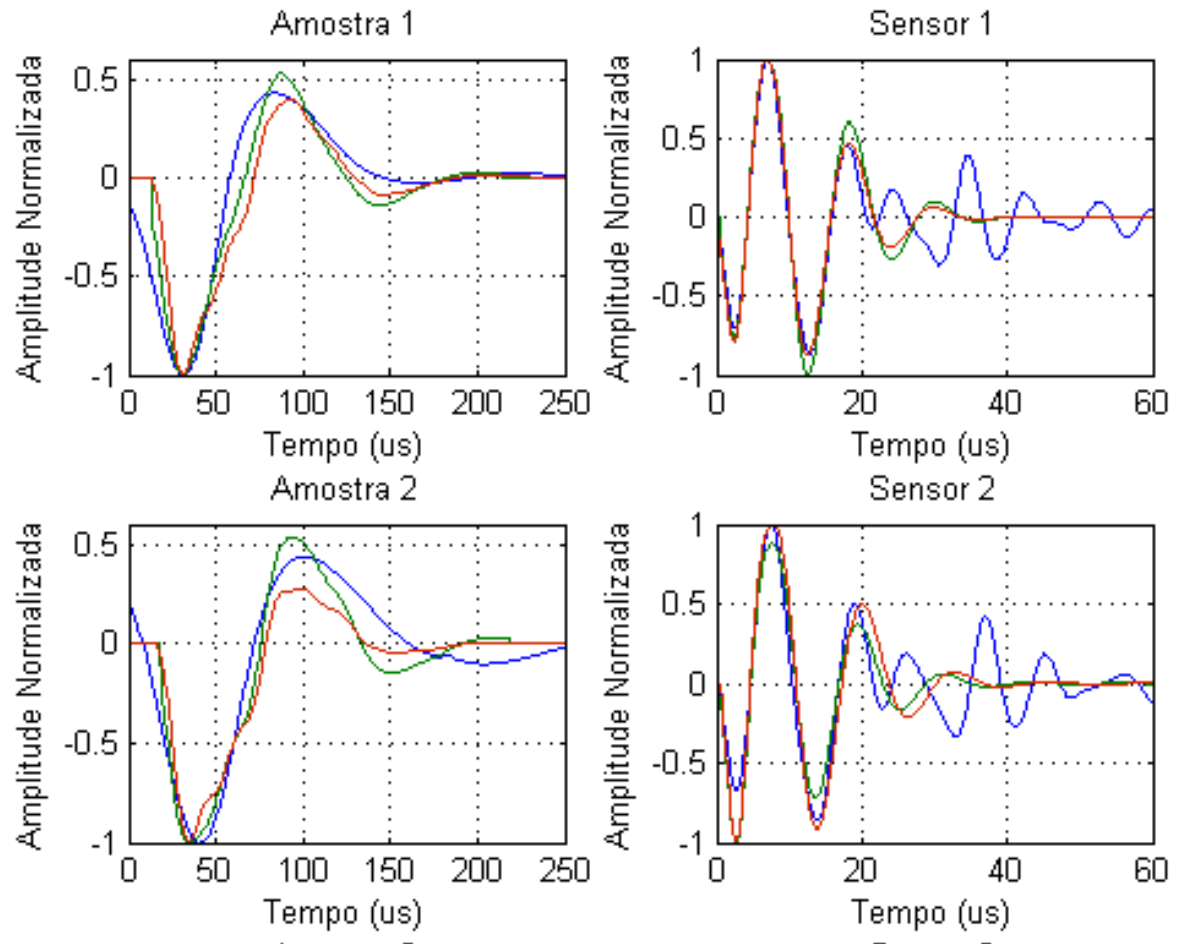

Amostra 3

Sensor 3
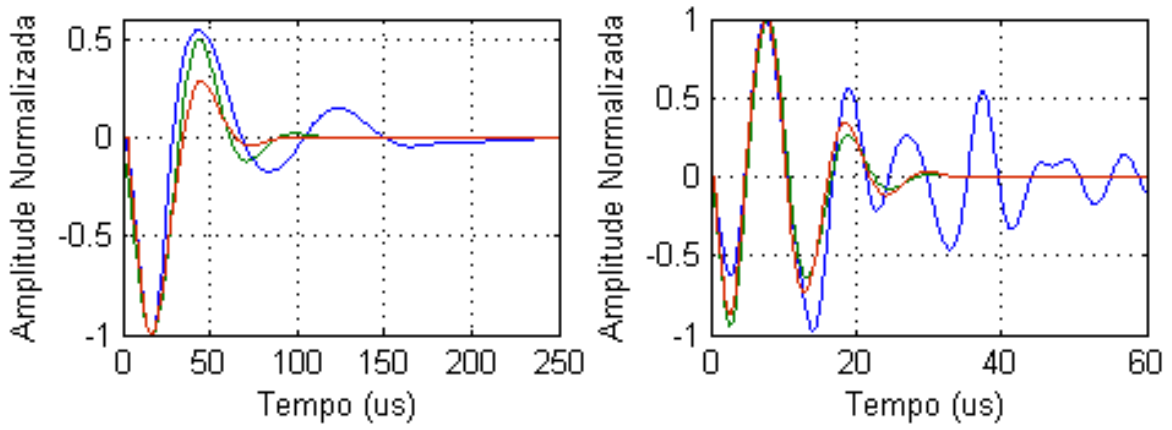

Figura 101: Sinal remodelado (azul), reconstruído (verde) e processado (vermelho) para todas as amostras de piezoeletreto e sensores padrão. Descarga em ar, caixa 2, posição P4. 

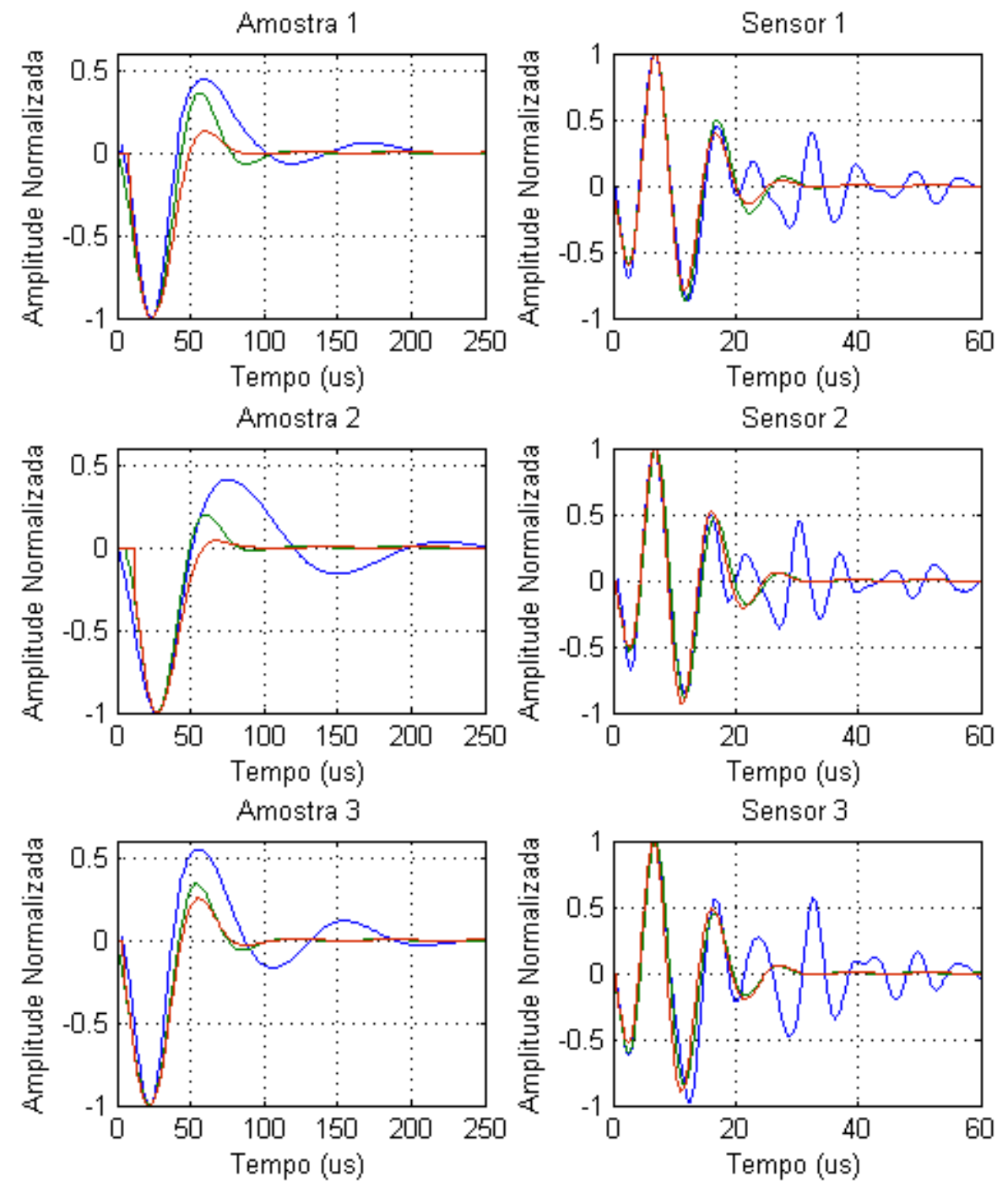

Figura 102: Sinal remodelado (azul), reconstruído (verde) e processado (vermelho) para todas as amostras de piezoeletreto e sensores padrão. Descarga em ar, caixa 2, posição P5.

\subsubsection{Análise para a caixa 2: descarga em óleo}

De forma similar ao que foi realizado na caixa 1, encheu-se a caixa 2 de óleo mineral isolante novo de modo que ocupasse, aproximadamente, $90 \%$ do volume total. Este óleo é do mesmo tipo que foi utilizado na caixa 1, todavia não é o mesmo daquela situação. As Figuras de 103 a 107 apresentam as respostas temporais médias filtradas e não filtradas para as amostras de piezoeletreto; as Figuras 108 a 112 apresentam o mesmo para os sensores padrão. Neste caso, todos os sinais foram 
amostrados a uma taxa de $10 \mathrm{MSa} / \mathrm{s}$ num total de 25 medidas para cada amostra/sensor. Calculou-se o sinal médio, e filtrou-se este sinal com o mesmo filtro utilizado no caso de descarga em óleo na caixa 1.

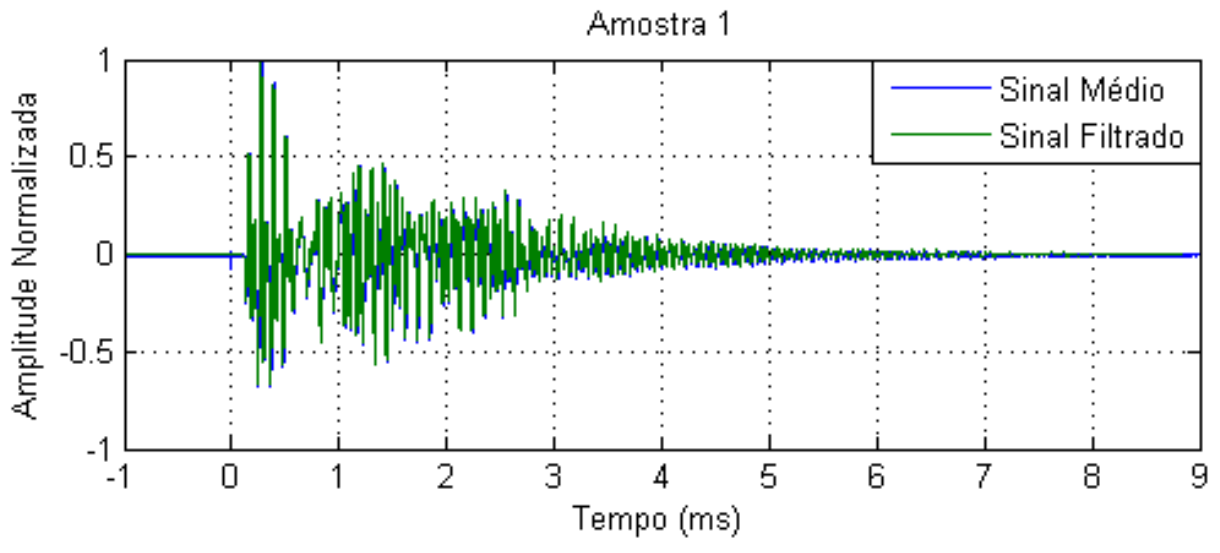

Amostra 2

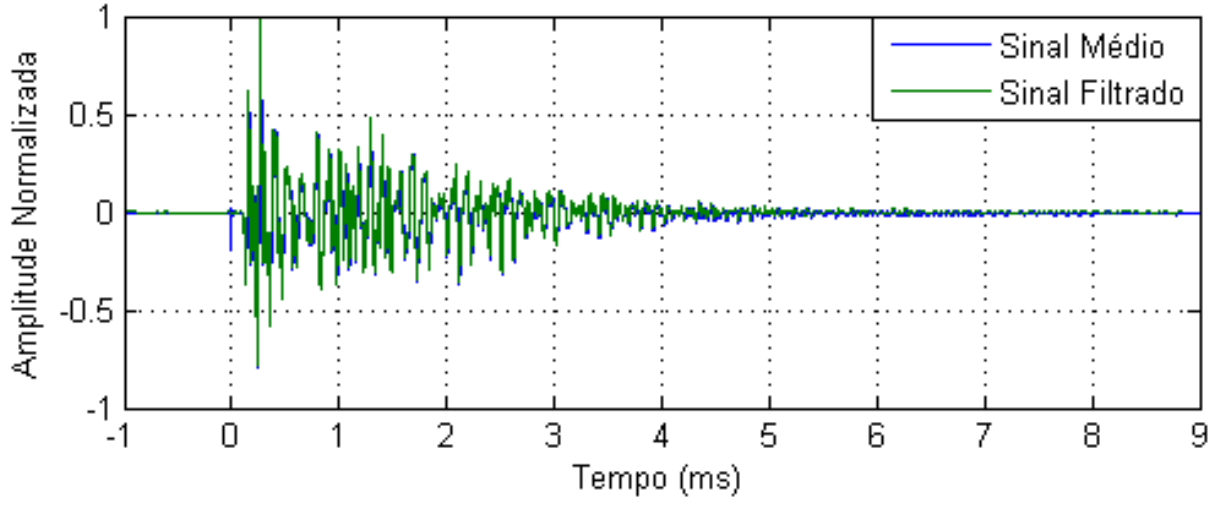

Amostra 3

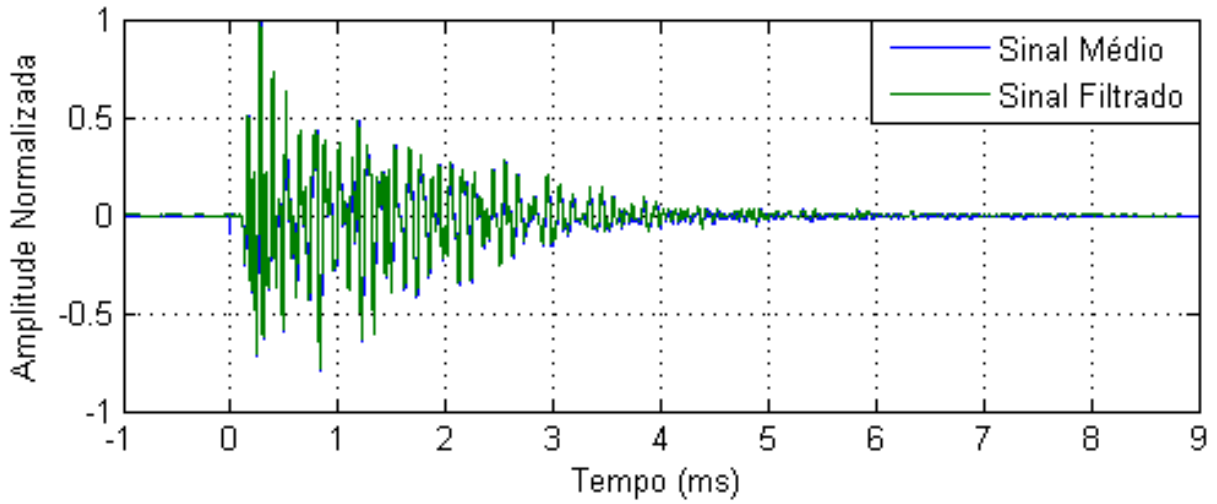

Figura 103: Resposta temporal média filtrada e não filtrada para cada amostra de piezoeletreto referente à posição P1. Descarga em óleo, caixa 2. 

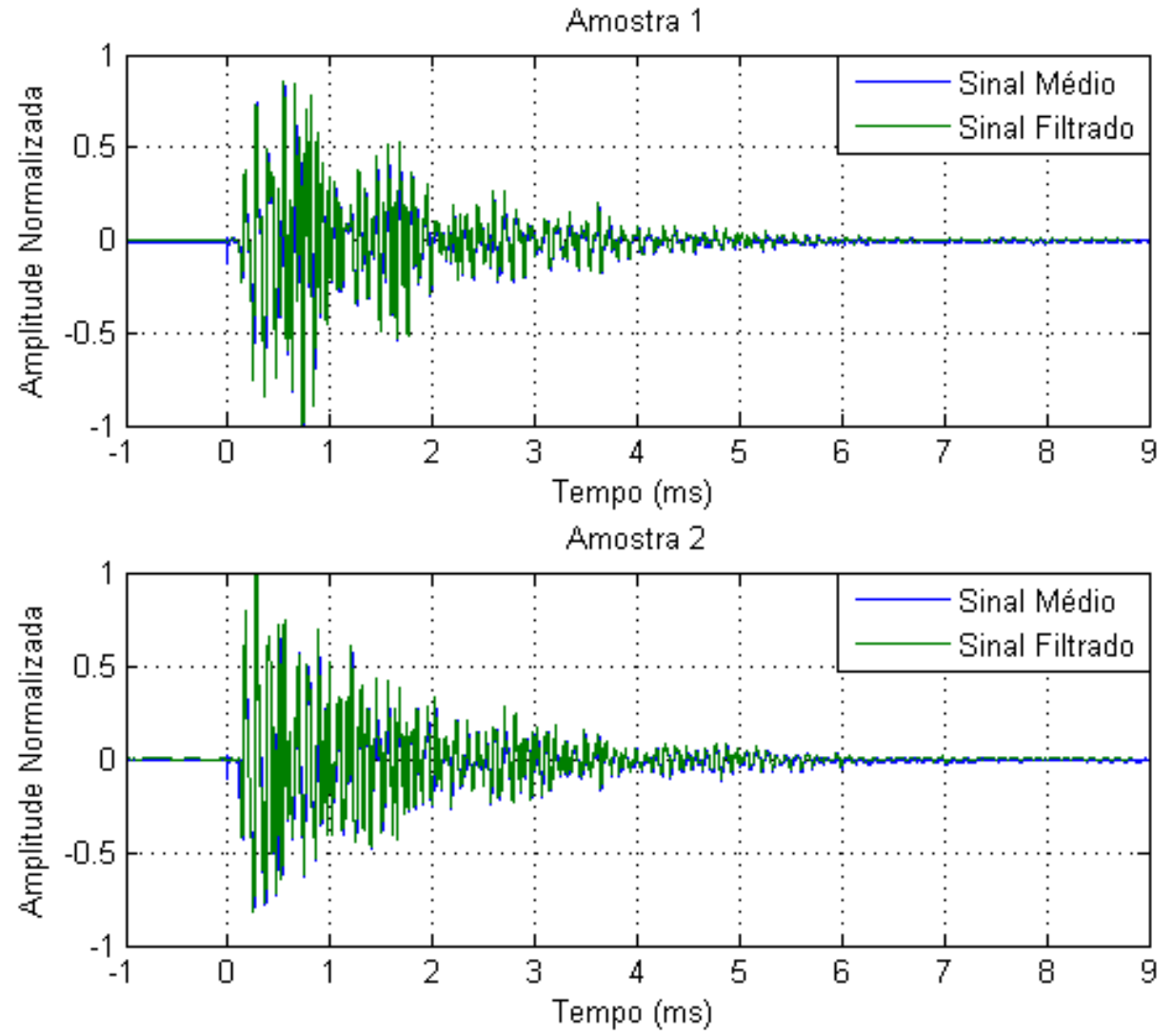

Amostra 3

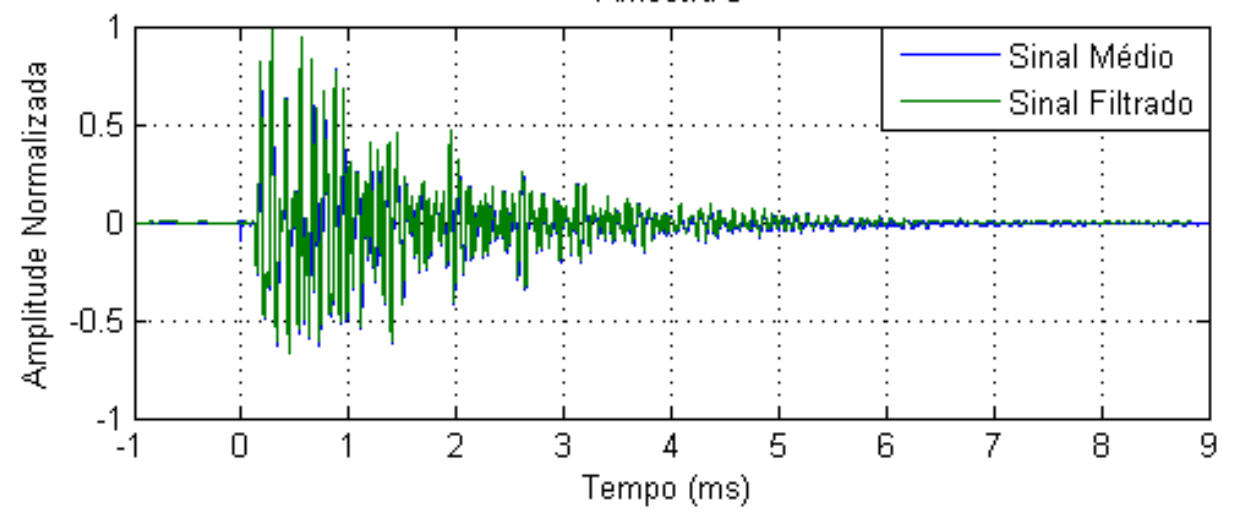

Figura 104: Resposta temporal média filtrada e não filtrada para cada amostra de piezoeletreto referente à posição P2. Descarga em óleo, caixa 2. 


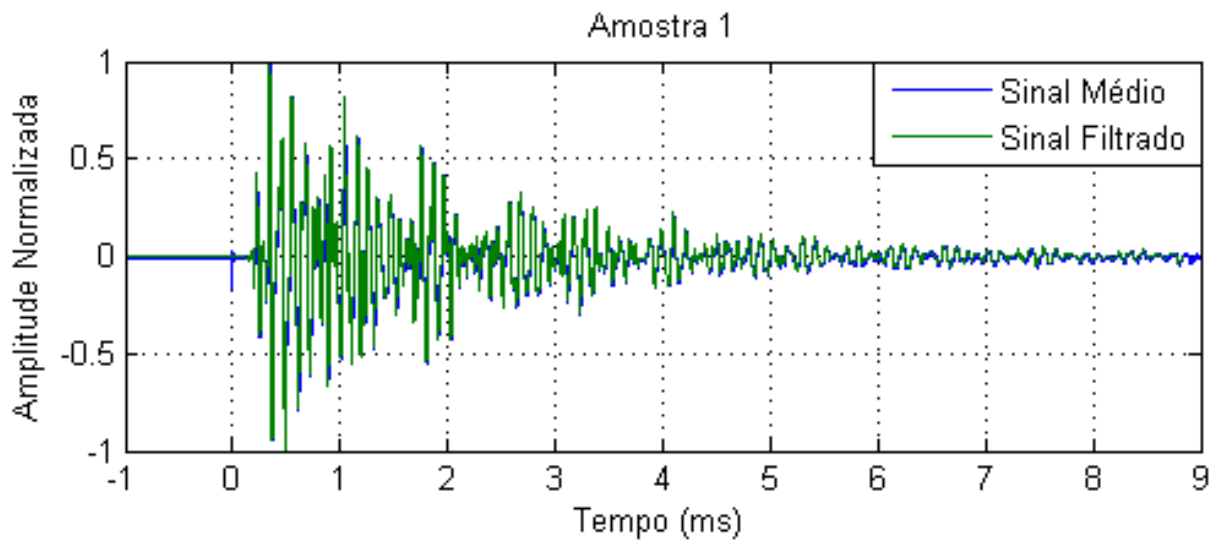

Amostra 2

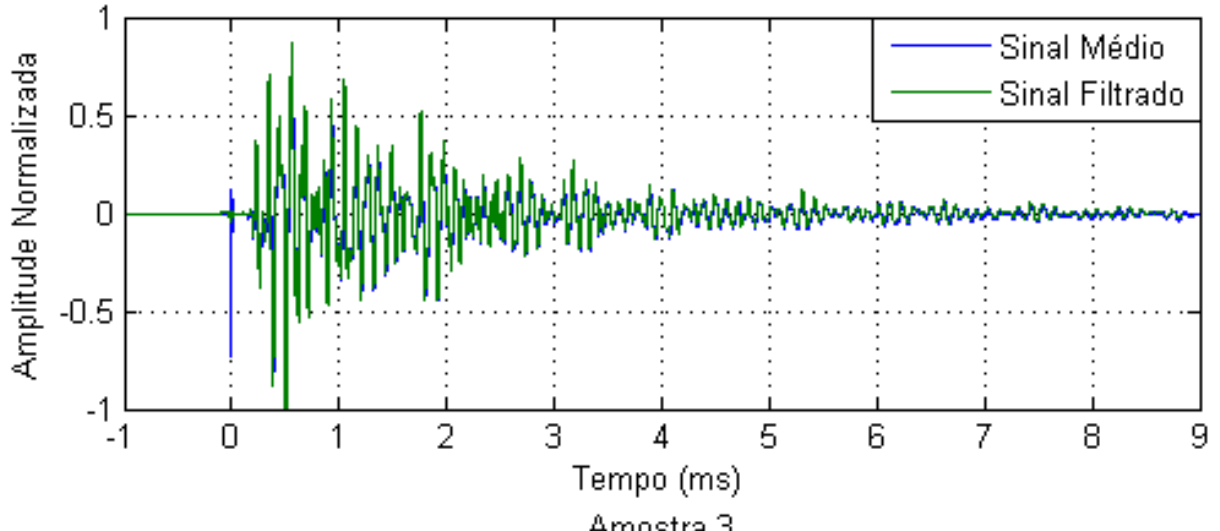

Amostra 3

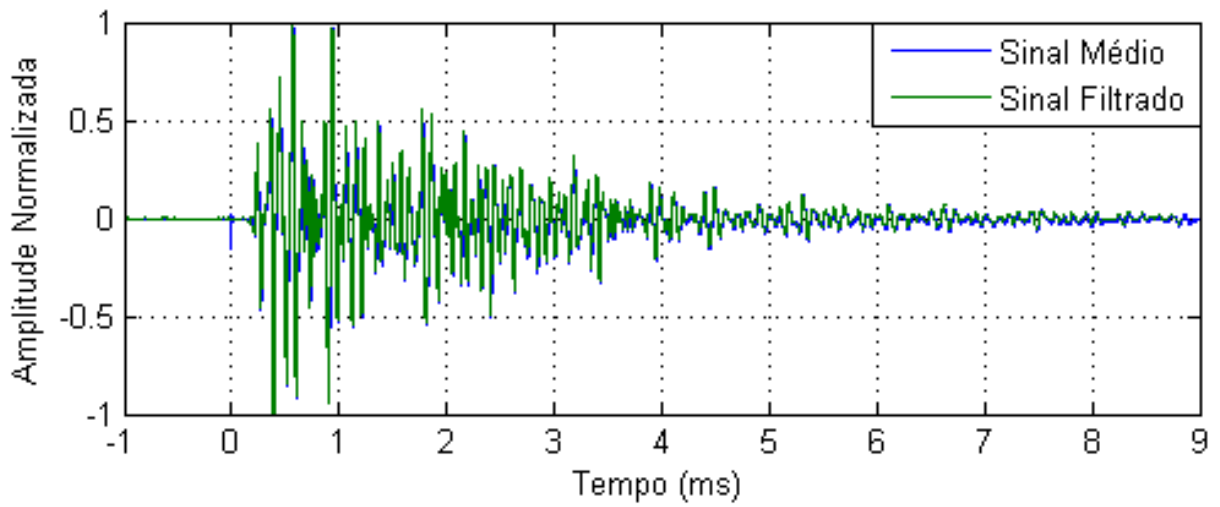

Figura 105: Resposta temporal média filtrada e não filtrada para cada amostra de piezoeletreto referente à posição P3. Descarga em óleo, caixa 2. 

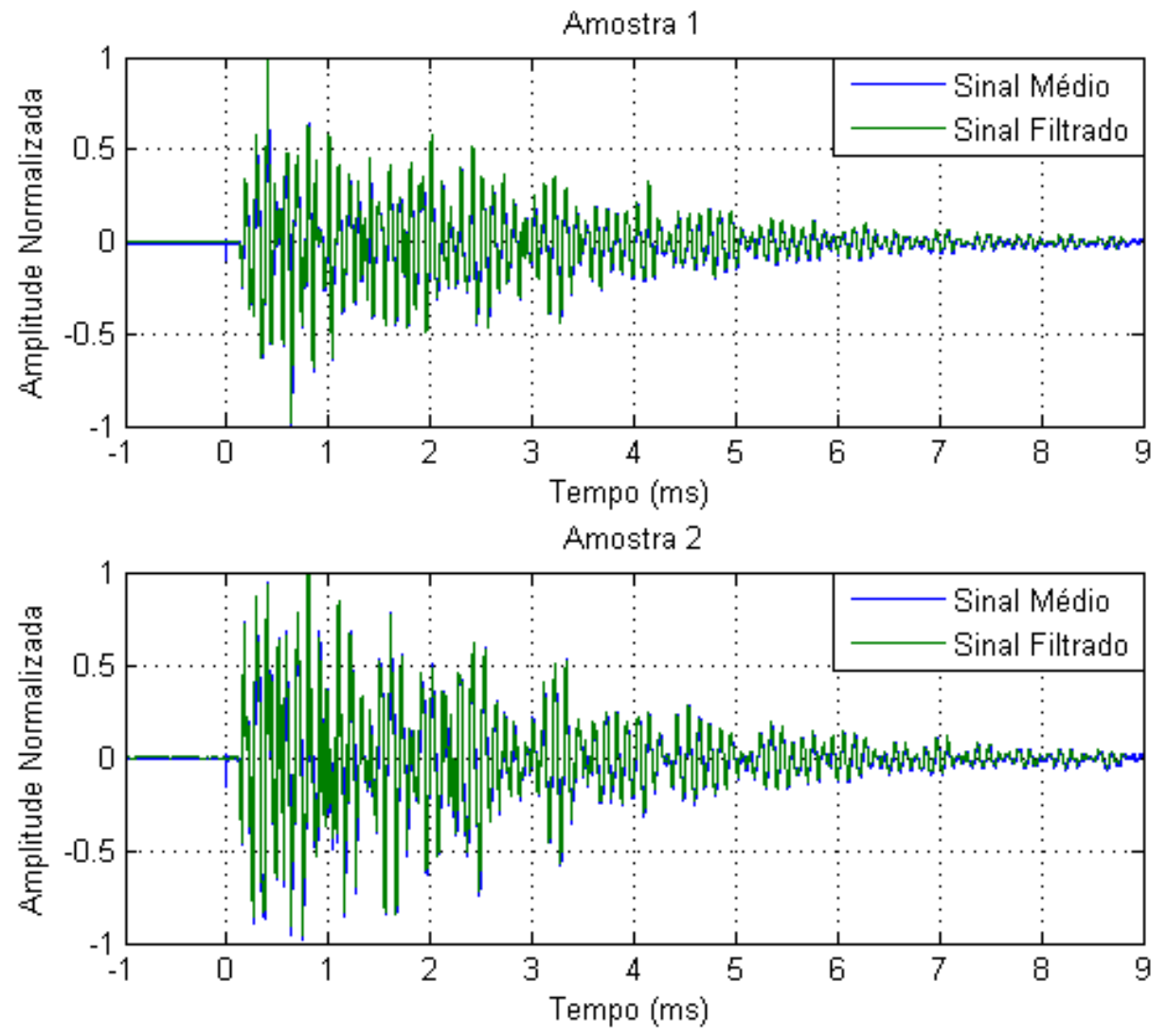

Amostra 3

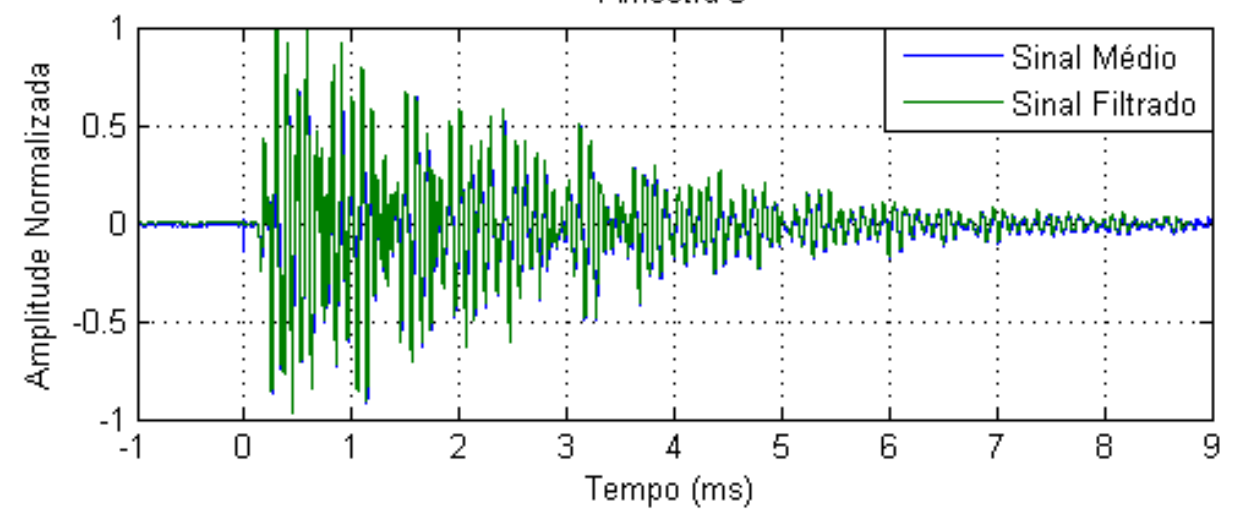

Figura 106: Resposta temporal média filtrada e não filtrada para cada amostra de piezoeletreto referente à posição P4. Descarga em óleo, caixa 2. 


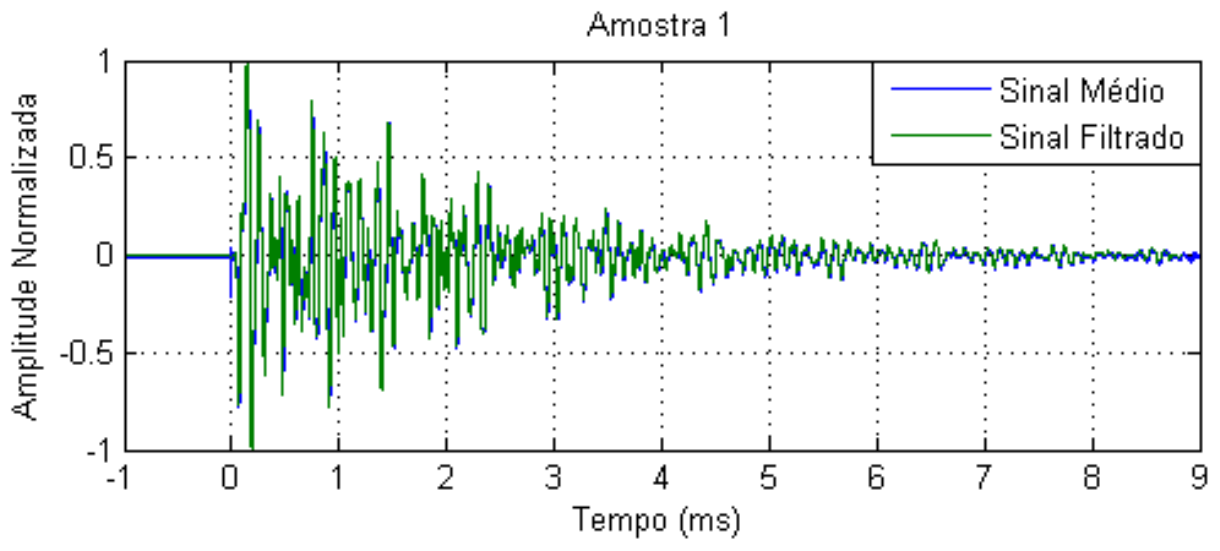

Amostra 2

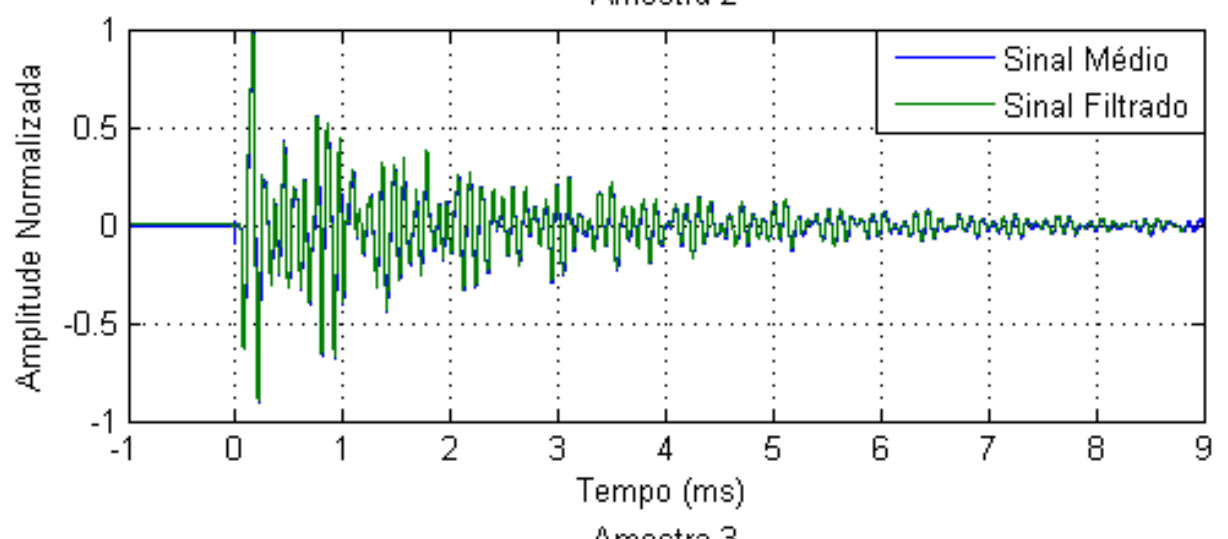

Amostra 3

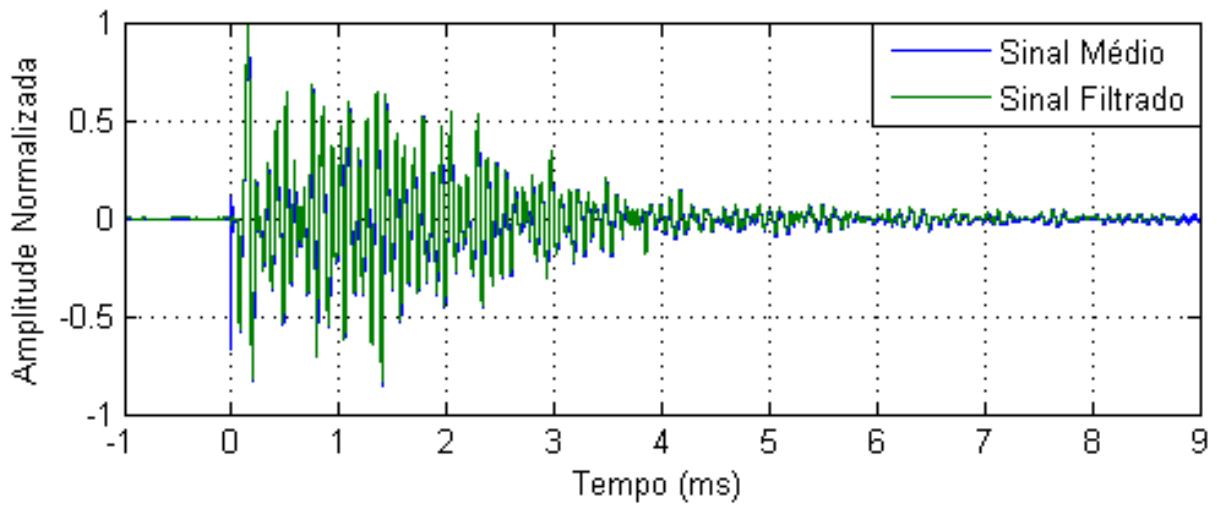

Figura 107: Resposta temporal média filtrada e não filtrada para cada amostra de piezoeletreto referente à posição P5. Descarga em óleo, caixa 2. 

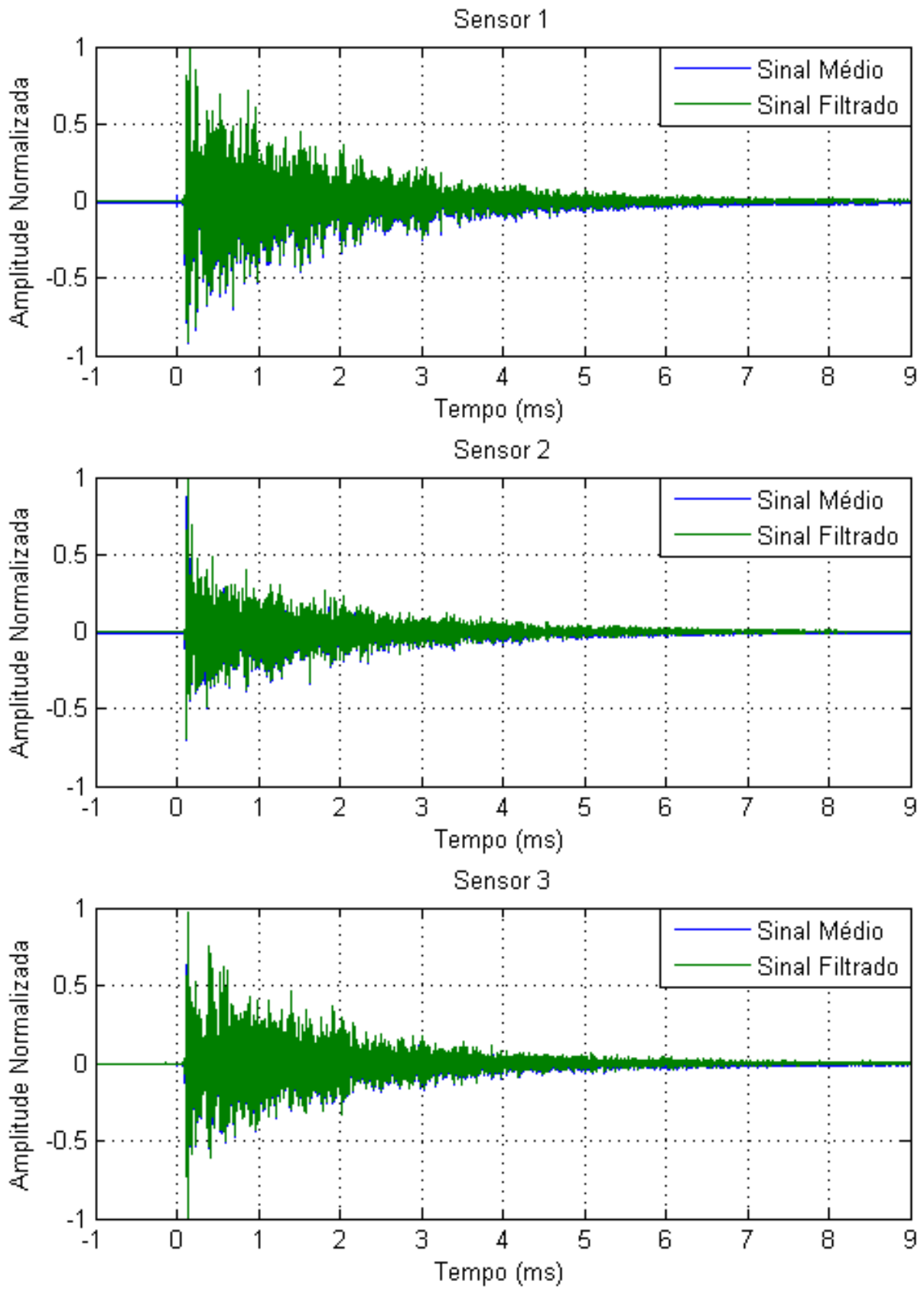

Figura 108: Resposta temporal média filtrada e não filtrada para cada sensor padrão referente à posição P1. Descarga em óleo, caixa 2. 

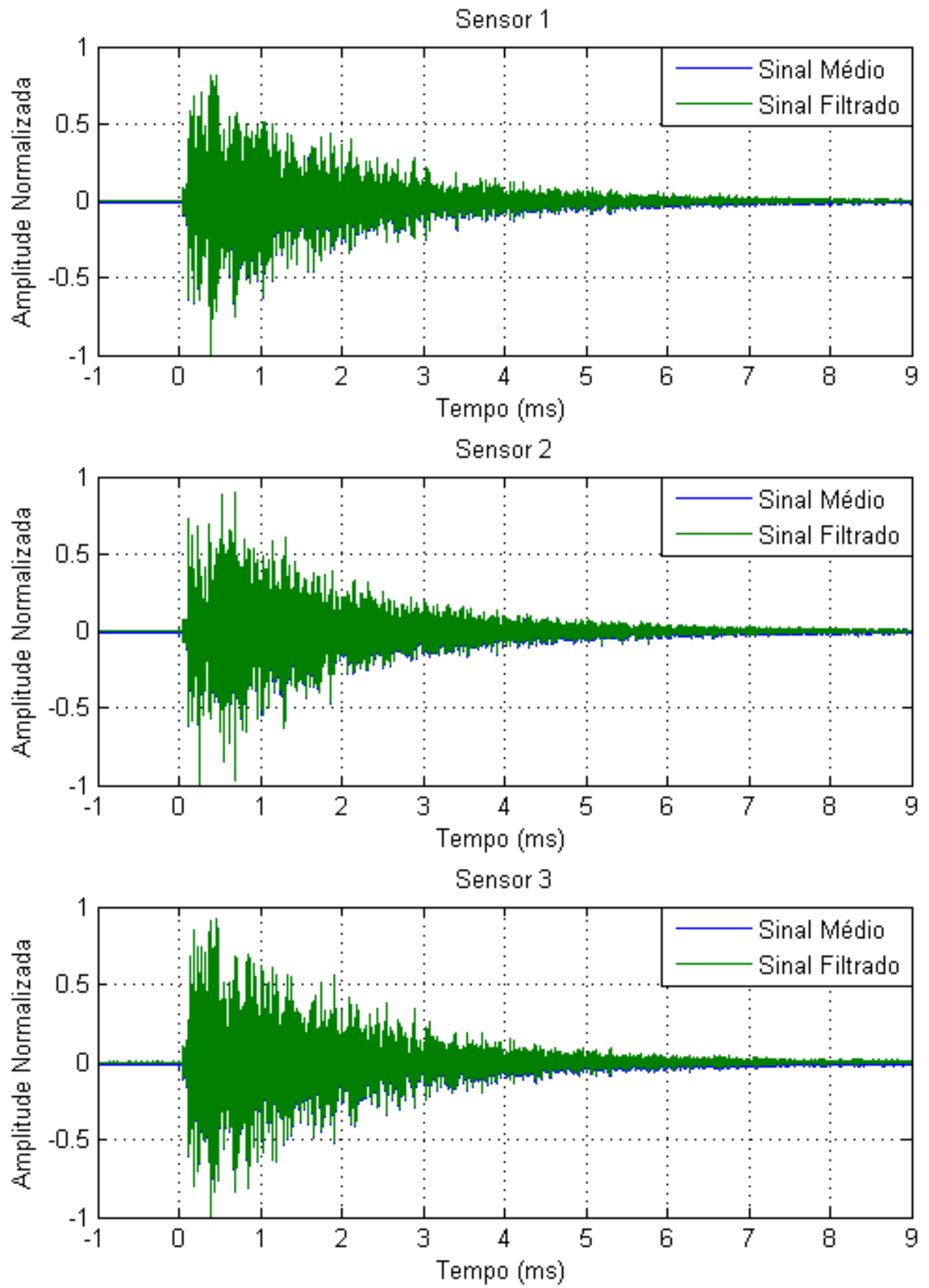

Figura 109: Resposta temporal média filtrada e não filtrada para cada sensor padrão referente à posição P2. Descarga em óleo, caixa 2. 

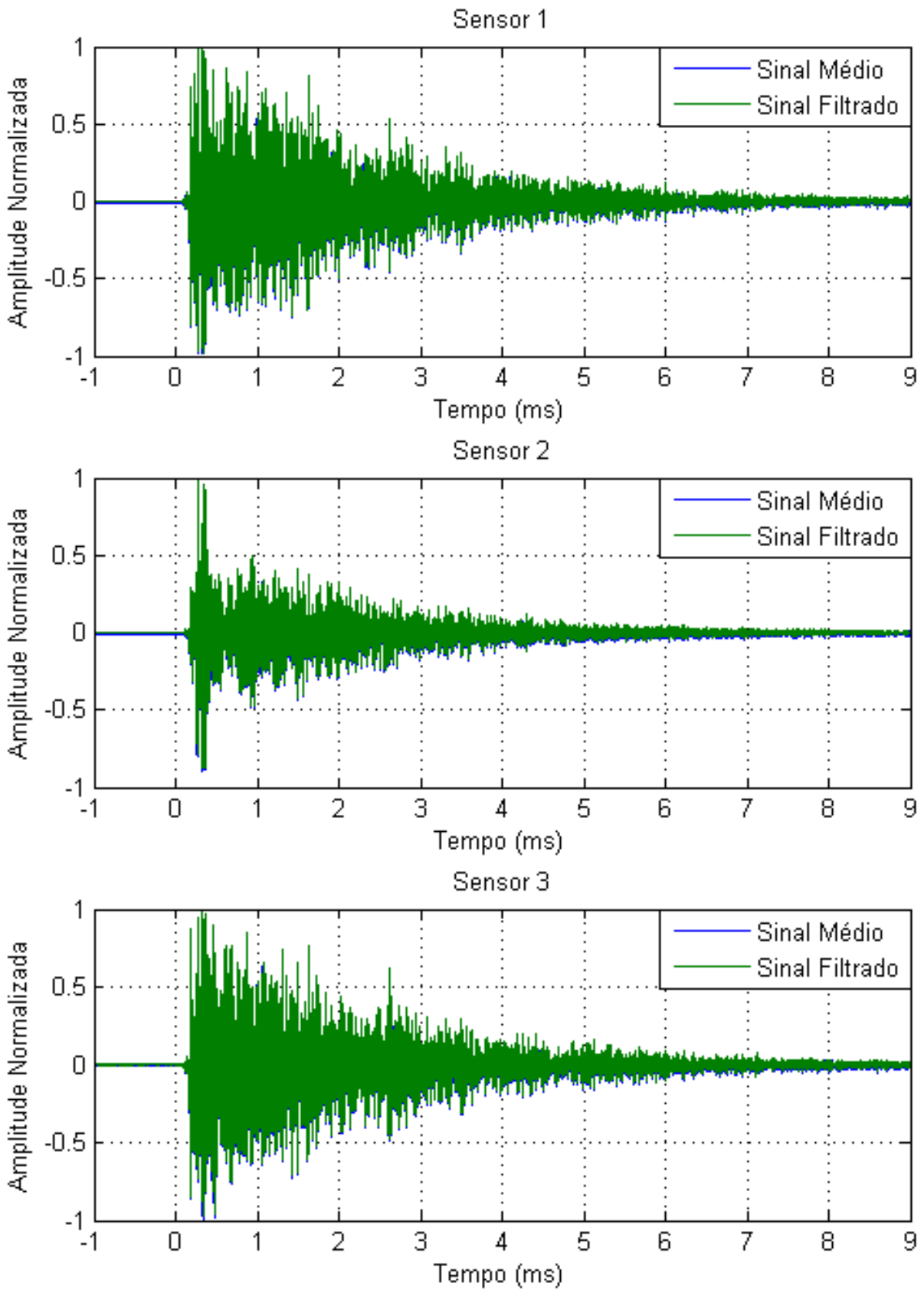

Figura 110: Resposta temporal média filtrada e não filtrada para cada sensor padrão referente à posição P3. Descarga em óleo, caixa 2. 

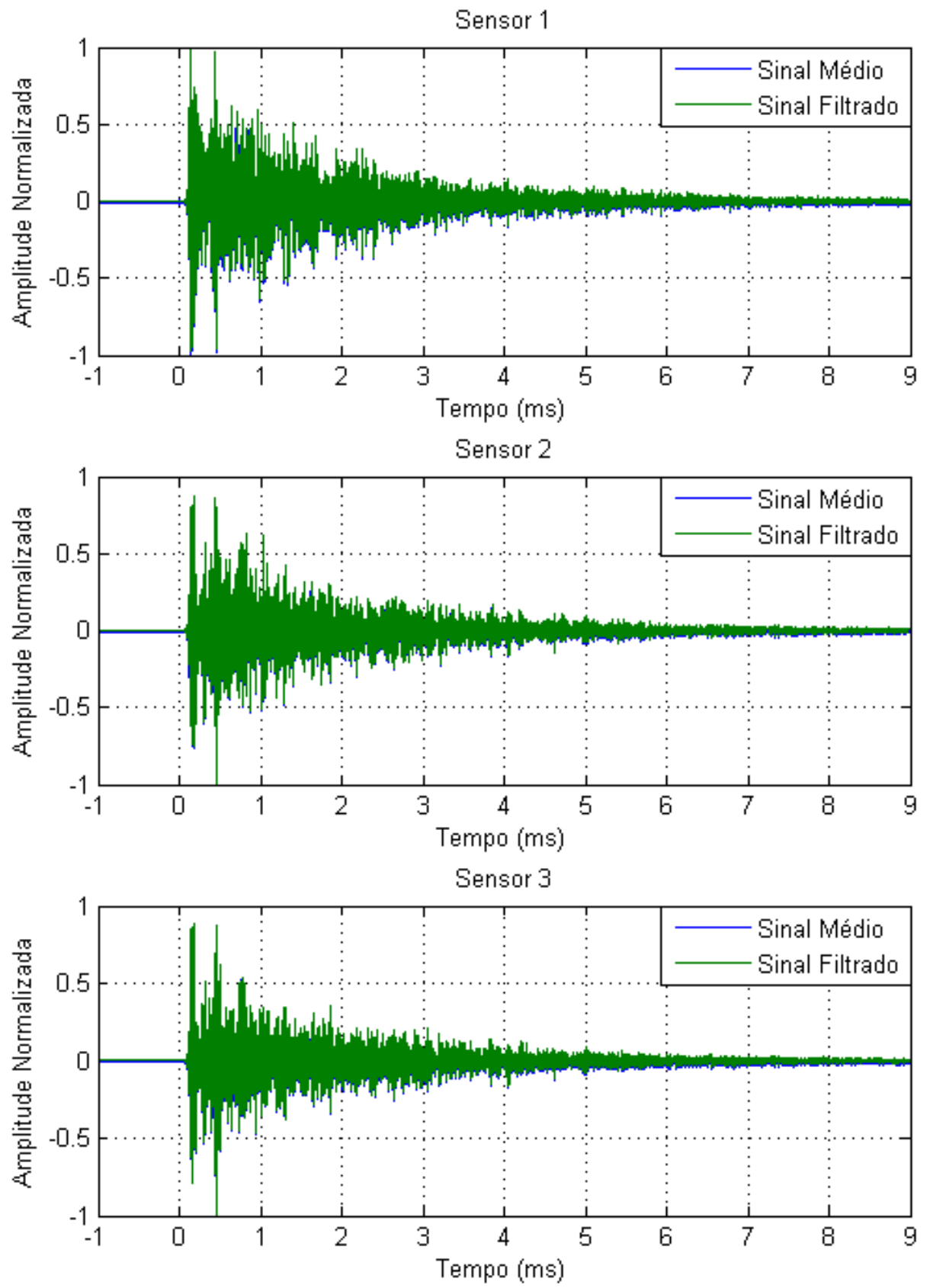

Figura 111: Resposta temporal média filtrada e não filtrada para cada sensor padrão referente à posição P4. Descarga em óleo, caixa 2.

A Tabela 18 apresenta a quantidade de cruzamentos por zero de acordo com a posição de medida, para cada amostra de piezoeletreto e sensor padrão, com janelas 
de 1 ms de duração, da mesma forma que se procedeu no caso da descarga em óleo, caixa1.
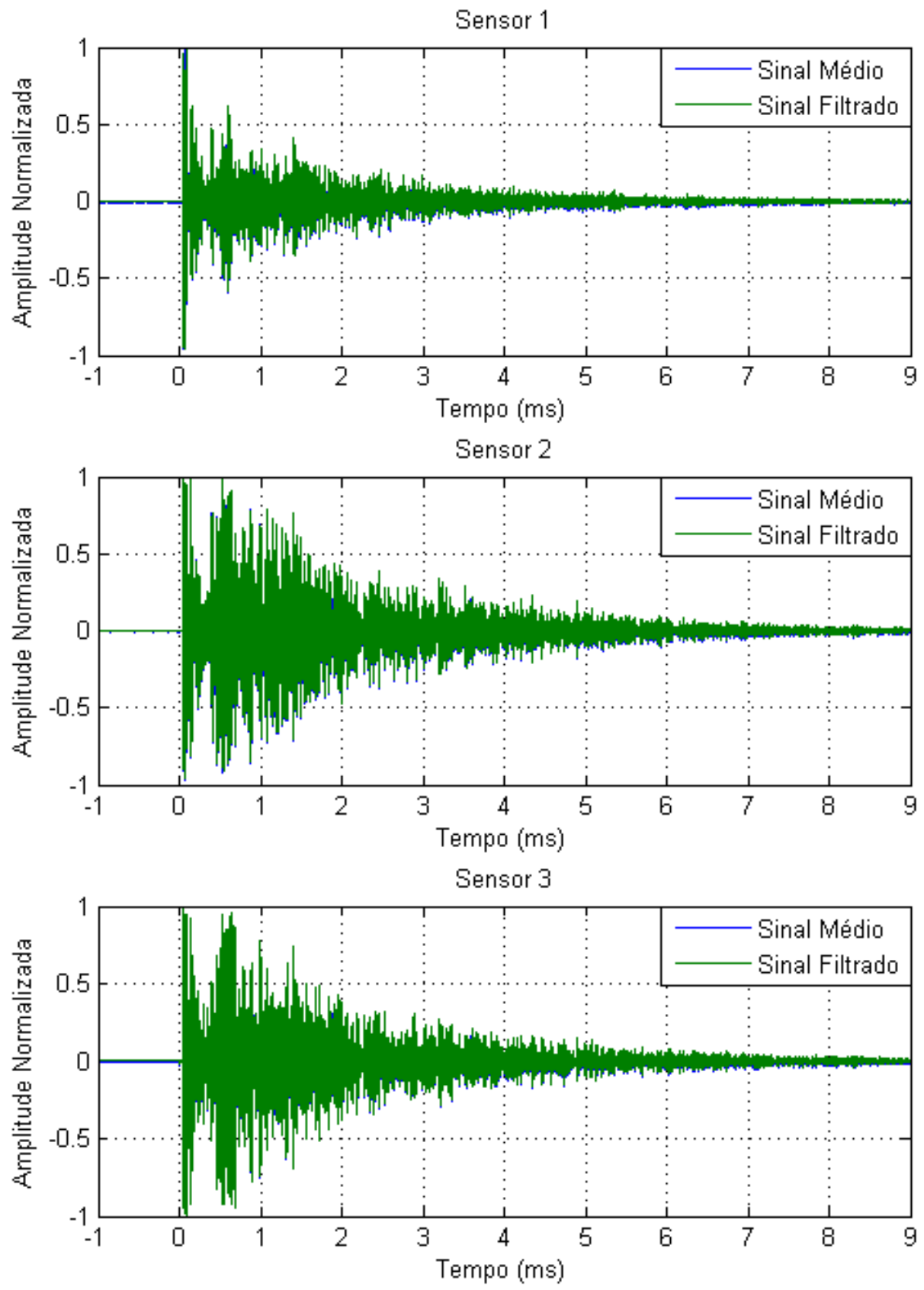

Figura 112: Resposta temporal média filtrada e não filtrada para cada sensor padrão referente à posição P5. Descarga em óleo, caixa 2. 
Tabela 18: Quantidade de cruzamentos por zero de acordo com a posição de medida, por amostra de piezoeletreto e sensor padrão, por janela. Descarga em óleo, caixa 2.

\begin{tabular}{|c|c|c|c|c|c|}
\hline \multirow{2}{*}{ Posição } & \multirow{2}{*}{ Amostras/Sensores } & \multicolumn{4}{|c|}{ Janelas } \\
\hline & & 0-1 ms & $1-2 \mathrm{~ms}$ & $2-3 \mathrm{~ms}$ & $3-4 \mathrm{~ms}$ \\
\hline \multirow{6}{*}{$\mathbf{P} 1$} & Amostra 1 & 41 & 30 & 36 & 35 \\
\hline & Amostra 2 & 32 & 25 & 26 & 28 \\
\hline & Amostra 3 & 37 & 24 & 24 & 23 \\
\hline & Sensor 1 & 263 & 270 & 270 & 267 \\
\hline & Sensor 2 & 297 & 290 & 282 & 289 \\
\hline & Sensor 3 & 263 & 281 & 291 & 269 \\
\hline \multirow{6}{*}{ P2 } & Amostra 1 & 29 & 32 & 29 & 22 \\
\hline & Amostra 2 & 29 & 32 & 30 & 32 \\
\hline & Amostra 3 & 35 & 36 & 36 & 34 \\
\hline & Sensor 1 & 269 & 281 & 273 & 261 \\
\hline & Sensor 2 & 313 & 319 & 323 & 323 \\
\hline & Sensor 3 & 292 & 291 & 291 & 297 \\
\hline \multirow{6}{*}{ P3 } & Amostra 1 & 34 & 28 & 30 & 26 \\
\hline & Amostra 2 & 38 & 19 & 30 & 22 \\
\hline & Amostra 3 & 34 & 33 & 28 & 30 \\
\hline & Sensor 1 & 254 & 272 & 267 & 273 \\
\hline & Sensor 2 & 288 & 273 & 275 & 267 \\
\hline & Sensor 3 & 263 & 275 & 266 & 274 \\
\hline \multirow{6}{*}{$\mathrm{P} 4$} & Amostra 1 & 29 & 26 & 22 & 22 \\
\hline & Amostra 2 & 32 & 28 & 24 & 20 \\
\hline & Amostra 3 & 40 & 30 & 26 & 24 \\
\hline & Sensor 1 & 268 & 264 & 273 & 244 \\
\hline & Sensor 2 & 255 & 259 & 274 & 257 \\
\hline & Sensor 3 & 260 & 262 & 266 & 255 \\
\hline \multirow{6}{*}{ P5 } & Amostra 1 & 27 & 23 & 23 & 21 \\
\hline & Amostra 2 & 22 & 20 & 20 & 19 \\
\hline & Amostra 3 & 31 & 24 & 25 & 26 \\
\hline & Sensor 1 & 276 & 267 & 268 & 268 \\
\hline & Sensor 2 & 300 & 271 & 300 & 284 \\
\hline & Sensor 3 & 300 & 275 & 288 & 286 \\
\hline
\end{tabular}


A Tabela 19 apresenta os tempos de corte nas curvas cepstrais para cada amostra/sensor. Já a Tabela 20 contém os fatores de compressão aplicados aos espectros dos sinais originais das amostras e sensores juntamente com as distâncias mínimas Euclidianas e de Chebychev. A Tabela 21 contém as médias das relações sinal/ruído, o desvio padrão, a menor relação e os coeficientes de variação para cada amostra/sensor conforme a posição de medida.

De modo geral, a quantidade de cruzamentos por zero apresentou, aproximadamente, o mesmo comportamento constatado no caso da descarga em óleo na caixa 1 (vide Tabela 8), tanto para as amostras quanto para os sensores. Ademais, a duração dos sinais acústicos de descarga, apresentados nas Figuras 103 a 112, foi similar para ambos os casos, isto é, sinais das amostras e dos sensores. Observa-se ainda que, quanto às assinaturas das formas de onda, constatou-se certa semelhança nas respostas das posições P4 e P5 para os sensores e P1 e P5 para as amostras. De todas as formas, a análise está voltada para uma janela que seja subsequente ao instante de ocorrência da descarga, e essa janela tem duração de $5 \mathrm{~ms}$ para os sinais das amostras e $1 \mathrm{~ms}$ para os sinais dos sensores. Com respeito aos sinais das amostras, realizou-se a mesma sub-amostragem do caso anterior, ou seja, um para cinco. Dessa forma, nova taxa de amostragem passou a ser $2 \mathrm{MSa} / \mathrm{s}$ e o sinal teve novo suporte de 10000 pontos em vez de 50000 pontos, os quais corresponderiam à janela de $5 \mathrm{~ms}$ não sub-amostrada. Foi a partir daí que se processaram os sinais das amostras. Já os sinais dos sensores não foram sub-amostrados, isto é, a janela de análise com duração de 1 ms teve suporte de 10000 pontos.

Tabela 19: Tempo de corte, em us, na curva cepstral para as amostras e sensores conforme posição de medida. Descarga em óleo, caixa 2.

\begin{tabular}{|c|c|c|c|c|c|}
\hline $\begin{array}{l}\text { Posição de Medida } \\
\text { Amostras/Sensores }\end{array}$ & $\mathbf{P 1}$ & P2 & P3 & $\mathbf{P} 4$ & P5 \\
\hline Amostra 1 & 23,5 & 25,5 & 27,5 & 26,5 & 49,5 \\
\hline Amostra 2 & 25,5 & 25,5 & 28,5 & 29,5 & 54,5 \\
\hline Amostra 3 & 24,5 & 23,5 & 27,5 & 27,5 & 49,5 \\
\hline Sensor 1 & 7,9 & 6,9 & 7,9 & 5,9 & 7,9 \\
\hline Sensor 2 & 7,9 & 5,9 & 6,9 & 5,9 & 7,9 \\
\hline Sensor 3 & 7,9 & 6,9 & 7,9 & 5,9 & 7,9 \\
\hline
\end{tabular}


Tabela 20: Distâncias mínimas e fatores de compressão referentes a estas distâncias para cada amostra de piezoeletreto e sensor padrão de acordo com a posição de medida (DE: distância Euclidiana; DC: distância de Chebychev). Descarga em óleo, caixa 2.

\begin{tabular}{|c|c|c|c|c|c|}
\hline Posição & Amostras/Sensores & $\mathrm{DE}$ & Fator (via DE) & DC & Fator (via DC) \\
\hline \multirow{6}{*}{$\mathbf{P} 1$} & Amostra 1 & 2,44 & 2,1 & 0,327 & 2,1 \\
\hline & Amostra 2 & 2,84 & 1,8 & 0,310 & 2,0 \\
\hline & Amostra 3 & 2,40 & 2,2 & 0,291 & 2,4 \\
\hline & Sensor 1 & 3,56 & 1,1 & 0,395 & 1,1 \\
\hline & Sensor 2 & 4,10 & 1,1 & 0,437 & 1,1 \\
\hline & Sensor 3 & 5,18 & 1,1 & 0,561 & 1,1 \\
\hline \multirow{6}{*}{ P2 } & Amostra 1 & 2,03 & 2,2 & 0,264 & 2,2 \\
\hline & Amostra 2 & 2,97 & 1,9 & 0,311 & 2,1 \\
\hline & Amostra 3 & 2,44 & 2,1 & 0,307 & 2,3 \\
\hline & Sensor 1 & 4,02 & 1,0 & 0,441 & 1,1 \\
\hline & Sensor 2 & 4,27 & 1,0 & 0,457 & 1,0 \\
\hline & Sensor 3 & 4,88 & 1,0 & 0,584 & 1,0 \\
\hline \multirow{6}{*}{ P3 } & Amostra 1 & 2,31 & 2,4 & 0,288 & 2,4 \\
\hline & Amostra 2 & 3,11 & 2,4 & 0,306 & 2,6 \\
\hline & Amostra 3 & 2,48 & 2,6 & 0,279 & 2,8 \\
\hline & Sensor 1 & 3,42 & 1,1 & 0,419 & 1,1 \\
\hline & Sensor 2 & 3,6 & 1,0 & 0,451 & 1,0 \\
\hline & Sensor 3 & 4,89 & 1,1 & 0,578 & 1,1 \\
\hline \multirow{6}{*}{$\mathbf{P} 4$} & Amostra 1 & 2,25 & 2,5 & 0,278 & 2,6 \\
\hline & Amostra 2 & 2,83 & 2,4 & 0,293 & 2,6 \\
\hline & Amostra 3 & 2,33 & 2,4 & 0,296 & 2,6 \\
\hline & Sensor 1 & 3,57 & 1,0 & 0,434 & 1,0 \\
\hline & Sensor 2 & 3,72 & 1,1 & 0,456 & 1,0 \\
\hline & Sensor 3 & 4,85 & 1,0 & 0,592 & 1,0 \\
\hline \multirow{6}{*}{ P5 } & Amostra 1 & 2,16 & 3,2 & 0,250 & 3,3 \\
\hline & Amostra 2 & 2,91 & 4,7 & 0,203 & 5,6 \\
\hline & Amostra 3 & 2,08 & 3,4 & 0,296 & 3,6 \\
\hline & Sensor 1 & 3,65 & 1,1 & 0,424 & 1,1 \\
\hline & Sensor 2 & 4,12 & 1,0 & 0,477 & 1,0 \\
\hline & Sensor 3 & 4,92 & 1,0 & 0,592 & 1,0 \\
\hline
\end{tabular}


Tabela 21: Média das relações sinal/ruído $(\mu)$, desvio padrão $(\sigma)$, menor relação $(M R)$ e coeficiente de variação percentual $\left(\boldsymbol{C}_{\boldsymbol{v}}\right)$ para todas as amostras e sensores de acordo com a posição de medida.

Descarga em óleo, caixa 2.

\begin{tabular}{|c|c|c|c|c|c|}
\hline Posição & Amostras/Sensores & $\mu$ & $\sigma$ & $M R$ & $C_{v}(\%)$ \\
\hline \multirow{6}{*}{$\mathbf{P} 1$} & Amostra 1 & 1390,1 & 219,3 & 1079,2 & 15,8 \\
\hline & Amostra 2 & 983,9 & 115,1 & 816,5 & 11,7 \\
\hline & Amostra 3 & 2359,0 & 503,8 & 1532,7 & 21,4 \\
\hline & Sensor 1 & 748,5 & 272,5 & 476,0 & 36,4 \\
\hline & Sensor 2 & 715,6 & 60,5 & 641,2 & 8,5 \\
\hline & Sensor 3 & 793,2 & 77,9 & 686,6 & 9,8 \\
\hline \multirow{6}{*}{ P2 } & Amostra 1 & 2396,1 & 564,0 & 1029,2 & 23,5 \\
\hline & Amostra 2 & 2230,0 & 613,8 & 1438,0 & 27,5 \\
\hline & Amostra 3 & 2093,5 & 371,5 & 1363,8 & 17,7 \\
\hline & Sensor 1 & 807,2 & 176,4 & 356,8 & 21,9 \\
\hline & Sensor 2 & 796,7 & 142,1 & 480,1 & 17,8 \\
\hline & Sensor 3 & 731,5 & 151,4 & 423,0 & 20,7 \\
\hline \multirow{6}{*}{ P3 } & Amostra 1 & 1648,8 & 213,9 & 1332,4 & 13,0 \\
\hline & Amostra 2 & 1113,6 & 97,0 & 966,0 & 8,7 \\
\hline & Amostra 3 & 1430,2 & 177,4 & 1061,5 & 12,4 \\
\hline & Sensor 1 & 2733,3 & 279,2 & 2268,5 & 10,2 \\
\hline & Sensor 2 & 1052,0 & 148,3 & 829,5 & 14,1 \\
\hline & Sensor 3 & 2142,5 & 246,4 & 1739,6 & 11,5 \\
\hline \multirow{6}{*}{$\mathbf{P} 4$} & Amostra 1 & 1424,6 & 131,5 & 1162,1 & 9,2 \\
\hline & Amostra 2 & 2539,4 & 811,5 & 522,6 & 32,0 \\
\hline & Amostra 3 & 1647,2 & 394,6 & 1047,2 & 24,0 \\
\hline & Sensor 1 & 1167,3 & 151,0 & 829,9 & 12,9 \\
\hline & Sensor 2 & 1306,4 & 209,5 & 1011,7 & 16,0 \\
\hline & Sensor 3 & 984,0 & 158,6 & 793,8 & 16,1 \\
\hline \multirow{6}{*}{ P5 } & Amostra 1 & 1767,5 & 110,3 & 1601,1 & 6,2 \\
\hline & Amostra 2 & 3345,9 & 704,3 & 2223,0 & 21,0 \\
\hline & Amostra 3 & 1632,7 & 328,1 & 962,7 & 20,1 \\
\hline & Sensor 1 & 1789,1 & 259,3 & 1215,0 & 14,5 \\
\hline & Sensor 2 & 8618,5 & 934,6 & 7128,0 & 10,8 \\
\hline & Sensor 3 & 9656,9 & 1334,2 & 7505,5 & 13,8 \\
\hline
\end{tabular}


Comparando-se a Tabela 20 com a Tabela 14, nota-se que neste caso os dados repetem, de forma mais enfática, para a maior similaridade entre os sinais remodelados e reconstruídos referente às amostras de piezoeletreto: todas as distâncias Euclidianas do presente caso, sem exceção, são menores que as distâncias referentes aos sensores. Ademais: os fatores de compressão estão mais estáveis neste caso do que no anterior, ou seja, são próximos não importando muito a posição específica de medida. Provavelmente esta melhora seja consequência da relação sinal/ruído superior comparado ao caso de descarga em ar. Fugindo um pouco à regra estão os fatores referentes à posição P5: é a única posição em que os fatores de compressão se apresentaram um pouco maior e é justamente nesta posição que o centelhador está mais próximo do ponto de medição. Para o caso dos sensores, os fatores se apresentaram mais estáveis ainda quando se compara com a Tabela 14, embora as distâncias Euclidianas entre os sinais remodelados e reconstruídos sejam maiores comparativamente às distâncias das amostras. A Tabela 22 apresenta a média dos fatores de compressão para as duas caixas, o desvio padrão e o coeficiente de variação. A Tabela 23 apresentará a média geral dos fatores de compressão, o desvio padrão e o coeficiente de variação para todas as amostras e sensores. Por fim, as Figuras 113 a 117 apresentam os sinais remodelados, reconstruídos e processados.

Tabela 22: Média dos fatores de compressão $(\mu)$, desvio padrão e coeficiente de variação $\left(\boldsymbol{C}_{\boldsymbol{v}}\right)$ para cada amostra/sensor referente às descargas em óleo para as caixas 1 e 2.

\begin{tabular}{cccc}
\hline Amostras/Sensores & $\boldsymbol{\mu}$ & $\boldsymbol{\sigma}$ & $\boldsymbol{C}_{\boldsymbol{v}}(\boldsymbol{\%})$ \\
\hline Amostra 1 & 2,45 & 0,394 & 16,1 \\
Amostra 2 & 2,55 & 1,082 & 42,4 \\
Amostra 3 & 2,47 & 0,497 & 20,1 \\
Sensor 1 & 1,07 & 0,052 & 4,8 \\
Sensor 2 & 1,05 & 0,055 & 5,2 \\
\hline Sensor 3 & 1,05 & 0,055 & 5,2 \\
\hline
\end{tabular}

Tabela 23: Média geral dos fatores de compressão $(\mu)$, desvio padrão e coeficiente de variação $\left(\boldsymbol{C}_{\boldsymbol{v}}\right)$ para cada grupo de amostras/sensores referente às descargas em óleo para as caixas 1 e 2.

\begin{tabular}{cccc}
\hline & $\boldsymbol{\mu}$ & $\boldsymbol{\sigma}$ & $\boldsymbol{C}_{\boldsymbol{v}}(\boldsymbol{\%})$ \\
\hline Amostras & 2,49 & 0,682 & 27,4 \\
Sensores & 1,06 & 0,051 & 4,8 \\
\hline
\end{tabular}



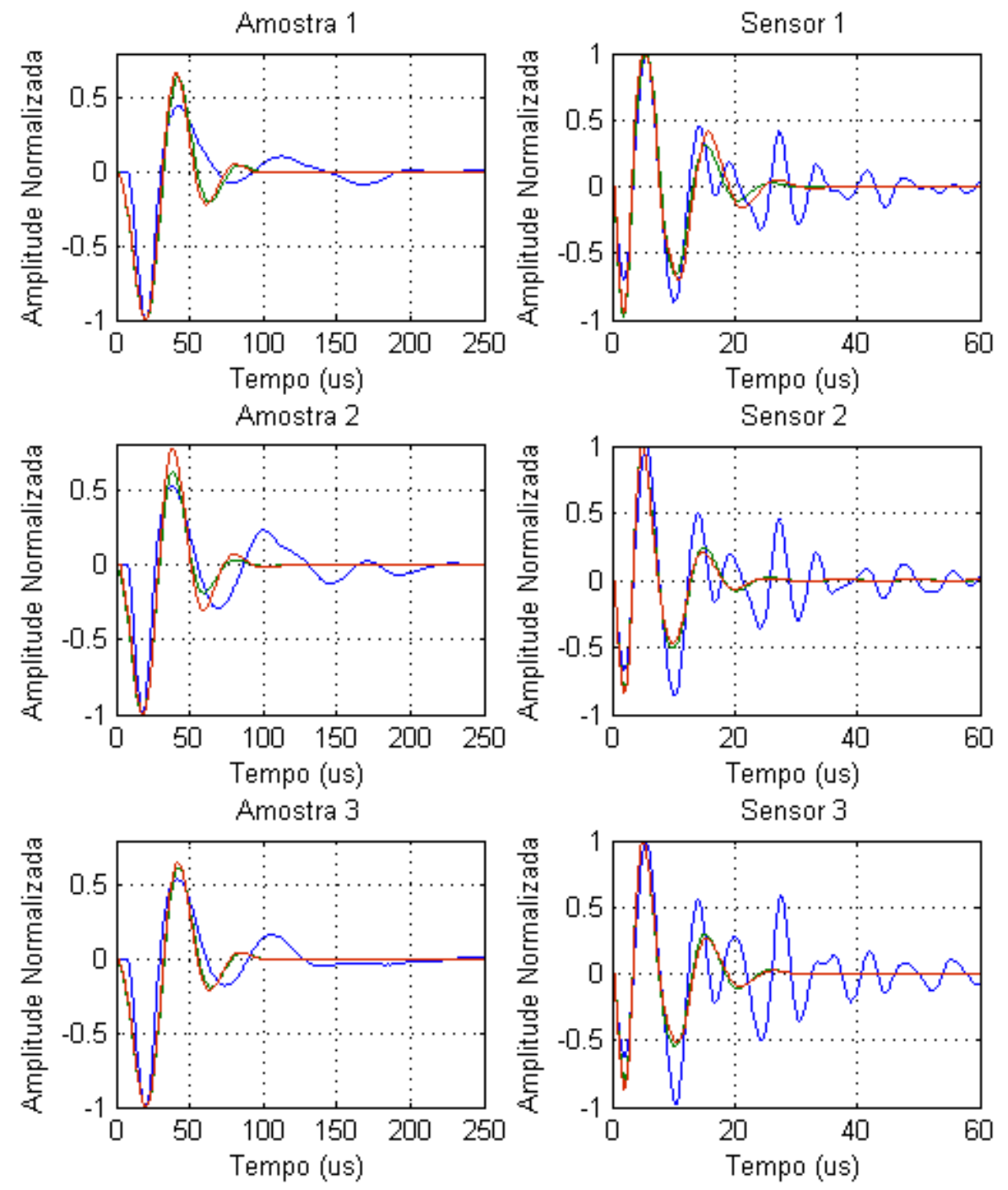

Figura 113: Sinal remodelado (azul), reconstruído (verde) e processado (vermelho) para todas as amostras de piezoeletreto e sensores padrão. Descarga em óleo, caixa 2, posição P1.

Os coeficientes de variação apresentados pelas amostras 1 e 3 na Tabela 22 mostraram-se similares, ao passo que para a amostra 2 foi diferente. Para os sensores os coeficientes foram praticamente os mesmos. O resultado inferior, apresentado pela amostra 2, provavelmente se explique pela observação de que o fator de compressão calculado para a posição P5 (4,7 na Tabela 20) foi bastante dispare dos demais. Subtraindo-se este fator somente, a nova média, na Tabela 22, seria 2,12, o desvio padrão, 0,278, e o coeficiente de variação seria 13,1\%. Já para a Tabela 23, retirando- 
se apenas este mesmo fator, a nova média seria 2,36, o desvio padrão, 0,412, e o coeficiente de variação, $17,5 \%$, ou seja, um resultado consideravelmente melhor.
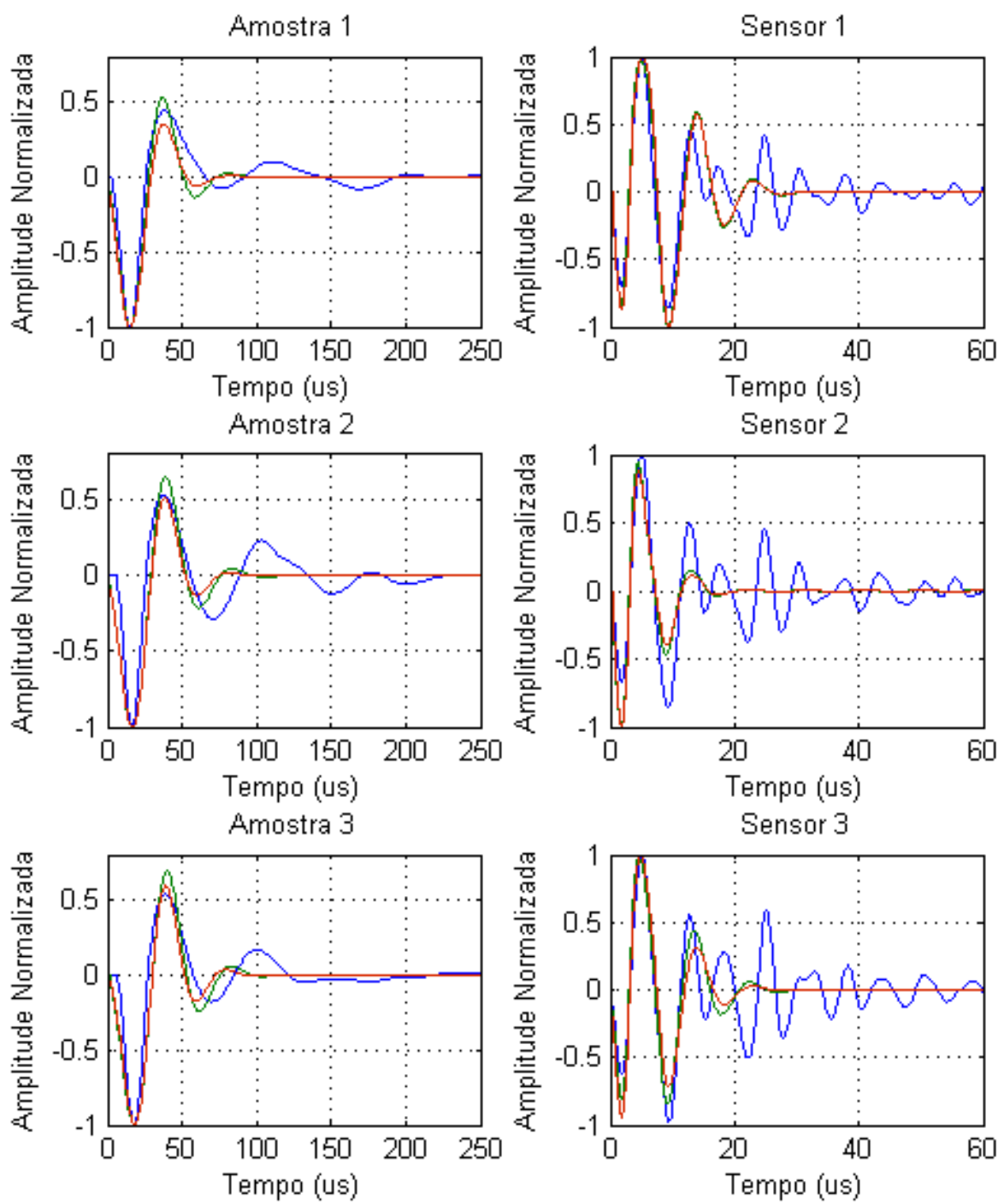

Figura 114: Sinal remodelado (azul), reconstruído (verde) e processado (vermelho) para todas as amostras de piezoeletreto e sensores padrão. Descarga em óleo, caixa 2, posição P2.

Ainda com relação à Tabela 23, retirando-se os dados das amostras de piezoeletreto referentes à posição $\mathrm{P} 5$, a nova media seria 2,23, o desvio padrão, 0,226, e o coeficiente de variação, 10\%, ou seja, um dado comparável com 4,8\% calculado para os sensores, onde foram consideradas todas as posições de medida. Ademais, os sinais reconstruídos e processados para a amostra 2, apresentados nas Figuras 98 a 102, 
mostraram-se mais suscetíveis a prováveis ruídos externos em comparação com os sinais das outras amostras. Já neste caso de descarga em óleo, porém, os sinais reconstruídos e processados apresentaram-se bastante estáveis e próximos dos sinais remodelados, conforme apresentam as Figuras 113 a 117. Portanto, de modo geral as amostras apresentaram resultados comparáveis com os sensores, mesmo com um resultado inferior, em termos de fator de compressão, apresentado pela amostra 2 numa posição específica de medida.
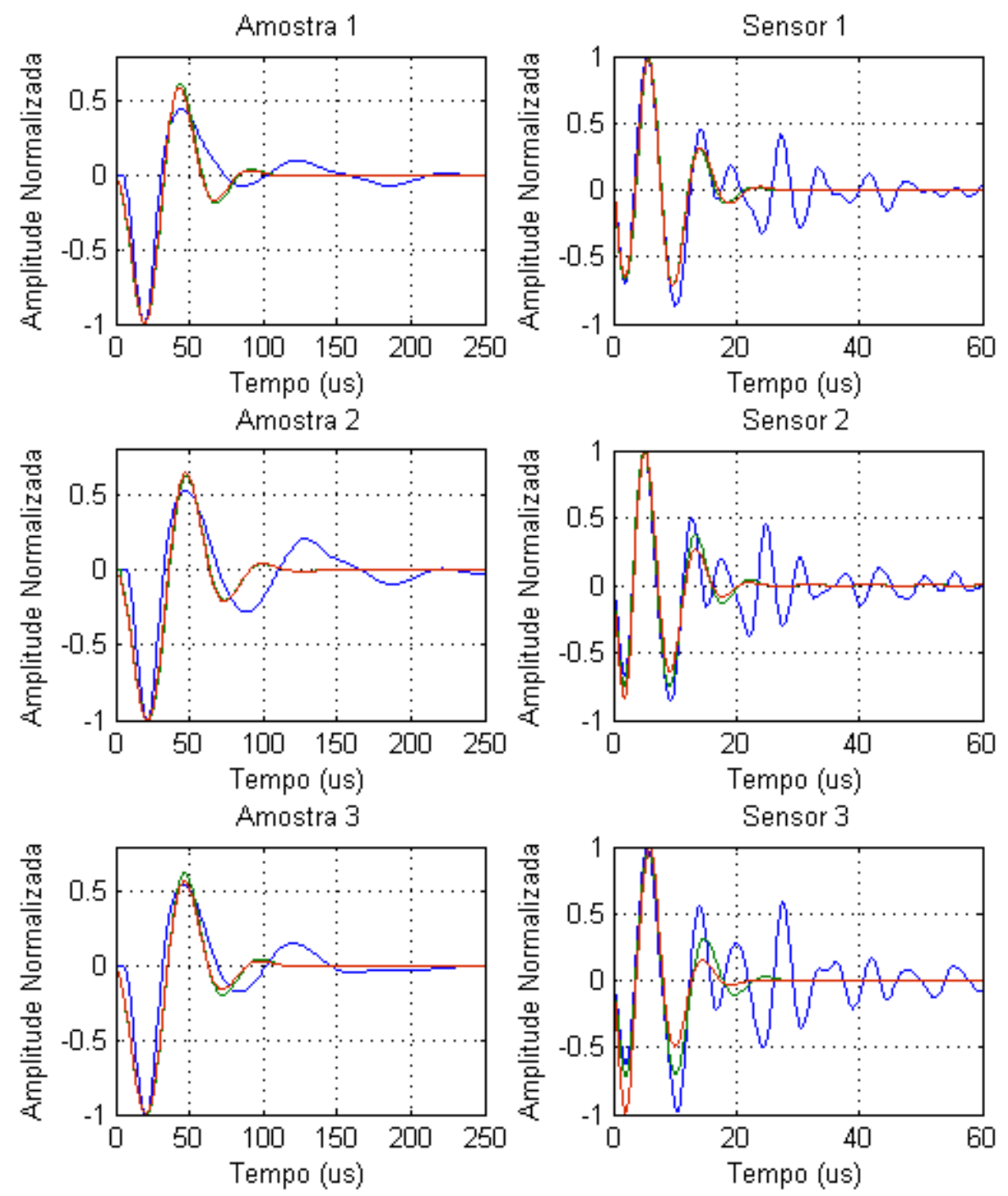

Figura 115: Sinal remodelado (azul), reconstruído (verde) e processado (vermelho) para todas as amostras de piezoeletreto e sensores padrão. Descarga em óleo, caixa 2, posição P3. 

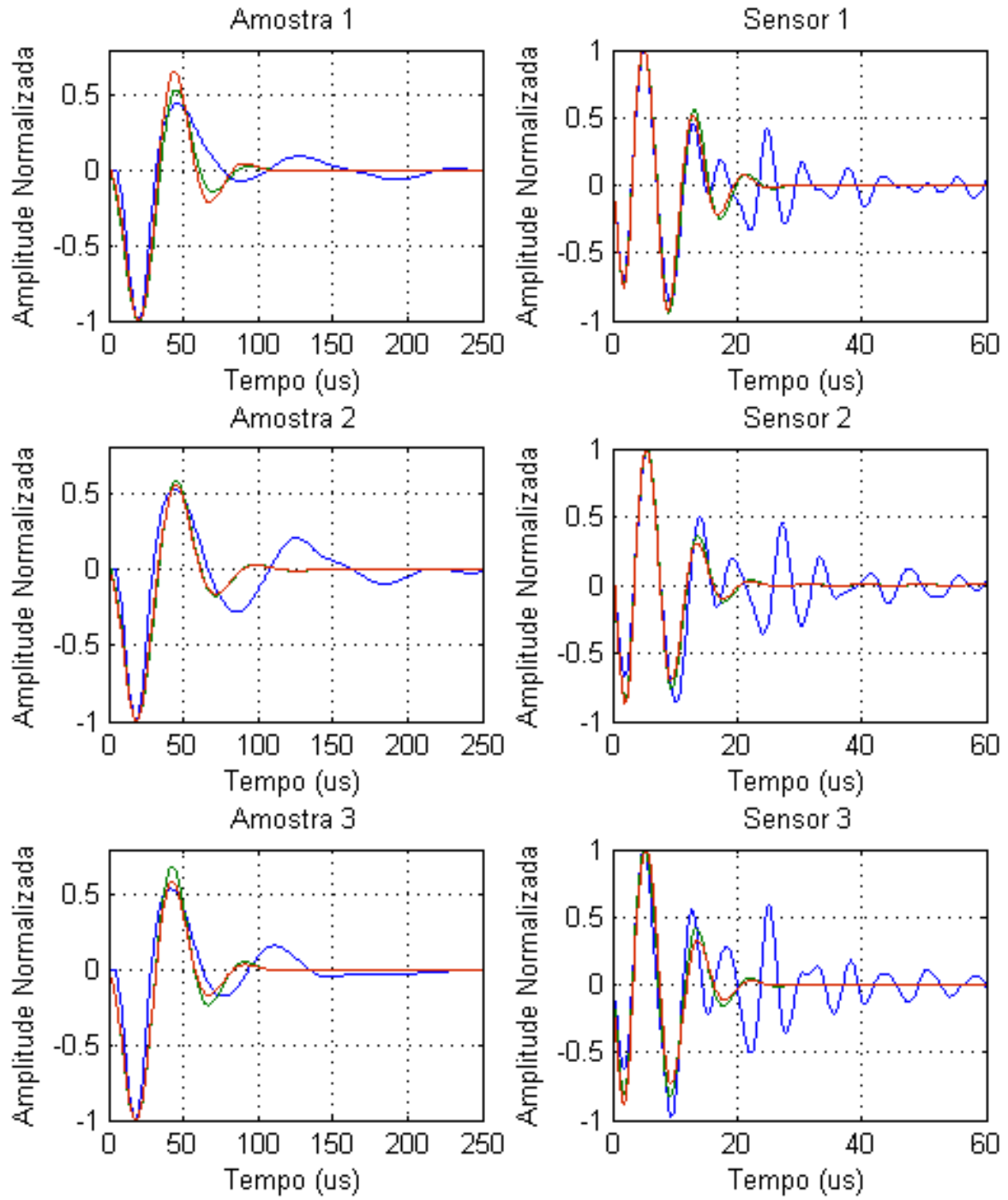

Figura 116: Sinal remodelado (azul), reconstruído (verde) e processado (vermelho) para todas as amostras de piezoeletreto e sensores padrão. Descarga em óleo, caixa 2, posição P4. 

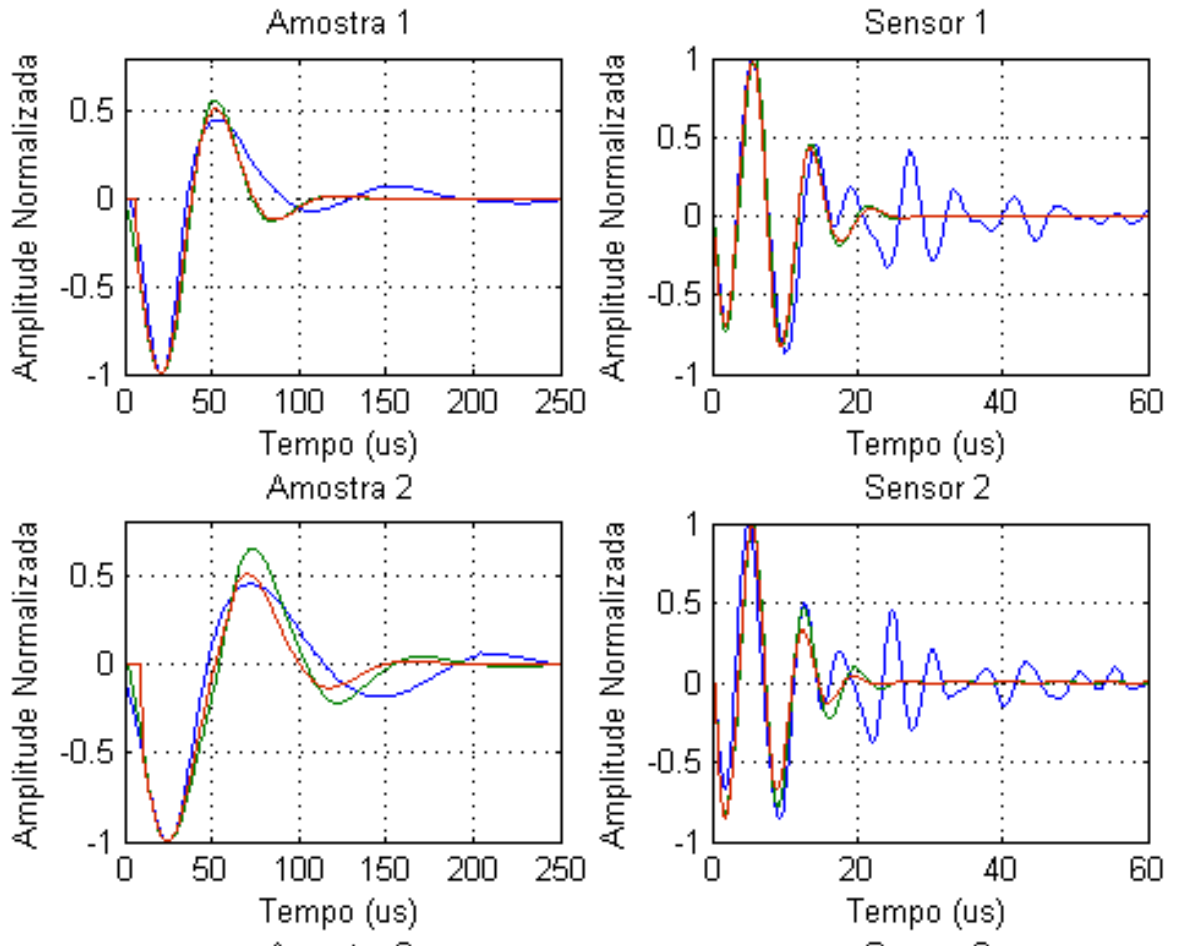

Amostra 3
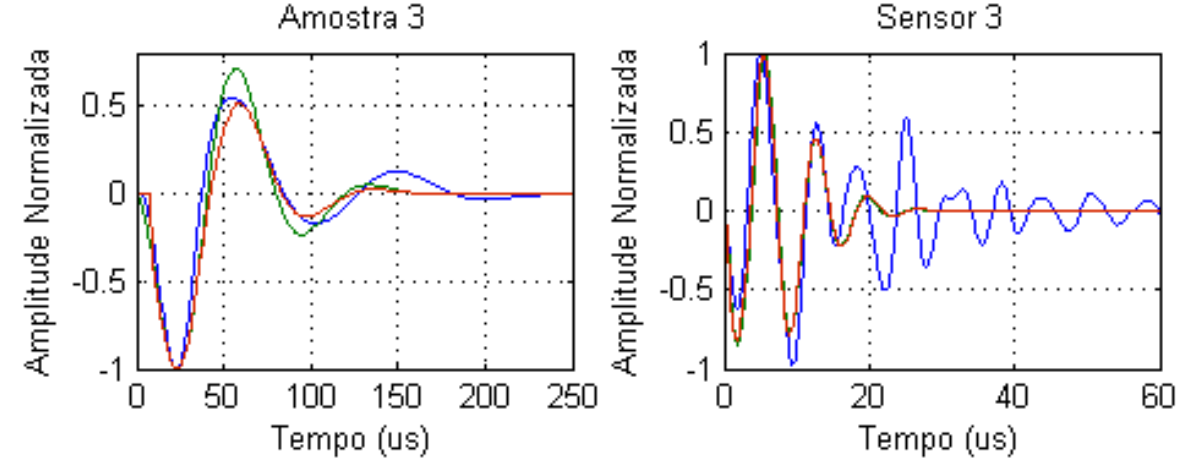

Figura 117: Sinal remodelado (azul), reconstruído (verde) e processado (vermelho) para todas as amostras de piezoeletreto e sensores padrão. Descarga em óleo, caixa 2, posição P5. 


\section{Conclusões e Trabalhos Futuros}

O presente trabalho, após uma importante e extensa pesquisa bibliográfica multidisciplinar, apresentou um protótipo de microfone com elemento sensor piezoelétrico, baseado na tecnologia dos piezoeletretos termoformados e de tecnologia nacional. Este dispositivo, com sensibilidade para detectar além das frequências

audíveis, isto é, as ultrassônicas, possui custo e potencial de aplicação muito competitivo com sensores padrão, sendo factível a deteç̧ão de descargas parciais que ocorrem no interior de transformadores.

No decorrer desta pesquisa, buscando-se aprimorar o protótipo e os ensaios a que este foi submetido, foram desenvolvidos novos circuitos de teste e novas metodologias de ensaio, todos mais bem descritos no corpo deste trabalho. Mais especificamente, obteve-se um importante avanço no aumento do ganho e da imunidade eletromagnética do circuito amplificador do elemento de piezoeletreto. Isto foi crucial para a realização de todas as medidas feitas com este elemento. Outro avanço muito importante foi a construção do sistema de gerador de descarga impulsiva, o qual opera de forma autônoma e é eletromagneticamente blindado. Mais um ponto importante a se mencionar foi a construção do circuito desacoplador fonte/sensor/sinal, utilizado para operar os sensores padrão adotados como referência nesta pesquisa. Foi possível realizar uma simplificação deste circuito proposto na literatura obtendo-se, praticamente, o mesmo resultado. Ressalta-se, também, a importância da câmara anecóica onde foi possível obter um sinal acústico livre de interferências eletromagnéticas e de ecos. Foi a partir deste experimento inicial que se tornou possível idealizar uma metodologia de estudo, ou seja, realizar outros experimentos mais complexos partindo de um sinal acústico sem a presença de ecos até sinais carregados de ecos e distorcidos pelo meio.

Ponto também de destaque, e uma das importantes contribuições originais deste trabalho, foi a decisão de utilizar a ferramenta matemática conhecida como deconvolução homomórfica na análise e processamento dos sinais acústicos de descarga. Essa ferramenta tem permitido a reconstrução do sinal original sem a influência de ecos associados. Os resultados desse processo de reconstrução, tanto dos 
sensores padrão quanto do novo protótipo, foram analisados e mostraram-se animadores principalmente nos casos de descarga em óleo indicando, inclusive, uma provável dependência do meio onde ocorre a descarga parcial, ou seja, se é em ar ou em óleo. Outro ponto de destaque foi a analise da influência da posição de medida e do ponto emissor da descarga. Os resultados, neste caso, apontam para uma não influência da posição de medida e fonte de descarga no sinal reconstruído. Tendo em vista que a quantidade de experimentos ainda é pequena, não se tem elementos suficientes para generalizar essas duas importantes conclusões. Isto será deixado para trabalhos futuros. Sugere-se, portanto, como estudos futuros:

- Testes com outras amostras de piezoeletreto que apresentem ressonância conforme apresenta a Figura 33.

- Estudo de um novo circuito amplificador objetivando uma melhora na relação sinal/ruído.

- Estudo de um processamento ótimo visando o monitoramento on-line de um equipamento.

- Estudo de uma geometria mais "enxuta" para abrigar a amostra de piezoeletreto e o circuito amplificador.

- Testes em transformadores reais e talvez em outros equipamentos que envolvam a temática de descargas parciais.

- Submeter os transformadores reais a outros eventos que não sejam descargas parciais (chuva, por exemplo), de modo a estudar o sinal captado pelo sensor padrão e microfone de piezoeletreto. Isto está baseado no tempo de interação da descarga com meio, que neste caso é de 1 ss, conforme apresentou a Figura 49. Outros eventos, provavelmente, interagem com o meio numa escala de tempo bem maior afetando o sinal reconstruído e, consequentemente, o fator de compressão do espectro. Se esta hipótese estiver correta, será possível, a priori, discriminar a descarga parcial de outros eventos que não sejam descargas. 


\section{Referências}

AGORIS, D. P.; HATZIARGYRIOU, N. D. Approach to partial discharge development in closely coupled cavities embedded in solid dielectrics by the lumped capacitance model. IEE Proceedings - A, v. 140, n. 2, p. 131 - 134, 1993.

ALTAFiM, R. A. C.; GIACOMETTI, J. A.; JANISZEWSKI, J. M. A Novel method for electret production using impulse voltage. IEEE Transactions on Dielectrics an Electrical Insulation, v. 27, n. 4, p. 739 - 743, 1992.

ALtAFim, R. A. C.; FERREIRA, G. F. L.; GIACOMETTI, J. A. Self-controlled pre-breakdown discharge in planar symmetry. IEEE Transactions on Dielectrics an Electrical Insulation, v. 5, n. 1, p. $77-81,1998$.

ALTAFIM, R. A. C. et al. Piezoelectricity of multi-layers space-charge electrets from Teflon FEP film with homogeneous voids distributed on its surface. In: IEEE ANNUAL REPORT CONFERENCE ELECTRICAL INSULATION AND DIELECTRIC PHENOMENA, 2003, Albuquerque. Proceedings... Piscataway: IEEE Service Center, 2003. p. 225 - 228.

ALTAFIM, R. A. C. et al. Piezoelectricity in multi-air voids electrets. In: IEEE ANNUAL REPORT CONFERENCE ON ELECTRICAL INSULATION AND DIELECTRIC PHEnOmenA, 2005, Nashville. Proceeding... Piscataway: IEEE Service Center, 2005. p. $669-672$.

ALTAFIM, R. A. C. et al. Piezoelectrets from Thermo-formed Bubble Structures of Flouropolymer-electret Films. IEEE Transactions on Dielectrics an Electrical Insulation, v. 13, n. 5, p. $979-985,2006$.

ALTAFIM, R. A. P. et al. Template-based fluoroethylenepropylene piezoelectrets with tubular channels for transducer applications, Journal of Applied Physics, v. 106, p. 014106, 2009. 
ALTAFIM, R. A. P. Novos piezoeletretos: desenvolvimento e caracterização. 2010. 138 f. Tese (Doutorado em Engenharia Elétrica) - Escola de Engenharia de São Carlos, Universidade de São Paulo, São Carlos, 2010.

ANDERSON, J. G. Transmission line reference book $-345 \mathrm{kV}$ and Above. $2^{\text {nd }}$ ed. Palo Alto: Electric Power Research Institute, 1982.

ALTWEGG, J. et al. O Telediagnóstico como ferramenta de otimização da manutenção. In: SEMINÁRIO NACIONAL DE PRODUÇÃO E TRANSMISSÃO DE ENERGIA ELÉTRICA, 15., 1999, Foz do Iguaçu. Anais... [S.l.:s.n.].

ARMAN, A. N.; STARR, A. T. The Measurement of discharge in dielectrics. Journal IEE, v. 79, n. 475, p. $67-81,1936$.

ASSOCIAÇÃO BRASILEIRA DE NORMAS TÉCNICAS. NBR 7274: Interpretação e análise dos gases no óleo de transformadores em serviço. Rio de Janeiro: ABNT, 1982.

\section{AMERICAN SOCIETY FOR TESTING MATERIALS. ASTM D1868-07:}

Standard test method for detection and measurement of partial discharge (Corona) pulses in evaluation of insulation systems. Philadelphia: ASTM, 2007.

AUSTEN, A. E. W.; WHITEHEAD, S. Discharge in insulation under alternatingcurrent stresses. Journal IEE, v. 88, n. 1, p. 18 - 22, 1941.

AUSTEN, A. E. W.; HACKETT, W. Internal discharge in dielectrics: their observation and analysis. Journal IEE, v. 91, n. 44, p. 298 - 312, 1944.

AZEVEDO, C. H. B. Metodologia para a eficácia da detecção de descargas parciais por emissão acústica como técnica preditiva de manutenção em transformadores de potência imersos em óleo isolante. 2009. 90 f. Dissertação (Mestrado em Engenharia Elétrica) - Escola de Engenharia Elétrica, Mecânica e de Computação, Universidade Federal de Goiás, Goiânia, 2009. 
BALLATO, A. Piezoelectricity: old effect, new thrusts. IEEE Transactions on Ultrasonics, Ferroelectrics and Frequency Control, v. 42, n. 5, p. 916 - 926, 1995.

- Piezoelectricity: history and new thrusts. In: IEEE ULTRASONICS SYMPOSIUM, 1996, San Antonio. Proceeding... Piscataway: IEEE Service Center, 1996. v. 1 , p. $575-583$.

BALLOU, G. M. Handbook of sound engineers - the new audio cyclopedia. Springer-Verlag, 1987.

BARTNIKAS, R. Use of a multichannel analyzer for corona pulse-height distribution measurements on cables and other electrical apparatus. IEEE Transactions on Instrumentation and Measurement, v. 22, n. 4, p. $403-407,1973$.

. Partial discharges: their mechanism, detection and measurement. IEEE Transactions on Dielectrics and Electrical Insulation, v. 9, n. 5, p. $763-808$, 2002 .

A Comment concerning the rise time of partial discharge pulses. IEEE Transactions on Dielectrics and Electrical Insulation, v. 12, n. 2, p. $196-202$, 2005 .

BARTNIKAS, R.; McMAHON, E. J. Engineering dielectrics: corona measurement and interpretation. Philadelphia: ASTM, 1979. v. 1, chapters $1-2$. (ASTM STP - 669).

BARTNIKAS, R.; NOVAK, J. P. On the Character of different forms of partial discharge and their related terminologies. IEEE Transactions on Dielectrics and Electrical Insulation, v. 28, n. 6, p. 956 - 968, 1993.

BASSO, H. C. et al. Piezoelectricity of a single bubble formed by two oppositely charged Teflon® - FEP films. In: IEEE ANNUAL REPORT CONFERENCE ON ELECTRICAL INSULATION AND DIELECTRIC PHENOMENA, 2006, Kansas City. Proceeding... Piscataway: IEEE Service Center, 2006. p. 146 - 149. 
BERANEK, L. L. Acoustic measurements. New York: Wiley, 1949.

BEYER, M. et al. A New method for detection and location of distributed partial discharges in high voltage cables under external interference. IEEE Transactions on Power Apparatus and Systems, v. 101, n. 9, p. 3431 - 3437, 1982.

BOGGS, S. A. Partial discharge - part III: cavity-induced pd in solid dielectrics. IEEE Electrical Insulation Magazine, v. 6, n. 6, p. 11 - 20, 1990.

BOTTOM, V.E. The Theory and design of quartz crystal units: an introduction to the basic principles of piezoelectricity and their application to the design of quartz. Texas: Mcmurry, 1968.

BRAUN, J. M.; RIZZETTO, S.; FUJIMOTO, N. Modulation of partial discharge activity in GIS insulators by X-ray. IEEE Electrical Insulation Magazine, v. 26, n. 3 , p. $460-468,1991$.

BRITISH STANDARD. BS EN 60270: 2001/IEC 60270: 2000: high-voltage test techniques - partial discharge measurements. Chicago: BS, 2001.

CAPRON B. A.; HESS, D. W. Microscopic models of piezoelectric polymers. IEEE Transactions on Ultrasonics, Ferroelectrics and Frequency Control, v. 33, n.1, p. $33-40,1986$.

CIGRÉ WORKING GROUP 05. An International survey on failures in large power transformers in service. Electra, n. 88, May 1983.

COBINE, J. D. Gaseous conductors - theory and engineering applications. Mineola: Dover, 1941.

COLE, P. T. Location of partial discharge and diagnostic of power transformer using acoustic methods. In: IEEE COLOQUIUM ON CONDITION MONITORING OF LARGE MACHINES AND POWER TRANSFORMERS, 1997, London. Proceedings... Piscataway: IEEE Service Center, 1997. 
CUENCA, W. M. H. Caracterização dos sinais de descargas parciais em equipamentos de alta tensão a partir de modelos experimentais. 2005. 140 f. Tese (Doutorado em Engenharia Elétrica) - Universidade Federal do Rio de Janeiro, Rio de Janeiro, 2005.

DAKIN, T. W.; MALINARIC, P. J. A Capacitance bridge method for measuring integrated corona charge transfer and power loss per cycle. AIEE Transactions on Power Apparatus and Systems, v. 79, n. 3, p. 648 - 653, 1960.

DAWES, C. L.; HOOVER, P. L. Ionization studies in paper-insulated cables --- I. AIEEE Transactions, v. 49, n. 2, p. 141 - 164, 1926.

DAWES, C. L.; REICHARD, H. H.; HUMPHRIES, P. H. Ionization studies in paper-insulated cables --- II. AIEEE Transactions, v. 48, n. 2, p.382 - 395, 1929.

DAWES, C. L.; HUMPHRIES, P. H. Ionization studies in paper-insulated cables --III. AIEEE Transactions, v. 49, n. 2, p. $766-782,1930$.

DEVINS, J. C. The Physics of Partial Discharges in Solid Dielectrics. IEEE Transactions on Electrical Insulation, v. EI-19, n. 5, p. 475 - 495, Oct. 1984.

DISSADO, L. A.; FOTHERGILL, J. C. Electrical degradation and breakdown in polymers. London: Peter Peregrinus, 1992.

DOERNENBURG, E.; GERBER, O. E. Analysis of dissolved and free gases for monitoring performance of oil-filled transformers. In: IEEE Std C57.104-1991 (Revision of IEEE C57.104-1978). IEEE guide for the interpretation of gases generated in oil - immersed transformers. New York: The Institute of Electrical and Electronics Engineers, 1991.

DONALD, C.; LUX, A. On-line monitoring of power transformers and components: a review of key parameters. In: ELECTRICAL INSULATION CONFERENCE AND ELECTRICAL MANUFACTURING \& COIL WINDING, 1999. Cinccinat. Proceedings... [S.l.:s.n.]. p. $669-675$. 
DUBSKY, F. The Dielectric strength of air films entrapped in solid insulation and a practical application of the problem for alternator coils and cables. AIEEE Transactions, v. 38 , n. 1 , p. $537-575,1919$.

DUVAL, M. Dissolved gas analysis: It can save your transformer. IEEE Electrical Insulation Magazine, v. 5, n. 6, p. 22 - 27, 1989.

EDIN, H. Partial Discharges Studied with Variable Frequency of the Applied Voltage. 2001. Thesis (Ph.D.) - Electrical Engineering, Kungl Tekniska Hogskolan, Stockholm, 2001.

ELEFTHERION, P. M. Partial discharge XXI: acoustic emission-based PD source location in transformers. IEEE Transactions on Dielectrics and Electrical Insulation, v. 11, n. 6, p. 22 - 26, 1995.

FALCONI, D. R. Sensor piezelétrico baseado na tecnologia dos eletretos termoformados: aprimoramentos dos processos de produção. 2010. $99 \mathrm{f}$. Dissertação (Mestrado em Engenharia Elétrica) - Escola de Engenharia de São Carlos, Universidade de São Paulo, São Carlos, 2010.

FEDOSOV, S. N.; SEGGERN, H. V. Pyroelectricity in PVDF: influence of polarization and charge. Journal of Applied Physics, v. 103, n. 1, p. 014105, Jan. 2008.

FLURSCHEIM, C.H. (Ed.). Power circuit breaker theory and design. [S.l.]: Peter Peregrinus; Institution of Electrical Engineers, 1985. (IEE Power Engineering Series, 1).

FORSYTH, K. W. Optical partial discharge detection. In: IRIS ROTATING MACHINE TECHNICAL CONFERENCE, 1998. Proceedings... [S.l.:s.n.].

FORTESCUE, C. L.; CONWELL, R. N. Lightning discharges and line protective measures. AIEEE Transactions, v. 50, n. 3, p. 1090 - 1100, 1931. 
FUJIMOTO, N.; RIZZETTO, S.; BRAUN, J. M. Improved PD testing of solid dielectrics using X-ray induced discharge initiation. IEEE Electrical Insulation Magazine, v. 8, n. 6, p. $33-41,1992$.

FUKADA, E. History and recent progress in piezoelectric polymers. IEEE Transactions on Ultrasonics, Ferroelectrics and Frequency Control, v. 47, n. 6 , p. $1277-1290,2000$.

FURUKAWA, T. Piezoelectricity and pyroelectricity in polymers. IEEE Transactions on Electrical Insulation, v. 24, n. 3, p. 375 - 394, 1989.

GAFVERT, U.; EDIN, H.; FORSSEN, C. Modeling of partial discharge spectra measured with variable applied frequency. In: INTERNATIONAL CONFERENCE ON PROPERTIES AND APPLICATIONS OF DIELECTRIC MATERIALS, 7., 2003. Proceedings... [S.l.:s.n.], 2003. p. $839-842$.

GAMEZ-GARCIA, M.; BARTNIKAS, R.; WERTHEIMER, M.R. Synthesis reactions involving XLPE subjected to partial discharges. IEEE Transactions on Electrical Insulation, v. EI-22, n. 2, p. 199 - 205, 1987.

GERHARD-MULTHAUPT, R. Preliminary study of multi-layer space-charge electrets with piezoelectric properties from porous and non-porous Teflon films. In: INTERNATIONAL SYMPOSIUM ON ELECTRETS, 10., 1999, Delphi. Proceeding... Piscataway: IEEE Service Center, 1999. p. $273-276$.

Less can be more - holes in polymer lead to a new paradigm of piezoelectric materials for electrets transducer. IEEE Transactions on Dielectric and Electrical Insulation, v. 9, n. 5, p. $850-859,2002$.

GJAERDE, A. C. Multifactor aging models - origin and similarities. IEEE Electrical Insulation Magazine, v. 13, n. 1, p. 6 - 13, 1997.

GOEL, M. Electrets sensors, filters and MEMS devices: new challenges in materials research. Current Science, v. 85, p. 443 - 453, 2003. 
GOLDMAN, M.; SIGMOND, R. S. Corona and Insulation. IEEE Transactions on Electrical Insulation, v. EI-17, n. 2, p. 90 - 105, Apr. 1982.

GOMES, M. V. C. N. Aplicação de deconvolução homomórfica a dados sísmicos. 1998. 100 f. Dissertação (Mestrado em Geofísica) - Centro de Geociências, Universidade Federal do Pará, 1998.

GRECHKO, O. N.; KALACHEVA, I. Current trends in the development of inservice monitoring and diagnostic systems for $110-750 \mathrm{kV}$ power transformers. Applied Energy: Russian Journal of Fuel, Power, and Heat Systems, v. 34, n. 5, p. $84-97,1996$.

GROSS, B. Static charge on dielectrics. British Journal of Applied Physics, v. 1, n. 10, p. $259-267,1950$.

GULSKI, E. Digital analysis of partial discharges. IEEE Transactions on Dielectric and Electrical Insulation, v. 2, n. 5, p. 822 - 837, 1995.

GUTFLEISCH, F.; NIEMEYER, L. Measurement and simulation of PD in epoxy voids. IEEE Transactions on Dielectric and Electrical Insulation, v. 2, n. 5, p. $729-743,1995$.

GUtmann, F. The Electret. Review of Modern Physics, v. 20, p. $457-472$, 1948.

HAROLD, R.T. Acoustical techniques for detecting and locating electrical discharges. West Conshohocken: ASTM Publication, 1979. V.1: Engineering Dielectrics, Cap. 10. (ASTM-STP, 669).

Acoustic theory applied to the physics of electrical breakdown in dielectrics. IEEE Transactions on Electrical Insulation, v. E1-21, n. 5, p. 781$792,1986$. 
HAUSCHILD, W. Zum Öldurchschlag in inhomogenen Feld bei Schaltspannungen. 1970. Thesis (Ph.D.) - Technical University Dresden, Dresden, 1970.

HILCZER, B.; MALECKI, J. Electrets. Warszawa: PWN-Polish Scientific, 1986.

HOLBOLL, J. The Resistance of composite materials against electrical discharges. 1992. Thesis (Ph.D.) - Technical University of Denmark, Denmark, 1992. (Publication n. 9204).

HOWATSON, A. M. Descargas elétricas en gases. Bilbao: Urmo, 1970.

HUDON, C.; BARTNIKAS, R.; WERTHEIMER, M. R. Surface conductivity of epoxy specimens subjected to partial discharges. In: INTERNATIONAL SYMPOSIUM ON ELECTRICAL INSUlatiOn, 1990, Toronto. Proceedings... Piscataway: IEEE Service Center, 1990. p. 153 - 155.

IEEE GUIDE for detection and location of acoustic emissions from partial discharges in oil-immersed power transformers an reactors. New York: IEEE, 2007. (IEEE Std C57.127 - Revision of IEEE C57.127-2000).

IEEE GUIDE for the interpretation of gases generated in oil - immersed transformers. New York: IEEE, 1991. (IEEE Std C57.104 - Revision of IEEE C57.104-1978).

INTERNATIONAL ELECTROTECHNICAL COMMISSION. Mineral oilimpregnated electrical equipment in service - Guide to the interpretation of dissolved and free gases analysis. New York: IEEE, 1999. (IEC 60599-1999)

INTERNATIONAL ELECTROTECHNICAL COMMISSION. Partial discharge measurement. New York: IEEE, 1968. (IEC 270).

JUDD, M. D.; YANG, L.; HUNTER, I. B. B. Partial discharge monitoring of power transformers using UHF sensors. Part I: sensors and signal interpretation. IEEE Electrical Insulation Magazine, v. 21, n. 2, p. 5 - 14, 2005. 
KACPRZYK, R.; MOTYL, E. Properties of PP-PS double layer electrets. In: INTERNATIONAL SYMPOSIUM ON ELECTRETS, 8., 1994, Paris. Proceedings... Piscataway: IEEE Service Center, 1994. p. $703-708$.

KARDEC, A.; NASCIF, J. Manutenção - função estratégica. 2.ed. Rio de Janeiro: Qualitymark, 2003.

KELEN, A.; DANIKAS, M. G. Evidence and presumption in PD diagnostic. IEEE Transactions on Dielectric and Electrical Insulation, v. 2, n. 5, p. $780-795$, 1995.

KIL, G. et al. Analysis of Partial Discharge in Insulation Oil using Acoustic Signal Detection Method. WSEAS TRANSACTIONS on POWER SYSTEMS, v. 3, n. 3, p. $90-94,2008$.

KIM, C. S.; MIZUTANI, T. Change in PD pattern with aging. IEEE Transactions on Dielectric and Electrical Insulation, v. 11, n. 1, p. 13 - 18, 2004 .

KOGAN, V. I. et al. Failure analysis of EHV transformers. IEEE Transactions on Power Delivery, v. 3, n. 2, p. $672-683,1988$.

KOLEV, N. P. et al. Development of partial discharge model, simulation and measurement. In: ANNUAL REPORT CONFERENCE ON ELECTRICAL INSULATION AND DIELECTRIC PHENOMENA, 1999. Proceedings... Piscataweay: IEEE Service Center, 1999. p. $214-217$.

KRESSMANN, R. Linear and nonlinear piezoelectric response of charged cellular polypropylene. Journal of Applied Physics, v. 90, n. 7, p. 3489 - 3496, 2001.

KREUGER, F. H. Partial discharge detection in high-voltage equipment. London: Butterworths, 1989.

KU, C. C.; LIEPENS, R. Electrical properties of polymers - chemical principles. New York: Hanser, 1987. 
KUFFEL, E.; ZAENGL, W. S.; KUFFEL, J. High voltage engineering: fundamentals. London: Butterworth-Heinemann, 2000.

KUISER, J. A. Protective apparatus for turbo-generators. Journal IEE, v. 60, n. 311, p. $761-776,1922$.

KUNDU, P.; KISHORE, N. K.; SINHA, A. K. Simulation and analysis of acoustic wave propagation due to partial discharge activity. In: IEEE ANNUAL REPORT CONFERENCE ELECTRICAL INSULATION AND DIELECTRIC PHENOMENA, 2006, Kansas City. Proceedings... Piscataweay: IEEE Service Center, 2006. p. 607 -610 .

LANG, S. B. Pyroelectricity: from ancient curiosity to modern imaging tool. Physics Today, v. 58, n. 8, p. $31-36$, Aug. 2005.

LAZAREVICH, A. K. Partial discharge detection and localization in high voltage transformer using an optical acoustic sensor. 2003. Thesis (Master of Science in Electrical Engineering) - Virginia Polytechnic and State University, Blacksburg Virginia, 2003.

LEMKE, E. Durchschlagmechanimus und schlagweitedurchschlagspannungs-kennlinien von inhomogenen luftfunkenstrecken bei schaltspannungen. 1967. Thesis (Ph.D.) - Technical University Dresden, Dresden, 1967.

LEMKE, E. WG D1.33: guide for partial discharge measurements in compliance to IEC 60270. Paris: CIGRE, 2008.

LUNDGAARD, L. E. Partial discharge - Part XIII: acoustic partial discharge detection - fundamental considerations. IEEE Electrical Insulation Magazine, v. 8, n. 4, p. $25-31,1992$.

LUNDGAARD, L. E. et al. Partial discharge in transformer insulation. Paris: CIGRE, 2000. 
LOEB, L. B.; MEEK, J.M. The Mechanism of electric spark. Stanford: Stanford University Press, 1940.

LUPI FILHO, G. Comparação entre os critérios de diagnósticos por análise cromatográfica de gases dissolvidos em óleo isolante de transformador de potência. 2012. 128 f. Dissertação (Mestrado em Engenharia Elétrica) - Escola de Engenharia de São Carlos, Universidade de São Paulo, 2012.

MASON, J. H. The Deterioration and breakdown of dielectrics resulting from internal discharges. Proceeding of the IEE - Part 1: General, v. 98, n. 109, p. $44-59$, Jan. 1951.

MASON, H. M. Enhancing the significance of PD measurements. IEEE Transactions on Dielectric and Electrical Insulation, v. 2, n. 5, p. $876-888$, Oct. 1995.

McALLISTER, I.W. Partial discharge in spheroidal voids - void orientation. IEEE Transactions on Dielectric and Electrical Insulation, v. 4, n. 4, p. 456 - 461, 1997.

MEIJER, S.; GULSKI, E.; SMIT, J. J. Pattern analysis of partial discharges in SF6 GIS. IEEE Transactions on Dielectric and Electrical Insulation, v. 5, n. 6, p. $830-842,1998$.

MERRIL, F. H.; HIPPEL, A. The Atomphysical interpretation of lichtenberg figures and their application on the study of gas discharge phenomena. Journal of Applied Physics, v. 10, p. $873-887,1939$.

MEYERS, S. D.; KELLY, J. J.; PERRISH, R. H. A Guide to transformer maintence. Akron: S.D., 1981.

MISTRAS - A Wolrd of NDT Solutions. Technology Package for Acoustic Emission Testing Instrument and Procedure for Detecting, Locating and Assessing Electrical and Thermal Faults in Power Transformers during 
On-Line Monitoring. MISTRAS Group, Inc. 2010(a). Disponível em: <http://www.pacndt.com/downloads/PowerPac.pdf>. Acesso em: 07 Mar. 2012.

MISTRAS - A Wolrd of NDT Solutions. R15I-AST Sensor - Integral Preamplifier Sensor. MISTRAS Group, Inc. 2010(b). Disponível em: $<$ http://www.mistrasgroup.com/products/company/publications/2\$Acoustic_Emissi on/Model_R15I-AST.pdf>. Acesso em: 07 Mar. 2012.

MOLE, G. Design and performance of a portable of AC discharge detector. California: Electrical Research Association, 1952. (Report V/T 115).

MONRO, H. A. J. Great books of the western world. Chicago: William Benton, 1952.

MORAIS, D.R.; ROLIM, J. G. A Neural network for detection of incipient faults in transformers based on the dissolved gas analysis of insulating oil. In: INDUSCON, 6., 2004, Joinville, 2004. Proceedings... [S.l.:s.n.], 2004.

MORSHUIS, P. Assessment of dielectric degradation by ultrawide-band PD detection. IEEE Transactions on Dielectrics and Electrical Insulation, v. 2, n. 5 , p. $744-760,1995$.

MORSHUIS, P. H. F. Partial discharge mechanisms. mechanisms leading to breakdown, analyzed by fast electrical and optical measurements. 1993. Thesis (Ph.D. in Electrical Engineering) - Delft University of Technology, Netherlands, 1993(a).

Time-resolved discharge measurements. In: INTERNATIONAL CONFERENCE ON PARTIAL DISCHARGE, 1993. Proceedings... Piscataway: IEEE Service Center, 1993(b). p. $43-46$.

MORSHUIS, P. H. F.; KREUGER, F. H. Transition from streamer to Townsend mechanisms in dielectric voids. Journal of Physics D: applied physics, v. 23, n. 12 , p. $1562-1568,1990$. 
MÖSER, M.; BARROS, J. L. Ingeniería Acústica. Berlin. Springer - Verlag, 2009.

MUHR, H. M.; SCHWARZ, R.; JAUFER, S. Electrical measurement as diagnostic tool for HV-insulations. 2005. Disponível em: $<$ https://online.tugraz.at/tug_online/_voe_main2.getvolltext?pCurrPk=13027>. Acesso em: 31 Mar. 2012.

NARBUT, P. Transformer corona measurement using condenser bushing tap and resonant measuring circuits. IEEE Transactions on Power Apparatus and Systems, v. 84, n. 8, p. $652-657,1965$.

NASSER, E. Fundamentals of gaseous ionization and plasma electronics. London: John Wiley, 1971.

NATIONAL ELECTRIC MANUFACTURERS ASSOCIATION. Methods of measurement of radio influence voltage (RIV) of high voltage apparatus. Rosslyn: NEMA, 1964. (NEMA, 107).

NEUMANN, C. et al. PD measurements on GIS of different designs by nonconventional UHF sensors. Paris: CIGRÉ, 2000. (15-305, Session 2000).

NIEMEYER, L.; FRUTH, B.; GUTFLEISCH, F. Simulation of partial discharge in insulation systems. In: SYMPOSIUM HIGH VOLTAGE ENGINEERING, 7., 1991, Dresden-Netherlands. Proceedings... [S.l.:s.n.], 1991. paper 71.05, p. 25-28.

OLIVEIRA, P. C. D. Aplicação do processamento homomórfico na codificação de voz a baixas taxas. 1992. 87 f. Dissertação (Mestrado em Engenharia Elétrica) - Faculdade de Engenharia Elétrica, Universidade Estadual de Campinas, 1992.

OPPENHEIM, A. V. Superposition in a class of nonlinear systems. Technical Report 432, Research Laboratory of Electronics. Cambridge: MIT, 1965. 
OPPENHEIM, A. V. Nonlinear filtering of convolved signals. Quart. Progr. Rept. 80, Research Laboratory of Electronics, MIT, Cambridge, Mass., p. 168 - 175, Jan. 1966.

OPPENHEIM, A. V. Generalized superposition. Information and Control, v. 11, ns. $5-6$, p. $528-536,1967$.

OPPENHEIM, A. V. Generalized Linear Filtering. Chapter 8 in Digital Processing of Signals. New York: McGraw-Hill Book Company, 1969.

OPPEnHEIM, A. V.; SCHAFER, R. W. Digital Signal Processing. London: Prentice-Hall International Editions, 1975.

OPENHEIM, A. V.; TRIBOLET, J. M. Signal Analysis by Homomorphic Prediction. IEEE Transaction on Acoustics, Speech and Signal Processing, v. 24, n. 4, p. $327-332,1976$.

OPPENHEIM, A. V.; SCHAFER, R. W. From frequency to quefrency: a history of the cepstrum. IEEE Signal Processing Magazine, v. 21, n. 1, p. 95 - 106, 2004.

PAOLETTI, G.; BOLUBEV, A. Partial discharge theory and appliactions To electrical systems. In: ANNUAL INDUSTRY TECHNICAL CONFERENCE RECORD OF PULP AND PAPER, 1999. Proceedings... Palo Alto: IEEE, 1999. p. 124 - 138. DOI: 10.1109/PAPCON.1999.779355.

PAULINO, M. E. C. Estado da arte da medição com múltiplos canais sincronizados para avaliação de descargas parciais. In: IEEE/PES 2010 TRANSMISSION AND DISTRIBUTION CONFERENCE AND EXPOSITION LATIN AMERICA, 2010, São Paulo. Anais... São Paulo: [s.n.], 2010. Session A23, paper 1094.

PEDERSEN, A.; CRICHTON, G. C.; McAlliSteR, I. W. The Theory and measurement of partial discharge transients. IEEE Transactions on Electrical Insulation, v. 26, n. 3, p. $487-497,1991$.

PEEK, F. W. Dielectric phenomena in high voltage engineering. New York: McGraw-Hill, 1929. 
PENA, M. C. M. Falhas em transformadores de potência: uma contribuição para análise, definições, causas e soluções. 2003. 134 f. Dissertação (Mestrado em Ciências da Engenharia) - Universidade Federal de Itajubá, Itajubá, 2003.

PILLING, J. Ein beitrag zur interpretation der lebensdauerkennlinien von feststoffisolierungen. Thesis (Habilitation) - Technical University Dresden, Dresden, 1976.

QUI, X. Patterned piezo- pyro- and ferroelectricity of poled polymer electrets. Journal of Applied Physics, v. 108, n. 1, p. 011101 - 011119, 2010.

RABINER, L. R.; SCHAFER, R. W. Digital Processing of Speech Signals. New Jersey: Prentice-Hall Signal Processing Series, 1978.

RICHARDSON, P. D. Piezoelectric polymers. IEEE Engineering in Medicine and Biology Magazine, v. 8, n. 2, p. 14 - 16, 1989.

ROGERS, R. R. Experiences in the interpretation of incipient faults in power transformers by dissolved gasin-oil chromatography analysis (a progress report), minutes of forty. In: ANNUAL INTERNATIONAL CONFERENCE OF DOBLE CLIENTS, 1975, Watertown. Proceedings... Watertown: Doble Engineering, 1975. sec. 10-201.

ROTH, A. Hochspannungstechnik. Aarau: Spring-Verlag Wien, 1959.

SÁ, A. L.; NEPOMUCENO, P. R. Introdução à cromatografia como técnica de manutenção preditiva: ciclo de palestras de manutenção e da transmissão. Salvador: [s.n.], 1993. p. $62-65$.

SCHAFER, R. W. Echo Removal by Discrete Generalized Linear Filtering. 1969. Thesis (Ph.D.) - Massachusetts Institute of Technology, Cambridge, 1969.

SCHWARZ, R.; MUHR, M. Modern technologies in optical partial discharge detection. In: IEEE ANNUAL REPORT CONFERENCE ELECTRICAL 
INSUlATION AND DIELECTRIC PHENOMENA, 2007. Proceeding... Piscataway: IEEE Service Center, 2007. p. 163 - 166.

SCHWARZ, R.; MUHR, M.; PACK, S. Partial discharge detection in oil with optical methods. In: IEEE INTERNATIONAL CONFERENCE ON DIELECTRIC LIQUIDS, 2005. Proceedings... Piscataway: IEEE Service Center, 2005. p. $245-$ 248.

SCHWARZ, R.; JUDENDORFER, T.; MUHR, M. Review of partial discharge monitoring tecniques used in high voltage equipament. In: IEEE ANNUAL REPORT CONFERENCE ELECTRICAL INSULATION AND DIELECTRIC PHENOMENA, 2008. Proceeding... Piscataway: IEEE Service Center, 2008. p. $400-403$.

SESSLER, G. M. Electrets. Berlin: Springer-Verlag, 1987.

. Bernard Gross and the evolution of modern electret research. Brazilian Journal of Physics, v. 29, n. 2, p. 220 - 225, June 1999.

SESSLER, G. M. Bernhard Gross and electret research, his contributions, our collaboration, and what followed. IEEE Transactions on Dielectrics and Electrical Insulation, v. 13, n. 5, p. $942-952,2006$.

SIVIAN, L. J. High frequency absorption in air and other gases. The Journal of The Acoustical Society of America, v. 19, n. 5, p. 914 - 916, 1947.

SOMEYA, T. et al. Conformable, flexible, large-area networks of pressure and thermal sensors with organic transistor active matrixes. Proceedings of the National Academy of Science of the United States of America, v. 102, n. 35, p. $12321-12325$, Aug. 2005.

TAKAHASHI, Y. Two hundred years of Lichtenberg figures. Journal of Electrostatics, v. 1, n. 6, p. 1 -13, Feb. 1979. 
TANAKA, T. Internal partial discharge and material degradation. IEEE Transactions on Electrical Insulation, v. EI-21, n. 6, p. 899 - 905, 1986.

TEMMEN, K. Evaluation of surface changes in flat cavities due to ageing by means of phase-angle resolved partial discharge measurement. Journal of Physics D: applied physics, v. 33, n. 6, p. 603 - 608, Mar. 2000.

TOWNSEND, J. S. Electricity in gases. Oxford: Oxford University Press. 1915.

TRAINER, M. Kelvin and piezoelectricity. IEEE Transactions on Dielectrics and Electrical Insulation, v. 10, p. $842-861,2003$.

TRIBOLET, J. M. A New Phase Unwrapping Algorithm. IEEE Transactions on Acoustics, Speech, and signal Processing, v. ASSP-25, n. 2, p. $170-177$, April 1977.

- Applications of Short-Time Homomorphic Signal Analysis to Seismic Wavelet Estimation. IEEE Transactions on Acoustics, Speech, and signal Processing, v. ASSP-26, n. 4, p. 343 - 353, August 1978.

UMAN, M. A. Lightning. New York: McGraw-Hill Book, 1969.

VOGEL, F. J. Corona measurements and their interpretation applied to oil insulated transformers. IEEE Winter Power Meeting, 1972. Paper T 72 093-8.

WADA, Y.; HAYAKAWA, R. Piezoelectricity and pyroelectricity of polymer. Japanese Journal of Applied Physics, v. 15, p. 2041 - 2047, 1976.

WANG, M. H.; VANDEMAAR, A. J.; SRISVASTAVA, K. D. Review of condition assessment of power transformer in service. IEEE Electrical Insulation Magazine, v. 18, n. 6, p. $12-26,2002$.

WESTINGHOUSE electrical Maintenance Hints. Trafford: Westinghouse Electric, 1976. 
WHITEHEAD, S. Dielectric breakdown of solids. Oxford: [s.n.], 1951.

WOLTER, K. D.; TANAKA, J.; JOHNSON, J. F. A Study of gaseous degradation products of corona-exposed polyethylene. IEEE Transactions on Electrical Insulation, v. EI-17, n. 3, p. 248 - 252, 1982.

XUNLIN, Q. Patterned piezo-, pyro-, and ferroelectricity of poled polymer electrets, Journal of Applied Physics, v. 108, p. 011101, 2010.

ZANG, X.; HILLENBRAND, J.; SESSLER, G. M. Thermally stable fluorocarbon ferroelectrets with high piezoelectric coefficient. Applied Physics A, v. 84, p. $139-$ $142,2006$. 


\title{
Anexo A: Dados das respostas em frequência dos sensores padrão
}

\author{
Neste anexo são apresentadas as respostas em frequência de cada sensor \\ padrão utilizado na realização de todos os ensaios. A primeira reposta em frequência \\ que aparece a seguir refere-se ao sensor 1; a segunda, ao sensor 2 e a terceira, ao \\ sensor 3.
}





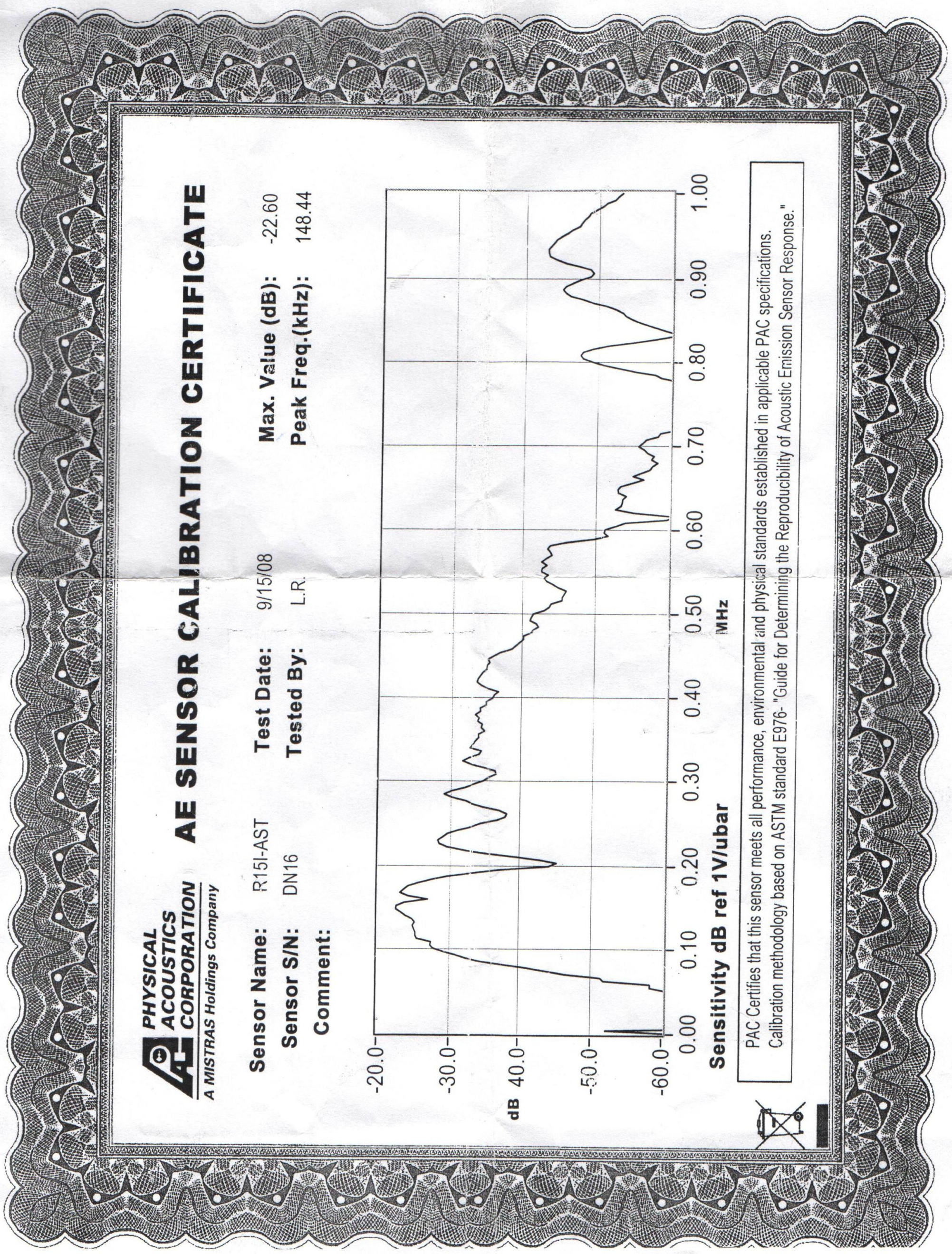




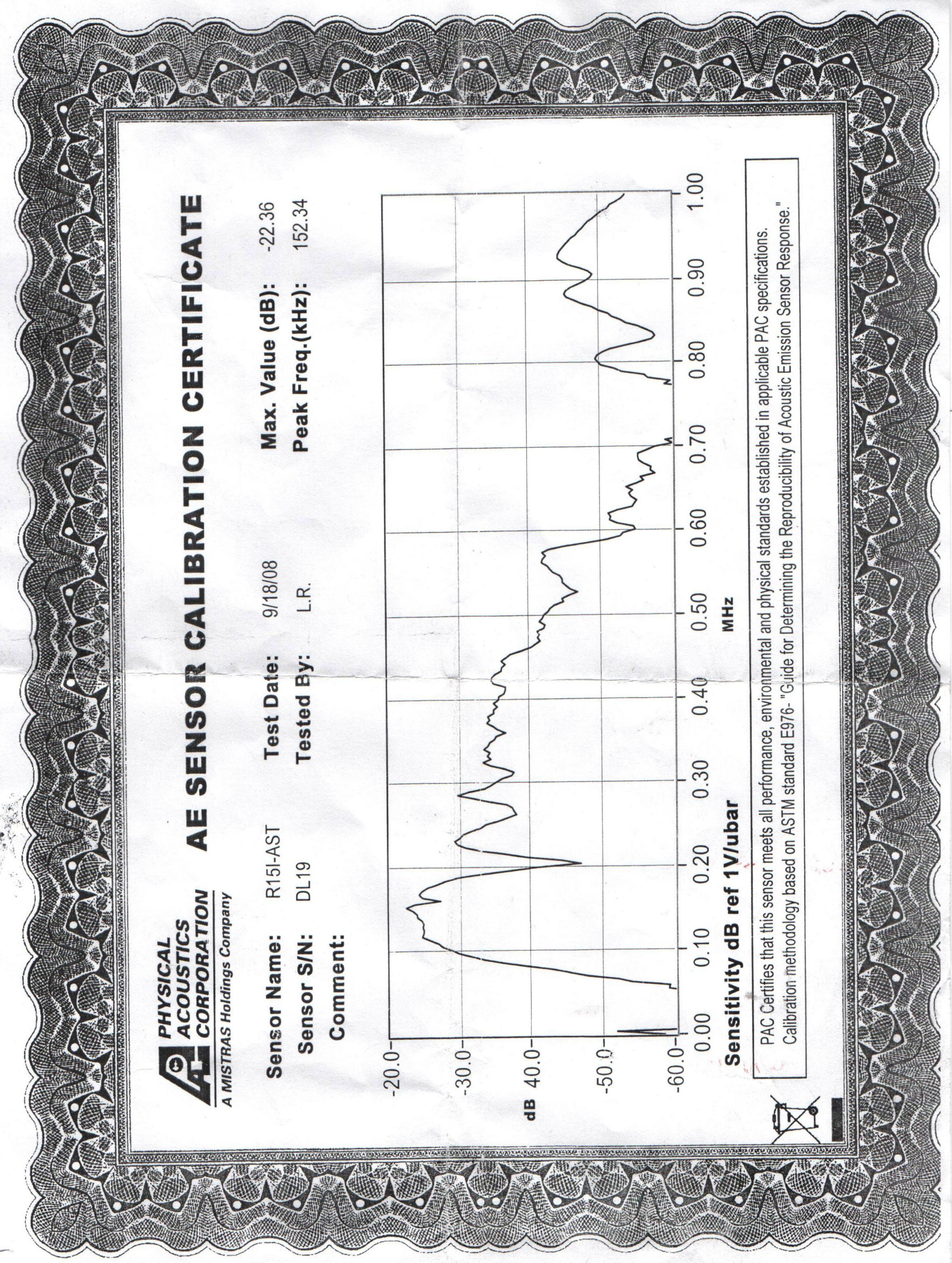




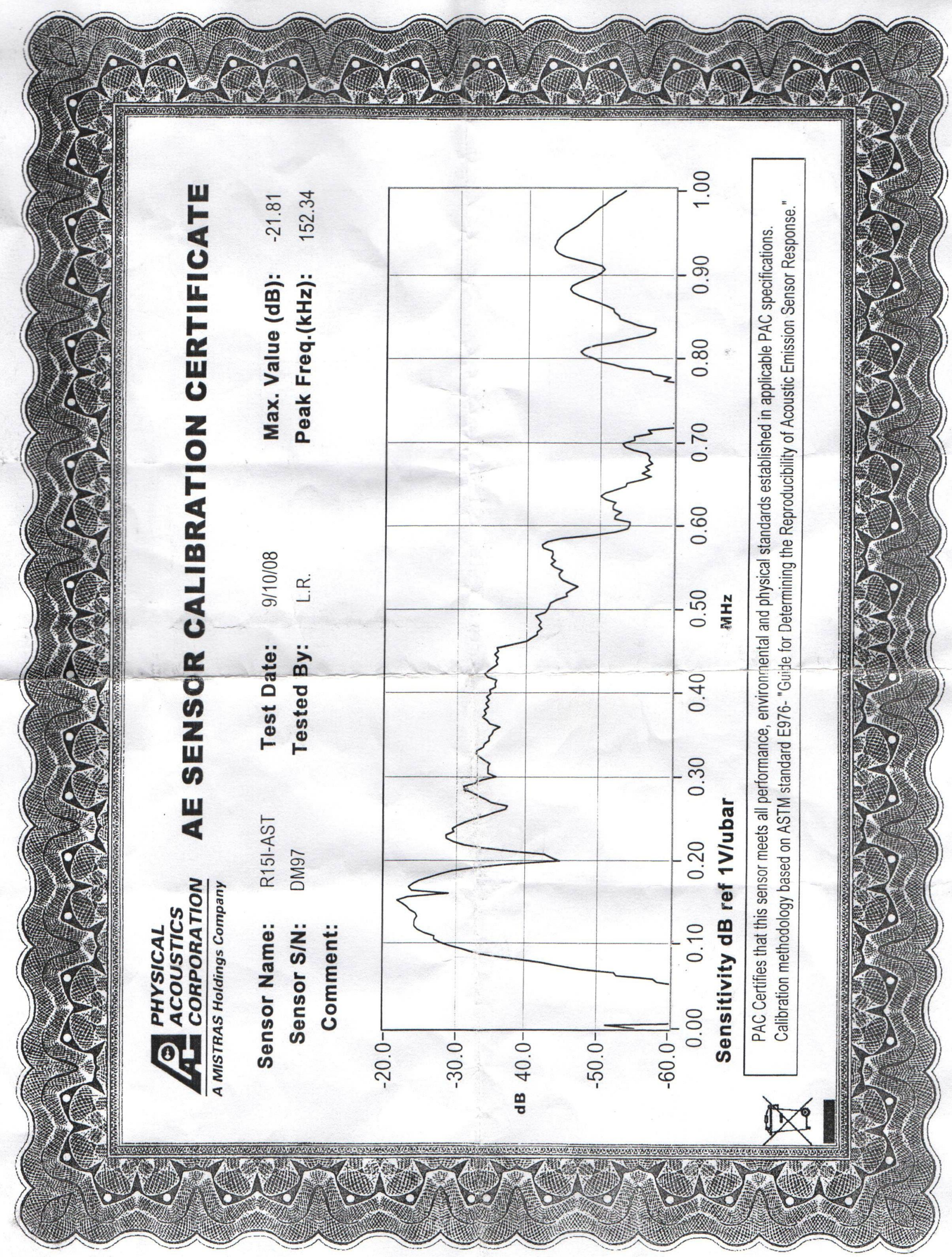





\section{Apêndice A:}

\section{Desenhos técnicos do microfone}

Neste apêndice estão presentes os desenhos técnicos básicos para manufatura de um novo protótipo de microfone. Estes arquivos foram gerados a partir do software Autodesk Inventor Professional 2013 e corrigidos na versão 2014, ambas dedicadas para estudantes.

Como foi apresentado no subitem 3.1, a amostra não está mais em contato com o referencial do circuito. Sendo assim, deve haver uma conexão do eletrodo superior, ou arruela de alumínio, com o circuito. Ademais, deve-se isolar a porca de alumínio da arruela, de modo a não conectar a amostra com o corpo do transdutor, que está conectado ao referencial do circuito. Outra alteração foi no eletrodo inferior, ou o suporte da amostra: substituiu-se o eletrodo vazado por um maciço, pois se constatou que a resposta piezelétrica era maior para o eletrodo maciço. Outro detalhe: o espaçador é de poliacetal de modo a evitar qualquer contato elétrico da placa do circuito amplificador com o corpo do microfone. A Figura 118 apresenta uma fotografia do novo microfone montado.

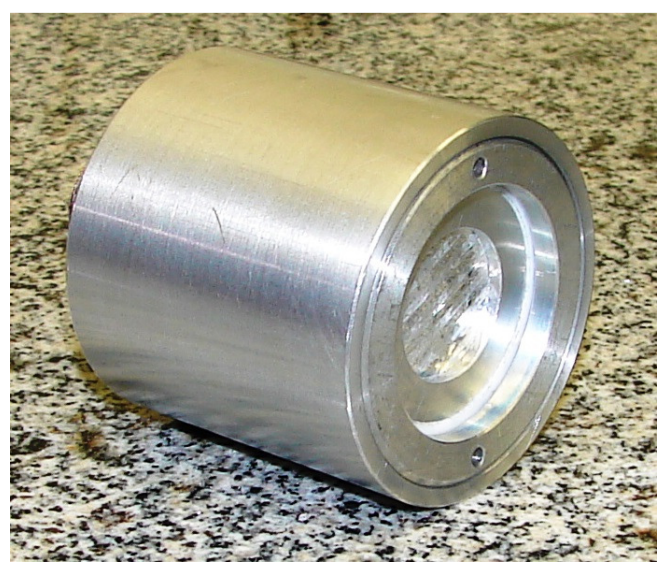

Figura 118: Fotografia do novo microfone de piezoeletreto. 



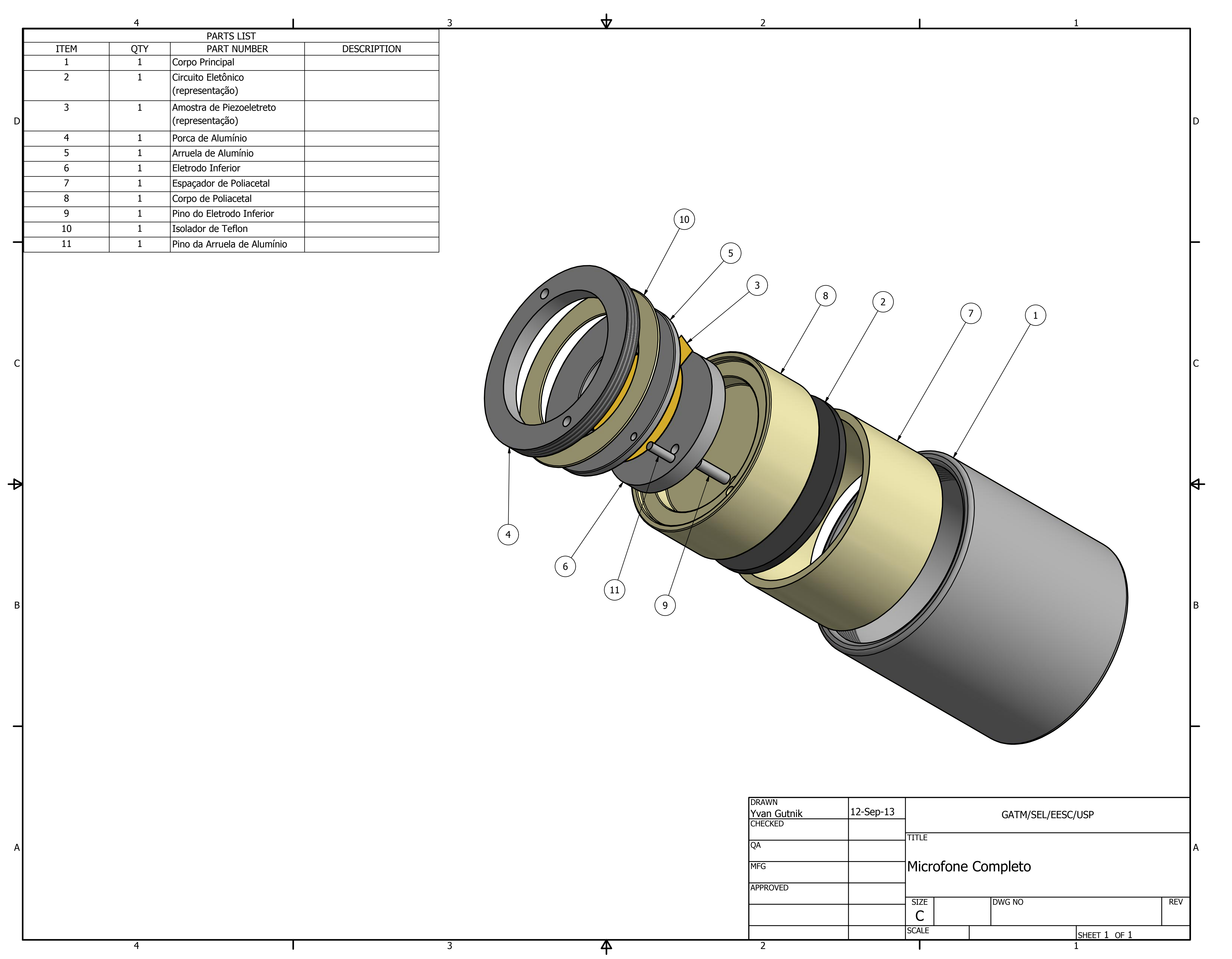



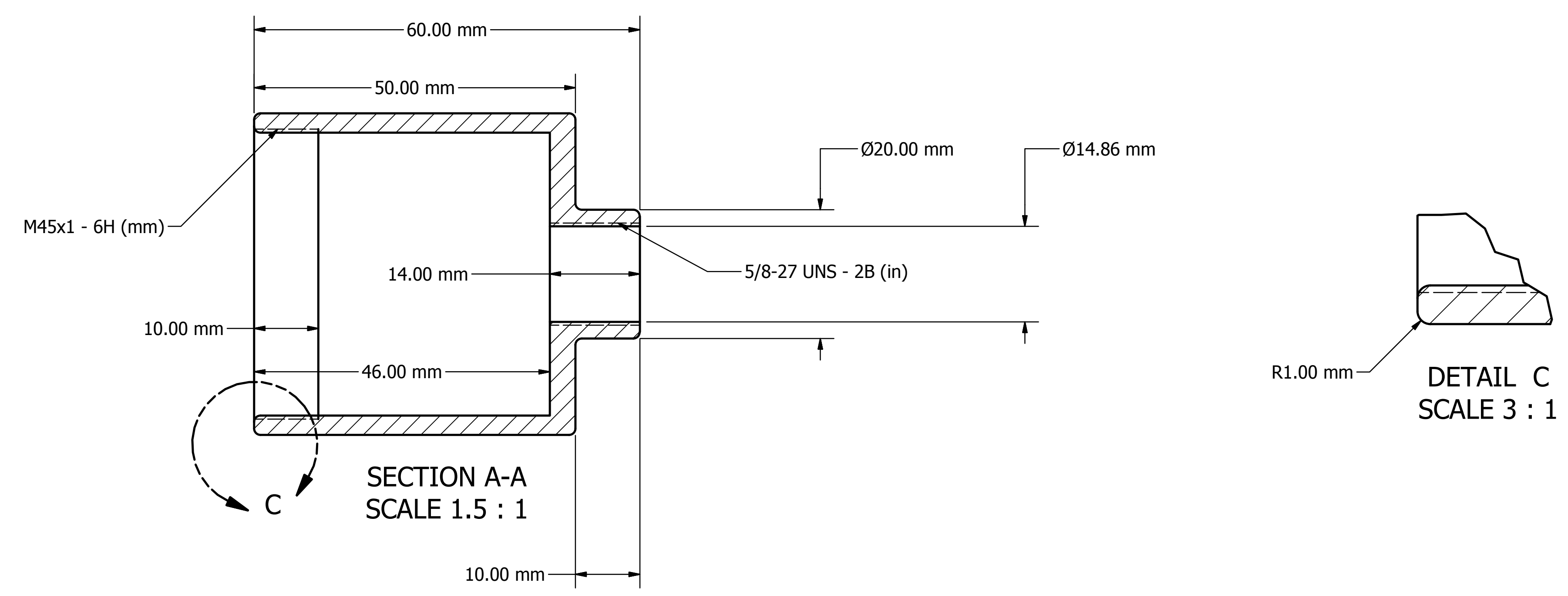

$\rightarrow$
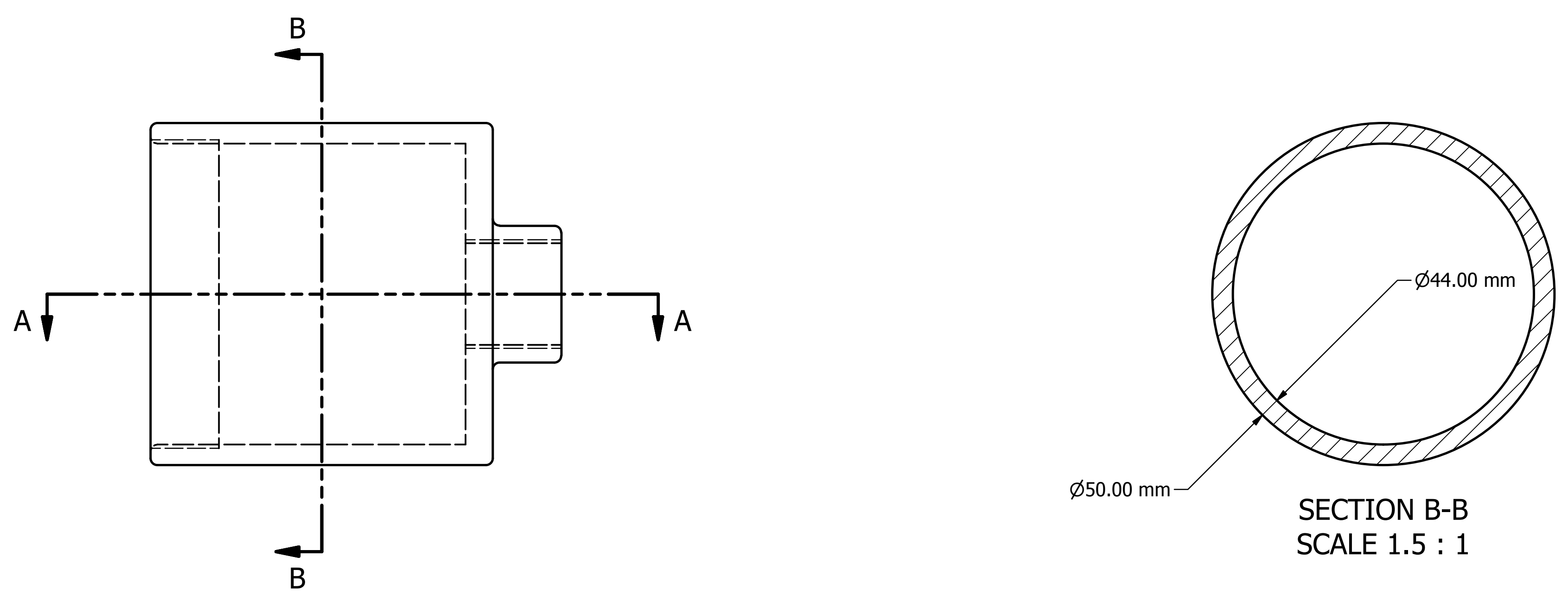

SECTION B-B

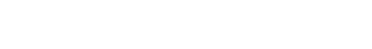


4

3

2

1

D

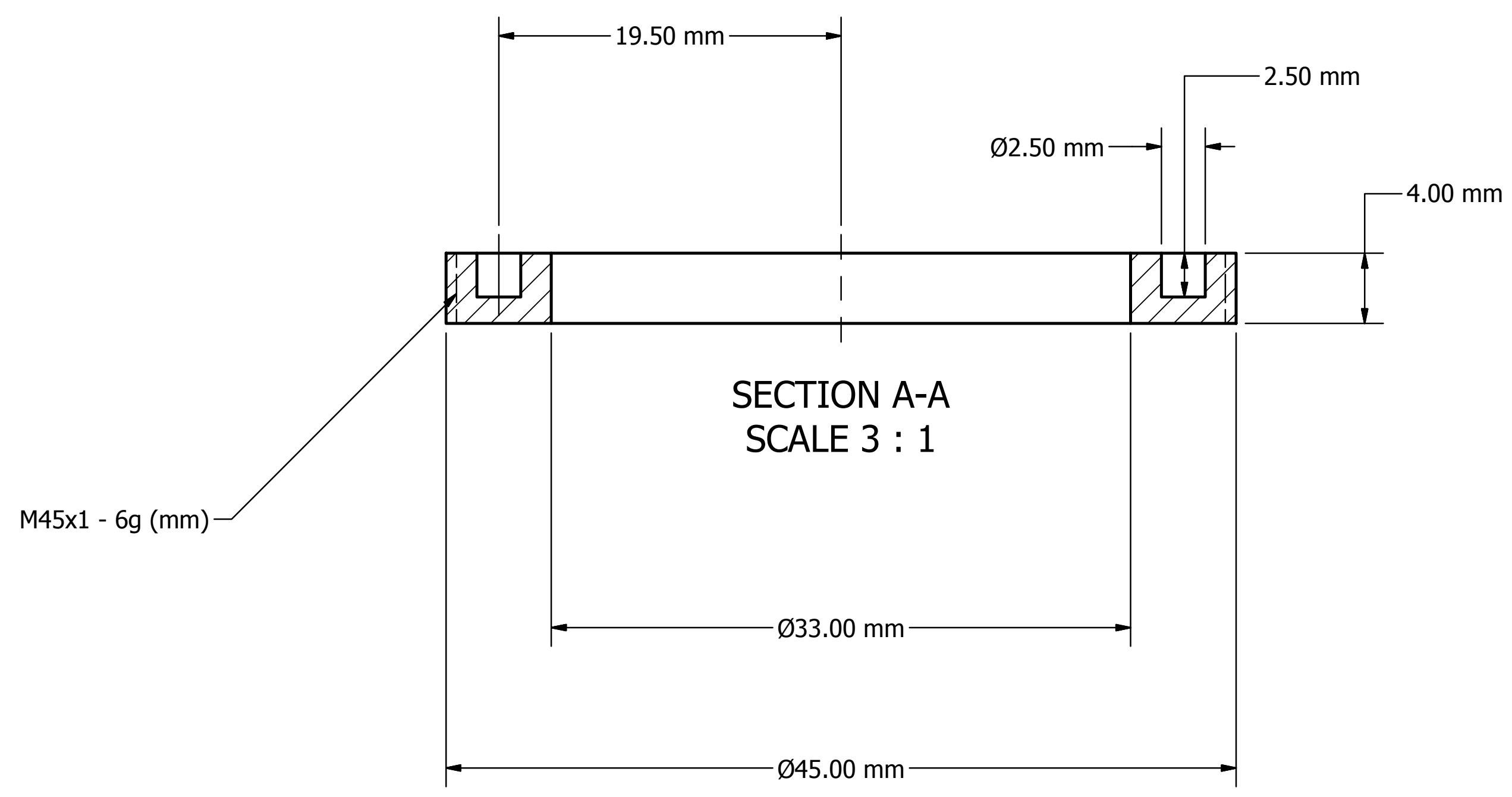

D
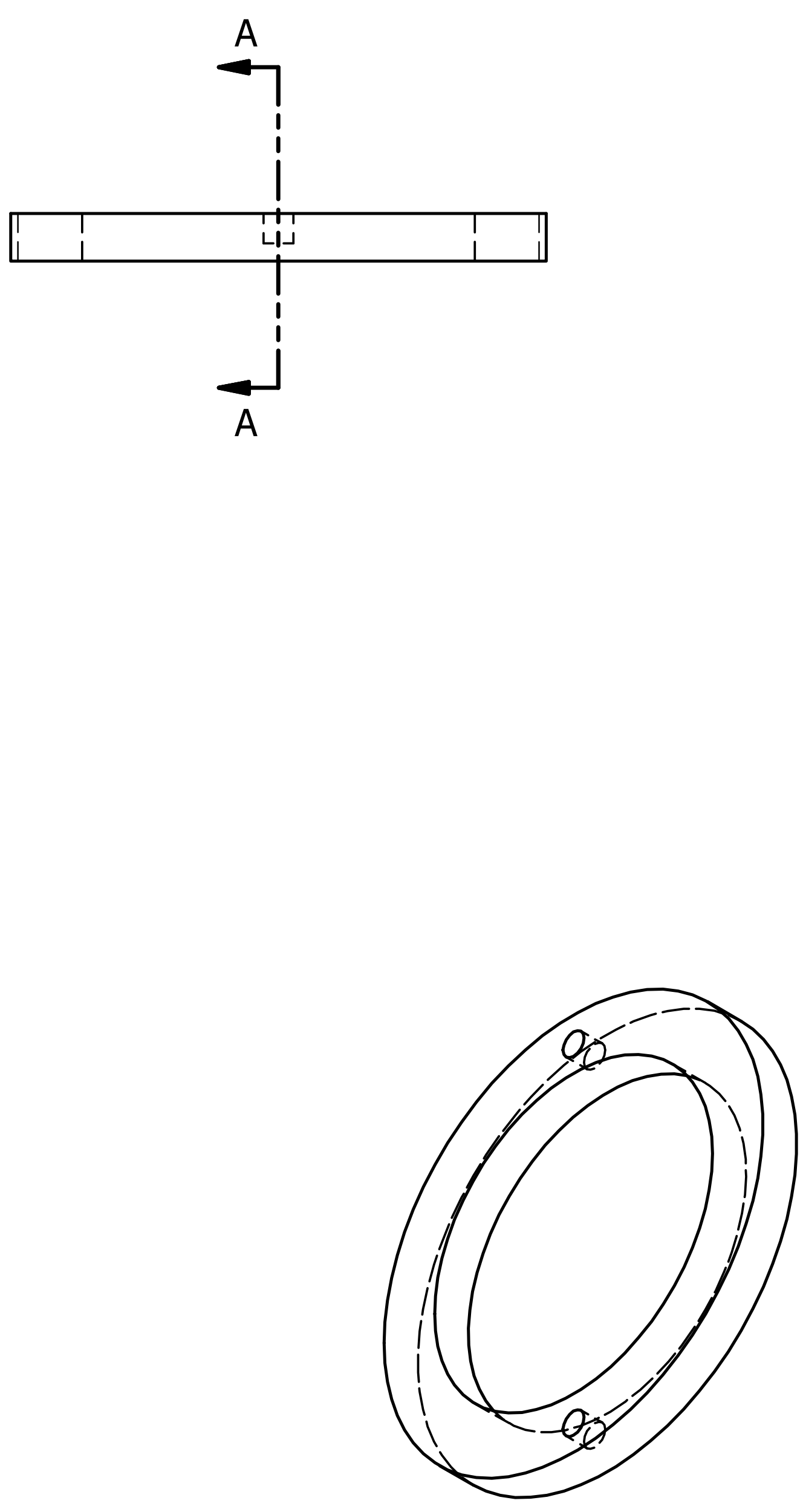

A

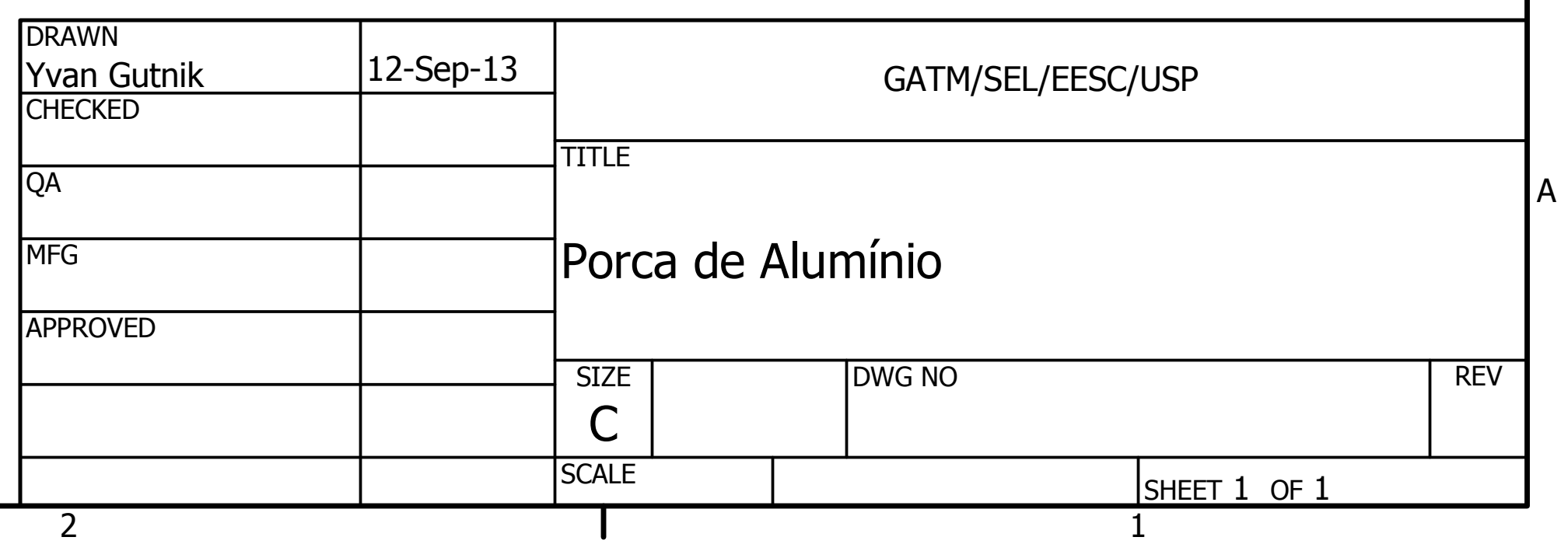




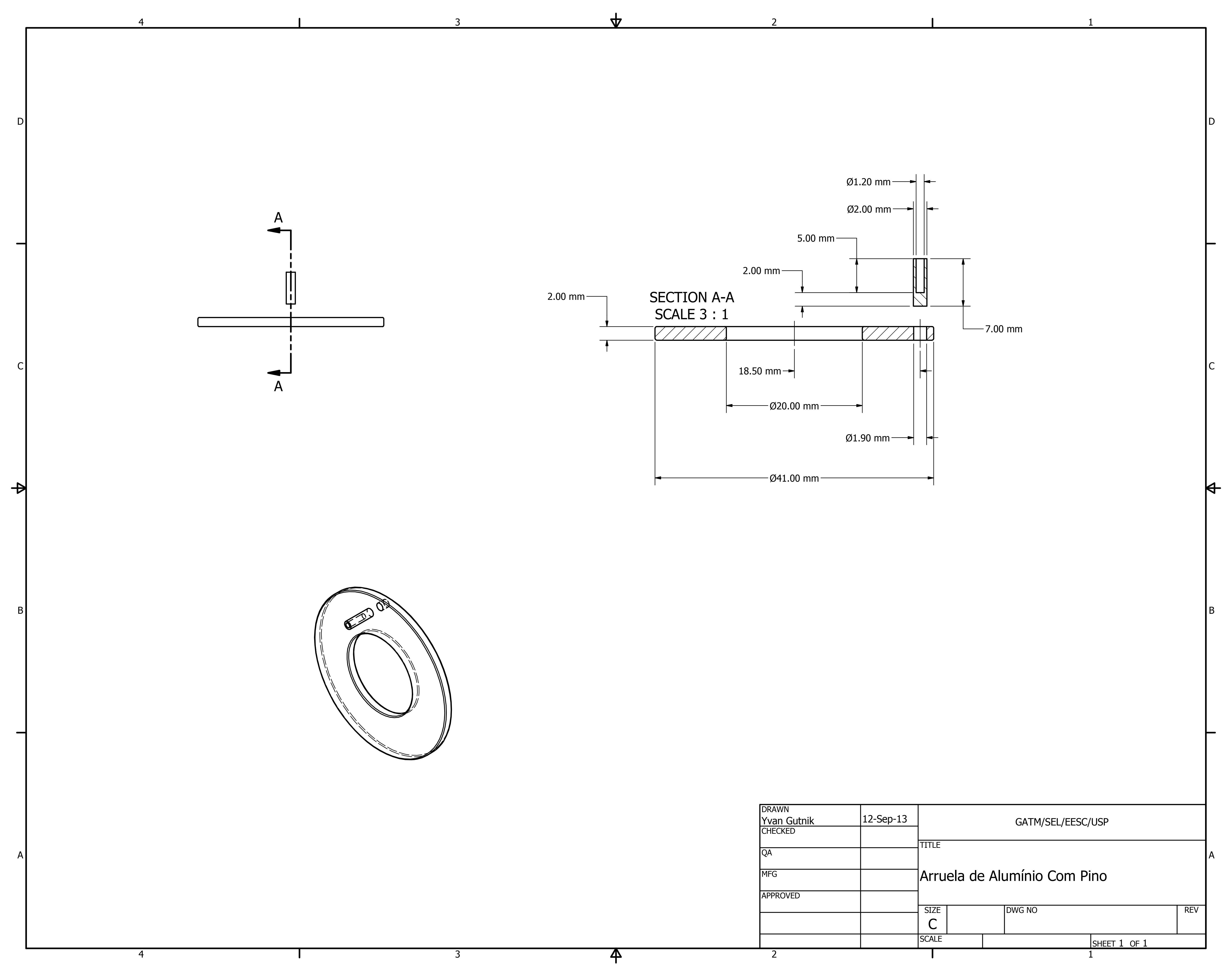




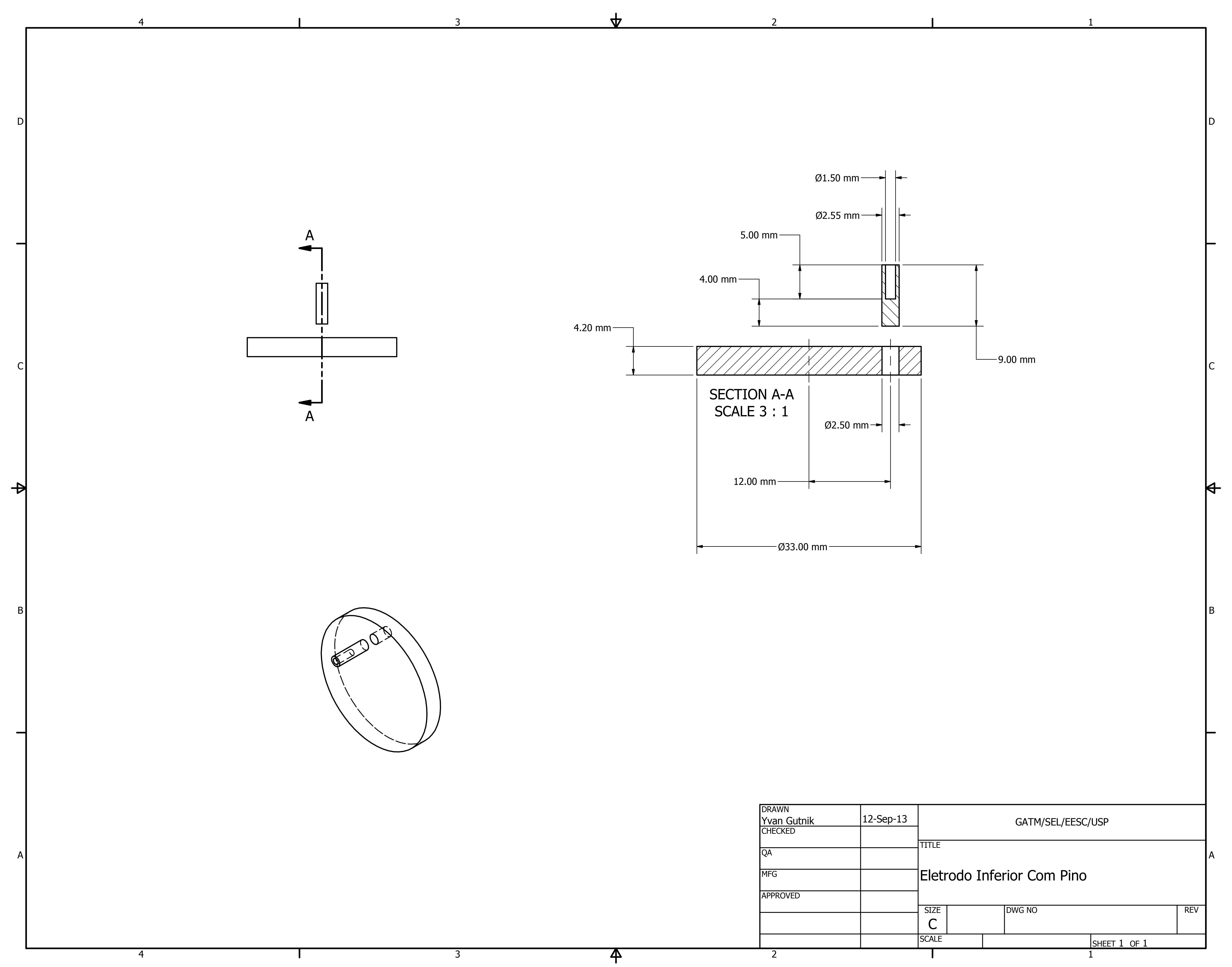




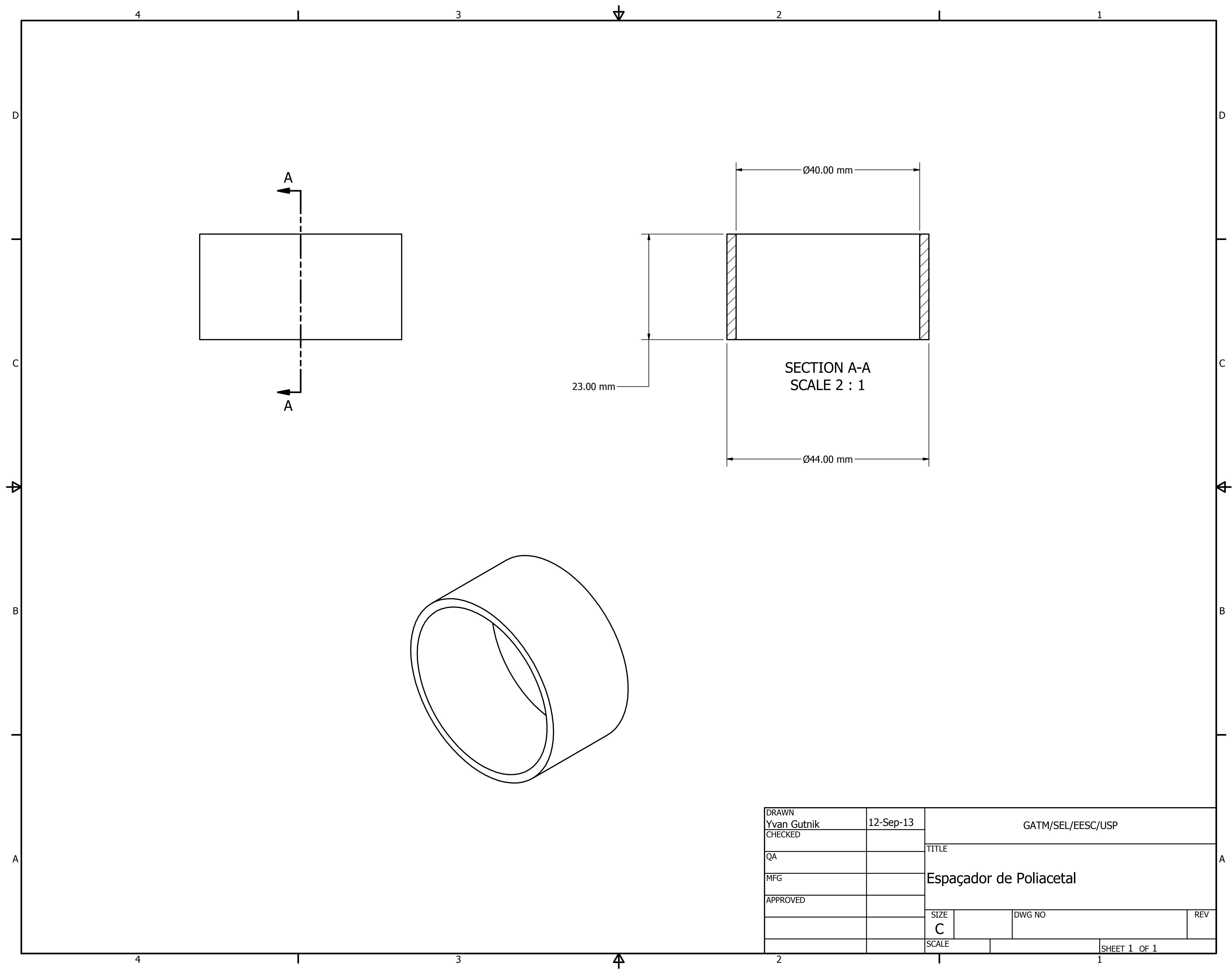




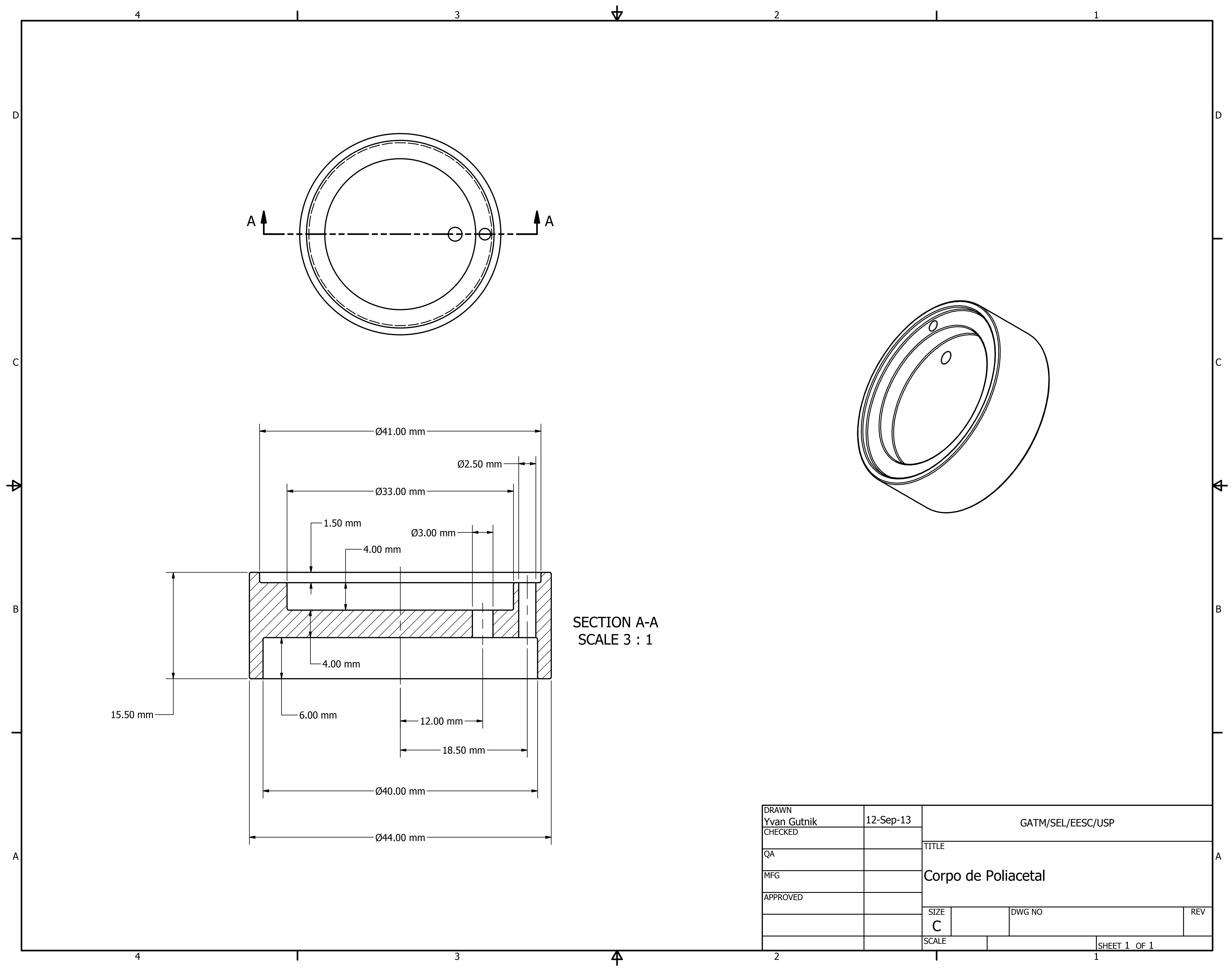




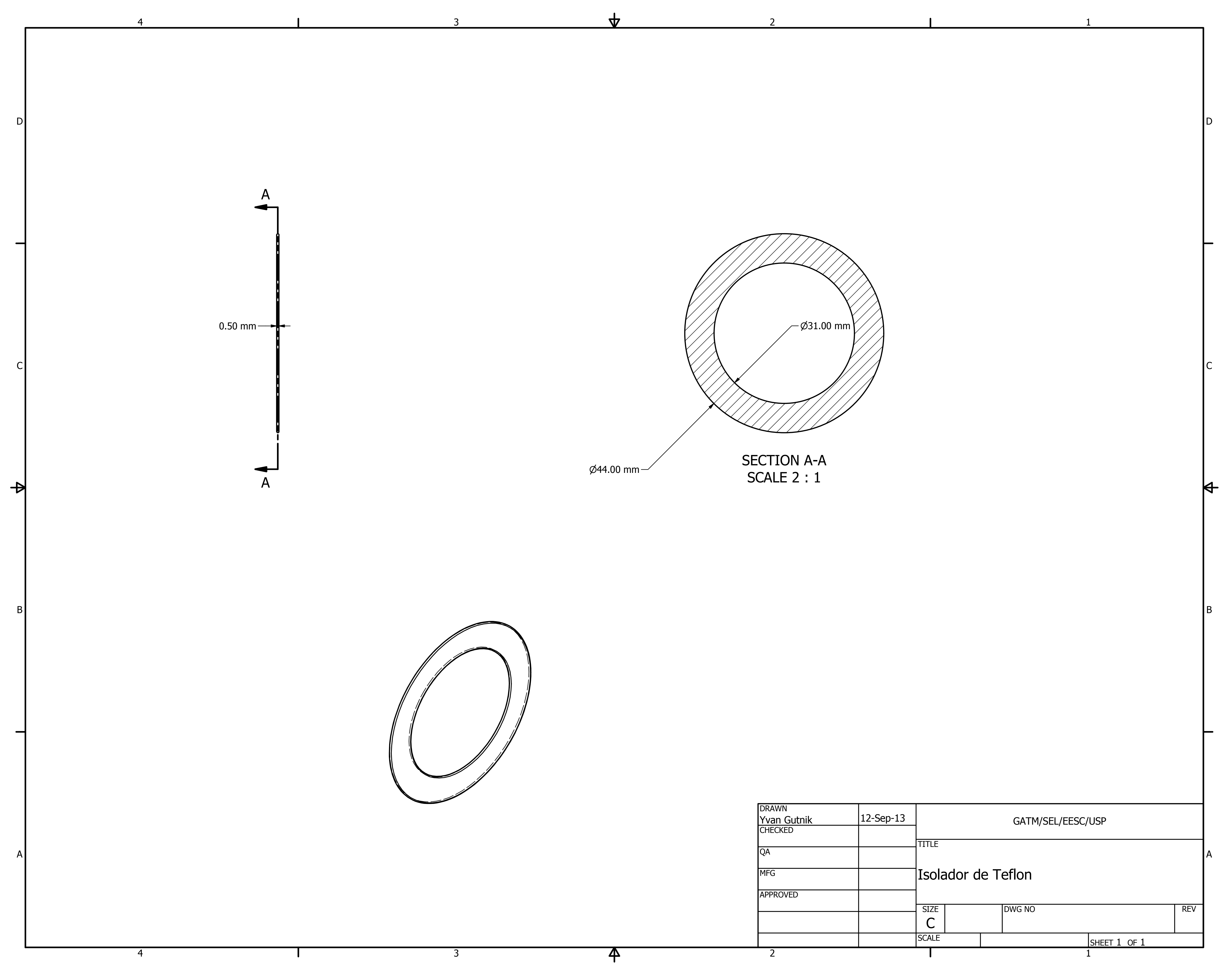




\section{Apêndice B: \\ Programas executados no Matlab®}

São apresentadas as principais rotinas utilizadas no Matlab® (versão 7.10) para processamento de todas as medidas. Especificamente, serão apresentadas as rotinas referentes à remoção de eco na câmara anecoica e remoção de ecos na caixa 1 . Para a caixa 2, a rotina é praticamente a mesma da caixa 1; a diferença é que em vez de se chamar a rotina graf_comp, chamar-se-á a função graf_comp2. A Figura 119 apresenta o esquemático construído no Simulink para contagem de cruzamentos por zeros de um determinado sinal.

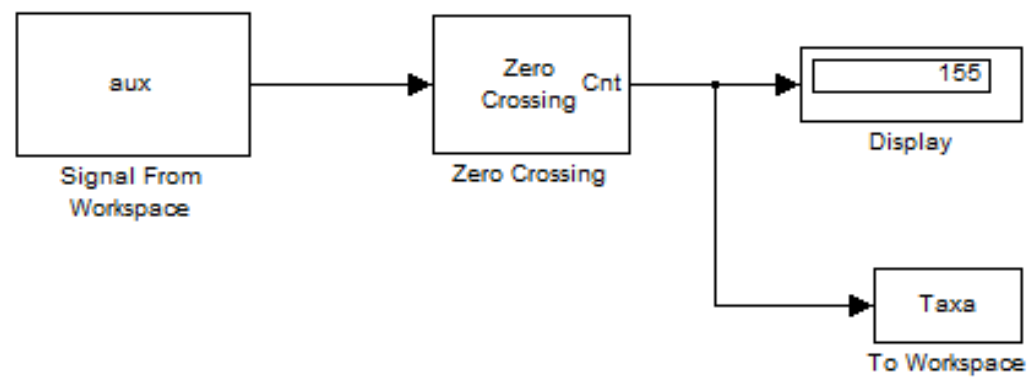

Figura 119: Esquemático construído no Simulink para contagem de cruzamentos por zero. 

\%\% Processamento das Medidas com Eco - Câmara Anecóica

\section{\%Inicialização}

clc; clear all; close all;

\%Carregando dados experimentais.

load('Anecoica_SN.mat'); $\mathrm{y} 1=\mathrm{md} ; \mathrm{x} 1=$ tempo;

load('Anecoica_Eco_SN_4mm.mat'); $y 2=\mathrm{md} ; \mathrm{x} 2=$ tempo;

load('Anecoica_SP.mat'); y3 = md; $\mathrm{x} 3=$ tempo;

load('Anecoica_Eco_SP_4mm.mat'); $y 4=\mathrm{md} ; \mathrm{x} 4=$ tempo;

\%Passos Temporais.

$\mathrm{Ts} 1=\mathrm{x} 1(2)-\mathrm{x} 1(1) ; \mathrm{Ts} 2=\mathrm{x} 2(2)-\mathrm{x} 2(1) ;$

Ts3 $=x 3(2)-x 3(1) ;$ Ts4 $=x 4(2)-x 4(1)$;

\%Vetor para titulação de gráficos.

$\mathrm{ca}=[$ 'Amostra 1'; 'Amostra 2'; 'Amostra 3'];

cs $=[$ 'Sensor 1'; 'Sensor 2'; 'Sensor 3'];

\%Reconstrução dos sinais sem eco em fase mínima e comparação gráfica.

\%Cálculo dos cepstros.

$\mathrm{a} 11=\operatorname{rceps}\left(\mathrm{y}^{\prime}{ }^{\prime}\right) ; \mathrm{a} \times 3=\operatorname{rceps}\left(\mathrm{y}^{\prime}{ }^{\prime}\right) ; \mathrm{M}=1 \mathrm{e} 5 ;$

\%Janela para reconstrução em fase mínima.

$w=\left[1 ; 2^{*}\right.$ ones $\left.(M / 2-1,1) ; \operatorname{ones}(1-\operatorname{rem}(M, 2), 1) ; \operatorname{zeros}(M / 2-1,1)\right]$;

$\operatorname{ax1}=-\operatorname{real}\left(\operatorname{ifft}\left(\exp \left(f f t\left(\operatorname{ax1}{ }^{*}[\mathrm{w} w w]\right)\right)\right)\right) ; \operatorname{ax1}=\operatorname{ax1}{ }^{\prime} ;$

$a \times 3=-\operatorname{real}\left(\operatorname{ifft}\left(\exp \left(f f t\left(a \times 3 .{ }^{*}[\mathrm{w} w \mathrm{w}]\right)\right)\right)\right) ; a \times 3=a \times 3{ }^{\prime}$;

$\operatorname{ax} 1(:, 1)=\operatorname{zeros}(3,1) ; \operatorname{ax} 3(:, 1)=\operatorname{zeros}(3,1)$;

\%Vetores temporais, janela correspondente e tempos de atraso.

$x a=0:$ Ts1*100:Ts1*100*(5e2-1); $x a=(x a+x 1(1)){ }^{*} 1 e 6 ;$

$x s=0:$ Ts3 ${ }^{*} 100: \operatorname{Ts}^{*} 100 *(5 \mathrm{e} 2-1) ; \mathrm{xs}=(\mathrm{xs}-13 \mathrm{e}-6){ }^{*} 1 \mathrm{e} 6 ;$

$\mathrm{ja}=1: 100: 5 \mathrm{e} 4-1 ; \mathrm{ta}=96 ; \mathrm{ts}=60$;

\%Gráficos

for $i=1: 3$

\%Normalizações dos sinais originais e originais em fase mínima;

\%plotagem dos gráficos, limitação dos eixos, nomeação dos eixos e

\%títulação de cada gráfico.

a1 $=y 1(i, j a) \cdot / \max (\operatorname{abs}(y 1(i, j a)))$;

a3 $=[\operatorname{zeros}(1, \mathrm{ta}) \operatorname{ax} 1(i, j a(1: 500-\mathrm{ta})) / \max (\operatorname{abs}(\operatorname{ax} 1(i, j a(1: 500-\mathrm{ta}))))]$;

subplot $\left(3,2,2^{*} i-1\right)$; $\operatorname{plot}(x a, a 1, x a, a 3)$;

axis( $\left.\left[\begin{array}{llll}-10 & 150 & -1.1 & 0.7\end{array}\right]\right)$;

xlabel('Tempo (us)'); ylabel('Amplitude Normalizada'); grid;

title(ca(i, : ));

\%Normalizações dos sinais originais e originais em fase mínima;

\%plotagem dos gráficos, limitação dos eixos, nomeação dos eixos e

\%títulação de cada gráfico.

a1 $=y 3(i, j a) \cdot / \max (\operatorname{abs}(y 3(i, j a)))$;

a3 $=[\operatorname{zeros}(1, \mathrm{ts}) \operatorname{ax3}(i, j a(1: 500-t s)) / \max (\operatorname{abs}(\operatorname{ax3}(i, j a(1: 500-t s))))]$;

subplot $(3,2,2 * i)$; $\operatorname{plot}(x s, a 1, x s, a 3)$;

$\operatorname{axis}\left(\left[\begin{array}{llll}-3 & 60 & -1 & 1.1\end{array}\right]\right)$;

xlabel('Tempo (us)'); ylabel('Amplitude Normalizada'); grid;

end title(cs $(i,:))$;

\%Salvando sinais originais nas variáveis yap (amostras) e yas (sensores).

\%0s novos sinais originais ou sem eco estão em fase mínima.

yap $=y 1 ; y 1=a \times 1 ; y a s=y 3 ; y 3=a \times 3 ;$ 
\%Gráficos com e sem eco para as amostras de piezoeletreto.

\%Limite de plotagem e vetor de atraso.

$1 \mathrm{a}=6 \mathrm{e} 3: 100: 68.5 \mathrm{e} 3 ;$ at $=\left[\begin{array}{lll}0.5 & 1 & 1.5\end{array}\right]$;

for $i=1: 3$

figure;

y11 = yap $(i, l a) . / \max (\operatorname{abs}(\operatorname{yap}(i,:))) ; \times 11=x 1(l a) ;$

y22 = y2 $(i, l a) \cdot / \max (\operatorname{abs}(y 2(i,:))) ; \times 22=x 2(l a) ;$

plot $(x 11 * 1 e 6+4, y 11, x 22 * 1 e 6-a t(i)+4, y 22)$; grid;

xlabel('Tempo (us)'); ylabel('Amplitude Normalizada');

legend('Sinal Sem ECo', 'Sinal Com Eco');

title $(\mathrm{ca}(i,:))$;

end

\%Gráficos com e sem eco para os sensores padrão.

\%Limite de plotagem e vetor de atraso.

ls $=3 \mathrm{e} 3: 100: 66 \mathrm{e} 3 ;$ at $=\left[\begin{array}{lll}0.5 & 0.5 & 0.5\end{array}\right]$;

for $i=1: 3$

figure;

y11 = yas $(i, 1 s) . / \max (\operatorname{abs}(\operatorname{yas}(i,:))) ; \times 11=\times 3(1 s) ;$

$\mathrm{y} 22=\mathrm{y} 4(i, l s) \cdot / \max (\operatorname{abs}(\mathrm{y} 4(i,:))) ; \mathrm{x} 22=\mathrm{x} 4(1 \mathrm{~s}) ;$

plot $(x 11 * 1 e 6+7.5, y 11, x 22 * 1 e 6-a t(i)+7.5, y 22)$; grid;

xlabel('Tempo (us)'); ylabel('Amplitude Normalizada');

legend('Sinal Sem Eco', 'Sinal Com Eco');

title $(\operatorname{cs}(i,:))$;

end

\%Gráfico da fft para as amostras e sensores dos sinais sem eco.

$\mathrm{F} 1$ = graf_fft_A(100*Ts1,y1 $(:, 1: 100: 1 \mathrm{e} 5), 100, \mathrm{ca})$;

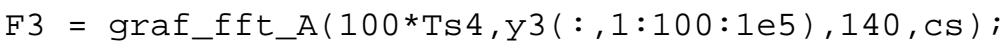

\%Gráficos das curvas cepstrais e reconstrução dos sinais em fase mínima $\%$ (amostras de piezoeletreto).

\%Intervalo de análise dos gráficos das amostras de piezoeletreto e dos

\%sensores padrão e variáveis auxiliares (curvas cepstrais).

$l \mathrm{a}=1: 100: 1 \mathrm{e} 5 ; 1 \mathrm{~s}=1 \mathrm{a} ; \mathrm{M}=2 \mathrm{e} 3 ; \mathrm{ya}=\operatorname{zeros}(3, \mathrm{M}) ; \mathrm{ys}=\mathrm{ya} ;$

\%Rotina que cria janela para reconstrução do sinal em fase mínima.

$w=\left[1 ; 2^{*}\right.$ ones $\left.(M / 2-1,1) ; \operatorname{ones}(1-\operatorname{rem}(M, 2), 1) ; \operatorname{zeros}(M / 2-1,1)\right]$;

\%Vetor ajuste de "tempo" para comparação gráfica, matriz de distâncias e \%limite de plotagem.

$\mathrm{k}=\left[\begin{array}{lll}2 & 3 & 2\end{array}\right] ; \mathrm{da}=\operatorname{zeros}(3,2) ; \mathrm{ds}=\mathrm{da} ; \mathrm{m}=4 \mathrm{e} 2 ; \mathrm{s}=\mathrm{m}$;

for $i=1: 3$

\%Cálculo dos cepstros reais para os gráficos das amostras (ya) e dos

\%sensores (ys).

$y a(i,:)=\operatorname{rceps}([\operatorname{zeros}(1,1 \mathrm{e} 3)$ y2(i,la) $])$;

\%etores de tempo.

$x a=0: 1 e 8 * T s 2:(M-1){ }^{*} 1 \mathrm{e} 8 * T s 2$;

\%Gráfico das curvas cepstrais para as amostras.

\%Reconstrução do sinal em fase mínima, normalização e comparação

\%gráfica do sinal reconstruído e sinal original.

ct $=48 ; y a c=[y a(i, 1: c t)$ zeros $(1, M-c t)] ;$ figure;

yac $=\operatorname{real}\left(\right.$ ifft $\left.\left(\exp \left(f f t\left(y a c \cdot{ }^{*} w^{\prime}\right)\right)\right)\right)$;

yac $=-y a c . / \max (\operatorname{abs}(y a c)) ;$

$y x=y 1(i, 1: 100: 4 e 4) ; y x=y x \cdot / \max (\operatorname{abs}(y x)) ;$ 
$y x=[\operatorname{zeros}(1, k(i)) y x(1: m-k(i))] ; \operatorname{plot}(x a(1: m), y x, x a(1: m), y a c(1: m)) ;$ title(ca(i,:)); xlabel('Tempo (us)'); ylabel('Amplitude Normalizada'); legend('Sinal Original', 'Sinal Processado'); grid;

qa $=[\operatorname{yac}(1: s) ; y x(1: s)]$;

\%Distância Euclidiana.

$\operatorname{da}(i, 1)=\operatorname{pdist}\left(q a,{ }^{\prime}\right.$ euclidean' $) ; \quad \operatorname{sum}(\operatorname{abs}(\operatorname{yac}(1: s)-y x(1: s)))$

\%istância de Chebyshev.

end

$\operatorname{da}(i, 2)=\operatorname{pdist}\left(q a,{ }^{\prime}\right.$ 'chebychev' $)$;

\%Gráficos das curvas cepstrais e reconstrução dos sinais em fase mínima $\%$ (sensores padrão).

\%Vetor ajuste de "tempo" para comparação gráfica, matriz de distâncias e \%limite de plotagem.

$\mathrm{k}=\left[\begin{array}{lll}2 & 2 & 1\end{array}\right] ; \mathrm{m}=5 \mathrm{e} 2$;

for $i=1: 3$

\%Cálculo dos cepstros reais para os gráficos das amostras (ya) e dos \%sensores (ys).

ys $(i,:)=\operatorname{rceps}([z \operatorname{zeros}(1,1 \mathrm{e} 3)$ y4 $(i, 1 \mathrm{a})])$;

\%Vetores de tempo.

$x s=0: 1 e 8 * T s 4:(M-1){ }^{*} 1 e 8 * T s 4 ;$

\%Gráfico das curvas cepstrais para as amostras.

\%Reconstrução do sinal em fase mínima, normalização e comparação

\%gráfica do sinal reconstruído e sinal original.

ct $=120 ; y a c=[y s(i, 1: c t)$ zeros $(1, \mathrm{M}-\mathrm{ct})]$; figure;

yac $=\operatorname{real}\left(\right.$ ifft $\left.\left(\exp \left(f f t\left(y a c \cdot{ }^{*} w^{\prime}\right)\right)\right)\right) ; y a c=-y a c . / \max (\operatorname{abs}(y a c))$;

$y x=y 3(i, 1: 100: 5 e 4) ; y x=y x \cdot / \max (\operatorname{abs}(y x)) ;$

$y x=[\operatorname{zeros}(1, k(i)) y x(1: m-k(i))] ; \operatorname{plot}(x s(1: m), y x, x s(1: m), y a c(1: m))$;

title(cs(i,:)); xlabel('Tempo (us)'); ylabel('Amplitude Normalizada');

legend('Sinal Original', 'Sinal Processado'); grid;

$q a=[y a c(1: s) ; y x(1: s)]$;

\%istância Euclidiana.

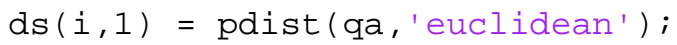

\%Distância de Chebyshev.

end

$\operatorname{ds}(i, 2)=\operatorname{pdist}\left(q a\right.$, 'chebychev' $^{\prime}$; 
\%\% Transformada de Fourier e Plotagem de Gráficos - Eco Anecóica

function $F=$ graf_fft_A $(T y, y, l, c)$

\%Frequência máxima, comprimento do vetor e passo de frequência. Neste caso \%foi acrescentado zeros. Por isso o fator "2" no cálculo de p.

$\mathrm{n}=1 / \mathrm{Ty} ; \mathrm{m}=\operatorname{length}(\mathrm{y}(1,:)) ; \mathrm{p}=\mathrm{n} /\left(2^{*} \mathrm{~m}\right)$;

\%atriz de saída e tamanho do vetor utilizado para análise.

$\mathrm{F}=\operatorname{zeros}\left(3,2^{*} \mathrm{~m}\right) ; \mathrm{lt}=3 \mathrm{e} 2 ;$ figure;

for $i=1: 3$

\%Retirada do valor Cc, normalização e acréscimo de zeros. Note que o

\%tamanho do vetor ax é $2 \mathrm{~m}$.

$a x=y(i, 1: 1 t) ; a x=a x-\operatorname{sum}(a x) / 1 t ;$

nor $=\max (\operatorname{abs}(a x)) ; a x=[\operatorname{zeros}(1, m-1 t / 2)$ ax/nor zeros(1,m-1t/2)];

\%Cálculo da fft, do espectro e plotagem de gráficos.

$\mathrm{ax}=\mathrm{fft}(\mathrm{ax}) ; \mathrm{F}(\mathrm{i},:)=\mathrm{ax} ; \mathrm{ax}=\mathrm{abs}(\mathrm{ax}) . / \max (\operatorname{abs}(\mathrm{ax}))$;

hold all; $\operatorname{plot}\left(0: \mathrm{p} / 1 \mathrm{e} 3:(1-1){ }^{*} \mathrm{p} / 1 \mathrm{e} 3, \operatorname{ax}(1: 1)\right)$;

end

\%Titulação de eixos e inserção de legendas.

xlabel('Frequência ( kHz)'); ylabel('Amplitude Normalizada');

legend $(c(1,:), c(2,:), c(3,:))$; grid;

end 
\%\% Processamento das Medidas com Eco - Caixa 1

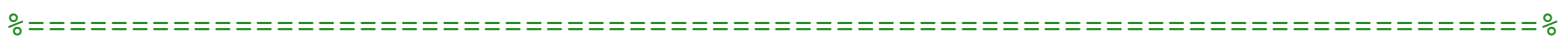

\%Inicialização e preparação dos dados para processamento.

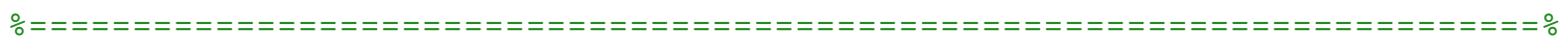

clc; clear all; close all;

\%Definição de variáveis globais para execução do arquivo "Taxa_ZC.mdl". global aux;

global Ts;

\%Definição de legendas

$\mathrm{ca}=[$ 'Amostra 1'; 'Amostra 2'; 'Amostra 3'];

cs $=[$ 'Sensor 1'; 'Sensor 2'; 'Sensor 3'];

\%atriz de janelas de para análise.

$\mathrm{J} 1=[12 ; 23 ; 34 ; 45]+0.02$;

\%"Struct" para guardar dados estatísticos dos sinais.

$\mathrm{R}=\operatorname{struct}\left({ }^{\prime} M d d^{\prime}, \operatorname{zeros}(12,1), \mathrm{DP}^{\prime}, \operatorname{zeros}(12,1),{ }^{\prime} P R^{\prime}, \operatorname{zeros}(12,2),{ }^{\prime} F 0^{\prime}, \ldots\right.$ zeros $(12,1 \mathrm{e} 5))$;

\%Carregando dados experimentais e executando a função "sig_nois.m".

load('Anecoica_SN.mat'); $\mathrm{y} 1=\mathrm{md} ; \mathrm{x} 1=$ tempo;

load('Caixa_1_ar_SN.mat'); y2 = md; $\mathrm{x} 2=$ tempo;

[R.Md(1:3) R.DP(1:3) R.PR(1:3,:) R.FO(1:3,:)] = sig_nois(S);

load('Caixa_1_oleo_SN.mat'); y3 = md; $x 3=$ tempo;

[R.Md(4:6) R.DP(4:6) R.PR(4:6,:) R.FO(4:6,:)] = sig_nois(S);

load('Anecoica_SP.mat'); $\mathrm{y} 4=\mathrm{md} ; \mathrm{x} 4=$ tempo;

load('Caixa_1_ar_SP.mat'); y5 = md; $x 5=$ tempo;

[R.Md(7:9) R.DP(7:9) R.PR(7:9,:) R.FO(7:9,:)] = sig_nois(S);

load('Caixa_1_oleo_SP.mat'); y6 = md; $x 6=$ tempo;

$[R \cdot M d(10: 12)$ R.DP(10:12) R.PR(10:12,:) R.F0(10:12,: )] = sig_nois(S);

\%Cálculo dos passos temporais.

Ts1 $=\times 1(2)-\times 1(1) ;$

Ts2 $=\times 2(2)-\times 2(1) ;$

Ts3 $=\times 3(2)-\times 3(1) ;$

Ts4 $=\times 4(2)-\times 4(1) ;$

Ts5 $=\times 5(2)-\times 5(1) ;$

Ts6 $=\times 6(2)-\times 6(1) ;$

\%Reconstrução dos sinais originais, ou sem eco, em fase mínima e comparação \%gráfica.

\%Cálculo dos cepstros.

$\mathrm{ax1}=\operatorname{rceps}\left(\mathrm{y} 1^{\prime}\right) ; \operatorname{ax4}=\operatorname{rceps}\left(\mathrm{y} 4^{\prime}\right) ; \mathrm{M}=1 \mathrm{e} 5 ;$

\%Janela para reconstrução em fase mínima.

$W=\left[1 ; 2^{*}\right.$ ones $(M / 2-1,1) ;$ ones $\left.(1-\operatorname{rem}(M, 2), 1) ; \operatorname{zeros}(M / 2-1,1)\right]$;

$\operatorname{ax1}=-\operatorname{real}\left(\operatorname{ifft}\left(\exp \left(\operatorname{fft}\left(\operatorname{ax1}{ }^{*}[w w w]\right)\right)\right)\right) ; \operatorname{ax1}=\operatorname{ax1}{ }^{\prime} ;$

$\operatorname{ax4}=-\operatorname{real}\left(\operatorname{ifft}\left(\exp \left(f f t\left(\operatorname{ax} 4{ }^{*}[\mathrm{w} w \mathrm{w}]\right)\right)\right)\right) ; \operatorname{ax4}=\operatorname{ax4}{ }^{\prime} ;$

$\operatorname{ax} 1(:, 1)=\operatorname{zeros}(3,1) ; \operatorname{ax} 4(:, 1)=\operatorname{zeros}(3,1)$;

\%Salvando sinais originais nas variáveis yap (amostras) e yas (sensores).

\%0s novos sinais originais ou sem eco estão em fase mínima.

yap $=\mathrm{y} 1 ; \mathrm{y} 1=\mathrm{ax} 1 ; \mathrm{yas}=\mathrm{y} 4 ; \mathrm{y} 4=\mathrm{ax} 4 ;$ 


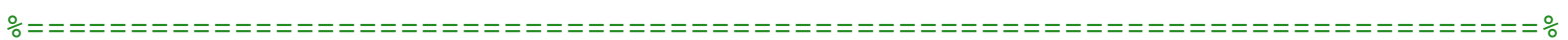

\%Análise para descarga em ar.

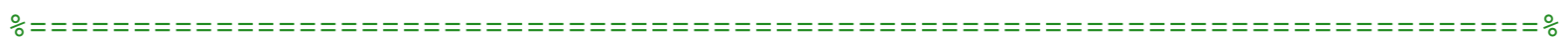

\%Filtragem do sinal com um filtro FIR utilizando-se janelamento de Kaiser. \%Esta rotina foi baseada no "HELP" do Matlab. Neste situação, está sendo \%elaborado dois filtros: uma para os sinais das amostras de piezoeletreto e \%outro para os sinais dos sensores padrão. Especificamente está

\%filtrando-se os sinais provenientes da descraga em ar, ou seja, y2 e y5. \%Taxa de amostragem do sinal.

$\mathrm{Ta}=1 / \mathrm{Ts} 2 ; \mathrm{Tp}=1 / \mathrm{Ts} 5 ;$

\%Frequência passante e frequência de corte.

$\mathrm{Fca}=[5.5 \mathrm{e} 46 \mathrm{e} 4] ; \mathrm{Fcp}=\left[\begin{array}{ll}1 \mathrm{e} 6 & 1.1 \mathrm{e} 6\end{array}\right] ;$

\%agnitudes na banda passante e banda de corte.

$M g=\left[\begin{array}{ll}1 & 0\end{array}\right] ;$

\%Desvios na banda passante e banda de corte.

DV $=\left[\begin{array}{lll}0.05 & 0.05\end{array}\right]$;

\%Cálculo do filtro e ralização da filtragem.

$\mathrm{H} 1$ = filtro_PB(Ta, Fca, Mg, Dv $) ; \mathrm{ya}=$ filtro $(\mathrm{H} 1, \mathrm{y} 2)$;

$\mathrm{H} 2$ = filtro_PB(Tp, Fcp, Mg, Dv $) ; \mathrm{yp}=$ filtro $(\mathrm{H} 2, \mathrm{y} 5)$;

\%Gráfico das medidas para todas as amostras de piezoeletreto (descarga em \%ar ).

\%Limite de plotagem.

lt $=100: 99.9 \mathrm{e} 3 ;$ at $=0$;

\%chamada à função .

Graf1(x2,y2, ya, 1t, ca, at);

\%Gráfico das medidas para todos os sensores padrão (descarga em ar).

Graf1(x5, y5, yp, 1t, cs, at);

\%Cálculo do Cepstro real para diversas variáveis e plotagem de gráficos. Os \%dados cepstrais estão armazenados na matriz Dxx conforme a janela e

\%amostra/sensor. Os gráficos, por sua vez, estão armazenados na matriz Gxx, \%também é conforme a janela e amostra/sensor.

\%Tamanho do vetor de pontos, limite de plotagem, tamanho da amostra para \%reconstrução e número de janelas para análise.

$M=1 e 4 ; L=400 ; n=\left[\begin{array}{lll}80 & 68 & 100\end{array}\right] ; j n=3$;

\%Chamda à função .

[D2 G2] = cepstrum(M, Ts2, ya, L, J1, n, ca, jn);

\%lotagem gráfico do cepstrum

$\mathrm{L}=500 ; \mathrm{Graf2}(\mathrm{Ts} 2, \mathrm{~L}, \mathrm{D} 2, \mathrm{ca}, \mathrm{jn})$;

\%Tamanho do vetor de pontos, limite de plotagem e tamanho da amostra para \%reconstrução .

$M=1 e 4 ; L=6 e 2 ; n=\left[\begin{array}{lll}130 & 130 & 130\end{array}\right] ; j n=4 ;$

\%Chamada à função.

[D5 G5] = cepstrum(M, Ts5, yp, L, J1, n, cs, jn);

\%lotagem gráfico do cepstrum.

$\mathrm{L}=500 ; \operatorname{Graf2}(\mathrm{Ts} 5, \mathrm{~L}, \mathrm{D} 5, \mathrm{Cs})$;

\%Cruzamentos por zeros.

$\mathrm{Ts}=\mathrm{Ts} 2 ; \mathrm{ZC2}=\mathrm{Tx} Z \mathrm{ZC}(\mathrm{ya}, \mathrm{J} 1)$;

$\mathrm{Ts}=\mathrm{Ts} 5 ; \mathrm{ZC5}=\mathrm{Tx} \_\mathrm{ZC}(\mathrm{yp}, \mathrm{J} 1)$;

\%Gráfico da fft de acordo com a janela (amostras). 
$\%$ Limite de plotagem.

$1=599 ;$ \%Note: $\operatorname{fmax}($ plotagem $)=1 /\left(\mathrm{Ts}_{2} * 2 * \mathrm{M}^{*} 1 \mathrm{e} 3\right)=59.9(\mathrm{kHz})$.

graf_fft_J1(J1,Ts2,ya, ca, 1, M) ;

\%Gráfico da fft de acordo com a janela (sensores).

\%Limite de plotagem.

$l=599 ; \%$ Note: $f \max ($ plotagem $)=1 /\left(\mathrm{Ts} 5^{*} 2 * \mathrm{M}^{*} 1 \mathrm{e} 3\right)=299.5(\mathrm{kHz})$.

graf_fft_J1(J1,Ts5,yp,cs, 1,M);

\%Gráficos das distâncias Euclidianas e de Chebychev para todas as amostras \%e sensores. Também é calculada a menor distância e o fator de compressão \%correspondente. Estes dados econtram-se na variável "mm".

\%Salvando curvas cepstrais referentes à janela $\mathrm{J} 1$ para nova reconstrução \%dos sinais e definição das janelas de reconstrução.

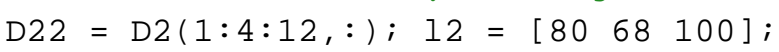

D55 = D5 $(1: 4: 12,:) ; 15=\left[\begin{array}{lll}130 & 130 & 130\end{array}\right]$;

\%Chamada à função.

$[\sim, \mathrm{mm}$ YR2 YR5 $]=\operatorname{sim} \_\operatorname{vet}(\mathrm{D} 22,12, \mathrm{Ts} 2, \mathrm{D} 55,15, \mathrm{Ts} 5, \mathrm{y} 1, \mathrm{Ts} 1, \mathrm{y} 4, \mathrm{Ts} 4, \mathrm{ca}, \mathrm{cs}, \ldots$ G2, G5)；

\%Gráficos dos espectros originais, remodelados e reconstruídos de acordo \%com o melhor fator de compressão.

\%Fator de compressão no espectro de frequências e frequência máxima de $\%$ plotagem .

$\mathrm{p} 2=\operatorname{round}(100 *(\mathrm{Ts} 2 /(100 *$ Ts 1$))) ; \mathrm{L} 2=6 \mathrm{e} 2 ;$

p5 $=\operatorname{round}(100 *($ Ts5 $/(100 *$ Ts4 $))) ; \mathrm{L} 5=7 \mathrm{e} 2 ;$

yam $=$ filtro(H1,R.FO(1:3,:)); yam = yam $(:, 1 \cdot 02 \mathrm{e} 4: 2 \cdot 02 \mathrm{e} 4-1)$;

yse $=$ filtro(H2,R.FO(7:9,:)); yse =yse $(:, 1.02 \mathrm{e} 4: 2.02 \mathrm{e} 4-1)$;

graf_comp(YR2,p2*Ts1,G2(1:4:12, :),yam,L2, [68 68 68],ca);

graf_comp(YR5, p5*Ts4,G5(1:4:12, :),yse, L5, [130 130 130], cs) ;

$\%$ No caso do processamento da caixa 2, em vez de se chamar duas vezes a \%função "graf_comp", chamar-se-á a função "graf_comp2" uma única vez da \%seguinte forma: graf_comp2(YR2, YR5, p2 ${ }^{*} T s 1, \mathrm{p} 5{ }^{*} T s 4, \mathrm{G} 2(1: 4: 12,:), \ldots$

\%G5(1:4:12, : ),yam,yse, L2, L5, [68 68 68] , [130 130 130], ca, cs) ;

\%Isto também é valido para a descarga em óleo.

\%ニニニニニニニニニニニニニニニニニニニニニニニニニニニニニニ
\%Análise para descarga em óleo.

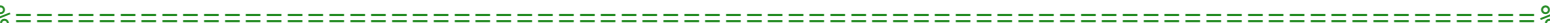

$\%$ Filtragem do sinal.

$\mathrm{Ta}=1 / \mathrm{Ts} 3 ; \mathrm{Tp}=1 / \mathrm{Ts} 6 ;$

\%Cálculo do filtro e ralização da filtragem.

$\mathrm{H} 1$ = filtro_PB(Ta,Fca, Mg, Dv $) ;$ ya = filtro(H1,y3);

$H 2$ = filtro_PB(Tp,Fcp,Mg, Dv $) ; y p=f i l t r o(H 2, y 6)$;

\%Gráfico das medidas para todas as amostras de piezoeletreto (descarga em \%ar).

\%Limite de plotagem.

lt $=1.5 \mathrm{e} 3: 59.9 \mathrm{e} 3 ;$ at $=-0.128 ;$

\%Chamada à função.

$\operatorname{Graf1}(x 3, y 3, y a, 1 t, c a$, at $) ;$ at $=-0.006$;

\%Gráfico das medidas para todos os sensores padrão (descarga em ar).

Graf1(x6, y6, yp, lt, cs, at); 
\%Readequação das janelas para processamento das medidas.

$\mathrm{J} 1=[12 ; 23 ; 34 ; 45]+0.195$;

\%Cruzamentos por zeros.

$\mathrm{Ts}=\mathrm{Ts} 3 ; \mathrm{ZC3}=\mathrm{Tx} \_\mathrm{ZC}(\mathrm{ya}, \mathrm{J} 1) ;$

$\mathrm{Ts}=\mathrm{Ts} 6 ; \mathrm{ZC6}=\mathrm{Tx} \_\mathrm{ZC}(\mathrm{yp}, \mathrm{J} 1)$;

\%Cálculo do Cepstro real para a janela de interesse: de 5 ms para as \%amostras e de $1 \mathrm{~ms}$ para os sensores.

$M=1 e 4 ; L=1000 ; n=\left[\begin{array}{lll}65 & 60 & 52\end{array}\right] ; j n=1 ;$

\%Chamada à função.

$[$ D3 G3 $]=\operatorname{cepstrum}(M, T s 3 * 5, y a(:, 1: 5: 1 e 5), L,[\odot .21 .2], n, c a, j n)$;

$\mathrm{n}=\left[\begin{array}{lll}70 & 70 & 70\end{array}\right]$;

$\left[\begin{array}{ll}\text { D6 } & \text { G6 }\end{array}\right]=\operatorname{cepstrum}(M, T s 6, y p, L,[1.062 .06], n, c s, j n)$;

\%Gráficos das distâncias Euclidianas e de Chebychev para todas as amostras \%e sensores. Também é calculada a menor distância e o fator de compressão \%correspondente. Estes dados econtram-se na variável "mm".

\%Salvando curvas cepstrais referentes à janela $\mathrm{J} 1$ para nova reconstrução \%dos sinais e definição das janelas de reconstrução.

D33 = D3 $(1: 3,:) ; 13=\left[\begin{array}{lll}65 & 60 & 52\end{array}\right] ;$

$\mathrm{D} 66=\mathrm{D} 6(1: 3,:) ; 16=\left[\begin{array}{lll}70 & 70 & 70\end{array}\right] ;$

\%Chamada à função.

$[\sim, \mathrm{mm}$ YR3 YR6 $]=\operatorname{sim} \_v e t\left(\mathrm{D} 33,13, \mathrm{Ts} 3{ }^{*} 5, \mathrm{D} 66,16, \mathrm{Ts} 6, \mathrm{y} 1, \mathrm{Ts} 1, \mathrm{y} 4, \mathrm{Ts} 4, \mathrm{ca}, \mathrm{cs}, \ldots\right.$ $\mathrm{G} 3, \mathrm{G} 6)$;

\%Gráficos dos espectros originais, remodelados e reconstruídos de acordo \%com o melhor fator de compressão.

\%Fator de compressão no espectro de frequências e frequência máxima de $\%$ plotagem.

p3 $=\operatorname{round}\left(100^{*}\left(\right.\right.$ Ts $^{*} 5 /\left(100^{*}\right.$ Ts 1$\left.\left.)\right)\right) ; \mathrm{L} 3=5 \mathrm{e} 2 ;$

p6 $=\operatorname{round}(100 *(\operatorname{Ts} 6 /(100 *$ Ts4 $))) ; L 6=6 e 2 ;$

yam $=$ filtro(H1,R.FO(4:6,:)); yam = yam $(:, 1.2 \mathrm{e} 4: 5: 6.2 \mathrm{e} 4-1)$;

yse $=$ filtro(H2,R.FO(10:12,:)); yse = yse $(:, 1.06 \mathrm{e} 4: 2.06 \mathrm{e} 4-1)$;

graf_comp(YR3,p3*Ts1,G3(1:3, : ),yam, L3, [57 56 50], ca) ;

graf_comp(YR6, p6*Ts4,G6(1:3, : ),yse, L6, [70 70 70],cs) ; 
\% Cálculo da Relação Sinal/Ruído

\%Esta função tem por objetivo o cálculo da relação média sinal/ruído, do \%desvio padrão e encontrar o sinal com a pior relação sinal/ruído.

function [md dp pr fo] = sig_nois(S)

\%Inicialização das variáveis.

$\operatorname{snr}=\operatorname{zeros}(1,75) ; \mathrm{md}=\operatorname{zeros}(3,1) ; \mathrm{dp}=\mathrm{md} ; \mathrm{pr}=[\mathrm{md} \mathrm{md}]$;

fo $=\operatorname{zeros}(3,1 \mathrm{e} 5)$;

\%Cálculo de todas as relações sinal/ruído.

for $i=1: 75$

$\mathrm{ax} 1=\mathrm{S}(\mathrm{i}) \cdot \mathrm{FO}(1: 9 \cdot 98 \mathrm{e} 3) ; \mathrm{ax} 2=\mathrm{S}(\mathrm{i}) \cdot \mathrm{FO}(1 \cdot 02 \mathrm{e} 4: 2 \mathrm{e} 4) ;$

$\operatorname{snr}(i)=\operatorname{sum}(a \times 2, \wedge 2) / \operatorname{sum}(\operatorname{ax} 1, \wedge 2) ;$

end

\%cálculo da média, desvio padrão e pior relação.

for $i=1: 3$

\%Cálculo da média e desvio padrão da relação sinal/ruído.

$\operatorname{ax}=\operatorname{snr}\left(25^{*}(i-1)+1: i^{*} 25\right)$;

$\operatorname{md}(i)=\operatorname{mean}(a x) ; \operatorname{dp}(i)=\operatorname{std}(a x)$;

\%Salvando as formas de onda com o pior índice de relação sinal/ruído.

$[\operatorname{pr}(i, 1) \operatorname{pr}(i, 2)]=\min (a x) ; \operatorname{pr}(i, 2)=\operatorname{pr}(i, 2)+25^{*}(i-1) ;$

end

$f o(i,:)=S(\operatorname{pr}(i, 2)) . F O$;

end 
\%\% Filtro Passa-Baixas com Janelamento de Kaiser

function $\mathrm{H}$ = filtro_PB $(\mathrm{Ta}, \mathrm{FC}, \mathrm{Mg}, \mathrm{DV})$

\%Taxa de amostragem do sinal: Ta.

\%Frequência passante e frequência de corte: Fc.

\%agnitudes na banda passante e banda de corte: Mg.

\%Desvios na banda passante e banda de corte: Dv.

\%Cálculo dos parâmetros do filtro com janelamento de Kaiser.

$[\mathrm{n}, \mathrm{Wn}$, beta, ftype $]=$ kaiserord $(\mathrm{Fc}, \mathrm{Mg}, \mathrm{DV}, \mathrm{Ta})$;

\%Cálculo do filtro propriamente dito.

$H=\operatorname{fir} 1(n, W n$, ftype, $\operatorname{kaiser}(n+1$, beta $)$, 'noscale' $) ;^{\prime}$

\%Gráfico da resposta em frequência do filtro.

figure; freqz $\left(H, 1,2^{\wedge} 11, T a\right)$;

subplot $(2,1,1) ; x$ label('Frequência $\left.(H z)^{\prime}\right)$; ylabel('Amplitude (dB)');

subplot $(2,1,2) ; \operatorname{xlabel}\left({ }^{\prime} F r e q u e ̂ n c i a(H z)^{\prime}\right) ;$ ylabel('Fase (Graus)');

end 
$\%$ Filtragem dos sinais

function $F=\operatorname{filtro}(H, y)$

\%Inicialização matriz $F$.

$F=\operatorname{zeros}(3, \max (\operatorname{size}(y)))$;

\%Realização da filtragem.

for $i=1: 3$

$F(i,:)=$ filter $(H, 1, y(i,:))$;

\%Retirada do valor CC.

end

$F(i,:)=F(i,:)-\operatorname{sum}(F(i,:)) / 1 e 5$;

end 
\% Plotagem das medidas filtradas e não filtrdas

function $\operatorname{Graf1}(x, y, y f, 1 t, c, a t)$

figure;

for $i=1: 3$

\%Constantes de normalização.

$a=\max (\operatorname{abs}(y(i,:))) ;$ af $=\max (\operatorname{abs}(y f(i,:)))$;

\%Plotagem dos gráficos.

subplot $(3,1, i) ; \operatorname{plot}(x(1 t) * 1 e 3, y(i, 1 t) / a, x(1 t) * 1 e 3+a t, y f(i, l t) / a f)$;

\%Nomenclatura de eixos e legenda.

xlabel('Tempo (ms)'); ylabel('Amplitude Normalizada'); grid;

legend('Sinal Médio', 'Sinal Filtrado');

\%Titulação de cada gráfico.

title(c(i,: ));

end

end 
\% Cálculo do cepstro e Plotagem de Gráficos

function $[D G]=\operatorname{cepstrum}(M, T y, y, L, J, n, C, j n)$

\%vetor de tempo e matriz para guardar as curvas cepstrais.

$\mathrm{xm}=0: \operatorname{Ty}: \mathrm{Ty}^{*}(\mathrm{~L}-1) ; \mathrm{D}=\operatorname{zeros}(12, \mathrm{M}) ; \mathrm{G}=\mathrm{D} ;$ figure;

\%Definição da janela para reconstrução em fase mínima.

$w=\left[1 ; 2^{*}\right.$ ones $\left.(M / 2-1,1) ; \operatorname{ones}(1-\operatorname{rem}(M, 2), 1) ; \operatorname{zeros}(M / 2-1,1)\right]$;

\%Contador e defasagem

$\mathrm{m}=1$; at $=5$;

for $i=1: 3$

for $\mathrm{k}=1: \mathrm{jn}$

\%álculo do cepstro real.

aux $=y(i, \operatorname{round}(J(k, 1) * 1 e 4): \operatorname{round}(J(k, 2) * 1 e 4)) ;$ aux $=\operatorname{rceps}(\operatorname{aux}) ;$

\%Guardar cada curva para comparação posterior.

$D(m,:)=\operatorname{aux}(1: 1 \mathrm{e} 4)$;

\%Filtragem passa-baixas no cepstro.

$\operatorname{aux1}=[\operatorname{aux}(1: \mathrm{n}(\mathrm{i})) \operatorname{zeros}(1, \mathrm{M}-\mathrm{n}(\mathrm{i}))]$;

\%Reconstrução do sinal.

$y m=\operatorname{real}\left(\operatorname{ifft}\left(\exp \left(f f t\left(\operatorname{aux} 1 \cdot{ }^{*} w^{\prime}\right)\right)\right)\right)$;

\%Adequação e plotagem das curvas cepstrais.

$\mathrm{ym}=-\mathrm{ym}(1: \mathrm{L}) \cdot / \max (\operatorname{abs}(\mathrm{ym}(1: \mathrm{L})))$;

hold all; $\operatorname{subplot}(3,1, i)$; $\operatorname{plot}\left(\mathrm{xm}^{*} 1 \mathrm{e} 6, \mathrm{ym}\right)$;

\%Salvando o sinal reconstruído.

end

$G(m, 1: L)=y m ; m=m+1$;

\%Nomeação dos eixos e plotagem da legenda dos sinais conforme a

\%quantidade de janelas processadas, ou seja, de uma a quatro.

if $j n==1$

subplot $(3,1, i) ; x$ label('Tempo (us)'); title(c(i,:));

end

ylabel('Amplitude Normalizada'); legend('J1'); grid;

if $\mathrm{jn}==2$

subplot $(3,1, i) ; x$ label('Tempo (us)'); title(c(i, : ));

end

ylabel('Amplitude Normalizada'); legend('J1','J2'); grid;

if $\mathrm{j} n==3$

subplot $(3,1, i) ; \operatorname{xlabel}(' T e m p o$ (us)'); title(c(i, : ));

end

ylabel('Amplitude Normalizada'); legend('J1','J2','J3'); grid;

if $\mathrm{jn}==4$

subplot $(3,1, i) ; \operatorname{xlabel}($ 'Tempo (us)'); title(c(i, : )); end

ylabel('Amplitude Normalizada'); legend('J1','J2','J3','j4'); grid;

end

end 
\%\% Plotagem das curvas cepstrais

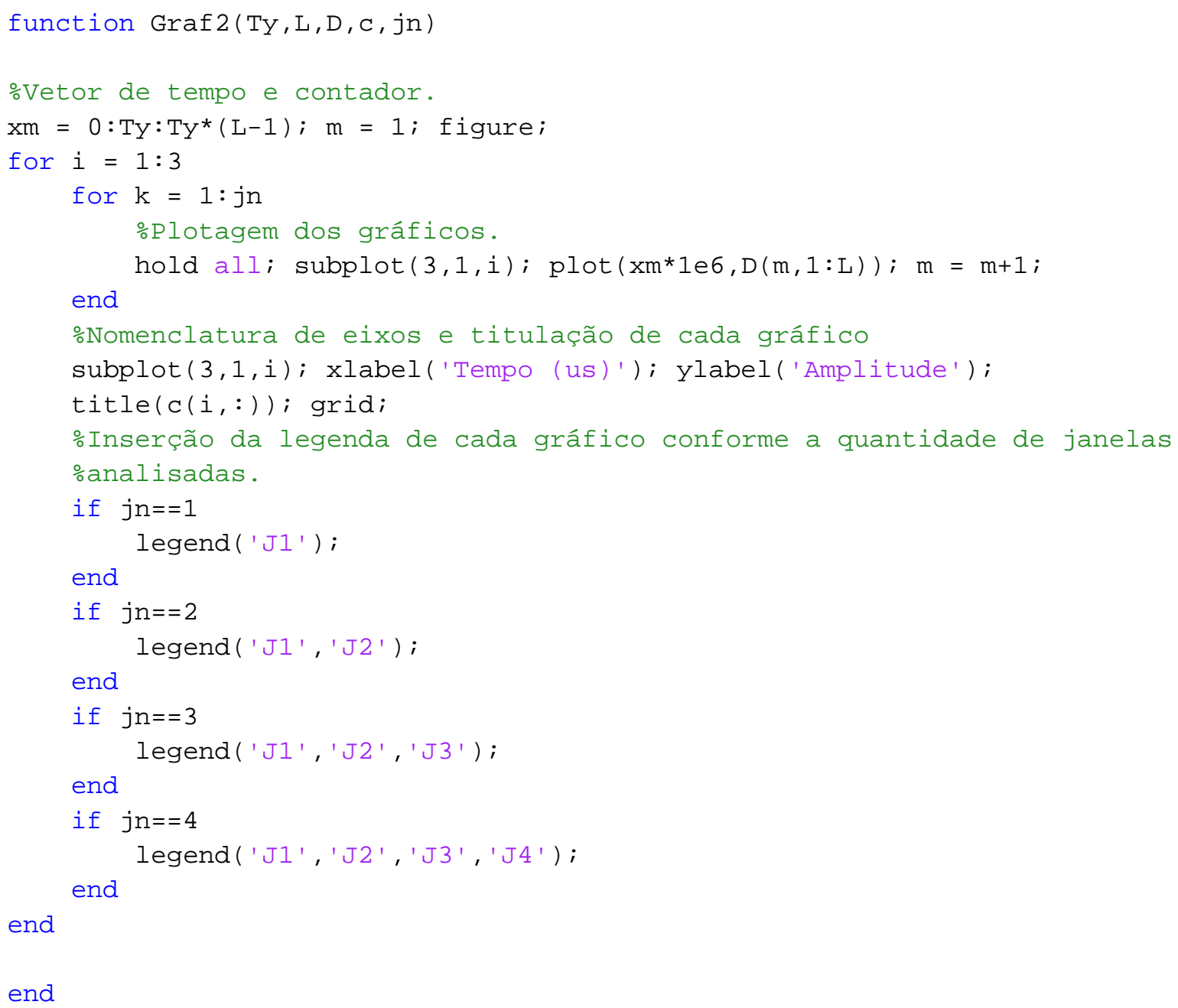

end 
\%\% Contagem de cruzamento por zeros

function $\mathrm{ZC}=\mathrm{Tx} \_\mathrm{ZC}(\mathrm{y}, \mathrm{J})$

\%Definição de variável global para execução do arquivo "Taxa_ZC". global aux;

global Ts;

\%Número de janelas para análise.

$\mathrm{n}=\max (\operatorname{size}(\mathrm{J}))$;

\%Inicialização da matriz "ZC".

$\mathrm{ZC}=\operatorname{zeros}(3, \mathrm{n})$;

\%Cálculo dos cruzamentos por zeros para cada janela e medida.

for $i=1: 3$

for $k=1: n$

\%Janela em análise.

aux $=y(i, \operatorname{round}(J(k, 1) * 1 e 4): \operatorname{round}(J(k, 2) * 1 e 4)) ;$

\%Execução de uma rotina no Simulink para quantificar os cruzamentos \%por zero.

sim('Taxa_ZC.mdl');

\%Salvar cada valor referente a cada janela e medida.

$\mathrm{ZC}(\mathrm{i}, \mathrm{k})=$ Taxa;

end

end

end 
\%\% Transformada de Fourier e Plotagem de Gráficos

\%Esta função tem por objetivo o cálculo do espectro de frequências de \%quatro janelas distintas num sinal de descarga.

function graf_fft_J1(J,Ty, y, c, l, M)

\%Taxa de amostragem e passo de frequência.

$\mathrm{n}=1 /($ Ty $) ; \mathrm{p}=\mathrm{n} /\left(2^{*} \mathrm{M}\right)$; figure;

for $i=1: 3$

for $k=1: 4$

\%Aquisição da janela a ser analizada.

$a x=[y(i, \operatorname{round}(J(k, 1) * 1 e 4): \operatorname{round}(J(k, 2) * 1 e 4))$ zeros $(1, M)]$;

\%Retirada do valor CC e normalização do sinal em energia.

$\mathrm{ax}=\operatorname{ax}-\operatorname{sum}(\mathrm{ax}) / 1 \mathrm{e} 4 ; \operatorname{nor}=\operatorname{sum}(\mathrm{ax} . \wedge 2) ; \mathrm{ax}=\operatorname{ax} . / \operatorname{sqrt}($ nor $) ;$

\%Cálculo do espectro em dB.

$a x=20 * \log 10(\operatorname{abs}(f f t(a x)))$;

\%lotagem de gráficos.

end

hold all; subplot $(3,1, i) ; \operatorname{plot}\left(0: p /(1 \mathrm{e} 3): p^{*} 1 /(1 \mathrm{e} 3), \operatorname{ax}(1: 1+1)\right)$;

\%Nomeação dos eixos plotagem da legenda dos sinais conforme a janela \%processada.

subplot $(3,1, i)$; xlabel('Frequência $(\mathrm{kHz})$ '); ylabel('Amplitude (dB)' );

legend('J1','J2','J3', 'J4'); title(c(i,:)); grid;

end

end 


\section{\% Cálculo de Similaridade Entre Dois Vetores}

\%Esta função tem por objetivo a melhor escolha do fator de compressão do \%espectro de frequências do sinal sem eco de modo que o sinal remodelado e \%reconstruído sejam os mais próximos possíveis. As medições de similaridade \%são por meio da distância Euclidiana e de Chebyshev. Por questão de \%simplicidade, já é calculada a forma de onda remodelada de acordo com o \%melhor fator de compressão.

function [S mm YR2 YR5] = sim_vet $(\mathrm{D} 2,12, \mathrm{Ts} 2, \mathrm{D} 5,15, \mathrm{Ts} 5, \mathrm{y} 1, \mathrm{~T} 1, \mathrm{y} 4, \mathrm{~T} 4, \mathrm{ca}, \mathrm{cs}, \ldots$ $\mathrm{G} 2, \mathrm{G} 5$ )

\%Ajuste da subamostragem para equalização temporal entre o sinal remodelado \%e reconstruído.

p2 $=\operatorname{round}(100 *(\operatorname{Ts} 2 /(100 * T 1))) ; p 5=\operatorname{round}(100 *(T s 5 /(100 * T 4))) ;$

\%Comprimento da fft.

$\mathrm{m} 2$ = length $(1: \mathrm{p} 2: 1 \mathrm{e} 5) ;$

m5 = length $(1: p 5: 1 e 5) ;$

\%Cálculo da fft.

$\mathrm{F} 2=\mathrm{fft} \_\mathrm{Cx}(\mathrm{y} 1(:, 1: \mathrm{p} 2: 3 \mathrm{e} 4-1), \mathrm{m} 2) ;$

$\mathrm{F} 5$ = fft_Cx(y4(:,1:p5:3e4-1),m5);

\%Fatores de escala: variando de 1 a 4 com passo 0.1 . S é a matriz que \%conterá cada distância entre os sinais remodelados e reconstruídos. aux $=1: 0.1: 4 ; 1=$ length $(\operatorname{aux}) ; \mathrm{S}=\operatorname{zeros}(12,1) ; \mathrm{mm}=\operatorname{zeros}(12,2) ; \mathrm{s}=8 \mathrm{e} 2 ;$ \%Vetor para reconstrução em fase mínima do sinal.

$M=1 \mathrm{e} 4 ; w=\left[1 ; 2^{*} \operatorname{ones}(M / 2-1,1) ; \operatorname{ones}(1-\operatorname{rem}(M, 2), 1) ; \operatorname{zeros}(M / 2-1,1)\right] ;$

for $i=1: 3$

\%Interoplação de nível 10 no espectro de frequências referente à \%amostra e sensor "i".

$f 2=i n t e r p(F 2(i,:), 10) ; f 5=\operatorname{interp}(F 5(i,:), 10)$;

\%Filtragem passa-baixas no cepstro.

$\operatorname{aux2}=[D 2(i, 1: 12(i)) \operatorname{zeros}(1, M-12(i))] ;$

$\operatorname{aux5}=[D 5(i, 1: 15(i)) \operatorname{zeros}(1, M-15(i))] ;$

\%Reconstrução do sinal de acordo com a nova janela escolhida.

$r c 2=\operatorname{real}\left(\right.$ ifft $\left.\left(\exp \left(f f t\left(w^{\prime} \cdot{ }^{*} a u x 2\right)\right)\right)\right) ;$

rc5 $=\operatorname{real}\left(\right.$ ifft $\left.\left(\exp \left(f f t\left(w^{\prime} \cdot{ }^{*} a u x 5\right)\right)\right)\right)$;

\%Adequação e normalização dos sinais reconstruídos

$r c 2=-r c 2 . / \max (\operatorname{abs}(r c 2)) ; r c 2(1)=0 ;$

$r c 5=-r c 5 . / \max (\operatorname{abs}(\operatorname{rc5})) ; \operatorname{rc5}(1)=0$;

for $\mathrm{k}=1: 1$

\%Multiplicação do fator de escala por 10, pois a interpolação foi

\%de nível 10.

$\mathrm{nf}=\operatorname{round}(\operatorname{aux}(\mathrm{k}) * 10)$;

\%Construção do novo espectro de frequências (amostras).

$\mathrm{a} 1=\mathrm{f2}\left(1: \mathrm{nf}: 10^{*} \mathrm{~m} 2 / 2\right) ; \mathrm{a} 2=\mathrm{f2}\left(10^{*} \mathrm{~m} 2:-\mathrm{nf}: 10^{*}(\mathrm{~m} 2 / 2+1)\right)$;

$\mathrm{a} 2=\mathrm{a} 2($ length $(\mathrm{a} 2):-1: 1) ; \mathrm{ax}=\operatorname{length}\left(\left[\begin{array}{ll}\mathrm{a} 1 & \mathrm{a} 2\end{array}\right]\right) ;$

\%Reconstruíndo o sinal remodelado no tempo.

$\mathrm{yr} 2=\operatorname{real}(\operatorname{ifft}([\mathrm{a} 1 \operatorname{zeros}(1, \mathrm{~m} 2-\mathrm{ax}) \mathrm{a} 2])) ; \mathrm{yr} 2=\mathrm{yr} 2 / \max (\operatorname{abs}(\mathrm{yr} 2)) ;$

\%Construção do novo espectro de frequências (sensores).

$\mathrm{a} 1=\mathrm{f5}\left(1: \mathrm{nf}: 10^{*} \mathrm{~m} 5 / 2\right) ; \mathrm{a} 2=\mathrm{f5}\left(10^{*} \mathrm{~m} 5:-\mathrm{nf}: 10^{*}(\mathrm{~m} 5 / 2+1)\right) ;$

a2 = a2(length (a2):-1:1); ax = length $\left(\left[\begin{array}{ll}a 1 & a 2\end{array}\right]\right) ;$

\%Reconstruíndo o sinal remodelado no tempo.

$\operatorname{yr} 5=\operatorname{real}(\operatorname{ifft}([\operatorname{a1} \operatorname{zeros}(1, \mathrm{m5}-\mathrm{ax})$ a2 $])) ; \mathrm{yr} 5=\mathrm{yr} 5 / \max (\operatorname{abs}(\mathrm{yr} 5)) ;$ $\operatorname{yr} 2(1)=0 ; \operatorname{yr} 5(1)=0$; 


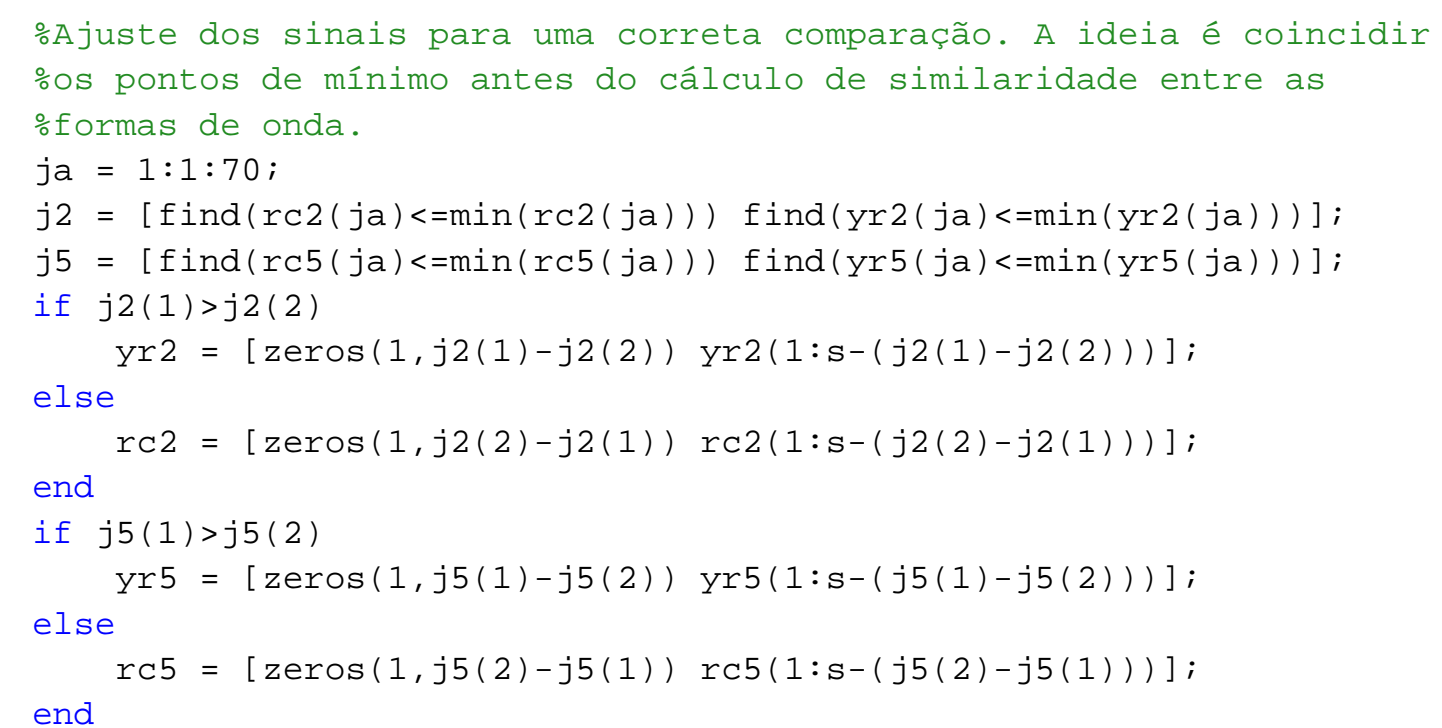

\%Cálculo das distâncias Euclidiana e de Chebyshev.

\%Vtores a serem analizados: sinal remodelado e reconstruído.

$q a=[r c 2(1: s) ; y r 2(1: s)] ;$

qs $=[\operatorname{rc5}(1: s) ; \operatorname{yr} 5(1: s)]$;

\%Cálculo das distâncias

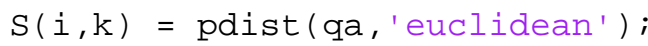

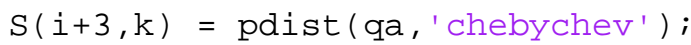

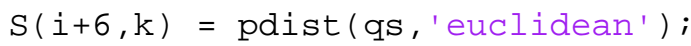

end

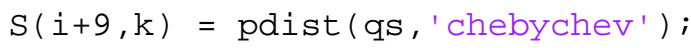

\%Localização dos pontos de mínimo de cada curva.

$[q r]=\min (S(i,:)) ; \operatorname{mm}(i,:)=[\operatorname{aux}(r) q] ;$

$[q r]=\min (S(i+3,:)) ; \operatorname{mm}(i+3,:)=[\operatorname{aux}(r) q] ;$

$[q r]=\min (S(i+6,:)) ; \operatorname{mm}(i+6,:)=[\operatorname{aux}(r) q] ;$

$[q r]=\min (S(i+9,:)) ; \operatorname{mm}(i+9,:)=[\operatorname{aux}(r) q] ;$

\%Normalização dos fatores de compressão.

for $j=1: 3$

$S(j,:)=s(j,:) / \max (s(j,:))$;

$S(j+3,:)=S(j+3,:) / \max (S(j+3,:))$;

$S(j+6,:)=S(j+6,:) / \max (S(j+6,:))$;

end

$S(j+9,:)=S(j+9,:) / \max (S(j+9,:))$;

end

\%Plotagem de todas as curvas de distâncias normalizadas.

for $j=1: 4$

subplot $(2,2, j) ; \operatorname{plot}\left(\operatorname{aux}, \mathrm{s}\left(3^{*}(j-1)+1: 3^{*} j,:\right) '\right)$; grid;

xlabel('Fator de compressão'); ylabel('Ampitude Normalizada');

if $j==1 \quad|| j==3$

title('Distância Euclidiana');

else

title('Distância de Chebychev');

end

if $j==1 \quad|| j==2$

legend(ca);

else

legend(cs);

end

end 
\%Plotagem do espectro do sinal original, reconstruído e remodelado $\%($ amostras).

$\mathrm{L}=8 \mathrm{e} 2 ; \mathrm{G} 2(:, 1)=0 ; \mathrm{FR} 2=\mathrm{fft} \_\mathrm{Cx}(\mathrm{G} 2(:, 1: \mathrm{L}), \mathrm{m} 2)$;

$\mathrm{nf}=\mathrm{mm}(1: 3,1)^{\prime} ; \mathrm{f}=1 \mathrm{e} 5$;

FTR2 = adequa_esp $(F 2, T 1 * p 2, F R 2, T s 2, m 2, n f, c a, f)$;

\%Plotagem do espectro do sinal original, reconstruído e remodelado $\%$ (sensores).

$\mathrm{L}=8 \mathrm{e} 2 ; \mathrm{G} 5(:, 1)=0 ; \mathrm{FR5}=\mathrm{fft} \_\mathrm{Cx}(\mathrm{G} 5(:, 1: \mathrm{L}), \mathrm{m5})$;

nf $=m(7: 9,1)^{\prime} ; f=4 e 5 ;$

FTR5 = adequa_esp $\left(\mathrm{F} 5, \mathrm{~T} 4{ }^{*} \mathrm{p} 5, \mathrm{FR} 5, \mathrm{Ts} 5, \mathrm{m5}, \mathrm{nf}, \mathrm{cs}, \mathrm{f}\right)$;

\%Reconstrução dos sinais remodelados de acordo com o melhor fator de \%compressão.

\%Iniciaçização das matrizes.

YR2 $=\operatorname{zeros}(3, \mathrm{~m} 2) ; \mathrm{YR5}=\operatorname{zeros}(3, \mathrm{m5})$;

for $i=1: 3$

$\operatorname{YR2}(i,:)=\operatorname{real}(i f f t(\operatorname{FTR} 2(i,:)))$;

$\operatorname{YR5}(i,:)=\operatorname{real}(i f f t(\operatorname{FTR} 5(i,:)))$;

end

end 
\%\% Transformada de Fourier

function $F=f f t \_c x(y, m)$

\%Comprimento do vetor e passo de frequência.

$1=\operatorname{length}(y(1,:))$;

\%atriz de saída e tamanho do vetor utilizado para análise.

$F=\operatorname{zeros}(3, \mathrm{~m})$;

for $i=1: 3$

\%Retirada do valor CC, normalização e acréscimo de zeros.

$\operatorname{ax}=y(i,:) ; \quad a x=a x-\operatorname{sum}(a x) / m$;

nor $=\max (\operatorname{abs}(a x)) ; a x=[a x / \operatorname{nor} \operatorname{zeros}(1, m-1)]$;

\%Cálculo da fft.

end

$F(i,:)=f f t(a x)$; 


\section{\%\% Comparação dos Espectros}

\%Esta função tem por objetivo comparar os espectros das formas de ondas \%originais, ou sem eco, com os espectros das formas de ondas reconstruídas, \%e calcular um espectro remodelado a partir dos fatores de compressão.

function FR = adequa_esp $(F T, T y, F M, T m, M, n, C, f m)$

$\mathrm{FR}=\operatorname{zeros}(3, \mathrm{M}) ; \mathrm{n} 1=1 / \mathrm{Ty} ; \mathrm{p} 1=\mathrm{n} 1 / \mathrm{M} ; \mathrm{n} 2=1 / \mathrm{Tm} ;$

$\mathrm{p} 2=\mathrm{n} 2 / \mathrm{M} ;$ figure; $\mathrm{L} 1=\mathrm{fm} / \mathrm{p} 1 ; \mathrm{L} 2=\mathrm{fm} / \mathrm{p} 2$;

for $i=1: 1$

\%Interpolação do sinal num fator 10 para que se possa realizar

\%sub-amostragem de números decimais de uma casa depois da vírgual como, \%por exemplo, $n=1.5$.

$\mathrm{a}=\operatorname{interp}(\mathrm{FT}(\mathrm{i},:), 10) ; \mathrm{nf}=\mathrm{n}(\mathrm{i})$;

\%Sub-amostragem do lado "direito" e "esquerdo" do espectro.

$a 1=a\left(1: n f^{*} 10: 10 * M / 2\right) ;$ a2 $=a\left(10 * M:-n f^{*} 10: 10 *(M / 2+1)\right) ;$

$\mathrm{a} 2=\mathrm{a} 2($ length $(\mathrm{a} 2):-1: 1) ; \mathrm{ax}=\operatorname{length}\left(\left[\begin{array}{ll}\mathrm{a} 1 & \mathrm{a} 2\end{array}\right]\right)$;

$\operatorname{FR}(i,:)=[$ a1 $\operatorname{zeros}(1, M-a x)$ a2 $]$;

\%Cálculo dos espectros em dB: sinal original, reconstruído e \%remodelado.

$\operatorname{aux1}=20 * \log 10(\operatorname{abs}(\mathrm{FT}(i,:)))$;

$\operatorname{aux2}=20 * \log 10(\operatorname{abs}(\mathrm{FM}(i,:)))$;

$\operatorname{aux3}=20 * \log 10(\operatorname{abs}(\mathrm{FR}(i,:)))$;

\%Definição de intervalos e plotagem de gráficos.

$11=0: \mathrm{p} 1 / 1 \mathrm{e} 3:(\mathrm{fm}-\mathrm{p} 1) / 1 \mathrm{e} 3 ; \mathrm{m} 1$ = length $(11)$;

$12=0: \mathrm{p} 2 / 1 \mathrm{e} 3:(\mathrm{fm}-\mathrm{p} 2) / 1 \mathrm{e} 3 ; \mathrm{m} 2$ = length $(12)$;

plot (11, aux1(1:m1)); hold all;

plot $(12, \operatorname{aux2}(1: \mathrm{m} 2)) ; \operatorname{plot}(11, \operatorname{aux3}(1: \mathrm{m} 1)) ; \operatorname{grid}$;

\%Nomeção de eixos e inserção de título e legenda.

xlabel('Frequência (kHz)'); ylabel('Amplitude (dB)');

legend('Espectro Sinal Sem Eco', 'Espectro Sinal Reconstruído',...

'Espectro Sinal Remodelado'); $\operatorname{title}(\mathrm{c}(\mathrm{i}, \mathrm{i}))$;

end

end 
\%\% Comparação das formas de Onda

\%Esta função tem por objetivo comparar as formas de onda dos sinais \%remodelados, reconstruídos e amostrados para o pior caso de relação \%sinal/ruído.

function graf_comp $(\mathrm{yr}, \mathrm{Tr}, \mathrm{yc}, \mathrm{ym}, \mathrm{L}, \mathrm{n}, \mathrm{c})$

\%Variáveis úteis para a deconvolução.

$M=1 \mathrm{e} 4 ; W=\left[1 ; 2^{*} \operatorname{ones}(M / 2-1,1) ; \operatorname{ones}(1-\operatorname{rem}(M, 2), 1) ; \operatorname{zeros}(M / 2-1,1)\right] ;$

\%Vetor de tempo para todos os sinais.

$\mathrm{x}=0: \operatorname{Tr}: \operatorname{Tr} *(\mathrm{~L}-1) ;$ aux $=\operatorname{zeros}(3, \mathrm{~L})$;

for $i=1: 3$

\%Normalização dos sinais remodelados e reconstruídos.

$\operatorname{aux}(1,:)=\operatorname{yr}(i, 1: L) \cdot / \max (\operatorname{abs}(\operatorname{yr}(i, 1: L))) ;$

$\operatorname{aux}(2,:)=\operatorname{yc}(i, 1: L) \cdot / \max (\operatorname{abs}(y c(i, 1: L)))$;

\%Deconvolução do sinal amostrado.

$\mathrm{a} 33=\operatorname{rceps}(\mathrm{ym}(\mathrm{i},:)) ; \mathrm{a} 3=[\mathrm{ax3}(1: \mathrm{n}(\mathrm{i})) \operatorname{zeros}(1, \mathrm{M}-\mathrm{n}(\mathrm{i}))] ;$

$\mathrm{a} \times 3=\operatorname{real}\left(\right.$ ifft $\left.\left(\exp \left(f f t\left(a \times 3 \cdot{ }^{*} w^{\prime}\right)\right)\right)\right) ;$

$\operatorname{aux}(3,:)=-\operatorname{ax3}(1: L) \cdot / \max (\operatorname{abs}(\operatorname{ax3}(1: L))) ; \operatorname{aux3}(3,1)=0 ;$

\%Adequação no tempo: colocação de zeros nas formas de onda para melhor \%comparação visual.

\%Janela de análise e pontos de mínimo.

$\mathrm{ja}=1: 1: 70$;

$\mathrm{t} 1=$ find $(\operatorname{aux}(1, \mathrm{ja})<=\min (\operatorname{aux}(1, j \mathrm{a})))$;

t2 = find $(\operatorname{aux}(2, j a)<=\min (\operatorname{aux}(2, j a))) ;$

t3 $=$ find $(\operatorname{aux}(3, j a)<=\min (\operatorname{aux}(3, j a)))$;

\%Localização do valor máximo para equalização das outras formas de onda \%em relação à forma de onda mais atrasada.

$v t=\left[\begin{array}{lll}t & t & t 3\end{array}\right] ;\left[\begin{array}{ll}p & r\end{array}\right]=\max (v t) ;[\sim, z]=$ find $(v t-p<=0)$;

\%Inserção de zeros, conforme a necessidade.

$\mathrm{ax}=\mathrm{vt}(\mathrm{r})-\mathrm{vt}(\mathrm{z}(1))$;

$\operatorname{aux}(z(1),:)=[z \operatorname{zeros}(1, \operatorname{ax}) \operatorname{aux}(z(1), 1: L-a x)]$;

$a x=v t(r)-v t(z(2))$;

$\operatorname{aux}(z(2),:)=[z \operatorname{coros}(1, \operatorname{ax}) \operatorname{aux}(z(2), 1: L-a x)]$;

if length $(z)==3$

$a x=v t(r)-v t(z(3))$;

$\operatorname{aux}(z(3),:)=[z e r o s(1, a x)$ aux $(z(3), 1: L-a x)]$;

end

\%Plotagem de gráficos.

figure; $\operatorname{plot}\left(x^{\star} 1 \mathrm{e} 6\right.$, aux'); grid;

\%Nomeção de eixos e inserção de título e legenda.

xlabel('Tempo (us)'); ylabel('Amplitude Normalizada'); title(c(i,:)); end

legend('Sinal Remodelado', 'Sinal Reconstruído', 'Sinal Processado');

end 


\section{\% Comparação das formas de onda}

\%Esta função tem por objetivo comparar as formas de onda dos sinais \%remodelados, reconstruídos e amostrados para o pior caso de relação \%sinal/ruído.

function graf_comp2(yr,ys, Tr, Ts, yc, ycs, ym, yse, Lr, Ls, $\mathrm{nr}, \mathrm{ns}, \mathrm{ca}, \mathrm{cs})$

\%Variáveis úteis para a deconvolução.

$M=1 e 4 ; W=\left[1 ; 2^{*} \operatorname{ones}(M / 2-1,1) ; \operatorname{ones}(1-\operatorname{rem}(M, 2), 1) ; \operatorname{zeros}(M / 2-1,1)\right] ;$

\%Vetor de tempo para todos os sinais.

$x r=0: \operatorname{Tr}: \operatorname{Tr}^{*}(\operatorname{Lr}-1) ; \operatorname{auxr}=\operatorname{zeros}(3, L r) ;$

$x s=0: T s: T s^{*}(L s-1) ;$ auxs $=\operatorname{zeros}(3$, Ls $) ;$

for $i=1: 3$

\%Normalização dos sinais remodelados e reconstruídos.

$\operatorname{auxr}(1,:)=\operatorname{yr}(i, 1: \operatorname{Lr}) \cdot / \max (\operatorname{abs}(\operatorname{yr}(i, 1: \operatorname{Lr})))$;

$\operatorname{auxr}(2,:)=\operatorname{yc}(i, 1: L r) \cdot / \max (\operatorname{abs}(y c(i, 1: L r)))$;

$\operatorname{auxs}(1,:)=\operatorname{ys}(i, 1:$ Ls $) \cdot / \max (\operatorname{abs}(y s(i, 1:$ Ls $))) ;$

$\operatorname{auxs}(2,:)=\operatorname{ycs}(i, 1: L s) \cdot / \max (\operatorname{abs}(\operatorname{ycs}(i, 1:$ Ls $)))$;

\%Deconvolução do sinal amostrado.

$\operatorname{ax3r}=r \operatorname{ceps}(y m(i,:)) ; \operatorname{ax3r}=[\operatorname{ax3r}(1: n r(i))$ zeros(1,M-nr(i))];

$\operatorname{ax} 3 r=\operatorname{real}\left(\right.$ ifft $\left.\left(\exp \left(f f t\left(\operatorname{ax} 3 r \cdot{ }^{*} w^{\prime}\right)\right)\right)\right)$;

$\operatorname{auxr}(3,:)=-\operatorname{ax} 3 r(1: \operatorname{Lr}) \cdot / \max (\operatorname{abs}(\operatorname{ax} 3 r(1: \operatorname{Lr}))) ; \operatorname{auxr}(3,1)=0 ;$

$\operatorname{ax3s}=\operatorname{rceps}(\operatorname{yse}(i,:)) ; \operatorname{ax3s}=[\operatorname{ax3s}(1: n s(i)) \operatorname{zeros}(1, M-n s(i))]$;

ax3s $=\operatorname{real}\left(\right.$ ifft $\left.\left(\exp \left(f f t\left(a \times 3 s .{ }^{*} w^{\prime}\right)\right)\right)\right)$;

$\operatorname{auxs}(3,:)=-\operatorname{ax3s}(1: L s) \cdot / \max (\operatorname{abs}(\operatorname{ax} 3 s(1: L s))) ; \operatorname{auxs}(3,1)=0 ;$

\%Adequação no tempo: colocação de zeros nas formas de onda para melhor \%comparação visual.

\%Janela de análise e pontos de mínimo.

ja $=1: 1: 70$;

for $j=1: 2$

if $j==1$

aux = auxr; L = Lr;

else

aux = auxs; L = Ls;

end

$\mathrm{t} 1=\operatorname{find}(\operatorname{aux}(1, j \mathrm{a})<=\min (\operatorname{aux}(1, j a)))$;

t2 = find $(\operatorname{aux}(2, j a)<=\min (\operatorname{aux}(2, j a)))$;

t3 $=$ find $(\operatorname{aux}(3, j a)<=\min (\operatorname{aux}(3, j a)))$;

\%Localização do valor máximo para equalização das outras formas de

\%onda em relação à forma de onda mais atrasada.

$v t=\left[\begin{array}{lll}t 1 & t & t 3\end{array}\right] ;\left[\begin{array}{ll}p & r\end{array}\right]=\max (v t) ;[\sim, z]=$ find $(v t-p<=0) ;$

\%Inserção de zeros, conforme a necessidade.

$a x=v t(r)-v t(z(1))$;

$\operatorname{aux}(z(1),:)=[z \operatorname{zeros}(1, a x) \operatorname{aux}(z(1), 1: L-a x)]$;

$a x=v t(r)-v t(z(2))$;

$\operatorname{aux}(z(2),:)=[z e r o s(1, a x) \operatorname{aux}(z(2), 1: L-a x)]$;

if length $(z)==3$

$\mathrm{ax}=\mathrm{vt}(\mathrm{r})-\mathrm{vt}(\mathrm{z}(3))$;

$\operatorname{aux}(z(3),:)=[z \operatorname{zeros}(1, \operatorname{ax}) \operatorname{aux}(z(3), 1: L-a x)]$;

end

if $j==1$

auxr = aux;

else 


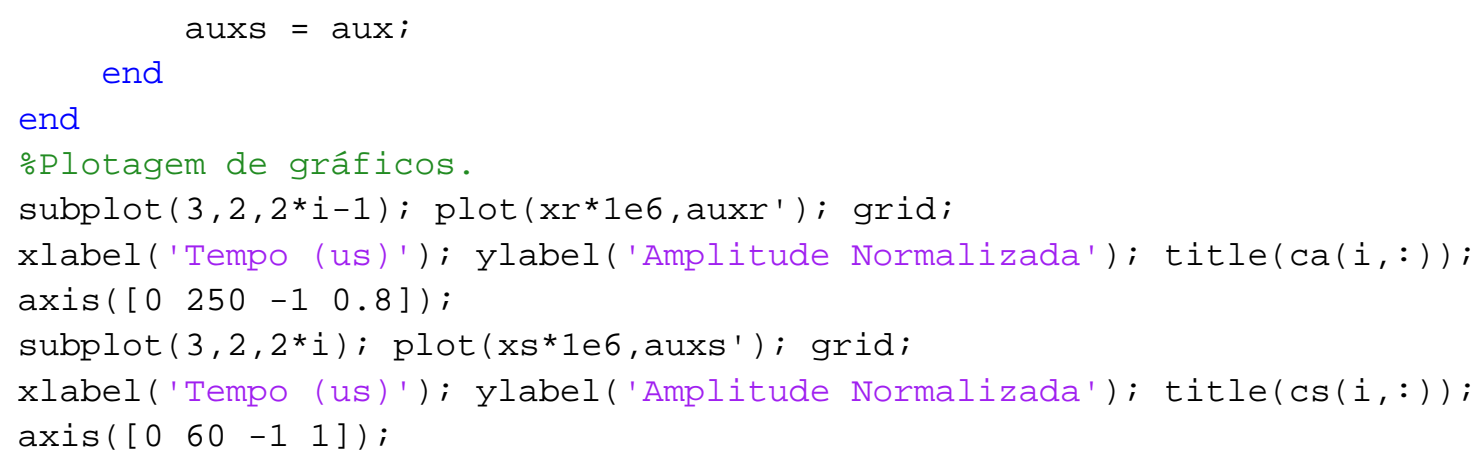

end 


\section{Apêndice C:}

\section{Publicações}

Neste apêndice são apresentadas quatro publicações que foram resultados desta pesquisa, que são descritas a seguir:

1) Título: Estudo dos Piezoeletretos como Transdutores Acústicos para Detecção de Descargas Elétricas em Transformadores.

Autores: Yvan Gutnik, Ruy Alberto Pisani Altafim, Heitor Cury Basso, Ruy Alberto Corrêa Altafim.

Congresso: IV Simpósio Brasileiro de Sistemas Elétricos, Goiânia, Goiás, 15 a 18 de Maio de 2012.

Resumo: Piezoeletretos são filmes poliméricos porosos carregados eletricamente que apresentam uma piezeletricidade similar à encontrada em cristais e cerâmicas. Por se tratar de estruturas poliméricas celulares, ou seja, compostas por cavidades gasosas, proporcionam fácil deformação mediante aplicação de uma força externa. Essa característica adicionada às cargas elétricas de diferentes polaridades aprisionadas nas superfícies internas dos poros resulta em coeficientes piezelétricos d33 elevados. Isso somado a flexibilidade dos polímeros, tornam os piezoeletretos excelentes transdutores acústicos. Neste contexto, o presente trabalho tem por objetivo analisar a viabilidade de aplicação de piezoeletretos, como transdutores acústicos, na detecção de descargas elétricas originárias em transformadores de potência e/ou distribuição. Em uma primeira abordagem, testes de reprodutibilidade da resposta do transdutor piezelétrico foram comparados com os obtidos em um microfone padrão. Após uma análise estatística de ambas as respostas, e de resultados preliminares com descargas reais, foi averiguado que o transdutor piezelétrico proposto atua com características promissoras para este tipo de aplicação. 
2) Título: Piezoelectret sensors detect geometry-related modifications of the acoustical signatures from partial discharges in an electrical equipment chamber

Autores: Yvan Gutnik, Ruy Alberto Pisani Altafim, José Francisco Resende, Heitor Cury Basso, Reimund Gerhard, Ruy Alberto Corrêa Altafim.

Congresso: 2012 Annual Report Conference on Electrical Insulation a Dielectric Phenomena (CEIDP), Montreal, Canadá, 14 a 17 de Outubro de 2012 .

Resumo: Piezoelectrets from thin electrically charged cellular polypropylenefoam films have been suggested for numerous transducer applications, such as force sensors for keyboards, flat microphones for conference environments, or devices for ultrasound generation and detection. In addition to polypropylene piezoelectrets, other materials systems - such as thermo-fused polymer-film stacks - were developed in order to generate piezoelectrets that are thermally more stable and contain geometrically well-controlled air cavities. Here, we demonstrate the viability of the recently developed piezoelectret systems that had been prepared by thermo-lamination with templates for the acoustical detection of electric discharges in air. Furthermore, we show that the resonance behavior of the air cavity in which the electric discharge occurs can also be assessed from the acoustic signal. For the experiments, a transducer prototype with a preamplifier directly connected to the laminated piezoelectret sensor inside an electrically shielded package was developed. Reproducible sound measurements according to the ASTM E976-10 standard were performed with the transducer prototype. The prototype was later employed in acoustical measurements of electric discharges in an air gap inside an acoustical chamber - in order to reduce external noise - and in a metallic chamber for reducing electrical interference. The recorded signals were compared by means of Fast-Fourier-Transform (FFT) analysis.

3) Título: Different piezoelectric structures applied to acoustic detection of impulse and corona partial discharge.

Autores: Yuri Andrey Olivato Assagra, Yvan Gutnik, Ruy Alberto Pisani Altafim, Antônio Carlos Cavalcanti, Ruy Alberto Corrêa Altafim. 
Congresso: 2013 Annual Report Conference on Electrical Insulation a Dielectric Phenomena (CEIDP), Shenzhen, China, 20 a 23 de Outubro de 2013.

Resumo: Electrical discharges are frequent phenomena responsible for most breakdown failures reported in electrical distribution systems and are commonly related to the accelerated aging of equipment. Therefore, the detection of electrical discharges is important to avoid severe damage to equipment and to improve companies" preventive maintenance. Acoustic sensors have been successfully used to monitor partial discharges (PD) in power transformers, although they are too costly for use with distribution transformers. An alternative solution to such sensors are electromechanical films (EMFi) also known as ferroelectrets or piezoelectrets, due to their frequency responses (up to hundreds of $\mathrm{kHz}$ ), high piezoelectric $d_{33}$ coefficients (hundreds of $\mathrm{pC} / \mathrm{N}$ ) and low cost of manufacture since they are polymer-based and can be produced on large scales. Focusing on piezoelectrets and electrical discharges in this work, we present a comparative study with two different piezoelectric structures applied to impulse and corona discharge detection. From this, different waveforms from different PD were obtained and the most suitable piezoelectric configuration for detecting electrical discharges was evaluated.

4) Título: Comparative analysis between impulsive detection methods applied on partial discharge acoustic signals.

Autores: Clovis Ferreira dos Reis, Ruy Alberto Pisani Altafim, Yvan Gutnik, Ruy Alberto Corrêa Altafim, Antônio Carlos Cavalcanti.

Congresso: 2014 IEEE International Instrumentation and Measurement Technology Conference (I2MTC), Montevideo, Uruguai, 12 a 15 de Maio de 2014.

Resumo: Partial discharges (PD) plays an important role on power transmission lines and equipment failures therefore detect this high-voltages phenomena previously can prevent sever damages avoiding further outlay. Spark gaps discharges are among the PD that are common in power transformers and other efficiency energy equipment. Besides the light emission, impulsive acoustic waves are another important characteristic of this PD, which has influence several protection and monitoring system. Nevertheless, 
detecting acoustical signals from PD can be difficult since they are normally followed by other sound noise. Therefore in this work we explore two methods that are regularly employed on impulsive signal processing, the Variance Method (VM) and the Conditional Median Filter (CMF), to analyze PD acoustic signals. From the presented results it is observed that the CMF presented the best performance in detecting $\mathrm{PD}$ although the $\mathrm{VM}$ is a much simple solution that still can be further optimized. 


\section{Apêndice D:}

\section{Equação de onda}

Para sons propagando-se no ar, por exemplo, as variáveis mais importantes são densidade, $\rho_{G}$, pressão, $P_{G}$ e temperatura $T_{G}$ do gás. $\mathrm{O}$ volume $V_{G}$ do gás é mais adequado no tratamento de problemas que envolvam uma massa de ar encerrada num reservatório. Dessa forma, a densidade seria resultado da massa $M$ do gás dividido pelo volume. Observe que a densidade seria redundante em relação volume, visto que a massa do gás é fixa. No presente caso, o tratamento utilizando-se a densidade é mais apropriado visto que se consideram grandes massas de ar, como são os casos dos campos sonoros. O tratamento para este gás, partindo da equação de Boyle-Mariotte, é como segue:

$$
\begin{gathered}
P_{G} V_{G}=\frac{M}{M_{m o l}} R T_{G} \leftrightarrow \\
\leftrightarrow P_{G}=\frac{R}{M_{m o l}} \frac{M}{V_{G}} T_{G} \therefore \\
P_{G}=\frac{R}{M_{m o l}} \rho_{G} T_{G}
\end{gathered}
$$

Onde $R=\frac{8,134 N m}{K}$ e $M_{m o l}$ é a massa molar do gás. É facilmente perceptível que as curvas isotérmicas são retas que passam pela origem, tendo-se $P_{G}$ como ordenada e $\rho_{G}$ como abscissa do gráfico. Entretanto, esta equação não fornece informação suficiente de como uma variável interfere noutra, ou seja, qual é o caminho de transformação no gráfico mencionado acima. Para se constatar isto, quando se diminui o volume de um gás, pressionando, por exemplo, um pistão num reservatório, pode-se produzir mudanças tanto na temperatura quanto na pressão. A experiência mostra que o prévio conhecimento de velocidade de compressão do gás e as condições do ambiente são decisivos no resultado obtido. Caso se pressione o gás rapidamente, de modo que as paredes do ambiente estejam isoladas termicamente, haverá um aumento de pressão e temperatura. Todavia, se o processo ocorrer lentamente de modo que haja troca de calor com o meio, pode-se aumentar somente a pressão do 
gás sem alterar sua temperatura. D'outra forma: em processos isotérmicos, mudança de volume a temperatura constante, a troca de calor com o meio é uma condição necessária e isto ocorre de maneira lenta. Sendo assim, os campos sonoros implicam em variações muito rápidas de pressão e densidade de modo que estas variações ocorrem sem a transferência de energia (calor) no gás. Em outras palavras, no caso de campos sonoros, quase sempre se pode assumir que os gases não têm capacidade de transportar calor, ou seja, os fenômenos de transferência de calor não desempenham qualquer papel nesta situação. Processos que não transportam ou transferem calor são denominados de adiabáticos (MÖSER, 2009).

Sabendo que a propagação de ondas sonoras é, basicamente, um processo adiabático, procura-se agora responder à pergunta de como se pode explicar e descrever fisicamente o fenômeno de propagação de ondas sonoras num meio gasoso. Concentrando-se primariamente no fundamento de propagação, será desconsiderado o efeito de atenuações e reflexões nesta análise. Um modelo simples é o caso de um campo sonoro unidimensional propagando-se num tubo de paredes rígidas, conforme apresenta a Figura 120.

Seções de coluna de ar

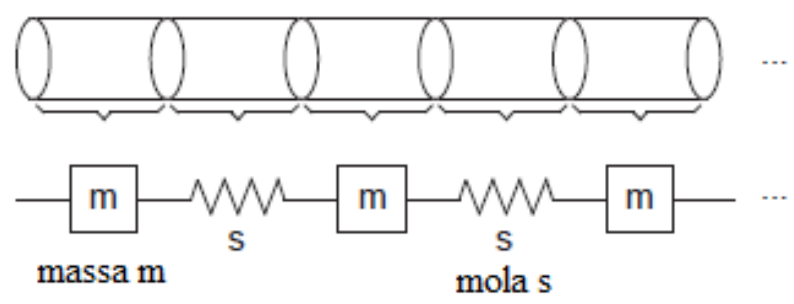

Figura 120: Modelo de uma coluna de ar, composta de elementos de volume, contida num tubo rígido.

Fonte: Modificado de Möser et al. (2009).

Na Figura 120, ao se aplicar uma força no primeiro elemento de volume da esquerda, este, por exemplo, se moverá para a direita comprimindo a mola " $s$ ". Como o elemento de volume é representado por uma massa, o próximo elemento não se moverá instantaneamente, visto que este possui inercia, ou seja, mesmo que uma força tipo degrau seja aplicada à massa, esta é colocada em movimento gradualmente. Dessa forma há um atraso na propagação do som, de modo que a informação é passada de massa a massa. Esta informação viaja da esquerda para a direita com 
velocidade constante. É importante diferenciar dois tipos de velocidades presentes nesta situação: uma é a velocidade de propagação sonora, que será denominada por $c$, e outra é a velocidade das massas " $m$ " individualmente, as quais se movem em torno de uma posição de equilíbrio enquanto a onda sonora se propaga num certo sentido.

Seja $\Delta x$ o comprimento do elemento de volume de ar, apresentado na Figura 120, e $S$ a área da seção transversal deste elemento, que é algo semelhante já apresentado anteriormente na Figura 18. Parte-se do fato de que a massa deste elemento de volume não varia, pois o modelo será equacionado tomando-se as superfícies limites do elemento de volume. Em repouso, a massa deste elemento pode ser dada por $S \Delta x \rho_{0}$. Havendo uma perturbação ou som, este elemento de volume se deformará, de modo que a massa será dada por $S[\Delta x+\delta(x+\Delta x)-\delta(x)] \rho_{G}$. A função $\delta(x)$ descreve o deslocamento, em função do espaço e do tempo, do limite lateral esquerdo do primeiro elemento de volume em torno de $x$, e o termo $\delta(x+\Delta x)$ descreverá o deslocamento do limite lateral direito do elemento de volume em torno de $(x+\Delta x)$. Ademais, a função densidade oscila em torno de um ponto de equilíbrio $\rho_{0}$, de modo que $\rho_{G}=\rho+\rho_{0}$, onde $\rho$ representa a variação dinâmica da densidade. Sendo as massas iguais para as duas situações, segue que:

$$
\begin{gathered}
S \Delta x \rho_{0}=S[\Delta x+\delta(x+\Delta x)-\delta(x)]\left(\rho+\rho_{0}\right) \leftrightarrow \\
\leftrightarrow \Delta x \rho_{0}=\Delta x \rho_{0}+\Delta x \rho+(\delta(x+\Delta x)-\delta(x)) \rho+(\delta(x+\Delta x)-\delta(x)) \rho_{0}
\end{gathered}
$$

O termo $(\delta(x+\Delta x)-\delta(x)) \rho$, que é o produto entre a deformação total do elemento de volume e a densidade sonora dinâmica, pode ser desprezado, pois é bastante pequeno se comparado aos demais termos da equação. Portanto, a equação pode ser reescrita da seguinte maneira:

$$
\begin{aligned}
0= & \Delta x \rho+(\delta(x+\Delta x)-\delta(x)) \rho_{0} \leftrightarrow \\
\leftrightarrow & \frac{\rho}{\rho_{0}}=-\frac{\delta(x+\Delta x)-\delta(x)}{\Delta x}
\end{aligned}
$$

Aproximando-se o elemento de volume a um infinitésimo, ou seja, $\Delta x \rightarrow d x$, segue que: 


$$
\frac{\rho}{\rho_{0}}=-\frac{\partial \delta(x)}{\partial x}
$$

A equação (AD.4) estabelece que a densidade sonora relativa se obtém a partir da derivada espacial da expansão e/ou dilatação multiplicada por -1. Esta equação será bastante importante para as próximas considerações e é conhecida como equação da continuidade.

Pode-se, também, modelar o sistema a partir da equação de uma mola. Isto é possível a partir da equação (AD.3.2), onde se realiza a substituição da densidade sonora pela pressão sonora de acordo com a seguinte relação (MÖSER, 2009):

$$
\rho=\frac{p}{c^{2}}
$$

Multiplicando-se ambos os membros por $S$, na mesma equação (AD.3.2), segue que:

$$
\begin{gathered}
S \frac{p}{\rho_{0} c^{2}}=-S \frac{\delta(x+\Delta x)-\delta(x)}{\Delta x} \leftrightarrow \\
\leftrightarrow S p=-\frac{S \rho_{0} c^{2}}{\Delta x}(\delta(x+\Delta x)-\delta(x))
\end{gathered}
$$

Onde o termo $S p$ indica força sobre o elemento de volume, pois é o produto da área pela pressão aplicada na superfície de separação deste elemento. A equação (AD.6.2) pode ser reescrita de acordo com a segunda lei de Hooke para molas com extremidades livres, ou seja:

$$
\begin{gathered}
S p=-k(\delta(x+\Delta x)-\delta(x)) \\
k=\frac{E S}{\Delta x} \\
E=\rho_{0} c^{2}
\end{gathered}
$$

Sendo $k$ a constante elástica da mola. Para o ar, que é um meio elástico, $E$ representa o módulo de elasticidade de Young, e depende da velocidade de propagação do som no meio.

As equações até aqui apresentadas dizem respeito ao comportamento do elemento de volume de ar em questão de expansão/compressão de seus limites 
laterais. Agora se pretende analisar como este pequeno volume de ar, ou massa, se move por meio das forças atuantes sobre ele. A resposta está na segunda lei de Newton, ou seja, o somatório das forças atuantes sobre o elemento de volume é igual à sua aceleração. Dessa forma, tomando como base o modelo da Figura 18, tem-se a força atuante no limite lateral esquerdo de $S p(x)$, e no limite lateral direito de $S(p(x+\Delta x))$. Considerando que o elemento de volume mova-se aceleradamente para a direita, teremos:

$$
\begin{aligned}
& m \frac{\partial^{2} \delta}{\partial t^{2}}=S(p(x)-p(x+\Delta x)) \leftrightarrow \\
& \leftrightarrow \frac{\partial^{2} \delta}{\partial t^{2}}=\frac{S}{m}(p(x)-p(x+\Delta x))
\end{aligned}
$$

Lembrando-se que massa é o produto da densidade pelo volume, isto é: $m=\rho_{0} S \Delta x$, segue:

$$
\begin{gathered}
\frac{\partial^{2} \delta}{\partial t^{2}}=\frac{S}{\rho_{0} S \Delta x}(p(x)-p(x+\Delta x)) \leftrightarrow \\
\leftrightarrow \frac{\partial^{2} \delta}{\partial t^{2}}=\frac{1}{\rho_{0}} \frac{p(x)-p(x+\Delta x)}{\Delta x} \therefore \\
\rho_{0} \frac{\partial^{2} \delta}{\partial t^{2}}=-\frac{p(x+\Delta x)-p(x)}{\Delta x}
\end{gathered}
$$

Tomando-se o limite para $\Delta x \rightarrow 0$, ter-se-á:

$$
\rho_{0} \frac{\partial^{2} \delta}{\partial t^{2}}=-\frac{\partial p}{\partial x}
$$

A equação (AD.12) descreve como se produz movimento numa partícula sonora em virtude pressão sonora aplicada. Já a equação (AD.4) apresenta a compressão sonora do gás com base nas deformações dependentes do espaço. D'outra forma, estas são as duas equações fundamentais da acústica de modo que todo evento sonoro unidimensional deve satisfazer a ambas. O próximo passo é reunir estas duas equações numa única equação. Para isto, eliminar-se-á a variável espaço, $\delta$, destas duas equações derivando a equação (AD.4) duas vezes no tempo e equação (AD.12) uma vez no espaço. Dessa forma, tem-se que: 


$$
\begin{gathered}
\frac{1}{\rho_{0}} \frac{\partial^{2} \rho}{\partial t^{2}}=-\frac{\partial^{3} \delta}{\partial x \partial t^{2}} \\
\frac{1}{\rho_{0}} \frac{\partial^{2} p}{\partial x^{2}}=-\frac{\partial^{3} \delta}{\partial x \partial t^{2}}
\end{gathered}
$$

Igualando-se as equações (AD.13) e (AD.14), obtém-se:

$$
\frac{\partial^{2} \rho}{\partial t^{2}}=\frac{\partial^{2} p}{\partial x^{2}}
$$

Substituindo a densidade pela pressão sonora de acordo com a equação (AD.5) teremos, por fim:

$$
\frac{\partial^{2} p}{\partial x^{2}}=\frac{1}{c^{2}} \frac{\partial^{2} p}{\partial t^{2}}
$$

A equação (AD.16) é conhecida como equação de onda. Esta reúne em si três equações, ou seja, a equação da continuidade (AD.4), da conservação do momento (AD.12) e a equação (AD.5), que pode ser interpretada, num caso particular, como equação da elasticidade (vide equação (AD.9)). Para o caso tridimensional, esta equação toma a seguinte forma:

$$
\Delta p=\frac{1}{c^{2}} \frac{\partial^{2} p}{\partial t^{2}}
$$

Neste caso, equação (AD.17), o símbolo " $\Delta$ " é o operador Laplaciano. 